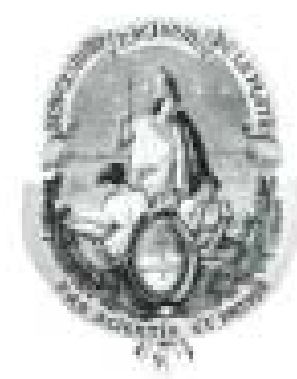

UNIVERSIDAD NACIONAL DE LA PLATA

Facultad de Ciencias Naturales y Museo

\title{
Palinoestratigrafia del Paleozoico Superior de la Cuenca Colorado, República Argentina y su correlación con áreas relacionadas
}
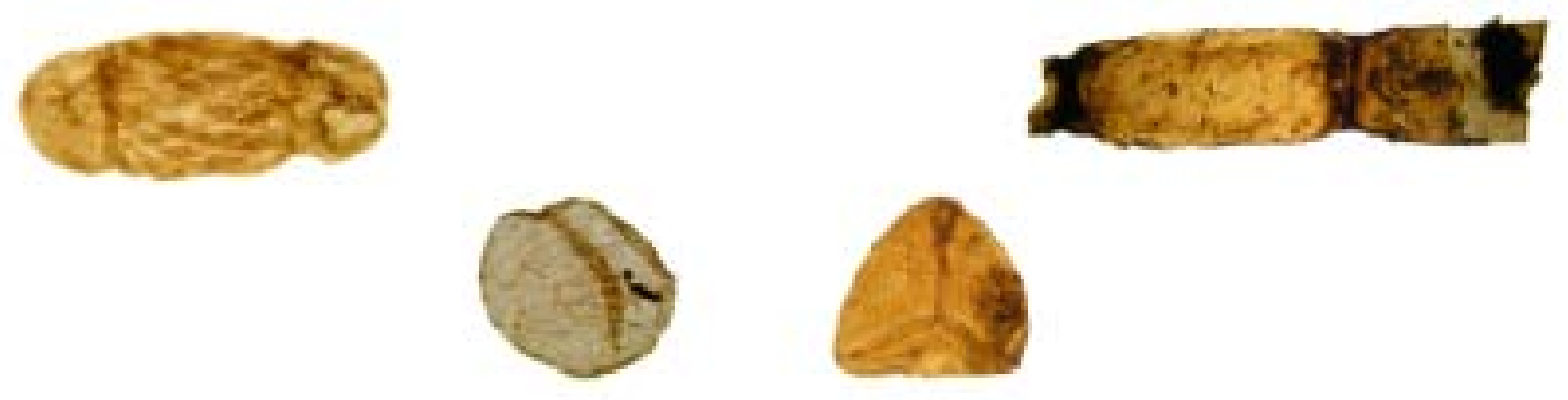

Lic. M. Lucia BALARINO

Tesis presentada para optar al titulo de Doctor en Ciencias Naturales otorgado por la Facultad de Ciencias Naturales y Museo, UNLP

Director de Tesis: Dr. Pedro R. GUTIERREZ

Co-director: Dra. Sara BALLENT

Lugar de trabujo: Musco Argentino de Ciencias Nahurales "B. Rvadavia" 


\section{CONTENIDO}

\begin{tabular}{|c|c|}
\hline RESUMEN & 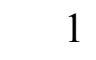 \\
\hline ABSTRACT & 4 \\
\hline I. INTRODUCCIÓN & 7 \\
\hline II. MARCO GEOLÓGICO REGIONAL & 17 \\
\hline II.1. Cuenca Claromecó & 19 \\
\hline II.1.1.Grupo Pillahuincó & 23 \\
\hline II.1.1.a. Formación Sauce Grande & 23 \\
\hline II.1.1.b. Formación Piedra Azul & 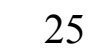 \\
\hline II.1.1.c. Formación Bonete & 26 \\
\hline II.1.1.d. Formación Tunas & 27 \\
\hline II.2. Cuenca Colorado & 30 \\
\hline II.2.1. Estadío de pre-rift & 32 \\
\hline II.2.2. Estadío de syn-rift (Jurásico Tardío-Cretácico Temprano) & 33 \\
\hline II.2.3. Estadío de post-rift (Cretácico Temprano) & 33 \\
\hline II.2.4. Estadío de margen pasivo (Paleógeno-Cuaternario) & 34 \\
\hline II.3. Perforaciones realizadas en las Cuencas Colorado y Claromecó & 38 \\
\hline II.3.1. Perforación UTAL-Cruz del Sur x-1 & 41 \\
\hline II.3.2. Perforación UTAL-Estrella x-1 & 41 \\
\hline II.3.3. Perforación YPF-Puelches x-1 & 42 \\
\hline III. MATERIALES Y MÉTODOS & 45 \\
\hline IV. LISTADO DE ESPECIES DESCRIPTAS & 55 \\
\hline IV.1. Auctóctonas & 57 \\
\hline IV.2. Retrabajo & 60 \\
\hline V. SISTEMÁTICA & 61 \\
\hline V.1. Auctóctonas & 63 \\
\hline V.2. Retrabajo & 377 \\
\hline VI. RESULTADOS ALCANZADOS & 387 \\
\hline VI.1. Bioestratigrafía & 388 \\
\hline VI.1.1. Perforación La Estrella x-1 & 388 \\
\hline VI.1.1.1. Listado de especies & 389 \\
\hline VI.1.1.2. Distribución estratigráfica de las especies identificadas & 391 \\
\hline VI.1.2. Perforación Cruz del Sur x-1 & 397 \\
\hline VI.1.2.1. Listado de especies & 397 \\
\hline VI.1.2.2. Distribución estratigráfica de las especies identificadas & 400 \\
\hline VI.2. Propuesta de Biozonación & 400 \\
\hline $\begin{array}{l}\text { VI.2.1. Biozona de Asociación Converrucosisporites confluens-Vittatina } \\
\text { vittifera }(\mathrm{CV})\end{array}$ & 402 \\
\hline $\begin{array}{l}\text { VI.2.2. Biozona de Asociación Tornopollenites toreutos-Reduviasporonites } \\
\text { chalastus (TC) }\end{array}$ & 405 \\
\hline VI.3. Edad de las biozonas & 407 \\
\hline VI.4. Comparaciones con biozonas de cuencas sudamericanas & 413 \\
\hline VI.4.1. Cuenca Chacoparaná & 413 \\
\hline VI.4.2. Cuencas del centro-oeste de Argentina & 417 \\
\hline VI.4.3. Cuenca Paraná, Brasil & 419 \\
\hline VI.4.4. Cuenca Amazonas, Brasil & 422 \\
\hline VI.4.5. Consideraciones & 426 \\
\hline VI.5. Correlaciones & 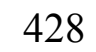 \\
\hline
\end{tabular}


VI.5.1. Cuencas Paganzo, Río Blanco, Calingasta-Uspallata, San Rafael 428 Bioestratigrafía

VI.5.2. Cuenca Chacoparaná

VI.5.3. Cuencas Claromecó-Colorado y Tepuel-Genoa

VI.5.4. Cuadro de correlación general

VII. CARACTERÍSTICAS DE LAS MICROFLORAS 433

VII.1. Composición de las microfloras $\quad 435$

VII.2. Consideraciones paleogeográfícas y paleoclimáticas 442

VII.2.1. Marco general

VII.2.2. Litoestratigrafía y evolución ambiental 445

VII.2.3. Características de la Flora 448

VIII. CONCLUSIONES 463

IX. AGRADECIMIENTOS 471

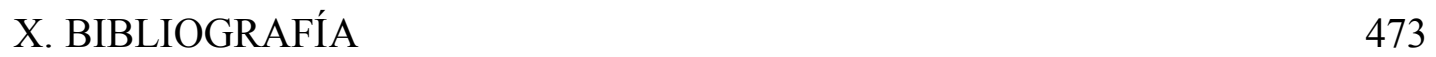

XI. ANEXOS 543

Figuras

Figura 1. Ubicación de las cuencas desarrolladas durante el PennsylvanianoCisuraliano en Argentina.

Figura 2. Esquema bioestratigráfico para el Pennsylvaniano-Guadalupiano de la Argentina.

Figura 3. Cuencas Claromecó-Colorado

Figura 4. Localización de las perforaciones en las Cuenca Claromecó y Colorado

Figura 5. Cuenca Claromecó

Figura 6. Esquema de evolución de la Cuenca Claromecó

Figura 7. Grupo Pillahuincó, cronoestratigrafía

Figura 8. Esquema de las 4 secuencias tectonoestratigráficas mayores: pre-rift (Paleozoico), syn-rift (Jurásico Tardío-Cretácico Temprano), post-rift y margen pasivo

Figura 9. Cuencas petroleras productoras y sin producción actual

Figura 10. Esquema de técnicas fisico-químicas utilizadas para el procesamiento de las muestras palinológicas

Figura 11. Parámetros medidos en las esporas triletes, granos de polen monosacados y bisacados

Figura 12. Esquema de la división del sistema Pérmico

36

Figura 13. Distribución estratigráfica de las especies presentes en la perforación La Estrella x-1

Figura 14. Distribución estratigráfica de las especies presentes en la perforación Cruz del Sur x-1

Figura 15. Principales cuencas sedimentarias de Sudamérica del Neopaleozoico.

Figura 16. Cuadro palinoestratigráfico de la Cuenca Paraná

Figura 17. Cuenca Amazonas (Brasil).

Figura 18. Correlación general entre las distintas biozonas de Argentina y Brasil

Figura 19. Grupo Pillahuincó: ajuste cronoestratigráfico de las unidades que lo integran a partir de la información palinológica

Figura 20. Gráfico de abundancia relativa de los grupos de palinomorfos en las 52 muestras testigo de la perforación La Estrella x-1. 


\section{Cuadros}

Cuadro 1. Perforación YPF.Puelches x-1; listado del contenido palinológico del Pérmico.

Cuadro 2. Preparados y números de colección de las muestras de la perforación La Estrella x-1.

Cuadro 3. Preparados y números de colección de las muestras de la perforación Cruz del Sur $\mathrm{x}-1$

Cuadro 4. Listado de las especies identificadas en la perforación La Estrella x-1.

Cuadro 5. Listado de especies de las Asociaciones CV y TC de la perforación La Estrella $\mathrm{x}-1$.

Cuadro 6. Lista de especies identificadas en la perforación Cruz del Sur x-1

Cuadro 7. Distribución estratigráfica de las especies identificadas en la Cuenca Claromecó-Colorado.

Cuadro 8. Especies comunes entre las biozonas de Cuenca Claromecó-Colorado.

Cuadro 9. Especies de las biozonas de Cuenca Claromecó-Colorado (CV y TC: perforación La Estrella; CVs: perforación Cruz del Sur) compartidas con las biozonas FS (Fusacolpites fusus-Vittatina subsaccata) y LW (LueckisporitesWeylandites) de las cuencas del Centro-Oeste de Argentina

Cuadro 10. Especies de las biozonas de Cuenca Claromecó-Colorado (CV y TC: perforación La Estrella; CVs: perforación Cruz del Sur) compartidas con las biozonas Vc (Vittatina costabilis) y Lv (Lueckisporite virkkiae) de la Cuenca Paraná, Brasil

Cuadro 11. Especies de las biozonas de Cuenca Claromecó-Colorado (CV y TC: perforación La Estrella; CVs: perforación Cruz del Sur) compartidas con las biozonas Vc (Vittatina costabilis) y Tt (Tornopollenites toreutos) de la Cuenca Amazonas, Brasil

Cuadro 12. Afinidad botánica de los palinomorfos que integran las palinofloras identificadas en las perforaciones La Estrella x-1 y Cruz del Sur x-1

Cuadro 13. Abundancia relativa de géneros según afinidades botánicas en las distintas muestras testigo de la perforación La Estrella x-1

Cuadro 14. Abundancia relativa de los grupos parentales en la perforación La Estrella X-1

Cuadro 15. Abundancia relativa de grupos en las muestras testigo de la perforación La Estrella x-1

Cuadro 16. Registro de los granos de polen durante el Pennsylvaniano-Triásico en el centro-oeste argentino.

Cuadro 17. Número de géneros y especies presentes en cada biozona propuesta para Cuenca Colorado:

Cuadro 18. Especies presentes en las biozonas definidas para Cuenca 458 Chacoparaná

Cuadro 19. Número de especies por género ordenados según afinidad botánica, 460 presentes en las biozonas definidas para Cuenca Chacoparaná. 
A todos quienes desde sus pequeños $y$ grandes lugares, creen, apoyan y trabajan por la Educación Pública. 


\section{RESUMEN}

Se estudiaron asociaciones palinoflorísticas provenientes de 2 perforaciones: UTAL.CMM1.La Estrella $\mathrm{x}-1$, de 10 niveles testigo y 25 de cutting, $\mathrm{y}$ UTAL.CMM1.Cruz del Sur x-1, y de 13 niveles de cutting. A partir del estudio de las muestras se describieron e ilustraron 179 especies, proponiéndose las siguientes combinaciones: Falcisporites parvus (de Jersey) nov. comb., Falcisporites similis (Balme) nov. comb. y Tiwarisporis anaverrucosus (Archangelsky y Gamerro) nov. comb.También se incorporaron 47 nuevos registros de especies para Argentina. Con el análisis sistemático y estratigráfico de los datos se propuso un nuevo esquema palinoestratigráfico con 2 biozonas para el Pérmico de la Cuenca Claromecó-Colorado: a) la Biozona de asociación Converrucosisporites confluens-Vittatina vittifera $(\mathrm{CV})$, que presenta su sección tipo en la perforación La Estrella x-1 (3549- $3231 \mathrm{mbnm})$, la cual también ha sido identificada en la perforación Cruz del Sur x-1 (4227-3995 mbnm), y es referida al Cisuraliano-Guadalupiano temprano y aparecería representada en las formaciones Piedra Azul y Bonete. Se caracteriza por la presencia exclusiva de $C$. confluens, Diatomozonotriletes subbaculiferus, Osmundacidites wellmanii, Verrucosisporites surangei, Horriditriletes uruguaiensis, H. filiformis, Didecitriletes uncinatus, Cyclogranisporites microgranus, Kraeuselisporites punctatus, K. apiculatus, Gondisporites serrulatus, Lundbladispora riobonitensis, Laevigatosporites vulgaris, Brazilea scissa, Potonieisporites densus, P. triangulatus, Caheniasaccites elongatus, Gondwanapollis frenguellii, Accinctisporites sp. A, Crucisaccites latisulcatus, Striomonosaccites cicatricosus, Polarisaccites bilateralis, Alisporites opii, Limitisporites amazoniensis, Triadispora epigona, Distriatites sp. A, Lueckisporites singrauliensis, Protohaploxypinus bharadwajii, Striatopodocarpites sp. cf. S. solitus, Praecolpatites sinuosus y Pakhapites ovatus. La desaparición de estas especies y de Cannanoropollis sp. cf. C. densus, Crucisaccites latisulcatus, Vittatina vittifera, Brazilea scissa y Quadrisporites granulatus, marcan el límite superior de la biozona. La misma ha sido subdividida a su vez en 3 asociaciones informales: A, B y C. b) la Biozona de asociación Tornopollenites toreutos-Reduviasporonites chalastus (TC), presenta su sección tipo en la perforación La Estrella x-1 (3231-2986 mbnm), es referida al Guadalupiano tardío-Lopingiano temprano y aparecería representada en la 
Formación Tunas. La base de la Biozona TC está definida por los primeros registros de Leiotriletes ulutus, L. corius, Convolutispora candiotensis, Tornopollenites toreutos, Weylandites magmus y Leiosphaeridia crescentica. La presencia exclusiva de $T$. toreutos, Reduviasporonites chalastus, Camptotriletes sp. cf. C. warchianus, Convolutispora candiotensis, Laevigatosporites flexus, Leiotriletes corius, L. ulutus, Leschikisporis chacoparanaense, Phaselisporites sp. cf. P. cicatricosus, Phidiaesporites fosteri, Pseudoreticulatispora pseudoreticulata, Vallatisporites arcuatus, Potonieisporites brasiliensis, Weylandites magmus, Circulisporites parvus, Leiosphaeridia crescentica, Mehlisphaeridium fibratum y $M$. sp. cf. M.? sp. B caracterizan esta biozona.

La Biozona CV sería equivalente temporalmente a las biozonas Cristatisporites y parte de Striatites (Cuenca Chacoparaná, Argentina), Cannanoropollis korbaensis y parte inferior de Lueckisporites virkkiae (Cuenca Paraná, Brasil), la mayor parte de Vittatina costabilis (Cuenca Amazonas, Brasil) y Pakhapites fusus-Vittatina subsaccata y Lueckisporites-Weylandites (centro oeste de Argentina). Por su parte, la Biozona TC, sería en tiempo a la parte superior de las biozonas Striatites (Cuenca Chacoparaná, Argentina), Lueckisporites virkkiae (Cuenca Paraná, Brasil), Vittatina costabilis y a toda la biozona Tornopollenites toreutos (Cuenca Amazonas, Brasil) .

La Biozona CV está caracterizada por la abundancia de granos de polen bisacados lisos (51,6-55,6\%), acompañando por esporas triletes $(12,7-20,6 \%)$ y granos de polen plicados (12,1-18,5\%); complementan los granos de polen estriados (7,0$12,3 \%)$, monosulcados $(0,2-3,7 \%)$, monosacados $(0,6-2,2 \%)$, algas $(0-3,9 \%)$ y acritarcas $(0-0,4 \%)$. Por su parte las asociaciones referidas a la Biozona TC aparecen compuestas por granos de polen bisacados $(74,3-88,9 \%)$ como elementos dominantes, mientras que el resto de los grupos constituyen conjuntos relictuales: esporas $(2,4-10,9 \%)$, granos de polen estriados $(3,4-9,4)$, plicados $(0,2-4,3 \%)$, monosacados $(0,7-3,0 \%)$, monosulcados $(0-0,9 \%)$, algas $(0-0,9 \%)$ y acritarcas $(0-0,4 \%)$.

Durante el Cisuraliano-Guadalupiano temprano (Biozona CV) las microfloras incluyen una alta representación de elementos de la vegetación que vivía en áreas más alejadas (alóctona: Coniferopsida, Caytoniales, Glossopteridales/Voltziales, que habrían tenido requerimientos xerófilos y/o mesófilos), y una baja representación de componentes de la flora autóctona (de hábitos hidro-higrófilos; en especial las 
Pteridophyta que dominan en este grupo, y la muy escasa presencia de Sphenophyta y Lycophyta).

Hacia el Guadalupiano tardío-Lopingiano temprano, las microfloras (Biozona TC) reflejan ligeros cambios en la composición de la flora parental, ésta también se habría desarrollado en un ambiente predominantemente continental. Las microfloras incluyen una elevada representación de granos de polen bisacados (lisos), y una escasa participación de los elementos acuáticos (esporas y algas-prasinofitas).

Por lo que, en el lapso considerado se observa un marcado empobrecimiento de la flora autóctona (con requerimientos higro-hidromesófilos, como las Pteridophyta, Sphenophyta y Lycophyta) hacia el Guadalupiano tardío-Lopingiano temprano lo que reflejaría un período de aridización y disminución de las fuentes de agua (insinuado durante el Cisuraliano-Guadalupiano temprano).

El empobrecimiento de la flora autóctona sumado a las pocas variaciones observadas entre las Glossopteridales y Podocarpaceae, el dominio de las Caytoniales y Majoniaceae, la marcada disminución de las Coniferales-Cordaitales en las microfloras, es coherente con las tendencias evolutivas de la paleoflora (inferidas a partir del registro palinológico) observadas en este sector de la Argentina durante el NeopaleozoicoTriásico.

Por último, las profundidades 3428, 3380, 3231 (Biozona CV), 3180, 3081, 3031 y 2992,9 mbnm (Biozona TC) registran la presencia del grupo Acritarca (Micrhystridium, Circulisporites y Buedingiisphaeridium), asociadas a las Prasinofitas (Leiosphaeridia y Brazilea) que presentarían la instalación de cuerpos de agua salobres.

Palabras clave. Paleopalinología, Sistemática, Palinoestratigrafía, Pérmico, Cuenca Claromecó-Colorado, Plataforma Continental Argentina. 


\begin{abstract}
Palynologycal associations recovered from borehole UTAL.CMM1.La Estrella $\mathrm{x}-1$ (10 test levels and 25 samples from cutting) and borehole UTAL.CMM1.Cruz del Sur x-1 (13 samples cutting) were hare analized. 179 species were described and new combinations proposed: Falcisporites parvus (de Jersey) nov. comb., Falcisporites similis (Balme) nov. comb. and Tiwarisporis anaverrucosus (Archangelsky \& Gamerro) nov. comb. Moreover, 47 new stratigraphical records were described for Argentina. Based on the systematic and stratigraphic analysis of these data, a new palynostratigraphical scheme with 2 biozones have for the Claromecó-Colorado Basin (Permian) was proposed: a) the Converrucosisporites confluens-Vittatina vittifera (CV) Biozone, with the stratotype in the La Estrella x-1 borehole (3549- $3231 \mathrm{mbnm}$ ), Cisuralian-early Guadalupian in age, and refered to the Piedra Azul and Bonete formations. This biozone, also identified at the Cruz del Sur x-1 borehole (4227-3995 mbnm) is characterized by the following exclusive taxa: C. confluens, Diatomozonotriletes subbaculiferus, Osmundacidites wellmanii, Verrucosisporites surangei, Horriditriletes uruguaiensis, H. filiformis, Didecitriletes uncinatus, Cyclogranisporites microgranus, Kraeuselisporites punctatus, K. apiculatus, Gondisporites serrulatus, Lundbladispora riobonitensis, Laevigatosporites vulgaris, Brazilea scissa, Potonieisporites densus, P. triangulatus, Caheniasaccites elongatus, Gondwanapollis frenguellii, Accinctisporites sp. A, Crucisaccites latisulcatus, Striomonosaccites cicatricosus, Polarisaccites bilateralis, Alisporites opii, Limitisporites amazoniensis, Triadispora epigona, Distriatites sp. A, Lueckisporites singrauliensis, Protohaploxypinus bharadwajii, Striatopodocarpites sp. cf. S. solitus, Praecolpatites sinuosus and Pakhapites ovatus. The disappearance of these species and joined with Cannanorpollis sp. cf. C. densus, Crucisaccites latisulcatus, Vittatina vittifera, Brazilea scissa and Quadrisporites granulatus marks the upper limit of the biozone. This biozone has been divided in to 3 informal associations: A, B y C.

b) the Tornopollenites toreutos-Reduviasporonites chalastus (TC) Biozone, with the stratotype in the La Estrella x-1 borehole (3231-2986 mbnm), late Guadalupianearlier Lopingian in age, and refered to the Tunas Formation. At the base of TC Biozone, the first records of Leiotriletes ulutus, L. corius, Convolutispora candiotensis,
\end{abstract}


Tornopollenites toreutos, Weylandites magmus and Leiosphaeridia crescentica occur. Exclusive taxa that characterized this biozone include: T. toreutos, Reduviasporonites chalastus, Camptotriletes sp. cf. C. warchianus, Convolutispora candiotensis, Laevigatosporites flexus, Leiotriletes corius, L. ulutus, Leschikisporis chacoparanaense, Phaselisporites sp. cf. P. cicatricosus, Phidiaesporites fosteri, Pseudoreticulatispora pseudoreticulata, Vallatisporites arcuatus, Potonieisporites brasiliensis, Weylandites magmus, Circulisporites parvus, Leiosphaeridia crescentica, Mehlisphaeridium fibratum and M. sp. cf. M.? sp. B.

The CV Biozone would be temporally equivalent to the Cristatisporites Biozone and part of the Striatites Biozone (Chacoparaná Basin, Argentina); to the Cannanoropollis korbaensis and the lower part of the Lueckisporites virkkiae (Paraná Basin, Brazil), and Pakhapites fusus-Vittatina subsaccata and LueckisporitesWeylandites biozones (in the central and western basins, Argentina). The TC Biozone, would be temporally similar to the upper part of the Striatites Biozone, Lueckisporites virkkiae, Vittatina costabilis and all Tornopollenites toreutos Biozone (Amazona Basin, Brazil).

The CV Biozone is characterized by the abundance of bisaccate pollen grains $(51,6-55,6 \%)$. Followed by spores $(12,7-20,6 \%)$ and plicate pollen grains $(12,1-18,5 \%)$. The assemblage is complemented by striate $(7,0-12,3 \%)$, colpate $(0,2-3,7 \%)$ and monosaccate pollen grains $(0,6-2,2 \%)$, algae (0-3,9\%) and acritarchs $(0-0,4 \%)$.

During the Cisuralian-earlier Guadalupian (CV Biozone) the microfloras were represented by a high proportion of vegetation that lived in remote areas (alochtonous: Coniferopsida, Caytoniales, Glossopteridales/Voltziales; that would have a xeromesophytic habit), and a low representation of components of the native flora (hydrohygrophil habit, dominantly the Pteridophyta and to a lesser degree Sphenophyta and Lycophyta).

Towards the late Guadalupian-early Lopingian, the microflora (TC Biozone) showed slight changes in the composition of the original flora becoming in a predominantly continental. These microfloras include a high representation of bisaccate pollen grains and a low participation of water elements (spores and algaeprasinophytes). 
During the time inteval here considered, there was a marked loss of native flora (with hygro-hydromesophytic requirements, like Pteridophyta, Sphenophyta and Lycophyta). Toward the early Guadalupian-late Lopingian, there was a period of decline of the water resources, and a increase in aridity (evidenced during the Cisuralian-early Guadalupian).

The impoverishment of the native flora in addition to the slight variations observed between the Glossopteridales and Podocarpaceae, the increase in dominance of Caytoniales and Majoniaceae, and the sharp decrease of Coniferales-Cordaitales, is consistent with the palynological trends observed in this part of Argentina during the Late Paleozoic-Triassic.

Finally, at depths 3428, 3380, 32313231 (CV Biozone), 3180, 3081, 3031 and 2992,9 mbnm (TC Biozone) are recorded the presence of Acritarchs (Micrhystridium, Circulisporites and Buedingiisphaeridium) which in association with Prasinophytas (Leiosphaeridia and Brazilea) represent the irruption of brackish waters.

Key words. Paleopalynology, Sistematic, Palynostratigraphy, Permian, ClaromecóColorado basin, Plataforma Continental Argentina. 


\section{INTRODUCCIÓN}

Los principales objetivos planteados en esta Tesis son 1) caracterizar el contenido palinológico del Pérmico de la Cuenca Claromecó-Colorado, 2) ajustar la edad de los sedimentos portadores del mismo, y 3) proponer un esquema palinoestratigráfico para dicha cuenca. Alcanzados éstos se propondrá plantear el marco de referencia bioestratigráfico para el Pérmico de esta cuenca y comparar los resultados alcanzados con la información proveniente de cuencas coetáneas y estrechamente vinculadas como son las de Chacoparaná, Paganzo, Calingasta-Uspallata, Río Blanco (en Argentina) y Paraná (Brasil y Uruguay) (véase Figura 1). A partir de las posibles relaciones parentales (véase Balme, 1995; Quadros et al., 1996, entre otros) de los componentes de las microfloras aquí analizadas se tratará de lograr un mayor grado de conocimiento de la vegetación que se desarrolló durante el Pérmico en esta área del Gondwana Occidental.

El conocimiento de microfloras del Neopaleozoico (Carbonífero-Pérmico) de Argentina ha sido sintetizado en esquemas palinoestratigráficos propuestos para las cuencas Paganzo, Calingasta-Uspallata, Río Blanco, San Rafael, Chacoparaná, Tarija, Claromecó-Colorado y Tarija (véase Figura 1) que evolucionaron en dicho lapso (Russo et al., 1980; Archangelsky et al., 1987a, 1987b, 1987c, 1996a, 1996b; Archangelsky y Vergel, 1996; Archangelsky, 1996a; Césari y Gutiérrez, 2001; di Pasquo, 2001; Gutiérrez et al., 2003a; véase Figura 2).

Con respecto al Pérmico la mayoría de la información referida al centro-oeste de la Argentina (Cuencas Paganzo, Calingasta-Uspallata, Río Blanco y San Rafael) se restringe a unas pocas asociaciones provenientes de las formaciones Bajo de Véliz, La Cuesta, Santa Máxima, El Imperial, La Puerta, Tasa Cuna, Andapaico, Tupe, Agua del Jagüel y La Veteada (Menéndez, 1971; Aceñolaza y Vergel, 1987; Ottone, 1989; García, 1995, 1996; Ottone y Rosello, 1996; Gutiérrez y Césari, 2000; Balarino y Gutiérrez, 2006; Carrevedo et al., 2008; Correa et al., 2008, en prensa; Gutiérrez, et al., 2008a; Césari et al., 2008; Vergel, 2008; véase también en Gutiérrez et al., 2006b; Gutiérrez, 2008) y asignables al Cisuraliano-Guadalupiano (biozonas Pakhapites fususVittatina subsacatta y Lueckisporites-Weylandites; FS y LW, respectivamente). 
Por su parte, la Cuenca Chacoparaná dispone de una mayor densidad de información para la palinología del Pérmico, proveniente del subsuelo de la cuenca que ha sido atravesado por las perforaciones La Josefina, Saira, Camilo Aldao, Ordoñez, Santiago Temple, Coronel Rico, Árbol Blanco, El Caburé y Las Mochas (Archangelsky y Gamerro, 1979; Vergel, 1986, 1987a, 1987b, 1990, 1998; Winn y Steinmetz, 1998; Césari et al., 1995; Gutiérrez et al., 1997, 2002, en prensa-a; Playford y Dino, 2002). Las microfloras pérmicas han sido referidas también al Cisuraliano-Guadalupiano (biozonas Cristatisporites y Striatites; $\mathrm{Cr}$ y S, respectivamente) (véase Russo et al., 1980; Vergel, 1993; Archangelsky y Vergel, 1996; Gutiérrez et al., 2003a).

Por último, menos conocida es la información que se dispone de la palinología del Pérmico de las cuencas Tepuel-Genoa (Gamerro y Archangelsky, 1981a; Archangelsky et al., 1990; Gutiérrez et al., 2005, 2007; Vergel y Cúneo, 2006) y Colorado (Archangelsky y Gamerro, 1980b; Gutiérrez et al., 2003b). Estas dos últimas cuencas también brindaron microfloras del Cisuraliano-Guadalupiano que fueron referidas a las biozonas de la Cuenca Chacoparaná (biozonas Cr y S), al extender la nomenclatura de la Cuenca Chacoparaná.

Por su parte, las microfloras del Lopingiano son muy escasas y solo los recientes hallazgos (Formación La Veteada, Zavattieri et al., 2008; Grupo Pillahuincó en la Perforación La Estrella, Balarino, 2008) brindaron los primeros datos que permitieron avanzar en el conocimiento de su composición. 


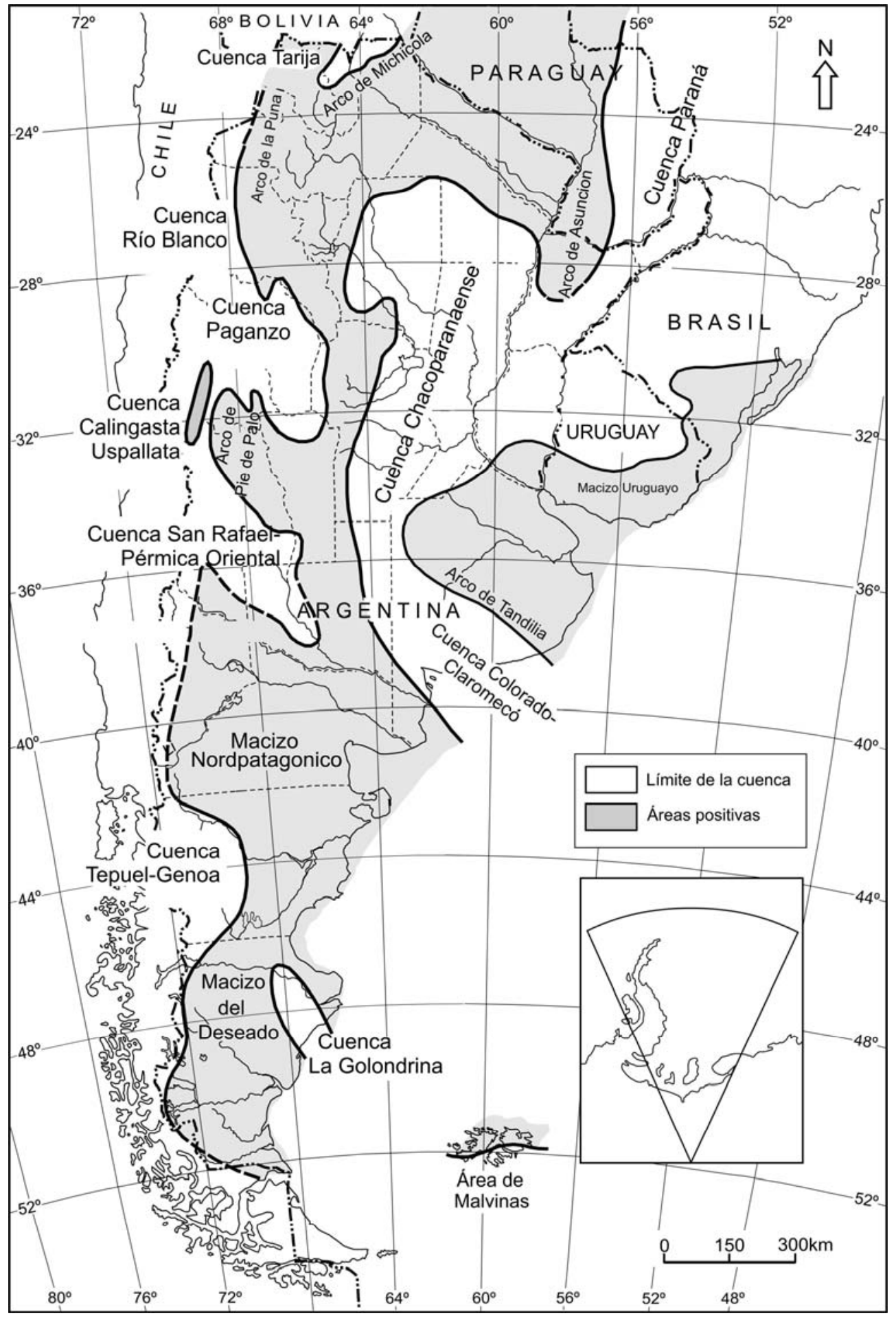

Figura 1. Ubicación de las cuencas desarrolladas durante el Pennsylvaniano-Cisuraliano en Argentina. (Tomado de Gutiérrez et al., 2003). 
En éste contexto el análisis palinológico aquí planteado de las sedimentitas pérmicas atravesadas por las perforaciones Cruz del Sur x-1 y La Estrella x-1 (en la Cuenca Claromecó-Colorado), permitirá ampliar el conocimiento sobre las palinofloras, en especial las del Lopingiano sumandose así a la información obtenida durante los últimos años para las Cuencas Paganzo, Río Blanco, Calingasta-Uspallata y TepuelGenoa.

Se debe destacar que la información de los últimos años incluye predominantemente listados publicados tanto en resumenes como en trabajos (Césari et al., 1999b, 2001, 2002, 2008; Vergel y Fasolo, 1999; Vergel et al., 2000, Gutiérrez et al., 2005, 2008a; Vergel y Cúneo, 2006; Gutiérrez y Limarino, 2006; Carrevedo et al., 2008; Correa et al., 2008, en prensa; Vergel, 2008; Zavattieri et al., 2008); siendo realmente mucho menos la contribuciones donde se han descripto microfloras pérmicas (Gutiérrez y Césari, 2000; Playford y Dino, 2002; Balarino y Gutiérrez, 2006; Gutiérrez et al., 2007, en prensa-b).

El análisis de los resultados aquí obtenidos (palinoestratigrafía de la Cuenca Claromecó-Colorado), en el marco de toda esta información disponible nos permitirá introducir ajustes y modificar los esquemas palinoestratigráficos del Paleozoico Superior conocidos hasta el momento para la Argentina. Se debe mencionar que recientemente el esquema bioestratigráfico del centro-oeste argentino ha sido levemente modificado (Césari, 2007; Limarino y Césari, 2007; Gutiérrez et al., 2008b) en los aspectos cronológicos, ajustando las edades de las biozonas. Estos esquemas van a ser seguidos en esta Tesis y discutidos en su parte final.

Las sedimentitas pérmicas analizadas en esta tesis constituyen el basamento de la Cuenca Colorado (Kaasschieter, 1963, 1965; Lesta et al., 1980) y se habrían originado en el ámbito de la denominada Cuenca Claromecó (Introcaso, 1982; Kostadinoff y Font de Affolter, 1982). Ya que como estas cuencas, aparentemente, habrían estado vinculadas durante el Paleozoico, a los objetivos de esta Tesis se la va a considerar como una única cuenca (Claramecó-Colorado), ya que representarían a los mismos eventos. 


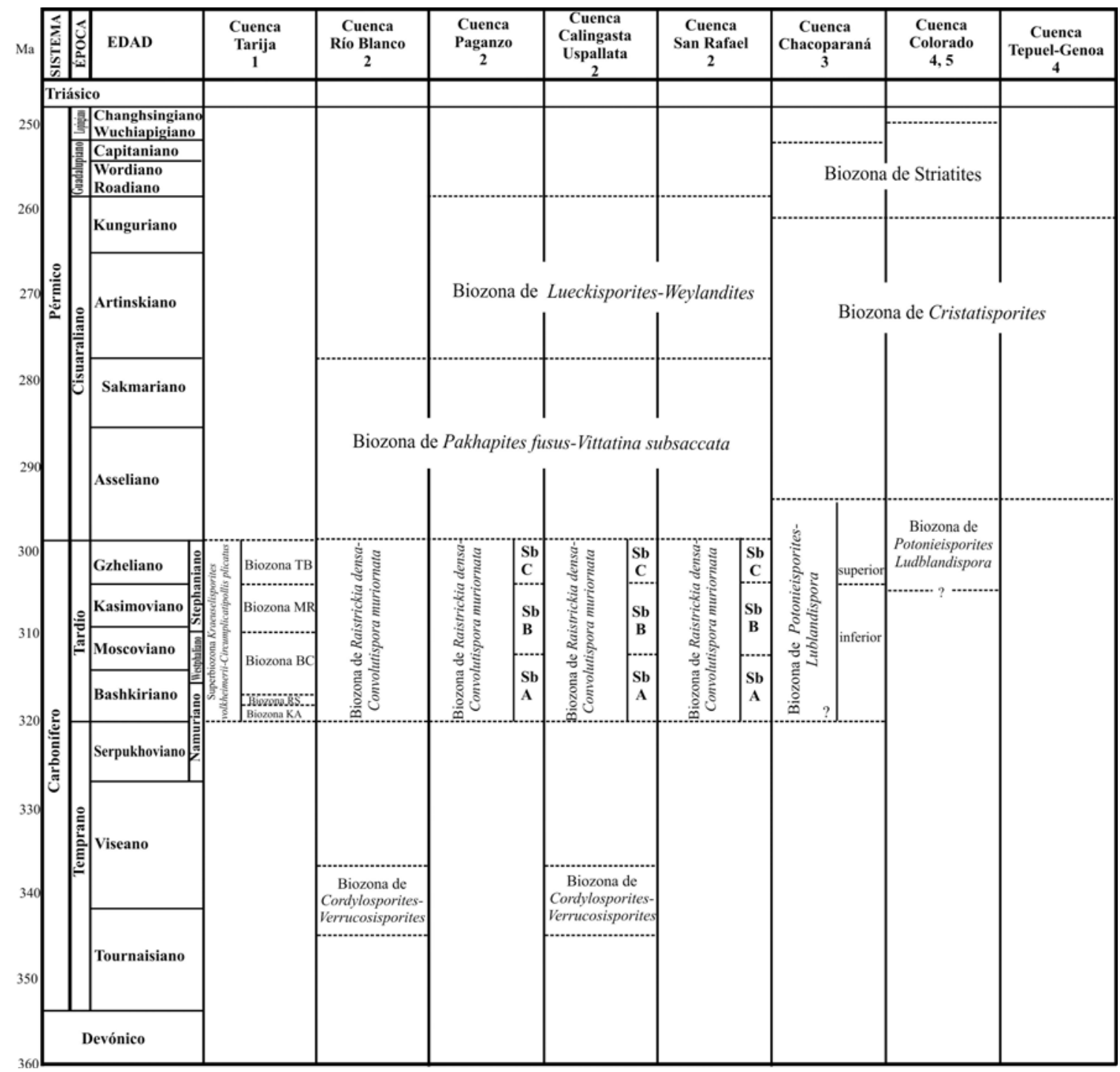

Figura 2. Esquema bioestratigráfico para el Pennsylvaniano-Guadalupiano de la Argentina (modificado de Gutiérrez et al., 2003a). 


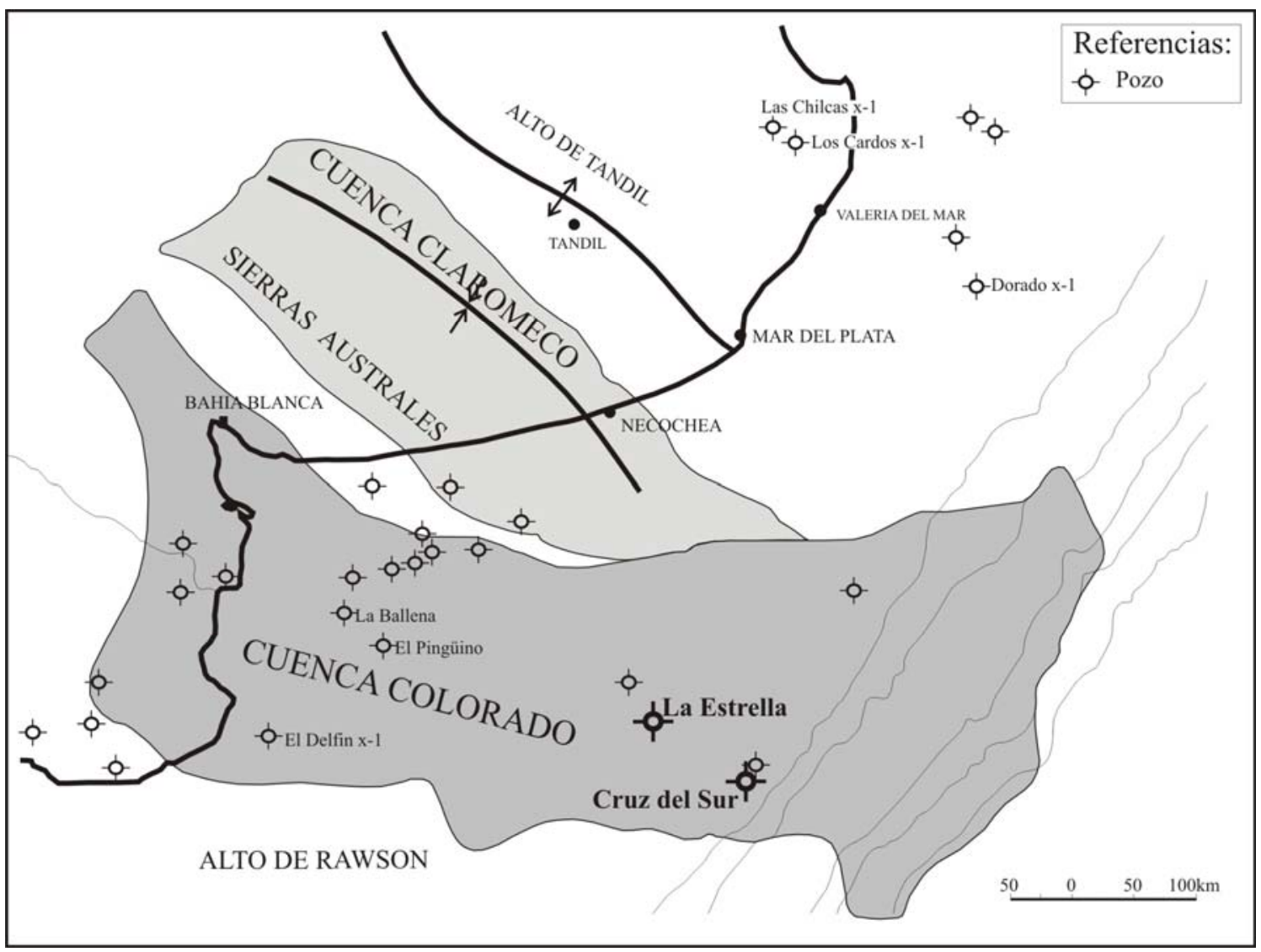

Figura 3. Cuencas Claromecó-Colorado (modificado de Mancilla et al., 2002).

La Cuenca Claromecó, de edad paleozoica, se ubica en el sudoeste de la provincia de Buenos Aires (Figura 3), cubre una superficie aproximada de $50.000 \mathrm{~km}^{2}$ sobre el territorio bonaerense y continúa sobre la plataforma continental argentina. En superficie está representada por los afloramientos que conforman las Sierras de Pillahuincó y de las Tunas, en el sector centro-oriental de las Sierras Australes bonaerenses, así como el sector interserrano que se extiende hacia el oriente, entre esas sierras y el Sistema de Tandilia (véase Amos, 1972; Amos et al., 1972; Yrigoyen, 1975; Urien et al., 1981; Andreis et al., 1987, 1990; Kostadinoff, 1993, 2007; Tankard et al., 1995; Andreis y Japas, 1996; Limarino et al., 2000; Cingolani, 2005).

Por su parte la Cuenca Colorado (Figuras 3 y 4), de edad mesozoica-cenozoica, está situada en la porción sudeste de la provincia de Buenos Aires y cubre una superficie aproximada de $160.000 \mathrm{~km}^{2}, 2 / 3$ de ella se desarrollan costa afuera en aguas de hasta $350 \mathrm{~m}$ de profundidad (plataforma continental). Como ya se mencionó en esta cuenca el Paleozoico constituye el basamento de la misma y sólo ha sido alcanzado por 
medio de perforaciones. Del total de 27 pozos exploratorios realizados en la Cuenca Colorado (Figura 4) en la plataforma continental argentina, sólo 4 alcanzaron el Paleozoico Superior: YPF-Puelches x-1, UTAL-Cruz del Sur x-1 (57 $17^{\prime} 40^{\prime \prime}$ O; 4056'10" S, $91 \mathrm{~m}$ de profundidad del nivel del mar; TD, $4288 \mathrm{mbnm})$, UTAL-Corona Austral x-1 (57²'45” O; 4050’00” S) y UTAL-La Estrella x-1 (58 12’52” O; 40³5'32” S, 89 m de profundidad del nivel del mar; TD, $3545 \mathrm{mbnm}$ ).

Estas perforaciones han permitido obtener datos intersantes sobre la geoquímica de las secuencias atravesadas en especial de las pelitas pérmicas que muestran un alto potencial como generadora de hidrocarburos (Figura 9; véase Archangelsky y Gamerro, 1980b; Gamerro y Archangelsky, 1981b; Keeley et al., 1992; Keeley y Light, 1993; Starling, 1994; Pucci, 1995, 2006; Tankard et al., 1995; Urien et al., 1995; Archangelsky, 1996b; Fryklund et al., 1996; Bushnell et al., 2000, Lesta, 2002; Mancilla et al., 2002; Schümann, 2002; Schümann et al., 2002; Turic, 2002; Schmidt, 2004), equivalente al de las pelitas de la Formación Iratí (Cuenca Paraná), que en Brasil son explotada a cielo abierto para extraer hidrocarburos.

En contraste con el abundante conocimiento de la palinología del CretácicoNeogeno (Gamerro y Archangelsky, 1981b; Quattrocchio et al., 1986, 1988, 2000; Guerstein y Quattrocchio, 1988, 1991; Quattrocchio y Guerstein, 1988, 1994; Guerstein, 1990a, 1990b, 1990c; Guerstein et al., 1995, 2001, 2005; Quattrocchio y Sarjeant, 1996; Ruiz y Quattrocchio, 1996, 1997a, 1997b; Quattrocchio y Ruiz, 1999; Guerstein y Guler, 2000; Guerstein y Junciel, 2001; Guler et al., 2001, 2002; Guler y Guerstein, 2002, 2003; Guler, 2003), poco es lo que se conoce sobre la palinología del Neopaleozoico de la Cuenca del Colorado. Hasta el momento de la realización de este trabajo, solo se conocían los estudios realizados por Archangelsky y Gamerro (1980b), quienes a partir de las asociaciones recuperadas de litologías asimilables a la Formación Sauce Grande, brindaron una edad carbonífera tardía-pérmica temprana.

También se dispone de referencias a informes inéditos (véase Fryklund et al., 1996; Juan et al., 1996b y Lesta y Sylwan, 2005) sobre la palinología del Paleozoico Superior de las perforaciones UTAL-Estrella.x-1 y UTAL-Cruz del Sur.x-1, ubicadas en la plataforma continental argentina, que atraviesan secuencias neopaleozoicas que comprenderían el lapso que va desde el inicio hasta el final del Pérmico; estas secuencias serían equivalentes, según Fryklund et al. (1996) y Juan et al. (1996b) al 
Grupo Pillahuincó, definido en el sector continental de la cuenca (provincia de Buenos Aires; véase Andreis et al., 1987, 1990; Andreis y Japas, 1996).

En la perforación UTAL-Estrella.x-1, el intervalo pérmico, predominantemente pelítico (2986-3427,5 mbnm) ha sido referido a las formaciones Piedra Azul, Bonete y probablemente Tunas y ha brindado microfloras indicadoras de todo el Pérmico. Mientras que la perforación UTAL-Cruz del Sur.x-1, atraviesa sedimentitas (3994-4288 mbnm) también asignables a la totalidad del Pérmico y equivalentes a las mismas unidades (véase Fryklund et al., 1996; Juan et al., 1996b; Archangelsky, 1996b; Gutiérrez et al., 2003a, 2003b).

En esta Tesis se ha realizado el estudio sistemático de las microfloras obtenidas del Pérmico de estas perforaciones y su análisis bioestratigráfico y paleoambiental, así como sus comparaciones en un contexto regional. 
II. MARCO GEOLÓGICO REGIONAL 


\section{MARCO GEOLÓGICO REGIONAL}

\section{II.1. Cuenca Claromecó}

Durante el Paleozoico, en la parte sudoeste de la provincia de Buenos Aires, la sedimentación tuvo lugar en la Cuenca Claromecó (Introcaso, 1982; Kostadinoff y Font de Affolter, 1982; Ramos, 1984; López-Gamundi y Rossello, 1992, Kostadinoff, 1993, 2007; López-Gamundí et al., 1994; Kostadonoff y Prozzi, 1998; Ploskiewicz, 1999, Alvarez, 2007) (Figura 5). Ésta, presenta una superficie aproximada de $50.000 \mathrm{~km}^{2}$ sobre el territorio bonaerense y se continúa sobre la plataforma continental argentina, superponiendose con la Cuenca Colorado (Figura 3).

La Cuenca Claromecó está representada por los afloramientos que conforman las Sierras de Pillahuincó y de las Tunas, en el sector centro-oriental de las Sierras Australes bonaerenses (Amos, 1972; Amos et al., 1972, Andreis et al., 1987), así como el sector interserrano que se extiende hacia el oriente, entre esas sierras y el Sistema de Tandilia (véase Furque, 1965; Yrigoyen, 1975; Urien et al., 1981; Cingolani, 2005; Alto de Tandil). Por su parte, las secuencias neopaleozoicas se extienden hacia el sudeste y subyacen en discordancia angular a las sucesiones cretácicas-terciarias de la Cuenca Colorado. Las características litofaciales y paleobiológicas observadas en las perforaciones que alcanzan este basamento neopaleozoico las hacen coetáneas con los afloramientos serranos de la Cuenca Claromecó (Lesta et al., 1980, Mainardi et al., 1979). Ambas cuencas, en conjunto cubren una superficie de $155,000 \mathrm{~km}^{2}$, aunque los afloramientos solo alcanzan a medir casi 40,000 $\mathrm{km}^{2}$ (Andreis et al., 1987, 1990) y, habrían estado vinculadas por lo menos durante el Neopaleozoico, ya que existirían conexiones en el subsuelo de la plataforma actual.

Esta cuenca interserrana (Cuenca Claromecó), con una pila sedimentaria de unos $9.000 \mathrm{~m}$ de potencia, ha sido dividida (Ramos y Kostadinoff, 2005) en dos sectores: sudocidental y nororiental. El primero, incluye los depósitos altamente deformados que afloran en la región serrana (Sierras Australes: Ventania) y que se continúan en el subsuelo. Por su parte en el sector nororiental, que se corresponde con la antefosa de Claromecó (Figura 5), la pila sedimentaria no presenta deformación, llegando a estar casi horizontales (Ramos y Kostadinoff, 2005). 


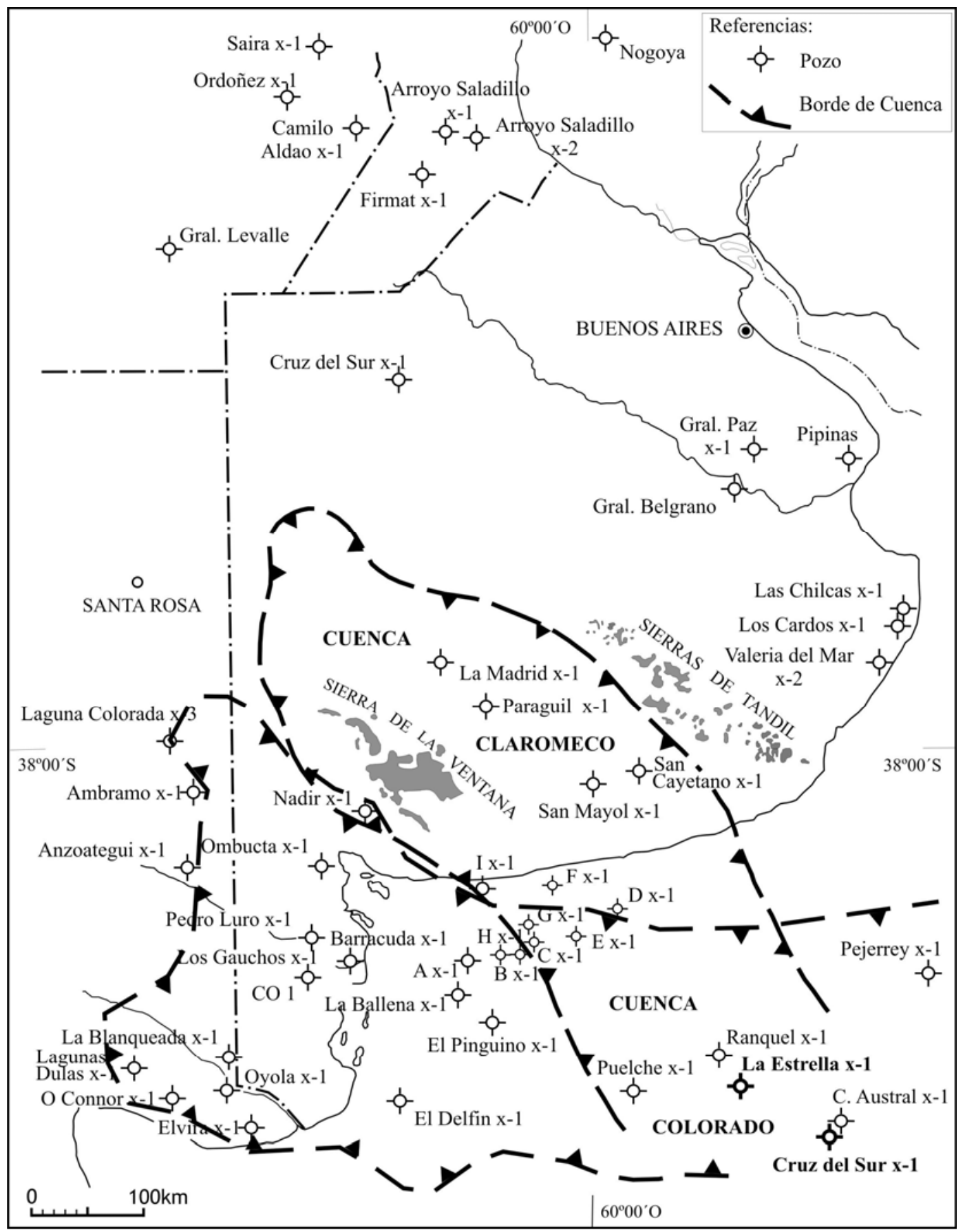

Figura 4. Localización de las perforaciones en las Cuenca Claromecó y Colorado (modifcado de Lesta y Sylwan, 2005). 


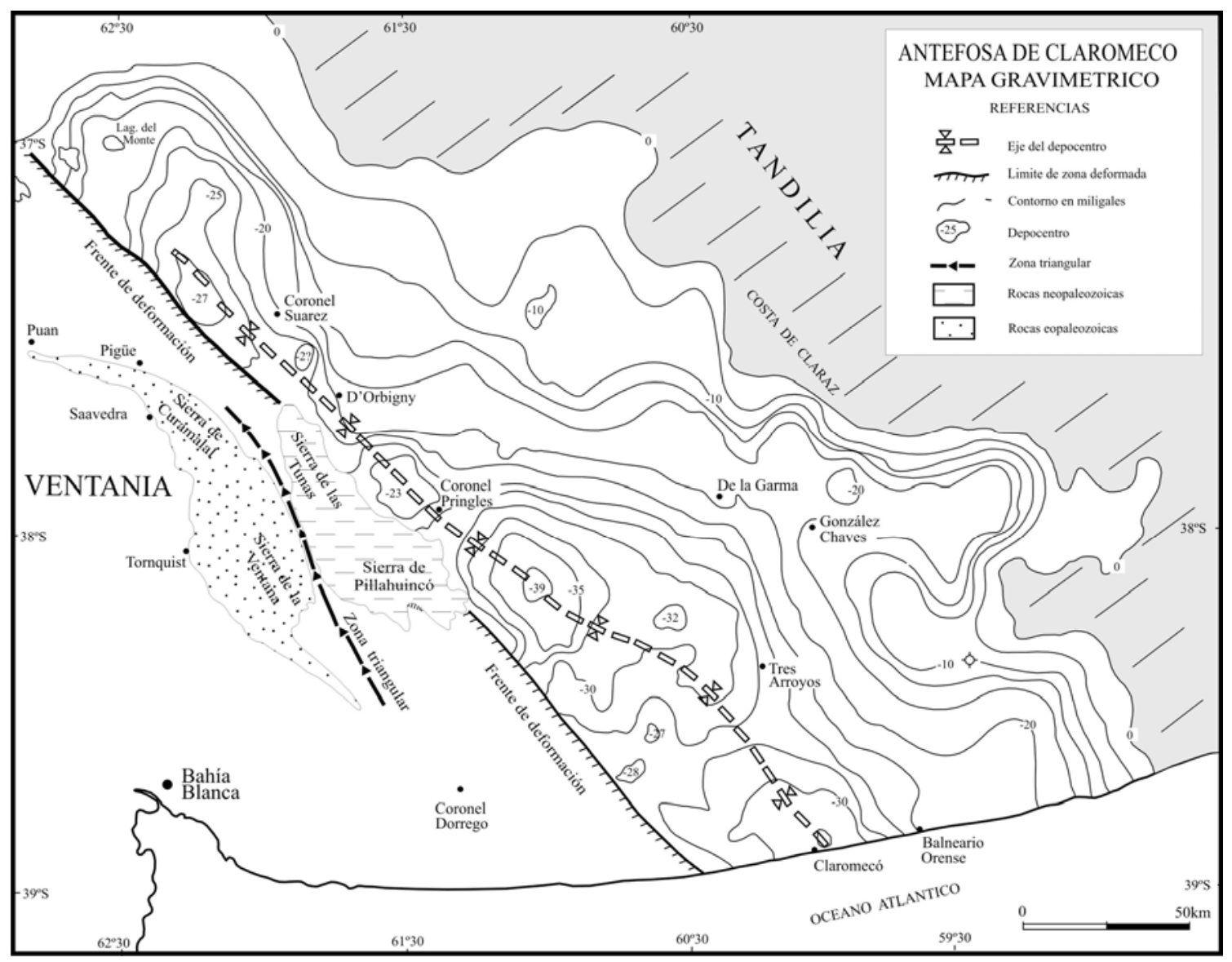

Figura 5. Cuenca Claromecó (tomado de Lesta y Sylwan, 2005).

La historia geológica de la Cuenca Claromecó (véase Lesta y Sylwan, 2005; Ramos y Kostadinoff, 2005) comienza con la apertura de la misma durante el Mesoproterozoico, y el relleno durante el lapso Neoproterozoico-Pérmico, para producirse el cierre de la sedimentación en el Lopingiano-Triásico Medio. Según el esquema de evolución de la Cuenca Claromecó (Figura 6) propuesto por Lesta y Sylwan (2005) a partir de información de subsuelo y afloramientos, las etapas de evolución serían:

a) basamento (Precámbrico Inferior): no ha sido perforado en subsuelo, aflora en el sector sur las Sierras Australes e incluye rocas metamórficas de bajo grado (equivalente a la Formación Sauce Chico en Ventania; Llambías y Prozzi, 1975) y rocas granitoides, migmatitas, milonitas y ectinitas (equivalentes al Complejo Buenos Aires 
de Tandilla), cuyas edades oscilan entre los 600 y 2000 Ma (véase Lesta y Sylwan, 2005).

b) Ciclo 1 (Precámbrico Superior-Cámbrico), incluye una pila sedimentaria (dolomitas, areniscas, conglomerados, calizas, arcilitas y limonitas) con un espesor mayor a los 520 m, litológicamente equivalente al Grupo Sierras Bayas y la Formación Cerro Negro de Tandilla, y probablemente correlacionable con el Grupo Curamalal de Ventania. Estas rocas se habrían formado en una plataforma marina estable con un alto nivel del mar.

c) Ciclo 2 (Ordovícico-Devónico Superior): involucra mas de $1370 \mathrm{~m}$ de sedimentitas equivalentes principalmente con el Grupo Ventana de Ventania (Lesta y Sylwan, 2005). Estas rocas se apoyan en discordancia erosiva y angular a escala regional, e incluye de base a techo conglomerados, areniscas cuarcíticas, alternancia de areniscas y pelitas negras, pelitas, areniscas, arcilitas y limonitas. Estás últimas portadoras de microfloras del Devónico Medio a Superior (Lesta y Sylwan, 2005). Por encima de estas rocas aparecería una unidad litoestratigráfica que sólo aparecen en el subsuelo (Formación Paragüil, Lesta y Sylwan, 2005) que incluye unos $250 \mathrm{~m}$ de areniscas y limonitas, también con microfloras neodevónicas.

d) Ciclo 3 (Pennsylvaniano-Guadalupiano-Lopingiano?): integrado por más de $2150 \mathrm{~m}$ de sedimentitas correlacionables al Grupo Pillahuincó de Ventania (véase Harrington, 1947, 1970, 1972, 1980). Este ciclo sedimentario incluye facies marinas, sedimentos marinos de plataforma y secuencias litorales hasta continentales. Dicho grupo sedimentario se apoya discordantemente sobre las sedimentitas devónicas de la Formación Lolén (Harrington, 1947). La primera información sobre Neopaleozoico serrano fue dada a conocer por Keidel (1916), quien mencionó la presencia de sedimentitas de origen glaciario en la zona. Posteriormente, Harrington (1933), dió a conocer la presencia de la Flora de Glossopteris ubicada sobre los niveles glaciales, años más tarde el mismo autor dió a conocer la presencia de invertebrados marinos, en particular pelecípodos asignados al género Eurydesma (Harrington, 1955). Ambas asociaciones fosilíferas incluyen elementos tipicamente gondwánicos y pérmicos.

El Grupo Pillahuincó, objetivo de este estudio, incluye de base a techo (Andreis et al., 1987, 1990; Andreis y Japas, 1996) a las formaciones Sauce Grande, Piedra Azul, Bonete y Tunas. En las tres últimas unidades, consideradas pérmicas, como se verá a 
continuación con más detalle presentan ciclos granocrecientes (Piedra Azul y Bonete) y granodecrecientes (Tunas).

e) Ciclo 4 (Cenozoico): incluye entre 120 y $200 \mathrm{~m}$ de sedimentitas, que por encima de una discordancia erosiva angular a escala regional, cubre la cuenca sedimentaria.

\section{II.1.1. Grupo Pillahuincó (Figura 7)}

II.1.1.a. Formación Sauce Grande (Keidel, 1916). Los depósitos basales del Ciclo 3 de Lesta y Sylwan (2005), fueron referidos a la Formación Sauce Grande (Pennsylvaniano), que fue definida para las Sierras Australes bonaerenses, e incluye unos $1100 \mathrm{~m}$ de depósitos (diamictitas, areniscas, pelitas y escasos conglomerados) de origen glacimarinos en un ambiente nerítico proximal de amplias plataformas someras (véase Harrington, 1972, 1980; Andreis, 1984; Andreis et al., 1987, 1990; Andreis y Japas, 1996; Andreis y Torres Ribeiro, 2003; Massabie et al., 2005; Gutiérrez et al., 2006a), con paleocorrientes generales hacia el N-NO.

Estos sedimentos fueron depositados por eventos de remosión en masa (Coates, 1969), motivo por el cual se formaron abundantes diamictitas. La alta frecuencia de diamictitas gruesas y la baja participación de facies traccionales, parecería indicar que el área de aporte de los materiales clásticos se hallaba en África austral (Cuencas de Karroo y Kalahari). La acción de los hielos flotantes ha sido inferida por la presencia de varvitas con cadilitos y de cúmulos de fenoclastos en las diamictitas (Andreis, 1984).

El evento glacimarino habría finalizado cuando se inició el proceso transgresivo relacionado con ajustes isostáticos que caracterizan épocas postglaciales (Andreis, 1984). Por esta causa se depositarán posteriormente las sedimentitas de la Formación Piedra Azul.

Por lo tanto dos glacihorizontes se identifican en la Formación Sauce Grande: el primero corresponde al megaciclo medio asociado con el avance de los glaciares en África del Sur (diamictitas y las variaciones litológicas asociadas), mientras que el segundo glacihorizonte estaría representando por las pelitas situadas en el sector del contacto de las formaciones Sauce Grande y Piedra Azul, vinculadas con el ascenso del mar. Es por ello que el pasaje entre las formaciones Sauce Grande y Piedra Azul es transicional debido al progresivo ascenso del nivel del mar en el sector superior de la 
primera formación, asociado con el progresivo deshielo ocurrido en las áreas continentales de la Cuenca Karroo.

Por su parte el contacto basal de la Formación Sauce Grande es con la Formación Lolén (pertenece al Grupo Ventana) y es del tipo angular.

En subsuelo (pozo Paragüil) esta unidad alcanza los $850 \mathrm{~m}$ de potencia y ha sido dividida en tres miembros (Lesta y Sylwan, 2005): superior, medio e inferior.

El miembro inferior (263 $\mathrm{m}$ de espesor) comprende principalmente diamictitas grises; mientras que el miembro medio $(428 \mathrm{~m})$ se encuentra conformado por una alternancia de areniscas cuarzosas y pelitas (limonitas tobáceas gris castaño y arcilitas gris oscuras). Estas rocas también se habrían formado en un ambiente glaciario y la mayor potencia aparecen hacia el oeste de la Cuenca. El miembro superior (165 m) incluye diacmictitas grises.

En las Sierras Australes bonaerenses, para la Formación Sauce Grande solamente se ha mencionado, para los bancos superiores que afloran en la región del Abra Fea, la presencia de bivalvos referidos a Astartella? pusilla Harrington (Riggi, 1935; Harrington, 1955), que según Amos (1980) no tendrían valor diagnótico.

Los restos provenientes de los asomos aledaños a la localidad de Lumb y asignados por Arrondo et al. (1982 en Andreis et al., 1987) y Arrondo y Petriella (1982 en Andreis et al., 1987) a Bumbudendron sp. cf. B. millani (Arrondo y Petriella) Arrondo y Petriella corresponderían según Morel y Gutiérrez (2000) a Malanzania nana Archangelsky et al.

En el subsuelo de la Cuenca Claromecó, la perforación Paragüil ha permitido obtener de las pelitas del miembro medio palinomorfos regularmente preservados, que según Lesta y Sylwan (2005) son referibles a la Biozona de PotonieisporitesLundbladispora.

En la plataforma continental las diamictitas superiores con contenido palinológico fueron atravesadas por la perforación Puelches x-1 (Archangelsky y Gamerro, 1980b), cuyos datos concuerdan con la edad pensylvanniana dada para la Formación Sauce Grande, lo que es ratificado por referencias posteriores (véase Archangelsky et al., 1987b, 1987c; López-Gamundi y Rossello, 1993, 1998), que precisan una edad pennsylvaniana (Stephaniano) a cisuraliana (Asseliano) para las sucesiones basales del Grupo Pillahuincó (véase también González, 1981). 
II.1.1.b. Formación Piedra Azul (Keidel, 1916). A ese evento glacial (Formación Sauce Grande) lo sucede un evento transgresivo (profundización de la cuenca asociado a un ascenso del nivel del mar), en el cual se retrabajan algunas de las diamictitas subyacentes. Este suceso se vincula al retroceso de los glaciares ubicados al este de Sudáfrica, durante el lapso comprendido desde fines del Asseliano y comienzos del Artinskiano.

Por lo tanto esta formación representaría el evento transgresivo postglacial (López-Gamundi, 1989, 1997; Andreis y Japas, 1996), que presenta un amplio registro geográfico (Cuencas Paraná, Chacoparaná, Calingasta-Uspallata, Río Blanco; véase Gutiérrez et al., 1997, 2006a; De Santa Ana, 2004; Limarino y Spalletti, 2006; Limarino y Césari, 2007). Las tillitas basales se habrían generado por la erosión de las diamictitas glaciales subyacentes (de la Formación Sauce Grande) y los ciclos grano y estratocrecientes de las secuencias pelíticas de la parte superior de la Formación Piedra Azul, reflejan el inicio de un evento regresivo (progradación en un sistema deltaico sobre las facies marinas).

En el área tipo (arroyo Piedra Azul), la Formación Piedra Azul y con una potencia de $300 \mathrm{~m}$, comprende dos secciones (inferior y superior) sobre la relación psamita/pelita. Hacia el NNO de la cuenca esta unidad exhibe una participación de psamitas y el espesor disminuye drásticamente.

La sección inferior está conformada básicamente por limolitas, fangolitas y escasas arcilitas de tonalidades azul negruzcas a verdosas. Incluye bancos de psamitas finas verdosas, amarillentas o castañas, con laminación, ondulas simétricas y capas macizas. Por su parte en la sección superior se incrementan las psamitas por sobre las pelitas, y se hacen más comunes la laminación ondulítica y las ondulitas (simétricas y asimétricas de crestas rectas) y aparecen algunas capas de laminación convoluta.

En subsuelo la Formación Piedra Azul (373 m de potencia), ha sido subdividida en tres secciones: inferior, medio y superior. La sección inferior (115 m) está integrada por arcilitas gris oscuro a negras, con pirita e intercalaciones de areniscas. Por su parte la sección media $(215 \mathrm{~m})$ incluye arcilitas gris a negras, limoarcilitas negras y limonitas negras grisáceas, con delgadas intercalaciones de areniscas finas de color gris y carbones. Por último la sección superior $(43 \mathrm{~m})$ comprende arcilitas y limonitas grises a 
negras. El ambiente sedimentario correspondería a un sistema de plataforma profunda (véase Lesta y Silwan, 2005).

Para la parte inferior de la unidad la Formación Piedra Azul, que aflora en la localidad tipo, han sido citados varios niveles con fauna marina (Keidel, 1938; Harrington, 1941, 1947, 1955; Andreis et al., 1987; Pagani, 1998), que incluye principalmente gasterópodos referidos al género Murchisonia, dispersos y mal conservados, y pueden hallarse también escasas bioturbaciones de tipo Endichnia.

Por su parte en el subsuelo las rocas referidas a la sección superior de la Formación Piedra Azul, han brindado palinomorfos referibles a la Biozona Cristatisporites (véase Lesta y Sylwan, 2005), característica del CisuralianoGuadalupiano de la Cuenca Chacoparaná (véase Archangelsky et al., 1996b).

López-Gamundi et al. (1995) asignaron a la Formación Piedra Azul una edad probable asseliana-sakmariana, a partir de las probables edades inferidas para las formaciones Sauce Grande (Asseliano) y Bonete (Sakmariano).

II.1.1.c. Formación Bonete (Harrington, 1947). En las Sierras Australes bonaerenses este evento transgresivo fue sucedido por un período regresivo, que dió origen a la aparición de extensas planicies de mareas, instalándose un sistema deltaico, dominado por olas y mareas (Formación Bonete). Este sistema deltaico habría sido destructivo ya que en el perfil tipo se obervan el dominio de estructuras sedimentarias originadas por la acción del oleaje y de las mareas (de amplitud meso a macromareal), tales como la abundancia de facies heterolíticas, bipolaridad de las paleocorrientes y ausencia de barras litorales (Andreis et al., 1987, 1990; Andreis y Japas, 1996).

En subsuelo presenta una potencia de $330 \mathrm{~m}$ y aparece compuesta por areniscas finas a muy finas y limonitas negras a gris oscuras que gradan a arcilitas; que por su contenido palinológico fue referida al Cisuraliano (Lesta y Sylwan, 2005).

En las Sierras Australes el contenido paleontológico de la Formación Bonete incluye moldes de valvas dispersas o agrupadas de bivalvos correspondientes a la fauna de Eurydesma (Harrington, 1955; Rocha Campos y Carvalho, 1975; Amos, 1980; Archangelsky et al., 1980b; Andreis et al., 1987; Andreis y Japas, 1996; Pagani 2000), también considerada como fauna Bonetiana por González (1993), caracterizada por una baja diversidad genérica y específica lo que sugeriría una restricción faunística debido a la 
retracción del "mar de Eurydesma" y el consecuente aislamiento paleogeográfico (González, 1993). Esta fauna indicaría una edad pérmica (Asseliano tardío-Sakmariano temprano).

El contenido paleontológico de esta unidad también incluye abundantes hojas, tallos y semillas de gimnospermas, Glossopteris juntos a escasos fragmentos de licofitas, articuladas y coníferas (Harrington, 1933, 1947; Menéndez, 1966; Archangelsky y Cúneo, 1984; Archangelsky et al., 1980b; Ruiz y Bianco, 1989; Andreis et al., 1987; Andreis y Japas, 1996), que se intercalan con los niveles marinos (Andreis et al., 1987). La flora ha sido referida a la Biozona de Glossopteris de edad sakmariana-artinskiana (Archangelsky y Cúneo, 1984; Archangelsky et al., 1996b).

La fauna de la Formación Bonete indicaría una edad asseliana temprana (González, 1981), en la transición Asseliano-Sakmariano (Runnegar, 1972; Rocha Campos y Carvalho, 1975) o asseliana tardía-artinskiana (Pagani, 2000); mientras que la flora una edad sakmariana-artinskiana (Archangelsky y Cúneo, 1984).

II.1.1.d. Formación Tunas (Harrington, 1933). Por encima de la Formación Bonete y en concordancia continúa la Formación Tunas, cuyos términos cuspidales no son conocidos, y representa la culminación del evento transgresivo, cuando se instalan ambientes con predominio de las condiciones continentales.

En las Sierras Australes incluye unos $1000 \mathrm{~m}$ de areniscas finas a medianas, grises, pelitas negras laminadas con restos de plantas y bivalvos marinos (véase Andreis et al., 1987, 1990; Andreis y Japas, 1996), chonitas vítreas y tobas. Mientras que en subsuelo la Formación Tuna incluye unos $600 \mathrm{~m}$ de pelitas carbonosas y calcáreas, potadoras de palinomorfos referibles al Cisuraliano (Lesta y Sylwan, 2005).

Esta secuencia sedimentaria representa un período regresivo que permitió la aparición de extensas planicies mareales o estuarios próximos a un área continental de bajo relieve, en condiciones más someras y oxidantes. Las secuencias cuspidales de la formación habrían sido depositadas en ambientes cercanos a la costa y con predominio parcial de las condiciones continentales (Andreis et al., 1987, 1990; Zavala et al., 1993).

La flora de la Formación Tunas es similar a aquella de la Formación Bonete (Harrington, 1970; Furque, 1967, 1973; Andreis et al., 1987; Andreis y Japas, 1996), en especial aquella correspondiente a la parte inferior de la unidad que incluye restos de 
Glossopteris indica Schimper, Gangamopteris obovata (Carruthers) D. White, articuladas Phyllotheca sp., y licópsidas?. Algunos restos mal preservados de bivalvos son mencionados por Iñíguez et al. (1988) para la región del Abra del Despeñadero.

Sobre la base de evidencias estratigráficas, tectónicas y de correlación, LópezGamundi et al. (1995) ubicaron la sedimentación correspondiente a la Formación Tunas en el intervalo Sakmariano-Kazaniano. Estudios paleomagnéticos realizados por Tomezzoli (1999) han establecido un intervalo mínimo de $20 \mathrm{Ma}$ (durante el Lopingiano) para la sedimentación de la Formación Tunas en el área de las Sierras Australes de Buenos Aires. De esta manera, se produce el cierre de la sedimentación en el lapso Lopingiano-Triásico Medio, con el apilamiento tectónico del relleno sedimentario de la Antefosa de Claromecó (vésae Massabie et al., 2005). 


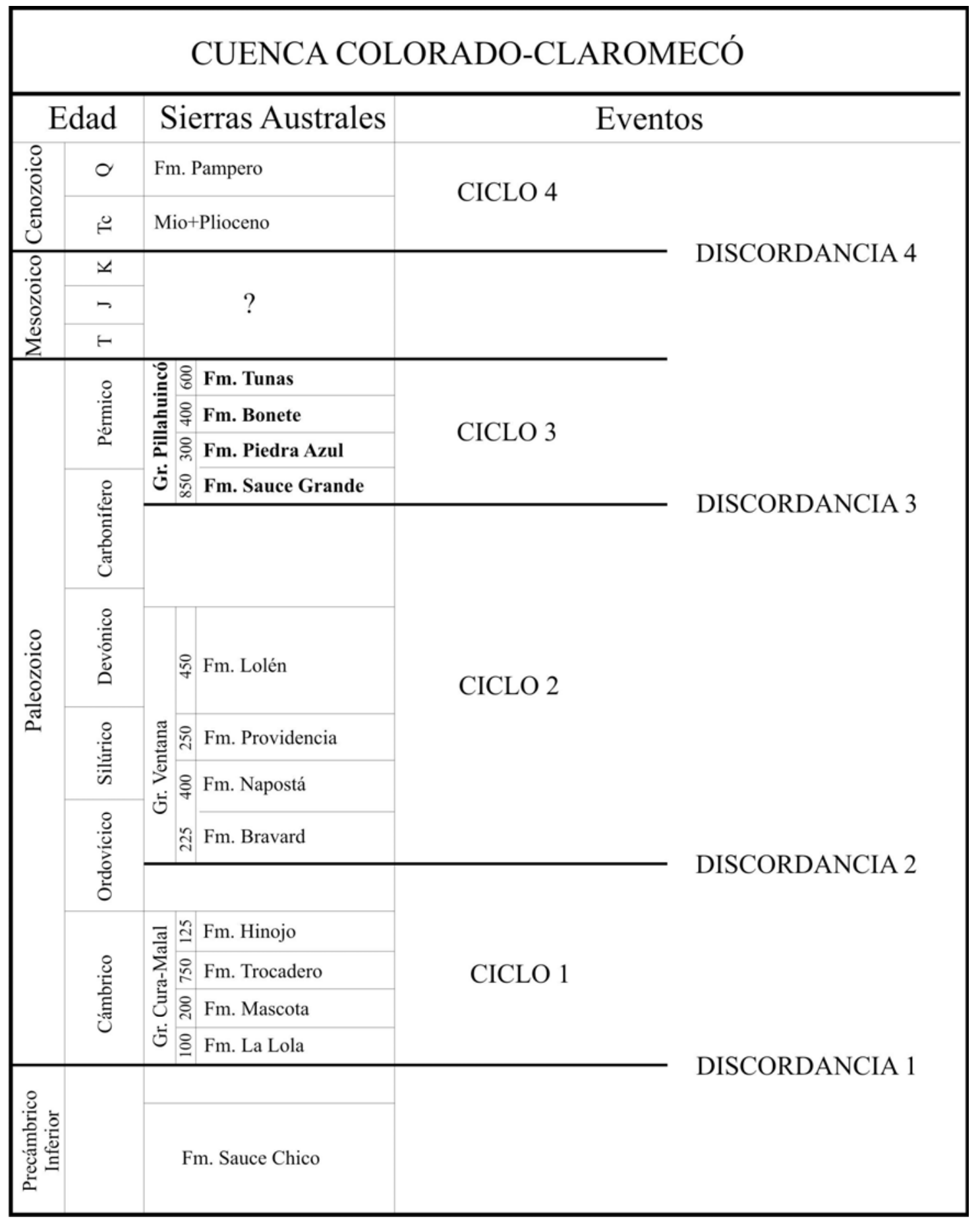

Figura 6. Evolución de la Cuenca Claromecó (tomado de Lesta y Sylwan, 2005). 


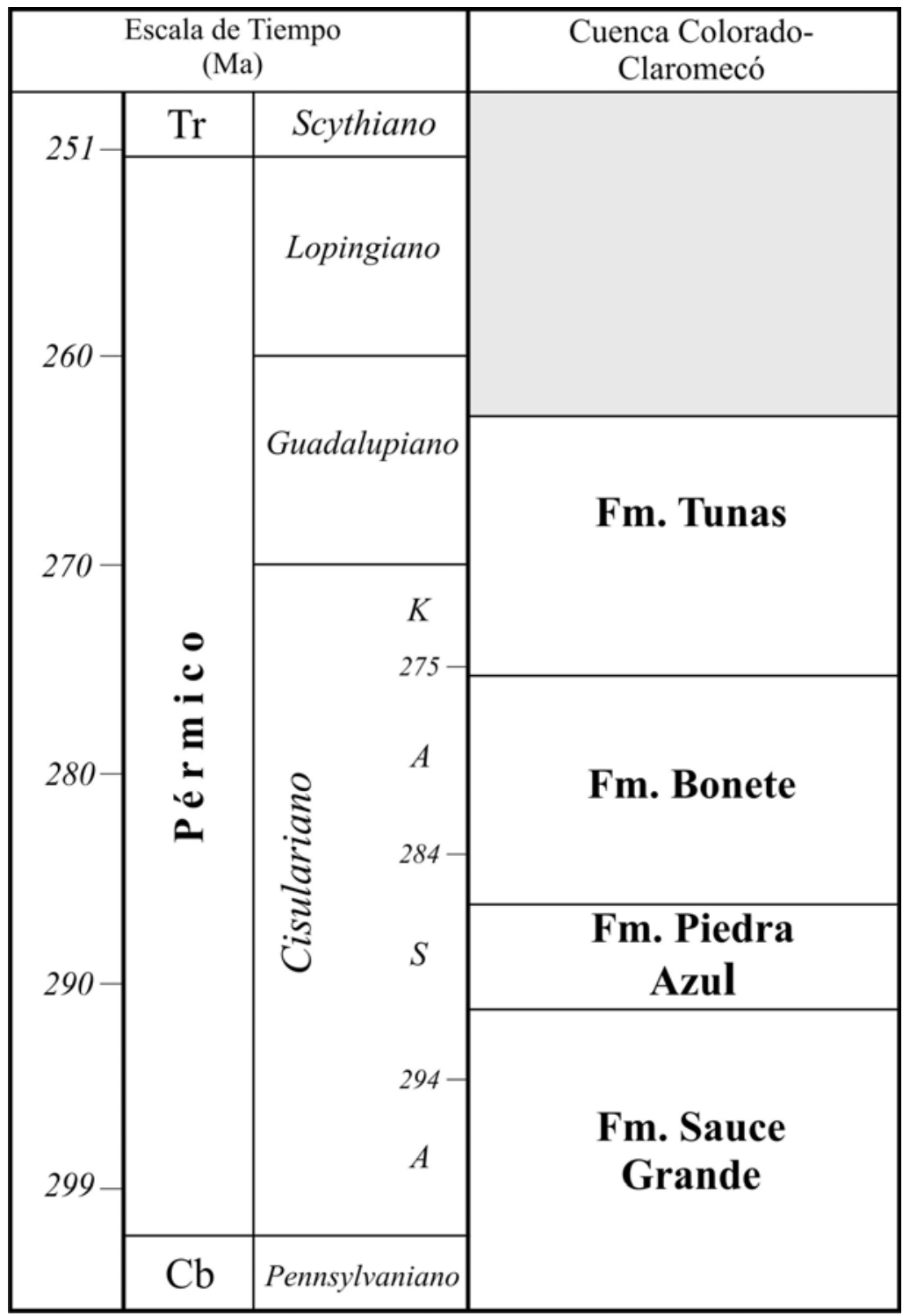

Figura 7. Grupo Pillahuincó: cronoestratigrafía.

\section{II.2. Cuenca Colorado}

La Cuenca Colorado pertenece a una serie de cuencas sedimentarias mesozoicas de rift localizadas en el margen continental atlántico (Figuras 1, 3 y 4). Presenta una forma elongada (con su eje mayor en dirección este-oeste), se desarrolla al sudeste de la provincia de Buenos Aires y cubre una superficie aproximada de $178.000 \mathrm{~km}^{2}$ (Debarre et al., 2002; Pucci, 2006), dos tercios de ella se desarrollan costa afuera en aguas de hasta $350 \mathrm{~m}$ de profundidad (Plataforma Continental Argentina) donde, como ya mencionamos, se superpone a la Cuenca Claromecó (Figura 3), también abarca la parte 
sur de la provincia de Buenos Aires, y pequeños sectores del oeste de las provincias de La Pampa y Río Negro; entre los 64²0’ O, al oeste, y el talud continental, al este (véase Zambrano, 1972, 1980; Fryklund et al., 1996; Juan et al., 1996a, 1996b; Yrigoyen, 2000; Casadío et al., 1999, 2000; Visconti et al., 2000, 2003, Elorriaga y Visconti, 2005, 2006; Gebhard, 2005).

En esta cuenca el Neopaleozoico subyace en discordancia angular a sucesiones cretácicas, cuyas características litofaciales y paleobiológicas las hacen coetáneas con los afloramientos serranos (Lesta et al., 1980, Mainardi et al., 1979), pudiéndose interpretar como la extensión marina de la Cuenca Claromecó y sólo puede ser alcanzado por medio de perforaciones.

Ambas cuencas cubren una superficie de $155,000 \mathrm{~km}^{2}$, aunque los afloramientos solo alcanzan a medir casi 40,000 $\mathrm{km}^{2}$ (Andreis et al., 1987, 1990). Las cuencas, aparentemente, estarían vinculadas, dada esta conexión por medio del subsuelo de la plataforma actual, motivo por el cual han de considerarse una única cuenca, ya que representarían a los mismos eventos (Cuenca Colorado-Claromecó).

Varios autores han aportado información para tratar de dilucidar el origen, evolución y estratigrafía de las Cuencas Colorado y Claromecó, entre los que podemos mencionar Kaasschieter (1963, 1965), Zambrano (1974), Yrigoyen (1975), Rolleri (1975), Lesta et al. (1979), Andreis et al. (1990), Urien y Zambrano (1996), Elorriaga y Visconti (2005, 2006), Franke et al. (2006, 2007). Sin embargo es partir de la exploración de hidrocarburos que se avanza en conocimiento de la geología de esta cuenca, comprobando por otra parte la presencia de un sistema petrolero activo, aunque sin hallar hasta el momento acumulaciones comerciales de hidrocarburos (Juan et al., 1996b; Fryklund et al., 1996; Figueroa et al., 2005; Lesta y Sylwan, 2005; Gehbard, 2005). En ambas cuencas el Paleozoico se desarrolla principalmente en el subsuelo (en especial la Cuenca Colorado) y el mismo sólo puede ser alcanzado por medio de perforaciones.

La Cuenca Colorado ha sido caracterizada como una cuenca aulacógena (Gehabrd, 2005), que se formó durante el Jurásico Tardío-Cretácico Temprano, cuando se produjo la apertura del Atlántico Sur, por procesos extensionales que tuvieron lugar sobre antiguas fracturas transcurrentes sobre el basamento y/o viejas zonas de sutura de sistema arco-fosa de edad precámbricas-paleozoicas existentes (Yrigoyen, 1975; 
Stoakes et al., 1991; Gehbard, 2005). La interpretación de su origen ha sido discutida por varios autores (Yrigoyen, 1975; Burke, 1976; Urien y Zambrano, 1996; Schümann, 2002), a los que referimos al lector que desee profundizar el tema. En este trabajo seguiremos el esquema propuesto y modificado por Fryklund et al. (1996), Juan et al. (1996b), Yrigoyen (2000), Gehbard (2005), que propone que el desarrollo de la cuenca está relacionado a las etapas de rift y posterior ruptura de la corteza continental, los que definen los límites de 4 secuencias tectonoestratigráficas mayores: pre-rift (Paleozoico), syn-rift (Jurásico Tardío-Cretácico Temprano), post-rift y margen pasivo (Figura 8).

\section{II.2.1. Estadío de Pre-rift}

Se desarrolla sobre un basamento de edad precámbrica-eopaleozoica, constituido por rocas ígneo-metamórficas con edades de hasta 2200 Ma que afloran en el Cratón de Tandilla, y por un paquete de sedimentitas eopaleozoicas afectadas por una fuerte deformación.

Sobre este basamento se produce la sedimentación continental gondwánica de edad paleozoica tardía, la que constituye la continuación costa afuera de la Cuenca Claromecó. Estos depósitos afloran en la Sierra de La Ventana y está representado por el Grupo Pillahuincó; allí con un espesor aproximado de $3000 \mathrm{~m}$ abarca el intervalo Carbonífero Tardío-Pérmico Tardío, según su contenido paleontológico (Fryklund et al., 1996; Juan et al,. 1996b). En la parte basal del grupo aparecen espesas secuencias glacimarinas (Formación Sauce Grande), seguidas por pelitas marinas oscuras de prodelta o frente deltaico (Formación Piedra Azul), pasando gradualmente a depósitos marinos marginales (Formación Bonete) y continentales (Formación Tunas).

Según Gehbard (2005), 15 perforaciones (Figura 4) han atravesado los depósitos del pre-rift, destacándose: Puelche x-1 (atravesó 400 m de diamictitas de la Formación Sauce Grande y 1200 de pelitas correspondientes a la Formación Piedra Azul); los pozos Cruz del Sur x-1 y Corona Austral x-1, perforaron areniscas cuarzosas referidas a la Formación Bonte; y la perforación Estrella x-1, por su parte atravesó lutitas pérmicas referidas a las formaciones Piedra Azul, Bonete y, probablemente, Tunas.

Según Schümann (2002) comprende unos $1500 \mathrm{~m}$ de pelitas negras lacustres equivalentes a la Formación Iratí (véase Stoakes et al., 1991). 


\section{II.2.2. Estadío de Syn-rift (Jurásico Tardío-Cretácico Temprano)}

Estos depósitos están circunscriptos al relleno de los hemigrábenes que están orientados regionalmente con rumbo noroeste-sudeste, y han sido identificadas en subsuelo como Formación Fortín (Zambrano, 1974). Esta unidad incluye unos $4550 \mathrm{~m}$ (potencia máxima en el centro de la cuenca) de depósitos continentales (sedimentos aluviales poco seleccionados que proviene de la erosión del Paleozoico, con abundante contenido de sedimentos rojos y fragmentos volcánicos, tal cual lo señalan Fryklund et al., 1996, para los pozos Corona Austral x-1 y Estrella x-1).

Estas rocas han sido perforadas en los sectores oriental y sur de la Cuenca (Corona Austral x-1, Estrella x-1 y Cruz del Sur x-1). La información palinológica dla perforación Cruz del Sur x-1 (Quattrochio y Guerstein, 1994) y las dataciones de las rocas volcánicas, permitieron a Fryklund et al. (1996) señalar una edad que varía entre los 140 y $110 \mathrm{Ma}$.

En sectoroccidental ha sido alcanzada por las perforaciones Ombuctá x-1 y Pedro Luro x-1, donde se apoyan directamente sobre el basamento precámbrico.

\section{II.2.3. Estadío de Post-rift (Cretácico Temprano: Albiano-Maastrichtiano)}

A partir del Barremiano, con el ingreso de las aguas atlánticas, se inicia la etapa de subsidencia térmica (sag), como consecuencia de ello la cuenca adquiere una geometría cóncava, tipo cabeza de toro (Gehbard, 2005).

Los sedimentos del post-rift (con un espesor máximo de $7000 \mathrm{~m}$ ) están representados por la Formación Colorado (Zambrano, 1974) de edad cretácica; incluye en su parte basal sedimentos clásticos continentales tipo red bed (según Zambrano, 1974, originados en una llanura aluvial), mientras que la parte superior incluye sedimentitas originadas en ambientes deltaicos a marinos de plataforma. Esta unidad presenta importantes cambios faciales en dirección este-oeste, pasando gradualmente de depósitos continentales en los bordes de la cuenca (pozos Puelches x-1, A x-1, B x-1, La Ballena x-1 y Pingüino x-1) a un ambiente marino hacia el este (Cruz del Sur: pelitas marinas profundas sobre areniscas fluvio deltaicas, que sobreyacen a una potente secuencia continental) (Gehbard, 2005). En la parte superior de la unidad los foraminíferos y microplancton presentes la ubican en el Turoniano-Santoniano (Guerstein y Junciel, 2001; Riccardi, 1988). 
La transgresión regional marina continúa durante el lapso AlbianoCenomaniano, y está representada en la parte superior de la Formación Colorado. Esta unidad pasa transicionalmente a la Formación Pedro Luro (Kaasschieter, 1963, 1965), constituida por pelitas y arciltas gris oscuras fosilíferas, areniscas y calizas depositadas en un ambiente netamente marino, probablemente de plataforma media externa durante el Daniano (Zambrano, 1974), en un clima subtropical a tropical (Quattrocchio y Sarjeant, 1996). Según Fryklund et al. (1996) habría un hiato de entre 5 y 10 Ma entre ambas unidades. La Formación Pedro Luro contiene foraminíferos y microplancton (Berggren, 1962; Quattrocchio y Sarjeant, 1996; Ruiz y Quattrochio, 1996; Ruiz y Quattrochio, 1997a, 1997b; Quattrocchio et al., 2000; Guerstein y Junciel, 2001; Guerstein et al., 2005). Por su parte Lesta et al. (1978) describieron basaltos y tobas (Formación Ranquel), datadas en $66+/-3$ Ma asociadas a esta formación.

Estas rocas (post-rift) aparecen en casi todo los sectores de la cuenca, salvo en sus márgenes donde el Terciario se apoya directamente sobre el basamento.

\section{II.2.4. Estadío de Margen Pasivo (Paleógeno-Cuaternario)}

Durante este lapso se estableció un margen pasivo y se depositaron las unidades paleogenas y neógenas: formaciones Elvira (Kaasschieter, 1965), Barranca Final (Kaasschieter, 1965) y Belén (Kaasschieter, 1965), así como los depósitos cuaternarios. Estas rocas representan una secuencia regresiva-transgresiva-regresiva, con un máximo evento transgresivo durante el Oligoceno, que responde a una secuencia progradacional mayor que estuvo controlada por el balance de las fluctuaciones eustáticas del nivel mar y el aporte sedimentario proveniente del oeste (Juan et al., 1996b).

La Formación Elvira y su equivalente Formación Ombuctá (Eoceno) incluye una alternancia de areniscas verde glauconíticas y bancos calcáreos depositados en una ambiente marino nerítico y de plataforma media (Zambrano, 1974), en un ambiente tropical (Eoceno temprano) a templado (Eoceno medio-tardío) (Guerstein et al., 1995); con ambundantes microfósiles (Malumián, 1970, 1972; Gamerro y Archangelsky, 1981b; Guerstein y Quattrocchio, 1988, 1991; Malumián y Náñez, 1996; Malumián et al., 1998; Guerstein, 1990a, 1990b, 1990c; Caramés y Malumián, 2000; Guerstein y Guler, 2000; Guerstein y Junciel, 2001). Por su parte la Formación Barranca Final (Mioceno), incluye arcilitas y pelitas grises a verdes fosilíferas (Malumián, 1970, 1972; 
Becker y Bertels, 1980; Gamerro y Archangelsky, 1981b; Guerstein y Quattrocchio, 1988, 1991; Quattrocchio et al., 1986; Guerstein, 1990a, 1990b, 1990c; Malumián et al., 1998; Guerstein y Guler, 2000; Guler et al., 2001, 2002; Guerstein y Junciel, 2001; Guler y Guerstein, 2002; Guler, 2003; Caccavari y Guler, 2006), con intercalaciones de areniscas, depositadas en un ambiente marino de plataforma media a interna (Zambrano, 1974). Por último la Formación Belén (Plioceno Medio-Superior), está constituida por areniscas gris azuladas, con intercalaciones de arcilitas y arcilitas tobáceas depositadas en un ambiente fluvial o en un complejo deltaico, en la parte occidental de la cuenca; mientras que hacia el este, corresponde a un ambiente marino de playa (Schürmann, 2002). Tambien contiene microplancton (Guler y Guerstein, 2002).

El ciclo sedimetario finaliza con depósitos clásticos cuaternarios, de origen continental. 


\begin{tabular}{|c|c|c|c|}
\hline Período & Edad & Unidades estratigráficas & Tectónica \\
\hline Cuaternario & & Sedimentos cuaternarios & \multirow{5}{*}{$\begin{array}{c}\text { Margen } \\
\text { pasivo }\end{array}$} \\
\hline & & . & \\
\hline Mioceno & & $\begin{array}{l}\text { Fm. } \\
\text { Barranca Final }\end{array}$ & \\
\hline \multicolumn{3}{|l|}{ Oligoceno } & \\
\hline Eoceno & & Fm. Elvira & \\
\hline $\begin{array}{l}\text { Cretácico } \\
\text { Superior }\end{array}$ & \begin{tabular}{|c|} 
Daniano \\
Maastrichtiano \\
Campaniano \\
Santoniano \\
Coniaciano \\
Turoniano \\
Cenomaniano \\
\end{tabular} & \multirow[t]{3}{*}{$\begin{array}{c}\text { Fm. } \\
\text { Colorado }\end{array}$} & \multirow[t]{3}{*}{ Post-rift } \\
\hline & \begin{tabular}{|c|} 
Aptiano \\
Barremiano \\
\end{tabular} & & \\
\hline $\begin{array}{l}\text { Cretácico } \\
\text { Inferior }\end{array}$ & 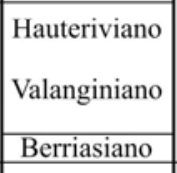 & & \\
\hline $\begin{array}{l}\text { Jurásico } \\
\text { Superior }\end{array}$ & Tithoniano & $\begin{array}{l}\text { Fm. } \\
\text { Fortín }\end{array}$ & Syn-rift \\
\hline $\begin{array}{c}\text { Pérmico } \\
\text { Pennsylvaniano }\end{array}$ & & $\begin{array}{c}\text { Grupo } \\
\text { Pillahuincó }\end{array}$ & Pre-rift \\
\hline
\end{tabular}

Figura 8. Esquema de las 4 secuencias tectonoestratigráficas mayores: pre-rift (Paleozoico), syn-rift (Jurásico Tardío), post-rift (Cretácico Temprano-Paleoceno) y margen pasivo (Eoceno-Cuaternario) (modificado de Fryklund et al., 1996; Juan et al., 1996b; Irigoyen, 2000; Gehbard, 2005). 


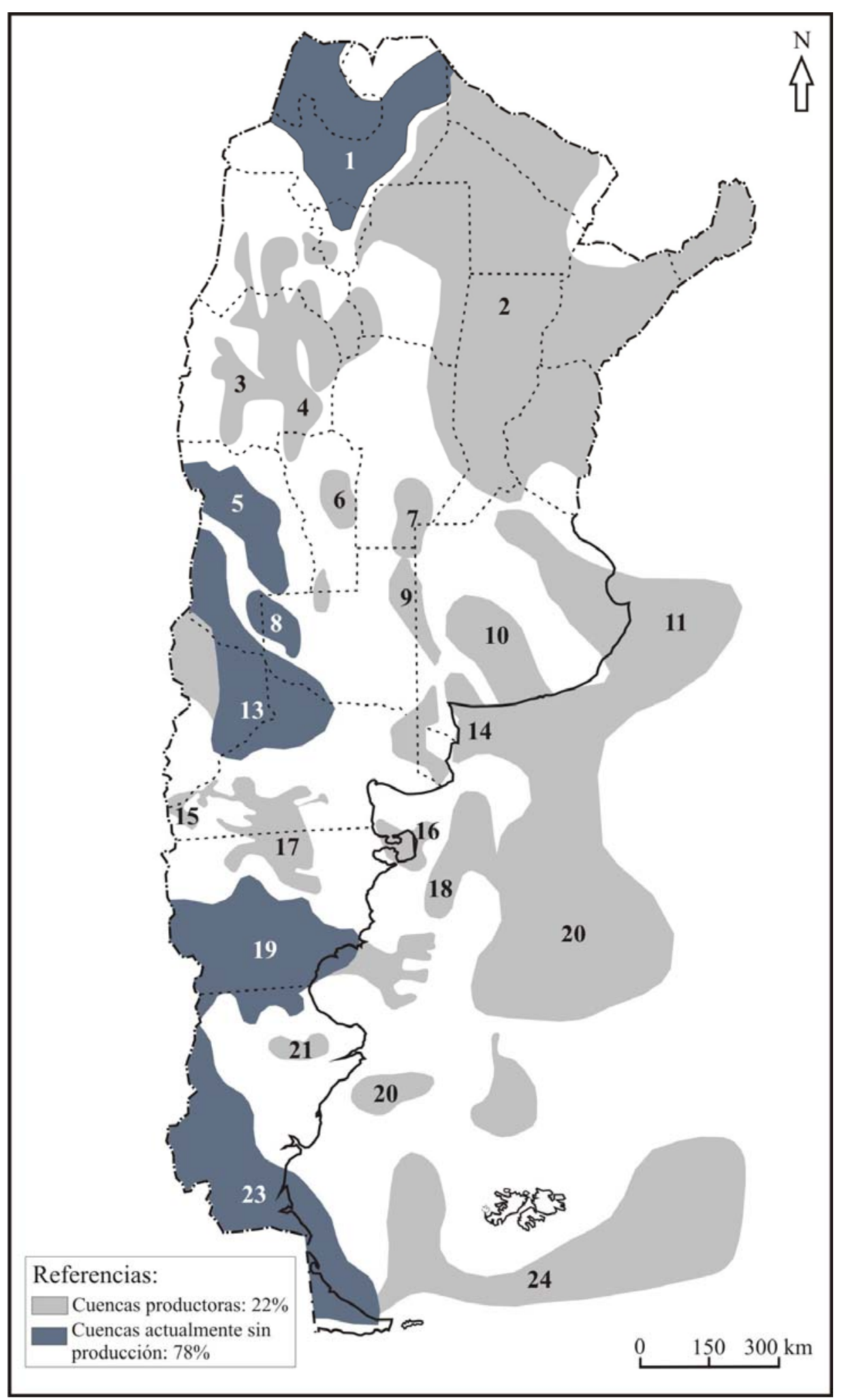

Figura 9. Cuencas petroleras productoras y sin producción actual. Cuencas: 1 Noroeste, 2 Chacoparaná, 3 Bolsones intermontanos, 4 San Luis, 5 Cuyana, 6 Mercedes, 7 Gral. Lavalle, 8 San Rafael, 9 Macachín, 10 Claromecó, 11 Del Salado, 12 NO de Neuquén, 13 Neuquina, 14 Del Colorado, 15 Nirihuau, 16 Península de Valdez, 17 Cañadón Asfalto, 18 Rawson, 19 Golfo de San Jorge, 20 Cuenca Argentina, 21 El Tranquilo, 22 San Julián, 23 Austral, 24 Malvinas (tomado de IAPG, 2005). 


\section{II.3. Perforaciones realizadas en las Cuencas Colorado y Claromecó}

Debido al potencial como cuencas petrolíferas (Figura 9) a partir de la segunda mitad del siglo pasado se han realizado una serie de perforaciones (Figura 4) y estudios sísmicos y gravimétrícos que permitieron comprender el origen y evolución de las cuencas y su potencial como generadora de hidrocarburos (véase Fryklund et al., 1996; Juan et al., 1996b; Bushnell et al., 2000; Ploszkiewicz, 1999; Franke et al., 2002, 2007; Lesta, 2002; Mancilla et al., 2002; Schümann et al., 2002; Gebhard, 2005; Ramos y Kostadinoff, 2005; Pucci, 2006) (Figura 9).

En la parte continental de la Cuenca Colorado, entre los años 1946 y 1948, YPF realizó las primeras perforaciones exploratorias YPF.Pedro Luro x-1 (1946; TD, 3278 mbnm) y Ombuctá x-1 (1948; TD, $1836 \mathrm{mbnm})$. Por su parte entre los años 1960 y 1961, Shell y Esso perforaron 7 pozos terrestres: Shell-Elvira x-1 (1960; TD 953 mbbp), La Blanqueada x-1 (1960; TD 944 mbbp), Lagunas Dulces x-1 (1960; TD 442 mbbp), Oyola x-1 (1960; TD 861 mbbp), O’Connor x-1 (1960; TD 654 mbbp), C.O x-1 (1961; TD 3394 mbbp) y Los Gauchos x-1 (1961; TD 2602 mbbp), y a mediados de los años 70 se inició la exploración costa afuera, en la parte occidental de la cuenca, en aguas con profundidades menores a los 200 metros. De este modo la petrolera Hunt perforó los pozos BB-II-La Ballena x-1 (1970), BB-II-Delfín x-1 (1970) y BB-II-Pingüino x-1 (1970); mientras que Phillips-AGIP otros nueve: BB-III-A x-1 (1970), BB-III-B x-1 (1970), BB-III-C x-1 (1970), BB-III-D x-1 (1970), BB-III-E x-1 (1970), BB-III-F x-1 (1970), BB-III-G x-1 (1970), BB-III-H x-1 (1970) e BB-III-I x-1 (1970) (Véase Figura 4). Para la nomenclatura de las perforaciones se siguió el criterio planteado por Robles (2003, 2005).

Según Fryklund et al. (1996) las perforaciones PP A x-1, PPC H x-1 y PPC I x1, habrían alcanzado las areniscas del Paleozoico. Por su parte el Paleozoico documentado por fósiles fue alcanzado con los pozos: YPF CCM I.Puelches x-1 y YPF CCM I.Ranquel x-1, realizados en el año 1977.

Recién a fines de la década del '80 se reabre la exploración en la Cuenca Colorado, y la UTE (Unión Transitoria de Empresas) conformada por las empresas Unión Texas, Pérez Companc e YPF, realizó en el sector oriental de la Cuenca (bloque exploratorio CCM-1) tres perforaciones: UTAL.CCM-1.Cruz del Sur x-1, UTAL.CCM1.Corona Austral x-1 y UTAL.CCM-1.La Estrella x-1, las que como tenían por objeto 
investigar el inicio del relleno de la cuenca (syn-rift de edad neojurásica). Las mismas alcanzaron el basamento de la misma, conformado por el Paleozoico Superior.

A partir de 1994 la empresas Shell e YPF exploran los Bloques CAA-42 y CAA4, y posteriormente en 1997 la UTE Shell-Pecten-Agip, realizaron la perforación Pejerrey x-1, en el último bloque (Archangelsky et al., 1997).

Por último, la exploración en aguas profundas se encaró a partir de 1999 cuando Repsol-YPF adquirió los Bloques CAA 7, CAA 47 y CCM 2, localizados en aguas cuya profundidad varía entre los 200 y $4000 \mathrm{~m}$ (plataforma externa y talud).

De los pozos exploratorios realizados en la Cuenca Colorado durante la década del '80 y ubicados en la plataforma continental argentina, sólo 3 alcanzaron el Paleozoico Superior: UTAL.CCM-1.CdS.x-1, UTAL.CCM-1.CA.x-1 y UTAL.CCM1.LE.x-1.

Por su parte en la Cuenca Claromecó la empresa Bridas realizó perforaciones en 1999 y 2003: Paragüil x-1 (1999, TD, 3378 mbnm), San Cayetano x-1 (1999, TD, 2047 mbnm), Lamadrid x-1 (2003, TD, 2488 mbnm) y San Mayol x-1 (2003, TD, 1395 mbnm). El conocimiento de la palinología del Neopaleozoico de esta cuenca se restringe a algunos informes inéditos no disponibles (Archangelsky, 1998, 1999) y a la información publicada por Lesta y Sylwan (2005).

Poco es lo que se conoce sobre la palinología del Neopaleozoico de la Cuenca del Colorado. Los primeros datos palinológicos para Cuenca Colorado se obtuvieron de las perforaciones efectuadas por YPF: Ranquel.x-1 y Puelches.X-1 y corresponden a informes inéditos (Archangelsky y Gamerro, 1980a) y algunos trabajos publicados, sin mucho detalle (Archangelsky y Gamerro, 1980b; Archangelsky, 1996b).

La perforación Puelches x-1 ha brindado, de litologías asimilables a la Formación Sauce Grande, asociaciones palinológicas que permitieron asignarle una edad carbonífera tardía-pérmica temprana (Archangelky y Gamerro, 1980b).

Por su parte, las perforaciones UTAL-Estrella.x-1 y UTAL-Cruz del Sur.x-1, también ubicadas en la plataforma continental argentina, atraviesan secuencias neopaleozoicas con un importante contenido palinológico, que comprenderían el lapso que va desde el inicio hasta el final del Pérmico; estas secuencias sedimentarias serían equivalentes a las formaciones Sauce Grande, Piedra Azul, Bonete y Tunas (véase 
Fryklund et al., 1996; Juan et al., 1996b), definidas en el sector continental de la cuenca (provincia de Buenos Aires; véase Andreis et al., 1987, 1990).

En la perforación La Estrella.x-1, un intervalo pelítico (3000-3430 m de profundidad) referible a las formaciones Piedra Azul, Bonete y Tunas (?), ha brindado microfloras indicadoras de todo el Pérmico. Por su parte, la perforación Cruz del Sur.X1, atraviesa sedimentitas (4000-4250 mbnm), también asignables a la totalidad del Pérmico equivalentes a las mismas unidades (véase Fryklund et al., 1996; Juan et al,. 1996b; Archangelsky, 1996b; Gutiérrez et al., 2003b; Balarino, 2006, 2008).

La perforación Puelche x-1 alcanzó las diamictitas glacimarinas (referidas a la Formación Sauce Grande), perforando unos $1500 \mathrm{~m}$ de sedimentitas, y su contenido palinológico (Archangelsky y Gamerro, 1980b) permitió asignarle una edad pennsylvaniana-cisuraliana. A partir de la determinación de dos asociaciones polínicas en la columna de sedimentitas neopaleozoicas a travesadas: una superior, con siete niveles fosilíferos y otra inferior con cinco niveles.

Según Archangelsky y Gamerro (1980b) la asociación superior está comprendida en los $300 \mathrm{~m}$ cuspidales del espesor neopaleozoico, que incluye granos de polen monosacados (Potonieisporites, Plicatipollenites, Cannanaropollis), bisacados lisos (Alisporites, Limitisporites, Platysaccus), bisacados estriados (Corisaccites, Lueckisporites, Lunatisporites, Protohaploxypinus, Staurosaccites, Striatopodocarpites), plicados (Marsupipollenites), esporas de morfología variada (Punctatisporites, Converrucosisporites, Convolutispora, Lundbladispora, Cristatisporites) y prasinofitas (Brazilea). Una transición de aproximadamente $100 \mathrm{~m}$, en la que disminuye la proporción de granos de polen estriados (Protohaploxypinus) y aumentan los monosacados (Cannanaropollis, Plicatipollenites, Potonieisporites) y las esporas (Vallatisporites, Krauselisporites, Cristatisporites, Lundbladispora, Punctatisporites), caracteriza a la asociación inferior que se desarrolla en los $1100 \mathrm{~m}$ restantes.

Las asociaciones estudiadas fueron comparadas (véase Archangelsky, 1996b), con las asociaciones provenientes de la Cuenca Chacoparanense, de este modo la asociación superior fue referida a la biozona Striatites (Guadalupiano), mientras que la asociación inferior a la biozona Cristatisporites (Cisuraliano) y, los términos basales de 
la asociación inferior serían referibles a la biozona Potonieisporites-Lundbladispora (Pennsylvaniano).

La perforación La Estrella x-1 atraviesa un intervalo rico en lutitas pérmicas vinculadas a las formaciones Piedra Azul, Bonete y posiblemente Tunas. De estas perforaciones, se han realizado análisis de detalle tanto petrográficos como así también datos de porosidad (véase Fryklund et al., 1996; Juan et al., 1996b).

\section{II.3.1. Perforación UTAL-Cruz del Sur x-1 (Figura 4)}

Esta perforación (57¹7’40” O; 4056’10” S), realizada en el año 1994, a $91 \mathrm{~m}$ de profundidad del nivel del mar (mbnm); atraviesa una espesa secuencia clástica (TD, 4288 mbnm) cuya edad va desde el Pleistoceno hasta el Pérmico. Las unidades perforadas incluyen, sucesivamente (Figura 8):

-Formación Belén (736 m de potencia; entre 91 y 827 mbnm), Plio-Pleistoceno

-Formación Barranca Final (826 m), Plioceno Superior-Eoceno

-Formación Elvira (75 m; entre los 1753 y 1828 mbnm), Eoceno-Paleoceno

-Formación Pedro Luro (205 m), Paleoceno-Cenomaniano

-Formación Colorado (679 m; entre los 2023 y 2072 mbnm), Cenomaniano-Albiano.

-Formación Fortín (148 m), Albiano

-Sedimentos referidos a la etapa Syn-rift (1144 m; entre 2850 y 3994 mbnm), Jurásico Superior?-Barremiano-Aptiano

-Sedimentitas referidas al techo del Pre-rift (294 m), entre los 3994-4288 mbnm, Pérmico. Comprende areniscas cuarzosas macizas y pelitas portadoras de una rica microflora, que es analizada en este trabajo.

De esta perforación se analizaron muestras de cutting (Cuadro 3) de las siguientes profundidades: 4010-4020 mbnm, 4095-4098 mbnm, 4113-4119 mbnm, 4173-4193 mbnm, 4176-4182 mbnm, 4209-4227 mbnm, 4212-4218 mbnm y del testigo $3995 \mathrm{mbnm}$ (todos del Pérmico). Material paleozoico aparece retrabajado en varias muestras de cutting, como por ejemplo en las profundidades 3540-3686 mbnm (Syn-rift inferior), y entre los 2900-3000 mbnm (techo del Syn-rift).

\section{II.3.2. Perforación UTAL-Estrella x-1}


Esta perforación realizada en el año 1995, está localizada a 58¹2'52” O; 40³5'32" S, a unos $89 \mathrm{~m}$ de profundidad del nivel del mar y un TD, $3545 \mathrm{mbnm}$, atraviesa una espesa secuencia clástica (3427,5 m de potencia) cuya edad va desde el Pleistoceno hasta el Pérmico. Las unidades perforadas incluyen, sucesivamente (Figura 8):

-Formación Belén (377 m de potencia; entre 89 y 466 mbnm), Plio-Pleistoceno

-Formación Barranca Final (1074 m), Oligoceno-Plioceno

-Formación Elvira (284 m; entre 1540 y1824 mbnm), Eoceno medio a superiorMioceno

-Formación Pedro Luro (51 m), Daniano-Maastrichtiano

-Formación Colorado (517 m; entre 1875 y 2492 mbnm), Cenomaniano-Albiano

-Formación Fortín (112 m), Albiano

-Sedimentos de syn-rift (382 m; entre 2604 y 2986 mbnm), Cretácico Inferior

-Sedimentitas referidas al Pre-rift (559 m), entre los 2986-3545 mbnm, Pérmico.

Comprende predominantemente pelitas no marinas, que según Fryklund et al. (1996) son equivalentes a las formaciones Piedra Azul y Bonete, y probablemente Tunas.

De esta perforación se estudiaron muestras de 10 testigos de las profundidades 3428 mbnm, 3380 mbnm, 3330 mbnm, 3280 mbnm, $3231 \mathrm{mbnm}, 3180$ mbnm, 3130 mbnm, 3081 mbnm, 3031 mbnm, 2992,9 mbnm. 24 muestras de cutting, 3522-3549 mbnm, 3498-3522 mbnm, 3474-3498 mbnm, 3450-3474 mbnm, 3426-3450 mbnm, 3399-3426 mbnm, 3375-3599 mbnm, 3351-3575 mbnm, 3327-3351 mbnm, 3303-3327 mbnm, 3279-3303 mbnm, 3255-3279 mbnm, 3231-3255 mbnm, 3207-3231 mbnm, 3183-3207 mbnm, 3159-3283 mbnm, 3132-3159 mbnm, 3108-3132 mbnm, 3084-3108 mbnm, 3060-3084 mbnm, 3036-3060 mbnm, 3012-3036 mbnm, 2988-3012 mbnm, 2964-2988 mbnm y 2940-2964 mbnm.

\section{II.3.3. Perforación YPF-Puelches x-1}

La palinología del Neopaleozoico atravesada por esta perforación fue estudiada por Archangelsky y Gamerro (1980), quienes analizaron el contenido de la secuencia entre los 2440 m y $3200 \mathrm{~m}$ de profundidad. Según la información publicada entre los 2440 y $2700 \mathrm{~m}$ la microflora aparece integrada por:

\section{Esporas triletes}

-Granulatisporites micronodosus Balme y Hennelly 1956 
-Convolutispora sp.

-Cristatisporites sp.

-Lundbladispora braziliensis (Pant y Srivastava) Marques-Toigo y Pons emend. Marques-Toigo y Picarelli 1985

-Punctatisporites gretensis Balme y Hennelly 1956a

Prasinofitas

-Brazilea sccisus (Balme y Hennelly) Foster 1975

Granos de polen monosacados

-Cananoropollis densus (Lele) Bose y Maheshwari 1968

-Plicatipollenites sp.

-Potonieisporites brasiliensis (Nahuys, Alpern e Ybert) Archangelsky y Gamerro 1979

Granos de polen bisacados

-Alisporites sp.

-Limitisporites sp.

-Platysaccus sp.

Granos de polen estriados-plicados

-Corisaccites $\mathrm{sp}$.

-Lueckisporites cf. virkkiae (Potonié y Klaus) emend. Klaus 1963

-Lunatisporites sp.

-Marsusipollenites sp.

-Protohaploxypinus sp.

-Staurosaccites sp.

-Striatopodocarpidites sp.

Este intervalo fue referido a la Biozona Striatites por Archangelsky y Gamerro (1980b) y Archangelsky (1996b).

\section{Esporas triletes}

Entre los $2800 \mathrm{~m}$ y $3200 \mathrm{~m}, 5$ niveles presentan asociaciones integradas por:

-Cristatisporites inconstans Archangelsky y Gamerro 1979

-Kraeuselisporites sp.

-Vallatisporites pp.

-Lundbladispora braziliensis (Pant y Srivastava) Marques-Toigo y Pons emend. Marques-Toigo y Picarelli 1985

-Punctatisporites gretensis Balme y Hennelly 1956a

Granos de polen monosacados

-Cannanoropollis cf. korbaensis (Bharadwaj y Tiwari) Foster 1975

-Plicatipollenites malaberensis (Potonié y Sah) Foster 1975

-Potonieisporites sp.

Granos de polen bisacados

-Alisporites sp.

-Limitisporites sp.

Granos de polen estriados

-Protohaploxypinus sp.

Este intervalo fue referido a las Biozonas Potonieisporites-Lunbladispora y Cristatisporites por Archangelsky y Gamerro (1980b) y Archangelsky (1996b).

Una revisión crítica de este listado (véase el Capítulo V. SISTEMÁTICA), a partir de las ilustraciones de Archangelsky y Gamerro (1980b, láminas I y II) se realizó 
para este trabajo, teniendo en cuenta también el listado brindado por Archangelsky (1996b), quedando de la siguiente manera el listado para la perforación Puelches x-1:

\begin{tabular}{|c|c|c|}
\hline Archangelsky y Gamerro (1980b) & Archangelsky (1996b) & Este trabajo \\
\hline \multicolumn{3}{|c|}{$2440 \mathrm{~m}-2700 \mathrm{~m}$} \\
\hline Granulatisporites micronodosus & G. micronodosus & Converrucosisporites micronodosus \\
\hline Convolutispora $\mathrm{sp}$. & C. sp. & Convolutispora $\mathrm{sp}$. \\
\hline Cristatisporites $\mathrm{sp}$. & C. sp. & Cristatisporites $\mathrm{sp}$. \\
\hline Lundbladispora braziliensis & L.braziliensis & Lundbladispora braziliensis \\
\hline Punctatisporites gretensis & P. gretensis & Punctatisporites gretensis \\
\hline Brazilea sccisus & B. sccisus & Brazilea sccisa \\
\hline Cannanoropollis cf. densus & C. cf. densus & Cannanoropollis cf. densus \\
\hline Plicatipollenites sp. & P. sp. & Plicatipollenites sp. \\
\hline Potonieisporites cf. brasiliensis & P. cf. brasiliensis & P. brasiliensis \\
\hline Alisporites sp. & A. sp. & A. australis \\
\hline Limitisporites sp. & L. sp. & Limitisporites sp. \\
\hline Platysaccus sp. & P. sp. & P. quenslandii \\
\hline Corisaccites sp. & & C. alutas \\
\hline Lueckisporites cf. virkkiae & L. cf. virkkiae & Lueckisporites cf. virkkiae \\
\hline Lunatisporites sp. & L. sp. & L. sp. cf. L. variesectus \\
\hline Marsusipollenites sp. & M. sp. & Marsusipollenites sp. \\
\hline Protohaploxypinus sp. & P.sp. & P. sp. cf. P. amplus \\
\hline Staurosaccites sp. & S. sp. & S. sp. cf. S. cordubensis \\
\hline Striatopodocarpidites sp. & S. sp. & Striatopodocarpidites sp. \\
\hline \multicolumn{3}{|c|}{$2800 \mathrm{~m}-3200 \mathrm{~m}$} \\
\hline Cristatisporites inconstans & C. inconstans & Cristatisporites inconstans \\
\hline Kraeuselisporites sp. & $K . \mathrm{sp}$. & K. sp. \\
\hline Vallatisporites sp. & V. sp. & V. arcuatus \\
\hline Lundbladispora braziliensis & L. braziliensis & Lundbladispora braziliensis \\
\hline Punctatisporites gretensis & P. gretensis & Punctatisporites gretensis \\
\hline Cannanoropollis cf. korbaensis & C. cf. korbaensis & C. korbaensis \\
\hline Plicatipollenites malabarensis & P. malabarensis & P. malabarensis \\
\hline Potonieisporites sp. & P. sp. & Potonieisporites sp. \\
\hline Alisporites sp. & A. sp. & Alisporites sp. \\
\hline Limitisporites sp. & L. sp. & Limitisporites sp. \\
\hline Protohaploxypinus sp. & P. sp. & Protohaploxypinus sp. \\
\hline
\end{tabular}

Cuadro 1. Perforación YPF.Puelches x-1; listado del contenido palinológico del Pérmico. 


\section{MATERIALES y MÉTODOS}

Para llevar a cabo el trabajo de Tesis se procedió al estudio de las microfloras obtenidas de muestras provenientes de dos perforaciones (UTAL.CMM.1.Estrella x-1 y UTAL.CMM.1.Cruz del Sur x-1), ubicadas en la plataforma continental argentina, las cuales atraviesan las secuencias neopaleozoicas. Las perforaciones fueron llevadas a cabo a fines de la década de los '90 por UTE (Unión Transitoria de Empresas) y se obtuvieron muestras tanto de testigo como de cutting. Los preparados y los residuos de las mismas estaban depositados en la Colección de Paleopalinología del MACN (Museo Argentino de Ciencias Naturales), bajo la sigla BAPal. De los residuos se montaron preparados para los correspondientes estudios en el microscopio óptico, como así también para el microscopio electrónico de barrido (MEB). Las muestras fueron depositadas en dicha colección.

El procesamiento de la muestras palinológicas fue realizado utilizando técnicas fisicoquímicas convencionales (véase Wood et al., 1996 y Figura 10). De la perforación La Estrella se realizaron preparados provenientes de 10 niveles testigo y 25 de cutting; y de la perforación Cruz del Sur se realizaron preparados provenientes de 12 muestras de cutting. Las muestras en general evidencian un variado grado de preservación, pudiendo observarse desde microfloras de excelente preservación a microfloras muy alteradas. El material estudiado se halla depositado en la colección Palinológica del Museo Argentino de Ciencias Naturales "Bernardino Rivadavia” (BA Pal) (Cuadros 2 y 3 ).

Listado de preparados y sus correspondientes números de colección:

\section{*Perforación La Estrella x-1}

\begin{tabular}{|c|l|l|l|}
\hline Unidad estratigráfica & La Estrella x-1 & Preparados & BA Pal \\
\hline $\begin{array}{c}\text { Syn-rift } \\
\text { Cretácico Inferior }\end{array}$ & $\mathbf{2 9 4 0 - 2 9 6 4 ~ m}$ & $1(\mathrm{a})$ & 6135 \\
\cline { 2 - 4 } Grupo Pillahuincó & $\mathbf{2 9 6 4 - 2 9 8 8 ~ \mathbf { ~ }}$ & $1(\mathrm{a})$ & 6136 \\
\cline { 2 - 4 } Pérmico & $\mathbf{2 9 8 8 - 3 0 1 2} \mathbf{~ m}$ & $1(\mathrm{a})$ & 6137 \\
\cline { 2 - 4 } & $\mathbf{2 9 9 2 , 9} \mathbf{~ m}$ & $3(\mathrm{a}, \mathrm{b}, \mathrm{c})$ & 6138 \\
\cline { 2 - 4 } & $\mathbf{3 0 1 2 - 3 0 3 6} \mathbf{~ m}$ & $1(\mathrm{a})$ & 6139 \\
\cline { 2 - 4 } & $\mathbf{3 0 3 6 - 3 0 6 0} \mathbf{~ m}$ & $1(\mathrm{a})$ & 6140 \\
\cline { 2 - 4 } & $\mathbf{3 0 3 1} \mathbf{~ m}$ & $1(\mathrm{a})$ & 6141 \\
\cline { 2 - 4 } & $\mathbf{3 0 6 0 - 3 0 8 4} \mathbf{~ m}$ & $1(\mathrm{a})$ & 6142 \\
\cline { 2 - 4 } & $\mathbf{3 0 8 1} \mathbf{~ m}$ & $2(\mathrm{a}, \mathrm{b})$ & 6143 \\
\cline { 2 - 4 } & $\mathbf{3 0 8 4 - 3 1 0 8} \mathbf{~ m}$ & $1(\mathrm{a})$ & 6144 \\
\hline
\end{tabular}




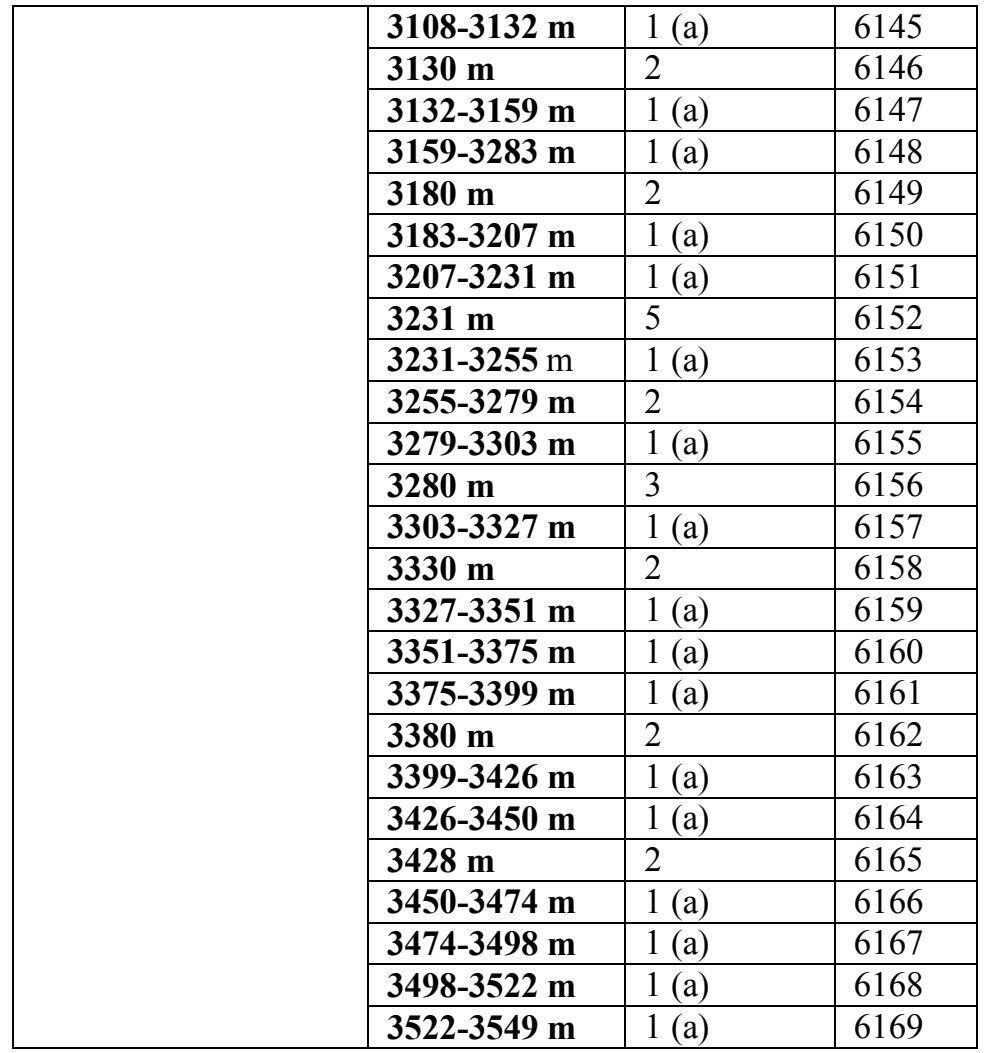

Cuadro 2. Preparados y números de colección de las muestras de la perforación La Estrella x-1.

\section{*Perforación Cruz del Sur x-1}

\begin{tabular}{|c|c|c|c|}
\hline Unidad estratigráfica & Cruz del Sur x-1 & Preparados & BA Pal \\
\hline \multirow{12}{*}{$\begin{array}{c}\text { Syn-rift } \\
\text { Jurásico Superior? } \\
\text { Barremiano-Aptiano }\end{array}$} & $2900-2920 \mathrm{~m}$ & 1 (a) & 6170 \\
\hline & $2920-2940 \mathrm{~m}$ & 1 (a) & 6171 \\
\hline & $2940-2960 \mathrm{~m}$ & 1 (a) & 6172 \\
\hline & $2950 \mathrm{~m}$ & $1(\mathrm{a})$ & 6173 \\
\hline & $2960-2980$ & 2 & 6174 \\
\hline & $2980-3000$ & 2 & 6175 \\
\hline & $3540 \mathrm{~m}$ & 1 (a) & 6176 \\
\hline & $3600 \mathrm{~m}$ & 1 (a) & 6177 \\
\hline & $3006 \mathrm{~m}$ & 2 & 6178 \\
\hline & $3630 \mathrm{~m}$ & $1(\mathrm{a})$ & 6179 \\
\hline & $3650 \mathrm{~m}$ & 1 (a) & 6180 \\
\hline & $3686 \mathrm{~m}$ & 1 (a) & 6181 \\
\hline \multirow{8}{*}{$\begin{array}{c}\text { Grupo Pillahuincó } \\
\text { Pérmico }\end{array}$} & $3995 \mathrm{~m}$ & $1(\mathrm{a})$ & 6182 \\
\hline & $4010-4020 \mathrm{~m}$ & 2 & 6183 \\
\hline & 4095-4098 m & 2 & 6184 \\
\hline & 4113-4119 m & 2 & 6185 \\
\hline & 4176-4182 m & $1(\mathrm{a})$ & 6186 \\
\hline & 4173-4193 m & 1 (a) & 6187 \\
\hline & $4209-4227 \mathrm{~m}$ & 1 (a) & 6188 \\
\hline & $4212-4218 \mathrm{~m}$ & $1(\mathrm{a})$ & 6189 \\
\hline
\end{tabular}

Cuadro 3. Preparados y números de colección de las muestras de la perforación Cruz del Sur x-1. 
Las muestras fueron examinadas utilizando un microscopio binocular de luz transmitida marca Olympus, modelo BX 51. Las fotografías de los ejemplares fueron realizadas utilizando una cámara de fotografía digital, marca Olympus, modelo C-5060.

Para ampliar estudios morfológicos se montaron muestras para estudio en microscopio electronico de barrido (MEB) marca Philips serie XL modelo 30 perteneciente al Museo Argentino de Ciencias Naturales, de las asociaciones con mejor preservación (pozo La Estrella, niveles testigo 3428, 3380 y $3231 \mathrm{mbnm}$ ). Los residuos se diluyeron en agua mineral, y utilizando el microscopio óptico, con objetivos de $\mathrm{x} 4 \mathrm{y}$ x 10 aumentos, se seleccionaron los mejores ejemplares con una pipeta y fueron montados sobre una película fílmica fijada con una emulsión adherente de purpurina y extracto de banana, sobre un taco de aluminio apto para el microscopio. Los concentrados obtenidos fueron deshidratados y una vez secos, fueron metalizados previamente a la observación. Las fotografías fueron tomadas entre los 650 y 1500 aumentos para el caso de los ejemplares completos, y con hasta 6500 aumentos para detalles de escultura.

En cada preparado fue barrida la totalidad de las microfloras observadas, tomándose fotografías, coordenadas y dimensiones en aquellos ejemplares que presentaban una buena preservación, y en aquellos otros de preservación más pobre se tomaban solo coordenadas y dimensiones.

Para la clasificación sistemática supragenérica de las esporas y granos de polen se siguió el esquema de Potonié y Kremp (1954), y las posteriores modificaciones (ver Playford y Dettmann, 1996). Las algas verdes fueron clasificadas en el presente estudio según la propuesta de Colbath (1996).

Los granos de polen de simetría bilateral fueron descriptos siguiendo la terminología utilizada por Playford y Dino (2002).

Todas las especies reconocidas fueron detalladamente descriptas e ilustradas. Para las descripciones se siguió el Glossary of Pollen and Spore Terminology (www.bio.uu.nl/ palaeo/glossary/; Punt et al., 2007). Para realizar los porcentajes relativos de los distintos grupos microflorísticos se contaron al menos 400 ejemplares en cada una de las muestras estudiadas de los niveles testigo. Aquellos ejemplares observados de pobre preservación y de dificil asignación genérica y/o específica fueron considerados también en los conteos, pero asignados a grupos morfológicos. 
Las medidas de los ejemplares estudiados son expresadas en micrones $(\mu \mathrm{m})$ y se consideran los valores mínimo y máximo y un valor de media aritmética que está expresado entre paréntesis. Se consideran medidas tanto de morfología general como de escultura. Los conceptos longitudinal y transversal, como así también los parámetros usados en las distintas mediciones se ilustran en la Figura 11.

En la sinonimia se incluyó solo el nuevo material, que presenta importancia bioestratigráfica, ya sean términos sinónimos o malas asignaciones, los que fueron discutidos detalladamente. 
MUESTRA DE ROCA

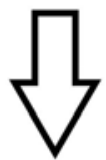

Disgregación por medios físicos

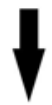

Eliminación de los carbonatos

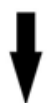

Tratamiento con solución de HCL (24 hs)

3 lavados del residuo

(decantando el sobrenadante)

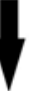

Eliminación de los silicatos

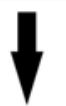

Tratamiento con solución de HF 70\% (48 hs)

3 lavados del residuo

(decantando el sobrenadante)

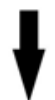

Concentración del residuo y montaje

Oxidación (agua oxigenada o HNO3)

Filtrado (malla mayor a 17 micrones)

Montaje (fracción +17)

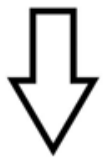

\section{OBSERVACIÓN DEL PREPARADO AL MICROSCOPIO ÓPTICO}

Figura 10. Esquema de técnicas fisico-químicas utilizadas para el procesamiento de las muestras palinológicas. 


\section{MEDIDAS EN ESPORAS}

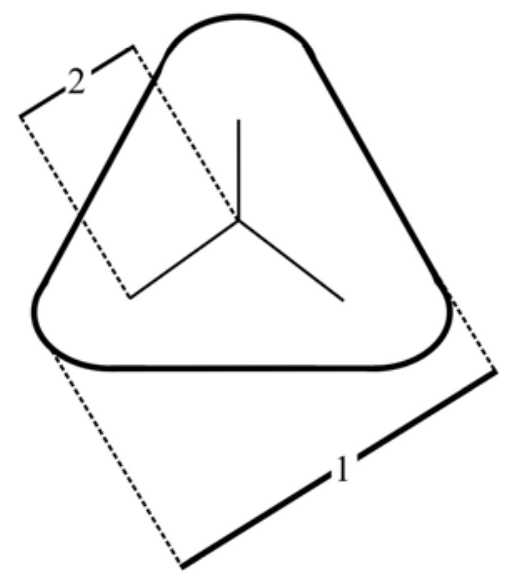

1- Diámetro total

2- Rayo de la lesura
MEDIDAS EN GRANOS DE

POLEN BISACADOS

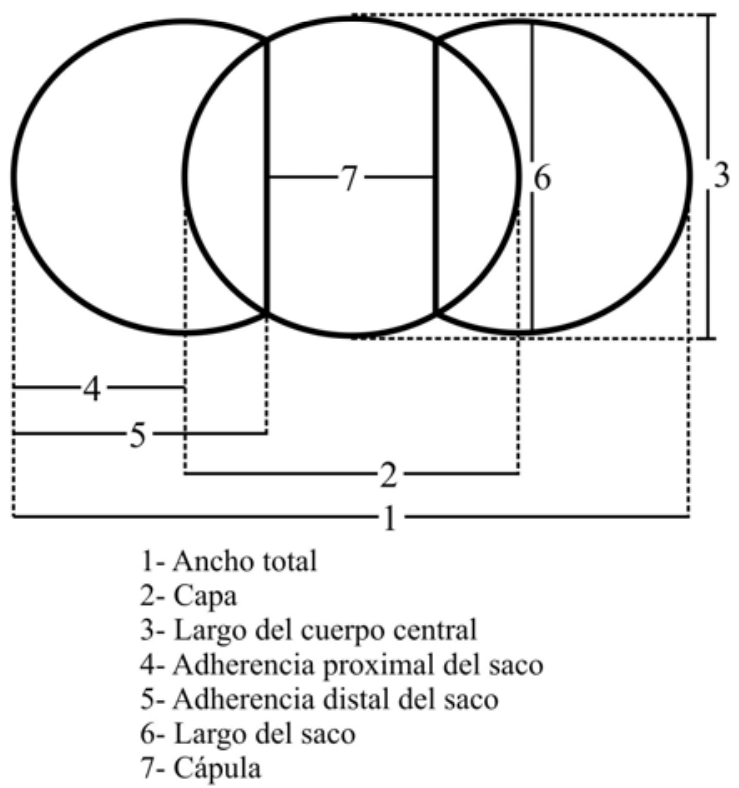

MEDIDAS EN GRANOS DE POLEN MONOSACADOS

DE SIMETRÍA RADIAL

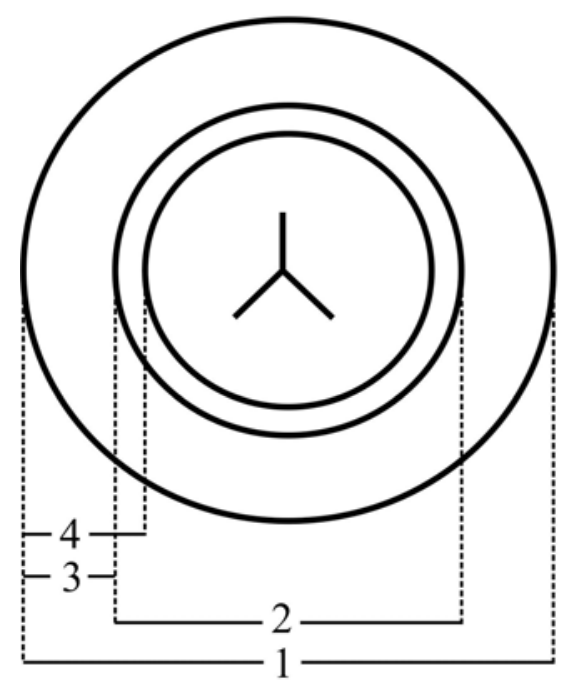

1- Diámetro total

2- Diámetro del cuerpo central

3- Adherencia proximal del saco

4- Adherencia distal del saco
DE SIMETRÍA BILATERAL

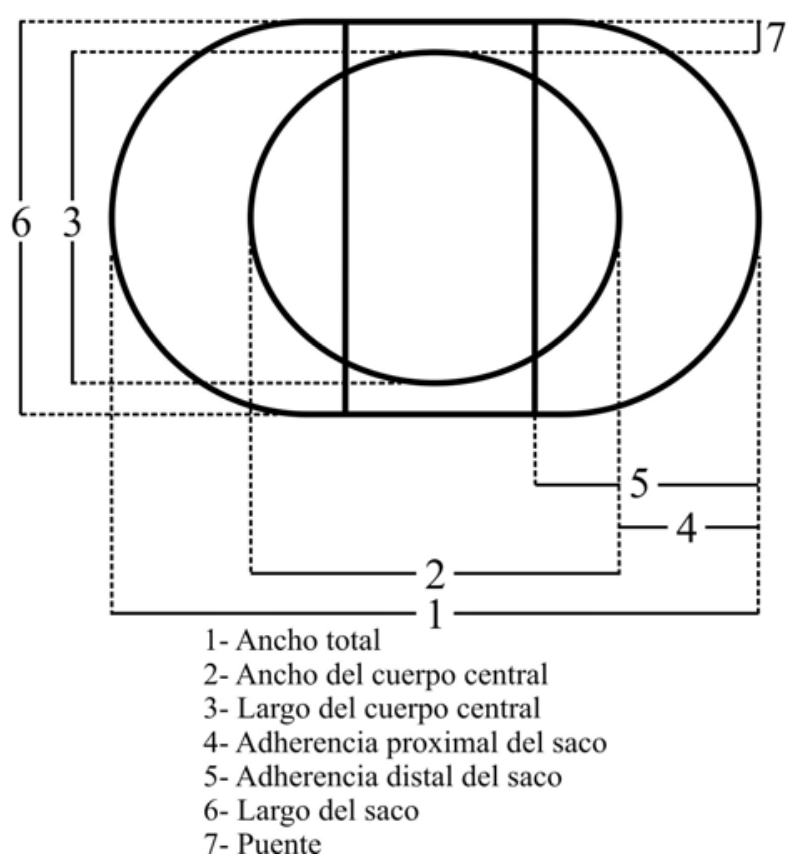

Figura 11 Parámetros de mediciones consideradas. 
Para cada especie descripta se consideró su distribución estratigráfica conocida y se la incluyó en ítem Registros previos, donde se comenta brevemente para que nivel, localidad y período fue descripta (presente), está listada y/o ilustrada. Esta información se ordenó de manera temporal y espacial, y está expresada también en el Cuadro 7, para su análisis cronológico.

En la presente Tesis se adoptó la división del Sistema Pérmico propuesto por Gradstein et al. (2004) (Figura 12).

\begin{tabular}{|c|c|c|c|c|c|}
\hline Era & Período & Subperíoc & Época & Edad & $0 \pm$ \\
\hline \multirow{16}{*}{$\begin{array}{c}0 \\
0 \\
0 \\
0 \\
0 \\
0 \\
0 \\
0 \\
0 \\
0 \\
0\end{array}$} & \multirow{9}{*}{ ○ِ } & \multirow{2}{*}{\multicolumn{2}{|c|}{ Lopingiano }} & Changhsiangiano & \\
\hline & & & & Wuchiapingiano & \\
\hline & & \multirow{3}{*}{\multicolumn{2}{|c|}{ Guadalupiano }} & Capitaniano & $00,+1$ \\
\hline & & & & Wordiano & \\
\hline & & & & Roadiano & \\
\hline & & \multirow{4}{*}{\multicolumn{2}{|c|}{ Cisulariano }} & Kunguriano & \\
\hline & & & & Artinskiano & \\
\hline & & & & Sakmariano & \\
\hline & & & & Asseliano & \\
\hline & \multirow{7}{*}{ 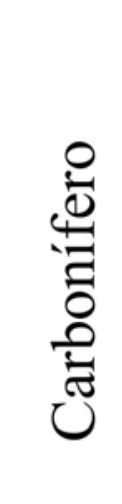 } & \multirow{4}{*}{ 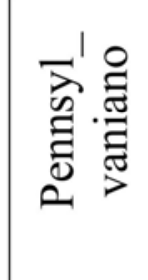 } & \multirow{2}{*}{ Superior } & Gzheliano & \\
\hline & & & & Kasimoviano & 9 \\
\hline & & & Medio & Moscoviano & \\
\hline & & & Inferior & Bashkiriano & \\
\hline & & $\pi^{1} 0$ & Superior & Serpukhoviano & $1+$ \\
\hline & & $\frac{2}{5} \cdot \frac{\vec{\pi}}{2}$ & Medio & Viseano & \\
\hline & & $\sum 2$ & Inferior & Tournaisiano & \\
\hline
\end{tabular}

Figura 12. Esquema de la división del sistema Pérmico (tomado de Gradstein et al., 2004). 
La distribución vertical de los taxones identificados fueron graficados en cada uno de los perfiles analizados (Figuras 13 y 14), teniendo en cuenta el origen de la información: para las muestras provenientes de testigos, círculos negros y trazados completos; para las provenientes de cutting, círculos blancos y trazados en líneas de puntos.

Para la caracterización de la biozonas se analizaron los datos obtenidos con el método de Correlación Gráfica, volcandolos en gráficos de 2 dimensiones considerando por un lado los diferentes taxones y por otro las distintas profundidades de las muestras estudiadas (ya sean provenientes de testigos como así también de cutting). De esta forma se analizaron los rangos de distribución de los taxones y es posible establecer Asociaciones de Unidad.

Para el análisis paleoambiental se procedió al conteo de 400 palinomorfos por muestra de testigo; las proporciones relativas de cada género identificado fueron expresadas con los valores más altos y bajos y la media aritmética entre paréntesis, por ejemplo 34(40,4)48 $\mu \mathrm{m}$. 


\section{LISTADO DE ESPECIES DESCRIPTAS}

En el siguiente listado se discriminan las especies y retrabajadas (* y en negrita) de las autóctonas reconocidas en las perforaciones La Estrella x-1 y Cruz del Sur x-1.

\section{IV.1. Especies autóctonas}

\section{Esporas}

1- Calamospora breviradiata Kosanke 1950

2- Calamospora hartungiana Schopf en Schopf, Wilson y Bentall 1944

3- Leiotriletes corius Kar y Bose 1967

4- Leiotriletes directus Balme y Hennelly 1956a

5- Leiotriletes tiwarii (Tiwari) Saxena 1993

6- Leiotriletes ulutus Utting 1994

7- Punctatisporites gretensis Balme y Hennelly 1956a

8- Punctatisporites sp. cf. P. priscus Bharadwaj y Salujha 1965

9- Punctatisporites sp. A

10- Retusotriletes diversiformis (Balme y Hennelly) Balme y Playford 1967

11- Retusotriletes sp. A

12- Cyclogranisporites microgranus Bharadwaj 1957

13- Granulatisporites austroamericanus Archangelsky y Gamerro 1979

14- Baculatisporites bharadwaji Hart 1963b

15- Anapiculatisporites tereteangulatus (Balme y Hennelly) Playford y Dino 2002

16- Brevitriletes cornutus (Balme y Hennelly) Backhouse 1991

17- Brevitriletes levis (Balme y Hennelly) Bharadwaj y Srivastava 1969

18- Osmundacidites wellmanii Couper 1953

19- Converrucosisporites confluens (Archangelsky y Gamerro) Playford y Dino 2002

20- Converrucosisporites micronodosus (Balme y Hennelly) Playford y Dino 2002

21- Converrucosisporites pustulatus Backhouse 1988

22- Verrucosisporites sp. cf. V. chiquiritensis Ottone 1989

23-Verrucosisporites microtuberosus (Loose) Smith y Butterworth 1967

24- Verrucosisporites surangei Maheshwari y Banerjee 1975

25- Pseudoreticulatispora pseudoreticulata (Balme y Hennelly) Bharadwaj y Srivastava 1969

26- Horriditriletes filiformis (Balme y Hennelly) Backhouse 1991

27- Horriditriletes ramosus (Balme y Hennelly) Bharadwaj y Salujha 1964

28- Horriditriletes superbus (Foster) Césari, Archangelsky y Seoane 1995

29- Horriditriletes uruguaiensis (Marques-Toigo) Archangelsky y Gamerro 1979

30- Interradiaspora sp. cf. I. robustus (Foster) Foster 1979

31- Lophotriletes sp. A

32- Dibolisporites sp. cf. D. disfacies Jones y Truswell 1992

33- Phidiaesporites fosteri Foster 1979

34- Didecitriletes ericianus (Balme y Hennelly) Venkatachala y Kar 1965

35-Didecitriletes uncinatus (Balme y Hennelly) Venkatachala y Kar 1965

36- Convolutispora archangelskyi Playford y Dino 2002

37- Convolutispora candiotensis Ybert 1975

38- Convolutispora ordonezii Archangelsky y Gamerro 1979

39- Convolutispora sp. A

40- Camptotriletes sp. cf. C. warchianus Balme 1970

41- Diatomozonotriletes ponticulus Foster 1975

42- Diatomozonotriletes subbaculiferus (Nahuys, Alpern e Ybert) Césari, Archangelsky y Seoane 1995

43- Diatomozonotriletes townrowii Segroves 1970* 
44- Kraeuselisporites apiculatus Jansonius 1962

45- Kraeuselisporites punctatus Jansonius 1962

46- Cristatisporites chacoparanaensis Ottone 1989

47- Cristatisporites sp. cf. C. inconstans Archangelsky y Gamerro 1979

48- Cristatisporites menendezi (Menéndez y Azcuy) Playford 1978

49- Cristatisporites rollerii Ottone 1989

50- Gondisporites serrulatus Césari, Archangelsky y Seoane 1995

51- Lundbladispora braziliensis (Pant y Srivastava) Marques-Toigo y Pons emend. Marques-Toigo y Picarelli 1985

52- Lundbladispora iphilegna Foster 1979

53- Lundbladispora riobonitensis Marques-Toigo y Picarelli 1985

54- Lundbladispora willmotti Balme 1963

55- Lundbladispora sp. A*

56- Vallatisporites arcuatus (Marques-Toigo) Archangelsky y Gamerro 1979

57- Indotriradites reidii Foster 1979

58- Spelaeotriletes triangulus Neves y Owens 1966

59- cf. Playfordiaspora sp.

60- Laevigatosporites flexus Segroves 1970

61- Laevigatosporites plicatus Kar 1968

62- Laevigatosporites vulgaris (Ibrahim) Ibrahim emend. Alpern y Doubinger 1973

63- Leschikisporis chacoparanaense Vergel 1990

64- Phaselisporites sp. cf. P. cicatricosus (Balme y Hennelly) Price 1984

65- Thymospora cicatricosa (Balme y Hennelly) Hart 1965

66- Thymospora criciumensis Quadros, Marques-Toigo y Krepzig 1996

Algas-Prasynophyta

67- Botryococcus braunii Kützing 1849

68- Brazilea scissa (Balme y Hennelly) Foster 1975

69- Brazilea sp. A Playford y Dino 2000b

70- Leiosphaeridia crescentica Sinha 1969

71- Leiosphaeridia talchirensis Lele y Karim 1971

72- Pilasporites sp. B Stephenson y Osterloff 2002

73- Portalites gondwanensis Nahuys, Alpern e Ybert 1968

74- Quadrisporites granulatus (Cramer) Stöther 1991

75- Maculatasporites minimus Segroves 1967

76- Cymatiosphaera gondwanensis (Tiwari) Backhouse 1991

Granos de polen monosacados

77- Cannanorpollis sp. cf. C. densus (Lele) Bose y Maheshwari 1968

78- Cannanoropollis janakii Potonié y Sah 1960

79- Cannanoropollis methae (Lele) Bose y Maheshwari 1968

80- Costatacyclus crenatus Felix y Burbridge emend. Urban 1971

81- Potonieisporites brasiliensis (Nahuys, Alpern e Ybert) Archangelsky y Gamerro 1979

82- Potonieisporites densus Maheshwari 1967

83- Potonieisporites lelei Maheshwari 1967

84- Potonieisporites magnus Lele y Karim 1971*

85- Potonieisporites sp. cf. P. pyriferus Playford y Dino 2000a

86- Potonieispoirtes triangulatus Tiwari 1965

87- Plicatipollenites malabarensis (Potonié y Sah) Foster 1975

88- Cahenisaccites densus Lele y Karim emend. Gutiérrez 1993

89- Caheniasaccites elongatus Bose y Kar 1966

90- Crucisaccites latisulcatus Lele y Maithy 1964

91- Crucisaccites sp. A

92- Bascanisporites sp. A

93- Gondwanapollis frenguellii (Césari) Gutiérrez 1993 
94- Stellapollenites sp. cf. S. talchirensis Lele 1965

95- Accinctisporites excentricus (Leschik) Jain 1968

96- Accinctisporites sp. A

97- Meristocorpus sp. A

98- Meristocorpus sp. B

99- Striomonosaccites cicatricosus Archangelsky y Gamerro 1979

100- Crustaesporites globosus Leschik 1956

101- Polarisaccites bilateralis Ybert y Marques-Toigo 1970

Granos de polen bisacados de cuerpo central liso

102- Alisporites australis de Jersey 1962

103- Alisporites opii Daugherty 1941

104- Alisporites rioclarensis Menéndez 1976

105- Chordasporites sp. cf. C. australiensis de Jersey 1962

106- Falcisporites parvus (de Jersey) nov. comb

107- Falcisporites similis (Balme) nov. comb.

108- cf. Ibisporites sp.

109- Pityosporites sp. A

110- Platysaccus crassimarginatus Lakhanpal, Sah y Dube 1960

111- Platysaccus leschikii Hart 1960

112- Platysaccus papilionis Potonié y Klaus 1954

113- Platysaccus queenslandi de Jersey 1962

114- Platysaccus sp. A

115- Pteruchipollenites sp. cf. P. gracilis (Segroves) Foster 1979

116- Scheuringipollenites circularis Césari, Archangelsky y Seoane 1995

117- Scheuringipollenites maximus (Hart) Tiwari 1973

118- Scheuringipollenites medius (Burjack) Dias-Fabrício 1981

119- Scheuringipollenites ovatus (Balme y Hennelly) Foster 1975

120- Colpisaccites granulosus Archangelsky y Gamerro 1979

121- Limitisporites amazoniensis Playford y Dino 2000b

122- Limitisporites sp. cf. L. rectus Leschik 1956

123- Triadispora epigona Klaus 1964

124- Vitreisporites sp. A

Granos de polen bisacados de cuerpo central estriado

125- Corisaccites alutas Venkatachala y Kar 1966

126- Distriatites sp. A

127- Illinites unicus Kosanke emend. Jansonius y Hills 1976

128- Hamiapollenites andiraensis Playford y Dino 2000b

129- Hamiapollenites fusiformis Marques-Toigo emend. Archangelsky y Gamerro 1979

130- Hamiapollenites ruditaeniatus Qu y Wang 1986

131- Lunatisporites noviaulensis (Leschik) Foster 1979

132- Lunatisporites paliensis Tiwari y Ram-Awatar 1989

133- Lunatisporites variesectus Archangelsky y Gamerro 1979

134- Lunatisporites sp. A

135- Lunatisporites sp. B

136- Lueckisporites sp. cf. L. nyakapendensis Hart 1960

137- Lueckisporites singhii Balme 1970

138- Lueckisporites singrauliensis Sinha 1972

139- Lueckisporites sp. cf. L. stenotaeniatus Menéndez 1976*

140- Lueckisporites virkkiae (Potonié y Klaus) emend. Klaus 1963

141- Protohaploxypinus amplus (Balme y Hennelly) Hart 1964

142- Protohaploxypinus bharadwajii Foster 1979

143- Protohaploxypinus diagonalis Balme 1970

144- Protohaploxypinus limpidus (Balme y Hennelly) Balme y Playford 1967 
145- Protohaploxypinus microcorpus (Schaarschmidt) Clarke 1965

146- Protohaploxypinus perexiguus (Potonié y Lele) Hart 1964

147- Protohaploxypinus varius (Bharadwaj) Balme 1970

148- Staurosaccites cordubensis Archangelsky y Gamerro 1979

149- Striatopodocarpites cancellatus (Balme y Hennelly) Hart 1963

150- Striatopodocarpites fusus (Balme y Hennelly) Potonié 1958

151- Striatopodocarpites gondwanensis Lekhanpal, Sah y Dube 1960

152- Striatopodocarpites sp. cf. S. phaleratus (Balme y Hennelly) Foster 1979

153- Striatopodocarpites sp. cf. S. solitus (Bharadwaj y Salujha) Foster 1979

154- Tornopollenites toreutos Morgan 1972

155- Verticipollenites sp. $\mathrm{A}^{*}$

Granos de polen plicados

156- Vittatina corrugata Marques-Toigo 1974

157- Vittatina costabilis Wilson 1962

158- Vittatina fasciolata (Balme y Hennelly) Bharadwaj 1962

159- Vittatina subsaccata Samoilovich 1953

160- Vittatina vittifera (Luber y Waltz) Samoilovich 1953

161- Tiwarisporis anaverrucosus (Archangelsky y Gamerro) nov. comb.

162- Tiwarisporis simplex (Tiwari) Maheshwari y Kar 1967

163- Weylandites magmus (Bose y Kar) Backhouse 1991

164- Weylandites lucifer (Bharadwaj y Salujha) Foster 1975

165- Marsupipollenites striatus (Balme y Hennelly) Hart 1965

166- Marsupipollenites triradiatus Balme y Hennelly 1956b

Granos de polen monosulcados

167- Praecolpatites sinuosus (Balme y Hennelly) Bharadwaj y Srivastava 1969

168- Pakhapites fusus (Bose y Kar) Menéndez 1971

169- Pakhapites ovatus (Bose y Kar) García 1996

170- Cycadopites crassimarginis (de Jersey) de Jersey 1964

171- Cycadopites follicularis Wilson y Webster 1946

\section{Acritarcas}

172- Buedingiisphaeridium permicum Schaarschmidt 1963

173- Circulisporites parvus de Jersey 1962

174- Micrhystridium fragile Deflandre 1947

175- Micrhystridium sp. cf. M. ? sp. B Foster 1979

176- Mehlisphaeridium fibratum Segroves 1967

177- Mehlisphaeridium regulare Anderson 1977

178- Peltacystia sp. cf. P. monile Balme y Segroves 1966*

Fungii

179- Reduviasporonites chalastus (Foster) Elsik 1999

\section{IV.2. Retrabajo}

43. Diatomozonotriletes townrowii Segroves 1970*

55. Lundbladispora sp. A*

65. Thymospora cicatricosa (Balme y Hennelly) Hart 1965*

84. Potonieisporites magnus Lele y Karim 1971*

139. Lueckisporites sp. cf. L. stenotaeniatus Menéndez 1976*

155. Verticipollenites sp. A*

178. Peltacystia sp. cf. P. monile Balme y Segroves 1966* 
V. SISTEMÁTICA 


\begin{abstract}
V. SISTEMÁTICA
V.1. Autóctonas

Anteturma PROXIMEGERMINANTES Potonié 1970

Turma TRILETES Reinsch emend. Dettmann 1963

Suprasubturma ACAVATITRILETES Dettmann 1963

Subturma AZONOTRILETES Lüber emend. Dettmann 1963

Infraturma LAEVIGATI Bennie y Kindston emend. Potonié 1956
\end{abstract}

Género Calamospora Schopf en Schopf, Wilson y Bentall 1944

Especie tipo. Calamospora hartungiana Schopf en Schopf et al., 1944.

Afinidad botánica. Sphenophyta (véase Balme, 1995; Quadros et al., 1996).

Calamospora breviradiata Kosanke 1950

Lámina I, figura A

Descripción. Espora radial trilete, de contorno circular a poligonal por hallarse generalmente plegada. Margen liso. Lesura simple, de rayos rectos y cortos, generalmente extendidos hasta 1/4 del radio de la espora. Exina levigada, delgada y con numerosos, irregulares y concéntricos pligues, productos de la compresión.

Dimensiones (5 ejemplares). Diámetro ecuatorial, 34(40,4)48 $\mu \mathrm{m}$; exina, 0,5(1)1,5 $\mu \mathrm{m}$; rayos de la lesura 3 a $10 \mu \mathrm{m}$.

Principal material estudiado. BAPal 6147 (a) O49/0; BAPal 6156 (b) V70/0; BAPal 6165 (a) M57/3; BAPal 6169 (a) Q34/2; BAPal 6185 (a) R36/0.

Registros previos. Calamospora breviradiata Kosanke fue descripta originalmente para el Pennsylvaniano de Illinois (Kosanke, 1950).

- Pennsylvaniano: Europa y USA: ampliamente distribuida para la región central y el oeste (Kosanke, 1950; Ravn 1979, 1986; Ravn y Fitzgerald 1982; Smith y Butterworth 1967).

- Pennsylvaniano-Cisuraliano: Brasil: ilustrada para el Grupo Trapajós, Cuenca Amazonas (Playford y Dino, 2000a).

Esta es la primera cita de la especie para la Argentina. 
Calamospora hartungiana Schopf en Schopf, Wilson y Bentall 1944

Lámina I, figura B

Sinonimia. Véase Gutiérrez (1988).

Descripción. Espora radial trilete, de contorno circular a subcircular, deformado por compresión. Margen liso. Lesura simple, de rayos rectos, difícilmente discernible. Exina levigada, delgada, de menos de $1 \mu \mathrm{m}$ de espesor, con numerosos e irregulares pliegues concéntricos, productos de la compresión.

Dimensiones (12 ejemplares). Diámetro ecuatorial, 31(45)55 $\mu \mathrm{m}$; exina, 0,5-1 $\mu \mathrm{m}$.

Principal material estudiado. BAPal 6143 (a) L68/0; BAPal 6152 (a) O45/3, N65/3, O46/0, R43/3, B46/4, G37/4, H37/0; BAPal 6152 (b) G70/3. Retrabajo: BAPal 6170 (a) V23/3; BAPal 6172 (a) J46/2; BAPal 6173 (a) M63/3.

Registros previos. Calamospora hartungiana fue descripta originalmente por Schopf (en Schopf et al., 1944) para el Pennsylvaniano de Illinois, Estados Unidos. Presenta una distribución mundial para el Paleozoico Superior.

- Mississipiano: Perú: presente en la Formación Tarma, Pongo de Mainique (Azcuy et $a l ., 2002$ ) e ilustrada para la Formación Ambo, Pongo de Mainique (Azcuy y di Pasquo, 2005).

- Pennsylvaniano: Argentina: presente en las formaciones Agua Colorada (Menéndez, 1965), Lagares (Menéndez y Azcuy, 1969; Morelli et al., 1984), Malanzán (Azcuy, 1975), Guandacol (Césari y Vázquez Nístico, 1988; Ottone y Azcuy, 1989), Tupe (Césari 1986a; Ottone y Azcuy, 1990; Ottone, 1991); nivel superior de Estratos de Mascasín (Pérez Loinaze y Césari, 2004); todas ellas de la Cuenca Paganzo. Listada para El Trampeadero (Gutiérrez y Barreda, 2006); Cuenca Paganzo. Ilustrada para las formaciones Agua Colorada, Cuenca Paganzo (Vergel et al., 1993) y San Telmo, Cuenca Tarija (di Pasquo et al., 2001). Brasil: ilustrada para el Subgrupo Itararé, Cuenca Paraná (di Pasquo et al., 2003a; Souza, 2006).

- Pennsylvaniano-Cisuraliano: Argentina: listada para la Formación Río del Peñón, Cuenca Río Blanco (Gutiérrez y Limarino, 2006); también por Vergel (1986) para la perforación YPF La Josefina 1 (Cuenca Paraná). Brasil: ilustrada para el Grupo Trapajós, Cuenca Amazonas (Playford y Dino, 2000a). 
- Pennsylvaniano-Guadalupiano: Argentina: presente en la Cuenca Chacoparaná fue descripta e ilustrada en las Biozonas Potonieisporites-Lundbladispora (parte baja), Cristatisporites y Striatites (Archangelsky y Gamerro, 1979).

- Cisuraliano: Argentina: ilustrada para la Formación El Imperial, Cuenca San Rafael (García, 1995) y la Formación Tasa Cuna, Cuenca Paganzo (Balarino y Gutiérrez, 2006). Uruguay: ilustrada para la Formación San Gregorio, Cuenca Paraná (Beri et al., 2006).

Género Leiotriletes Naumova emend. Potonié y Kremp 1954

Especie tipo. Leiotriletes sphaoerotriangulus (Loose) Potonié y Kremp, 1954.

Afinidad botánica. Pteridophyta-Filicopsida (véase Balme, 1995).

Leiotriletes corius Kar y Bose 1967

Lámina I, figura $\mathrm{C}$

Sinonimia. Véase Kar y Bose (1967) y Gutiérrez y Césari (1989).

Descripción. Espora radial trilete, de contorno subtriangular, de lados convexos y ápices redondeaos. Margen liso. Lesura simple, claramente discernible, de rayos rectos $\mathrm{y}$ extendidos hasta $3 / 4$ del radio de la espora. Exina gruesa, de 2,5 $\mu \mathrm{m}$ de ancho y levigada.

Dimensiones ( 1 ejemplar). Diámetro ecuatorial, 36-41 $\mu \mathrm{m}$.

Principal material estudiado. BAPal 6146 (b) F41/4.

Registros previos. Leiotriletes corius fue descripta originalmente por Kar y Bose (1967) para los esquistos negros de Lukuga, Congo.

- Pennsylvaniano: Argentina: presente en la Formación Lagares, Cuenca Paganzo (Césari y Gutiérrez, 1985; Gutiérrez y Césari, 1989).

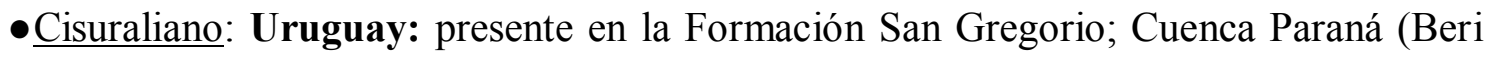
et al., 2006).

Leiotriletes directus Balme y Hennelly 1956a

Lámina I, figuras D y E 
1969. Leiotriletes plicatus Maheshwari y Bose, p. 11, pl. 1, figs. 10, 11, text-fig. 3.

1977. Microbaculispora plicata (Maheshwari y Bose) Anderson, p. 39(9.3), pl. 45, figs. 19-26, pl. 47, figs. 8-12, 15-17, 20-27.

1977. Microbaculispora directa (Balme y Hennelly) Anderson, p. 40(9.3), pl. 45, figs. 1-18, pl. 47, figs. 1-7.

1981. Deltoidospora directa (Balme y Hennelly) Hart [sic.]; Fabricio, p. 76, pl. 1, figs. 3-4.

Sinonimia adicional. Véase Raine et al. (2006).

Descripción. Espora radial trilete, de contorno triangular, de lados rectos, aunque pueden presentarse también cóncavos a levemente convexos; y de ápices redondeaos. Margen liso. Lesura simple, a veces acompañada por pliegues comisurales producto de compresión, de rayos rectos y extendidos hasta $3 / 4$ del radio de la espora. Exina delgada (de espesor menor a $1 \mu \mathrm{m}$ ), levigada en cara proximal y finamente granulada en cara distal.

Dimensiones (10 ejemplares). Diámetro ecuatorial, 25(33,8)42 $\mu \mathrm{m}$; exina, 0,8-1 $\mu \mathrm{m}$.

Principal material estudiado. BAPal 6152 (a) J56/0, M58/2, N56/0, S49/0, D37/1, F65/0, V61/2; BAPal 6162 (a) O43/0.

Registros previos. Leiotriletes directus fue descripta originalmente por Balme y Hennelly (1956a) para la perforación Nº5 D.D.H., parte superior del Newcastle Stage, Pérmico de Australia. Presenta un amplio registro geográfico para el Pérmico-Jurásico (véase Raine et al., 2006).

- Pennsylvaniano: Argentina: ilustrada para la Formación San Telmo, Cuenca Tarija (di Pasquo et al., 2001); y listada para la Formación El Trampeadero, Cuenca Paganzo (Gutiérrez y Barreda, 2006) y los Grupos Macharetí y Mandiyutí (Cuenca Tarija; di Pasquo 2003; di Pasquo et al., 2001).

- Cisuraliano: Argentina: presente en las formaciones Bajo de Véliz, Cuenca Paganzo (Menéndez, 1971; Gutiérrez y Césari, 2001) y Río Genoa, Cuenca Tepuel-Genoa (Gutiérrez et al., 2007). Ilustrada para la Formación El Imperial, Cuenca San Rafael (García, 1995). Uruguay: descripta para la Formación San Gregorio, Cuenca Paraná (Beri et al., 2006). Australia: presente en Blair Athol Coal Measures (Foster, 1975); ilustrada para la Formación Stockton y Collie Coal Measures, Cuenca Collie (Backhouse, 1991) y listada, Cuenca Perth (Segroves, 1970). Antártida: listada para 
Vestfjella, Dronning Maud Land (Lindström, 1995, 1996, 2005) y para Milorgfjella, Dronning Maud Land (Larsson et al., 1990). Perú: listada para el Grupo Copacabana (Doubinger y Marocco, 1981). África: Anderson, 1977; listada (Hart, 1965). Omán y Arabia Saudita: ilustrada para la Formación Al Khlata (Stephenson y Filatoff, 2000a).

- Cisuraliano-Guadalupiano: Brasil: ilustrada para la Formación Rio Bonito, Cuenca Chacoparaná (Días-Fabricio, 1981). Uruguay: ilustrada para la Formación Melo (Mautino et al., 1998a), Cuenca Paraná (Beri et al., 2006). Papúa: descripta para las formaciones Ainim y Aiduna (Playford y Rigby, 2008).

- Guadalupiano: Australia: presente en Baralaba Coal Measures, Cuenca Bowen (Foster, 1979).

- Lopingiano-Triásico Inferior: presente en la Formación Rewan, Cuenca Bowen (Foster, 1979).

\section{Leiotriletes tiwarii (Tiwari) Saxena 1993 \\ Lámina I, figura $\mathrm{F}$}

1965. Leiotriletes virkkii Tiwari, pp. 170-171, pl. 1, figs. 2-3 (non Leiotriletes virkkii Biswas 1962, pp. 43, pl. 9, fig. 53).

Descripción. Espora radial trilete, de contorno triangular, de lados rectos a suavemente cónvexos y ápices ampliamente redondeados. Margen liso. Lesura de rayos rectos, extendidos hasta 5/6 del radio de la espora, acompañados por delicados pliegues de hasta $3 \mu \mathrm{m}$ de ancho. Exina levigada y delgada.

Dimensiones (10 ejemplares). Diámetro ecuatorial, 29(42,1)58 $\mu \mathrm{m}$; espesor de la exina, $1(1,7) 2 \mu \mathrm{m}$.

Principal material estudiado. BAPal 6151 (a) Q48/4; BAPal 6152 (a) G47/4, Q45/3, Q72/3; BAPal 6156 (b) O44/0; BAPal 6162 (a) R68/3; BAPal 6165 (a) D44/3; BAPal 6165 (b) J56/3; BAPal 6169 (a) F68/4; BAPal 6187 (a) R63/2.

Comentarios. Saxena (1993) propuso reemplazar el término Leiotriletes virkki por Leiotriletes tiwarii, ya que el mismo había sido ultilizado previamente por Biswas (1962).

Registros previos. Descripta originalmente por Tiwari (1965) para el Korba Coalfield del Pérmico de India. Presenta un amplio registro en el Pérmico del Gondwana. 
- Pennsylvaniano: Brasil: presente en el Subgrupo Itararé, Cuenca Paraná (MarquesToigo et al., 1989; di Pasquo et al., 2003a; Souza, 2006).

- Pennsylvaniano-Cisuraliano: Argentina: mencionada para la Formación Sachayoj Cuenca Chacoparaná (Vergel, 1998).

- Cisuraliano: Argentina: ilustrada en la Biozona Cristatisporites Cuenca Chacoparaná, (Césari et al., 1995) y en la Formación Río Genoa, Cuenca Tepuel-Genoa (Gutiérrez et al., 2007). Uruguay: descripta para la Formación San Gregorio (Beri et al., 2006), Cuenca Paraná. Brasil: ilustrada para el Subgrupo Itararé, Cuenca Paraná (Dias, 1993); ilustrada, Subgrupo Itararé, Biozona Vittatina costabilis, sub-biozona Protohaploxypinus goraiensis, Cuenca Paraná (Souza y Callegari, 2004). Australia: ilustrada para la Formación Stockton y Collie Coal Measures, Cuenca Collie (Backhouse, 1991). Antártida: ilustrada para Vestfjella, Dronning Maud Land (Lindström, 1995). Sudáfrica: ilustrada para la Formación Ecca (sección media) Sistema Karroo (Chandra et al., 1977).

- Cisuraliano-Guadalupiano: Uruguay: ilustrada para la Formación Melo (Beri y Pecoits, 2001; Mautino et al., 1998a), Cuenca Paraná. Brasil: presente en la Formación Rio Bonito, Cuenca Candiota-Hulha Negra (Ybert, 1975) y Matos Costa, Santa Catarina Cuenca Paraná (Quadros et al., 1996).

- Lopingiano: Sudáfrica: ilustrada para la Formación Beaufort (sección inferior), Sistema Karroo (Chandra et al., 1977).

Leiotriletes ulutus Utting 1994

Lámina I, figuras G y H

2006. Waltzispora? sp. A; Beri et al., p. 230, pl. 2, fig. D.

Descripción. Espora radial trilete, de contorno triangular, lados cóncavos a rectos y ápices redondeados. Margen liso. Lesura simple, de rayos rectos extendidos entre 2/3 y $3 / 4$ del radio de la espora. Sobre la cara proximal presenta un espesamiento que rodean la lesura. Exina delgada, menor a $1 \mu \mathrm{m}$ de espesor, levigada.

Dimensiones (9 ejemplares). Diámetro ecuatorial, 25(36,3)47 $\mu \mathrm{m}$, espesor de la exina, $0,8-1 \mu \mathrm{m}$. 
Principal material estudiado. BAPal 6151 (a) Q66/3; BAPal 6152 (a) T55/3, W37/3, E5373.

Discusión. El ejemplar ilustrado y descripto como Waltzispora? sp. A por Beri et al. (2006, p. 230, pl. 2, fig. D) podría ser incluido en la especie Leiotriletes ulutus Utting (1994, p. 33, pl. 1, figs. 4-8) por las características que exhibe (contorno triangular de lados cóncavos y ápices redondeados, y además presenta el característico espesamiento proximal que rodea la lesura). Dicha especie (Utting, 1994, p. 33) incluye formas con un contorno que grada desde lados rectos a fuertemente cóncavos, pero la transición entre los interradios y los ápices es por medio de líneas curvas. El género Walzispora Staplin (1960) se caracteriza por presentar el contorno triangular, de lados fuertemente cóncavos y ápices redondeados, pero la unión entre ambas partes se produce por medio de un quiebre de alto grado de ángulo entre la línea curva de los ápices. Además del conspicuo carácter, generalmente las formas asignadas a éste género presentan una fina granulación de la exina, sin que en la descripción del género sea mencionado el espesamiento proximal.

Registros previos. Leiotriletes ulutus fue descripta originalmente por Utting (1994) para Sabine Bay, Assistance, formaciones Trold Fiord, Degerböls y Hauen, Cuenca Sverdrup, Cisuraliano (Kunguriano) de Canadá.

- Cisuraliano: Uruguay: presente en la Formación San Gregorio, Cuenca Paraná (Beri et al., 2006).

Esta es la primera cita de la especie para la Argentina.

Género Punctatisporites Ibrahim emend. Potonié y Kremp 1954

Especie tipo. Punctatisporites punctatus (Ibrahim) Ibrahim 1933.

Afinidad botánica. Pteridophyta-Filicopsida (véase Balme, 1995; Quadros et al., 1996).

Punctatisporites gretensis Balme y Hennelly 1956a

Lámina I, figura I

Descripción. Espora radial trilete, de contorno circular a subcircular, de margen liso. Lesura simple, de rayos rectos, acompañados por delicados labios o espesamientos 
comisurales, rayos extendidos hasta 3/4 del radio de la espora. Exina levigada, de más de $1,5 \mu \mathrm{m}$ de espesor.

Dimensiones (10 ejemplares). Diámetro ecuatorial, 30(57,3)94 $\mu \mathrm{m}$; exina, 1,5(2,5)3,5 $\mu \mathrm{m}$.

Principal material estudiado. BAPal 6145 (a) R60/0; BAPal 6152 (a) H68/0, J74/2, J36/0, L40/0; BAPal 6158 (a) J54/4; BAPal 6160 (a) L70/1; BAPal 6184 (a) Q75/0; BAPal 6187 (a) X75/0.

Registros previos. Punctatisporites gretensis fue descripta originalmente por Balme y Hennelly (1956a) para Main Greta seam, Hebburn No 2 Colliery, Greta Coal Measures, Pérmico de Australia, y presenta un amplio registro para el Cisuraliano mundial (veáse Foster, 1975; Rigby y Heckel, 1977).

- Pennsylvaniano: Argentina: presente en las formaciones Agua Colorada (Azcuy et al., 1982), Guandacol (Césari y Vázquez Nístico, 1988), Tupe (Césari 1986a; Ottone y Azcuy, 1990; Ottone, 1991); y el nivel superior de Estratos de Mascasín (Pérez Loinaze y Césari, 2004); todas en la Cuenca Paganzo. Ilustrada para la Formación Sachayoj Cuenca Chacoparaná (Vergel, 1998) y para las formaciones Agua Colorada, Cuenca Paganzo (Vergel y Luna 1992; Vergel et al., 1993) y San Telmo, Cuenca Tarija (di Pasquo et al., 2001). Listada para las formaciones Guandacol (Vazquez Nístico y Césari, 1987; Ottone y Azcuy, 1989) y Jejenes (Césari y Bercowski, 1997), Cuenca Paganzo. Brasil: presente en Atanasio-Rio Grande do Sul (Carbonífero SuperiorLopingiano), Cuenca Paraná (Quadros et al., 1996); ilustrada para el Subgrupo Itararé, Cuenca Paraná (Marques-Toigo et al., 1989; Souza et al., 2003; Souza, 2006) y la Formación Piauí, Cuenca Paranaíba (Dino y Playford, 2002).

- Pennsylvaniano-Cisuraliano: Argentina: presente en las biozonas PotonieisporitesLundbladispora y Cristatisporites (Archangelsky y Gamerro, 1979; Archangelsky et al., 1980; Vergel, 1987a, 1987b; Césari et al., 1995); en la Formación Sachayoj (Vergel, 1998); todas de Cuenca Chacoparaná. Presente también en la Formación Piedra Shotel, en las biozonas Potonieisporites-Lundbladispora y Cristatisporites, Cuenca Tepuel Genoa (Gamerro y Archangelsky, 1981a); listada para la Formación Río del Peñón, Cuenca Río Blanco (Gutiérrez y Limarino, 2006). India: ilustrada para Gankra Nalla Beds (Saksena, 1971). 
- Cisuraliano: Argentina: ilustrada para la Formación El Imperial, Cuenca San Rafael (García, 1995); Formacion Tasa Cuna, Cuenca Paganzo (Balarino y Gutiérrez, 2006) y Formación Río Genoa, Cuenca Tepuel-Genoa (Gutiérrez et al., 2007). Brasil: ilustrada en el Subgrupo Itararé, Cuenca Paraná (Dias, 1993); en la Biozona Vittatina costabilis, subzona Protohaploxypinus goraiensis, Cuenca Paraná (Souza y Callegari, 2004). Uruguay: ilustrada para la Formación San Gregorio (Beri y Daners, 1996; Beri et al., 2006), Cuenca Paraná. Paraguay: ilustrada para la Formación Tacuary, Cuenca Chacoparaná (Muff et al., 1999). Australia: en Blair Athol Coal Measures (Foster, 1975), en la Formación Stockton y Collie Coal Measures, Cuenca Collie (Backhouse, 1991). Antártida: listada para Milorgfjella, Dronning Maud Land (Larsson et al., 1990) e ilustrada para Vestfjella, Dronning Maud Land (Lindström, 1995). Sudáfrica: ilustrada para las formaciones Ecca (sección media, Cisuraliano) y Beaufort (sección inferior, Lopingiano), Sistema Karroo (Anderson, 1977; Chandra et al., 1977). Omán y Arabia Saudita: listada para la Formación Al Khlata (Stephenson y Filatoff, 2000a).

- Cisuraliano-Guadalupiano: Argentina: presente en la Formación Victoriano Rodríguez, biozonas Cristatisporites y Striatites, Cuenca Chacoparaná (Playford y Dino, 2002). Brasil: presente en la Formación Rio Bonito, Cuenca Candiota-Hulha Negra (Ybert, 1975; Burjack, 1978; Souza y Marques-Toigo, 2005). Ilustrada en la Formación Pedra do Fogo, Cuenca Parnaíba (Dino et al., 2002). Uruguay: listada para la Formación Melo (Mautino et al., 1998a; Beri y Pecoits, 2001), Cuenca Paraná.

- Guadalupiano: Australia: mencionada para la Formación Bandanna, Springsure Anticline (Rigby y Hekel, 1977); ilustrada para Baralaba Coal Measures, Cuenca Bowen (Foster, 1979).

- Lopingiano-Triásico Inferior: Australia: mencionada para la Formación Rewan, Cuenca Bowen (Foster, 1979).

\section{Punctatisporites sp. cf. P. priscus Bharadwaj y Salujha 1965} Lámina II, figura A

Descripción. Espora radial trilete, de contorno circular, subcircular a subtriangular por compresión. Margen liso. Lesura recta, acompañada por delgados labios $(1,5 \mu \mathrm{m}$ de 
ancho total), que se extiende hasta 3/4 del radio de la espora. Exina delgada, levigada, generalmente con pliegues exinales generados por compresión.

Dimensiones (5 ejemplares). Diámetro ecuatorial, 41(52)59 $\mu \mathrm{m}$; espesor de la exina, 1 $\mu \mathrm{m}$.

Principal material estudiado. BAPal 6152 (a) J62/3, O48/2, U41/1; BAPal 6167 (a) S57/1.

Comentarios. Los ejemplares aquí estudiados comparten con Punctatisporites priscus Bharadwaj y Salujha los siguientes caracteres: presencia de labios marginales, largo de las ramas de lesura varía entre $2 / 3$ y $3 / 4$ del radio de la espora, una exina delgada, levigada y los característicos pliegues por compresión, lo que le otorga a los ejemplares un contorno subcircular a subtriangular; aunque en el material de la Cuenca Colorado los pliegues son escasos y aparecen irregularmente distribuidos y no pueden observarse los extremos de las ramas de la lesura, para identificar si los mismos terminan bifurcándose como lo caracteriza la especie.

\section{Punctatisporites sp. A}

Lámina I, figuras J y K

Descripción. Espora radial trilete, de contorno subcircular a oval debido a la deformación. Margen liso. Lesura simple, de rayos cortos y rectos, que se extienden entre 1/6 a 1/7 del radio de la espora. Exina mediana, levigada, con la cara distal convexa y la proximal cóncava; sobre el ecuador aparecen pliegues periféricos circumpolares que le confieren un aspecto más robusto sobre el contorno.

Dimensiones (5 ejemplares). Diámetro ecuatorial, 28(37,8)40 $\mu \mathrm{m}$; espesor de la exina, $1-3 \mu \mathrm{m}$.

Principal material estudiado. BAPal 6152 (a) S47/0, V43/2; BAPal 6159 (a) O33/3; BAPal 6167 (a) G57/3; BAPal 6169 (a) L55/4.

Comparaciones. Los ejemplares asignados a Punctatisporites sp. A se distinguen de las demás especies referidas a Punctatisporites, por los cortos rayos de la lesura (1/7 a 1/6 de radio de la espora), naturaleza cóncavo-convexo y por los pliegues exinales perféricos que modifican secundariamente el contorno general de la espora (de circular a oval). Solamente $P$. irrasus Hacquebard (1957) presenta una lesura con rayos cortos 
(hasta $1 / 2$ radio de la espora) aunque no tan cortos como en los ejemplares aquí estudiados. P. priscus Bharadwaj y Salujha (1965) también presenta conspicuos pliegues originados por la compresión, pero los mismos son semilunares y se ubican concéntricamente en el cuerpo de la espora, y no como repliegues del borde de la misma como ocurre en los ejemplares de $P$. sp. A.

\section{Infraturma RETUSOTRILETI Streel 1964}

\section{Género Retusotriletes Naumova emend. Streel 1964}

Especie tipo. Retusotriletes simplex Naumova 1953.

Afinidad botánica. Pteridophyta (véase Balme, 1995; Quadros et al., 1996).

Retusotriletes diversiformis (Balme y Hennelly) Balme y Playford 1967

Lámina I, figuras L y M

1956b. Calamospora diversiformis Balme y Hennelly, p. 246, pl. 2, figs. 14-18.

1977. Apiculatisporis diversiformis (Balme y Hennelly) Anderson, p. 81, pl. 77, fig. 118.

Sinonima adicional. Véase Playford y Dino (2002).

Descripción. Espora radial trilete, de contorno circular y margen liso. Lesura simple, de rayos rectos, que se extienden entre $2 / 3$ y $3 / 4$ del radio de la espora. Áreas de contacto delimitadas por curvaturas perfectas, claramente discernibles. Exina levigada, de menos de $1 \mu \mathrm{m}$ de ancho. Zona circular oscura desarrollada sobre la exina en el centro de la cara proximal.

Dimensiones (3 ejemplares). Diámetro ecuatorial, 30-36 $\mu \mathrm{m}$; longitud de las ramas de la lesura, 8-9 $\mu \mathrm{m}$; exina, $1 \mu \mathrm{m}$.

Principal material estudiado. BAPal 6152 (a) T65/4; BAPal 6162 (a) G41/4; BAPal 6168 (a) H69/1.

Registros previos. Retusotriletes diversiformis fue descripta originalmente por Balme y Hennelly (1956a) para Main Greta seam, Cessnock No. 1 Colliery, Greta Coal, Australia. 
- Pennsylvaniano: Argentina: listada para la Formación El Trampeadero, Cuenca Paganzo (Gutiérrez y Barreda, 2006).

- Pennsylvaniano-Cisuraliano: Argentina: listada para la Formación Río del Peñón, Cuenca Paganzo (Gutiérrez y Limarino, 2006).

- Cisuraliano: Argentina: ilustrada para la Formación Victoriano Rodríguez, Biozona Cristatisporites, Cuenca Chacoparaná (Playford y Dino, 2002) y para el tope de la Formación Tupe, Cuenca Paganzo (Vergel, 2008). Brasil: presente en Matos Costa, Santa Catarina, Cuenca Paraná (Quadros et al., 1996). Sudáfrica: presente en Cuenca Karroo (Anderson, 1977).

- Guadalupiano: Australia: presente en Baralaba Coal Measures, Cuenca Bowen (Foster, 1979).

- Lopingiano-Triásico Inferior: Australia: presente en la Formación Rewan, Cuenca Bowen (Foster, 1979).

\section{Retusotriletes sp. A}

Lámina I, figuras $\mathrm{N}$ y $\tilde{\mathrm{N}}$

Descripción. Espora radial trilete, de contorno circular a irregular por plegamientos y margen liso. Lesura de rayos levemente ondulados, acompañados por delgados y altos labios, que acentúan la sinuosidad de la misma. Rayos extendidos hasta el límite del área de contacto, en aproximadamente $4 / 5$ a $5 / 6$ del radio de la espora. Áreas de contacto delimitadas por curvatura imperfecta. Exina levigada, delgada, de 0,5 a $1 \mu \mathrm{m}$ de espesor. Pliegue submarginal presente sobre uno de los rayos de la lesura.

Dimensiones (4 ejemplares). Diámetro ecuatorial, 28(36,7)40 $\mu \mathrm{m}$.

Principal material estudiado. BAPal 6139 (a) M45/0; BAPal 6152 (a) M46/0; BAPal 6152 (b) H60/2; BAPal 6164 (a) J66/3.

Comparaciones. Los ejemplares aquí estudiados son comparables con Retusotriletes anfractus Menéndez y Azcuy (1969) por presentar una lesura con rayos levemente sinuosos que se extienden hasta $4 / 5$ respecto del radio que se continúan en una curvatura formada por pliegues de ancho y alto variable, a veces imperfecta y en algunos casos débilmente marcada. Generalmente, uno de los extremos de la lesura se encuentra plegado hacia el centro de la espora, caracter observable en los ejemplares aquí 
estudiados. Sin embargo, la pobre preservación de los mismos impide realizar una aproximación específica.

Infraturma APICULATI Bennie y Kidston emend. R. Potonié 1956

Subinfraturma GRANULATI Ibrahim emend. Potonié y Kremp 1954

\title{
Género Cyclogranisporites Potonié y Kremp 1954
}

Especie tipo. Cyclogranisporites leopoldi (Kremp) Potonié y Kremp, 1954.

Afinidad botánica. Pteridophyta-Filicopsida (véase Balme, 1995; Quadros et al., 1996).

\section{Cyclogranisporites microgranus Bharadwaj 1957}

\author{
Lámina II, figura B
}

Descripción. Espora radial trilete, de contorno circular a subcircular, de margen liso. Lesura simple, de rayos rectos de aproximadamente $2 / 3$ a $3 / 4$ del radio de la espora, poco discernible. Ornamentación conformada por microgránulos de base circular a oval, de hasta 0,5 $\mu \mathrm{m}$ de ancho, dispuestos irregularmente. Exina de menos de $2 \mu \mathrm{m}$ de ancho, generalmente plegada por compresión.

Dimensiones (9 ejemplares). Diámetro ecuatorial, 20(38,6)49 $\mu \mathrm{m}$; exina, 1-2 $\mu \mathrm{m}$.

Principal material estudiado. BAPal 6152 (a) T53/4, T54/0, U49/4; BAPal 6162 (b) G51/3; BAPal 6166 (a) O49/3; 6183 (b) L44/0; BAPal 2940-60: E37/4; BAPal 6184 (a) M33/0; BAPal 6184 (b) M28/1; BAPal BAPal 6188 (b) S60/2.

Comentarios. Si bien los ejemplares aquí estudiados presentan un alto grado de corrosión, la presencia de los microgránulos y la forma de los mismos, permiten hacer una asignación específica sin dudas.

Registros previos. Cyclogranisporites microgranus fue descripta originalmente por Bharadwaj (1957) para el filón Wahlschied, Mina Göttelborn, Bahía de Saar, Pennsylvaniano, Alemania. También muestra un registro amplio en el Pennsylvaniano de Estados Unidos (Habib, 1968; Peppers, 1997) y Cisuraliano (Turquía; Ăgrali y Akyol, 1967). 
- Pennsylvaniano: Argentina: presente en las formaciones Tupe (Césari, 1986a) y Guandacol (Césari y Limarino, 2002); ilustrada para la Formación Agua Colorada (Limarino y Gutiérrez, 1990), Cuenca Paganzo.

- Pennsylvaniano-Cisuraliano: Argentina: presente en la Formación Santa Máxima, Cuenca Calingasta-Uspallata (Ottone, 1989).

- Cisuraliano-Guadalupiano: Brasil: presente en el Grupo Itararé y formaciones Rio Bonito y Palermo, Cuenca Paraná (Marques-Toigo, 1988).

Género Granulatisporites Ibrahim emend. Potonié y Kremp 1954

Especie tipo. Granulatisporites granulatus Ibrahim, 1933.

Afinidad botánica. Pteridophyta-Filicopsida (véase Balme, 1995).

Granulatisporites austroamericanus Archangelsky y Gamerro 1979

Lámina I, figura C

Sinonimia. Véase Archangelsky y Gamerro (1979) y Playford y Dino (2002).

Descripción. Espora radial trilete, de contorno triangular, de lados rectos a suavemente convexos y ápices redondeados. Margen levemente sinuoso, por proyección de la ornamentación. Lesura de rayos rectos a sinuosos, extendidos hasta los extremos de los ápices, acompañados de labios delgados. Cara proximal lisa o con gránulos pequeños dispuestos de manera dispersa. Cara distal cubierta por gránulos mayores, uniforme y densamente distribuidos, de bases subcirculares y chatos. Exina de hasta $1 \mu \mathrm{m}$ de espesor.

Dimensiones (8 ejemplares). Diámetro ecuatorial, 22(35,5)45 $\mu \mathrm{m}$; ornamentación, hasta $1 \mu \mathrm{m}$ de base y $0,5 \mu \mathrm{m}$ de altura; exina $0,5-1 \mu \mathrm{m}$.

Principal material estudiado. BAPal 6146 (b) U38/1; BAPal 6152 (a) K46/0, K47/3, H75/2; BAPal 6162 (b) J62/4; BAPal 6165 (a) Q49/0; BAPal 6188 (a) T45/2. Retrabajo: BAPal 6135 (a) F35/3.

Registros previos. Granulatisporites austroamericanus fue descripta originalmente por Archangelsky y Gamerro (1979) para la perforación YPF Cd Ordóñez es-1, biozonas Potonieisporites-Lundbladispora, parte alta; Cristatisporites y Striatites, parte baja de la Cuenca Chacoparaná. 
- Pennsylvaniano: Argentina: presente en las formaciones Agua Colorada y E1 Trampeadero, Cuenca Paganzo (Gutiérrez, 1988; Gutiérrez y Barreda, 2006) y para la Cuenca Chacoparaná (Vergel, 1986). Ilustrada para Tupambi, Cuenca Tarija (di Pasquo 2003). Brasil: ilustrada para la Formación Piauí, Cuenca Paranaíba (Dino y Playford, 2002).

- Pennsylvaniano-Cisuraliano: Argentina: presente en las formaciones Sachayoj, Cuenca Chacoparaná (Vergel, 1998) y Santa Máxima, Cuenca Calingasta-Uspallata (Ottone, 1989). Listada para la Formación Río del Peñón, Cuenca Río Blanco (Gutiérrez y Limarino, 2006). Presente en la Formación Sauce Grande, Sierras Australes (di Pasquo et al., 2008). Brasil: listada para el Subgrupo Itararé, Itaporanga, Cuenca Paraná (Souza, 2006).

- Cisuraliano-Guadalupiano: Argentina: en las biozonas PotonieisporitesLundbladispora (parte alta), Cristatisporites y Striatites (parte baja), Cuenca Chacoparaná; (Archangelsky y Gamerro, 1979; Vergel, 1987; Césari et al., 1995). Uruguay: ilustrada para la Formación Melo (Mautino et al., 1998a; Beri y Pecoits, 2001), Cuenca Paraná. Brasil: presente en Matos Costa, Santa Catarina, Cuenca Paraná (Quadros et al., 1996) y en la Formación Rio Bonito (Tiwari y Navale, 1967; Nahuys et al., 1968; Ybert, 1975). Papúa: ilustrada para las formaciones Ainim y Aiduna (Playford y Rigby, 2008).

- Cisuraliano: Argentina: ilustrada para las formaciones El Imperial, Cuenca San Rafael (García, 1995), Piedra Shotel, Cuenca Tepuel Genoa (Gamerro y Archangelsky, 1981a) y Tupe (miembro cuspidal), Cuenca Paganzo (Vergel, 2008). Presente en la Formación Victoriano Rodríguez, Biozona Cristatisporites, Cuenca Chacoparaná (Playford y Dino 2002). Uruguay: presente en la Formación San Gregorio (Beri y Daners, 1996; Beri et al., 2006), Cuenca Paraná.

\section{Género Baculatisporites Thompson y Pflug 1953}

Especie tipo. Baculatisporites bharadwaji Hart, 1963b.

Afinidad botánica. Filicopsida; Osmundaceae (véase Raine et al., 2008).

\section{Baculatisporites bharadwaji Hart 1963b}

Lámina II, figura D 
Sinonimia. Véase Backhouse (1991) y Lindström (1996).

Descripción. Espora radial trilete, de contorno circular a subcircular, deformado por pliegues de compresión. Margen levemente sinuoso, por proyección de la ornamentación. Lesura simple, de rayos rectos a sinuosos, extendidos hasta el margen ecuatorial. Cara proximal ornamentada por pequeños gránulos dispuestos de manera dispersa. Cara distal cubierta por báculas de baja altura y verrugas, uniforme y densamente distribuidos. Espesor de la exina de 0,5-1,5 $\mu \mathrm{m}$.

Dimensiones (5 ejemplares). Diámetro ecuatorial, 37(43,4)52 $\mu \mathrm{m}$; ornamentación, 1-2 $\mu \mathrm{m}$ de ancho basal y 1-2 $\mu \mathrm{m}$ de altura

Principal material estudiado. BAPal 6148 (a) S58/3; BAPal 6158 (a) L41/0; BAPal 6169 (a) P57/1. Retrabajo: BAPal 6135 (a) N38/2; BAPal 6171 (a) H46/3.

Comentarios. Si bien los ejemplares aquí estudiados se hallaron en bajo número, ellos presentan las características diagnósticas de la especie: contorno circular a subcircular, ornamentación proximal granulada y distal conformada por báculas de baja altura y verrugas, densamente dispuestas.

Registros previos. Baculatisporites bharadwaji fue descripta originalmente por Hart (1963b) para Mchuchuma Coalfield, Tanganyika.

- Cisuraliano: Australia: ilustrada para la Formación Stockton y Collie Coal Measures, Cuenca Collie (Backhouse, 1991). Antártida: presente en Vestfjella, Dronning Maud Land (Lindström, 1996). África: mencionada para la Cuenca del Karroo (Anderson, 1977).

Esta es la primera cita de la especie para la Argentina.

Subifraturma NODATI Dybová y Jachowicz 1957

Género Anapiculatisporites Potonié y Kremp 1954

Especie tipo. Anapiculatisporites isselburgensis Potonié y Kremp 1954.

Afinidad botánica. Licofitas (véase Balme, 1995).

Anapiculatisporites tereteangulatus (Balme y Hennelly) Playford y Dino 2002

Lámina II, figura $\mathrm{E}$ 
1956b. Acanthotriletes tereteangulatus Balme y Hennelly, pp. 247-248, pl. 2, figs. 2729.

1964. Lophotriletes sparsus Singh, p. 247, pl. 44, fig. 23.

Sinonimia adicional. Véase Dino y Playford (2002) y Raine et al. (2006).

Descripción. Espora radial trilete, de contorno triangular, lados desde cóncavos a rectos y ángulos redondeadas. Margen irregular por proyección de la ornamentación. Lesura simple, discernible, de rayos extendidos entre $2 / 3$ a 4/5 del radio de la espora. Ornamentación conformada por espinas y conos aguzados, dispuestos de forma laxa a densa. Ocasionalmente pueden observarse báculas acuminadas o romas.

Dimensiones (27 ejemplares). Diámetro ecuatorial, 23(32,1)40 $\mu \mathrm{m}$; ornamentación, $1(1,9) 4 \mathrm{de}$ ancho basal y $0,8(2,2) 4 \mu \mathrm{m}$ de altura; exina, $0,5(1,08) 3 \mu \mathrm{m}$.

Principal material estudiado. BAPal 6152 (a) D61/0, D49/1, J42/1, H37/3, J40/0, J63/2, K74/1, N63/2, N62/0; BAPal 6156 (a) C38/0; BAPal 6157 (a) E63/0; BAPal 6161 (a) T37/2; BAPal 6162 (a) U52/1; BAPal 6165 (a) E65/4; BAPal 6167 (a) G66/4; BAPal 6180 (a) T59/2. Retrabajo: BAPal 6170 (a) U37/2.

Comparación. Los ejemplares aquí estudiados presentan una estrecha similitud morfológica con Horriditriletes spinobaculosus (Marques-Toigo) Souza y Callegari (2004). Dicha especie quizás no debería ser ubicada en Horriditriletes Bharadwaj y Salujha (1964, p. 193), ya que el género incluye formas de contorno triangular a subtriangular ornamentadas por elementos que incluyen mayoritariamente báculas cilíndricas más largas que anchas. La especie H. spinobaculosus (Marques-Toigo, 1974, p. 602, pl. I, figs. 1-1a) descripta por Souza y Callegari (2004, pp. 443-444, pl. 1.6-1.7) se caracteriza por presentar entre los elementos esculturales un predominio de espinas, con ocasionales conos y báculas y rara vez se observan verrugas, disminuyendo proximalmente en tamaño dichos elementos. Es por ello dicha especie debería ser excluída de Horriditriletes.

Por otra parte, Anapiculatisporites Potonié y Kremp (1954, p. 130) según la enmienda de Smith y Butterworth (1967, p. 160) incluye formas de contorno triangular a ocasionalmente circular, lesura simple y prominente, cara proximal levigada y ornamentación de cara distal compuesta por conos o espinas de similar tamaño. Anapiculatisporites tereteangulatus (Balme y Hennelly) Playford y Dino (2002, p. 252, 
pl. 4, fig. 1) se caracteriza por presentar una ornamentación dominada por espinas, pocos conos y raras báculas, disminuyendo en tamaño proximalmente dichos elementos.

A partir de lo discutido se considera que A. tereteangulatus y $H$. spinobaculosus comprenderían formas con las mismas caracterísricas (tamaño, contorno general, forma y tamaño de la lesura, ornamentación y dimensiones de la ornamentación), tratándose de esta forma de una misma especie y que hallaría una mejor ubicación dentro del género Anapiculatisporites. La diferencia más conspicua entre ambas diagnosis sería la presencia de raras verrugas (en $H$. spinobaculosus), la que se considera un rasgo de poco valor para separarla de A. tereteangulus, ya que las mismas tienen una escasa representación entre los elementos esculturales.

Registros previos. Esta especie fue descripta originalmente por Balme y Hennelly (1956b) para Greta Coal Measures, Pérmico de Australia. Ampliamente distrubuida en el Pérmico del Gondwana (véase Balme, 1970; Anderson, 1977; Rigby y Heckel, 1977; Foster, 1979; Backhouse, 1991; Lindström, 1995; Stephenson, 2004; Raine et al., 2006).

- Cisuraliano-Guadalupiano: Argentina: presente en la Formación Victoriano Rodríguez, Biozona Cristatisporites, Cuenca Chacoparaná (Playford y Dino, 2002). Uruguay: presente en la Formación Melo, Cuenca Paraná (Mautino et al., 1998a).

- Cisuraliano: Argentina: presente en la Formación Sachayoj, Cuenca Chacoparaná (Vergel, 1998), ilustrada en la Formación Tupe (miembro cuspidal), Cuenca Paganzo (Vergel, 2008). Uruguay: presente en la Formación San Gregorio (Marques-Toigo, 1974; Beri et al., 2006); Cuenca Paraná. Brasil: presente en el Subgrupo Itararé, Cuenca Paraná (Souza y Callegari, 2004). Australia: presente en Blair Athol Coal Measures (Foster, 1975) y Formación Bandanna, Springsure Anticline (Rigby y Hekel, 1977). Ilustrada para Baralaba Coal Measure y las formaciones Rewan (Foster, 1979), Stockton y Collie Coal Measures, Cuenca Collie (Backhouse, 1991). Omán y Arabia Saudita: ilustrada para la Formación Al Khlata (Stephenson y Filatoff, 2000a). Pakistán: presente en la Formación Amb, del Grupo Zaluch (Balme, 1970). África del Sur: ilustrada para el Keetewa-Mchuchuma Coalfield en Tanzania (Manum y Duc Tien, 1973).

- Guadalupiano-Lopingiano: Pakistán: presente en Wargal Limestone y Formación Chhidro, Grupo Zaluch (Balme, 1970). 
Género Brevitriletes (Balme y Hennelly) Bharadwaj y Srivastava 1969

Especie tipo. Brevitriletes communis Bharadwaj y Srivastava, 1969.

Afinidad botánica. Pteridophyta-Filicopsida (véase Balme, 1995).

\author{
Brevitriletes cornutus (Balme y Hennelly) Backhouse 1991 \\ Lámina II, figuras $\mathrm{G}$ y $\mathrm{H}$
}

1956a. Apiculatisporites cornutus Balme y Hennelly, p. 247, pl. 2, figs. 24-26.

1975. Apiculatisporis levis (Balme y Hennelly); Ybert, p. 187, pl. 1, figs 31, 32.

1980. Apiculatisporis sp. Russo et al., pl. I, fig. 5.

2000. Apiculatisporis cornutus (Balme y Hennelly) Segroves; Gutiérrez y Césari, p. 442, figs. 1.I, 1.M.

Descripción. Espora radial trilete, de contorno circular y margen irregular por proyección de los elementos de la escultura. Lesura simple, claramente discernible, con rayos extendidos hasta el contorno ecuatorial, resolviéndose en curvaturas imperfectas. Cara proximal levigada y cara distal con elementos ornamentales mamoides (base bulbosa y ápice cónico), dispuestos densamente, que en ocasiones coalescen en sus bases. Espesor de la exina de 1 a 2 de $\mu \mathrm{m}$.

Dimensiones (11 ejemplares). Diámetro ecuatorial, 20(30,7)44 $\mu \mathrm{m}$; ornamentación, $1,5(2,7) 5 \mu \mathrm{m}$ de ancho basal y $2(3,6) 5 \mu \mathrm{m}$ de altura.

Principal material estudiado. BAPal 6151 (a) X47/0; BAPal 6152 (a) N53/0; BAPal 6152 (b) H52/1; BAPal 6161 (a) N64/2; BAPal 6162 (a) P44/0, W44/1; BAPal 6169 (a) G62/3; BAPal 6187 (a) Y56/1; BAPal 6188 (b) M71/0. Retrabajo: BAPal 6181 (a) $\mathrm{U} 63 / 0$.

Comentarios. Vergel et al. (1993, lám-1, fig. 6) ilustran material que refieren a esta especie para Formación Agua Colorada, Cuenca Paganzo, en Catamarca. En el mismo, de pobre preservación, no se observan los caracteres diagnósticos de la especie (tipo y tamaño de la ornamentación, área de contacto, lesura, contorno, etc.).

Registros previos. Esta especie fue descripta originalmente por Balme y Hennelly (1956a) para Greta Coal Measures, Pérmico de Australia, y presenta un amplio registro 
en las sedimentitas pérmicas del Gondwana (véase Stephenson, 2004; Raine et al., 2006).

- Pennsylvaniano-Cisuraliano: Argentina: mencionada para la Formación Río del Peñón, Cuenca Paganzo (Gutiérrez y Limarino, 2006).

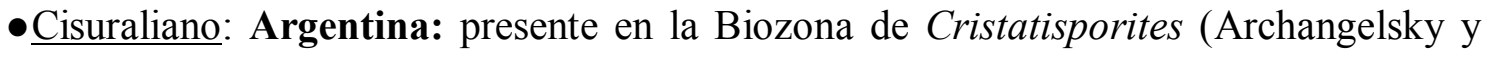
Gamerro, 1979; Vergel, 1987) y en la Formación Sachayoj (Vergel, 1998); ilustrada para las Biozonas Potonieisporites-Lundbladispora y Cristatisporites (Archangelsky et al., 1980; Césari et al., 1995) todas en la Cuenca Chacoparana. Ilustrada para la Formación E1 Imperial, Cuenca San Rafael (García, 1995); y para las formaciones Bajo de Véliz (Gutiérrez y Césari, 2000) y Tupe (miembro cuspidal), ambas de Cuenca Paganzo (Vergel, 2008), y para la Formación Río Genoa, Cuenca Tepuel-Genoa (Gutiérrez et al., 2007). Uruguay: presente en la Formación San Gregorio (Beri et al., 2006), Cuenca Paraná. Brasil: presente en Matos Costa, Santa Catarina (Quadros et al., 1996); ilustrada, Subgrupo Itararé, Cuenca Paraná (Dias, 1993). Australia: ilustrada para la Formación Stockton y Collie Coal Measures, Cuenca Collie (Backhouse, 1991). Omán y Arabia Saudita: presente en la Formación Al Khlata (Stephenson, 2003; Stephenson y Filatoff, 2000a). Antártida: ilustrada para Vestfjella, Dronning Maud Land (Lindström, 1995). Perú: listada para el Grupo Copacabana (Doubinger y Marocco, 1981). Bolivia: ilustrada para la localidad Capinota, Grupo Copacabana (Cousminer, 1965). Sudáfrica: ilustrada para las formaciones Ecca (sección media, Cisuraliano) y Beaufort (sección inferior, Lopingiano), Sistema Karroo (Anderson, 1977; Chandra et al., 1977).

- Cisuraliano-Guadalupiano: Uruguay: ilustrada para la Formación Melo (Mautino et al., 1998a), Cuenca Paraná. Brasil: presente en la Formación Rio Bonito, Cuenca Paraná (Ybert, 1975).

- Guadalupiano: Australia: presente en la Formación Bandanna, Springsure Anticline (Rigby y Hekel, 1977).

- Lopingiano: Argentina: mencionada para la Formación La Veteada, Cuenca Paganzo (Zavattieri et al., 2008).

Brevitriletes levis (Balme y Hennelly) Bharadwaj y Srivastava 1969 Lámina II, figura $\mathrm{F}$ 
1956. Apiculatisporis levis Balme y Hennelly, pl. 2, figs. 19-21.

1969. Anapiculatisporites? variornatus Menéndez y Azcuy, pp. 88, 90; lám. 3, figs. AH.

1971. Apiculiretusispora variornata (Menéndez y Azcuy) Menéndez y Azcuy, p. 28.

1975. Retusotriletes baculiferus Ybert, p. 186, pl. 1, figs. 21-23.

1977. Apiculatisporis bulliensis Anderson, p. 85, pl. 78, figs. 1-17.

1995. Apiculatisporis levis Balme y Hennelly (sic); Cesari et al., p. 78, pl. 1, fig. 2.

1997. Retusotriletes golatensis Staplin; Souza et al., p. 12, pl. 1, fig. 3.

2003a. Apiculiretusispora variornata (Menéndez y Azcuy) Menéndez y Azcuy; di Pasquo et al., p. 282, fig. 3.E.

Sinonimia. Véase Foster (1979), Souza et al. (2003), Beri et al. (2006) y Raine et al. (2006).

Comentarios. Siguiendo lo propuesto por Stephenson (2004) el género Brevitriletes incluye esporas pequeñas, retusoides, de contorno circular y ornamentación distal variada apiculada. Por lo tanto $B$. levis se considera dentro del género.

Descripción. Espora radial trilete, de contorno circular a subcircular, de margen irregular por proyección de la ornamentación. Lesura simple claramente discernible, con rayos extendidos hasta el contorno ecuatorial, resolviéndose en curvaturas imperfectas. Cara proximal levigada y cara distal con ornamentara por espinas de base bulbosa, regularmente distribuidas. Exina de 1 a $2 \mu \mathrm{m}$ de espesor.

Dimensiones (8 ejemplares). Diámetro ecuatorial, 24(30,7)50 $\mu \mathrm{m}$; ornamentación, 0,5-3 $\mu \mathrm{m}$ de ancho basal y $1-5 \mu \mathrm{m}$ de altura.

Principal material estudiado. BAPal 6150 (a) S52/0; BAPal 6159 (a) N57/4; BAPal BAPal 6162 (a) G37/4, L61/0, V61/2, W48/1; BAPal 6162 (b) O46/1; BAPal 6165 (b) M60/3.

Registros previos. Brevitriletes levis (Balme y Hennelly) Bharadwaj y Srivastava fue descripta originalmente para Greta Coal Measures, Pérmico de Australia (Balme y Hennelly, 1956b). Presenta un amplio registro para el Pérmico del Gondwana (véase Raine et al., 2006).

- Pennsylvaniano: Argentina: presente en las formaciones Lagares (Menéndez y Azcuy, 1971) y Tupe (Ottone y Azcuy, 1990), Cuenca Paganzo. Brasil: ilustrada para 
los carbones Monte Mor, Buri y Cerquilho, Grupo Tubarão, Cuenca Paraná (Souza et al., 1997).

- Pennsylvaniano-Cisuraliano: Argentina: presente en la Formación Sachayoj, (Vergel, 1998) e ilustrada (Césari et al., 1995) en la Cuenca Chacoparaná, y presente en la Formación San Telmo, Cuenca Tarija (di Pasquo et al., 2001).

- Cisuraliano: Argentina: presente en las formaciones Tasa Cuna de Cuenca Paganzo (Balarino y Gutiérrez, 2006) y en Río Genoa de Cuenca Tepuel Genoa (Gutiérrez et al., 2007). Uruguay: presente en la Formación San Gregorio (Beri et al., 2006), Cuenca Paraná. Brasil: presente el Subgrupo Itararé, Cuenca Paraná (Souza et al., 1997, 2003; di Pasquo et al., 2003a). India: presente en Barakar Stage (Bharadwaj y Srivastava, 1969a). Sudáfrica: presente en Cuenca Karroo (Anderson, 1977).

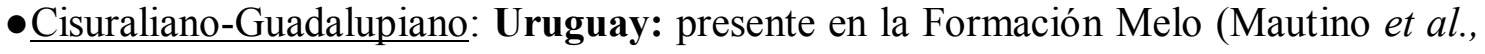
1998a), Cuenca Paraná. Brasil: presente en la Formación Rio Bonito, Cuenca Paraná (Ybert, 1975).

\section{Género Osmundacidites Couper 1953}

Especie tipo. Osmundacidites wellmanii Couper 1953.

Afinidad botánica. Filicopsida; Osmundaceae (véase Raine et al., 2008).

\section{Osmundacidites wellmanii Couper 1953}

Lámina II, figura I

Descripción. Espora radial trilete, de contorno circular a subcircular por los plegamientos exinales. Lesura con rayos extendidos hasta 4/5 del radio de la espora, acompañada por labios altos y rectos. Ornamentación compuesta por gránulos de diámetro variable, dispuestos aislada e irregularmente en ambas caras, incluso alcanzando los labios de la lesura. Exina de $1 \mu \mathrm{m}$ de espesor.

Dimensiones (2 ejemplares). Diámetro ecuatorial, 32-42 $\mu \mathrm{m}$; ornamentación, 0,5 $\mu \mathrm{m}$ de diámetro basal y $0,5-1,5 \mu \mathrm{m}$ de altura.

Principal material estudiado. BAPal 6166 (a) V50/3. Retrabajo: BAPal 6181 (a) T69/0. 
Registros previos. Osmundacidites wellmanii fue descripta originalmente por Couper (1953) para Ohika beds, Cretácico de Nueva Zelanda; presenta un registro que va del Pérmico al Paleógeno (véase Raine et al., 2006). Esta especie está muy bien representada en sedimentos pérmicos y triásicos de Antártida (Lindström, 1996 y bibliografía allí citada).

- Cisuraliano: Antártida: presente en Fossilryggen, Vestfjella, Dronning Maud Land (Lindström, 1996, 2005).

- Guadalupiano: Australia: ilustrada para Baralaba Coal Measures, Cuenca Bowen (Foster, 1979).

- Lopingiano-Triásico Inferior: Australia: presente en la Formación Rewan, Cuenca Bowen (Foster, 1979).

- Triásico Superior: Argentina: ilustrada para las formaciones Potrerillos y Cacheuta, Cuenca Cuyana (Rojo y Zavattieri, 2005). Antártida: ilustrada para la Formación Falla, Mount Falla (Farabee et al., 1989).

Subinfraturma VERRUCATI Dyvobá y Jachowics 1957

Género Converrucosisporites Potonié y Kremp 1954

Especie tipo. Converrucosisporites triquetrus (Ibrahim) Potonié y Kremp, 1954.

Afinidad botánica. Pteridophyta-Filicopsida (véase Balme, 1995).

Converrucosisporites confluens (Archangelsky y Gamerro) Playford y Dino 2002

Lámina II, figuras J, K y L

1979. Granulatisporites confluens Archangelsky y Gamerro, p. 422, lám. I, figs. 5 y 6.

1996. Granulatisporites austroamericanus Archangelsky y Gamerro; Beri y Goso, pl. 1, fig. 6 .

Sinonimia adicional. Véase Playford y Dino (2002) y Stephenson (2004).

Descripción. Espora radial trilete, de contorno triangular de lados rectos y ápices redondeados a punteagudos. Lesura simple, rayos se prolongan hasta los $3 / 4$ del radio de la espora. Cara distal y zona ecuatorial ornamentadas con granos y verrugas chatas, de bases circulares a poligonales, en contacto entre sí y fusionados formando en algunos 
sectores un retículo negativo. Cara proximal también ornamentada con granos y verrugas, aunque levemente menores en tamaño. Exina de 1 a 1,5 $\mu \mathrm{m}$ de espesor.

Dimensiones (6 ejemplares). Diámetro ecuatorial, 28(37,8)49 $\mu \mathrm{m}$; ornamentación, 1-2 $\mu \mathrm{m}$ de ancho basal y $1-2 \mu \mathrm{m}$ de altura.

Principal material estudiado. BAPal 6152 (a) Q40/0, D48/1, G42/2; BAPal 6187 (b) Q48/0; BAPal 6168 (a) K67/0; BAPal 6189 (a) T59/2.

Registros previos. Converrucosisporites confluens fue descripta originalmente por Archangelsky y Gamerro (1979) para los pozos YPF Cd Ordóñez es-1 (Biozona Potonieisporites-Lundbladispora, parte alta; Biozona Cristatisporites y Biozona Striatites, parte basal); Cd Camilo Aldao es-1 (Biozona Cristatisporites) y Cd Saira es-1 (Biozona Cristatisporites), Cisuraliano-Guadalupiano de la Cuenca Chacoparaná, Argentina.

- Cisuraliano: Argentina: presente en las formaciones Victoriano Rodríguez (Césari et al., 1995), Biozona Cristatisporites, Cuenca Chacoparaná (Playford y Dino 2002) y Tasa Cuna, Cuenca Paganzo (Balarino y Gutiérrez, 2006); ilustrada para la Formación Piedra Shotel, Biozona Cristatisporites, Cuenca Tepuel Genoa (Gamerro y Archangelsky, 1981a); y en la Formación Sachayoj, Cuenca Chacoparaná (Vergel, 1998); ilustrada para la Formación Tupe (miembro cuspidal), Cuenca Paganzo (Vergel, 2008). Uruguay: presente en la Formación San Gregorio (Beri y Daners, 1996; Beri et al., 2006); ilustrada para la Formación Tres Islas (Veroslavsky et al., 2003), Cuenca Paraná. Brasil: ilustrada para el Subgrupo Itararé, Biozona Vittatina costabilis, subbiozona Protohaploxypinus goraiensis, Cuenca Paraná (Souza y Callegari, 2004). Omán y Arabia Saudita: presente en la Formación Al Khlata (Stephenson y Filatoff, 2000a; Stephenson et al., 2002; Stephenson, 2003) y en la Formación Gharif (Stephenson y Osterloff, 2002; Stephenson et al., 2002); ilustrado en la Formación Unayzah (Stephenson et al., 2002) Antártida: listada para Milorgfjella, Dronning Maud Land (Larsson et al., 1990) e ilustrada para Vestfjella, Dronning Maud Land (Lindström, 1995). Sudáfrica: ilustrada para la Formación Grant (Stephenson, 1998).

Converrucosisporites micronodosus (Balme y Hennelly) Playford y Dino 2002 Lámina II, figura M 
1956b. Granulatisporites micronudosus Balme y Hennelly, p. 245, pl.1, figs. 9, 10.

1967. Granulatisporites micronodosus Balme y Playford, p. 245, pl. I, figs. 9, 10.

1971. Granulatisporites cf. trisinus Balme y Hennelly; Menendez, p. 270, pl. 1, fig. 4.

1974. Converrucosisporites microverrucatus Marques-Toigo, pp. 602, 604, pl. 1, figs 2, 2a, 3, 3a.

1977. Microbaculispora micronodosus (Balme y Playford) Anderson, p. 49, pl. 50, figs. 1-37 (9-3).

1975. Microbaculispora micronodosa (Balme y Playford) Falcon, p. 217, pl. I, fig. 5 (non Anderson).

1980. Granulatisporites micronodosus Balme y Hennelly; Archangelsky y Gamerro, lám. I, fig. 2.

2001. Granulatisporites micronodosus Balme y Hennelly; di Pasquo et al., p. 88, fig. $2 \mathrm{G}$.

Sinonimia adicional. Véase Playford y Dino (2002) y Raine et al. (2006).

Descripción. Espora radial trilete, de contorno subtriangular, de lados rectos a levemente convexos y ápices redondeados. Lesura simple, de rayos rectos, levemente sinuosos. Ornamentación conformada por verrugas dispuestas homogeneamente, de bases circulares a poligonales y ápices redondeados. Ocasionalmente coalescen los elementos por sus bases. Los espacios entre las verrugas son levigados y más claros. Exina de 1-2 $\mu \mathrm{m}$ de espesor.

Dimensiones (5 ejemplares). Diámetro ecuatorial, 30(46)60 $\mu \mathrm{m}$; ornamentación, 1-3 $\mu \mathrm{m}$ de ancho basal y $0,5-2 \mu \mathrm{m}$ de altura.

\section{Principal material estudiado. BAPal 6156 (c) U51/0; BAPal 6158 (a) G57/3; BAPal} 6159 (a) D59/1; BAPal 6163 (a) G49/2; BAPal 6164 (a) D65/3.

Comentario. Esta especie ha sido listada e ilustrada para el Grupo Mandiyutí, Cuenca Tarija (di Pasquo y Azcuy, 1997, lám. 1, fig. 12; di Pasquo et al., 2001, fig. 2.G), constituyendo éste el registro más antiguo. Sin embargo, al carecer de descripciones y a juzgar por las ilustraciones, dicho material parece no presentar las altas verrugas anastomosadas y el contorno general triangular, rasgos diagnósticos de la especie (Archangelsky y Gamerro, 1979, Playford y Dino, 2002). Por lo expuesto, se consideran dudosas estas asignaciones. 
Registros previos. Esta especie fue descripta originalmente para Greta Coal Measures, Pérmico de Australia (Balme y Hennelly, 1956b) y presenta un amplio registro para el Pérmico del Gondwana (véase Raine et al., 2005) y Triásico de Australia (de Jersey, 1979).

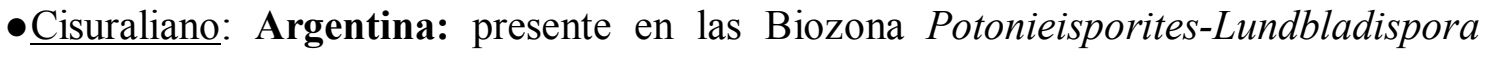
(parte alta) y Cristatisporites, Cuenca Chacoparaná (Archangelsky y Gamerro, 1979; Césari et al., 1995), en la Biozona Cristatisporites en las formaciones Victoriano Rodríguez (Playford y Dino, 2002) y Sachayoj (Vergel, 1998), todas de Cuenca Chacoparaná. Ilustrada para la Biozona Cristatisporites, Cuenca Claromecó-Colorado (Archangelsky y Gamerro, 1980b); para la Formación Piedra Shotel, Biozonas Potonieisporites-Lundbladispora y Cristatisporites, Cuenca Tepuel Genoa (Gamerro y Archangelsky, 1981a); presente en Bajo de Véliz, Cuenca Paganzo (Menéndez, 1971). Uruguay: presente en la Formación San Gregorio (Marques-Toigo, 1974; Beri, 1988; Beri y Daners, 1996; Beri y Goso Aguiar, 1998; Beri et al., 2006). Cuenca Paraná. Brasil: presente en Matos Costa, Cuenca Paraná (Quadros et al., 1996). Australia: presente en Greta Coal Measure (Balme y Hennelly, 1956b). Ilustrada para las formaciones Grant, Cuenca Canning, (Foster y Waterhouse, 1988) y Stockton y Collie Coal Measures, Cuenca Collie (Backhouse, 1991). Antártida: ilustrada para Prince Charles Mountains (Balme y Playford, 1967). África: presente en la Secuencia Inferior del Karroo (Falcon, 1975) y en Lower Coal Measures (Anderson, 1977).

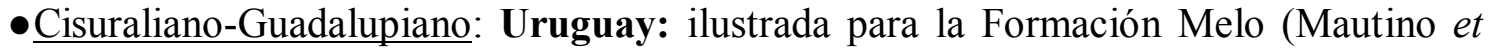
al., 1998a), Cuenca Paraná. Brasil: presente en la Formación Rio Bonito (Burjack, 1978), Cuenca Paraná. Papúa: ilustrada para las formaciones Ainim y Aiduna (Playford y Rigby, 2008).

Converrucosisporites pustulatus Backhouse 1988

Lámina II, figuras $\mathrm{N}$ y $\tilde{\mathrm{N}}$

Descripción. Espora radial trilete, de contorno subtriangular, de lados convexos y ápices redondeados. Lesura de rayos rectos acompañados por pliegues comisurales de1,5 $\mu \mathrm{m}$ de ancho, que alcanzan el margen de la espora. Ornamentación conformada por altas verrugas de bases subcirculares y ápices redondeados; densamente dispuestas 
sobre la cara distal y separadas por espacios menores al diámetro de las verrugas; sobre la cara proximal, la ornamentación disminuye de tamaño. Cara proximal levemente convexa, y distal fuertemente convexa. Exina de $2 \mu \mathrm{m}$ de espesor en los ángulos, mientras que en los interradios aumenta de espesor.

Dimensiones (1 ejemplar). Diámetro ecuatorial, $60 \mu \mathrm{m}$; ornamentación distal, $3 \mu \mathrm{m}$ de diámetro basal y $2 \mu \mathrm{m}$ de altura; ornamentación proximal, 1,5-2 $\mu \mathrm{m}$ de diámetro.

Principal material estudiado. BAPal 6159 (a) D59/1.

Comentarios. El ejemplar aquí estudiado es asignado a la especie Converrucosisporites pustulatus Backhouse (1988, pp. 54-55, figs. 3-4) por presentar coincidencia en las caracteristicas diagnósticas de las especie (labios altos, tipo, distribución y dimensiones de la ornamentación, contorno, espesor de la exina y dimensiones). Converrucosisporites sp. descripta para la perforación Las Mochas (Césari et al., 1995, p. 81), a pesar de no haber sido ilustrada, presentaría una morfología similar (dimensiones, contorno y escultura distal), sin embargo es descripta sin labios y no sería anisopolar.

Registros previos. Converrucosisporites pustulatus fue descripta por Backhouse (1988) para el Pérmico de Ewington Member, Collie Coal Measures, Australia.

- Cisuraliano: Australia: presente en la Formación Stockton y Collie Coal Measures, Cuenca Collie (Backhouse, 1988, 1991).

Esta es la primera cita para el Pérmico de la Argentina.

Género Verrucosisporites Ibrahim emend. Smith 1971

Especie tipo. Verrucosisporites verrucosus (Ibrahim) Ibrahim, 1933.

Afinidad botánica. Pteridophyta-Filicopsida (véase Quadros et al., 1996).

Verrucosisporites sp. cf. V. chiquiritensis Ottone 1989

Lámina III, figura A

Descripción. Espora radial trilete de contorno subcircular a oval, deformado por compresión, de margen suavemente ondulado por la proyección de la ornamentación. Lesura trilete, no siempre discernible por quedar enmascarada por los elementos de la escultura y los pliegues. Ornamentación conformada por verrugas equidimensionales, 
de bases irregulares de baja altura y redondeadas, dispuestas densamente. Pueden observarse algunos conos aislados, de similares dimensiones que las verrugas. Algunos elementos esculturales pueden fusionarse formando pequeñas crestas integradas por 2 a 3 verrugas. Exina de 1,5 $\mu \mathrm{m}$ de espesor.

Dimensiones (1 ejemplar). Diámetro ecuatorial, $40 \mu \mathrm{m}$; ornamentación, 1-2 $\mu \mathrm{m}$ de diámetro basal y hasta $2 \mu \mathrm{m}$ de altura.

Principal material estudiado. BAPal 6152 (a) R41/0.

Comentarios. El ejemplar aquí estudiado presenta un pobre grado de preservación, lo que impide hacer una asignación específica certera. Sin embargo, características tales como la forma general, el tamaño, la ornamentación verrucosa y la densa disposición de las verrugas permiten comparar al ejemplar con la especie Verrucosisporites chiquiritensis Ottone (1989).

Verrucosisporites microtuberosus (Loose) Smith y Butterworth 1967

$$
\text { Lámina III, figura D }
$$

1932. Sporonites microtuberosus Loose en Potonié et al., p. 450, pl. 18, fig. 33.

Descripción. Espora radial trilete, de contorno subcircular deformada por compresión. Lesura simple, de rayos rectos extendidos aproximadamente $3 / 4$ del radio de la espora, poco discernible. Ornamentación conformada por granos muy bajos, irregulares a subpoligonales, densamente distribuídos. Exina de 1,5 $\mu \mathrm{m}$ de espesor.

Dimensiones (4 ejemplares). Diámetro ecuatorial, 38(51,3)64 $\mu \mathrm{m}$; ornamentación, 2-6 $\mu \mathrm{m}$ de ancho basal y 1,5-2 $\mu \mathrm{m}$ de altura.

Principal material estudiado. BAPal 6150 (a) V41/0; BAPal 6152 (a) J56/4, S44/2, D42/2.

Comentarios. Los ejemplares estudiados presentan las características diagnósticas de la especie Verrucosisporites microtuberosus: esporas generalmente deformadas por compresión, de contorno subcircular, con una ornamentación conformada por granos bajos, de bases poligonales, densamente distribuídos. Por ello se realiza la asignación específica.

Registros previos. Verrucosisporites microtuberosus (Loose) Smith y Butterworth fue descripta originamente para la mina Köln-Neussen (Westphaliano), Ruht, Alemania. 
Presenta un amplio registro para el Carbonifero Superior de USA y Europa (véase Smith y Butterworth, 1967; Ravn, 1979), recientemente Amenábar et al. (2006, fig. 10.B) ilustran especie para el Mississippiano de Argentina (Formación Chiguas).

- Cisuraliano: Brasil: presente en Chapéu do Sol (Quadros et al., 1996) y para el Subgrupo Itararé (Souza y Calegari, 2004), Cuenca Paraná.

- Cisuraliano-Guadalupiano: Uruguay: ilustrada para la Formación Melo (Beri y Daners, 1995), Cuenca Paraná.

Esta es la primera cita para la Argentina.

Verrucosisporites surangei Maheshwari y Banerjee 1975

Lámina III, figuras B y C

Descripción. Espora radial trilete de contorno circular y margen irregular por proyección de la ornamentación. Lesura trilete, difícilmente discernible por la ornamentación, de rayos simples y rectos, de hasta $2 / 3$ del radio de la espora. Ornamentación conformada por verrugas robustas, de bases irregulares a veces en contacto entre sí y ápices redondeados a agudos. Los elementos esculturales en cara proximal son más pequeños y se disponen aisladamente. Exina de $2 \mu \mathrm{m}$ de espesor, y puede presentar pliegues irregulares producidos por la compresión.

Dimensiones (3 ejemplares). Diámetro ecuatorial, 50-80 $\mu \mathrm{m}$; ornamentación, 2-4 $\mu \mathrm{m}$ de diámetro basal y 2-3 $\mu \mathrm{m}$ de altura.

Principal material estudiado. BAPal 6152 (a) D52/0; BAPal 6152 (b) C63/3; BAPal 6165 (a) K41/2.

Comentarios. Características tales como el contorno circular con proyección de la ornamentación, elementos esculturales conformados por verrugas robustas que aumentan en tamaño hacia la cara distal, permiten asignar a los ejemplares aquí estudiados sin dudas a la especie Verrucosisporites surangei.

Registros previos. Verrucosisporites surangei fue descripta por Maheshwari y Banerjee (1975) para la Formación Maitur, Grupo Panchet, India.

- Guadalupiano: Australia: presente en la sección superior de Baralaba Coal Measures (Foster, 1979). 
- Lopingiano-Triásico Inferior: Australia: presente en la Formación Rewan (Foster, 1979).

- Triásico Inferior: India: presente en la Formación Maitur, Grupo Panchet (Maheshwari y Banerjee, 1975).

Esta es la primera cita de la especie para cuencas sudamericanas.

Pseudoreticulatispora Bharadwaj y Srivastava emend Price y Foster en Price 1984 Especie tipo. Pseudoreticulatispora barakarensiss Bharadwaj y Srivastava, 1969.

Afinidad botánica. Desconocida.

Pseudoreticulatispora pseudoreticulata (Balme y Hennelly) Bharadwaj y Srivastava 1969 Lámina III, figuras E y F

Sinonimia. Price (1984).

Descripción. Espora radial trilete, de contorno triangular, de lados rectos a levemente convexos y ápices redondeados. Lesura discernible, de rayos rectos a levemente sinuosos, extendidos hasta la línea ecuatorial, acompañados por delgados labios que pueden bifurcarse en los extremos de los rayos. Ornamentación conformada por verrugas densamente distribuidas, de base circular a irregular, que se contactan entre sí, de baja altura y forma redondeada. Los espacios generados entre verrugas generan una esculturación foveolada, de lúminas poligonales, circulares a elongadas. La ornamentación es de tamaño reducido en la cara proximal. Exina de $2 \mu \mathrm{m}$ de espesor.

Dimensiones (3 ejemplares). Diámetro ecuatorial, 45(51)58 $\mu \mathrm{m}$; ornamentación, 2-5 $\mu \mathrm{m}$ de diámetro basal y 2-7 $\mu \mathrm{m}$ de altura.

Principal material estudiado. BAPal 6152 (b) F40/3. Retrabajo: BAPal 6171 (a) N58/4; BAPal 6178 (a) S53/1.

Comentarios. La conspicua ornamentación de verrugas densamente dispuestas que alcanzan a contactarse por sus bases, generando así un patrón foveolado, como así también el contorno general subtriangular y la lesura que alcanza el contorno ecuatorial acompañada de delgados labios, permiten asignar sin dudas a los ejemplares aquí estudiados a la especie Pseudoreticulatispora pseudoreticulata. 
Registros previos. Esta especie fue descripta originalmente por Balme y Hennelly (1956) para Greta Coal Measures, Pérmico de Australia.

Vergel (1993) mencionó $P$. pseudoreticulata como una de las especies que caracterizan a la Palinozona Potonieisporites-Lundbladispora. Considerando la distribución estratigráfica conocida para dicha especie, esta sería el registro más antiguo. Al no contar con descripción ni ilustraciones para poder comparar, no se considera por el momento dicha mención entre los registros previos de la especie.

- Cisuraliano: África: ilustrada para el miembro cuspidal de la Formación Tupe (Vergel, 2008). África: presente en Lower Coal Measures (Hart, 1960, 1963; Anderson, 1977); presente en Siankondobo Coalfield, Zambia (Utting, 1978).

- Guadalupiano: Australia: presente en Baralaba Coal Measures, Cuenca Bowen (Foster, 1979); presente en la Cuenca Perth (Segroves, 1970); ilustrada por Balme (1964). Brasil: ilustrada por Pant y Srivastava (1965).

-Lopingiano-Triásico Inferior: Australia: presente en la Formación Rewan, Cuenca Bowen (Foster, 1975, 1979 y bibliografía allí citada).'

Esta es la primera cita de la especie para Argentina.

Subinfraturna BACULATI Dybová y Jachowicz 1957

Género Horriditriletes Bharadwaj y Salujha 1964

Especie tipo. Horriditriletes curvibaculosus Bharadwaj y Salujha, 1964.

Afinidad botánica. Pteridophyta-Filicopsida (véase Balme, 1995).

Horriditriletes filiformis (Balme y Hennelly) Backhouse 1991

Lámina III, figuras G, H e I

1956a. Apiculatisporites filiformis Balme y Hennelly, p. 247, pl. 2, figs. 22-23.

1965. Apiculatisporis filiformis (Balme y Hennelly) Pant y Srivastava, p. 472, pl. 1, fig. 21.

1965. Acanthotriletes filiformis (Balme y Hennelly) Tiwari, p. 173, pl. 1, figs. 19-20

Descripción. Espora radial trilete, de contorno triangular, de lados desde rectos a levemente convexos y ápices fuertemente redondeados. Margen irregular por 
proyección de la ornamentación. Lesura discernible y simple, de rayos rectos que se extienden hasta $2 / 3$ del radio de la espora, parcialmente cubierta por la ornamentación. Ornamentación conformada dominantemente por báculas y, en menor medida, por espinas dispuestas homogéneamente. Exina de 1 a $2 \mu \mathrm{m}$ de espesor.

Dimensiones (10 ejemplares). Diámetro ecuatorial, 27(31,8)43 $\mu \mathrm{m}$; ornamentación, 2-3 $\mu \mathrm{m}$ de ancho basal y 3-7 $\mu \mathrm{m}$ de altura.

Principal material estudiado. BAPal 6152 (b) H75/1, T44/4; BAPal 6158 (a) F52/2; BAPal 6162 (a) O49/1; BAPal 6165 (a) C57/0; BAPal 6166 (a) W45/0; BAPal 6183 (a) N32/0. Retrabajo: BAPal 6172 (a) U68/2.

Comentarios. El material incluido por Zavattieri (1991a, pp. 120-121, lám. V, fig. 3) en Apiculatisporis filiformis (Balme y Hennelly) Venkatachala y Kar presenta una ornamentación integrada por elementos biformes (base subcircular y ápice espinoso) densamente dispuestos, por lo que muy probablemente no se trate de esta especie.

El material proveniente de la Formación Bajo de Véliz que fuera referido por Menéndez (1971, p. 271, lám. I, figs. 6-7) a Acanthotriletes filiformis, así como aquel ilustrado por Azcuy y Jelín (1980, lám. III, fig. 2), Hünicken et al. (1981, lám. III, fig. 1), RochaCampos y Archangelsky (1985, lám. XIII, fig. 2) y Archangelsky (1987, lám. XIII, fig. 8) fue includio en Kraeuselisporites sanluisensis Menéndez (1971) por Gutiérrez y Césari (2000, p. 445). Los ejemplares aquí estudiados presentan las características diagnósticas de la especie (contorno subtriangular, ornamentación conformada por báculas, y en menor medida espinas, etc.), y es por ello que es posible realizar una asignación específica sin dudas.

Registros previos. Horriditriletes filiformis (Balme y Hennelly) Backhouse fue descripta originalmente por Balme y Hennelly (1956a) para Greta Coal Measures, Pérmico de Australia. Presenta un amplio registro en el Pérmico de Australia, India y Antártida (véase Zavattieri, 1991a; Raine et al., 2006).

- Cisuraliano: Australia: presente en la Formación Stockton y Collie Coal Measures, Cuenca Collie (Backhouse, 1991). Brasil: ilustrada por Pant y Srivastava (1965). India: presente en Barakar Stage (Tiwari, 1965).

- Cisuraliano-Guadalupiano: Papúa: descripta para las formaciones Ainim y Aiduna (Playford y Rigby, 2008).

Esta es la primera cita de la especie para la Argentina. 
Horriditriletes ramosus (Balme y Hennelly) Bharadwaj y Salujha 1964

Lámina III, figura J

1956b. Acanthotriletes ramosus Balme y Hennelly, p. 249, pl. 3, figs. 39-41.

1960. Neoraistrickia ramosus (Balme y Hennelly) Hart, pp. 3-4, pl. 3, fig. 39.

1965. Neoraistrickia taylorii Playford y Dettmann, pp. 138-139, pl. 12, figs. 14-15.

1968. Horriditriletes sp., Bose y Maheshwari, p. 27, pl. 5, fig. 9.

1977. Raistrickia ramosa (Balme y Hennelly) Rigby y Hekel, p. 14, pl. 3, figs 2-3, 5, 89.

Sinonimia adicional. Véase Foster (1979).

Descripción. Espora radial trilete, de contorno subtriangular, de lados cóncavos a levemente convexos y ápices redondeados. Margen irregular por proyección de la ornamentación. Lesura discernible y simple, de rayos rectos que se extienden hasta $4 / 5$ del radio de la espora, a veces parcialmente cubierta por la proyección de la ornamentación. En algunos casos puede observarse a los lados de los rayos de la lesura una zona más oscura, sin alcanzar a definirse como labios o espesamientos comisurales. Ornamentación compuesta por predominantemente báculas, y escasos conos y espinas. Los elementos ornamentales se distribuyen de manera heterogénea, pudiendo observarse elementos separados entre sí por 1 y $3 \mu \mathrm{m}$, como también pueden hallarse elementos cuyas bases coalescen entre sí. Exina de $1 \mu \mathrm{m}$ de espesor.

Dimensiones (13 ejemplares). Diámetro ecuatorial, 29(34)42 $\mu \mathrm{m}$; ornamentación, 1,5-3 $\mu \mathrm{m}$ de ancho apical y 3-4 $\mu \mathrm{m}$ de altura.

Principal material estudiado. BAPal 6152 (a) F47/0, M71/0; BAPal 6165 (b) W71/3; BAPal 6166 (a) T58/0; BAPal 6182 (a) K41/0; BAPal 6189 (a) M61/0.

Comentarios. Esta especie es caracterizada por su contorno triangular a subtriangular y una ornamentación principalmente compuesta por báculas y ocasionales espinas (Balme y Hennelly, 1956a; Bharadwaj y Salhuja, 1964).

Registros previos. Esta especie fue descripta originalmente para el Pérmico de Australia; Greta Coal Measures por Balme y Hennelly (1956a) y presenta un registro que va desde el Pérmico al Jurásico (véase Raine et al., 2006); aunque en Sudamérica presenta registros más antiguos (Pennsylvaniano). 
- Pennsylvaniano: Brasil: ilustrada para la Formación Piauí, Cuenca Paranaíba (Dino y Playford, 2002).

- Pennsylvaniano-Cisuraliano: Argentina: presente en la Formación Sauce Grande, Sierras Australes (di Pasquo et al., 2008).

- Cisuraliano: Argentina: presente en la perforación Las Mochas, Cuenca Chacoparaná (Césari et al., 1995); ilustrada en la Formación Tupe (miembro cuspidal), Cuenca Paganzo (Vergel, 2008). Uruguay: presente en la Formación San Gregorio, Cuenca Paraná (Beri et al., 2006). Brasil: presente en Matos Costa, Santa Catarina (Quadros et al., 1996); ilustrada para el Subgrupo Itararé, Biozona Vittatina costabilis, sub-biozona Protohaploxypinus goraiensis (Dias, 1993; Souza y Callegari, 2004), todas en Cuenca Paraná. Australia: presente en Ketewaka-Mchuchuma Coalfield, Tanganyika (Hart, 1960) y en Blair Athol Coal Measures (Foster, 1975). Ilustrada para la Formación Stockton y Collie Coal Measures, Cuenca Collie (Backhouse, 1991). Omán y Arabia Saudita: presente en la Formación Al Khlata (Stephenson et al., 2002; Stephenson, 2003); ilustrado en las Formaciones Unayzah y Khuff(Stephenson et al., 2002). Africa: ilustrada para el Keetewa-Mchuchuma Coalfield en Tanzania (Manum y Duc Tien, 1973) y el Grupo Dwyka en la perforación Strat Test 1, en Namibia (Stapleton, 1977). Antártida: listada para Milorgfjella, Dronning Maud Land (Larsson et al., 1990); ilustrada para Vestfjella, Dronning Maud Land (Lindström, 1995). Perú: listada para Grupo Copacabana (Doubinger y Marocco, 1981).

- Guadalupiano: Australia: presente en Baralaba Coal Measures, Cuenca Bowen (Foster, 1979).

- Cisuraliano-Guadalupiano: Papúa: descripta para las formaciones Ainim y Aiduna (Playford y Rigby, 2008).

- Lopingiano: Argentina: mencionada para la Formación La Veteada, Cuenca Paganzo (Zavattieri et al., 2008).

- Lopingiano-Triásico Inferior: Australia: presente en Formación Rewan, Cuenca Bowen (Foster, 1979).

- Triásico Medio-Superior: Australia: presente en Leigh Creek, Cuenca Northern y en Leigh Creek Coal Measures (Playford y Dettmann, 1965).

Horriditriletes superbus (Foster) Césari, Archangelsky y Seoane 1995 


\section{Lámina III, figura $\mathrm{K}$}

1979. Acanthotriletes superbus Foster, p. 34-35, lám. 5, figs. 20-25.

Descripción. Espora radial trilete, de contorno triangular, de lados desde rectos a levemente cóncavos, y ápices redondeados. Margen irregular por proyección de la ornamentación. Lesura discernible y simple, de rayos rectos que se extienden hasta el margen ecuatorial, parcialmente cubierta por la ornamentación. Ornamentación conformada por báculas, y en menor medida por verrugas, dispuestos de manera densa y homogénea. Las báculas son generalmente de ápice redondeado, aunque también se presentan formas truncas y hasta biformes, en menor medida. Exina de $2 \mu \mathrm{m}$ de espesor. Dimensiones ( 2 ejemplares). Diámetro ecuatorial, 27-42 $\mu \mathrm{m}$; ornamentación, 2-3 $\mu \mathrm{m}$ de ancho apical y 3-5 $\mu \mathrm{m}$ de altura.

Principal material estudiado. BAPal 6149 (a) N51/0; BAPal 6156 (c) U41/2.

Comentarios. Para este estudio se acepta la combinación realizada por Césari et al. (1995, p. 77, lám. I, fig. 7), sin embargo se debe mencionar que el epíteto Horriditriletes superbus fue propuesto previamente por Nakoman (1975, p. 66, pl. VII, fig. 46; del Pennsylvaniano de Turquía), para formas con escultura predominantemente compuesta por rugulas de hasta $4 \mu \mathrm{m}$ de alto por 1-2 $\mu \mathrm{m}$ de ancho, y escasas báculas. Este tipo de ornamentación permitiría pensar que quizás halle una ubicación sistemática fuera del género Horriditriletes (ornamentada predominantemente con baculas).

Registros previos. Horriditriletes superbus (Foster) Césari, Archangelsky y Seoane, fue descripta originalmente para Baralaba Coal Measures, Australia (Foster, 1979).

- Cisuraliano: Argentina: presente en la perforación Las Mochas (Césari et al., 1995) e ilustrada para la Formación Sachayoj, Cuenca Chacoparaná (Vergel, 1998).

- Cisuraliano-Guadalupiano: Uruguay: presente en la Formación Melo, Cuenca Paraná (Mautino et al., 1998a). Brasil: presente en la Formación Rio Bonito, Cuenca Paraná (Smaniotto et al., 2006).

Horriditriletes uruguaiensis (Marques-Toigo) Archangelsky y Gamerro 1979 Lámina III, figura L

1974. Neoraistrickia uruguaiensis Marques-Toigo, p. 604, lám. I, figs. 4, 5. 
Sinonimia adicional. Véase Archangelsky y Gamerro (1979).

Descripción. Espora radial trilete, de contorno subtriangular, de lados desde cóncavos a levemente convexos, y ápices redondeados. Margen levemente irregular por proyección de la ornamentación. Lesura discernible y simple, de rayos rectos que se extienden hasta 5/6 del radio de la espora, parcialmente cubierta por la escultura. Ornamentación conformada por báculas y verrugas, y en menor medida por conos y espinas, dispuestos todos de manera heterogénea. Las verrugas son bajas, de bases subcirculares a irregulares. Las báculas son elementos más altos, de hasta $5 \mu \mathrm{m}$ altura. Exina 1,5 $\mu \mathrm{m}$ de espesor.

Dimensiones (10 ejemplares). Diámetro ecuatorial, 29(34)42 $\mu \mathrm{m}$; ornamentación, 1,5-3 $\mu \mathrm{m}$ de ancho basal y $2-5 \mu \mathrm{m}$ de altura.

Principal material estudiado. 6143 (b) J41/1; BAPal 6152 (a) D38/1; BAPal 6152 (e) D56/4; BAPal BAPal 6167 (a) U47/0. Retrabajo: BAPal 6173 (a) W44/2.

Registros previos. Originalmente fue descripta para el Cisuraliano del Uruguay (Maques-Toigo, 1974), presenta un amplio registro para el Pennsylvaniano-Cisuraliano de Sudamérica.

- Pennsylvaniano: Argentina: presente en las formaciones Malanzán (Gutiérrez y Limarino, 2001) y Guandacol (Ottone y Azcuy, 1989); el nivel inferior de Estratos de Mascasín (Pérez Loinaze y Césari, 2004), listada para la Formación El Trampeadero (Gutiérrez y Barreda, 2006); todas ellas del ámbito de la Cuenca Paganzo. Brasil: ilustrada para la Formación Piauí, Cuenca Paranaíba (Dino y Playford, 2002).

- Pennsylvaniano-Cisuraliano: Argentina: presente en la Formación Sachayoj (Vergel, 1998); en las Biozonas Potonieisporites-Lundbladispora y Cristatisporites (Archangelsky et al., 1980; Césari et al., 1995); Cuenca Chacoparaná. Ilustrada para la Formación Piedra Shotel, Biozonas Potonieisporites-Lundbladispora y Cristatisporites, Cuenca Tepuel Genoa (Gamerro y Archangelsky, 1981a) y en las Formacioners Río del Peñón, Cuenca Río Blanco (Gutiérrez y Limarino, 2006) y Tupe (miembro cuspidal), Cuenca Paganzo (Vergel, 2008). Brasil: listada para el Subgrupo Itararé, Cuenca Paraná (Souza, 2006).

- Cisuraliano: Argentina: presente en las Biozonas Potonieisporites-Lundbladispora (parte alta) y Cristatisporites (Archangelsky y Gamerro, 1979; Vergel, 1987) y en la Formación Victoriano Rodríguez, Biozona Cristatisporites (Playford y Dino 2002); en 
el ámbito de la Cuenca Chacoparaná. También presente en las formaciones El Imperial, Cuenca San Rafael (García, 1995) y Tasa Cuna, Cuenca Paganzo (Balarino y Gutiérrez, 2006). Ilustrada para las formaciones Piedra Shotle (Gamerro y Archangelsky, 1981a) y Río Genoa (Gutiérrez et al., 2007), Cuenca Tepuel-Genoa. Uruguay: listada para la Formación San Gregorio (Marques-Toigo, 1974; Beri y Daners, 1996; Beri et al., 2006), Cuenca Paraná. Brasil: ilustrada para el Subgrupo Itararé, Cuenca Paraná (Pons, 1977; Dias, 1993) y para el Subgrupo Itararé, Biozona Vittatina costabilis, sub-biozona Protohaploxypinus goraiensis (Cuenca Paraná; Souza y Callegari, 2004). Omán y Arabia Saudita: presente en la Formación Al Khlata (Stephenson, 2003; Stephenson y Filatoff, 2000a).

- Cisuraliano-Guadalupiano: Uruguay: listada para la Formación Melo (Mautino et al., 1998a; Beri y Pecoits, 2001), Cuenca Paraná.

\section{Género Interradispora Price en Foster 1979}

Especie tipo. Interradispora versus Price en Foster, 1979.

Afinidad botánica. Pteridophyta-Filicopsida? (véase Raine et al., 2006).

Interradiaspora sp. cf. I. robustus (Foster) Foster 1979

Lámina III, figura M

Descripción. Espora radial trilete, de contorno triangular, de lados rectos y ápices redondeados. Lesura no visible en su totalidad, aparentemente simple y de rayos rectos extendidos unos 3/4 del radio de la espora. Anisopolar, exhibe la ornamentación circunscripta a la cara distal y parte de la proximal, ya que sobre los lados interadiales los elementos de la escultura son de mayor tamaño (hasta $2,5 \mu \mathrm{m}$ de diámetro y $1,5 \mu \mathrm{m}$ de altura) y se disponen en hilera, delimitando el área de contacto levigada. En el resto de la superficie la ornamentación está compuesta por verrugas y báculas bajas, claramente distinguibles en el contorno, dispuestas de manera espaciada y homogénea; los elementos esculturales presentan la base circular a poligonal y la altura es menor al micrón. Exina de 1,5 $\mu \mathrm{m}$ de espesor.

Dimensiones (2 ejemplares). Diámetro ecuatorial, 30-55 $\mu \mathrm{m}$; ornamentación, 1,5-2,5 $\mu \mathrm{m}$ de ancho basal y $1-1,5 \mu \mathrm{m}$ de altura. 
Principal material estudiado. BAPal 6152 (b) L74/2; BAPal 6165 (b) R59/2.

Comentarios. La ejemplar descripto es asignado con dudas a Interradiaspora robustus (Foster) Foster (1979, p. 40, pl. 8, figs 14-16) ya que si bien se aprecia el área de contacto levigada y presenta la conspicua ornamentación de verrugas y báculas bajas, no ha podido apreciarse la naturaleza de la lesura.

Género Lophotriletes Naumova ex Ischenko emend. Potonié y Kremp 1954 Especie tipo. Lophotriletes gibbosus (Ibrahim) Potonié y Kremp, 1955.

Afinidad botánica. Pteridophyta-Filicopsida (véase Balme, 1995).

\section{Lophotriletes sp. A}

Lámina III, figura N; Lámina XVI, figuras E y H

Descripción. Espora radial trilete, de lados rectos a levemente cóncavos y ápices fuertemente redondeados. Margen levemente irregular por proyección de la ornamentación. Lesura simple, de rayos rectos, de hasta 3/4 del radio de la espora. Ornamentación compuesta por conos y granos, de ápice redondeado, agudo ó trunco, de 1 a 1,5 $\mu \mathrm{m}$ tanto de base como de altura. Los elementos ornamentales se distribuyen irregularmente en ambas caras, sin observarse una disminución de los mismos en las zonas de contacto. Exina de $1 \mu \mathrm{m}$ de espesor.

Dimensiones (6 ejemplares). Diámetro ecuatorial, 22(29,6)36 $\mu \mathrm{m}$; ornamentación, 1,5 $\mu \mathrm{m}$ de ancho basal y $1-1,5 \mu \mathrm{m}$ de altura.

Principal material estudiado. BAPal 6152 (a) B24/2, J54/0, Q68/3, J73/1; BAPal 6161 (a) $\mathrm{N} 70 / 0$.

Comentarios. Los ejemplares aquí estudiados presentan un grado de preservación pobre, por lo que no es posible realizar una asignación específica certera. Sin embargo, caracteres como morfología general, tipo, forma y tamaño de la ornamentación y lesura, permiten asignarlos al género Lophotriletes.

Género Dibolisporites (Richardson) Playford 1976

Especie tipo. Dibolisporites echinaceus (Eisenack) Richardson 1965.

Afinidad botánica. Pteridophyta-Filicopsida (Balme, 1995). 
Dibolisporites sp. cf. D. disfacies Jones y Truswell 1992

Lámina III, figura $\tilde{\mathrm{N}}$

Descripción. Espora radial, trilete, de contorno circular, subcircular a irregular, deformado por compresión. Margen irregular debido a la proyección de los elementos de la escultura. Lesura simple, de rayos extendidos hasta el margen ecuadorial de la espora. Cara proximal lisa, frecuentemente rota. Cara distal y región ecuatorial ornamentada con elementos biformes. Cada elemento individual está conformado por una verruga circular de ápice redondeado de 0,5-2 $\mu \mathrm{m}$ de diámetro basal y 2-3 $\mu \mathrm{m}$ de alto, sobre el cual se observa una pequeña espina simple en su ápice. Elementos ornamentales dispuestos de manera homogénea, próximos entre sí pero sin fusionarse por sus bases. Exina de entre 1 y $2 \mu \mathrm{m}$ de espesor.

Dimensiones (3 ejemplares). Diámetro ecuatorial, 52-70 $\mu \mathrm{m}$; ornamentación, 0,5-2 $\mu \mathrm{m}$ de ancho basal y 2,5-4 $\mu \mathrm{m}$ de altura.

Principal material estudiado. BAPal 6183 (b) V54/4; BAPal 6185 (a) J48/2; BAPal 6186 (a) F54/1.

Comentarios. Los ejemplares aquí estudiados son asignados con dudas a la especie Dibolisporites disfacies por presentar las bases de los elementos de la escultura levemente menores y dispuestos en forma más espaciada entre sí. En el material original los elementos se disponen compactamente y el diámetro de las bases varía entre 1,5-2 $\mu \mathrm{m}$.

\section{Género Phidiaesporites Foster 1979}

Especie tipo. Phidiaesporites fosteri Foster, 1979.

Afinidad botánica. Pteridohyta?.

Phidiaesporites fosteri Foster 1979

Lámina IV, figura A

Descripción. Espora radial trilete, de contorno circular a subtriangular, de lados convexos y ápices fuertemente redondeados. Lesura bien definida, extendida hasta 3/4 
del radio de la espora, recta, acompañada por delgados y sinuosos labios de 1 a 1,5 de ancho. Curvatura perfecta, con áreas de contacto hundidas, de exina delgada, levigada a finamente granulada. Exina distal gruesa, con conos y gránulos homogéneamente distribuídos, menores al micrón de tamaño. Los elementos ornamentales no se contactan entre sí.

Dimensiones (1 ejemplar). Diámetro ecuatorial, $57 \mu \mathrm{m}$; ornamentación, $0,8 \mu \mathrm{m}$ de diámetro basal y $0,5 \mu \mathrm{m}$ de altura; espesor de la exina, $3 \mu \mathrm{m}$ (cara distal).

Comparaciones. El ejemplar aquí descripto es referido a Phidiasporites fosteri Foster (1979, p. 37, pl. 6, figs. 2-13) por la naturaleza de la cara proximal (hundida) y la caraterística ornamentación distal (discretos conos y gránulos, menores a $1 \mu \mathrm{m}$ ).

Principal material estudiado. BAPal 6143 (b) H53/2.

Registros previos. Phidiasporites fosteri fue descripta originalmente por Foster (1979) para Baralaba Coal Measures, Guadalupiano, Australia.

Esta es la primera cita para cuencas sudamericanas.

SubInfraturma VARITRILETI Venkatachala y Kar 1965

Género Didecitriletes Venkatachala y Kar 1965

Especie tipo. Didecitriletes horridus Venkatachala y Kar, 1965.

Afinidad botánica. Pteridophyta-Filicopsida? (véase Raine et al., 2006).

Didecitriletes ericianus (Balme y Hennelly) Venkatachala y Kar 1965

Lámina IV, figuras B y C

1956b. Acanthotriletes ericianus Balme y Hennelly, p. 238, pl. 3, figs. 30-33.

1962. Anapiculatisporites ericianus (Balme y Hennelly) Bharadwaj, p. 79, pl. 1, figs. 16-17.

1967. Anapiculatisporites ericianus (Balme y Hennelly) Balme y Playford, p. 181.

1977. Didecitriletes longispinosus (Bharadwaj y Salujha) Rigby y Hekel, p. 10, pl. 2, figs. 12-13 (pars).

1977. Microbaculispora ericiana (Balme y Hennelly) Anderson, p. 49(9.3), pl. 55, figs. $1-6$. 
Sinónima adicional. Véase Foster (1979) y Backhouse (1991).

Descripción. Espora radial trilete, de contorno triangular, lados rectos y ápices redondeados. Margen irregular por proyección de la ornamentación. Lesura de rayos rectos, extendidos hasta el margen ecuatorial y acompañados por una delgada labra. Ornamentación compuesta por báculas mayoritariamente y en menor medida espinas de base bulbosa, generalmente flexionadas y ápice agudo. La base de los elementos ornamentales es poligonal, pueden contactarse entre sí en algunos casos y la disposición de los mismos es compacta. La densidad de elementos es mayor en la cara distal que en la distal. Cara proximal plana y distal piramidal. Exina de hasta $2 \mu \mathrm{m}$ de espesor.

Dimensiones (7 ejemplares). Diámetro ecuatorial, 43(53,2)73 $\mu \mathrm{m}$; ornamentación, 1,2-3 $\mu \mathrm{m}$ de ancho basal y 1-2 $\mu \mathrm{m}$ de altura.

Principal material estudiado. BAPal 6143 (b) N44/2; BAPal 6149 (a) X59/1; BAPal 6147 (a) S53/3; BAPal 6151 (a) O46/0; BAPal 6152 (b) J71/3; BAPal 6160 (a) P63/4; BAPal 6162 (a) K42/2. Retrabajo: BAPal 6172 (a) O60/0.

Comentarios. Los ejemplares aquí estudiados presentan una menor proporción de elementos espiniformes y por lo contrario, una mayor representación de báculas. Sin embargo es posible referirlos a Didecitriletes ericianus (Balme y Hennelly) Venkatachala y Kar (1965, pp. 338-339), por exhibir espinas de base bulbosa cilíndrica y ápice acumiados que se presentan generalmente flexionados. Si bien los ejemplares descriptos e ilustrados por Foster (1979, p. 44, pl. 9, figs. 10-14) presentan una disposición más laxa de los elementos esculturales, Backhouse (1991, pp. 270-272, pl. VII, figs. 13-15) señala que en los ejemplares por él estudiados se observa que los elementos de la escultura muestran una disposición más densa y compacta que en el material original. Por este motivo se entiende que se trata de un carácter intraespecífico. Parte del material incluido en Didecitriletes longispinosus (Bharadwaj y Salujha) por Rigby y Hekel (1977, p. 10, pl. 2, figs. 12-13) debería ser incluido en esta especie por las características que exhibe, ern especial el tipo, tamaño y distribución de la escultura. Registros previos. Didecitriletes ericianus (Balme y Hennelly) Venkatachala y Kar fue descripta originalmente para Newcastle Coal Measures, Cuenca Sydney, Australia (Balme y Hennelly, 1956a). Presenta un registro restringido al Pérmico-Triásico de Australia, Nueva Zelanda, India, África y Antártida (véase Zavattieri, 1991a; Raine et al., 2006). 
- Pennsylvaniano: Argentina: presente en la Formación Guandacol, Cuenca Paganzo (Césari y Vázquez Nístico, 1988). Probablemente presente en la Formación Jejenes (Césari y Bercowski, 1997), en la misma cuenca.

- Pennsylvaniano-Cisuraliano: Argentina: presente en la Formación El Imperial, Cuenca San Rafael (García, 1995).

- Cisuraliano: Australia: ilustrada para la Formación Stockton y Collie Coal Measures, Cuenca Collie (Backhouse, 1991). India: presente en Barakar Stage (Venkatachala y Kar, 1965). Sudáfrica: presente en la Grupo Ecca, Cuenca Karroo (Anderson, 1977).

- Guadalupiano: Australia: presente en la Formación Bandanna, Springsure Anticline (Rigby y Hekel, 1977) y en Baralaba Coal Measures, Cuenca Bowen (Foster, 1979). Antártida: presente en Prince Charles Mountains (Balme y Playford, 1967).

- Lopingiano: Antártida: presente en Formación Bukley (Farabee et al., 1991); India: presente en Raniganj Coal Measures (Bharadwaj, 1962).

- Triásico: Argentina: presente en la Formación Las Cabras, Cuenca Cuyana (Zavattieri, 1991a).

Didecitriletes uncinatus (Balme y Hennelly) Venkatachala y Kar 1965 Lámina IV, figura D

1956b. Acanthotriletes uncinatus Balme y Hennelly, p. 249, pl.3, figs. 35-36. 1977. Didecitriletes longispinosus (Bharadwaj y Salujha) Rigby y Hekel, p. 10 (pars).

Descripción. Espora radial trilete, de contorno triangular, lados rectos ó levemente cóncavos o convexos y ápices redondeados. Margen irregular por proyección de la ornamentación. Lesura recta de rayos extendidos hasta el margen ecuatorial acompañados por delgados y sinuosos labios. Ornamentación compuesta por espinas de base bulbosa, generalmente flexionadas y ápice agudo. Las mismas se disponen de manera aislada, sin contactarse entre sí. La densidad de elementos es mayor en la cara distal. Cara proximal plana y distal piramidal. Exina de $2-3 \mu \mathrm{m}$ de ancho.

Dimensiones (1 ejemplar). Diámetro ecuatorial, $42 \mu \mathrm{m}$; ornamentación, 1,2 $\mu \mathrm{m}$ de ancho basal y $0,5-1 \mu \mathrm{m}$ de altura.

Principal material estudiado. BAPal 6155 (a) W38/2. 
Comentarios. Si bien se ha hallado y estudiado un solo ejemplar, el mismo es posible referirlo a la especie Didecitriletes uncinatus porque presenta caracteres diagnósticos de la misma. Estos son: contorno triangular, lesura acompañada por delgados y sinuosos labios, y ornamentación conformada por espinas de base bulbosa, generalmente se presentan flexionados o quebrados, y su ápice es agudo.

Registros previos. Didecitriletes uncinatus (Balme y Hennelly) Venkatachala y Kar fue descripta originalmente para Newcastle Coal Measures, Cuenca Sydney, Australia (Balme y Hennelly, 1956b). Presenta un registro restringido al Pérmico de África, Australia, Nueva Zelanda y Antártida (véase Raine et al., 2006).

- Cisuraliano: India: presente en Barakar Stage (Venkatachala y Kar, 1965), listada para Kaharbari Stage (Lele y Maithy, 1969).

- Guadalupiano: Australia: presente en la Formación Bandanna, Springsure Anticline (Rigby y Hekel, 1977), ilustrada para Baralaba Coal Measures, Cuenca Bowen (Foster, 1979) y mencionada (rara) para la Cuenca Galilee (Rigby, 1973).

Este es el primer registro para la Argentina.

Infraturma MURORNATI Potonié y Kremp 1954

Género Convolutispora Hoffmeister, Staplin y Malloy 1955

Especie tipo. Convolutispora florida Hoffmaister, Staplin y Malloy, 1955.

Afinidad botánica. Pteridophyta-Filicopsida (véase Balme, 1995).

Convolutispora archangelskyi Playford y Dino 2002

Lámina IV, figuras E y F; Lámina XVI, figura A y B

1976. Convolutispora pintoi Dellazanna, pp. 4-6, pl. III, figs. 4, 5.

1995. Verrucosisporites cf. V. microtuberosus (Loose) Smith y Butterworth; Beri y Daners, pl. I, fig. 3.

1995. Convolutispora sp. Beri y Daners, lám. I, fig. 6.

1995. Convolutispora sp. Césari et al., p. 81, lám. II, fig. 16.

?1998a. Microreticulatisporites inaequalis Menéndez y Azcuy; Mautino et al., p. 73, lám. I, fig. q. 
2002. Convolutispora sp., Dino et al., pl. I, fig. 4.

Sinonimia adicional. Véase Playford y Dino (2002).

Descripción. Espora radial trilete, de contorno ecuatorial circular a subcircular, de margen irregular por la proyección de la ornamentación. Lesura simple poco discernible, de rayos rectos, de $1 / 2$ a $3 / 4$ del radio de la espora. En algunas ocasiones se desarrollan anchos labios por fusión de elementos esculturales. Ornamentación vermiculada, compuesta por rúgulas sinuosas dispuestas densamente $\mathrm{y}$, entre ellas, algunas verrugas de base subcircular a poligonal. Entre los elementos esculturales se desarrollan delgados e irregulares espacios, tanto lineales como en forma de aréolas, y se disponen homogéneamente en ambas caras. Exina de hasta $3 \mu \mathrm{m}$ de espesor.

Dimensiones (17 ejemplares). Diámetro ecuatorial, 30(41,9)47 $\mu \mathrm{m}$; ornamentación, 0,51,5 $\mu \mathrm{m}$ de ancho basal y $1,5 \mu \mathrm{m}$ de altura; espesor de la exina, 1-3 $\mu \mathrm{m}$.

Principal material estudiado. BAPal 6152 (a) B45/0, C42/0, F51/2, H43/4, L42/2, R51/1, S50/3, U62/0, J65/1, L61/0, O42/0, P47/4, P70/4, Q69/0.

Discusion y comparaciones. Convolutispora archangelskyi fue descripta originalmente por Archangelsky y Gamerro (1979, p. 430, lám. III, figs. 4-5) como Convolutispora sp. Posteriormente, Playford y Dino (2002, p. 254, pl. 4, figs. 12-13, 15-16) caracterizan la nueva especie. Convolutispora archangelskyi Playford y Dino presenta generalmente una exina más fina y con una escultura predominantemente vermiculada y rúgulas densamente dispuestas, al contrario de lo que se observa en C. ordonezii Archangelsky y Gamerro (1979) donde predominan las verrugas entre la ornamentación. Por otra parte se ha observado una transición, en cuanto al predomino de los elementos de ornamentación y su distribución, entre ambas especies, tal cual lo señalara Playford y Dino (2002), quienes remarcan que existe una gradación morfológica entre las mismas. Microreticulatisporites inaequalis Menéndez y Azcuy descripta por Mautino et al. (1998a, p. 73, lám. I, fig. q), del Pérmico de Uruguay (Formación Melo), es muy similar en apariencia a $C$. archangelskyi, y probablemente sean coespecíficas; aunque ha sido descripta con una ornamentación reticulada. A partir de observación de la ilustración del material, se diferencia una escultura compuesta por rugulas anastomosadas en un modelo sinuoso, diferente del reticulado del material original (Menéndez y Azcuy, 1973, p. 57, pl. I, figs. 3-6). Por lo tanto y hasta no ver el material de Uruguay, se asigna con dudas a C. archangelskyi. Del mismo modo C. pintoi Dellazana (1976, pp. 4-6, lám. 
I, figs. 4-6) y el material asignado a Verrucosisporites cf. V. microtuberosus (Loose) Smith y Butterworth (Beri y Daners, 1995, lám. I, fig. 3), a Convolutispora sp. (Beri y Daners, 1995, lám. I, fig. 6), Convolutispora sp. (Césari et al., 1995, p. 81, lám. II, fig. 16) y Convolutispora sp. (Dino et al., 2002, pl. I, fig. 4), entendemos deben ser reasignado a $C$. archangelskyi, por las características de la ornamentación (tipo, distribución, dimensiones).

Convolutispora archangelskyi presenta una estrecha semejanza con Verrucosisporites insuetus Playford y Dino (2000a, p. 15, pl. 4, figs. 1-4, pl. 6, figs. 1-3), la que fue caracterizada como una espora de contorno circular, lesura recta que alcanza el margen, acompañada por delgados labios producto de la fusión de la escultura, la cual se compone de verrugas y rúgulas. Llama la atención que Playford y Dino (2002) al redescribir esta especie no la hayan comparado con $V$. insuetus, ya que según nuestro criterio hallaría una mejor ubicación dentro del género Convolutispora y no en Verrucosisporites, ya que entre los elementos ornamentales dominan las rúgulas y verrugas fusionadas. Por lo tanto al comparar las formas (sobre todo la ilustración de la lámina IV, fig. 1-4 de Playford y Dino, 2000a) y considerando además el caracter variable de la longitud de la lesura que exhiben este tipo de esporas, parte del material incluido en $V$. insuetus podría ser sinonimizado con $C$. archangelskyi. Esta discusión será pospuesta hasta poder consultar el material brasilero.

Según Archangelsky y Gamerro (1979) esta especie (Convolutispora sp.), es comparable con C. pintoi Dellazanna (1976, pl. III, figs. 4, 5) pero solo difiere de la misma por presentar una lesura de ramas más largas (0,7-0,9 respecto del radio de la espora). A juzgar por los ejemplares aquí estudiados y asignados a C. archangelskyi, la extensión de los rayos de la lesura es variable (de $1 / 2$ a 3/4 del radio de la espora), por lo que ese caracter no tendría valor sistemático como para separar ambas especies, sobre todo, si se tiene en cuenta la conspicua ornamentación observada (rúgulas y verrugas).

Registros previos. Convolutispora archangelskyi fue descripta para la perforación YPF Cd Ordóñez es-1, Biozona Striatites, Cisuraliano-Guadalupiano de la Cuenca Chacoparaná (Playford y Dino, 2002).

- Cisuraliano-Guadalupiano: Argentina: presente en la Biozona Cristatisporites (Archangelsky y Gamerro, 1979) y en la Formación Victoriano Rodríguez, biozonas Cristatisporites y Striatites (Playford y Dino 2002), dentro del ámbito de la Cuenca 
Chacoparaná. Uruguay: presente en la Formación Melo, Cuenca Paraná (Beri y Daners, 1995; Mautino et al., 1998a). Brasil: presente en la Formación Iratí, Cuenca Paraná (Dellazana, 1976; Dino et al., 2002).

\section{Convolutispora candiotensis Ybert 1975}

\section{Lámina IV, figura $\mathrm{G}$}

Descripción. Espora radial trilete, de contorno ecuatorial circular, y margen ondulado. Lesura poco discernible, oculta por la ornamentación. Los rayos son rectos, de 4/5 del radio de la espora, y cuando visible, se desarrollan conspicuos engrosamientos a lo largo de la lesura, formados éstos por la fusión de las rúgulas adyacentes. Ornamentación vermiculada, compuesta por rúgulas sinuosas y anchas que se anastomosan, dispuestas densamente en ambas caras. Entre las rúgulas se generan espacios subcirculares, similares a foveas. Exina de hasta 3,5 $\mu \mathrm{m}$ de ancho.

Dimensiones (4 ejemplares). Diámetro ecuatorial, 30(38,5)53 $\mu \mathrm{m}$; ornamentación, 1,5-2 $\mu \mathrm{m}$ de base, 1,5 $\mu \mathrm{m}$ de altura y de hasta $5 \mu \mathrm{m}$ de longitud; exina 2-4,5 $\mu \mathrm{m}$.

Principal material estudiado. BAPal 6142 (a) U47/0; BAPal 6185 (b) M33/3; BAPal 6188 (b) Q47/3. Retrabajo: BAPal 6181 (a) G55/4.

Registros previos. Convolutispora candiotensis fue descripta originalmente por Ybert (1975) para la Formación Rio Bonito, Cisuraliano-Guadalupiano de la Cuenca Paraná, Brasil.

- Cisuraliano: Argentina: presente en la Bizona Cristatisporites (Archangelsky y Gamerro; 1979), ilustrada para la Formación Sachayoj, Cuenca Chacoparaná (Vergel, 1998). Brasil: presente en la perforación 2-AO-RS Rio Grande do Sul, Cuenca Paraná (Quadros et al., 1996). Paraguay: listada para la Formación Tacuary, Cuenca Paraná (Vergel et al., 1987).

- Cisuraliano-Guadalupiano: Uruguay: presente en la Formación Melo, Cuenca Paraná (Gutiérrez et al., en prensa-b). Brasil: presente en la Formación Rio Bonito (Ybert, 1975; Jasper et al., 2006; Smaniotto et al., 2006, Cazzulo Klepzig et al., 2007).

Convolutispora ordonezii Archangelsky y Gamerro 1979

Lámina IV, figuras H e I; Lámina XVI, figura C y D 
Descripción. Espora radial trilete, de contorno ecuatorial circular y levemente irregular por la proyección de la ornamentación. Lesura poco discernible, oculta por la ornamentación. Los rayos de la lesura, cuando visibles, son rectos de entre $1 / 2$ a $3 / 4$ del radio de la espora y desarrollan conspicuos engrosamientos a lo largo de la lesura, formados por la fusión de las rúgulas adyacentes. Ornamentación vermiculada, compuesta por rúgulas sinuosas, dispuestas densamente en forma homogénea sobre ambas caras, entre las rúgulas aparecen escasas verrugas de base irregular. El espacio entre los elementos de la escultura es de 1/5 respecto del ancho de las rúgulas. Las zonas adyacentes a las verrugas suelen ser subcirculares, como aréolas. Exina de hasta 3 $\mu \mathrm{m}$ de espesor.

Dimensiones (27 ejemplares). Diámetro ecuatorial, 30(41,5)57 $\mu \mathrm{m}$; ornamentación, 1,5$3 \mu \mathrm{m}$ de ancho y 1,5 $\mu \mathrm{m}$ de altura; espesor de la exina 1-3 $\mu \mathrm{m}$.

Principal material estudiado. BAPal 6138 (c) M43/1; BAPal 6152 (a) B37/0, F58/4, F48/0, F45/4, H49/4, M60/2, M65/1, N55/2, N58/1, Q56/4, S41/2, S69/0, T39/3, U37/0.

Registros previos. Convolutispora ordonezii fue descripta originalmente por Archangelsky y Gamerro (1979) para la perforación YPF Cd Ordóñez es-1 (Biozona Cristatisporites, parte alta y Biozona Striatites); Cd Saira es-1 (Biozona Cristatisporites, parte alta), Cuenca Chacoparaná.

- Pennsylvaniano: Argentina: ilustrada para la Formación Jejenes (Césari y Bercowski, 1997) y listada para las formaciones Guandacol y Tupe (Ottone, 1991), todas en el ámbito Cuenca Paganzo. Ilustrada para la Formación San Telmo, Cuenca Tarija (di Pasquo et al., 2001). Brasil: ilustrada para el Subgrupo Itararé, Cuenca Paraná (di Pasquo et al., 2003a; Souza, 2006).

- Pennsylvaniano-Cisuraliano: Argentina: presente en perforaciones en la provincia de Santa Fe, del ámbito de la Cuenca Chacoparaná (Vergel, 1987).

- Cisuraliano: Argentina: presente en la Formación El Imperial, Cuenca San Rafael (García, 1995), ilustrada para la Biozona Cristatisporites superior, Cuenca Chacoparaná (Césari et al., 1995). Uruguay descripta en Formación San Gregorio (Beri et al., 2006); Cuenca Paraná. Paraguay: ilustrada para la Formación Tacuary, Cuenca Chacoparaná (Muff et al., 1999). 
- Cisuraliano-Guadalupiano: Argentina: presente en la Formación Victoriano Rodríguez, biozonas Cristatisporites y Striatites, Cuenca Chacoparaná (Playford y Dino, 2002). Uruguay: ilustrada para la Formación Melo (Mautino et al., 1998a); Cuenca Paraná.

\section{Convolutispora sp. A}

Lámina IV, figuras J y K

Descripción. Espora radial trilete, de contorno subcircular, deformado por compresión y margen fuertemente crenulado por la proyección de la ornamentación. Lesura no discernible claramente, por quedar cubierta por la ornamentación. Elementos ornamentales compuestos mayoritariamente por rúgulas y algunas verrugas y conos aislados, tanto de ápices agudos como redondeados. Todos los elementos esculturales son altos llegando a superponerse unos con otros hacia el borde ecuatorial, y se disponen de manera homogénea en ambas caras. Exina de 1 hasta 3,5 $\mu \mathrm{m}$ de espesor.

Dimensiones (6 ejemplares). Diámetro ecuatorial, 28(35,6)56 $\mu \mathrm{m}$; ornamentación, 1,5-3 $\mu \mathrm{m}$ de base y $3 \mu \mathrm{m}$ de altura; exina 1-3 $\mu \mathrm{m}$.

Principal material estudiado. BAPal 6137 (a) K60/0; BAPal 6139 N40/3; BAPal 6152 (a) E39/1, F40/1, Q60/3; BAPal 6160 (a) F33/3.

Discusión. Convolutispora sp. A se diferencia de C. ordonezii Archangelsky y Gamerro (1979) porque ésta última presenta una ornamentación conformada mayoritariamente por rúgulas vermiformes dispuestas de manera compacta (en $C$. sp A está constituída en su mayoría por verrugas y algunas rúgulas, resultado de la fusión de 2 a 3 verrugas). Se diferencia de C. archangelskyi Playford y Dino (2002), porque su ornamentación está conformada por rúgulas vermiformes de menores tamaños y más compactamente dispuestas. Por su parte C. pintoi Dellazzana (1976) exhibe las rúgulas mucho más gruesas y el espacio entre las mismas es más ancho que el ancho de las rúgulas y los radios de la lesura, que es bien visible, se extienden entre $1 / 4$ y $1 / 2$ del radio de la espora.

Convolutispora candiotensis Ybert (1975, p. 190, pl. II, figs. 52-53) se diferencia por su contorno subtriangular, presentar rúgulas más angostas dispuestas más laxamente. Convolutispora muriornata Menéndez (1965, p. 59, lám. II, fig. 2, lám. III, figs. 2-8) se 
separa claramente por exhibir sobre los muros granos y espinas. Convolutispora sinuosa Menéndez (1965, p. 60, lám. II, fig. 1) presenta una ornamentación compuesta mayoritariamente de rúgulas y muros bajos y anchos. Mientras que C. globosa Ottone (1991, p. 126, pl. 2, figs. 1, 3) presenta una ornamentación más variada (rúgulas delgadas poco desarrolladas, verrugas y gránulos). Por último, en C. sculptilis Félix y Burbridge (1967) la ornamentación se compone de rúgulas bien desarrolladas y el espacio libre entre ellas es mayor al ancho de las mismas.

Género Camptotriletes Naumova ex Potonié y Kremp 1954

Especie tipo. Camptotriletes corrugatus (Ibrahim) Potonié y Kremp, 1955.

Afinidad botánica. Pteridophyta-Filicopsida, Botryopteridales (véase Balme, 1995).

\section{Camptotriletes sp. cf. C. warchianus Balme 1970}

\section{Lámina IV, figura L}

Descripción. Espora radial trilete, de contorno subtriangular, de lados rectos y ángulos redondeados. Lesura simple, de rayos rectos, extendidos hasta $2 / 3$ del radio de la espora. Ornamentación dominada por crestas y rúgulas sinuosas, densamente distribuidas, aunque no llegan a contactarse entre sí. Las mismas son menores al micrón de ancho de su base y de hasta $2,5 \mu \mathrm{m}$ de ancho. La ornamentación se hace más conspicua y densa hacia el polo distal. Exina delgada, de aproximadamente $1 \mu \mathrm{m}$ de espesor.

Dimensiones (1 ejemplar). Diámetro ecuatorial, $39 \mu \mathrm{m}$; ornamentación, $1 \mu \mathrm{m}$ de ancho basal y hasta $2,5 \mu \mathrm{m}$ de altura.

Principal material estudiado. BAPal 6138 (c) D60/0.

Comparaciones. El ejemplar aquí estudiado es comparable con Camptotriletes warchianus aunque no se pueden observar características tales como naturaleza de lesura, detalles de ornamentación, además de presentar una exina más delgada que la observada en la descripción original (2-4 $\mu \mathrm{m})$ (Balme 1970, p. 327, pl. 3, fig. 12-13).

Subturma ZONOTRILETES Waltz 1935

Infraturma TRICRASSATI Dettmann 1963 
Género Diatomozonotriletes Naumova ex Playford 1963

Especie tipo. Diatomozonotriletes saetosus (Hacquebard y Barss) Hughes y Playford, 1961.

Afinidad botánica. Pteridophyta-Filicopsida? (véase Raine et al., 2006).

\title{
Diatomozonotriletes ponticulus Foster 1975
}

\author{
Lámina IV, figura M
}

1963a. Reinchospora plumsteadi Hart; p. 142, text-fig. 6 Q-T, pl. 1, fig. 9.

1977. Microbaculispora plumsteadi (Hart) Anderson; p. 55, pl. 59, figs. 1-25.

Descripción. Espora radial trilete, de contorno triangular, de lados cóncavos y ápices redondeados. Margen liso, sin ornamentación proyectada. Lesura simple, de rayos rectos, extendidos hasta $3 / 4$ del radio de la espora. Cara proximal plana y levigada. Cara distal piramidal, ornamentada por gránulos de base circular y disposición espaciada. Lados interradiales con hileras de más de 18 báculas, próximas al margen ecuatorial, de hasta $2,2 \mu \mathrm{m}$ de alto, y ápice redondeado o trunco. La altura de las báculas disminuye levemente hacia los ápices. Exina delgada, con espesor menor al micrón.

Dimensiones (1 ejemplar). Diámetro ecuatorial, $38 \mu \mathrm{m}$; ornamentación, 1,5-2 $\mu \mathrm{m}$ de base y 2,2 $\mu \mathrm{m}$ de ancho; espsor de la exina, 0,5-1 $\mu \mathrm{m}$.

Principal material estudiado. BAPal 6188 (b) R67/0.

Comentarios. Si bien se ha hallado un solo ejemplar, características tales como la forma general y la conspicua ornamentación (lados interadiales con hileras de más de 18 báculas) permiten realizar la asignación a Diatomozonotriletes ponticulus Foster (1975, pp. 133-134, pl. 3, figs. 9-12). Las mismas características exhiben Reinchospora plumsteadi Hart (1963a, p. 142, text-fig. 6 Q-T, pl. 1, fig. 9) y Microbaculispora plumsteadi (Hart) Anderson (1977, p. 55, pl. 59, figs. 1-25), por lo que son pasadas en sinonimia.

Registros previos. Diatomozonotriletes ponticulus fue descripta originalmente por Foster (1975) para el Pérmico de Blair Athol Coal Measures, Australia.

- Cisuraliano: Australia: presente en Blair Athol Coal Measures, Cuenca Bowen (Foster, 1979). Sudáfrica: presente en Cuenca Karroo (Hart, 1963a; Anderson, 1977).

Esta es la primera cita de la especie para cuencas sudamericanas. 
Lámina I 


\section{Lámina I}

A. Calamospora breviradiata Kosanke 1950, BAPal 6147 (a) O49/0 (X 700).

B. Calamospora hartungiana Schopf en Schopf, Wilson y Bentall 1944, BAPal 6172 (a) J46/2 (X 750).

C. Leiotriletes corius Kar y Bose 1967, BAPal 6146 (b) F41/4 (X650).

D y E. Leiotriletes directus Balme y Hennelly 1956a, BAPal 6152 (a) F65/0 (X 600); BAPal 6162 (a) R68/3 (X 700).

F. Leiotriletes tiwarii (Tiwari) Saxena 1993, BAPal 6169 (a) F68/4 (X 650)

G y H. Leiotriletes ulutus Utting 1994, BAPal 6152 (b) L50/0; BAPal 6169 (a) (X 650 $\mu \mathrm{m}) \mathrm{L} 51 / 4$ (X 650).

I. Punctatisporites gretensis Balme y Hennelly 1956a, BAPal 6187 (a) X75/0 (X 300).

J y K. Punctatisporites sp. A, BAPal 6169 (a) L55/4 (X 700).

L y M. Retusotriletes diversiformis (Balme y Hennelly) Balme y Playford 1967, BAPal 6152 (a) T65/4 (X 650); BAPal 6168 (a) H69/1 (X 650).

N y Ñ. Retusotriletes sp. A, BAPal 6158(a) C35/3 (X 600); 6152 (a) L63/0 (X 700). 

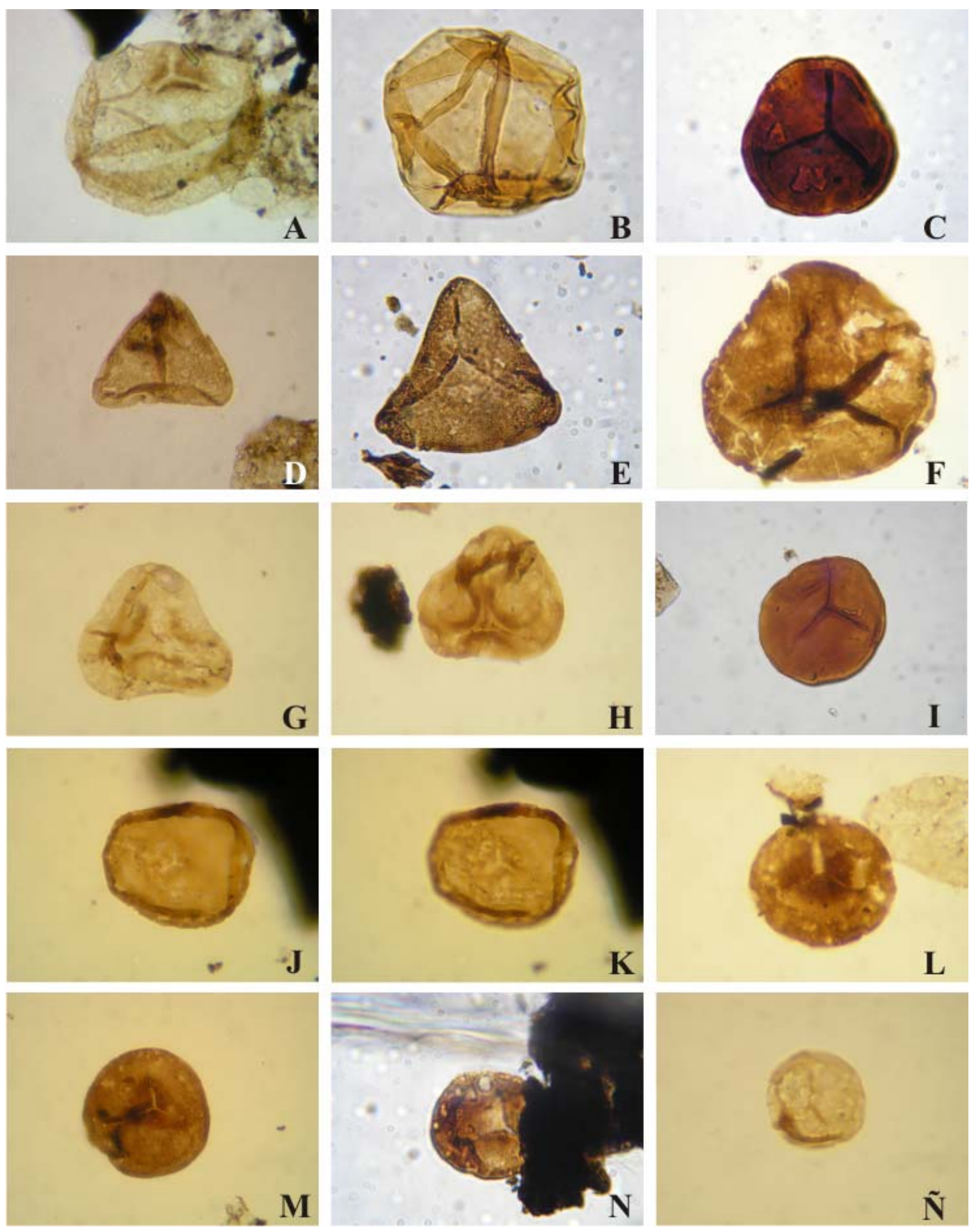


\section{Lámina II}

A. Punctatisporites sp. cf. P. priscus Bharadwaj y Salujha 1965, BAPal 6152 (a) J62/3 (X 700).

B. Cyclogranisporites microgranus Bharadwaj 1957, BAPal 6183 (b) L44/0 (X 950).

C. Granulatisporites austroamericanus Archangelsky y Gamerro 1979, BAPal 6188 (a) $\mathrm{T} 45 / 2$ (X 650).

D. Baculatisporites bharadwaji Hart 1963b, BAPal 6135 (a) N38/2 (X 650).

E. Anapiculatisporites tereteangulatus (Balme y Hennelly) Playford y Dino 2002, BAPal 6161(a) T/37/2 (X 500).

F. Brevitriletes levis (Balme y Hennelly) Bharadwaj y Srivastava 1969, BAPal 6188 (a) $\mathrm{G} 46 / 0$ (X 750).

G y H. Brevitriletes cornutus (Balme y Hennelly) Backhouse 1991, BAPal 6188 (b) M71/0 (X 750); BAPal 6181 (a) U63/0 (X 650).

I. Osmundacidites wellmanii Couper 1953, BAPal 6181 (a) T69/0 (X 1000).

J, K y L. Converrucosisporites confluens (Archangelsky y Gamerro) Playford y Dino 2002, BAPal 6187 (b) Q48/0 (X 750); BAPal 6189 (a) T59/2 (X 650).

M. Converrucosisporites micronodosus (Balme y Hennelly) Playford y Dino 2002, BAPal 6188(2) L43/1 (X 600).

N y $\tilde{\mathbf{N}}$. Converrucosisporites pustulatus Backhouse 1988, BAPal 6158(a) D59/1 (X 650). 

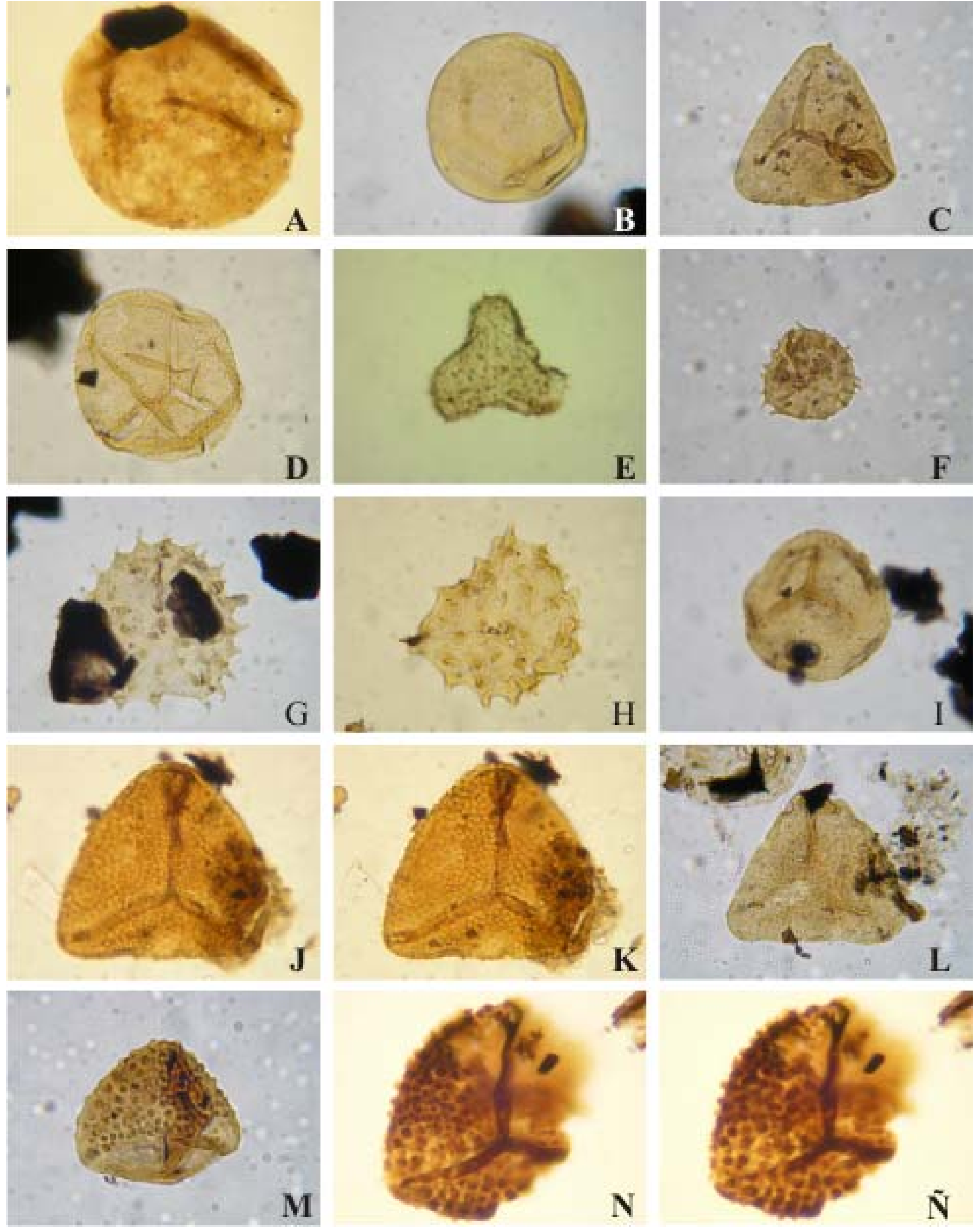


\section{Lámina III}

A. Verrucosisporites sp. cf. $V$. chiquiritensis Ottone 1989, BAPal 6152(a) 41/0 (X 850).

B y C. Verrucosisporites surangei Maheshwari y Banerjee 1975, BAPal 6152 (a) D52/0 (X 650); BAPal 6152 (b) C63/3 (X 450).

D. Verrucosisporites microtuberosus (Loose) Smith y Butterworth 1967, BAPal 6152 (a) $\mathrm{S} 44 / 2$ (X 700).

E y F. Pseudoreticulatispora pseudoreticulata (Balme y Hennelly) Bharadwaj y Srivastava 1969, BAPal 6152 (b) F40/3 (X 600); BAPal 6178 (a) S53/1 (X 700).

G, H e I. Horriditriletes filiformis (Balme y Hennelly) Backhouse 1991, BAPal 6183 (a) N32/0 (X 700); BAPal 6172 (a) U68/2 (X 700).

J. Horriditriletes ramosus (Balme y Hennelly) Bharadwaj y Salujha 1964, BAPal 6189 (a) $\mathrm{M} 61 / 0$ (X 700).

K. Horriditriletes superbus (Foster) Césari, Archangelsky y Seoane 1995, BAPal 6156 (c) U41/2 (X 700).

L. Horriditriletes uruguaiensis (Marques-Toigo) Archangelsky y Gamerro 1979, BAPal 6173 (a) W44/2 (X 750).

M. Interradiaspora sp. cf. I. robustus (Foster) Foster 1979, BAPal 6165 (b) R59/2 (X $650)$.

N. Lophotriletes sp. A, BAPal 6152 (a) J73/1 (X 750).

N. Dibolisporites sp. cf. D. disfacies Jones y Truswell 1992, BAPal 6185 (a) J48/2 (X 700). 


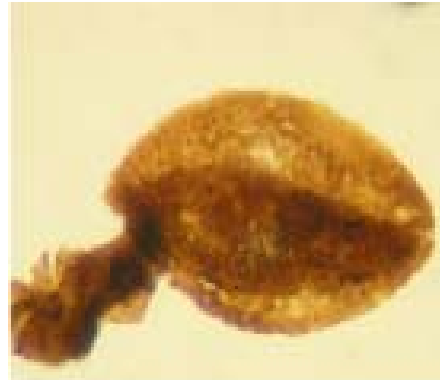

A

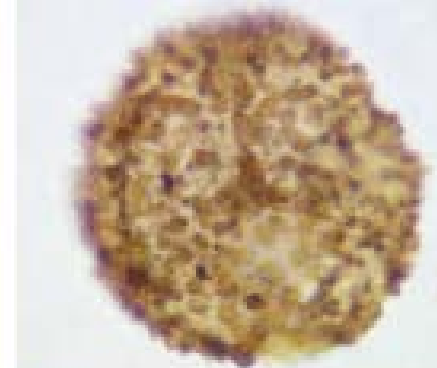

B
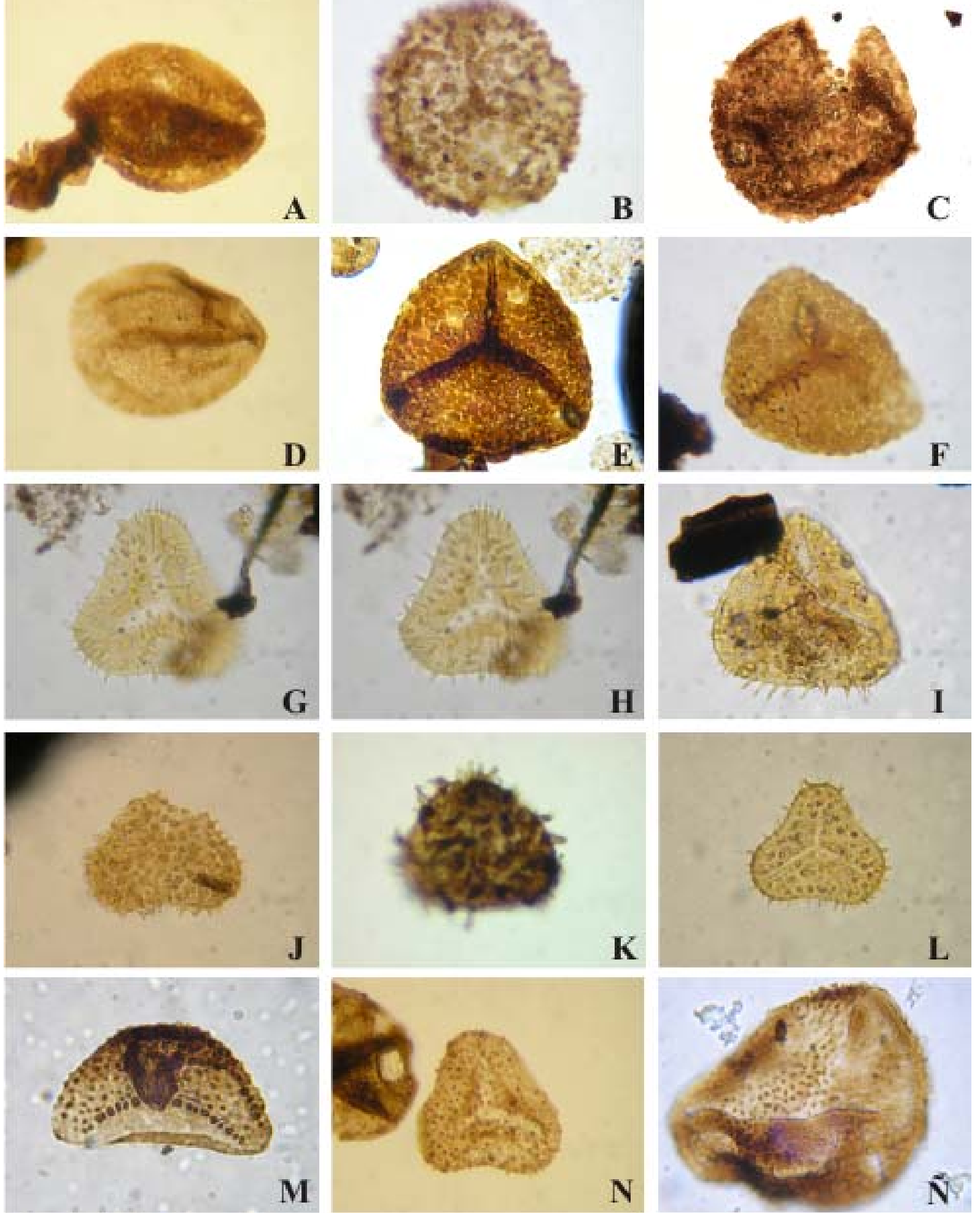
Lámina IV 


\section{Lámina IV}

. Phidiaesporites fosteri Foster 1979, BAPal 6143(a) H53/2 (X 600).

B y C. Didecitriletes ericianus (Balme y Hennelly) Venkatachala y Kar 1965, BAPal 6160 (a) P63/4 (X 700); BAPal 6147 (a) S53/3 (X 650).

D. Didecitriletes uncinatus (Balme y Hennelly) Venkatachala y Kar 1965, BAPal 6155 (a) W38/2 (X 750).

E y F. Convolutispora archangelskyi Playford y Dino 2002, BAPal 6152 (a) H43/4 (X $650)$.

G. Convolutispora candiotensis Ybert 1975, BAPal 6142 (a) U47/0 (X 500).

H e I. Convolutispora ordonezii Archangelsky y Gamerro 1979, BAPal 6152 (a) Q56/4 (X 700); M60/2 (X 650).

J y K. Convolutispora sp. A, BAPal 6152 (a) B38/4 (X 700); 6187 (a) M31/1 (X 650).

L. Camptotriletes sp. cf. C. warchianus Balme 1970, BAPal 6138 (c) D60/0 (X 700).

M. Diatomozonotriletes ponticulus Foster 1975, BAPal 6188 (b) R67/0 (X 600).

N y $\tilde{\mathbf{N}}$. Diatomozonotriletes subbaculiferus (Nahuys, Alpern e Ybert) Césari, Archangelsky y Seoane 1995, BAPal 6181 (a) Q53/0 (X 800). 

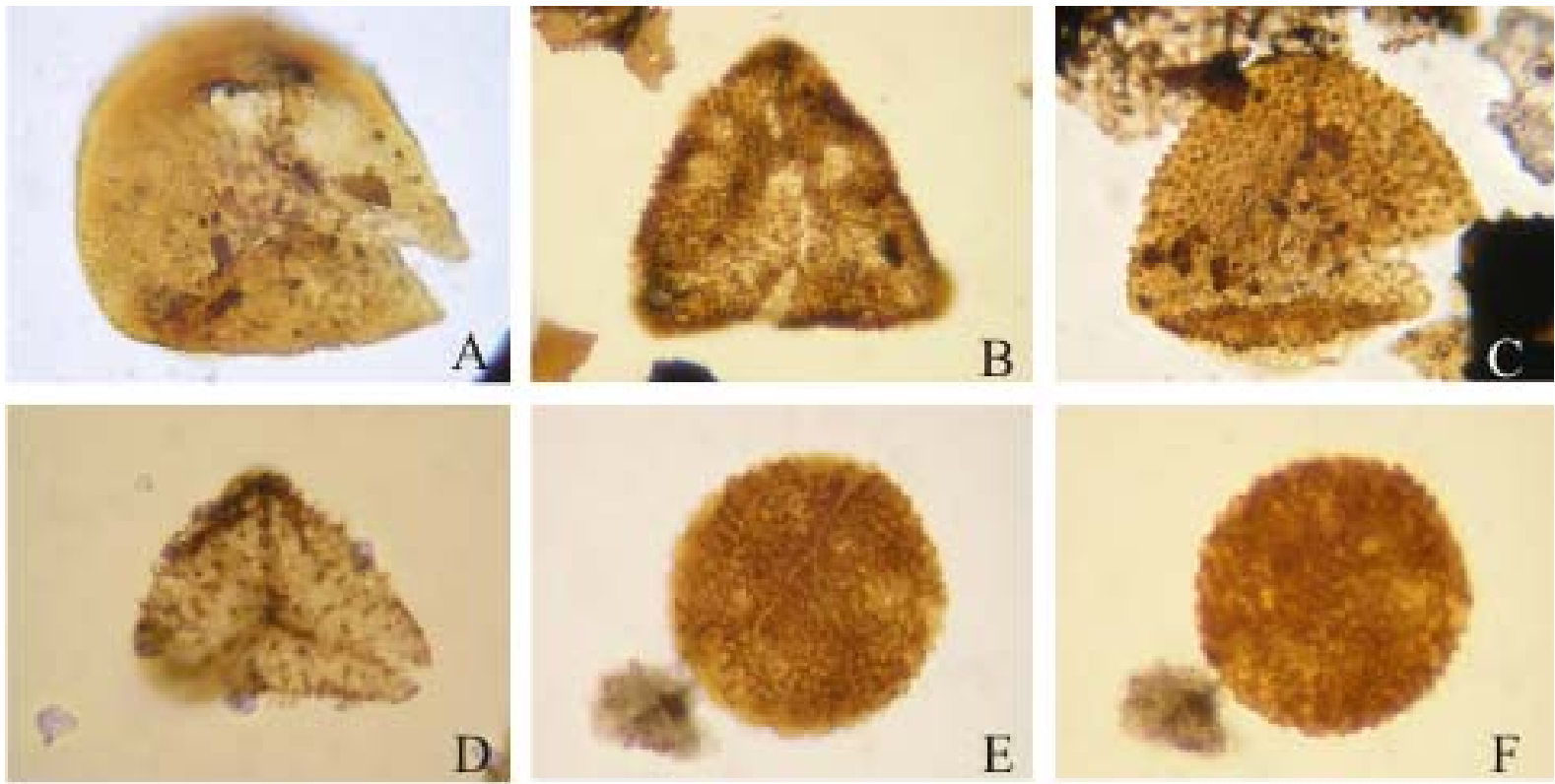

E
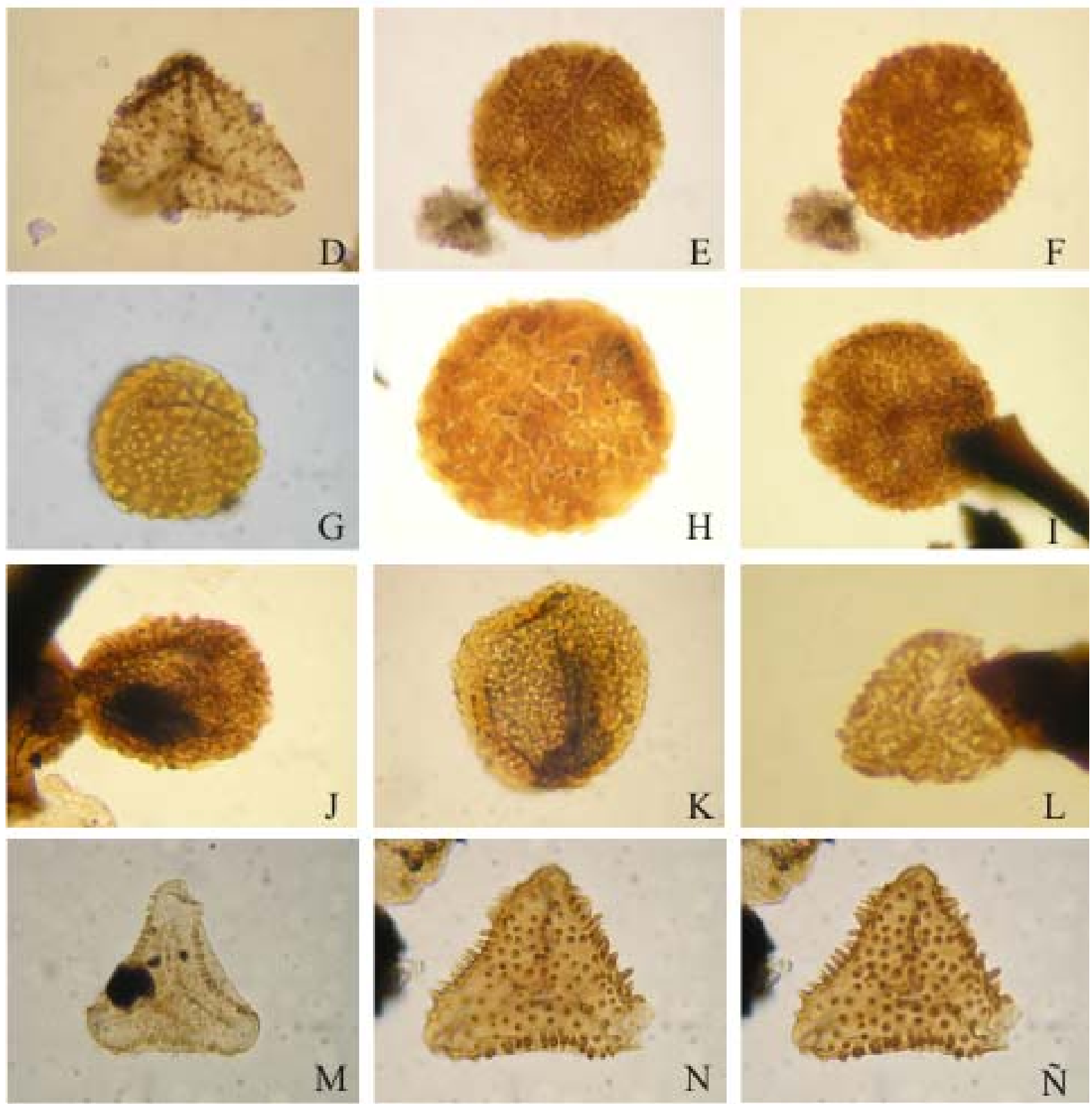
Diatomozonotriletes subbaculiferus (Nahuys, Alpern e Ybert) Césari, Archangelsky y Seoane 1995

Lámina IV, figuras $\mathrm{N}$ y $\tilde{\mathrm{N}}$

1968. Anapiculatisporites subbaculiferus Nahuys, Alpern e Ybert, p. 18, figs. 18-21.

Descripción. Espora radial trilete, de contorno triangular, con lados levemente cóncavos, rectos a levemente convexos. Margen irregular por proyección de la ornamentación. Lesura acompañada por delgados labios, de rayos algo sinuosos, extendidos hasta el borde ecuatorial. Cara proximal levigada. Cara distal ornamentada por granos de base circular y ápice redondeado, dispuestos espaciadamente. Zonas interradiales próximas al margen ecuatorial ormanentadas con báculas de base ancha, de hasta $4 \mu \mathrm{m}$ de largo y ápice redondeado y en ocasiones aguzado. Las mismas se proyectan fuera del contorno de la espora y disminuyen levemente en altura hacia los ápices. Exina de $2 \mu \mathrm{m}$ de ancho.

Dimensiones (5 ejemplares). Diámetro ecuatorial, 34(43,2)47 $\mu \mathrm{m}$; ornamentación, 2-3 $\mu \mathrm{m}$ de base y $3-4 \mu \mathrm{m}$ de altura; exina $1-1,5 \mu \mathrm{m}$.

Principal material estudiado. BAPal 6162 (a) P46/0; BAPal 6162 (b) V43/1; BAPal 6169 (a) V73/0; BAPal 6181 (a) Q53/0; BAPal 6187 (a) U57/3.

Registros previos. Diatomozonotriletes subbaculiferus fue descripta originalmente por Nahuys et al. (1968) para el Cisuraliano de Brasil.

- Pennsylvaniano-Cisuraliano: Argentina: presente en las biozonas PotonieisporitesLundbladispora y Cristatisporites, Cuenca Chacoparaná (Césari et al., 1995).

- Cisuraliano: Argentina: presente en la Formación Victoriano Rodríguez, Biozona Cristatisporites, Cuenca Chacoparaná (Playford y Dino, 2002).

- Cisuraliano-Guadalupiano: Brasil: presente en la Formación Rio Bonito, Cuenca Paraná (Ybert, 1975; Burjack, 1978; Piccarelli y Marques-Toigo, 1983).

\author{
Suprasubturma CAMERATITRILETES Neves y Owens 1966 \\ Subturma SOLUTITRILETES Neves y Owens 1966 \\ Infraturma CINGULICAMERATI Neves y Owens 1966
}

Género Kraeuselisporites Leschik emend. Jansonius 1962 
Especie tipo. Kraeuselisporites dentatus Leschik, 1956.

Afinidad botánica. Licofitas (véase Balme, 1995).

Kraeuselisporites apiculatus Jansonius 1962

Lámina $\mathrm{V}$, figuras A y B

Descripción. Espora radial trilete cavada de contorno subtriangular, de lados convexos y ángulos redondeados y margen ondulado. Exina dividida en dos capas en el ecuador. Cuerpo central bien definido, triangular. Lesura extendida por todo el cuerpo, alcanzando la zona. Rayos de contorno sinuosos, acompañados de delgados labios. Cara proximal escabrada de forma plana a cóncava, portando pequeñas espinas. Cara distal fuertemende convexa, cubierta por espinas y conos cortos de bases anchas, homogéneamente distribuidos hacia la zona central, a veces coalesciendo. Zona transparente, de ancho constante, equivalente al 1/3 del radio de la espora.

Dimensiones (3 ejemplares). Diámetro total, 54(58)65 $\mu \mathrm{m}$; diámetro del cuerpo, $42 \mu \mathrm{m}$; ornamentación distal, 1-2,5 $\mu \mathrm{m}$ de ancho basal y 2-4 $\mu \mathrm{m}$ de altura; ancho de la zona, 5$10 \mu \mathrm{m}$; intexina de hasta $1 \mu \mathrm{m}$ de espesor.

Principal material estudiado. BAPal 6157 (a) U56/0, V55/0; BAPal 6169 (a) V60/0.

Registros previos. Kraeuselisporites apiculatus fue descripta originalmente por Jansonius (1962) para el Triásico Inferior de Canadá.

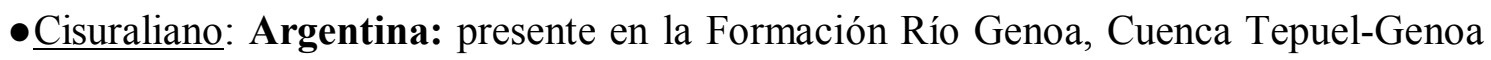
(Gutiérrez et al., 2007). Uruguay: presente en la Formación San Gregorio, Cuenca Paraná (Beri y Goso, 1996). Gabón: presente en el Sistema Karoo (Jardiné, 1974). Svalbard (Europa): mencionada para la Formación Kappstarostin (Mangerud y Konieczny, 1991).

- Cisuraliano-Guadalupiano: Brasil: presente en Formación Rio Bonito (Días-Fabricio 1981) y en Matos Costa (Quadros et al., 1996), Cuenca Paraná.

- Lopingiano-Triásico Inferior: Rusia: mencionada para la plataforma Finnmark, Mar Artico (Mangenrud 1994). Canadá: Jansonius (1962) y Balme (1979).

Kraeuselisporites punctatus Jansonius 1962

Lámina $\mathrm{V}$, figura $\mathrm{C}$ 
Descripción. Espora radial trilete cavada y zonada, de contorno subtriangular, de lados rectos a convexos y ángulos redondeados. Margen sinuoso por proyección de la zona. Exina dividida en dos capas en el ecuador. Cuerpo central bien definido, triangular. Lesura extendida por todo el cuerpo, alcanzando la zona. Rayos acompañados de labios de hasta $3 \mu \mathrm{m}$ de ancho. Cara proximal plana a cóncava, levigada. Cara distal fuertemende convexa, ornamentada por verrugas compacta y homogéneamente distribuidas. Zona de ancho constante.

Dimensiones (2 ejemplares). Diámetro total, 47-50 $\mu \mathrm{m}$; diámetro del cuerpo, 37-40 $\mu \mathrm{m}$; ornamentación, 2-3 $\mu \mathrm{m}$ de base y $1 \mu \mathrm{m}$ de altura; zona, $9 \mu \mathrm{m}$ de ancho; exina de hasta 1 $\mu \mathrm{m}$.

\section{Principal material estudiado. BAPal 6159 (a) D59/4; BAPal 6164 (a) F48/0.}

Comentarios. La especie Krauselisporites punctatus se diferencia de las especies $K$. apiculatus Jansonius (1962, p. 47, pl. 11, fig. 26); K. spinosus Jansonius (1962, p. 47, pl. 11, fig. 22); K. sommeri Cauduro (1970, p. 11, figs. 30-36) y K. noduspiniferus Cauduro (1970, p. 11, figs. 37-42) por la ausencia de la conspicua ornamentación distal. “Krauselisporites punctatus" (non Jansonius 1962, p. 48, pl. XI, figs. 2, 20) propuesta por Marques-Toigo (1974, p. 605, pl. II, figs. 1-2) para la Formación San Gregorio difiere del resto de las especies por presentar acompañando a la lesura sinuosos y elevados labios; aunque dicho caracter también es posible observarlo en otras especies. Además, la especie de Marques-Toigo es una nomina nuda (sensu McNeil et al., 2006, art. 53.1) por ser homónimo de la especie válidamente propuesta por Jansonius. Vallatisporites punctatus (Marques-Toigo) Souza et al. (2003, p. 55, pl. 3, fig. 1) y V. sp. A Playford y Dino (2000a, p. 20, pl. 4, fig. 7) se diferencian por presentar una zona ecuatorial vacuolada.

Registros previos. Krauselisporites punctatus fue descripta originalmente por Jansonius (1962) para el Triásico Inferior de Canadá.

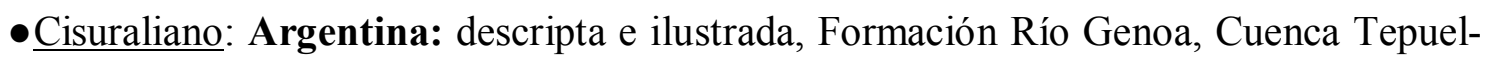
Genoa (Gutiérrez et al., 2007). Uruguay: presente en la Formación San Gregorio, Cuenca Paraná (Marques-Toigo, 1974; Beri y Goso, 1996; Gutiérrez et al., en prensa-b). Svalbard (Europa): mencionada para la Formación Kappstarostin (Mangerud y Konieczny, 1991). 
- Triásico: Argentina: presente en la Formación Cacheuta, Cuenca Cuyana (Jain, 1968). Rusia: en Svalis Dome, Mar Artico (Vigran et al., 1998).

\author{
Suprasubturma LAMINATRITRILETES Smith y Butterworth 1967 \\ Subturma ZONOLAMINATITRILETES Smith y Butterworth 1967 \\ Infraturma CINGULICAVATI Smith y Butterworth 1967
}

Género Cristatisporites Potonié y Kremp 1954

Especie tipo. Cristatisporites indignabundus (Loose) Potonié y Kremp emend. Staplin y Jansonius, 1964.

Afinidad botánica. Licofitas (véase Balme, 1995; Quadros et al., 1996).

Cristatisporites chacoparanaensis Ottone 1989

Lámina $\mathrm{V}$, figura D

Descripción. Espora radial trilete, cingulizonada y de contorno irregular. Cuerpo central subtriangular a subcircular. Lesura simple o con delgados labios, levemente sinuosa, que alcanzan el margen interno de la cingulizona. Cara proximal lisa, piramidal. Cara distal fuertemente convexa, ornamentada por verrugas y elementos mameliformes en la zona central, y espinas fusionadas por sus bases conformando crestas hacia la zona periférica. La cingulizona es translúcida y presenta también espinas.

Dimensiones (2 ejemplares). Diámetro ecuatorial, 32-45 $\mu \mathrm{m}$; diámetro del cuerpo, 38 $\mu \mathrm{m}$; ornamentación, $3 \mu \mathrm{m}$ de ancho basal y 3-4 $\mu \mathrm{m}$ de alto; ancho de la cíngulizona, 6-8 $\mu \mathrm{m}$.

Principal material estudiado. BAPal 6187 (b) L52/0. Retrabajo: BAPal 6181 (a) Q44/3.

Registros previos. Cristatisporites chacoparanaensis fue descripta originalmente (como C. sp. B) para la Biozona Cristatisporites, Cuenca Chacoparaná (Archangelsky y Gamerro, 1979).

- Pennsylvaniano: Argentina: presente en las formaciones Jejenes (Césari y Bercowski, 1997), Tupe (Ottone y Azcuy, 1990) y listada para la Formación El Trampeadero (Gutiérrez y Barreda, 2006), todas en el ámbito del Cuenca Paganzo. 
- Pennsylvaniano-Cisuraliano: Argentina: presente en la Formación Santa Máxima, Cuenca Calingasta-Uspallata (Ottone, 1989).

- Cisuraliano: Uruguay: presente en la Formación San Gregorio, Cuenca Paraná (Beri et al., 2006). Argentina: ilustrada en la Formación Tupe (miembro cuspidal), Cuenca Paganzo (Vergel, 2008).

- Cisuraliano-Guadalupiano: Argentina: ilustrada para las Biozonas PotonieisporitesLundbladispora, Cristatisporites y Striatites, Cuenca Chacoparaná (Césari et al., 1995).

Cristatisporites sp. cf. C. inconstans Archangelsky y Gamerro 1979

Lámina $\mathrm{V}$, figura $\mathrm{E}$

Descripción. Espora radial trilete, cingulizonada y de contorno subtriangular. Cuerpo central subtriangular a subcircular. Lesura simple o con delgados labios, levemente sinuosa, que alcanzan el margen interno de la cingulizona. Cara proximal lisa, con algunas espinas hacia la periferia. Cara distal fuertemente convexa, ornamentada por verrugas en la zona central, dispuestas aisladamente, y por espinas hacia la zona periférica que se fusionan por sus bases conformando crestas irregulares. La cingulizona es translúcida, y en el mismo ejemplar se pueden observar áreas con elementos proyectados y dispuestos densamente, como también áreas reducidas, o hasta ausente.

Dimensiones ( 1 ejemplar). Diámetro ecuatorial, $33 \mu \mathrm{m}$; diámetro del cuerpo, $29 \mu \mathrm{m}$; ornamentación, $2 \mu \mathrm{m}$ de ancho basal y $4 \mu \mathrm{m}$ de alto; ancho de la cingulizona, 3-4 $\mu \mathrm{m}$.

Principal material estudiado. BAPal 6187 (a) N44/0.

Comentarios. La pobre preservación del único ejemplar hallado impide realizar una asignación específica certera, sin embargo algunas de las características que presenta (en especial la presencia de una cingulizona translúcida y de ancho variable), permiten confrontarlo con Cristatisporites inconstans (véase Archangelsky y Gamerro, 1979, p. 435, lám. V, figs. 1-5).

Cristatisporites menendezi (Menéndez y Azcuy) Playford 1978

Lámina $\mathrm{V}$, figura $\mathrm{F}$ 
Descripción. Espora radial trilete, cingulizonada y de contorno subtriangular. Cuerpo central subtriangular. Cingulizona densa y estrecha, de borde aserrado. Cara proximal rota, ligeramente cóncava. Cara distal fuertemente convexa, ornamentada por verrugas de 3-4 de ancho base, que se fusionan conformando crestas aserradas que se proyectan sobre la cingulizona.

Dimensiones (1 ejemplar). Diámetro ecuatorial, $43 \mu \mathrm{m}$; crestas, 3-4 $\mu \mathrm{m}$ de ancho basal у $2 \mu \mathrm{m}$ de alto; cingulizona de 5-6 $\mu \mathrm{m}$ de ancho.

Principal material estudiado. BAPal 6186 (a) W70/1.

Registros previos. Cristatisporites menendezi (Menéndez y Azcuy) Playford (1978) fue descripta orignalmente para la Formación Lagares, Cuenca Paganzo (Menéndez y Azcuy, 1972).

- Pennsylvaniano: Argentina: ilustrada para las formaciones Malanzán (Gutiérrez y Limarino, 2001), Tupe (Ottone y Azcuy, 1991), Agua Colorada (Limarino y Gutiérrez, 1990) y El Trampeadero (Gutiérrez y Barreda, 2006), todas en la Cuenca Paganzo; ilustrada para los grupos Macharetí y Mandiyutí, Cuenca Tarija (di Pasquo, 2003); y descripta para las formaciones Malanzán y Loma Larga (Azcuy, 1975), Tupe (Césari, 1984), Cortaderas (Pérez Loinaze, 2007), todas de la Cuenca Paganzo. Brasil: presente en Andirá, Cuenca Amazonas (Quadros et al., 1996) y listada para el Subgrupo Itararé, Cuenca Paraná (Souza et al., 2003). Australia: presente en la Formación Ducabrook, Cuenca Drummond (Playford, 1978).

- Pennsylvaniano-Cisuraliano: Argentina: presente en las formaciones Sachayoj, Cuenca Chacoparaná (Vergel, 1998), Santa Máxima, Cuenca Calingasta-Uspallata (Ottone, 1989) y El Imperial, Cuenca San Rafael (García, 1995).

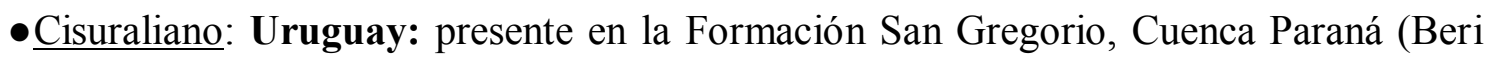
et al., 2006).

\section{Cristatisporites rollerii Ottone 1989}

$$
\text { Lámina } \mathrm{V} \text {, figuras } \mathrm{G} \text { y } \mathrm{H}
$$

Sinonimia. Véase Gutiérrez y Barreda (2006).

Descripción. Espora radial trilete, cingulizonada y de contorno subtriangular. Cuerpo central subtriangular a subcircular. Lesura simple o con delgados labios, levemente 
sinuosa, que alcanzan el margen interno de la cingulizona. Cara proximal lisa, piramidal. Cara distal fuertemente convexa, ornamentada por conos de anchas bases y ápices acuminados, elementos mamoides y escasas espinas. Los elementos ornamentales suelen fusionarse por sus bases, formando crestas y algunos muros. La ornamentación, conspicua sobre el polo distal de la espora hasta el cíngulo, disminuyendo en densidad y tamaño sobre la zona, donde se proyectan las crestas en forma radial. Cingulizona delgada ornamentada por pequeños conos y elementos mamoides.

Dimensiones (3 ejemplares). Diámetro ecuatorial, 62-90 $\mu \mathrm{m}$; diámetro del cuerpo, 55$72 \mu \mathrm{m}$; ornamentación, $3 \mu \mathrm{m}$ de ancho basal y 2-4 $\mu \mathrm{m}$ de alto; ancho de la cingulizona, 6-20 $\mu \mathrm{m}$.

Principal material estudiado. BAPal 6149 (a) G56/3; BAPal 6158 (a) M57/2; BAPal 6187 (b) G49/2.

Registros previos. Cristatisporites rollerii fue descripto originalmente por Ottone (1989) para la Formación Santa Máxima, Pennsylvaniano-Cisuraliano de la Cuenca Calingasta-Uspallata.

- Pennsylvaniano: Argentina: listada para los grupos Macharetí y Mandiyutí, Cuenca Tarija (di Pasquo 2003; di Pasquo y del Papa, 2004); descripta para la Formación E1 Trampeadero, Cuenca Paganzo (Gutiérrez y Barreda, 2006). Brasil: presente en el Subgrupo Itararé, Cuenca Paraná (Amaral et al., 2001; Souza et al., 2003).

- Cisuraliano: Argentina: presente en las formaciones Tasa Cuna, Cuenca Paganzo (Balarino y Gutiérrez, 2006) y Río Genoa, Cuenca Tepuel-Genoa (Gutiérrez et al., 2007).

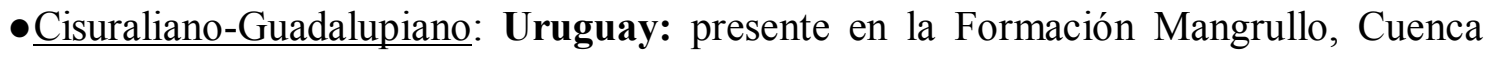
Paraná (Gutiérrez et al., en prensa-b).

Género Gondisporites Bharadwaj 1962

Especie tipo. Gondisporites raniganjensis Bharadwaj 1962.

Afinidad botánica. Licofitas?.

Gondisporites serrulatus Césari, Archangelsky y Seoane 1995

Lámina $\mathrm{V}$, figuras J y K 
Descripción. Espora radial trilete cingulizonada, cavada y de contorno subtriangular de lados convexos y ángulos fuertemente redondeados. Margen finamente aserrado a irregular por la presencia de la ornamentación. Lesura simple o con labios delgados, de rayos rectos extendidos hasta el borde interno del cíngulo. Cara proximal cóncava a plana, con áreas de contacto levigadas a escabrada, a veces con pequeños conos y grana. Cara distal fuertemente convexa, ornamentada con numerosas espinas y algunas verrugas y báculas cortas. Los elementos ornamentales pueden fusionarse por sus bases, generando crestas de 2 a 3 componentes. La zona es más traslúcida que el cuerpo central, de ancho constante, de hasta $7 \mu \mathrm{m}$.

Dimensiones (3 ejemplares). Diámetro ecuatorial, 39(53)65 $\mu \mathrm{m}$; diámetro del cuerpo central, 39(53)65 $\mu \mathrm{m}$; ornamentación, $1 \mu \mathrm{m}$ de ancho basal y 1-3 $\mu \mathrm{m}$ de alto; ancho de la zona cíngulo, 4-7 $\mu \mathrm{m}$.

Principal material estudiado. BAPal 6160 (a) T60/1; BAPal 6183 (a) N28/2; BAPal 6188 (a) Q64/2.

Registros previos. Gondisporites serrulatus fue descripta originalmente por Césari et al. (1995) para la Perforación Las Mochas, Biozona Cristatisporites, Pérmico Inferior de la Cuenca Chacoparaná, Argentina.

- Cisuraliano-Guadalupiano: Uruguay: presente en la Formación Melo, Cuenca Paraná (Anzótegui et al., 1998a).

Género Lundbladispora (Balme) Playford 1965

Especie tipo. Lundbladispora wilmotti Balme, 1963.

Afinidad botánica. Licofitas (véase Balme, 1995).

Lundbladispora braziliensis (Pant y Srivastava) Marques-Toigo y Pons emend.

Marques-Toigo y Picarelli 1984

Lámina V, figuras I y L

1965. Densosporites braziliensis Pant y Srivastava, pp. 469-470, pl. 1, figs. 1-6, Textfigs. 2G-I. 
Sinonimia adicional. Véase Marques-Toigo y Picarelli (1985) y Playford y Dino (2002).

Descripción. Espora radial trilete cingulicavada de contorno subcircular a subtriangular, de margen ondulado. Lesura poco discernible, de rayos rectos extendidos hasta el borde interno del cíngulo, con labios delgados y elevados. Exina dividida en dos capas, cavada. Exoexina engrosada ecuatorialmente y extendida a modo de cíngulo, el cual es de apariencia membranosa. Cara proximal de cóncava a plana, con áreas de contacto levigadas a escabrada. Cara distal fuertemente convexa, con pequeños conos y grana que le dan una apariencia esponjosa. En el cíngulo aparecen los elementos de mayor tamaño. Cíngulo de de un ancho equivalente a 1/4 del radio total de la espora.

Dimensiones (11 ejemplares). Diámetro ecuatorial, 38(69,4)102 $\mu \mathrm{m}$; diámetro del cuerpo, 31(59,4)83 $\mu \mathrm{m}$; ancho del cíngulo, 5-7 $\mu \mathrm{m}$.

Principal material estudiado. BAPal 6143 (a) C62/0; BAPal 6152 (b) T64/2; BAPal 6163 (a) R55/0; BAPal 6165 (a) J52/4, J69/4; BAPal 6165 (b) X41/4; BAPal 6183 (b) R36/0; BAPal 6185 (b) U70/3; BAPal 6189 (a) U70/3.

Registros previos. Lundbladispora braziliensis (Pant y Srivastava) Marques-Toigo y Pons emend. Marques-Toigo y Picarelli 1985, fue descripta originalmente para la Formación Rio Bonito, Cisuraliano-Guadalupiano de la Cuenca Paraná de Brasil (Pant y Sirvastava, 1965).

- Pennsylvaniano: Argentina: presente en las formación Jejenes (Césari y Bercowski, 1997), Guandacol (Césari y Vázquez Nístico, 1988; Ottone, 1991) e ilustrada para la Formación El Trampeadero (Gutiérrez y Barreda, 2006), Cuenca Paganzo. Ilustrada para las formaciones San Telmo, Cuenca Tarija (di Pasquo et al., 2001) y Río del Peñón, Cuenca Río Blanco (Gutiérrez y Limarino, 2006).

- Pennsylvaniano-Cisuraliano: Argentina: presente para las Biozonas PotonieisporitesLundbladispora y Cristatisporites (Archangelsky y Gamerro, 1979; Archangelsky et al., 1980; Vergel, 1986; Césari et al., 1995); Cuenca Chacoparaná, y las formaciones Sachayoj, Cuenca Chacoparaná (Vergel, 1998) y El Imperial, Cuenca San Rafael (García, 1995). Mencionada para la Formación Río del Peñón, Cuenca Paganzo (Gutiérrez y Limarino, 2006). Brasil: presente en Matos Costa, Santa Catarina, Cuenca Paraná (Quadros et al., 1996). 
- Cisuraliano: Argentina: presente en las formaciones Victoriano Rodríguez, Biozona Cristatisporites, Cuenca Chacoparaná (Playford y Dino 2002) y Tasa Cuna, Cuenca Paganzo (Balarino y Gutiérrez, 2006). Ilustrada para la Formación Río Genoa, Cuenca Tepuel-Genoa (Gutiérrez et al., 2007). Uruguay: ilustrada para las formaciones Tres Islas (Veroslavsky et al., 2003) y San Gregorio (Beri y Daners, 1996; Beri et al., 2006), Cuenca Paraná. Omán y Arabia Saudita: ilustrada para la Formación Al Khlata (Stephenson y Filatoff, 2000a).

- Cisuraliano-Guadalupiano: Uruguay: ilustrada para la Formación Melo (Mautino et al., 1998a; Beri y Pecoits, 2001), Cuenca Paraná. Brasil: presente en la Formación Rio Bonito (Burjack, 1978; Jasper et al., 2006; Souza y Marques-Toigo, 2005), Cuenca Paraná.

- Lopingiano: Argentina: mencionada para la Formación La Veteada, Cuenca Paganzo (Zavattieri et al., 2008).

\title{
Lundbladispora iphilegna Foster 1979
}

\author{
Lámina $\mathrm{V}$, figuras $\mathrm{M}$ y $\mathrm{N}$
}

Descripción. Espora radial trilete cingulicavada, de contorno subcircular a subtriangular, de margen liso y levemente ondulado. Lesura bien definida, de rayos rectos extendidos hasta el borde interno del cíngulo, con labios delgados y elevados, de 1 a $2 \mu \mathrm{m}$ de ancho. Exina dividida en dos capas, cavada. Exoexina finamente texturada, con apariencia esponjosa, con un ancho menor a $1 \mu \mathrm{m}$. Cara proximal levemente hundida, levigada a granulada. Intexina delgada, frecuentemente plegada, adherida a la exoexina por el polo proximal. Cara distal fuertemente convexa, con verrugas y gránulos pequeños dispuestos de manera dispersa. Cíngulo esponjoso, de 1/5 de ancho respecto del radio total de la espora. Exina gruesa y oscura.

Dimensiones (3 ejemplares). Diámetro ecuatorial, 45(51,3)59 $\mu \mathrm{m}$; diámetro del cuerpo, 30-40 $\mu \mathrm{m}$; ornamentación, 1-2 $\mu \mathrm{m}$ de base y $1 \mu \mathrm{m}$ de altura; exina 1-1,5 $\mu \mathrm{m}$.

Principal material estudiado. BAPal 6183 (a) J28/0; BAPal 6185 (a) W40/3. Retrabajo: BAPal 6181 (a) K57/2.

Comentarios. El material aquí estudiado presenta las principales características diagnósticas de Lundbladispora iphilegna Foster (1979, pp. 53-54, pl. 14, figs. 7-12), 
tales como intexina delgada, tipo, tamaño y distribución de la escultura (discretos granos y verrugas), cingulo esponjoso, etc.

Registros previos. Lundbladispora iphilegna fue descripta originalmente por Foster (1979) para Baralaba Coal Measures, Pérmico, Australia.

- Cisuraliano: Brasil: presente en Matos Costa, Cuenca Paraná (Quadros et al., 1996). Antártida: Lindström (2005). Perú: ilustrada para el Grupo Copacabana (Doubinger y Moroco, 1981).

- Lopingiano-Triásico Inferior: China: presente en las formaciones Xuanwei y Kayitou (Jiguan et al., 1992).

Esta es la primera cita de la especie para la Argentina.

\section{Lundbladispora riobonitensis Marques-Toigo y Picarelli 1985 \\ Lámina $\mathrm{V}$, figura $\tilde{\mathrm{N}}$}

Descripción. Espora radial trilete cingulicavada, de contorno subcircular a subtriangular, de margen levemente ondulado. Lesura de rayos rectos extendidos hasta el borde interno del cíngulo, con labios delgados y elevados. Exina dividida en dos capas, cavada, finamente texturada, con apariencia esponjosa. Cara proximal, levemente hundida, mientras que la distal fuertemente convexa. Cíngulo esponjoso, con un ancho de $1 / 5$ del radio de la espora.

Dimensiones (3 ejemplares). Diámetro ecuatorial, 42(61,6)80 $\mu \mathrm{m}$; exoexina sobre la cara distal, $3 \mu \mathrm{m}$ de espesor.

Principal material estudiado. BAPal 6152 (a) J72/4; BAPal 6187 (a) T57/0; BAPal 6189 (a) $072 / 1$.

Registros previos. Lundbladispora riobonitensis fue descripta por Marques-Toigo y Picarelli (1985) para la Formación Rio Bonito, Cisuraliano-Guadalupiano de la Cuenca Paraná, Brasil.

- Pennsylvaniano: Argentina: presente en las formaciones Tupe (Ottone y Azcuy, 1991), Guandacol y Tupe (Ottone y Azcuy, 1990; Ottone, 1991) y listada para la Formación E1 Trampeadero (Gutiérrez y Barreda, 2006), todas del ámbito de la Cuenca Paganzo. Ilustrada para la Formación San Telmo, Cuenca Tarija (di Pasquo et al., 
2001). Brasil: ilustrada para el Subgrupo Itararé, Cuenca Paraná (Marques-Toigo et al., 1989; Souza et al., 2003; Souza, 2006).

- Pennsylvaniano-Cisuraliano: Argentina: presente en la Formación Sachayoj (Vergel, 1998) e ilustrada para las Biozonas Potonieisporites-Lundbladispora y Cristatisporites (Vergel, 1986; Césari et al., 1995), en el ámbito de la Cuenca Chacoparaná. Brasil: presente en la Formación Rio Grande do Sul, Cuenca Paraná (Quadros et al., 1996).

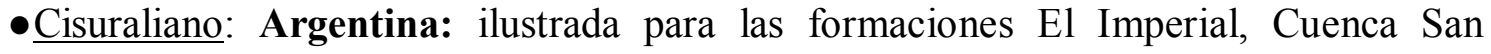
Rafael (García, 1995) y Río Genoa, Cuenca Tepuel-Genoa (Gutiérrez et al., 2007). Presente en la Formación Tasa Cuna, Cuenca Paganzo (Balarino y Gutiérrez, 2006). Uruguay: ilustrada para la Formación San Gregorio (Beri y Daners, 1996; Beri et al., 2006), Cuenca Paraná. Brasil: ilustrada para el Subgrupo Itararé, Biozona Vittatina costabilis, sub-biozona Protohaploxypinus goraiensis, Cuenca Paraná (Souza y Callegari, 2004). Paraguay: ilustrada para la Formación Tacuary, Cuenca Chacoparaná (Muff et al., 1999). Omán y Arabia Saudita: ilustrada para la Formación Al Khlata (Stephenson y Filatoff, 2000a).

- Cisuraliano-Guadalupiano: Uruguay: ilustrada para la Formación Melo (Mautino et al., 1998a; Beri y Pecoits, 2001), Cuenca Paraná. Brasil: ilustrada para la Formación Rio Bonito (Jasper et al., 2006).

- Lopingiano: Argentina: mencionada para la Formación La Veteada, Cuenca Paganzo (Zavattieri et al., 2008).

\section{Lundbladispora willmotti Balme 1963}

Lámina VI, figuras A y B

Descripción. Espora radial trilete cingulicavada, de contorno subcircular a subtriangular, de margen aserrado por proyección de la ornamentación. Lesura pobremente definida, de rayos rectos hasta $2 / 3$ del radio de la espora. Exina dividida en dos capas, cavada. Exoexina texturada, de apariencia esponjosa, ornamentada con espinas, con un cíngulo de hasta $6 \mu \mathrm{m}$ de ancho. Las espinas son de base ancha (de hasta $4 \mu \mathrm{m}$ ) y ápice agudo y filiforme (de hasta $4 \mu \mathrm{m}$ de altura), y se presentan generalmente curvadas. Cara distal fuertemente convexa. Cara proximal hundida, 
levigada a granulada, con elementos dispuestos de manera dispersa. Intexina delgada. Cíngulo esponjoso, de 1/5 de ancho respecto del diámetro de la espora.

Dimensiones (8 ejemplares). Diámetro ecuatorial, 41(59)95 $\mu \mathrm{m}$; ornamentación, 2-4 $\mu \mathrm{m}$ de ancho basal y 3-4 $\mu \mathrm{m}$ de altura; ancho del cíngulo, 3-6 $\mu \mathrm{m}$.

Principal material estudiado. BAPal 6151 (a) Q53/3; 0BAPal 6158 (a) O49/0; BAPal 6188 (a) N45/0, S67/0; BAPal 6188 (b) K72/. Retrabajo: BAPal 6180 (a) M57/1; O47/1.

Comentarios. El material aquí descripto presenta el tipo de escultura característica de Lundbladispora willmotti (Balme, 1963, pp. 22-23, pl. 5, figs. 1-3).

Registros previos. Lundbladispora willmotti fue descripta originalmente por Balme (1963) para Kockatea Creek No 19 Bole, área superior del Río Greenough, Triásico Inferior de Australia.

- Lopingiano: Argentina: mencionada para la Formación La Veteada, Cuenca Paganzo (Zavattieri et al., 2008).

En esta oportunidad se describe por primera vez para la Argentina.

\section{Género Vallatisporites Hacquebard 1957}

Especie tipo. Vallatisporites vallatus Hacquebard, 1957.

Afinidad botánica. Licofitas (véase Balme, 1995).

Vallatisporites arcuatus (Marques-Toigo) Archangelsky y Gamerro 1979 Lámina VI, figura C

1974. Kraeuselisporites arcuatus Marques-Toigo, p. 605, lám. 1, figs. 6-7.

1980. Vallatisporites sp. Archangelsky y Gamerro, lám. I, figs. 7-8.

Descripción. Espora radial trilete, cavada y zonada, de contorno subtriangular, de lados levemente convexos y ápices fuertemente redondeados. Margen irregular por proyección de la ornamentación. Lesura recta a levemente sinuosa, alcanzando aproximadamente el ecuador, acompañada por delgados labios. Cara proximal plana y lisa, cara distal con verrugas de bases irregulares y conos, todos de de diversos tamaños, dispuestos entre laxa y densamente, y de manera compacta en el borde de la espora, 
formando un anillo. Las verrugas se contactan por sus bases, aunque no se fusionan totalmente. Zona traslúcida, de ancho variable, lisa, con excepción de la zona periférica. Dimensiones (3 ejemplares). Diámetro ecuatorial, 43(52,6)70 $\mu \mathrm{m}$; diámetro del cuerpo, 28-47 $\mu \mathrm{m}$; ornamentación, $2 \mu \mathrm{m}$ de ancho basal y $2-5 \mu \mathrm{m}$ de alto; zona de 4 a $8 \mu \mathrm{m}$ de ancho.

Principal material estudiado. BAPal 6152 (a) F44/2; BAPal 6183 (a) P28/0; BAPal 6184 (a) L34/0.

Registros previos. Vallatisporites arcuatus (Marques-Toigo) Archangelsky y Gamerro fue descripta originalmente para la Formación San Gregorio (Marques-Toigo, 1974), Cisuraliano de Uruguay.

- Pennsylvaniano: Brasil: presente en el Subgrupo Itararé, Cuenca Paraná (Souza et al., 1997); ilustrada en la Formación San Telmo, Cuenca Tarija (di Pasquo et al., 2001).

- Pennsylvaniano-Cisuraliano: Argentina: ilustrada para la Formación Sachayoj, Cuenca Chacoparaná (Vergel, 1998) y presente en las Biozona PotonieisporitesLundbladispora (parte alta) y Cristatisporites (Cuenca Chacoparaná; Archangelsky y Gamerro, 1979; Archangelsky et al., 1980; Césari et al., 1995; Vergel, 1998); y las formaciones Río del Peñón, Cuenca Paganzo (Gutiérrez y Limarino, 2006); Santa Máxima, Cuenca Calingasta-Uspallata (Ottone, 1989) y El Imperial, Cuenca San Rafael (García, 1995). Listada para la Formación Río del Peñón, Cuenca Paganzo (Gutiérrez y Limarino, 2006). Brasil: presente en Matos Costa, Santa Catarina, Cuenca Paraná (Quadros et al., 1996).

- Cisuraliano: Argentina: ilustrada para la Biozona Cristatisporites, Cuenca Claromecó-Colorado (Archangelsky y Gamerro, 1980b); listada para la Formación Piedra Shotle (Gamerro y Archangelsky, 1981) y presente para la Formación Río Genoa, Cuenca Tepuel-Genoa (Gutiérrez et al., 2007); presente en la Formación Victoriano Rodríguez, Biozona Cristatisporites, Cuenca Chacoparaná (Vergel, 1987a; Playford y Dino, 2002). Uruguay: presente en la Formación San Gregorio (MarquesToigo, 1974; Beri et al., 2006), Cuenca Paraná. Omán y Saudi Arabia: Stephenson (2004).

- Cisuraliano-Guadalupiano: Uruguay: ilustrada para la Formación Melo (Mautino et al., 1998a), Cuenca Paraná. 
Género Indotriradites Tiwari emend. Foster 1979

Especie tipo. Indotriradites korbaensis Tiwari 1964.

Afinidad botánica. Licofitas?.

\section{Indotriradites reidii Foster 1979}

Lámina VI, figuras D y E

Descripción. Espora radial trilete, cavada y zonada, de contorno subtriangular, de lados fuertemente convexos y ápices redondeados. Margen sinuoso. Lesura recta a levemente sinuosa, alcanzando el borde ecuatorial, acompañada por labios de hasta 1,5 $\mu \mathrm{m}$ de ancho. Exoexina proximal finamente texturada, cara distal ornamentada con verrugas y elementos mamoides de diámetro variable (entre 1 y $3 \mu \mathrm{m}$ ), irregularmente dispuestos. Los mismos alcanzan la zona, la cual tiene un ancho variable entre 10 y $13 \mu \mathrm{m}$, es más clara que el resto de la espora y presenta un margen irregular. Los elementos ornamentales se distribuyen en forma heterogénea, desde bien separados hasta muy próximos, aunque sus bases no llegan a fusionarse. Zona amplia, de ancho variable, lisa sobre la cara proximal, mientras que sobre el ecuador y la cara distal aparecen elementos de la escultura. Intexina levigada.

Dimensiones (1 ejemplar). Diámetro ecuatorial, $70 \mu \mathrm{m}$; diámetro del cuerpo, $42 \mu \mathrm{m}$; ornamentación, 2-3 $\mu \mathrm{m}$ de ancho y 2-3 $\mu \mathrm{m}$ de alto.

Principal material estudiado. BAPal 6185 (b) P43/2.

Comentarios. Se coincide con Pérez Loinaze (2008, p.427) respecto de la justificación de no incluír al género Indotriradites dentro de Kraeuselisporites, tal como lo propone Azcuy y di Pasquo (2005), y considerando que la enmienda que propone Scheuring (1974) basado sobre el material tipo de Krauselisporites debe incluir solamente formas acavadas.

Por otra parte el ejemplar aquí descripto presenta las características diagnósticas del material tipo (Foster, 1979, pp. 55-56, pl. 16, figs. 6-9), tales como el tipo de escultura distal, sus dimensiones y la amplia zona que aparece ornamentada.

Registros previos. Indotriradites reidii fue descripta originalmente por Foster (1979) para Baralaba Coal Measures, Cuenca Bowen, Australia. 
- Cisuraliano: Australia: ilustrada para la Formación Stockton y Collie Coal Masures, Cuenca Collie (Backhouse, 1991).

Este es el primer registro para cuencas sudamericanas.

Infraturma MONOPSEUDOSACCITI Smith y Butterworth 1967

Género Spelaeotriletes Neves y Owens 1966

Especie tipo. Spelaeotriletes triangulus Neves y Owens 1966.

Afinidad botánica. Pteridophyta (véase Balme, 1995; Quadros et al., 1996).

Spelaeotriletes triangulus Neves y Owens 1966

Lámina VI, figuras G y H

Sinonimia. Véase Playford et al. (2001).

Descripción. Espora radial trilete, cavada, de contorno subtriangular irregular, de lados convexos y ápices fuertemente redondeados. Margen sinuoso por proyección de la ornamentación. Lesura recta a levemente sinuosa, alcanza aproximadamente el borde ecuatorial, simple o acompañada por delgados labios. Exoexina esculturada e intexina levigada. Cara proximal hundida y ornamentada con gránulos y conos, distribuídos homogénea y aisladamente. Cara distal convexa, ornamentada con verrugas y conos dispuestos compactamente, fusionados en algunos casos por sus bases. Exina 1-3 $\mu \mathrm{m}$.

Dimensiones (4 ejemplares). Diámetro ecuatorial, 58-125 $\mu \mathrm{m}$; ornamentación, 1,5-3,5 $\mu \mathrm{m}$ de ancho basal y $1-3 \mu \mathrm{m}$ de alto.

Principal material estudiado. BAPal 6184 (b) K50/1; BAPal 6185 (b) Y41/2; BAPal 6186 (a) P60/0. Retrabajo: BAPal 6179 (a) $\mathrm{H} 72 / 0$.

Registros previos. Spelaeotriletes triangulus fue descripta originalmente por Neves y Owens (1966) para el Namuriano de Inglaterra. Según Playford et al. (2001) presenta un rango de distribucion que va desde el Viseano hasta el Pérmico Temprano.

- Mississippiano: Bolivia: ilustrada para la Formación Itacuá, Cuenca Tarija (di Pasquo, 2007) y listada para la Formación Kaka, Subandino Norte (Fasolo et al., 2006) 
- Pennsylvaniano-Cisuraliano: Argentina: presente en la Formación El Imperial, Cuenca San Rafael (García, 1995). Brasil: presente en el Grupo Tapajós, Cuenca Amazonas (Playford y Dino, 2000a).

\section{Suprasubturma PSEUDOSACCITRILETES Richardson 1965 \\ Infraturma MONOPSEUDOSACCITI Smith y Butterworth 1967}

Género Playfordiaspora Maheshwari y Banerjee 1975

Especie tipo. Playfordiaspora crenulata (Wilson) Foster, 1979.

Afinidad botánica. Licofitas?.

\section{cf. Playfordiaspora sp.}

Lámina VI, figura F

Descripción. Espora radial trilete, cavada, de contorno subcircular irregular. Margen irregular debido a hallarse frecuentemente plegada. Exina separada en dos capas, claramente distinguibles. Exoexina menor a $1 \mu \mathrm{m}$ de ancho, translúcida, con pliegues radiales y con una irregular y poco discernible infraestructura. La misma, delimita lúminas irregulares. Intexina oscura, circular a subcircular, frecuentemente plegada, levigada, de $2 / 3$ respecto del diámetro de la espora.

Dimensiones (2 ejemplares). Diámetro ecuatorial, 46-62 $\mu \mathrm{m}$; diámetro del cuerpo, 26$48 \mu \mathrm{m}$; espesor de la exoexina, menor a $1 \mu \mathrm{m}$.

Principal material estudiado. BAPal 6149 (a) T68/0. Retrabajo: BAPal 6171 (a) W57/2.

Comentarios. El bajo grado de preservación que exhiben los ejemplares aquí estudiados no permite realizar una asignación genérica precisa; aunque algunas de las características observadas (exina dividida en dos capas, exoexina translúcida con un infraretículo irregular, e intexina oscura y levigada) permiten compararla con Playfordiaspora.

Turma MONOLETES Ibrahim 1933

Supraturma ACAVATOMONOLETES Dettmann 1963 
Subturma AZONOMONOLETES Luber 1935

Infraturma LAEVIGATOMONOLETI Luber 1935

Género Laevigatosporites Ibrahim 1933

Especie tipo. Laevigatosporites vulgaris (Ibrahim) Ibrahim, 1933.

Afinidad botánica. Sphenophyta (véase Balme, 1995; Quadros et al., 1996).

\section{Laevigatosporites flexus Segroves 1970}

Lámina VI, figura I

Descripción. Espora bilateral monolete. Contorno longitudinalmente oval a subcircular por la presencia de pliegues de la exina. Lesura simple o con delicados labios, extendida hasta $3 / 4$ partes del eje longitudinal. Exina levigada, con un espesor menor a $1 \mu \mathrm{m}$.

Dimensiones (2 ejemplares). Diámetro mayor, 30-36 $\mu \mathrm{m}$; diámetro menor, 26-27 $\mu \mathrm{m}$.

Principal material estudiado. BAPal 6152 (a) R48/0. Retrabajo: BAPal 6173 (a) $\mathrm{H} 46 / 2$.

Comentarios. La naturaleza delgada y plegada de la exina, así como su contorno general permite incluir en Laevigatosporites flexus Segroves (1970, pp. 60-70, pl. 11, figs. C-D) el material aquí descripto.

Registros previos. Laevigatosporites flexus fue descripta originalmente para el Pérmico de Australia (Segroves, 1970).

- Pennsylvaniano: España: ilustrada para la sucesión Demués (Sánchez de Posada et al., 1999).

- Guadalupiano: Australia: ilustrada para Baralaba Coal Measures, Cuenca Bowen (Foster, 1979).

- Cisuraliano-Guadalupiano: Papúa: ilustrada para las formaciones Ainim y Aiduna (Playford y Rigby, 2008).

- Lopingiano-Triásico Inferior: Australia: ilustrada para la Formación Rewan, Cuenca Bowen (Foster, 1979).

Esta es la primera cita de la especie para cuencas sudamericanas.

Laevigatosporites plicatus Kar 1968 
Lámina VI, figura J

1969. Laevigatosporites plicatus Clendening, p. 264.

1970. Laevigatosporites dunkardensis Clendening, p.788.

Descripción. Espora bilateral monolete. Contorno extendido longitudinalmente, oval a subrectangular, de lados mayores rectos, lados menores convexos y ángulos redondeados. Lesura simple, extendida hasta $5 / 6$ del eje longitudinal de la espora. Exina delgada, menor a $1 \mu \mathrm{m}$ de espesor, levigada y con numerosos pliegues, en general paralelos al eje mayor, producidos por compresión.

Dimensiones (6 ejemplares). Diámetro mayor, 45(55,6)70 $\mu \mathrm{m}$; diámetro menor, 27(35,5)50 $\mu \mathrm{m}$; espesor de la exina, 0,5-1 $\mu \mathrm{m}$.

Principal material estudiado. BAPal 6149 (a) R60/0; BAPal 6152 (a) H60/1, K51/0; BAPal 6157 (a) D55/1; BAPal 6163 (a) N53/4; BAPal 6165 (a) F70/4.

Discusión. Clendening (1969) describió para Dunkard Strata (Cuenca de los Apalaches) Laevigatosporites plicatus, para esporas monoletes lisas, de contorno general oval, de 46 a $95 \mu \mathrm{m}$ de largo, y que presentan numerosos pliegues producto de la compresión. Posteriormente el mismo autor, observó que incurre en un problema de homonimia al proponer dicha especie, ya que anteriormente $\operatorname{Kar}$ (1968, pp. 120-12, pl. 1, figs. 28-29) había utilizado el mismo nombre específico. Clendening (1970, p. 778) consideró que hay diferencias significativas entre la especie por él propuesta y la propuesta por Kar, con lo que le asignó un nombre nuevo, pasando a llamarse Laevigatosporites dunkardensis. Comparando las especies nominadas por ambos autores, tanto en forma como en tamaño, se observa que no hay rasgos distintivos con los que se pueda separarlas, por lo tanto se considera que ambas podrían ser incluídas bajo una misma especie. Ambas son formas ovales y presentan pliegues generados por compresión. El rango de tamaños de L. plicatus es de 41 a $55 \mu \mathrm{m}$, siendo de 46 a $95 \mu \mathrm{m}$ para $L$. dunkardensis. Los tamaños aquí observados se encuentran entre los 45 a $70 \mu \mathrm{m}$.

Registros previos. Laevigatosporites plicatus fue descripta originalmente por Kar (1968) para la secuencia Barren Measures, Pérmico de India.

- Guadalupiano: Australia: ilustrada para Baralaba Coal Measures, Cuenca Bowen (Foster, 1979). 
- Lopingiano-Triásico Inferior: Australia: ilustrada para la Formación Rewan, Cuenca Bowen (Foster, 1979).

- Lopingiano: Antártida: presente en la Formación Buckley, central Transantarctic Mountains (Farabee et al., 1991).

Esta es la primera cita de la especie para cuencas sudamericanas.

Laevigatosporites vulgaris (Ibrahim) Ibrahim emend. Alpern y Doubinger 1973

$$
\text { Lámina VI, figura } \mathrm{K}
$$

1932. Sporonites vulgaris Ibrahim en Potonie et al., p. 448, pl. 15, fig. 16.

1933. Laevigatosporites vulgaris (Ibrahim) Ibrahim, p. 39, pl. 2, fig. 16.

1973. Laevigatosporites vulgaris (Ibrahim) Pot. Kremp, 1956 (sic) emend. Alpern y Doubinger, p. 2674, pl. 1, fig. 2.

Sinonimia adicional. Véase Raine et al. (2006).

Descripción. Espora bilateral monolete. Contorno oval, elongado longitudinalmente, de lados mayores cóncavo-convexos y extremos redondeados. Lesura simple o acompañada por delicados labios, extendida hasta 4/5 del largo de la espora. Exina delgada, de menos de $1 \mu \mathrm{m}$ de ancho, levigada, con esporádicos pliegues por compresión.

Dimensiones (3 ejemplares). Diámetro mayor, 46-57 $\mu \mathrm{m}$; diámetro menor, 33-37 $\mu \mathrm{m}$; exina, 1-1,5 $\mu \mathrm{m}$ de espesor.

Principal material estudiado. BAPal 6152 (a) V70/1; BAPal 6165 (b) T36/1; BAPal 6183 (a) W34/4.

Registros previos. Laevigatosporites vulgaris fue descripta originalmente como Sporonites vulgaris por Ibrahim para Mina Wehofer, Cuenca Ruhr, Alemania. Posteriormente Alpern y Doubinger (1973), la combinaron al género Laevigatosporites.

- Pennsylvaniano: Argentina: presente en las formaciones Jejenes, Cuenca Paganzo (González Amicón, 1973), Lagares (Menéndez y Azcuy, 1973), Malanzán (Azcuy, 1975),

- Pennsylvaniano-Cisuraliano: Argentina: presente en la Formación Sachayoj, Cuenca Chacoparaná (Vergel, 1998) e ilustrada para la Formación El Imperial, Cuenca Cuyana 
(García, 1995). Brasil: presente en Chapéu do Sol, Cuenca Paraná (Quadros et al., 1996).

- Cisuraliano: Argentina: presente en la Formación Sachayoj, Biozona Cristatisporites (Vergel, 1998). Perú: listada para el Grupo Copacabana (Doubinger y Marocco, 1981). Omán y Arabia Saudita: ilustrada para la Formación Al Khlata (Stephenson y Filatoff, 2000a). Sudáfrica: presente en la Cuenca Karroo (Anderson, 1977).

- Cisuraliano-Guadalupiano: Argentina: presente en las formaciones Victoriano Rodríguez, biozonas Cristatisporites y Striatites, Cuenca Chacoparaná (Playford y Dino, 2002). Brasil: ilustrada para la Formación Pedra do Fogo, Cuenca Parnaíba (Dino et al., 2002). Papúa: ilustrada para las formaciones Ainim y Aiduna (Playford y Rigby, 2008).

- Lopingiano: Argentina: mencionada para la Formación La Veteada, Cuenca Paganzo (Zavattieri et al., 2008).

Infraturma SCULPATOMONOLETES Dybová y Jachowicz 1957

Género Leschikisporis Potonié 1958

Especie tipo. Leschikisporis aduncus (Leschik) Potonié, 1958.

Afinidad botánica. Pteridophyta-Filicopsida, Marattiacea (véase Bharadwaj y Singh, 1956).

\section{Leschikisporis chacoparanaense Vergel 1990}

Lámina VI, figura L

Descripción. Espora bilateral monolete, de contorno general oval a subcircular y de margen suavemente ondulado por proyección de la ornamentación. Lesura simple, bien definida, frecuentemente monolete y recta a trilete marcadamente asimétrica, con uno de los rayos más cortos. Ornamentación compuesta por gránulos, dispuestos espaciada y homogéneamente. Entre los mismos se generan áreas poligonales levigadas. Exina de 1 $\mu \mathrm{m}$ de espesor.

Dimensiones (3 ejemplares). Diámetro mayor, 33-42 $\mu \mathrm{m}$; diámetro menor, 25-30 $\mu \mathrm{m}$; ornamentación, $0,5 \mu \mathrm{m}$ de ancho basal y hasta $0,5 \mu \mathrm{m}$ de alto. 
Principal material estudiado. BAPal 6143 (a) R64/0; BAPal 6188 (a) G68/3. Retrabajo: BAPal 6173 (a) S59/3.

Registros previos. Leschikisporis chacoparanaense fue descripta originalmente por Vergel (1990) para las perforaciones YPF.SE. Árbol Blanco e YPF.Ch.Gancedo, en la Cuenca Chacoparaná.

- Cisuraliano: Argentina: presente en la Formación Sachayoj, Cuenca Chacoparaná (Vergel, 1998).

- Cisuraliano-Guadalupiano: Uruguay: presente en la Formación Melo, Cuenca Paraná (Mautino et al., 1998a).

Género Phaselisporites Price 1984

Especie tipo. Phaselisporites cicatricosus (Balme y Hennelly) Price 1984.

Afinidad botánica. Pteridophyta-Filicopsida?

Phaselisporites sp. cf. P. cicatricosus (Balme y Hennelly) Price 1984

Lámina VI, figura $\mathrm{M}$

Descripción. Espora bilateral monolete, de contorno general oval con compresión polar a reñiforme en compresión lateral, con la cara distal fuertemente convexa respecto de la cara proximal. Margen irregular por la proyección de la ornamentación. Lesura recta extendida hasta el margen ecuatorial. Ornamentación compuesta por verrugas prominentes, irregulares, redondeadas, frecuentemente con sus bases en contacto. La ornamentación genera un retículo por su densa disposición. La exina es gruesa, entre 4 y $5 \mu \mathrm{m}$ de espesor.

Dimensiones (2 ejemplares). Diámetro mayor, 45-53 $\mu \mathrm{m}$; diámetro menor, 30-40 $\mu \mathrm{m}$; ornamentación, 4-6 $\mu \mathrm{m}$ de ancho basal y 2-4 $\mu \mathrm{m}$ de alto.

Principal material estudiado. BAPal 6141 (a) N41/0, T37/3.

Comparaciones. La preservación del material y su gruesa exina no permiten apreciar claramente la naturaleza de la exina, sin embargo la conspicua ornamentación verrucosa-rugulada que presenta éste material permite referirlo con dudas a Phaselisporites cicatricosus (Balme y Hennelly) Price (1984, p. 176, pl. 15, figs. 1-11). 
Género Thymospora Wilson y Venkatachala emend. Alpern y Doubinger 1973

Especie tipo. Thymospora thiesseni (Kosanke) Wilson y Venkatachala, 1963.

Comentarios. Este género incluye esporas monolete con exina ornamentada por rúgulas-verrugas separadas por vermículas que no forman retículos negativos como en Polypodiisporites Potonié emend. Khan y Martin (1971).

Afinidad botánica. Pteridophyta-Filicopsida (véase Balme, 1995; Quadros et al., 1996).

Thymospora criciumensis Quadros, Marques-Toigo y Krepzig 1996

$$
\text { Lámina VI, figuras } \mathrm{N} \text { y } \tilde{\mathrm{N}}
$$

Descripción. Espora bilateral monolete, de contorno general subcircular a oval y de margen crenulado. Lesura simple, bien definida, de hasta 1/4 de extensión respecto del eje mayor de la espora. Ornamentación vermiculada, conformando un retículo denso y oscuro. Elementos esculturales separados entre sí por delgados, profundos y sinuosos canales. Ornamentación distal más gruesa que la observada en la cara proximal.

Dimensiones (3 ejemplares). Diámetro mayor, 33-36 $\mu \mathrm{m}$; diámetro menor, 25-34 $\mu \mathrm{m}$; ornamentación, $4-5 \mu \mathrm{m}$ de base y $1 \mu \mathrm{m}$ de alto; espesor de la exina, hasta $5 \mu \mathrm{m}$.

Principal material estudiado. BAPal 6152 (a) P65/2; BAPal 6162 (a) C45/1, H56/1.

Comentarios. Los ejemplares aquí estudiados, a pesar de ser pocos, pueden referirse a la especie Thymospora cruciumensis descripta por Quadros et al. (1996: pl. 127) por presentar la característica ornamentación reticulada, densamente dispuesta, que genera un patrón negativo de canales sinuosos profundos.

Registros previos. Thymospora criciumensis fue descripta por Quadros et al. (1996) para la perforación 2-CS-1-PR, Chapéu do Sol, Cisuraliano, Cuenca Paraná. Ha sido citada como una de las especies característica de la Biozona de Lueckisporites virkkiae (Souza y Marques-Toigo, 2005; Souza, 2006).

Esta es la primera cita de la especie para la Argentina.

ALGAE

División CHLOROPHYTA Pacher 1914

Clase CHLOROPHYCEAE Kützing 1849 
Género Botryococcus Kützing 1849

Especie tipo. Botryococcus braunii Kützing, 1849.

Afinidad botánica. Chlorophyceae.

\section{Botryococcus braunii Kützing 1849}

Lámina VII, figura A, B y C

Sinonimia. Véase Raine et al. (2006).

Descripción. Alga de hábito colonial, de forma subcircular, oval a irregular, con bordes ondulados. Cada colonia está compuesta por tecas piriformes unidas a un talo común que forma el centro de la colonia.

Dimensiones (10 ejemplares). Diámetro mayor, 49-99 $\mu \mathrm{m}$; diámetro menor, 40-83 $\mu \mathrm{m}$; diámetro de teca, $30 \mu \mathrm{m}$; hasta $5 \mu \mathrm{m}$ de ancho.

Principal material estudiado. BAPal 6143 (a) F73/0; BAPal 6152 (a) D41/0; BAPal 6157 (a) G48/0; BAPal 6165 (b) O68/4; BAPal 6189 (a) N53/0.

Registros previos. Desde el Carbonífero presenta una amplio mundial (Véase Raine et al., 2006).

- Pennsylvaniano: Argentina: presente en la Formación Malanzán, Cuenca Paganzo (Gutiérrez y Limarino, 2001); listado en la Formación San Telmo, Cuenca Tarija (Pasquo et al., 2001). Brasil: ilustrada para el Subgrupo Itararé, Cuenca Paraná (Marques-Toigo et al., 1989; di Pasquo et al., 2003a).

- Pennsylvaniano-Guadalupiano: Argentina: presente en las biozonas PotonieisporitesLundbladispora, Cristatisporites y Striatites, Cuenca Chacoparaná (Césari et al., 1995).

- Cisuraliano: Uruguay: ilustrada para la Formación San Gregorio (Beri et al., 2006), Cuenca Paraná. Brasil: ilustrada para el Subrupo Itararé, Cuenca Paraná (Dias, 1993; Souza y Callegari, 2004).

- Cisuraliano-Guadalupiano: Uruguay: ilustrada para la Formación Melo (Mautino et al., 1998b), Cuenca Paraná.

- Guadalupiano: Australia: ilustrada para Baralaba Coal Measures, Cuenca Bowen (Foster, 1979). 
- Lopingiano-Triásico Inferior: Australia: ilustrada para Formación Rewan, Cuenca Bowen (Foster, 1979).

Género Brazilea Tiwari y Navale 1967

Especie tipo. Brazilea puntata Tiwari y Navale, 1967.

Comentario. Se coincide con Foster (1979) y Yi (1997), quienes consideran a Psilochizosporites (Jain, 1968) como un sinónimo junior de Brazilea.

\section{Brazilea scissa (Balme y Hennelly) Foster 1975}

Lámina VII, figura D

1956b. Laevigatosporites scissus Balme y Hennelly, p. 56, pl. 1, figs. 6-9.

1975. Brazilea scissus (Balme y Hennelly) Foster, pp. 156-157, pl. 8, figs. 12-13.

Sinonima adicional. Véase Foster (1979).

Descripción. Cuerpo subcircular a irregular, dado por la compresión y ruptura del mismo. Contorno liso. Exina lisa y delgada (menor al micrón de espesor). Fisura hemisférica que divide irregularmente al cuerpo en dos valvas.

Dimensiones (3 ejemplares). Diámetro mayor, 32-54 $\mu \mathrm{m}$; diámetro menor, 32-43 $\mu \mathrm{m}$; exina, $0,5 \mu \mathrm{m}$ de ancho.

Principal material estudiado. BAPal 6152 (a) O41/1, P64/3; BAPal 6162 (b) F56/3.

Registros previos. Brazilea scissa (Balme y Hennelly) Foster fue descripta originalmentte para Greata seam, Hebburn No 2 Colliery, Greta Coal Measures, Pérmico de Australia (Balme y Hennelly, 1956).

- Pennsylvaniano: Argentina: listada para las formaciones Guandacol y Tupe (Ottone, 1991); ilustrada para la Formación Agua Colorada (Vergel et al., 1993) y presente en la Formación Malanzán (Gutiérrez y Limarino, 2001), todas en el ámbito de la Cuenca Paganzo. Listada en la Formación San Telmo, Cuenca Tarija (di Pasquo et al., 2001). Brasil: ilustrada para el Subgrupo Itararé, Cuenca Paraná (di Pasquo et al., 2003a).

- Pennsylvaniano-Cisuraliano: Argentina: presente en la Cuenca Chacoparaná (Archangelsky y Gamerro, 1979).

- Cisuraliano: Argentina: ilustrada en la Formación Tupe (miembro cuspidal), Cuenca Paganzo (Vergel, 2008). Uruguay: ilustrada para la Formación San Gregorio (Beri et 
al., 2006), Cuenca Paraná. Brasil: ilustrada para el Subgrupo Itararé (Dias, 1993), Cuenca Paraná. Australia: presente en Blair Athol Coal Measures (Foster, 1975) y Formación Stockton y Collie Coal Measures, Cuenca Collie (Backhouse, 1991). Arabia Saudita: listada para la Khuff (Stephenson y Filatoff, 2000b, 2003). Antártida: listada para Milorgfjella, Dronning Maud Land (Larsson et al., 1990; Lindström, 1995). Perú: listada para el Grupo Copacabana (Doubinger y Marocco, 1981).

- Cisuraliano-Guadalupiano: Argentina: listado para la perforación YPF.Puelches X-1, Cuenca Claromecó-Colorado (Archangelsky y Gamerro, 1980b). Presente en la Cuenca Chacoparaná (Vergel, 1987b; Césari et al., 1995). Uruguay: ilustrada para la Formación Melo (Mautino et al., 1998b), Cuenca Paraná. Brasil: ilustrada para la Formación Rio Bonito (Burjack, 1978; Smaniotto et al., 2006), Cuenca Paraná.

- Guadalupiano: Australia: ilustrada para Baralaba Coal Measures, Cuenca Bowen (Foster, 1979).

- Lopingiano-Triásico Inferior: Australia: ilustrada para la Formación Rewan, Cuenca Bowen (Foster, 1979).

Brazilea sp A Playford y Dino 2000b

Lámina VII, figura $\mathrm{E}$

1977. Inaperturosporites inapertus Anderson, p. 78, pl. 75, figs. 6-19.

1978. Inapertisporites inapertus van der Hammen por Falcon, p. 19, pl. 3, fig. 6.

1995. Cycadopites alhuampai Césari et al., p. 97, pl. VIII, fig. 59.

Descripción. Cuerpo oval de contorno liso. Exina lisa, de una capa, muy delgada y generalmente plegada. Rotura hemisférica de hasta $3 / 4$ de extensión respecto del radio mayor. La misma se halla generalmente acompañada por pliegues exinales.

Dimensiones (3 ejemplares). Diámetro mayor, 70-72 $\mu \mathrm{m}$; diámetro menor, 43-60 $\mu \mathrm{m}$; exina, $0,5 \mu \mathrm{m}$ de espesor.

Principal material estudiado. BAPal 6152 (a) L39/0; BAPal 6152 (e) M51/3; BAPal 6156 (b) B46/2.

Comentarios. Los ejemplares aquí estudiados son similares en características generales y tamaño con los asignados e ilustrados a la especie Brazilea sp. A por Playford y Dino (2000b, pp. 118-119, pl. 14, figs. 2, 3). A su vez, Vergel (1987a, pp. 75-76, lám. II, fig. 
27) describió e ilustró B. scissus para varias perforaciones de la Cuenca Chacoparaná, similares en forma y tamaño, con lo que corresponderían a la misma especie. Cycadopites alhuampai descripta por Césari et al. (1995, p. 97, pl. VIII, fig. 59) presenta similares características a las descriptas por Playford y Dino (2000b), por lo que también se podría considerar la misma especie. Lo mismo sucede para parte del material ilustrado por Anderson (1977, p. 78, pl. 75, figs. 6-19) como Inaperturosporites inapertus Anderson, que fuera combinado al género Inapertisporites van der Hammen por Falcon (1978, p. 19, pl. 3, fig. 6).

Registros previos. Brazilea sp A Playford y Dino (2000b) fue descripta para las formaciones Itaituba y Nova Olinda, Pennsylvaniano-Cisuaraliano de la Cuenca Amazonas.

- Pennsylvaniano-Cisuraliano: Argentina: presente en la Cuenca Chacoparaná (Vergel, 1987; Césari et al., 1995).

- Cisuraliano: Sudáfrica: presente en la Cuenca Karroo (Anderson, 1977).

$$
\text { División PRASINOPHYTA Round } 1971
$$

Género Leiosphaeridia Eisenack emend. Downie y Sarjeant 1963 Especie tipo. Leiosphaeridia baltica Eisenack, 1958.

\section{Leiosphaeridia crescentica Sinha 1969}

Lámina VII, figura F

Descripción. Cuerpo circular a suboval, deformación dada por compresión, de contorno suavemente ondulado. Exina delgada, lisa, hialina, presentando series de 2 a 4 pliegues concéntricos ubicados próximos al margen.

Dimensiones (4 ejemplares). Diámetro mayor, 41-70 $\mu \mathrm{m}$; diámetro menor, 29-48 $\mu \mathrm{m}$; exina, $0,5 \mu \mathrm{m}$ de espesor.

Principal material estudiado. BAPal 6145 (a) N66/4; BAPal 6152 (a) D42/2, F73/0, O56/2.

Comentarios. Los ejemplares aquí estudiados son referidos a la especie Leiosphaeridia crescentica descripta por Sinha (1969: p. 328, pl. 1, figs. 14 y 15) por presentar los 
caracteres diagnósticos de la especie: forma subcircular deformada por compresión, exina hialina, con pliegues concéntricos marginales.

Registros previos. Leiosphaeridia crescentica fue descripta orignalmente por Sinha (1969) para Singrauli Coalfield, Barakar Stage, Cisuraliano de India.

Esta es la primera cita de la especie para la Argentina.

Leiosphaeridia talchirensis Lele y Karim 1971

Lámina VII, figura G

2006. Leiosphaeridia sp. Beri et al., p. 241, fig. 4.O.

2006. Leiosphaeridia sp. Smaniotto et al., pp. 318-319, fig. 5.P.

Descripción. Cuerpo circular a subcircular de margen liso. Exina delgada y lisa, con pliegues en número variable y de forma semilunar, irregularmente dispuestos sobre toda la superficie.

Dimensiones (10 ejemplares). Diámetro, 21(25,2)38 $\mu \mathrm{m}$; exina, 0,5-1 $\mu \mathrm{m}$ de espesor.

Principal material estudiado. BAPal 6152 (a) J68/2, G55/3, S36/0, D39/0, D63/3; BAPal 6162 (b) J58/4. Retrabajo: BAPal 6173 (a) D52/3.

Comentarios. Esta especie se caracteriza por presentar una exina delgada lisa con numerosos pliegues en forma semilunar que se distribuyen en forma irregular (Lele y Karim, 1871) rasgos que permiten diferenciarla de L. crescentica Sinha (1969). Leiosphaeridia sp. descripto por Beri et al. (2006, p. 241, fig. 4.O) y Leiosphaeridia sp. descripta por Smaniotto et al. (2006, pp. 318-319, fig. 5.P) son incluidas en $L$. talchirensis porque exhiben el mismo tipo de patrón de distribución de los pliegues y el mismo tipo de pared exinal.

Registros previos. Leiosphaeridia talchirensis fue descripta originalmente por Lele y Karim (1971) para Jayanti Coalfield, Bihar, India.

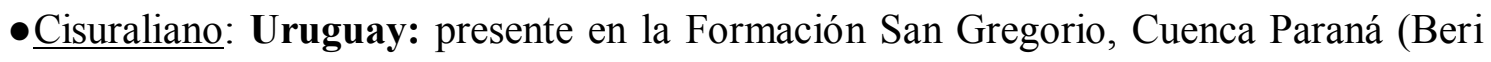
et al., 2006). Brasil: presente en la parte superior del Subgrupo Itararé, Cuenca Paraná (Smaniotto et al., 2006). India: ilustrada para la Formación Talchir (Kunguriano), Manendragarh, Madhya Pradesh (Bharadwaj et al., 1979; Lele, 1975).

Esta es la primera cita de la especie para la Argentina. 


\section{INCERTAE SEDIS}

Género Pilasporites Balme y Hennelly 1956a

Especie tipo. Pilasporites calculus Balme y Hennelly, 1956a.

\section{Pilasporites sp. B Stephenson y Osterloff 2002}

Lámina VII, figura $\mathrm{H}$

Descripción. Cuerpo esférico de contorno circular a subcirular, de margen sinuoso. Exina de 2-3 $\mu \mathrm{m}$ de espesor, plegada y puncteada. Las punctuaciones se observan claramente en el ecuador, atraviesan toda la pared y se distribuyen irregularmente. Tienen un diámetro menor a $0,5 \mu \mathrm{m}$.

Dimensiones (1 ejemplar). Diámetro mayor, $72 \mu \mathrm{m}$; diámetro menor, $61 \mu \mathrm{m}$. Principal material estudiado. BAPal 6185 (a) E31/1.

Comparaciones $\mathbf{y}$ registros previos. El ejemplar estudiado presenta marcadas coincidencias con el descripto como Pilasporites sp. B por Stephenson y Osterloff (2002, p. 18, pl. 10, figs. 8-9, 12; Formación Gharif, Cisuraliano de Omán) y con el descripto por Beri et al. (2006, p. 242, fig. 4.A; Cisuraliano de Uruguay). A pesar de contar con un sólo ejemplar y con una regular preservación es posible referirla a la forma descripta por Stephenson y Osterloff (2002), aunque la mismas características impiden avanzar en una asignación específica.

Género Portalites Hemer y Nygreen 1967

Especie tipo. Portalites confertus Hemer y Nygreen, 1967.

Portalites gondwanensis Nahuys, Alpern e Ybert 1968

Lámina VII, figura I

Descripción. Cuerpo circular a levemente oval. Exina gruesa y dividida en 2 capas, generalmente plegada. Escultura compuesta por verrugas irregulares, redondeadas y densamente dispuestas, que le otorgan un aspecto esponjoso. En la pared de cuerpo se 
observa un poro subcircular, entre 1 y $2 \mu \mathrm{m}$ de diámetro, que conecta ambas capas de la exina.

Dimensiones (7 ejemplares). Diámetro del cuerpo, 28(42)48 $\mu \mathrm{m}$; Sexina, 2-6 $\mu \mathrm{m}$ de espesor.

Principal material estudiado. BAPal 6148 (a) H66/0; BAPal 6152 (a) P66/1; BAPal 6184 (b) U32/4; BAPal 6185 (b) O30/3; BAPal 6187 (b) K53/0; BAPal 6189 (a) L57/0. Redepósito: BAPal 6173 (a) P57/3.

Registros previos. Originalmente descripto para el Cisuraliano de Brasil (Nahuy et al., 1968).

- Pennsylvaniano: Argentina: presente en las formaciones Guandacol (Vázquez Nístico y Césari, 1987; Césari y Vázquez Nístico, 1988); Tupe (Césari 1986a; Ottone, 1991) y Estratos de Mascasín (Pérez Loinaze y Césari, 2004), todas en el ámbito de la Cuenca Paganzo. Brasil: listada para la Formación Rio do Sul, Subgrupo Itararé, Cuenca Paraná (Marques-Toigo et al., 1989).

- Pennsylvaniano-Cisuraliano: Argentina: presente en Cuenca Chacoparaná (Vergel, 1987a, 1987b; Césari et al., 1995).

- Cisuraliano: Argentina: presente en las formaciones Tasa Cuna, Cuenca Paganzo (Balarino y Gutiérrez, 2006) y Río Genoa, Cuenca Tepuel-Genoa (Gutiérrez et al., 2007). Uruguay: presente en las formaciones Tres Islas (Beri, 1988) y San Gregorio (Beri et al., 2006), Cuenca Paraná. Brasil: presente en las formaciones Nova Olinda y Andirá; biozonas Raistrickia cephalata, Vittatina costabilis, Tornopollenites toreus, del Grupo Trapajós, Cuenca Amazonas (Playford y Dino, 2000b). Ilustrada para el Subgrupo Itararé; Biozona Vittatina costabilis, sub-biozona Protohaploxypinus goraiensis, Cuenca Paraná (Dias, 1993; Souza y Callegari, 2004). Omán y Arabia Saudita: ilustrada para la Formación Al Khlata (Stephenson y Filatoff, 2000a).

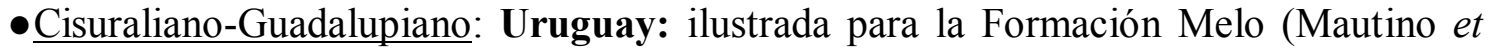
al., 1998b), Cuenca Paraná.

Anteturma CRYPTOSPORITES Richarson, Ford y Parker 1984

Turma TETRASPORITES Ströther 1991

Subturma TETRADYMOSPORITES Ströther 1991 
Género Quadrisporites Hennelly ex Potonié y Lelé 1961

Especie tipo. Quadrisporites horridus Hennelly ex Potonié y Lele 1961.

Quadrisporites granulatus (Cramer) Stöther 1991

Lámina VII, figura J

1967. Disectispora lobata Tiwari y Navale, p. 598, pl. 4, figs. 68-72.

1975. Quadrisporites lobatus (Tiwari y Navale) Ybert, p. 203, pl. 8, ph. 132-133.

Sinonima adicional. Véase Amenábar et al. (2006).

Descripción. Tétrada tetragonal formada por cuatro individuos unidos entre sí en un mismo plano. Individuos de forma subcircular a irregular, 2 de ellos mas grandes respecto del resto. Los mismos se disponen de manera apretada, cerrando el espacio central. Exina delgada, de menos de $1 \mu \mathrm{m}$ de espesor, lisa o finamente granulada, plegada, por la compresión de los individuos entre sí.

Dimensiones (3 ejemplares). Diámetro total, 40-60 $\mu \mathrm{m}$; diámetro de los individuos, 20$32 \mu \mathrm{m}$; espesor de la exina, $0,5 \mu \mathrm{m}$.

Principal material estudiado. BAPal 6152 (a) H37/1; BAPal 6152 (b) J68/1; BAPal 6163 (a) R36/4.

Registros previos. Quadrisporites granulatus (Cramer) Stöther 1991 presenta una amplia distribución estratigráfica, comprendida entre el Silúrico Superior y el Pérmico (véase Amenábar et al., 2006, p. 352).

Turma ALETES Ibrahim 1933

Subturma AZONALETES Luber emend. Potonié y Kremp 1954

Infraturma RETICULONAPITI Erdtman ex Vimal 1952

Género Maculatasporites Tiwari 1964

Especie tipo. Maculatasporites indicus Tiwari, 1964.

Maculatasporites minimus Segroves 1967

Lámina VII, figura K 
Descripción. Espora alete, de contorno circular a poligonal. Exina gruesa, de $4 \mu \mathrm{m}$ de ancho. Ornamentación compuesta por muros que conforman un retículo irregular, el cual se proyecta en la línea ecuatorial. Las celdas generadas por el retículo son poligonales.

Dimensiones (1 ejemplar). Diámetro, 28(42)48 $\mu \mathrm{m}$; muros, 2-3 $\mu \mathrm{m}$ de ancho basal y menor a $1 \mu \mathrm{m}$ de alto; espeso de la exina, $4 \mu \mathrm{m}$.

Principal material estudiado. BAPal 6187 (a) U60/3.

Comentarios. A pesar de haber sido hallado un solo ejemplar, el mismo presenta las caracteristicas diagnósticas de la especie Maculatasporites minimus. Estas son: el contorno circular a poligonal y la ornamentación de retículo irregular.

Registros previos. Maculatasporites minimus fue descripta originalmente por Segroves (1967) para la Formación Carynginia (Artinskiano), Cuenca Perth, Australia.

- Cisuraliano: Australia: presente en la Formación Carynginia, Cuenca Perth (Segroves, 1967, 1972) e ilustrada para la Formación Stockton y Collie Coal Measures, Cuenca Collie (Backhouse, 1991).

Esta es la primera cita de la especie para cuencas sudamericanas.

Género Cymatiosphaera Wetzel 1933 emend. Deflandre 1954

Especie tipo. Cymatiosphaera radiata (Wetzel) Deflandre 1954.

Cymatiosphaera gondwanensis (Tiwari) Backhouse 1991

Lámina VII, figura L

1965. Maculatasporites gondwanensis Tiwari, p. 205, pl. 8, figs. 191-192.

1977. Mehlisphaeridium gondwanensis (Tiwari) Anderson (pars), p. 5, pl. 2, figs. 24$34,44$.

Sinonimia adicional. Véase Backhouse (1991) y Playford y Rigby (2008).

Comentario. Originalmente esta especie fue asignada al género Maculatasporites Tiwari (Tiwari, 1965) y posteriormente combinada por Anderson (1977) al género Mehlisphaeridium Segroves (1967). Es Backhouse (1991) quien combinó a la especie 
dentro del género Cymatiosphaera por presentar ésta forma delgados y membranosos muros, distinguibles de los anchos y gruesos muros de Maculatasporites.

Descripción. Espora alete, de contorno circular a levemente oval, y margen con suaves ondulaciones. Exina separada en 2 capas. Intexina raramente separada de la exoexina, de menos de $1 \mu \mathrm{m}$ de espesor, más oscura. Exoexina reticulada, con muros de $1 \mu \mathrm{m}$ de ancho y 5 a $6 \mu \mathrm{m}$ de largo, que definen lúminas irregulares poligonales, de hasta $10 \mu \mathrm{m}$ de diámetro. Cíngulo ecuatorial, de ancho irregular, de 2,5 a $5 \mu \mathrm{m}$, claro.

Dimensiones (5 ejemplares). Diámetro, 20(31,4)49 $\mu \mathrm{m}$; muros, 1-2 $\mu \mathrm{m}$ de base y de hasta $6 \mu \mathrm{m}$ de largo; cíngulo, 2,5 a $5 \mu \mathrm{m}$; espesor de la exina, 2-6 $\mu \mathrm{m}$.

Principal material estudiado. BAPal 6146 (a) U62/0; BAPal 6152 (a) S60/0, E65/0; BAPal 6155 (a) E53/4; BAPal 6168 (a) V50/3.

Comentarios. Di Pasquo (2003) listó, sin descripción ni ilustración, Cymatiosphaera gondwanensis para los grupos Macharetí y Mandiyutí, Cuenca Tarija, del Pennsylvaniano. Este sería el registro más antiguo para la especie confirmando su presencia en Carbonífero Superior, por lo que no teniendo elementos para la comparación, tanto la asignación como la distribución son considerada con dudas para dichas rocas.

Parte del material descripto por Anderson (1977, p. 5, pl. 2, figs. 24-34, 44) como Mehlisphaeridium gondwanensis (Tiawari) Anderson es incluido en Cymatiosphaera gondwanensis, por las característica de la exina y su escultura.

Registros previos. Cymatiosphaera gondwanensis (Tiwari) Backhouse fue descripta para el Cisuraliano de Barakar Stage, India (Tiwari, 1965).

- Cisuraliano: Antártida: ilustrada para Vestfjella, Dronning Maud Land (Lindström, 1995, 1996, 2005). India: ilustrada para Barakar Stage (Sinha, 1969).

- Cisuraliano-Guadalupiano: Uruguay: presente en la Formación Melo, Cuenca Paraná (Mautino et al., 1998b). Papúa: descripta para las formaciones Ainim y Aiduna (Playford y Rigby, 2008).

- Guadalupiano: Australia: presente en Baralaba Coal Measures, Cuenca Bowen (Filatoff, 1972; Foster, 1979).

- Lopingiano-Triásico Inferior: Australia: presente en la Formación Rewan, Cuenca Bowen, (Filatoff, 1972; Foster, 1979).

Esta es la primera cita de la especie para la Argentina. 
Anteturma VARIEGERMINANTES Potonié 1970

Turma SACCITES Erdtman 1947

Subturma MONOSACCITES Chitaley emend. Potonié y Kremp 1954

Infraturma DIPOLSACCITI Hart emend. Dibner 1971

Subinfraturma APERTACORPINI Dibner 1971

Género Cannanoropollis Potonié y Sah 1960

Especie tipo. Cannanoropollis janakii Potonié y Sah, 1960.

Afinidad botánica. Gimnospermas-Coniferopsida (véase Archangelsky y Cúneo, 1987;

Balme, 1995).

Cannanoropollis sp. cf. C. densus (Lele) Bose y Maheshwari 1968

Lámina VIII, figura A

Descripción. Grano de polen monosacado, de simetría radial, de contorno general circular a subcircular dado por la deformación. Cuerpo central de de contorno definido, y exina oscura. Saco de ancho constante, de adherencia proximal ecuatorial y distal subecuatorial. La zona de adherencia es de ancho irregular. Sexina del saco infrareticulada, conformando muros irregulares en forma y ancho que delimitan lúminas irregulares que marcan tenues pliegues radiales.

Dimensiones (2 ejemplares). Ancho total, 72-85 $\mu \mathrm{m}$; ancho del cuerpo, 40-42 $\mu \mathrm{m}$; ancho del saco sobre cara proximal, $15-16 \mu \mathrm{m}$.

Principal material estudiado. BAPal 6153 (a) Q68/0; BAPal 6169 (a) L42/2.

Comentarios. La pobre preservación de los ejemplares estudiados impide una asignación específica. Sin embargo, características tales como la simetría radial y el cuerpo central más oscuro que el saco permiten compararlos con la especie Cannanoropollis densus (Lele) Bose y Maheshwari (1968). 
Lámina $\mathrm{V}$ 


\section{Lámina V}

A y B. Kraeuselisporites apiculatus Jansonius 1962, BAPal 6157 (a) U56/0 (X 650); $\mathrm{V} 55 / 0$ (X 650).

C. Kraeuselisporites punctatus Jansonius 1962, BAPal 6159 (a) D59/4 (X 700).

D. Cristatisporites chacoparanaensis Ottone 1989, BAPal 6187 (b) L52/0 (X 850).

E. Cristatisporites sp. cf. C. inconstans Archangelsky y Gamerro 1979, BAPal 6187(a) N44/0 (X 850).

F. Cristatisporites menendezi (Menéndez y Azcuy) Playford 1978, BAPal 6186(a) W70/1 (X 750).

G. Cristatisporites rollerii Ottone 1989, BAPal 6187 (b) G49/2 (X 450).

H. Cristatisporites rollerii Ottone 1989, BAPal 6187 (b) G49/2(X 1000).

I y L. Lundbladispora braziliensis (Pant y Srivastava) Marques-Toigo y Pons emend. Marques-Toigo y Picarelli 1985, BAPal 6189 (a) U70/3 (X 600); BAPal 6183 $\mathrm{R} 36 / 0$ (X 400)

J y K. Gondisporites serrulatus Césari, Archangelsky y Seoane 1995, BAPal 6188 (a) $\mathrm{Q} 64 / 2(55 \mu \mathrm{m})$.

M y N. Lundbladispora iphilegna Foster 1979, BAPal 6185 (a) W40/3 (X 700).

Ñ. Lundbladispora riobonitensis Marques-Toigo y Picarelli 1985, BAPal 6187 (a) T57/0 (X 700). 

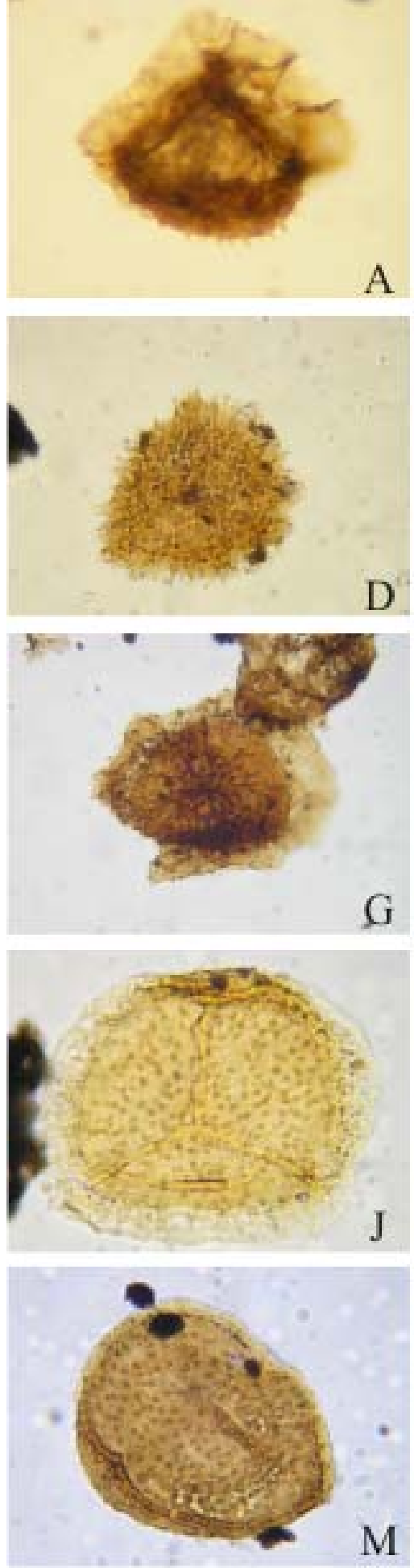
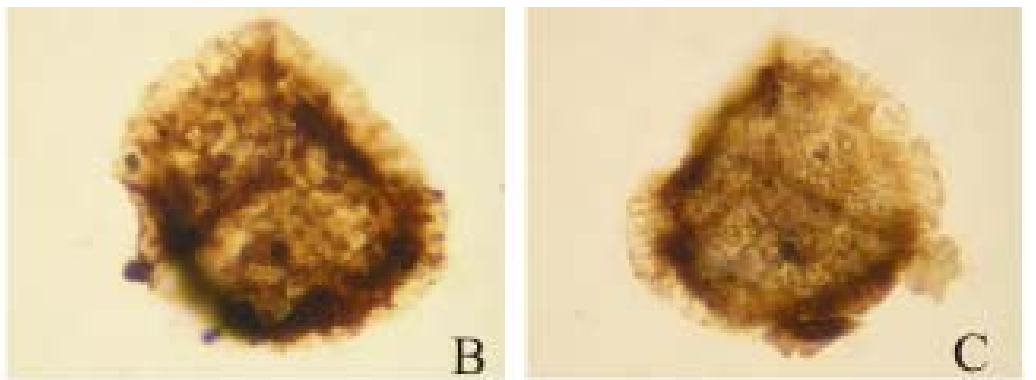

E
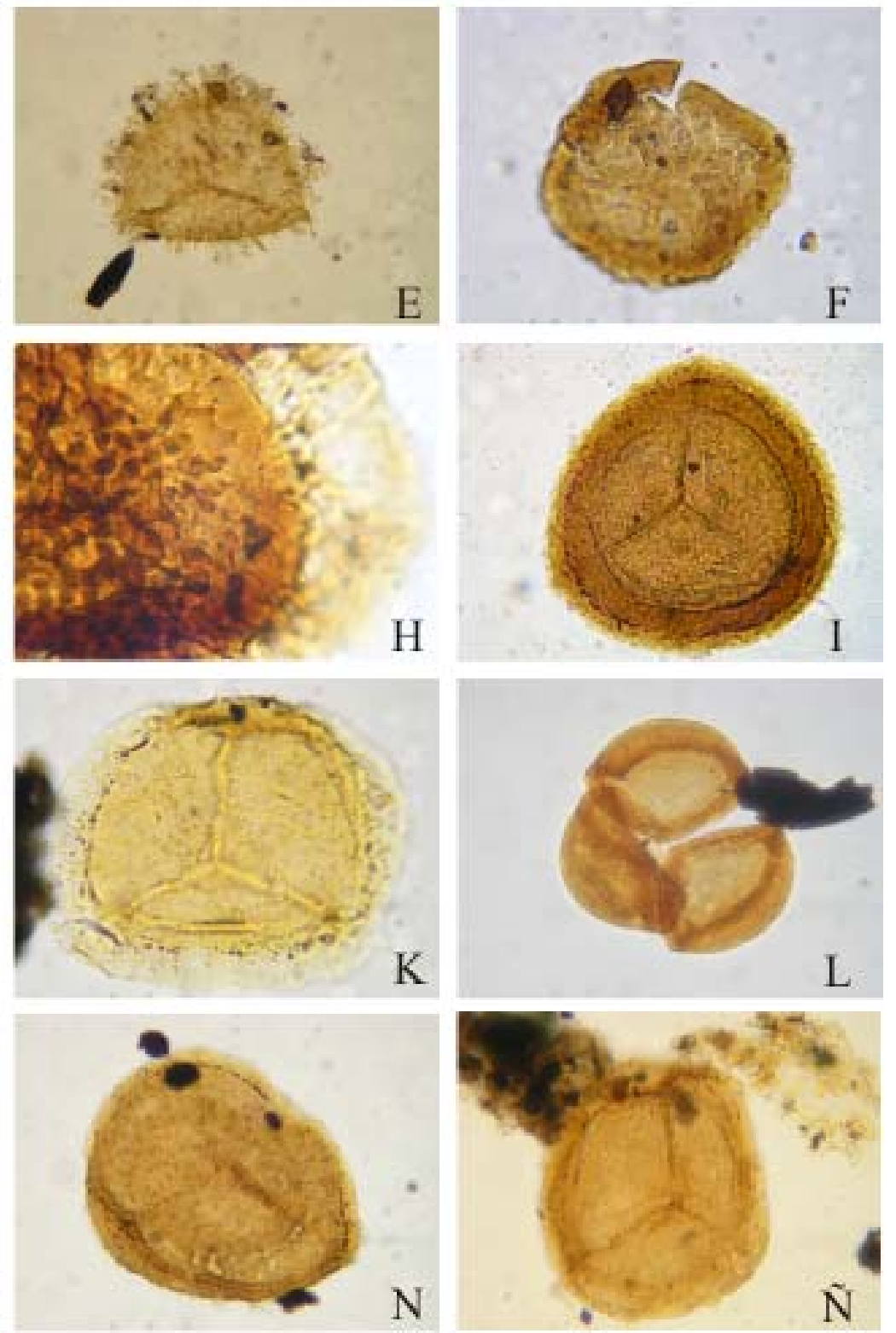
Lámina VI 


\section{Lámina VI}

A y B. Lundbladispora willmotti Balme 1963, BAPal 6185(a) N32/4 (42 $\mu \mathrm{m})$.

C. Vallatisporites arcuatus (Marques-Toigo) Archangelsky y Gamerro 1979, BAPal 6183 (a) P28/0 (X 700).

D y E. Indotriradites reidii Foster 1979, BAPal 6185(b) P43/2 (X 600).

F. cf. Playfordiaspora sp., BAPal 6149 (a) T68/0 (X 650).

G y H. Spelaeotriletes triangulus Neves y Owens 1966, BAPal 6185 (b) Y41/2 (X 700).

I. Laevigatosporites flexus Segroves 1970, BAPal 6152 (a) R48/0 (X 700).

J. Laevigatosporites plicatus Kar 1968, BAPal 6152 (a) H60/1, K51/0 (X 700).

K. Laevigatosporites vulgaris (Ibrahim) Ibrahim emend. Alpern y Doubinger 1973, BAPal 6183 (a) W34/4 (X 700).

L. Leschikisporis chacoparanaense Vergel 1990, BAPal 6173 (a) S59/3 (X 650).

M. Phaselasporites sp. cf. P. cicatricosus (Balme y Hennelly) Price 1984, BAPal 6141 (a) N41/0 (X 650).

N y $\mathbf{N}$. Thymospora criciumensis Quadros, Marques-Toigo y Krepzig 1996, BAPal 6162 (a) C45/1 (X 650); 6152 (a) P65/2 (X 650). 

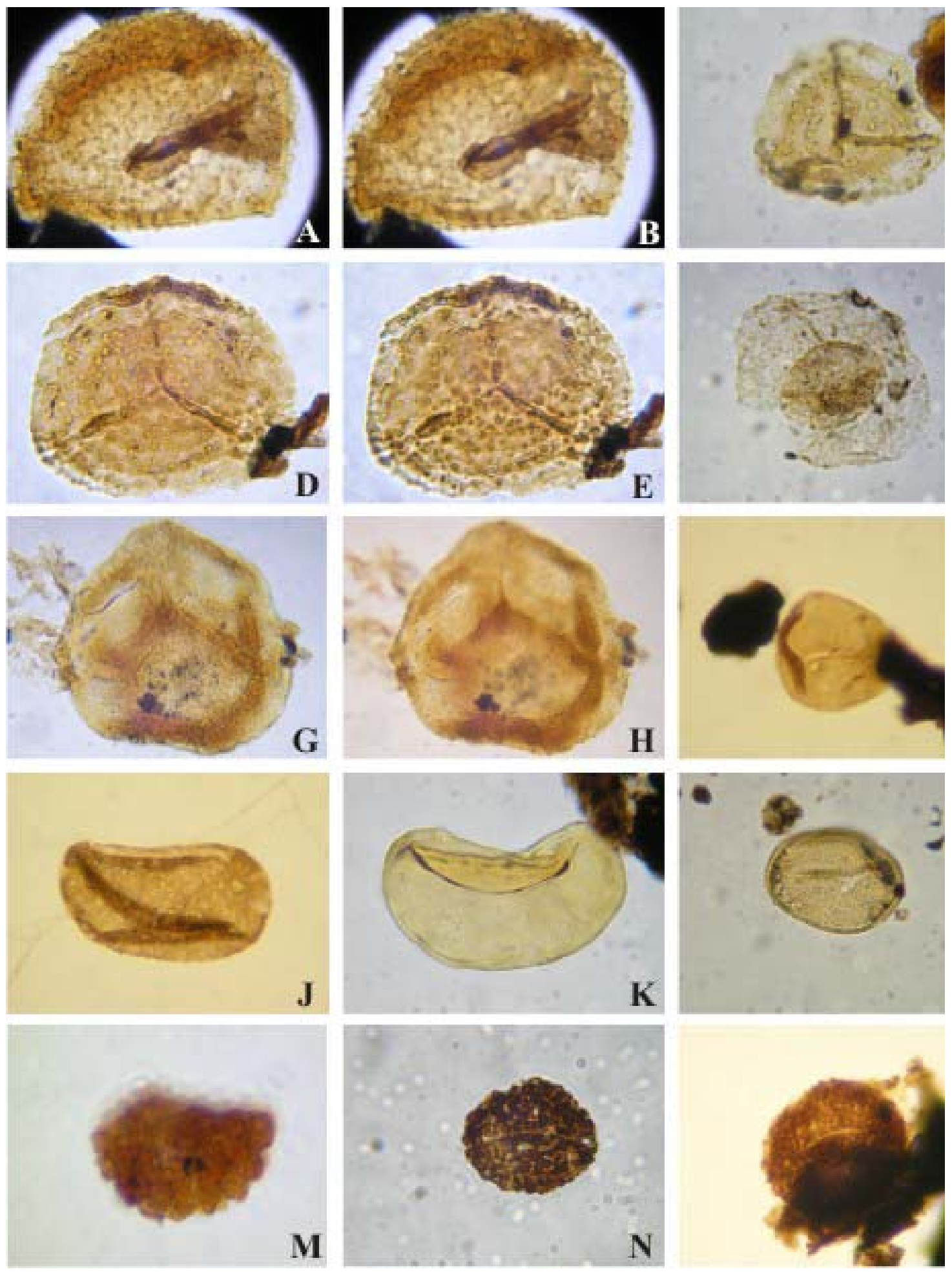
Lámina VII 


\section{Lámina VII}

A, B y C. Botryococcus braunii Kützing 1849, BAPal 6189 (a) N53/0 (X 350) (X 500).

D. Brazilea scissa (Balme y Hennelly) Foster 1975, BAPal 6162 (b) F56/3 (X 700).

E. Brazilea sp. A Playford y Dino 2000b, BAPal 6152 (a) G49/a (X 600).

F. Leiosphaeridia crescentica Sinha 1969, BAPal 6152 (a) D42/2 (X 750).

G. Leiosphaeridia talchirensis Lele y Karim 1971, BAPal 6152 (a) G55/3 (X 650).

H. Pilasporites sp. B Stephenson y Osterloff 2002, BAPal 6185(a) E31/1 (X 600).

I. Portalites gondwanensis Nahuys, Alpern e Ybert 1968, BAPal 6184 (b) U32/4 (X 700).

J. Quadrisporites granulatus (Cramer) Stöther 1991, BAPal 6163 (a) R36/4 (X 750).

K. Maculatasporites minimus Segroves 1967, BAPal 6187(a) U60/3 (X 700).

L. Cymatiosphaera gondwanensis (Tiwari) Backhouse 1991, BAPal 6168 (a) V50/3 (X $600)$. 

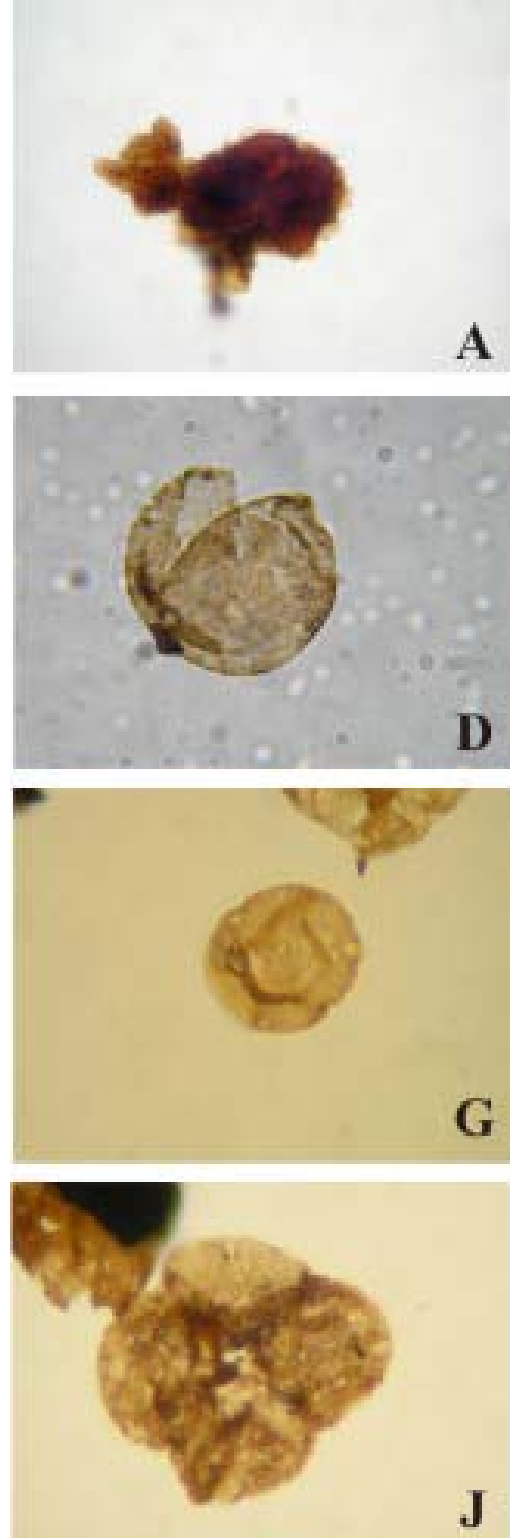
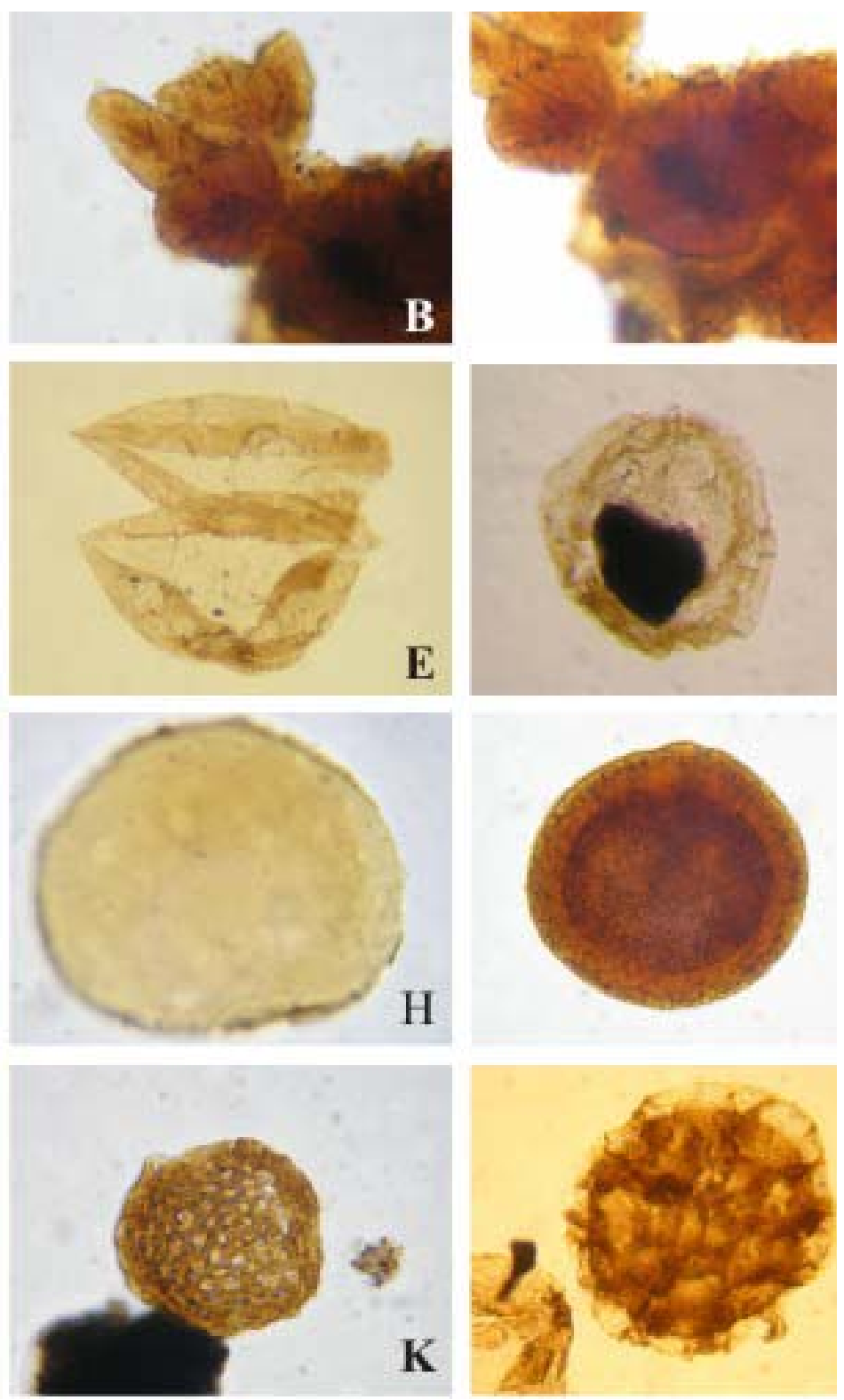
Cannanoropollis janakii Potonié y Sah 1960

Lámina VIII, figura B

Sinonimia. Véase Foster (1979).

Descripción. Grano de polen monosacado, de simetría radial, de contorno general circular y margen ondulado. Cuerpo central de contorno pobremente definido y de exina delgada, que le otorga una coloración más clara que la del saco. Marca trilete poco visible, de ramas rectas que alcanzan por lo menos $1 / 2$ del radio del cuerpo central. Saco de ancho constante, de adherencia proximal ecuatorial y distal subecuatorial. La zona de adherencia es de ancho irregular. Sexina del saco infrareticulada, conformando muros irregulares en forma y ancho que delimitan lúminas irregulares que marcan tenues pliegues radiales.

Dimensiones (4 ejemplares). Ancho total, 55(103,6)144 $\mu \mathrm{m}$; ancho del saco sobre cara proximal, 11,6(21,4)37 $\mu \mathrm{m}$; ancho del saco sobre cara distal, 12(14,6)20 $\mu \mathrm{m}$.

Principal material estudiado. BAPal 6143 (a) H43/0; BAPal 6152 (a) H73/2, L42/3; BAPal 6156 (a) U65/0; BAPal 6156 (b) T66/0; BAPal 6158 (a) K40/2.

Comentarios. Si bien algunos de los ejemplares estudiados son un poco más chicos que el límite inferior de rangos al que se refieren Foster (1979) y Gutiérrez (1993): $75(96) 117 \mu \mathrm{m}$ y $85(100-120) 130 \mu \mathrm{m}$ respectivamente, características tales como la forma del cuerpo, espesor de la pared del mismo y la marca trilete levemente distinguible, de ramas rectas y de $1 / 2$ del largo del radio del cuerpo, permiten asignarlos sin dudas a la especie Cannanoropollis janakii.

Registros previos. Cannanoropollis janakii fue definida originalmente sobre la base de ejemplares redepositados en el Mio-Plioceno de la India (Potonié y Sah, 1960).

- Pennsylvaniano: Argentina: mencionada para las Formaciones Guandacol (Ottone y Azcuy, 1990; Ottone, 1991), Tupe (Ottone, 1991) y Malanzán (Gutiérrez y Limarino, 2001), y presente en las formaciones Agua Colorada, Sierra de Famatina (Gutiérrez, 1993) y Guandacol (Ottone y Azcuy, 1989), y en los Estratos de Mascasín (Pérez Loinaze y Césari, 2004), todas de Cuenca Paganzo. Presente en la Formación San Telmo, Cuenca Tarija (Azcuy y di Pasquo, 2000; di Pasquo et al., 2001). Brasil: mencionada para el Subgrupo Itararé, Cuenca Paraná (di Pasquo et al., 2003b; Souza et al., 2003; Souza, 2006); ilustrada para la Formación Monte Alegre, del Grupo Trapajós, 
Cuenca Amazonas (Melo y Loboziak, 2003, playford y Dino, 2000b). Perú: presente en la Formación Tarma, Pongo de Mainique (Azcuy et al., 2002). Libia: Ilustrada por Brugman et. al. (1985).

- Pennsylvaniano-Cisuraliano: Australia: presente en el Grupo Joe Joe, Cuenca Galilee (Jones y Truswell, 1992).

- Cisuraliano: Argentina: presente en las formaciones Bajo de Véliz (Gutiérrez y Césari, 2000) y Tasa Cuna (Balarino y Gutiérrez, 2006), Cuenca Paganzo; y en la Formación Victoriano Rodríguez, Biozona Cristatisporites, Cuenca Chacoparaná (Playford y Dino 2002). Uruguay: presente en la Formación San Gregorio (Gutiérrez et al., 2006b), Cuenca Paraná. Brasil: mencionada para el Subgrupo Itararé, Cuenca Paraná (Souza y Callegari, 2004). Paraguay: ilustrada para la Formación Tacuary, Grupo Independencia, Cuenca Chacoparaná (Muff et al., 1999). Antártida: presente en Dronning Maud Land (Lindström, 1995, 2005). Australia: ilustrada para la Formación Fossil Cliff, Cuenca Perth (Foster et al., 1984). Arabia Saudita: mencionada para la Formación Khuff (Stephenson y Filatoff, 2003). Sudáfrica: presente en Cuenca Karroo (Anderson, 1977).

-Cisuraliano-Guadalupiano: Uruguay: presente en la Formación Melo (Mautino et al., 1998b), Cuenca Paraná. Papúa: ilustrada para las formaciones Ainim y Aiduna (Playford y Rigby, 2008).

- Lopingiano-Triásico Inferior: Australia: presente en el la Formación Rewan, Cuenca Bowen (de Jersey 1979).

Cannanoropollis methae (Lele) Bose y Maheshwari 1968

Lámina VIII, figura C

1964. Virkkipollenites methae Lele, p. 152, fig. 16.

Sinonimia adicional. Véase Gutiérrez (1993) y Gutiérrez y Césari (2000).

Descripción. Grano de polen monosacado, de simetría radial, de contorno general circular a subcircular, de margen ondulado. Cuerpo central de contorno discernible y de exina delgada, de similar coloración a la del saco. Marca trilete no siempre visible, de ramas rectas que alcanzan por 1/3 del radio del cuerpo central. Saco de ancho constante, de adherencia proximal ecuatorial y distal subecuatorial. La zona de adherencia es de 
ancho de ancho constante. Raíces y pliegues de disposición radial. Sexina del saco infrareticulada, conformando muros irregulares en forma y ancho que delimitan lúminas irregulares que marcan tenues pliegues.

Dimensiones (2 ejemplares). Ancho total, 60-100 $\mu \mathrm{m}$; ancho del saco sobre cara proximal, 7-11,4 $\mu \mathrm{m}$; ancho del saco sobre cara distal, 10-30 $\mu \mathrm{m}$.

Principal material estudiado. BAPal 6186 (a) J49/1; BAPal 6188 (a) F68/1.

Registros previos. Cannanoropollis methae (Lele) Bose y Maheswari fue descripta originalmente por Lele (1964, p. 152) para Talchir Beds, Cisuraliano de la India.

- Pennsylvaniano: Argentina: presente en la Formación Agua Colorada, Cuenca Paganzo (Limarino y Gutiérrez, 1990; Gutiérrez, 1993); ilustrada en la Formación Malanzán (Gutiérrez y Limarino, 2001).

- Pennsylvaniano-Cisuraliano: Argentina: presente en las biozonas PotonieisporitesLublandispora y Cristatisporites (Archangelsky y Gamerro, 1979; Césari et al., 1995), Cuenca Chacoparaná. Presente en la Formación El Imperial (García, 1996); Cuenca San Rafael. Listada para la Formación Río del Peñón, Cuenca Paganzo (Gutiérrez y Limarino, 2006).

- Cisuraliano: Argentina: presente en las formaciones Bajo de Véliz (Gutiérrez y Césari, 2000) y Tasa Cuna (Balarino y Gutiérrez, 2006), Cuenca Paganzo. Presente en la Formación Río Genoa, Cuenca Tepuel-Genoa (Gutiérrez et al., 2007); Uruguay: mencionada para las formaciones San Gregorio (Gutiérrez et al., 2006b) y Tres Islas (Veroslavsky et al., 2003), Cuenca Paraná.

Género Costatacyclus Felix y Burbridge emend. Urban 1971 Especie tipo. Costatacyclus crenantus Felix y Burbridge emend. Urban, 1971. Afinidad botánica. Gimnospermas-Coniferopsida?

Costatacyclus crenatus Felix y Burbridge emend. Urban 1971 Lámina VIII, figura D

Descripción. Grano de polen monosacado, de simetría bilateral, contorno general ovalado en sentido transversal y margen ondulado. Cuerpo central subcircular, bien notorio, de coloración más oscura que el saco. Saco adherido a ambas caras 
subecuatorialmente, evidenciandose una zona de adherencia anular en el borde del cuerpo, de ancho constante. Fuertes pliegues de disposición radial. Intexina del saco infrareticulada, conformando muros irregulares en forma y ancho que delimitan lúminas pequeñas.

Dimensiones (4 ejemplares). Ancho mayor, 72(79,2)98 $\mu \mathrm{m}$; diámetro menor, 42(48,2)56 $\mu \mathrm{m}$; diámetro del cuerpo central, 26(39,2)50 $\mu \mathrm{m}$; ancho del saco, 15(18)22 $\mu \mathrm{m}$.

Principal material estudiado. BAPal 6174 (a) E36/2; BAPal 6188 (a) R54/2; BAPal 6189 (a) F62/1, Q63/4.

Comentarios. Los ejemplares son referidos sin duda a la especie Costatacyclus crenatus por presentar las características diagnósticas. Las mismas son: contorno oval transversal, de margen ondulado, cuerpo central oscuro, y adherencia del saco de manera subecuatorial en ambas caras.

Registros previos. Costatacyclus crenatus fue descripto por Felix y Burbridge (1967) para la Formación Springer, Oklahoma, Estados Unidos.

- Pennsylvaniano: Brasil: ilustrada para el Grupo Itararé, Cuenca Paraná (Souza et al., 2003) y presente en el Grupo Trapajós, Cuenca Amanzonas (Playford y Dino, 2000a).

Estados Unidos: presente en las formaciones Springer (Felix y Burbridge, 1967) y Cherokee (Ravn, 1979).

- Pennsylvaniano-Cisuraliano: Brasil: presente en el Grupo Trapajós, Cuenca Amazonas (Playford y Dino, 2000a).

- Cisuraliano: Uruguay: presente en las formaciones Tres Islas (Beri 1988) y San Gregorio (Gutiérrez et al., 2006b), Cuenca Paraná.

Esta es la primera cita de la especie para la Argentina.

Género Potonieisporites Bhardwaj, 1954 emend. Bharadwaj, 1964

Especie Tipo. Potonieisporites novicus Bharadwaj, 1964.

Afinidad botánica. Gimnospermas-Coniferopsida (Staplin et al., 1967; Nygreen y Bourn, 1967; Rothewell, 1982; Taylor, 1982; Clement-Westerhof, 1984).

Potonieisporites brasiliensis (Nahuys, Alpern e Ybert) Archangelsky y Gamerro 1979 Lámina VIII, figuras E y F 
1968. Vestigisporites brasiliensis Nahuys, Alpern e Ybert, p. 32, figs. 57-61.

1980b. Potonieisporites cf. brasiliensis (Nahuys, Alpern e Ybert) Archangelsky y

Gamerro; Archangelky y Gamerro, lám. II, fig. 1.

Sinonimia adicional. Véase Archangelsky y Gamerro (1979) y Gutiérrez (1993).

Descripción. Grano de polen monosacado, de simetría bilateral, de contorno general ovalado a subrectangular. Cuerpo central subcircular, marca dilete a monolete proximal, de rectas que alcanzan 1/2 del radio del cuerpo central. Cara distal con un pliegue contínuo y periférico, de ancho variable, con mayor desarrollo en los lados transversales que en los longitudinales del cuerpo central. Este pliegue delimita un área libre distal subcircular a oval. Saco de adherencia proximal ecuatorial y distal subecuatorial. Raíces y pliegues pequeños de disposición radial. Sexina del saco infrareticulada, conformando muros irregulares en forma y ancho que delimitan lúminas irregulares.

Dimensiones (11 ejemplares). Ancho total, 81(107,2)155 $\mu \mathrm{m}$; cuerpo central, ancho $40(52,5) 80 \mu \mathrm{m}$ y $46(56,6) 77 \mu \mathrm{m}$ de largo; ancho del saco sobre cara proximal, 18(28)43 $\mu \mathrm{m}$; ancho del saco sobre cara distal, 31(42,7)87 $\mu \mathrm{m}$; ancho de pliegues 5(9,3)15 $\mu \mathrm{m}$.

Principal material estudiado. BAPal 6143 (b) F56/0; BAPal 6187 (a) M39/0, T64/1; BAPal 6188 (a) T50/3. Retrabajo: BAPal 6171 (a) F57/3; BAPal 6172 (a) T34/0; BAPal 6174 (a) Y71/0; BAPal 6174 (b) Q72/1; BAPal 6175 (a) U44/2; BAPal 6181 (a) $\mathrm{H} 68 / 0$.

Comentarios. El material ilustrado como Potonieisporites cf. brasiliensis por Archangelky y Gamerro (1980b, lám. II, fig. 1) para la perforación Puelches x-1, se incluye sin dudas en la especie.

Registros previos. Potonieisporites brasiliensis (Nahuys, Alpern e Ybert) Archangelsky y Gamerro fue descripta originalmente por Nahuys et al. (1968) para el Cisuraliano de Brasil.

- Pennsylvaniano: Argentina: presente en las formaciones Agua Colorada (Limarino y Gutiérrez, 1990; Gutiérrez 1993), Guandacol (Ottone y Azcuy, 1990), Malanzán (Gutiérrez y Limarino, 2001), Trampeadero (Gutiérrez y Barreda, 2006), y en los Estratos de Mascasín (Pérez Loinaze y Césari, 2004), Cuenca Paganzo. Presente en la Formación San Telmo, Cuenca Tarija (Azcuy y di Pasquo, 2000, 2002). 
- Pennsylvaniano-Guadalupiano: Argentina: presente en las biozonas PotonieisporitesLundbladispora, Cristatisporites y Striatites, Cuenca Chacoparaná (Archangelsky y Gamerro, 1979; Archangelsky et al., 1980a; Vergel 1987a; Césari et al., 1995). Presente en las formaciones Santa Máxima (Ottone, 1989), Cuenca Calingasta-Uspallata y El Imperial (García, 1996), Cuenca San Rafael.

- Cisuraliano: Argentina: ilustrada para la Biozona Cristatisporites, Cuenca Claromecó-Colorado (Archangelsky y Gamerro, 1980b); ilustrada en la Formación Tupe (miembro cuspidal), Cuenca Paganzo (Vergel, 2008). Uruguay: presente en la Formación San Gregorio (Beri y Daners 1996; Beri y Goso, 1996; Gutiérrez et al., 2006b), Cuenca Paraná. Brasil: descripta en el Grupo Trapajós, Cuenca Amazonas (Playford y Dino, 2000a). Arabia Saudita: ilustrada para la Formación Al Khlata (Stephenson y Filatoff, 2000a).

- Cisuraliano-Guadalupiano: Argentina: presente en la Formación Victoriano Rodríguez, biozonas Cristatisporites y Striatites, Cuenca Chacoparaná (Playford y Dino, 2002). Uruguay: presente en la Formación Melo (Beri y Pecoits, 2001), Cuenca Paraná. Brasil: descripta en la Formación Rio Bonito, Cuenca Paraná (Nahuy et al., 1968; Quadros et al., 1996). Arabia Saudita: ilustrada para la Formación Al Khlata (Stephenson y Filatoff, 2000a).

\section{Potonieisporites densus Maheshwari 1967}

Lámina VIII, figura G

Descripción. Grano de polen monosacado, de simetría bilateral, de contorno general oval. Cuerpo central romboidal, marca dilete proximal poco discernible. Cara distal con un sistema de pliegues periféricos, paralelos al contorno del cuerpo, asociados a las raíces de los sacos. Saco de adherencia proximal ecuatorial y distal subecuatorial. Raíces de disposición radial. Sexina del saco infrareticulada, conformando muros irregulares en forma y ancho que delimitan lúminas irregulares.

Dimensiones (2 ejemplares). Ancho total, 70-106 $\mu \mathrm{m}$; cuerpo central, ancho 40-53 $\mu \mathrm{m}$ y 40-53 $\mu \mathrm{m}$ de largo; ancho del saco sobre cara proximal, 28-35 $\mu \mathrm{m}$; ancho del saco sobre cara distal, 37-38 $\mu \mathrm{m}$; ancho de pliegues, hasta $9 \mu \mathrm{m}$.

Principal material estudiado. BAPal 6154 (a) P73/2; BAPal 6162 (b) M61/0. 
Registros previos. Potonieisporites densus fue descripta por Maheshwari (1967) para el Valle Bansloi, Santhal Parganas, Bihar, India.

- Pennsylvaniano: Argentina: presente en las formaciones Agua Colorada, Cuenca Paganzo (Limarino y Gutiérrez, 1990; Gutiérrez, 1993) y San Telmo, Cuenca Tarija (Azcuy y di Pasquo, 2000; di Pasquo et al., 2001). Brasil: mencionada para el Subgrupo Itararé, Cuenca Paraná (Souza et al., 2003). Perú: presente en la Formación Tarma, Pongo de Mainique (Azcuy et al., 2002).

- Pennsylvaniano-Cisuraliano: Argentina: presente en la Formación El Imperial (García, 1996), Cuenca San Rafael.

- Cisuraliano: Uruguay: ilustrada para la Formación Tres Islas, Cuenca Paraná (Veroslavsky et al., 2003) y para la Cuenca Chacoparaná (Césari et al., 1995).

\section{Potonieisporites lelei Maheshwari 1967}

Lámina VIII, figura $\mathrm{H}$

Descripción. Grano de polen monosacado, de simetría bilateral y contorno general ovalado, elongado longitudinalmente. Cuerpo central subcircular, marca monolete proximal, poco discernible. Cara distal con un pliegue periférico, asociado a las raíces del saco. Saco de adherencia proximal ecuatorial y distal subecuatorial. Raíces dispuestas radialmente. Sexina del saco infrareticulada, conformando muros irregulares en forma y ancho que delimitan lúminas irregulares.

Dimensiones (2 ejemplares). Ancho total, 88-125 $\mu \mathrm{m}$; cuerpo central, ancho 47-56 $\mu \mathrm{m}$ y 55-60 $\mu \mathrm{m}$ de largo; ancho del saco sobre cara proximal, 10-35 $\mu \mathrm{m}$; ancho del saco sobre cara distal, 25-46 $\mu \mathrm{m}$; ancho del pliegue 7-9 $\mu \mathrm{m}$.

Principal material estudiado. BAPal 6143 (a) F67/0; BAPal 6158 (a) J64/1.

Registros previos. Potonieisporites lelei fue descripta originalmente por Maheshwari (1967) para el Valle Bansloi, Santhal Parganas, Bihar, India.

- Pennsylvaniano: Argentina: presente en la Formación Agua Colorada, Cuenca Paganzo (Gutiérrez, 1993).

Potonieisporites sp. cf. P. pyriferus Playford y Dino 2000a

Lámina IX, figura A 
Descripción. Grano de polen monosacado, de simetría bilateral, de contorno general levemente oval. Cuerpo central circular, oscuro, con marca monolete a geniculada proximal. Cara distal con 2 pliegues semilunares, subparalelos a los lados longitudinales del cuerpo, que no se contactan entre sí en los extremos del mismo. Estos pliegues delimitan un área libre distal amplia, subrectangular a oval. Saco oval, levemente biconstricto, de adherencia proximal ecuatorial y distal subecuatorial, esta última tiene mayor desarrollo en los lados transversales del cuerpo central. Raíces de disposición radial. Sexina del saco infrareticulada, conformando muros irregulares en forma y ancho que delimitan lúminas irregulares.

Dimensiones ( 2 ejemplares). Ancho total, 102-107 $\mu \mathrm{m}$; cuerpo central, ancho 64-80 $\mu \mathrm{m}$ y 76-80 $\mu \mathrm{m}$ de largo; ancho del saco sobre cara proximal, 15-20 $\mu \mathrm{m}$; ancho del saco sobre cara distal, 34-38 $\mu \mathrm{m}$; ancho de pliegues, hasta $10 \mu \mathrm{m}$.

Principal material estudiado. BAPal 6187 (a) U44/0. Retrabajo: BAPal 6178 (a) $\mathrm{X} 44 / 2$.

Comparaciones. Potonieisporites pyriferus fue descripta por Playford y Dino (2000a) para la Formación Nova Olinda, Cuenca Amazonas, Brasil, y se distingue del resto de las especies por la apariencia piriforme del cuerpo central y el par de pliegues distales asociados a las bases longitudinales del saco. Si bien los ejemplares aquí estudiados presentan dichos pliegues, problemas de preservación y escaso material impiden la observación nítida de la forma del cuerpo central, motivo por el cual no se realiza la asignación específica.

\section{Potonieispoirtes triangulatus Tiwari 1965}

Lámina IX, figura B

Descripción. Grano de polen monosacado, de simetría bilateral, de contorno general ovalado. Cuerpo central triangular a subtriangular, de lados levemente convexos y ángulos redondeados. Cara proximal con marca monolete a dilete, poco discernible. Cara distal con 3 pliegues paralelos a los lados, que delimitan un área libre distal subtriangular. Saco de adherencia proximal ecuatorial y distal subecuatorial. Raíces de 
disposición radial. Sexina del saco infrareticulada, conformando muros irregulares en forma y ancho que delimitan lúminas irregulares.

Dimensiones ( 1 ejemplar). Ancho total, $120 \mu \mathrm{m}$; diámetro del cuerpo central, $55 \mu \mathrm{m}$; ancho del saco sobre cara proximal, $17 \mu \mathrm{m}$; ancho del saco sobre cara distal, $29 \mu \mathrm{m}$; ancho de pliegues, $4 \mu \mathrm{m}$.

Principal material estudiado. BAPal 6155 (a) Y53/1.

Registros previos. Potonieispoirtes triangulatus fue descripta originalmente por Tiwari (1965) para Korba Coalfield, India.

- Pennsylvaniano: Argentina: presente en las formaciones Agua Colorada (Gutiérrez 1993) y Guandacol (Ottone y Azcuy, 1990), Cuenca Paganzo, y en la Formación San Telmo, Cuenca Tarija (Azcuy y di Pasquo, 2000).

- Pennsylvaniano-Cisuraliano: Brasil: presente en el Grupo Trapajós, Cuenca Amazonas (Playford y Dino, 2000a).

\section{Género Plicatipollenites Lele, 1964}

Especie tipo. Plicatipollenites malabarensis (Potonié y Sah) Foster, 1975.

Afinidad botánica. Coniferophyta (Bharadwaj, 1975; Clement-Westerhof, 1984).

Plicatipollenites malabarensis (Potonié y Sah) Foster 1975

Lámina IX, figuras C y D

1960. Cannanoropollis malabarensis Potonié y Sah, p. 128, lám. II, figs. 19-21, lám. III, fig. 22.

Sinonimia adicional. Véase Foster (1979), Azcuy y Gutiérrez (1985), Gutiérrez (1993) y Félix et al. (2006).

Descripción. Grano de polen monosacado, de simetría radial y contorno general circular a subcircular por deformación, de margen liso a levemente irregular. Cuerpo central circular a subcircular con un pliegue distal, periférico y submarginal. Marca trilete proximal no discernible claramente, de ramas asimétricas. Saco de ancho uniforme, de inserción proximal ecuatorial y distal subecuatorial. Raíces poco marcadas y pliegues de disposición radial. Sexina del saco infrareticulada, conformando muros irregulares en forma y ancho que delimitan lúminas irregulares. 
Dimensiones (3 ejemplares). Ancho total, 90(117,6)120 $\mu \mathrm{m}$; diámetro cuerpo central, 55,5(77,3)97 $\mu \mathrm{m}$; ancho del saco sobre cara proximal, 19(22)24 $\mu \mathrm{m}$; ancho del saco sobre cara distal, 29(30,5)32 $\mu \mathrm{m}$; ancho de pliegues $4(6,3) 9 \mu \mathrm{m}$.

Principal material estudiado. BAPal 6183 (b) V46/1. Retrabajo: BAPal 6172 (a) R71/0; BAPal 6174 (a) C33/0.

Registros previos. Plicatipollenites malabarensis (Potonié y Sah) Foster fue definida originalmente sobre la base de ejemplares redepositados en el Mio-Plioceno de la India (Potonié y Sah, 1960).

- Pennsylvaniano: Argentina: presente en las formaciones Agua Colorada (Limarino y Gutiérrez, 1990; Gutiérrez 1993); Guandacol (Vázquez Nístico y Césari, 1987; Ottone y Azcuy, 1990), Tupe (Césari, 1984; Ottone y Azcuy, 1991), Malanzán (Gutiérrez y Limarino, 2006) y en los Estratos de Mascasín (Pérez Loinaze y Césari, 2004), todas de Cuenca Paganzo. Presente en la Formación San Telmo, Cuenca Tarija (Azcuy y di Pasquo, 2000; di Pasquo et al., 2001) y en la Cuencas Colorado (Archangelsky y Gamerro, 1980b) y Chacoparaná (Vergel, 1987a). Presente en la Formación El Imperial (Azcuy y Gutiérrez, 1984). Brasil: mencionada para el Subgrupo Itararé, Cuenca Paraná (Daemón y Quadros, 1970; Pons, 1977; Souza et al., 2003) y presente en los pozos 2CS-1-PR y T-2 para la misma cuenca (Quadros et al., 1996).

- Pennsylvaniano-Cisuraliano: Argentina: presente en la Cuenca Chacoparaná (Césari et al., 1995), en las formaciones Santa Máxima (Ottone, 1989), Cuenca CalingastaUspallata y El Imperial (García, 1996), Cuenca San Rafael. Mencionada para la Formación Río del Peñón, Cuenca Cuyana (Gutiérrez y Limarino, 2006). Brasil: presente en el Grupo Trapajós, Cuenca Amazonas (Playford y Dino, 2000b).

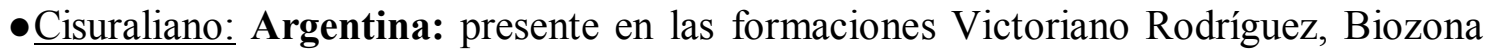
Cristatisporites, Cuenca Chacoparaná (Playford y Dino 2002) y Río Genoa, Cuenca Tepuel-Genoa (Gutiérrez et al., 2007). Uruguay: presente en la Formación San Gregorio (Beri y Goso, 1996; Beri y Daners, 1996; Gutiérrez et al., 2006b), Cuenca Paraná. Sudáfrica: presente en Cuenca Karroo (Anderson, 1977). Brasil: presente en la Formación Rio Bonito (Ybert, 1975), Cuenca Paraná.

-Cisuraliano-Guadalupiano: Uruguay: presente en las Formación Melo (Mautino et al., 1998b), Cuenca Paraná. Argentina: ilustrada para la Formación De La Cuesta (Aceñolaza y Vergel, 1987). 
- Pennsylvaniano-Guadalupiano: Argentina: presente en las biozonas PotonieisporitesLublandispora, Cristatisporites y Striatites, Cuenca Chacoparaná (Archangelsky y Gamerro, 1979; Archangelsky et al., 1980a) Brasil: véase Félix et al. (2006).

\section{Subinfraturma CLAUSICORPINI Dibner 1971}

Género Caheniasaccites Bose y Kar emend. Archangelsky y Gamerro 1979 Especie tipo. Caheniasaccites flavatus Bose y Kar, 1966.

Afinidad botánica. Gimnospermas-Coniferopsida (véase Balme, 1995; Archangelsky, 1996c).

\section{Cahenisaccites densus Lele y Karim emend. Gutiérrez 1993}

Lámina IX, figuras E y F

Sinonimia. Véase Gutiérrez (1993).

Descripción. Grano de polen monosacado, de simetría bilateral, elongado transversalmente, haploxilonoide a levemente diploxilonoide, debido a pequeñas constricciones del saco. Cuerpo central oval a subcircular de exina gruesa, otorgándole una coloración oscura y densa a la pared. Marca monolete a dilete pobremente definida. Saco de contornos lisos o levemente ondulados en algunas zonas, de mayor desarrollo en sentido longitudinal que en el transversal. La disminución transversal del ancho del saco genera puentes, de ancho variable, continuos, aún en los casos en los que estan biconstrictos. Se observan fuertes pliegues radiales que asentúan el área de adherencia subecuatorial distal, la que delimita un área libre subcirular a suboval. La adherencia proximal es ecuatorial. Sexina del saco infrareticulada, conformando muros irregulares en espesor y en forma, que delimitan lúminas de márgenes poco discernibles.

Dimensiones (6 ejemplares). Ancho total, 60(73,8)107 $\mu \mathrm{m}$; cuerpo central, ancho $29(33,8) 46 \mu \mathrm{m}$ y $25(34,1) 53 \mu \mathrm{m}$ de largo; ancho del saco sobre cara proximal, $15(18,4) 23 \mu \mathrm{m}$; ancho del saco sobre cara distal, hasta $15(25,7) 30 \mu \mathrm{m}$; ancho de los puentes $4(6,8) 10 \mu \mathrm{m}$.

Principal material estudiado. BAPal 6153 (a) X42/1; BAPal 6161 (a) D56/1; BAPal 6165 (a) L43/1; BAPal 6165 (b) G47/2; BAPal 6185 (b) P37/3; BAPal 6189 (a) X41/0. 
Registros previos. Caheniasaccites densus fue descripta originalmente por Lele y Karim (1971) para la Flora de Talchir, India.

- Pennsylvaniano: Argentina: presente en las formaciones Agua Colorada (Gutiérrez, 1993), Guandacol (Césari y Vázquez Nístico, 1988) y Tupe (Césari, 1984), y en los Estratos de Mascasín (Pérez Loinaze y Césari, 2004), todas de la Cuenca Paganzo, y en la Formación San Telmo, Cuenca Tarija (di Pasquo et al., 2001). Para mayor detalle véase Césari y Gutiérrez (2001).

- Pennsylvaniano-Cisuraliano: Argentina: Cuenca Chacoparaná (Archangelsky y Gamerro, 1979); formaciones Santa Máxima (Ottone, 1989) y El Imperial (García, 1996).

- Cisuraliano: Argentina: presente en las formaciones Bajo de Véliz, Cuenca Paganzo (Gutiérrez y Césari, 2000) y Victoriano Rodríguez, Biozona Cristatisporites, Cuenca Chacoparaná (Playford y Dino, 2002). Uruguay: presente en la Formación San Gregorio (Gutiérrez et al., 2006b), Cuenca Paraná. India: presente en la Formación Talchir, Cuenca South Rewa (Lele, 1975; Chandra y Lele, 1980).

- Cisuraliano-Guadalupiano: Uruguay: presente en la Formación Melo (Mautino et al., 1998b), Cuenca Paraná.

\section{Caheniasaccites elongatus Bose y Kar 1966}

\section{Lámina IX, figura $\mathrm{G}$}

Descripción. Grano de polen monosacado, de simetría bilateral, elongado transversalmente, haploxilonoide a levemente diploxilonoide, debido a pequeñas constricciones de los puentes. Cuerpo central subrectangular elongado en sentido transversal, difuso, con una coloración más clara que el saco. Marca monolete a dilete pobremente definida. Saco de contornos lisos a levemente ondulados. Puentes anchos y continuos, aún en los casos en los que estan biconstrictos. Adherencia subecuatorial, en la cara distal se observan raíces marcadas, de disposición radial, que delimitan un área libre de contorno subrectangular. Sexina del saco infrareticulada, conformando muros densamente dispuestos.

Dimensiones ( 1 ejemplar). Ancho total, $78 \mu \mathrm{m}$; cuerpo central, ancho $40 \mu \mathrm{m}$ y $35 \mu \mathrm{m}$ de largo; ancho del saco sobre cara proximal, $20 \mu \mathrm{m}$; ancho de los puentes 10-11 $\mu \mathrm{m}$. 


\section{Principal material estudiado. BAPal 6158 (b) $\mathrm{C} 41 / 3$.}

Registros previos. Caheniasaccites elongatus fue descripta originalmente por Bose y Kar (1966) para Kindu Kalima, Congo, África.

- Pennsylvaniano-Cisuraliano: Argentina: presente en la Formación El Imperial, Cuenca San Rafael (García 1996).

Subinfraturma AMPHISACCINI Dibner, 1971

Género Crucisaccites Lele y Maithy, 1964

Especie tipo. Crucisaccites latisulcatus Lele y Maithy, 1964.

Afinidad botánica. Gimnospermas? (Gutiérrez, 1993).

Crucisaccites latisulcatus Lele y Maithy 1964

Lámina IX, figura $\mathrm{H}$

Descripción. Grano de polen monosacado, de simetría bilateral, contorno general oval elongado transversalmente. Cuerpo central grande, de contorno oval, también elongado en sentido transversal, de contorno pobremente definido. Saco adherido al cuerpo en forma bilateral con zonas de adherencia cruzadas, una respecto de la otra, sobre ambas caras del cuerpo. Áreas libres sobre el cuerpo de hasta 1/3 de largo respecto del largo total y de forma rectangular. Las zonas de adherencia del saco generalmente aparecen asociadas a unos delgados pliegues, observables más nítidamente en las zonas transversales.

Comentarios. Si bien los tamaños observados en el material estudiado son menores (longitud total: 61-65 $\mu \mathrm{m}$ ) a los considerados por Gutiérrez (1993, p. 193, tabla 11: longitud total, 100-175 $\mu \mathrm{m})$, características tales como la forma general oval, el saco adherido al cuerpo de manera bilateral con zonas de adherencia cruzadas sobre ambas caras y la presencia de tenues plegamientos asociados a las zonas de adherencia permiten asignarlos sin dudas a la especie Crucisaccites latisulcatus.

Dimensiones (3 ejemplares). Ancho total, 61(63)65 $\mu \mathrm{m}$; cuerpo central, ancho 30(32)33 $\mu \mathrm{m}$ y 10-15 $\mu \mathrm{m}$ de largo; ancho del saco, 8(13,3)16 $\mu \mathrm{m}$; ancho de los puentes, 4-15 $\mu \mathrm{m}$. Principal material estudiado. BAPal 6152 (a) Q57/1, M47/3; BAPal 6162 (b) F48/1. 
Registros previos. Crucisaccites latisulcatus fue descripta originalmente por Lele y Maithy (1964) Central Pit, Serampur Colliery, Giridh Coalfield, India.

- Pennsylvaniano: Argentina: presente en las formaciones Guandacol (Vázquez Nístico y Césari, 1987), Tupe (Ottone y Azcuy, 1991), Agua Colorada (Gutiérrez, 1993) y Jejenes (Césari y Bercowski, 1997), Cuenca Paganzo. Brasil: ilustrada y/o listada para el Subgrupo Itararé (Sundarán, 1986; Félix et al., 2006).

- Pennsylvaniano-Cisuraliano: Brasil: presente en las formaciones Itaituba y Nova Olinda, Grupo Trapajós, Cuenca Amazonas (Playford y Dino, 2000b).

- Pennsylvaniano-Guadalupiano: Argentina: presente en las Biozonas PotonieisporitesLundbladispora, Cristatisporites y Striatites, Cuenca Chacoparaná (Césari et al., 1995).

- Cisuraliano: Argentina: presente en las formaciones Tasa Cuna, Cuenca Paganzo (Balarino y Gutiérrez, 2006) y Río Genoa, Cuenca Tepuel-Genoa (Gutiérrez et al., 2007); ilustrada en la Formación Tupe (miembro cuspidal), Cuenca Paganzo (Vergel, 2008). Uruguay: presente en la Formación San Gregorio, Cuenca Paraná (Gutiérrez et al., 2006b).

\section{Crucisaccites sp.}

Lámina X, figura A

Descripción. Grano de polen monosacado, monolete, de contorno subcircular circular suboval. Saco adherido subecuatorialmente en sentido transverso-proximal y longitudinal-distal. Sexina conformando un delgado y poco discernible infraretículo.

Dimensiones (2 ejemplares). Ancho total, 40-90 $\mu \mathrm{m}$; ancho del saco, 10-19 $\mu \mathrm{m}$.

Principal material estudiado. BAPal 6156 (c) C50/4. Redepósito: BAPal 6170 (a) N65/2.

Compraraciones. Los ejemplares aquí estudiados se asemejan en forma general a Crucisaccites monoletus, aunque son menores a dicha especie (ancho de 70 a 140 para C. monoletus y de 40 a 90 de ancho para $C$. sp.). Por esta diferencia de tamaños y la pobre preservación de los ejemplares estudiados, que impiden la observación de la marca monolete-dilete característica de la especie antes mencionada, no se realiza la asignación específica. 
Infraturma TRILETESACCITI Leschik 1955

Género Bascanisporites Balme y Hennelly 1956

Especie tipo. Bascanisporites undosus Balme y Hennelly 1956.

Afinidad botánica. Gimnospermópsida (Raine et al. 2008).

\section{Bascanisporites sp. A}

Lámina X, figuras C y D

Descripción. Grano de polen monosacado, con el saco con marcadas constricciones, que delimitan 4 sacos. Marca trilete pequeña, de rayos simples, rectos y cortos. Contorno general oval en sentido transversal, de margen irregular dado por la proyección de los sacos. Cuerpo central oval, elongado transversalmente, oscuro y de pared lisa. Saco con adherencia subecuatorial, que determinan áreas semilunares en las bases de los sacos resultantes de la división. Los mismos son subcirculares, no se contactan entre sí en las áreas libres, con pliegues radiales. Sexina del saco delgada, menor al micrón de ancho, conformando un infrareticulado de trabéculas pequeñas poco discernible.

Dimensiones (1 ejemplar). Diámetro total, $56 \mu \mathrm{m}$; ancho del cuerpo, $22 \mu \mathrm{m}$; ancho del saco, $42 \mu \mathrm{m}$.

\section{Principal material estudiado. BAPal 6152 (b) L61/4.}

Comentarios. El ejemplar estudiado es asignado al género Bascanisporites por presentar un saco con 4 constricciones, de las cuales resultan 4 sacos claramente diferenciables entre sí. Además exhibe el cuerpo central ovalado y los sacos tienen una marcada inclinación distal. Estos rasgos permiten separarlos de B. undosus Balme y Hennelly (1956), que si bien presenta un número variable de constricciones del saco (1 a 5), generalmente son 4 , pero los mismos son pequeños y de forma oval, además el cuerpo central es circular. Por su parte en B. varians (Sadkova) Dibner (1971) los sacos son mucho más pequeños y no son lobulados.

Subinfraturma BITERMINALSACCINI Dibner, 1971

Género Gondwanapollis Lele y Maithy, 1969

Especie tipo. Gondwanapollis ganjraensis Lele y Maithy, 1969. 
Afinidad botánica. Gimnospermas? (Gutiérrez, 1993).

Gondwanapollis frenguellii (Césari) Gutiérrez 1993

Lámina X, figura B

1972. Potonieisporites bisaccoidus Kar, Kieser y Jain, p. 422, pl. 5, fig. 14-15.

1984. Potonieisporites frenguellii Césari, pp. 94-96; lám. I, fig. 5.

Sinonimia adicional. Véase Gutiérrez (1993).

Descripción. Grano de polen monosacado, de simetría bilateral y apariencia bisacada. Cuerpo central oval longitudinalmente, de pared lisa y delgada. Saco de contorno oval, de adherencia subecuatorial sobre la cara proximal y bilateral-longitudinal sobre la distal; sobre esta cara las raíces rectas delimitan un área rectangular, con su eje mayor elongado en sentido longitudinal; en los laterales mayores aparecen asociados dos pliegues semilunares delgados. La apariencia bisacada se debe a una reducción en el ancho del saco en los lados transversales del grano, que forma gruesos puentes exinales. Sexina infrareticulada, conformando muros de ancho variable, que en la zona próxima a la adherencia al cuerpo central se alinean radialmente. Lúminas del saco de contornos irregulares.

Dimensiones ( 1 ejemplar). Ancho total, $65 \mu \mathrm{m}$; cuerpo central, ancho $30 \mu \mathrm{m}$ y $35 \mu \mathrm{m}$ de largo; ancho del saco sobre cara proximal, 14,8 $\mu \mathrm{m}$; ancho del saco sobre cara distal, $24,3 \mu \mathrm{m}$; ancho de los puentes $3 \mu \mathrm{m}$.

Principal material estudiado. BAPal 6152 (a) R50/4.

Comentarios. Los ejemplares aquí estudiados fueron comparados con Potonieisporites bisaccoidus Kar et al, por presentar asociadas a las zonas de adherencia distales bilaterales dos pliegues semilunares de orientación longitudinal (Kar et al., 1972, pp. 422, pl. 5, figs 14-15), carácter éste descripto y observable en las ilustraciones. La adherencia distal bilateral no es un carácter que defina a Potonieisporites, pero sí a Gondwanapollis (Lele y Maithy, 1969), que también presenta pliegues notorios semilunares asociados a las zonas de adherencia distal, motivo por el cual se considera la reubicación de la especie.

Potonieisporites pyriferus (Playford y Dino, 2000a), del Grupo Trapajós, en Brasil, presenta un tipo de adherencia distal del saco similar (distal bilateral), aunque ésta no es 
completa como en Gondwanapollis. Además, el material aquí descripto presenta un marcado aspecto bisacado, con una reducción a puentes de los lados adelgazados del saco, mientras que en $P$. pyriferus se aprecia una variación en el desarrollo del saco, desde formas con delgados puentes a formas de aspecto conspicuamente monosacado. El material de la Cuenca Colorado, se asemeja a los descritos e ilutrados por Césari (1984) y Gutiérrez (1993), como G. frenguellii, en especial por su tipo de adherencia y por su aspecto pseudo-diploxilonoide, dado por la biconstricción del saco.

Registros previos. Originalmente fue descripta para la Formación Tupe (Césari, 1984), Sierra de Maz, Cuenca Paganzo.

- Pennsylvaniano: Argentina: presente en las formaciones Tupe (Césari, 1984), Agua Colorada (Gutiérrez, 1993) y Guandacol (Césari y Limarino, 2002), Cuenca Pangazo.

- Pennsylvaniano-Cisuraliano: Argentina: presente en la Formación El Imperial, Cuenca San Rafael (García, 1996).

- Cisuraliano-Guadalupiano: Brasil: presente en la Formación Rio Bonito (Cauduro, 1970; Ybert, 1975).

- Lopingiano-Triásico Inferior: Libia: Kar et al. (1972).

\section{Subinfraturma AMPHISACCINI Dibner 1971}

Género Stellapollenites Lele 1965

Especie tipo. Stellapollenites talchirensis Lele, 1965.

Afinidad botánica. Gimnospermas? (véase Quadros et al., 1996).

Stellapollenites sp. cf. S. talchirensis Lele 1965

Lámina X, figura $\mathrm{E}$

Descripción. Grano de polen monosacado, de simetría radial, contorno general subcircular a subtriangular. Cuerpo central poco discernible. Saco adherido proximalmente de manera trilobular, dejando un área triangular que permite observar parte del cuerpo central y cuyos lados alcanzan el margen ecuatorial del grano. Adherencia distal del saco no discernible claramente. Sexina del mismo infrareticulada, que conforma muros gruesos, cortos y de forma irregular, que delimitan lúminas 
irregulares. Los muros se disponen densamente, carácter que le otorga una coloración siempre más oscura al saco que al cuerpo central.

Dimensiones (2 ejemplares). Ancho total, 57-90 $\mu \mathrm{m}$.

Principal material estudiado. BAPal 6152 (a) E43/0, M43/0.

Comentarios. La mala preservación del material estudiado, así como la escasa cantidad de ejemplares observados impiden tener una mayor precisión en la asignación.

Registros previos. Stellapollenites talchirensis fue descripta originalmente por Lele (1965) para la Talchir Flora, Cuenca de South Rewa Gondwana, India.

Infraturma ALETESACCITES Leschik, 1955

Género Accinctisporites Leschik, 1955

Especie tipo. Accinctisporites ligatus Leschik, 1955.

Afinidad botánica. Desconocida.

Accinctisporites excentricus (Leschik) Jain 1968

Lámina X, figuras $\mathrm{F}$

1955. Succintisporites excentricus Leschik, en Kräusel y Leschik, p. 50, pl. 7, fig. 2.

Descripción. Grano de polen monosacado, de simetría bilateral, contorno general circular a suboval, elongado en sentido transversal. Cuerpo central subcircular a ovaltransverso. Pared del cuerpo central lisa, sin esculturación discernible y coloración más clara que la del grano. Saco de margen liso, adherencia proximal ecuatorial y distal bilateral. Los lados del saco en la inserción distal son rectos y paralelos, se continúan hasta el borde del saco y dejan un área descubierta de la cara distal del cuerpo de forma rectangular-longitudinal. El área de adherencia proximal es contínua y angosta, de 2 a 3 $\mu \mathrm{m}$ de ancho. Sexina del saco infrareticulada, conformando muros delgados.

Dimensiones (16 ejemplares). Ancho total, 31(46,5)54 $\mu \mathrm{m}$; cuerpo central, ancho $25(29,3) 43 \mu \mathrm{m}$ y $22(26,5) 30 \mu \mathrm{m}$ de largo; ancho del saco sobre cara proximal, $8(11,5) 16 \mu \mathrm{m}$; ancho del saco sobre cara distal, 9(16,8)30 $\mu \mathrm{m}$.

Principal material estudiado. BAPal 6150 (a) P48/4; BAPal 6152 (a) B38/2, A45/5, W37/2, O68/0, Y50/1; BAPal 6152 (d) C56/0; BAPal 6155 (a) D53/3; BAPal 6164 (a) W51/0. Redepósito: BAPal 6174 (b) U52/1. 
Discusión y comparaciones. Jain (1968) combinó Accinctisporites excentricus Leschik y la redefine considerando como carácter diagnóstico la elongación ecuatorial del saco. No mencionó otros caracteres tales como forma general del saco y del cuerpo, como tampoco el tipo de inserciones, por lo que se entiende que es muy pobre la definición de la misma. Comparando los ejemplares aquí estudiados con los ilustrados por Jain (1968, p. 17, lám 2, fig. 36), existe una gran similitud (aspecto general, forma subcircular del cuerpo central, saco marcadamente oval, e inserciones proximal-ecuatorial y distal bilateral), motivo por el cual son incluidos en la especie. Si bien los ejemplares estudiados por Jain presentan un tamaño mayor a los observados en los ejemplares de Cuenca Colorado $(74$ × $52 \mu \mathrm{m}$ para los primeros y 45-59 x 25-38 $\mu \mathrm{m}$ para los segundos), esta misma diferencia de tamaños fue mencionada por Zavattieri (1987, pp. 174-175, lám. 1, fig 1) para el ejemplar ilustrado para la Formación Potrerillos (Triásico), de la Cuenca Cuyana.

Registros previos. Accinctisporites excentricus fue originalmente descripta por Leschik (1955) para el Keuper medio de Suecia. Esta es la primera mención para la especie en el Pérmico.

- Triásico: Argentina: presente en la Formación Cacheuta (Jain, 1968); mencionada para la Formación Potrerillos (Zavattieri, 1987; Zavattieri y Volkheimer, 1992) e ilustrada para la Formación Las Cabras (Zavattieri, 1991a); todas del ámbito de la Cuenca Cuyana. Chile: ilustrada para la Formación Panguipulli (Zavattieri et al., 2003).

\section{Accinctisporites sp. A}

Lámina X, figuras $\mathrm{G}$ y $\mathrm{H}$

Descripción. Grano de polen monosacado, de simetría bilateral y contorno general subcircular a levemente circular, elongado en sentido transversal. Cuerpo central subcircular, de pared delgada y coloración clara, sin escultura evidente. Se observa un repliegue sinuoso (¿chorda?) que bisecta transversalmente al cuerpo central y que se extiende por todo el ancho del mismo, hasta contactar las zonas proximales de adherencia. Saco subcircular de margen liso. Adherencia de saco proximal ecuatorial y distal de manera bilateral de lados subparalelos, levemente cóncavos. La zona de adherencia delimitada por el tipo de inserción proximal y distal es más oscura tanto 
como la coloración de la chorda. Los bordes distales del saco delimitan un área subrectangular transverso en la cara distal del cuerpo, de coloración màs clara. Sexina del saco infrareticulada, de muros de ancho variable y lúminas circulares-subcirculares. Pliegues del saco cortos ubicados en el borde externo, orientados radialmente.

Dimensiones (5 ejemplares). Ancho total, $32(46,2) 74 \mu \mathrm{m}$; largo total, $18(29,4) 45 \mu \mathrm{m}$; cuerpo central, ancho 10(19)24 $\mu \mathrm{m}$ y 22(25)34 $\mu \mathrm{m}$ de largo; ancho del saco sobre cara proximal, 5(8,6)15 $\mu \mathrm{m}$; ancho del saco sobre cara distal, 12(17)30 $\mu \mathrm{m}$.

Principal material estudiado. BAPal 6152 (a) N74/2, L45/3; A45/4, G47/3; BAPal 6156 (b) $X 39 / 2$.

Discusión. El repliegue (¿chorda?) ubicado en el centro del cuerpo central y de orientación transversal, no ha sido observado en ningún género de granos de polen monosacados registrados desde el Carbonífero hasta el Triásico, aunque el resto de las características son compartidas con el género Accinctisporites. Estas son: forma general oval, elongada transversalmente, cuerpo circular a oval, elongado también transversalmente, inserción del saco proximal-ecuatorial y distal bilateral, y tamaño pequeño. Por dichos caracteres probablemente se trate de una nueva especie de Accinctisporites.

Infraturma STRIASACCITES Bharadwaj 1962

Género Meristocorpus Playford y Dino 2000

Especie tipo. Meristocorpus explicatus Playford y Dino 2000.

Afinidad botánica. Desconocida.

\section{Meristocorpus sp. A}

Lámina XI, figura A

Descripción. Grano de polen monosacado, de contorno general oval a subrectangular, de lados transversales mayores y rectos, lados longitudinales cóncavos hacia el cuerpo y ángulos redondeados. Cuerpo central subrectangular, de lados rectos y ángulos rectos, elongado transversalmente. Presencia de tenias en la cara proximal del cuerpo (aproximadamente 10), orientadas transversalmente, de ancho constante, completas o en algunos casos bifurcadas, separadas entre sí por angostas estrías; tenias de 2 a $3 \mu \mathrm{m}$ de 
ancho. La pared del cuerpo es delgada y de coloración clara. Saco de contorno liso, de inserción proximal subecuatorial bilateral, de lados longitudinales rectos y paralelos y puentes perpendiculares de ancho constante. Esta adherencia proximal deja liberada un área rectangular de la cara proximal del cuerpo. Adherencia distal no discernible. Sexina del saco infrareticulada, conformando muros delgados, cortos e irregulares, que delimitan lúminas poco discernibles.

Dimensiones (4 ejemplares). Ancho total, $80-81 \mu \mathrm{m}$; largo total, $40-52 \mu \mathrm{m}$; cuerpo central, ancho 38-43 $\mu \mathrm{m}$ y 35-40 $\mu \mathrm{m}$ de largo; $\mu \mathrm{m}$; ancho del saco sobre cara distal, 19$20 \mu \mathrm{m}$.

Principal material estudiado. BAPal 6152 (a) H42/4, K48/1, B51/3. Redepósito: BAPal 6171 (a) S50/0.

Discusión y comparaciones. Meristocorpus sp. A se diferencia del resto de las especies referidas a éste género por su baja relación entre las dimensiones del cuerpo, las dimensiones generales y la ausencia de pliegues exinales sobre el cuerpo. Los ejemplares aquí estudiados se asemejan en forma general y tamaño a los ejemplares considerados M. sp A para la Formación Tasa Cuna (Balarino y Gutiérrez, 2006, p. 448, fig. 5.A), aunque presentan un menor número de tenias (entre 6 y 8 contra las 10 de material de Cuenca Colorado). Los ejemplares aquí estudiados presentan un número similar de tenias que los observados en M. explicatus (Playford y Dino, 2000, pp. 9899), aunque la ausencia de marca monolete diagnóstica para ésta especie, impide su asignación.

La mala preservación de los ejemplares aquí descriptos impide avanzar en una asignación específica.

\section{Meristocorpus sp. B}

Lámina XI, figura B

Descripción. Grano de polen monosacado, de simetría bilateral, contorno general oval a subrectangular, de lados rectos y ángulos redondeados. Cuerpo central elongado transversalmente, de pared delgada. Presencia en cara proximal de 7 tenias, de ancho constante (5 a $6 \mu \mathrm{m}$ ), orientada en el sentido del eje mayor del cuerpo, separadas entre sí por estrías delgadas, de ancho menor a $1 \mathrm{~mm}$. Las tenias no se ahusan en sus 
extremos ni se bifurcan. Saco de contorno liso, inserción proximal ecuatorial y distal subecuatorial, que permite observar un área de adherencia semilunar a cada lado del cuerpo, y un área distal descubierta rectangular. Sexina del saco infrareticulada, conformando muros delgados poco discernibles.

Dimensiones (6 ejemplares). Ancho total, 46(57,5)68 $\mu \mathrm{m}$; largo total, $27(38,1) 48 \mu \mathrm{m}$; cuerpo central, ancho $30(35,1) 45 \mu \mathrm{m}$ y $18(26,1) 35 \mu \mathrm{m}$ de largo; ancho del saco sobre cara proximal, 8,9(11)17 $\mu \mathrm{m}$; ancho del saco sobre cara distal, 14,9(19,1)23,4 $\mu \mathrm{m}$.

Principal material estudiado. BAPal 6152 (a) E54/2; BAPal 6152 (b) N70/0; BAPal 6157 (a) N64/4; BAPal 6158 (b) Q54/3; BAPal 6163 (a) G71/0; BAPal 6167 (a) N63/2; BAPal 6168 (a) E48/0.

Discusión y comparaciones. Meristocorpus sp B se diferencia de M. sp. A, por presentar menor número de tenias (7 contra al menos 10), por la forma de las tenias (ancho constante, mientras que en $M$. sp. A se ahusan hacia los extremos y a veces se bifurcan), la forma del cuerpo central (oval en $M$. sp. B y subrectangular en la segunda especie) y por la adherencia distal bilateral, que es más conspicua en $M$. sp B.

\section{Género Striomonosaccites Bharadwaj 1962}

Especie tipo. Striomonosaccites ovatus Bharadwaj, 1962.

Afinidad botánica. Gimnospermas (véase Quadros et al., 1996); Glossopteridales (Lindström et al., 1977).

\section{Striomonosaccites cicatricosus Archangelsky y Gamerro 1979}

$$
\text { Lámina XI, figuras D y F }
$$

Descripción. Grano de polen monosacado, de contorno general subcircular a oval, elongado en sentido transversal. Cuerpo central ovalado, también elongado transversalmente, con numerosas tenias en la cara proximal (al menos 10, de 4 a $6 \mu \mathrm{m}$ de ancho), de orientación transversal, de forma ahusada y continua, sin observarse bifurcaciones, y que confluyen en los extremos. Las tenias presentan una fina granulación a veces observable. Pared del cuerpo gruesa, que le otorga una coloración oscura. Saco de contorno ondulado y de 1/3 de ancho respecto del ancho del cuerpo central. Adherencia proximal ecuatorial, de lados transversales elongados y cóncavos 
hacia el centro del cuerpo, lados longitudinales también fuertemente cóncavos, y ángulos redondeados. Adherencia distal no discernible. Sexina del saco infrareticulada, conformando muros irregulares y densamente dispuestos que delimitan lúminas de contorno irregular.

Dimensiones (10 ejemplares). Ancho total, 59(74,3)84 $\mu \mathrm{m}$; largo total, 49(59,5)72 $\mu \mathrm{m}$; cuerpo central, ancho 44(57,2)82 $\mu \mathrm{m}$ y $38(39,7) 60 \mu \mathrm{m}$ de largo; ancho del saco sobre cara proximal, $44(57,2) 82 \mu \mathrm{m}$.

Principal material estudiado. BAPal 6152 (a) V64/0, B52/0, D38/1; BAPal 6152 (b) J60/3, N49/1; BAPal 6160 (a) J53/3; BAPal 4176-82A: H67/0; BAPal 6187 (a) J39/0. Redepósito: BAPal 6174 (a) P33/2; BAPal 6178 (b) S60/0.

Registros previos. Striomonosaccites cicatricosus fue descripta originalmente por Archangelsky y Gamerro (1979) para las biozonas Striatites y Cristatisporites, Cuenca Chacoparaná (Cisuraliano-Guadalupiano).

- Cisuraliano: Brasil: ilustrada para el Grupo Itararé, Cuenca Paraná (Dias, 1993). Uruguay: presente en las formaciones San Gregorio, Cuenca Paraná (Gutiérrez et al., 2006b). Paraguay: ilustrada para la Formación Tacuary, Grupo Independencia, Cuenca Chacoparaná (Muff et al., 1999).

- Cisuraliano-Guadalupiano: Argentina: presente en la Cuenca Chacoparanense (Archangelsky y Gamerro, 1979; Vergel, 1987b; Césari et al., 1995). Uruguay: presente en la Formación Melo, Cuenca Paraná (Mautino et al., 1998b; Beri y Pecoits, 2001).

\section{Infraturma STRIATORNATI Jansonius 1962}

Género Crustaesporites Leschik emend. Jansonius 1962

Especie tipo. Crustaesporites globosus Leschik, 1956.

Afinidad botánica. Glossopteridales (Lindström et al., 1997).

\section{Crutaesporites globosus Leschik 1956}

Lámina XI, figuras G y H

Descripción. Grano de polen monosacado, de contorno general subtriangular trilobado, de contorno ondulado. Cuerpo central suboval, elongado en sentido transversal, de 
bordes irregulares. Cara proximal con estrías que delimitan tenias subparalelas (aproximadamente de 5 a 7), de disposición horizonal u oblícua, completas, de extremos ahusados. El cuerpo está delimitado por un pliegue o engrosamiento periférico irregular y discontinuo. Saco irregular, con 1 a 3 constricciones generando subsacos, adherido subecuatorialmente por ambas caras. En algunos casos pueden observarse pliegues radiales. Intexina infrarreticulada, delimitando lúminas irregulares a ovales, orientadas radialmente.

Dimensiones (3 ejemplares). Ancho total, 60(77,3)100 $\mu \mathrm{m}$; largo total, 48(58)66 $\mu \mathrm{m}$; cuerpo central, ancho $36(50,5) 66 \mu \mathrm{m}$ y $28(39,6) 47 \mu \mathrm{m}$ de largo; subsaco sobre cara proximal, ancho $20(25,3) 29 \mu \mathrm{m}$ y $38(48) 59 \mu \mathrm{m}$ de largo. Ancho de las tenias, 3(4,7)6,5 $\mu \mathrm{m}$. Ancho del engrosamiento, 4(4,6)5,2 $\mu \mathrm{m}$.

Principal material estudiado. BAPal 6148 (a) M55/3; BAPal 6158 (a) O39/2; BAPal 6167 (a) $X 44 / 2$.

Comentarios. Los ejemplares estudiados son referidos sin dudas a la especie Crutaesporites globosus por evidenciar las características diagnósticas: grano monosacado de contorno irregular, trilobado por constricciones del saco, con cuerpo central con estrías proximales subparalelas (de 5 a 7 ).

Registros previos. Crustaesporites globosus fue descripto por Leschik (1956) para Salzton von Neuhof (Bei Fulda), Lopingiano de Alemania.

Esta es la primera cita de la especie para cuencas sudamericanas.

Subturma POLYSACCITES Cookson 1947

Género Polarisaccites Ybert y Marques-Toigo 1970

Especie tipo. Polarisaccites bilateralis Ybert y Marques-Toigo, 1970.

Afinidad botánica. Desconocida.

Polarisaccites bilateralis Ybert y Marques-Toigo 1970

Lámina XI, figuras C y D

Descripción. Grano de polen polisacado, de simetría bilateral y contorno oval a subrectangular, elongado transversalmente. Cuerpo central bien definido, de contorno similar al general. Cara proximal rodeada por un saco de disposición ecuatorial, de 
ancho constante, y con 2 subsacos separados por un surco angosto longitudinal. Cara distal con saco oval elongado paralelo al eje mayor, dispuesto en todo el ancho del cuerpo. Sexina del saco ecuatorial con un retículo orientado radialmente, delimitando lúmenes angostos. Infraretículo de los sacos polares más pequeño.

Dimensiones (3 ejemplares). Ancho total, 69(91,3)108 $\mu \mathrm{m}$; largo total, 52(62)68 $\mu \mathrm{m}$; cuerpo central, ancho 52(62,3)74 $\mu \mathrm{m}$ y 42(55)66 $\mu \mathrm{m}$ de largo; ancho del saco sobre cara proximal, 9(18)24 $\mu \mathrm{m}$.

Principal material estudiado. BAPal 6183 (a) L36/0. Redepósito: BAPal 6172 (a) O58/3; BAPal 6181 (a) M40/0.

Registros previos. Polarisaccites bilateralis fue descripta originalmente por Ybert y Marques-Toigo (1970) para la Formación San Gregorio, Cuenca Paraná, Uruguay.

- Pennsylvaniano-Cisuraliano: Argentina: ilustrada para la Formación Río del Peñón, Cuenca Paganzo (Gutiérrez y Limarino, 2006).

- Cisuraliano: Brasil: presente en el Grupo Itararé, Cuenca Paraná (Dias, 1993) y en la Formación Nova Olinda, Grupo Trapajós, Cuenca Amazonas (Playford y Dino, 2000b). Uruguay: presente en la Formación San Gregorio, Cuenca Paraná (Marques-Toigo, 1972).

- Cisuraliano-Guadalupiano: Argentina: presente en las biozonas PotonieisporitesLundbladispora (parte alta), Cristatisporites y Striatites (parte basal), Cuenca Chacoparaná (Archangelsky y Gamerro, 1979; Vegel, 1987b; Césari et al., 1995). Brasil: presente en la Formación Rio Bonito (Ybert, 1975; Dias-Fabrício, 1981).

\section{Subturma DISACCITES Cookson 1947}

Infraturma DIASACCITRILETES Leschik emend. Potonié 1958

\section{Género Alisporites Daugherty emend. Jansonius 1971}

Especie tipo. Alisporites opii Daugherty, 1941.

Afinidad botánica. Gymnospermopsida-Caytoniales-Corystopermaceae (véase Balme, 1995; Retallack, 2002; Raine et al., 2006).

Observaciones al género. Alisporites opii fue descripta originalmente por Daugherty (1941, p. 48, pl. 34, fig.2.), quien destacó la presencia de un sulco simple y fusiforme. Posteriormente, Nilsson (1958, p. 81) tras revisar algunos materiales, redescribió la 
especie, observando que algunos de los ejemplares presentan la exina central distal rota, dañada o ausente, minimizando de ésta forma la importancia de la zona distal, por lo tanto la presencia o ausencia del sulco, para la diferenciación genérica. Balme (1970, p. 390) comparó a los géneros Alisporites y Falcisporites, concluyendo que pueden ser separados ambos por ausencia y presencia, respectivamente, de un sulco bien definido en la cápula. Jansonius (1971, pp. 355-356), en un minucioso trabajo de recopilación de sucesivas descripciones e interpretaciones del género, concluyó que Alisporites presenta un sulco distinguible en la cápula, al igual que Falcisporites, y que puede ser separado claramente por poseer éste último sacos con infraretículo más grueso, cápula bien definida y delineada por las bases de los sacos, y por la presencia de engrosamientos proximales de la exina a lo largo del eje longitudinal. Foster (1979, p. 72) coincide con que ambos géneros presentan sulco, y considera que la única característica clara para separar Falcisporites de Alisporites es la presencia de la exina del protosaco expandida sobre la capa. Tomando en consideración los criterios de Jansonius y Foster, aquí se entiende que las formas bisacadas de cuerpo central liso que presentan en la cápula un sulco, deben ser consideradas dentro del género Alisporites, y solo aquellas que, además de éstos caracteres, presentan un engrosamiento proximal a modo de pliegue, el infraretículo de los sacos más grueso, un hábito típicamente haploxilonoide y sacos que no presenten una marcada inclinación distal, deberán ser incluídas en el género Falcisporites.

Dentro del género Alisporites, se han estudiado formas que no presentan un evidente $\mathrm{u}$ observable sulco, y se asume que esta ausencia podría deberse al grado de madurez de los granos, ya que se considera que éste carácter estaría ligado a éste factor, como así también al variable grado de preservación de los mismos, situación que puede enmascarar este carácter.

Satsangisaccites Bharadwaj y Srivastava (1969b), se diferencia de Alisporites por presentar un estrecho sulco, estar los sacos adheridos lateralmente de manera continua y por presentar también pliegues proximales asociados a las raíces de los sacos.

La mayoría de los trabajos que involucran el estudio de Alisporites, incluyen dentro del género formas que pueden o no presentar sulco. 
Lámina VIII 


\section{Lámina VIII}

A. Cannanorpollis sp. cf. C. densus (Lele) Bose y Maheshwari 1968, BAPal 6153 (a) Q68/0 (X 850).

B. Cannanoropollis janakii Potonié y Sah 1960, BAPal 6152 (a) L42/3 (X 650).

C. Cannanoropollis methae (Lele) Bose y Maheshwari 1968, BAPal 6186 (a) J49/1 (X $850)$.

D. Costatacyclus crenatus Felix y Burbridge emend. Urban 1971, BAPal 6189 (a) F62/1 (X 850).

E y F. Potonieisporites brasiliensis (Nahuys, Alpern e Ybert) Archangelsky y Gamerro 1979, BAPal. 6188 (a) T50/3 (X 350); BAPal 6187 (a) T64/1. (X 400)

G. Potonieisporites densus Maheshwari 1967, BAPal 6154 (a) P73/2 (X 800).

H. Potonieisporites lelei Maheshwari 1967, BAPal 6158 (a) J64/1 (X 700). 

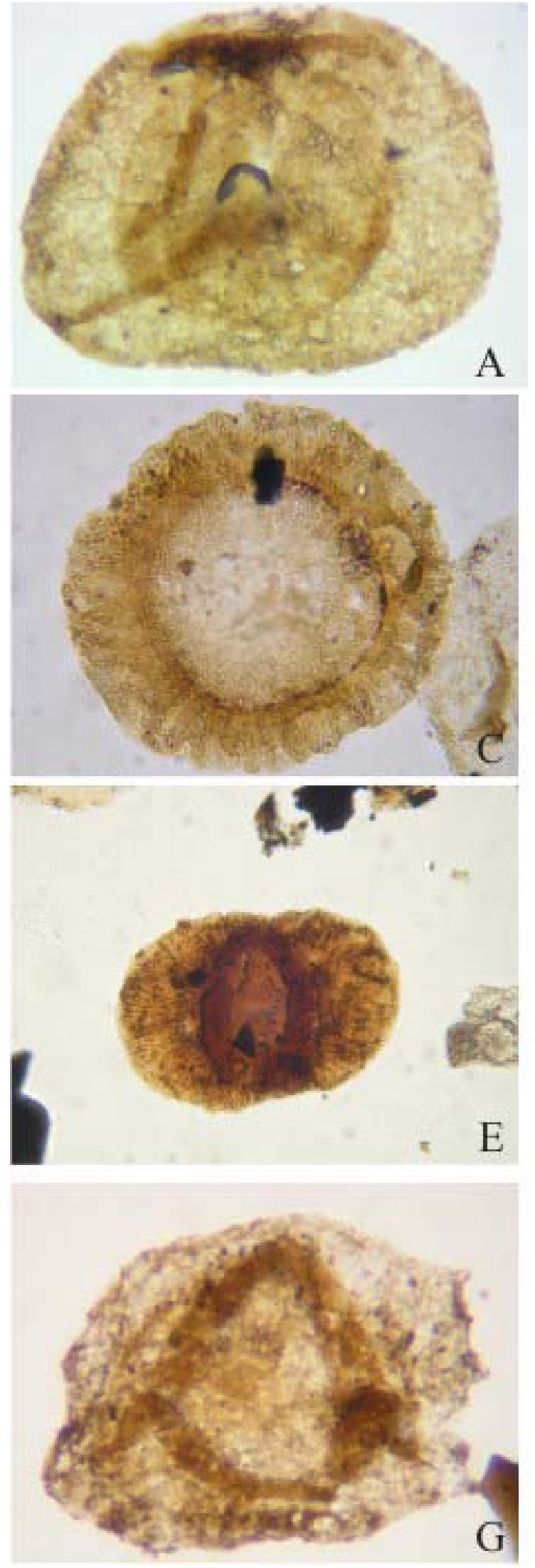
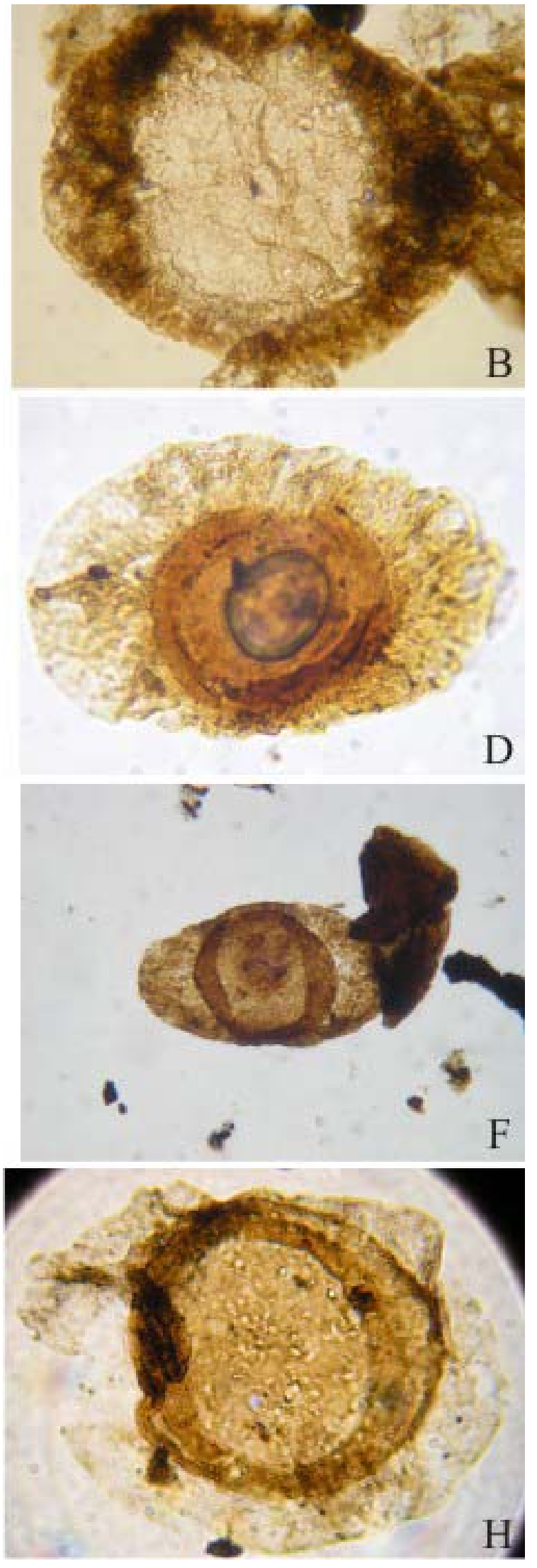


\section{Lámina IX}

A. Potonieisporites sp. cf. P. pyriferus Playford y Dino 2000a, BAPal 6187 (a) U44/0 (X 350).

B. Potonieispoirtes triangulatus Tiwari 1965, BAPal 6155(a) Y53/1 (X 350).

C y D. Plicatipollenites malabarensis (Potonié y Sah) Foster 1975, BAPal 6172 (a) R71/0 (X 350); BAPal 6183 (b) V46/1 (X 350)

E y F. Cahenisaccites densus Lele y Karim emend. Gutiérrez 1993, BAPal 6155(a) H45/1 (X 350); BAPal 6185 (b) P37/3 (107 m). (X 350).

G. Caheniasaccites elongatus Bose y Kar 1966, BAPal 6158(b) C41/3 (X 800).

H. Crucisaccites latisulcatus Lele y Maithy 1964, BAPal 6162 (b) F48/1 (X 900). 

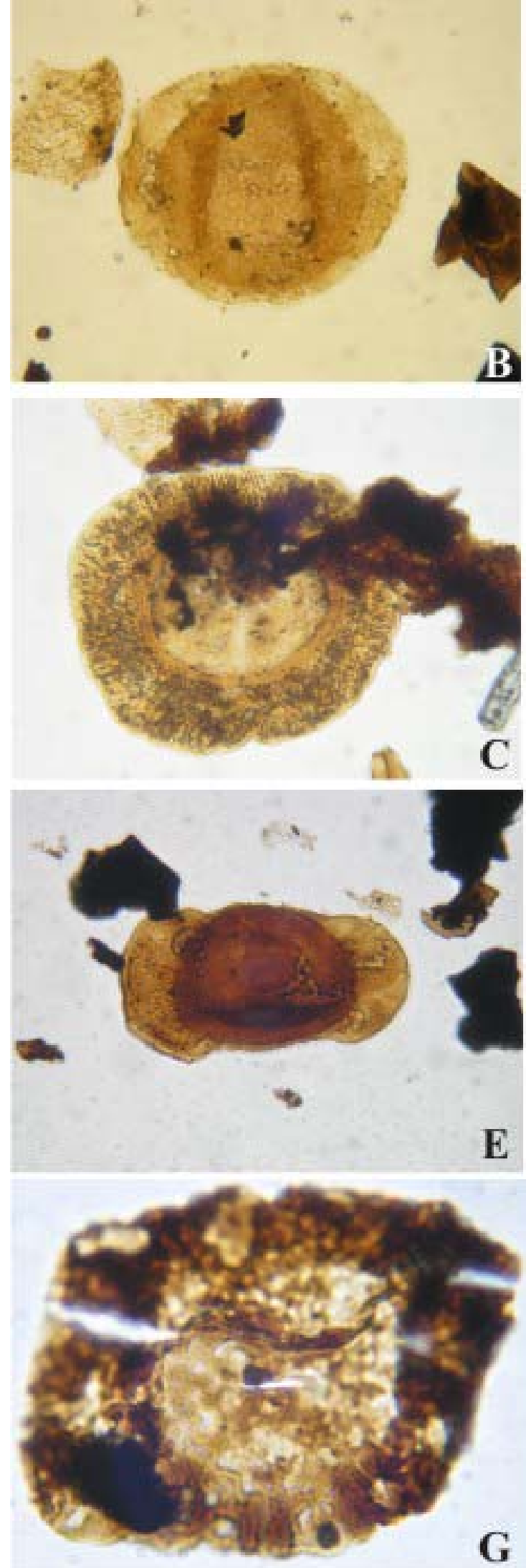
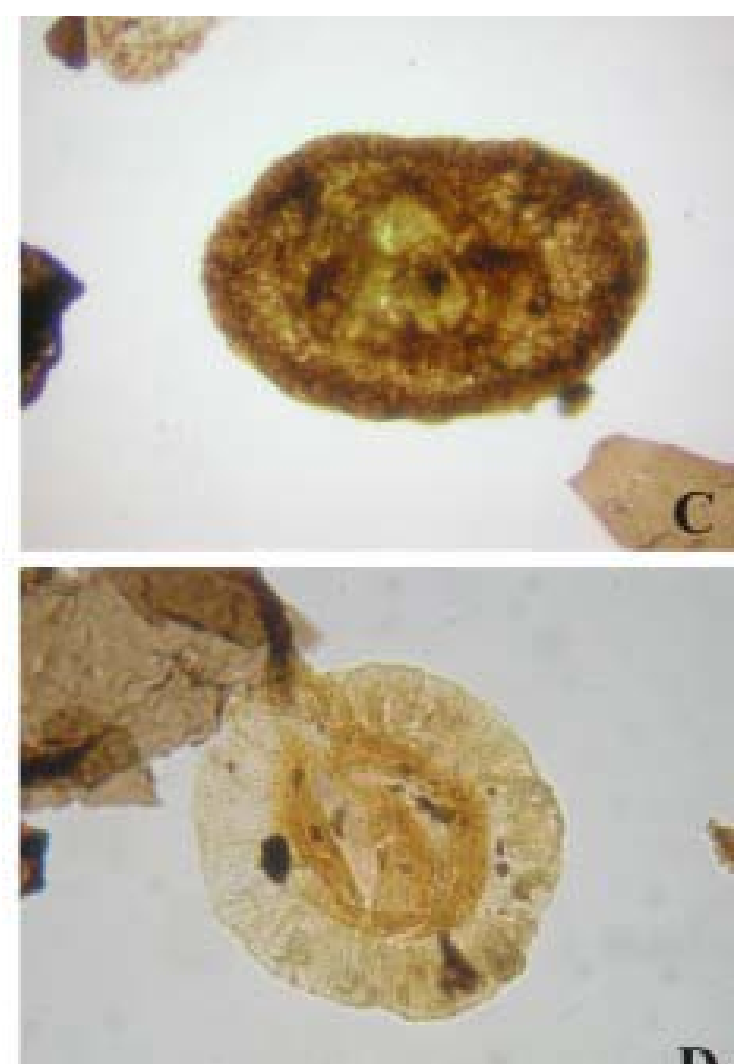

D

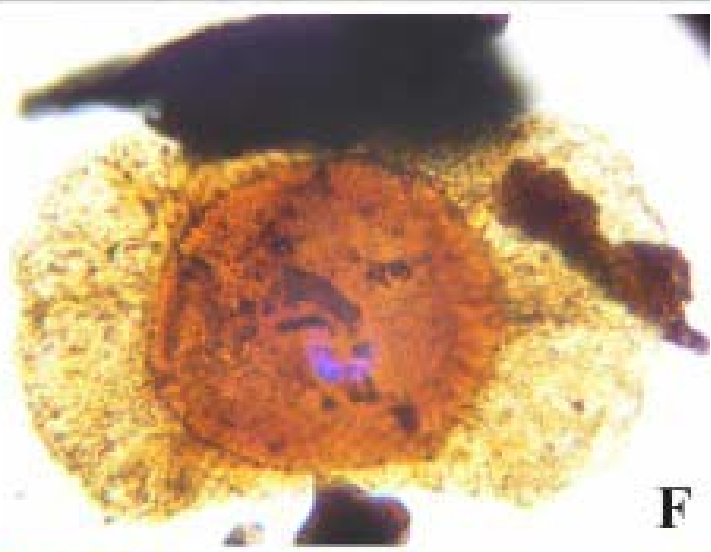

F

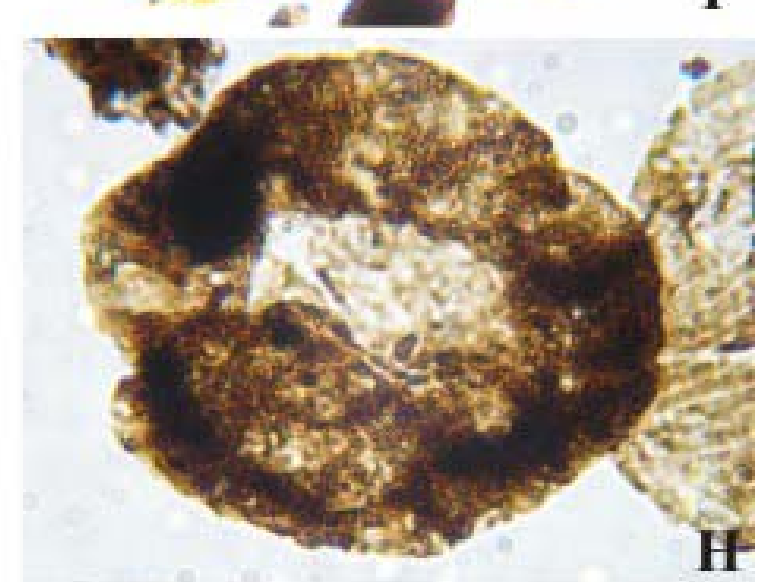




\section{Lámina $\mathrm{X}$}




\section{Lámina X}

A. Crucisaccites sp. A, BAPal 6156 (c) C50/4 (X 850).

B. Gondwanapollis frenguellii (Césari) Gutiérrez 1993, BAPal 6152(a) Q44/0 (X 900).

C y D. Bascanisporites sp. A, BAPal 6152(b) L61/4 (X 1000).

E. Stellapollenites sp. cf. S. talchirensis Lele 1965, BAPal 6152 (a) M43/0 (X 650).

F. Accinctisporites excentricus (Leschik) Jain 1968, BAPal 6164 (a) W51/0 (X 850).

G y H. Accinctisporites sp. A, BAPal 6152 (a) G47/3 (X 800); L45/3 (X 700). 

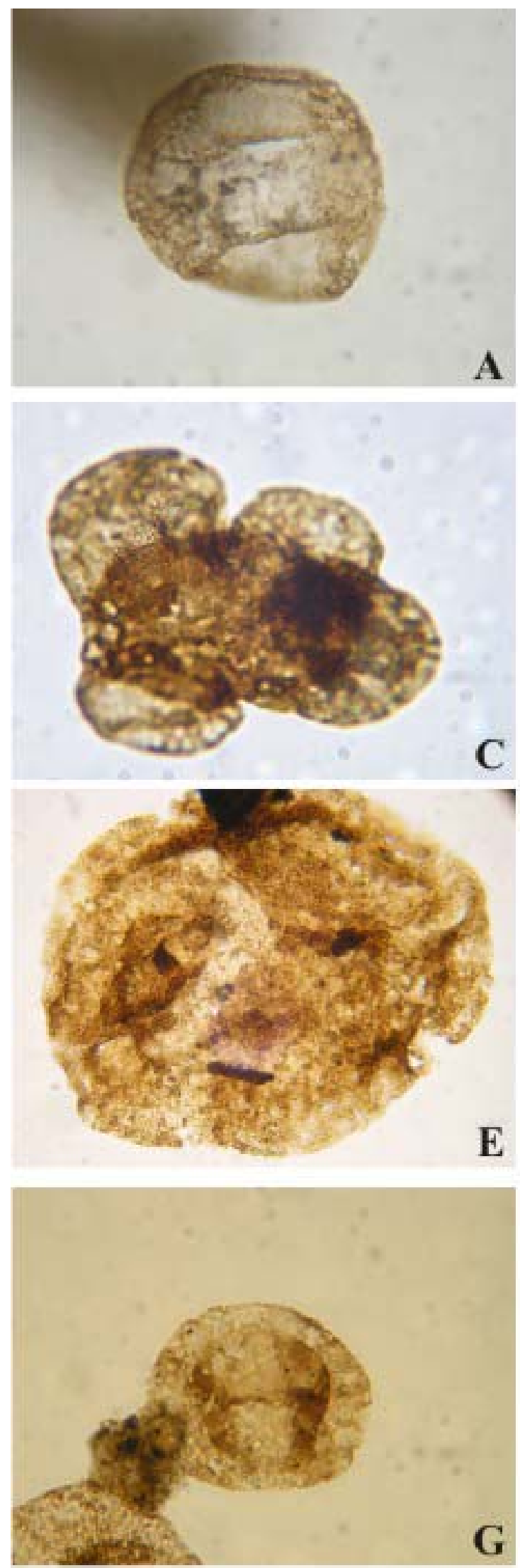
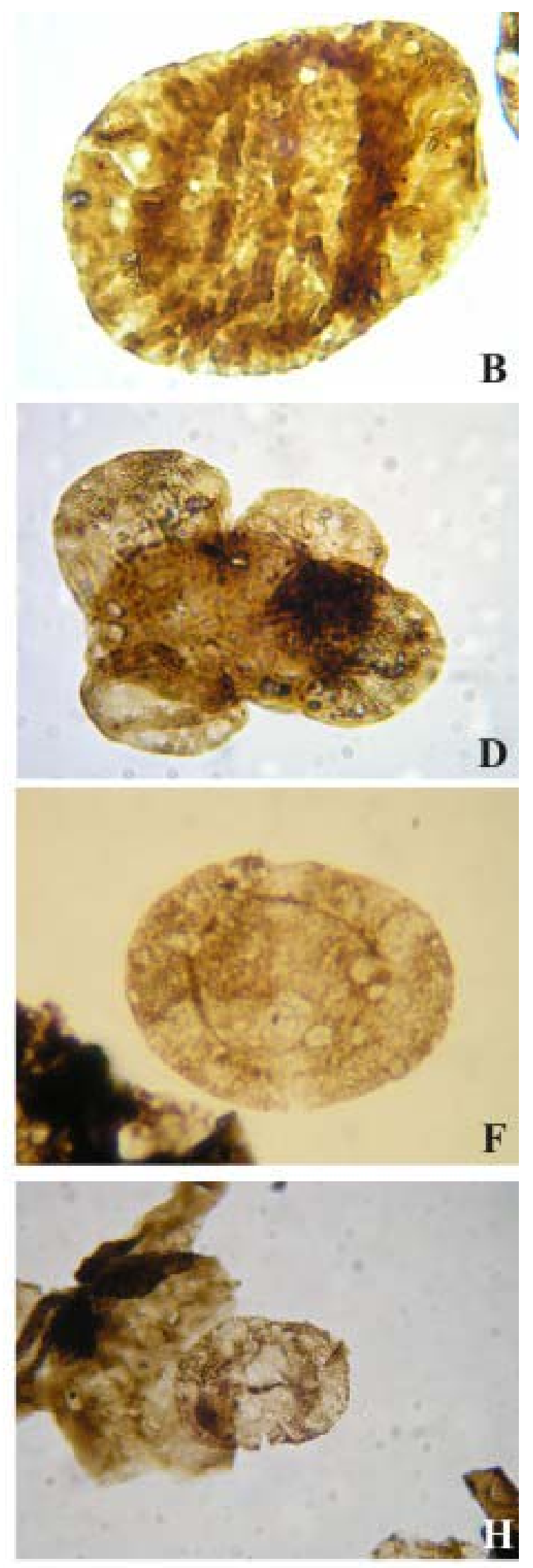
Lámina XI 


\section{Lámina XI}

A. Meristocorpus sp. A, BAPal 6171 (a) S50/0 (X 900).

B. Meristocorpus sp. B, BAPal 6152 (a) U45/3 (X 800).

C y D. Polarisaccites bilateralis Ybert y Marques-Toigo 1970, BAPal 6181 (a) M40/0 (X 500); BAPal 6183 (a) L36/0 (X 350).

E y F. Striomonosaccites cicatricosus Archangelsky y Gamerro 1979, BAPal 6186 H67/0 (X 700); BAPal 6152 (a) V64/0 (X 800).

G y H. Crutaesporites globosus Leschik 1956, BAPal 6148 (a) M55/3 (X 850); BAPal 6159(a) O66/3 (X 750). 

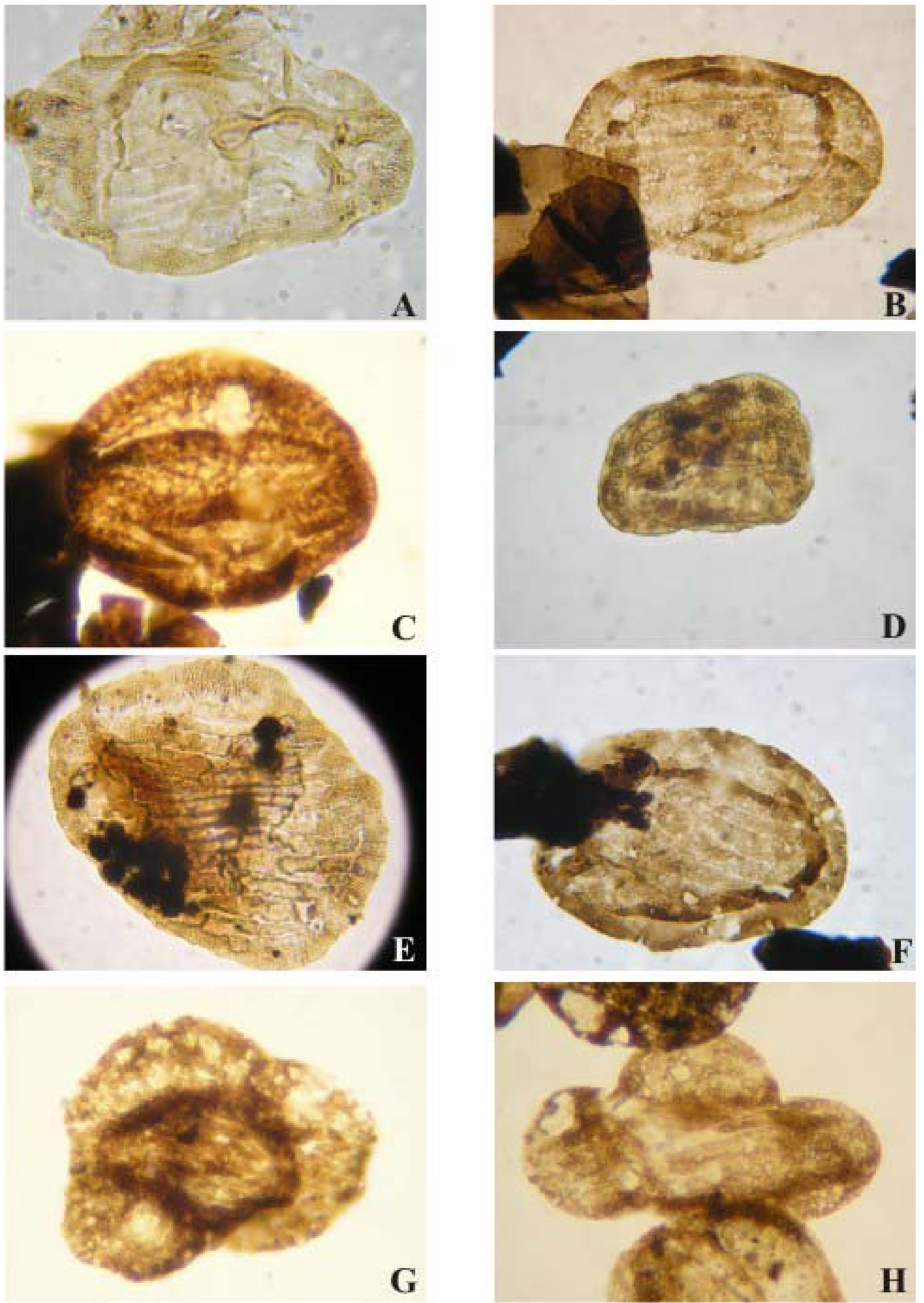
Alisporites australis de Jersey 1962

Lámina XII, figuras A y B; Lámina XVI, figura G

1980b. Alisporites sp. Archangelsky y Gamerro, lám. II, fig. 8.

Descripción. Grano de polen bisacado, de contorno general haploxilonoide. Cuerpo central de pared lisa, de contorno oval elongando transversalmente, rara vez circular. Cápula siempre distinguible, angosta, de lados rectos y extremos ahusados. Sacos iguales o levemente mayores a $1 / 2$ círculo, de implantación ecuatorial proximal y bilateral distal, levemente inclinados. Sexina de los sacos infrareticulada con muros gruesos (de hasta $1 \mu \mathrm{m}$ ), delimitando lúminas irregulares.

Dimensiones (10 ejemplares). Ancho total, 32(47,1)75 $\mu \mathrm{m}$; cuerpo central, ancho $18(24) 35 \mu \mathrm{m}$ y $23(33,8) 48 \mu \mathrm{m}$ de largo; ancho del saco sobre cara proximal, $7(11) 15$ $\mu \mathrm{m}$ y sobre cara distal, 12(19,3)27 $\mu \mathrm{m}$; ancho de la cápula, 3-5 $\mu \mathrm{m}$; largo del saco, $20(31,5) 45 \mu \mathrm{m}$.

Principal material estudiado. BAPal 6152 (a) F50/0, S44/4, D40/0, J60/3, G44/0; BAPal 6155 (a) M69/0; BAPal 6158 (a) G70/4; BAPal 6165 (a) E59/2; BAPal 6168 (a) $\mathrm{H} 43 / 1$.

Comentarios. Alisporites indicus Bharadwaj y Srivastava (1969b, pp. 134-135, pl. 23, figs. 78-79) no es considerado sinónimo de A. australis, como lo consideró Foster (1979, p. 79), ya que según se observa en las fotografías del material estudiado por los autores, la característica forma del cuerpo central truncado no permite ser incluído dentro de las formas de A. australis.

Por las características observadas en el material referido a Alisporites sp. por Archangelsky y Gamerro (1980b, lám. II, fig. 8), tales como la forma general y del cuerpo, así como de la cápula, el mismo es aquí incluido en $A$. australis.

Registros previos. Alisporites australis fue descripta por de Jersey (1962) para Ipswich Coalfield, Triásico, Australia. De amplia y abundante distribución en sedimentos del Pérmico al Jurásico de Gondwana (Raine et al., 2006), y restringido al AnisianoLadiniano de Europa y Rusia.

- Cisuraliano: Argentina: presente en la Formación Tasa Cuna, Cuenca Paganzo (Balarino y Gutiérrez, 2006). Uruguay: presente en la Formación Tres Islas (Fasolo y Vergel, 1994), Cuenca Paraná. Antártida: presente en Fossilryggen (Lindström, 1996). 
- Cisuraliano-Guadalupiano: Uruguay: presente en la Formación Melo (Beri y Pecoits, 2001), Cuenca Paraná. Argentina: ilustrada para la Biozona Cristatisporites, Cuenca Claromecó-Colorado (Archangelsky y Gamerro, 1980b).

- Lopingiano-Triásico Inferior: Australia: presente en la Formación Rewan, Cuenca Bowen (Foster, 1979).

- Triásico: Argentina: presente en las formaciones Cacheuta (Jain, 1968; Zavattieri, 1991b), Potrerillos (Zavattieri, 1987; Zavattieri y Volkheimer, 1992), Las Cabras (Zavattieri, 1991), Puesto Viejo (Ottone y García 1991), El Tranquilo (Zavattieri, 1992), Rancho de Lata (Ottone et al., 1992) y Santa Clara Arriba (Zavattieri y Batten, 1996), todas de Cuenca Cuyana.

- Jurásico: Argentina: presente en la Formación Nestares (Zavattieri y Volkheimer, 2003).

- Cretácico: Argentina: presente en la Formación Malargüe (Papú, 1990).

\section{Alisporites opii Daugherty 1941}

\section{Lámina XII, figuras C y D}

Descripción. Grano de polen bisacado, levemente diploxilonoide. Cuerpo central de pared lisa, de forma oval elongando longitudinalmente. Cápula siempre distinguible, angosta, rectangular a ahusada. Sacos mayores a 1/2 círculo, de implantación proximal ecuatorial y distal bilateral, inclinados distalmente. Sexina de los sacos infrareticulada con muros gruesos (de hasta $1 \mu \mathrm{m}$ ), delimitando lúminas irregulares.

Dimensiones (4 ejemplares). Ancho total, 32(54,2)71 $\mu \mathrm{m}$; cuerpo central, ancho $19(22,7) 35 \mu \mathrm{m}$ y $24(36,6) 45 \mu \mathrm{m}$ de largo; ancho del saco sobre cara proximal, 9(12,2)16 $\mu \mathrm{m}$ y sobre cara distal, 15(24,7)34 $\mu \mathrm{m}$; ancho de la cápula, 4-8 $\mu \mathrm{m}$; largo del saco, 34(43,3)49 $\mu \mathrm{m}$.

Principal material estudiado. BAPal 6145 (a) P44/0; BAPal 6152 (a) P44/0, S74/1; BAPal 6155 (a) Q68/4.

Comentarios. Los ejemplares estudiados son asignados a la especie Alisporites opii por presentar un contorno haploxilonoide a levemente diploxilonoide, un cuerpo central oval longitudial y cápula angusta oval, etc.; características diagnósticas de la especie. 
Registros previos. Alisporites opii fue descripta por Daugherty (1941) para el Triásico de Arizona.

- Triásico: Estados Unidos: mencionada para el Rift Richmond, Cuenca Virginia (Cornet, 1989).

Esta es la primera cita de la especie para la Argentina.

\section{Alisporites rioclarensis Menéndez 1976 \\ Lámina XII, figura $\mathrm{E}$}

Descripción. Grano de polen bisacado, haploxilonoide. Cuerpo central de subrectangular a suboval, elongado en sentido transversal, de pared delgada lo que le otorga similar coloración respecto de los sacos. Cápula ancha desarrollada de igual manera que el contorno del cuerpo central. Sacos iguales o levemente mayores a medio círculo, sin puentes exinales, con una amplia superficie de adherencia al cuerpo. Sexina de los sacos finamente infrareticulada, donde se distinguen delgados muros que definen irregulares lúminas.

Dimensiones (7 ejemplares). Ancho total, 46(59,5)100 $\mu \mathrm{m}$; cuerpo central, ancho $22(26,1) 50 \mu \mathrm{m}$ y $25(26,4) 48 \mu \mathrm{m}$ de largo; ancho del saco sobre cara proximal, 6(13)25 $\mu \mathrm{m}$ y sobre cara distal, 10(23,4)39 $\mu \mathrm{m}$; ancho de la cápula, 6-9 $\mu \mathrm{m}$; largo del saco, 29$48 \mu \mathrm{m}$.

Principal material estudiado. BAPal 6152 (a) O69/1, H59/3, P51/0, S53/3; BAPal 6162 (a) R58/2; BAPal 6164 (a) H61/0; BAPal 6165 (b) M40/2.

Comentarios. Los ejemplares son asignados a la especie Alisporites rioclarensis por presentar la característica forma del cuerpo oval transversal, una ancha cápula y sacos de implantación proximal-ecuatorial y distal bilateral, generando un área amplia de inserción, características éstas diagnósticas de la especie.

Registros previos. Alisporites rioclarensis fue descripta por Menéndez (1976) para los "Estratos con Mesosaurus", Formación Iratí, de la localidad de Río Claro, en Brasil.

- Cisuraliano-Guadalupiano: Uruguay: presente para la Formación Mangrullo, Cuenca Paraná (Gutiérrez et al., en prensa-b).

Esta es la primera cita de la especie para la Argentina. 


\section{Género Chordasporites Klaus 1960}

Especie tipo. Chordasporites cingulichordata Klaus, 1960.

Afinidad botánica. Gimnospermopsida (véase Raine et al., 2006).

Chordasporites sp. cf. C. australiensis de Jersey 1962

Lámina XII, figura F

Descripción. Grano de polen bisacado, de formas transicionales desde haploxilonoide a diploxilonoide, de contorno general oval, elongado en sentido transversal. Cuerpo central de forma variable, de subcircular a suboval tanto longitudinal como trasversal. Chorda de posición transversal que bisecta al cuerpo. El ancho de la chorda varía de 1 a $3 \mu \mathrm{m}$ y puede variar el ancho en distintas alturas de su extensión. El borde del mismo es liso y el trayecto puede ser algo sinuoso. Cápula de ancho variable, subrectangular. Sacos iguales o levemente mayores a $1 / 2$ círculo, de inserción proximal ecuatorial y distal subecuatorial, de inclinación distal. Zonas de adherencia de bordes distales rectos y ecuatoriales cóncavos, de ancho variable. Sexina de los sacos infrareticulada, de muros gruesos que limitan lúminas de contornos irregulares.

Dimensiones (27 ejemplares). Ancho total, 39(57,8)80 $\mu \mathrm{m}$; cuerpo central, ancho 19(31,6)61 $\mu \mathrm{m}$ y 18(29,2)37 $\mu \mathrm{m}$ de largo; ancho del saco sobre cara proximal, 19(14)18 $\mu \mathrm{m}$ y sobre cara distal, 10(22,1)32 $\mu \mathrm{m}$; largo del saco, 19(37,3)52 $\mu \mathrm{m}$.

Principal material estudiado. BAPal 6138 (a) G65/1; BAPal 6146 (b) R62/4; BAPal 6152 (a) U60/3, U54/3, D56/0, J48/0, K56/0, L41/0; BAPal 6152 (c) P52/4.

\section{Género Falcisporites (Leschik) Klaus, 1963}

Especie tipo. Falcisporites zapfei Potonié y Klaus, 1954.

Observaciones. Falcisporites se diferencia de Alisporites por presentar un engrosamiento proximal a modo de pliegue; infraretículo de los sacos más grueso; hábito típicamente haploxilonoide y sacos sin una marcada inclinación distal (véase Observaciones al género Alisporites).

Afinidad botánica. Gymnospermopsida-Caytoniales-Corystopermaceae (véase Balme, 1995; Raine et al., 2006). 
Falcisporites parvus (de Jersey) nov. comb.

Lámina XII, figuras $\mathrm{G}$ y $\mathrm{H}$

1962. Alisporites parvus de Jersey, p. 9, pl. 4, figs 1-4.

1977. pars. Pityosporites triassicus (Bharadwaj y Srivastava) Anderson, p. 111, pl. 137, figs. 1,2 y 8 .

1977. pars. Platysaccus nucleoparvus Anderson, p. 112, pl. 138, figs. 24-26, 28-29, 31, 33- 34, 38, 41.

Descripción. Grano de polen bisacado, haploxilonoide a levemente diploxilonoide. Cuerpo central de pared delgada, la que le otorga una coloración similar a la de los sacos. Contorno del cuerpo oval elongado longitudinalmente, rara vez subcircular. Cápula de lados cóncavos, alcanza un gran desarrollo y no presenta sulco visible. Sacos iguales o mayores a $1 / 2$ círculo, de inserción proximal ecuatorial y distal subecuatorial, con una leve inclinación distal. Engrosamientos de la exina desarrollados en las bases proximales de los sacos, conformando pliegues semicirculares, algo menores que la zona de inserción. Los mismos se desarrollan en los lados longitudinales del cuerpo, son contínuos, no se contactan entre sí y su ancho se afina hacia los extremos. Sexina de los sacos infrareticulada, conformando delgados muros que definen lúminas irregulares.

Dimensiones (26 ejemplares). Ancho total, 32(48,6)67 $\mu \mathrm{m}$; cuerpo central, ancho $18(26,1) 38 \mu \mathrm{m}$ y $20(30,6) 38 \mu \mathrm{m}$ de largo; ancho del saco sobre cara proximal, $8(11,2) 13 \mu \mathrm{m}$ y sobre cara distal, $14(20,4) 25 \mu \mathrm{m}$; largo del saco, 19(37,3)52 $\mu \mathrm{m}$.

Principal material estudiado. BAPal 6152 (a) B43/0, B36/4, C39/2, H75/0, G51/4, J39/0, K65/0, N63/0, O68/1, Q69/1, L62/0.

Comentarios. Alisporites parvus ha sido definida por de Jersey (1962), sin mencionar en la diagnosis la presencia de los pliegues exinales proximales en las bases de los sacos, como sí puede observarse en las figuras que la ilustran (pl. 4, figs. 1-4). Estos pliegues pueden ser confundidos con la zona de adherencia, ya que ésta se presenta como una zona oscura y ancha, pero pueden ser diferenciados éstos por exhibir límites bien definidos, son incluso aún más oscuros, y estar incluidos en la zona. Zavattieri (1991a) en su trabajo sobre los granos de polen del Triásico de la Formación Las Cabras, Mendoza, menciona e ilustra ejemplares que asignó como A. parvus, pudiendo observarse en el material ilustrado (lám. IV, fig. 6) la presencia bien notoria de estos 
pliegues exinales proximales. Así mismo, asignó ejemplares a $A$. sp. cf. A. parvus, y en éste material ilustrado (lám. III, fig. 8), también pueden observarse los engrosamientos mencionados. Volkheimer y Papú (1993, p. 96, lám. II, fig. 3), mencionan A. parvus para el Triásico de la Formación Chihuido, Cuenca de Malargüe, provincia de Mendoza. En el material ilustrado, se pueden observar tanto la zona oscura de adherencia, como así también, parte de los engrosamientos antes mencionados. Por presentar tanto el material aquí estudiado, como el material ilustrado en los trabajos mencionados estos engrosamientos exinales proximales, se combina la especie, siendo entonces una especie del género Falcisporites, diagnosticandose por la presencia de dichos engrosamientos.

Comparaciones. Parte de los ejemplares ilustrados por Anderson (1977, pl. 137, solo figuras 1, 2 y 8) encuentran mejor ubicación en Falcisporites parvus por exhibir pliegues proximales asociados a las raíces de los sacos. Lo mismo sucede con algunos de los ejemplares ilustrados como Platysaccus nucleoparvus Anderson (1977, p. 112, pl. 138, figs. 24-26, 28-29, 31, 33-34, 38, 41).

Registros previos. Alisporites parvus ha sido descripta para el Triásico de Australia (de Jersey, 1962).

- Cisuraliano: Bolivia: ilustrada para la Formación Vitiacua (Sempere et al., 1992). Sudáfrica: presente en Cuenca Karroo (Anderson, 1977).

- Triásico: Argentina: mencionada para las formaciones Las Cabras (Zavattieri 1990; 1991a) y Potrerillos (Zavattieri y Volkheimer, 1992), ambas comprendidas en la Cuenca Cuyana. También es reconocida la especie para la Formación Chihuido, Cuenca de Malargüe (Volkheimer y Papú, 1993). Ilustrada para la Formación Comallo, Río Negro (Zavattieri et al., 1994). Chile: ilustrada para la Formación Panguipulli (Zavattieri et al., 2003). Antártida: mencionada para Beardmore Glacier Area (Kyle y Fasola, 1978); presente en la Formación Falla, Central Transactartic Mountains (Farabee et al., 1989). Australia: presente en Ipswich Coalfield (de Jersey, 1962; Dolby y Balme, 1976). Europa: Cuenca Hessen, Scythiano-Anisinano, Alemania (Doubinger y Buhman, 1981); Francia, Landiano superior-Reto-Liásico (Doubinger y Adloff, 1977); presente en la Formación Heiberg, Noriano y Retiano (Fisher, 1979). Asia: presente en la Cuenca Kerman, Reto-Liásico, Irán central (Arjang, 1975). Estados Unidos: Texas, Carniano (Moy y Traverse, 1986). 
Falcisporites similis (Balme) nov. comb.

Lámina XIII, figuras A y B

1957. Pityosporites similis Balme, p. 36, pl. 10, figs. 108-109.

1963. Alisporites similis (Balme) Dettmann, p. 102, pl. 25, figs. 5-7.

1977. pars. Platysaccus nucleoparvus Anderson, p. 112, pl. 138, figs. 36, 37, 40.

1977. pars. Pityosporites tenuicorpus (Balme) Anderson, p. 114, pl. 139, fig. 21, pl. 140, figs. 4, 12-14, 28, 30, 35-40, pl. 141, figs. 12, 28, 33-34, 37.

Descripción. Grano de polen bisacado, haploxilonoide, de contorno general circular a levemente oval, elongado en sentido transversal. Cuerpo central de pared lisa, de contorno similar al contorno oval transversal. Cápula conspicua rectangular, de lados rectos bien definidos, rectos, de 1(4,5)9 $\mu \mathrm{m}$ de ancho. Sacos semicirculares, de adherencia proximal ecuatorial y distal bilateral. Asociados a las raíces proximales de los sacos se observan un par de pliegues semilunares, extendidos en el largo del cuerpo central, sin contactarse entre sí por los extremos del mismo. Sexina de los sacos infrareticulada, con muros delgados y lúminas irregulares.

Dimensiones (16 ejemplares). Ancho total, 29(41,6)49 $\mu \mathrm{m}$; cuerpo central, ancho $18(25,2) 30 \mu \mathrm{m}$ y $21(30,1) 36 \mu \mathrm{m}$ de largo; ancho del saco sobre cara proximal, $6(8,7) 12$ $\mu \mathrm{m}$ y sobre cara distal, 14(17,4)20 $\mu \mathrm{m}$; largo del saco, 22(31,6)36 $\mu \mathrm{m}$.

Principal material estudiado. BAPal 6152 (a) N64/4, M68/3, S69/4, S46/3, G38/1, H65/2, S55/2, T47/2; BAPal 6154 (a) M67/0, T65/0; BAPal 6156 (a) S44/2; BAPal 6165 (a) $\mathrm{O} 44 / 0$.

Discusión. Originalmente fue definida y descripta por Balme (1957, p. 35, pl. 10, figs. 108-109) como Pityosporites similis. Posteriormente Dettmann (1963, p. 102, pl. XXV, figs. 5-7) la combinó al género Alisporites. Tanto en la descripción de Balme como en la de Dettman, no son descriptos los pliegues exinales que sí pueden observarse en el material ilustrado. Por esta razón ha sido recombinada como especie de Falcisporites, ya que presenta dichos pliegues, los cuales definen el género. Zavattieri (1991a) mencionó sin describir a dicha especie para el Triásico, de la Formación Las Cabras, provincia de Mendoza, midiendo 34 ejemplares e ilustrando 2. Ambos ejemplares presentan los pliegues proximales que los definen como Falcisporites. Zavattieri y Volkheimer (2003) mencionaron para el Jurásico inferior de la Formación Nestares, en 
la localidad tipo, represa Alicurá, a ambos lados del Río Limay, en el límite de las provincias de Neuquén y Río Negro, e ilustraron un ejemplar, al que no se puede observar la presencia de los engrosamientos.

Algunos de los ejemplares asignados a Platysaccus nucleoparvus Anderson (1977, p. 112, pl. 138, figs. 36, 37, 40) encuentran mejor asignación dentro de Falcisporites similis por ser formas haploxilonoides, de cuerpo central pobremente definido y con pliegues proximales semilunares, asociados a las raíces de los sacos. Lo mismo sucede con el ejemplar asignado como Pityosporites tenuicorpus (Balme) Anderson (1977, p. 114, pl. 139, fig. 21, pl. 140, figs. 4, 12-14, 28, 30, 35-40, pl. 141, figs. 12, 28, 33-34, 37), todos ellos provenientes del Cisuraliano de Sudáfrica.

Registros previos. Alisporites similis fue descripta por Dettmann (1993), para el Jurásico Superior-Cretácico Inferior de Australia.

- Cisuraliano: Sudáfrica: presente en Cuenca Karroo (Anderson, 1977).

- Cisuraliano-Guadalupiano: Uruguay: presente en la Formación Mangrullo, Cuenca Paraná (Gutiérrez et al., en prensa-b).

- Triásico: Argentina: presente en la Formación Potrerillos (Zavattieri, 1987) y mencionada para la Formación Las Cabras (Zavattieri, 1990, 1991a), Cuenca Cuyana.

- Jurásico: Argentina: mencionada para la Formación Nestares, provincias de Neuquén y Río Negro (Zavattieri y Volkheimer, 2003), mencionada para el Jurásico-Cretácico Inferior de la Cuenca Neuquina (Volkheimer y Quattrocchio, 1981).

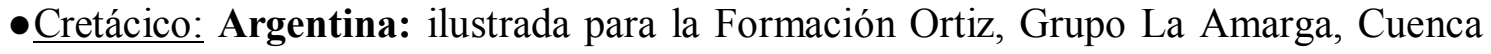
Neuquina (Volkheimer et al., 1977); mencionada para el borde austral de la Cuenca Neuquina (Volkheimer y Prámparo, 1984); ilustrada para la Formación La Amarga, Miembro Bañados de Caichigüe (Prámparo y Volkheimer, 2002); y mencionada para la Formación Springhill, Cuenca Austral (Ottone y Aguirre-Urreta, 2000) y para el Miembro Avilé de la Formación Agrio (Hauteriviano inferior), Cuenca Neuquina (Prámparo y Volkheimer, 1999).

\section{Género Ibisporites Tiwari 1968}

Especie tipo. Ibisporites diploaccus Tiwari, 1968.

Afinidad botánica. Gimnospermosida?. 


\section{cf. Ibisporites sp.}

Lámina XIII, figura C

Descripción. Grano de polen bisacado, de cuerpo central liso y contorno general subrectangular, de lados rectos y ángulos redondeados, y mayor elongación en sentido transversal. Cuerpo central de contorno no discernible. Cápula angosta (de $3 \mu \mathrm{m}$ de ancho) y ahusada que recorre el largo del cuerpo pero sin alcanzar los extremos del mismo por presencia de puentes que contactan los sacos entre sí. Sacos subrectangulares, de inserción proximal no discernible y distal bilateral. Las bases distales de los sacos presentan una banda engrosada, de ancho constante, que recorre todo el contorno de la cápula. Los sacos se contactan entre sí por medio de puentes ubicados en los extremos de la cápula. Los sacos presentan una sexina infrareticulada, que conforma gruesos e irregulares muros que limitan lúminas pequeñas. Pueden observarse algunos pliegues en los sacos dados por la compresión, ubicados radialmente.

Dimensiones ( 1 ejemplar). Ancho total, $58 \mu \mathrm{m}$; ancho del saco sobre cara distal, $27 \mu \mathrm{m}$; largo del saco, $49 \mu \mathrm{m}$.

\section{Principal material estudiado. BAPal 6152 (a) L64/0.}

Comentarios. El aspecto monosacoide, dado por la presencia de esos anchos puentes entre los sacos, como así también la angosta cápula ahusada y su simetría bilateral, permiten referir el material aquí estudiado, con dudas al género Ibisporites (Tiwari, 1968, pp. 233-235, pl. 6, fig. 67); aunque en el mismo no sea posible la observación nítida del cuerpo central, como tampoco la adherencia proximal invadiendo la capa, características éstas propias del género. Además, el ejemplar de Cuenca Colorado presenta un aspecto general subrectangular, y un reborde engrosado asociado a las bases distales de los sacos, que recorre todo el margen de la cápula, caracteres éstos no observados en la especie tipo.

Género Pityosporites Seward emend. Manum 1962

Especie tipo. Pityosporites antarticus Seward, 1914.

Afinidad botánica. Gimnospermas-Pinaceae (véase Balme, 1995). 


\section{Pityosporites sp. A}

Lámina XII, figura D; Lámina XIII, figura D

Descripción. Grano de polen bisacado, diploxilonoide, de margen oval elongado transversalmente. Cuerpo central grande, subrectangular a oval transversal, de contorno poco discernible. Pared delgada, de coloración más clara que los sacos, y sin ningún tipo de ornamentación o marca alguna visible tanto en cara proximal como en la distal. Cápula casi siempre visible, de forma subrectangular, con su mayor extensión longitudinal y de ancho variable, desde apenas visible hasta alcanza casos la mitad del ancho del cuerpo. Sacos mayores a $1 / 2$ círculo adheridos al cuerpo proximal ecuatorial y distal bilateral, con zonas de adherencia distales rectas. Marcada inclinación distal de los sacos. Sexina de los mismos infrareticulada, de muros anchos y lúminas de márgenes irregulares.

Dimensiones (12 ejemplares). Ancho total, 52(70)99 $\mu \mathrm{m}$; ancho del saco sobre cara distal, 24(33)45 $\mu \mathrm{m}$; largo del saco, 35(44,3)55 $\mu \mathrm{m}$.

Principal material estudiado. BAPal 6152 (a) H53/1, P64/3, W50/1, T48/4, R42/0, Q52/0, M71/2, K43/1, M60/2.

Comentarios. Los ejemplares observados están muy pobremente preservados, motivo por el cual no se ha podido realizar una determinación específica. Sin embargo, cabe destacar que los ejemplares descriptos por Zavattieri (1991a, p. 14, lám. V, figs 1, 2, 4) referidos a Pityosporites scaurus (Nilsson) Schulz 1967 presentan una morfología general aproximada, aunque el tamaño de los sacos es menor. Algunos de los ejemplares ilustrados como P. nucleoparvus Anderson (1977, p. 112, pl. 138, figs 1-8) se asemejan a $P$. sp. A. El resto de los ejemplares muestran un cuerpo subcircular a oval elongado longitudinalmente, carácter no observado en los materiales aquí descriptos.

\section{Género Platysaccus Naumova 1939}

Especie tipo. Platysaccus papilionis Potonié y Klaus, 1954.

Afinidad botánica. Coniferales y posiblemente Coníferas incertae sedis (véase Balme, 1995).

Platysaccus crassimarginatus Lakhanpal, Sah y Dube 1960 


\section{Lámina XIII, figura E}

Descripción. Grano de polen bisacado, diploxilonoide. Cuerpo central circular, de pared lisa y gruesa, lo que le otorga un color oscuro al mismo. Cápula de 1/3 hasta 2/3 del ancho total del cuerpo (entre 11 y $12 \mu \mathrm{m}$ ), de márgenes subparalelos a cóncavos. Sacos mayores a 1/2 círculo, hasta 1/3 más altos que el cuerpo, de inserción proximal ecuatorial y distal subecuatorial, de inclinación distal. La zona de adherencia de cada saco al cuerpo central genera una ancha faja oscura, de forma semilunar, que acompaña el contorno del cuerpo y que, en algunos casos, se contactan entre sí por sus extremos superior e inferior. Sexina de los sacos infrareticulada con muros gruesos que limitan lúminas de contornos irregulares.

Dimensiones (9 ejemplares). Ancho total, 50(61,8)90 $\mu \mathrm{m}$; cuerpo central, ancho $21(35,6) 52 \mu \mathrm{m}$ y $22(32,7) 40 \mu \mathrm{m}$ de largo; ancho del saco sobre cara proximal, 7(17,6)34 $\mu \mathrm{m}$ y sobre cara distal, 16(24,6)43 $\mu \mathrm{m}$; largo del saco, 29(42)62 $\mu \mathrm{m}$.

Principal material estudiado. BAPal 6152 (a) R41/0, N66/2, T44/1, H58/1, H57/2, C61/0; BAPal 6152 (b) X59/3; BAPal 6156 (c) U48/1; BAPal 6165 (a) U63/0.

Comentarios. Lakhanpal et al. (1960, p.116, pl. 2, fig. 27) en la discusión de Platysaccus crassimarginatus remarcaron como característica destacable de la especie la presencia de un grueso borde en el cuerpo. Se considera que dicho carácter corresponde a la zona de adherencia proximal engrosada de los sacos. Platysaccus nitidus Pautsch (1971, pl. 5, figs. 9-10) se parece por poseer también un engrosamiento marginal en el cuerpo central, aunque $P$. crassimarginatus difiere del mismo por presentar los bordes de la cápula cóncavos y los sacos levemente mayores respecto del cuerpo. $P$ nitidus presenta su cápula de lados rectos y los sacos son 1/5 mayores respecto del largo del cuerpo central.

Registros previos. Platysaccus crassimarginatus fue descripta para la Serie Krol, Lopingiano de Naini Tal, India (Lakhanpal et al., 1960). No había sido registrada esta especie para cuencas sudamericanas, pero sus características diagnósticas permiten hacer la asignación específica.

Platysaccus leschikii Hart 1960

Lámina XIII, figuras G y $\mathrm{H}$ 
Descripción. Grano de polen bisacado, fuertemente diploxilonoide, con infraestructura protosacada, con lo que no se definen zonas de inserción de los sacos. Cuerpo central poco discernible, de contorno oval a subromboidal, elongado longitudinalmente. Capa no discernible y cápula angosta extendida a lo largo de todo el cuerpo, de lados paralelos a cóncavos, convergiendo en los extremos del cuerpo. Sacos mayores a 1/2 círculo, reniformes en vista ecuatorial, inclinados distalmente. Sexina de los sacos infrareticulada, conformando muros delgados dispuestos de manera comprimida y radial en la base de los sacos. Lúminas de contornos irregulares.

Dimensiones (8 ejemplares). Ancho total, 57(82,3)132 $\mu \mathrm{m}$; cuerpo central, ancho $20(30,8) 52 \mu \mathrm{m}$ у $25(37) 65 \mu \mathrm{m}$ de largo; ancho del saco sobre cara proximal, 22(30)42 $\mu \mathrm{m}$ y sobre cara distal, $29(38,5) 64 \mu \mathrm{m}$; largo del saco, 37(58,3)100 $\mu \mathrm{m}$.

Principal material estudiado. BAPal 6152 (a) H67/2; BAPal 6152 (b) F36/0; BAPal 6156 (a) F34/0; BAPal 6184 (b) E37/0. Redepósito: BAPal 6172 (a) Q46/0, U47/2; BAPal 6173 (a) F60/0; BAPal 6175 (a) L44/4.

Registros previos. Platysaccus leschikii fue descripta para Lower Coal Measures, Pérmico de Tanganyika (Hart, 1960).

- Pennsylvaniano-Guadalupiano: Brasil: ilustrada para el Subgrupo Itararé (superior) y la Formación Rio Bonito, Cuenca Paraná (Bharadwaj et al., 1976).

- Cisuraliano: Australia: descripta para Blair Athol Coal Measures, Cuenca Bowen (Foster, 1979); ilustrada para la Formación Bandanna, Springsure Anticline (Rigby y Hekel, 1977). Antártida: mencionada para Fossilryggen, Vestjella Mountain (Lindströn, 1996, 2005); ilustrada para Heimefrontfjella mountain-range, Dronning Maud Land (Lindströn, 1995). India: descripta para Lower Coalf Measures (Hart, 1960). África del Sur: mencionada para Lower Karroo (Hart, 1963a) e ilustrada para el Keetewa-Mchuchuma Coalfield en Tanzania (Manum y Duc Tien, 1973).

- Guadalupiano: Australia: presente en Baralaba Coal Measures, Cuenca Bowen (Foster, 1979).

- Cisuraliano-Guadalupiano: Papúa: ilustrada para las formaciones Ainim y Aiduna (Playford y Rigby, 2008).

- Pérmico-Triásico: Israel: mencionada para las formaciones Arqov y Yamin (Eshet, 1990). 
- Triásico: Argentina: descripta para la Formación Puesto Viejo, Cuenca Cuyana (Ottone y García, 1991). Australia: mencionada para el Triásico Inferior (Balme y Hennelly, 1956a; Balme, 1963).

\section{Platysaccus papilionis Potonié y Klaus 1954}

\section{Lámina XIII, figura $\mathrm{F}$}

Descripción. Grano de polen bisacado, fuertemente diploxilonoide. Cuerpo central circular de pared lisa. Cápula angosta poco visible, de lados rectos a cóncavos. Sacos mayores a 1/2 círculo, bien inflados, unidos al cuerpo subecuatorial distalmente, por medio de zonas de adherencia semicirculares que bordean todo el contorno del cuerpo. Sacos inclinados distalmente. Sexina de los sacos infrareticulada, con muros delgados y lúminas irregulares.

Dimensiones (16 ejemplares). Ancho total, 31(53)75 $\mu \mathrm{m}$; cuerpo central, ancho $12(24,4) 34 \mu \mathrm{m}$ y $13(22,2) 27 \mu \mathrm{m}$ de largo; ancho del saco sobre cara proximal, $8(15,8) 26 \mu \mathrm{m}$ y sobre cara distal, 15(24,7)46 $\mu \mathrm{m}$; largo del saco, 20(31)46 $\mu \mathrm{m}$.

Principal material estudiado. BAPal 6152 (a) E46/3, C49/0, E53/1, D53/3, S53/4, L62/1; BAPal 6158 (a) H60/1; BAPal 6158 (b) F35/4; BAPal 6167 (a) O52/4; BAPal 6189 (a) $\mathrm{T} 70 / 2$.

Registros previos. Platysaccus papilionis fue descripta originalmente para el Pérmico y Triásico de Austria (Potonié y Klaus, 1940). Esta especie es ampliamente reconocida para el Pérmico y el Triásico de ambos hemisferios.

- Pennsylvaniano: Argentina: presente en la Formación Guandacol, localidad Mina Esperanza (Ottone, 1991). Bolivia: mencionada para el Grupo Copacabana (Ottone et al., 1998).

- Pennsylvaniano-Cisuraliano: Polonia: ilustrada para la Cuenca Itrasudetic (Jerzykiewicz, 1987). Estados Unidos: ilustrada para las Series Virginian, Wolfcampian y Leonardian, Kansas, Texas y Oklahoma (Jizba, 1962).

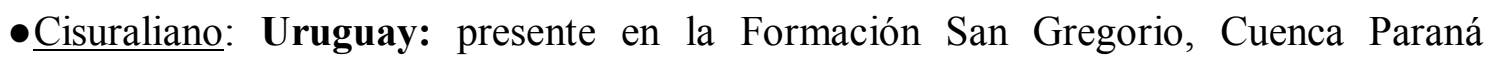
(Gutiérrez et al., 2006b). Austria: (Pérmico-Triásico) Potonié y Klaus (1940). India: mencionada para la Formación Talchir, Jayanti Coalfield, Bihar (Lele y Makada, 1972); mencionada para la Formación Barakar (Srivastava y Jha, 1998). África: ilustrada para 
la Cuenca de Gabón, probablemente asignable a Dwyka, atribuíbles a Karroo (Jardiné, 1974; Chandra et al., 1977); presente para el Grupo Ecca, Cuenca Waterberg (Macrae, 1988). Australia: ilustrada para la Formación Bandanna, Springsure Anticline (Rigby y Hekel, 1977).

- Guadalupiano: India: presente para Raniganj Coal Measures (Bharadwaj, 1962).

- Lopingiano: Estados Unidos: presente en la Formación Flowerpot, Oklahoma (Wilson, 1962a; Clapham, 1970).

- Lopingiano-Triásico Inferior: Israel: mencionada para las formaciones Arqov y Yamin (Eshet, 1990).

- Triásico: Argentina: presente en las formaciones Cacheuta (Jain, 1968), Potrerillos (Zavattieri, 1987), Las Cabras (Zavattieri, 1990, 1991b) y Puesto Viejo (Ottone y Garcia, 1991), y mencionada para la Formación Los Rastros (Ottone et al., 2005), todas de Cuenca Cuyana. Presente en la Formación Rancho de Lata (Ottone et al., 1992); Canadá: presente en la Formación Belloy (Guadalupiano), y formaciones Toad/Glayling (Scyathiano-Anisiano) (Jansonius, 1962). Italia: presente en las Dolomitas Oeste (van der Eem, 1982). Israel: mencionada para el Triásico MedioSuperior por Horowitz (1973).

Platysaccus queenslandi de Jersey 1962

Lámina XIV, figuras A y B

1968. Platysaccus densus Kar, p. 126, pl. 2, figs. 52-58.

1976. Platysaccus densus Kar, Bharadwaj et al., p. 83, pl. 6; figs. 77-78.

1980b. Plasatysaccus sp. Archangelsky y Gamerro, lám. II, fig. 4.

Descripción. Grano de polen bisacado diploxilonoide, de similar forma y tamaño entre el cuerpo y los sacos. Cuerpo central liso y oscuro, circular a levemente oval, en sentido longitudinal. Cápula rectangular, de hasta 1/3 del ancho respecto del cuerpo. Sacos mayores a 1/2 círculo, inflados, de inserción proximal ecuatorial y distal subecuatorial, inclinados distalmente. En la inserción proximal de los sacos se forman fuertes pliegues radiales, en donde se observa el infraretículo más comprimido. Sexina de los sacos delgada, con un retículo conformado por muros delgados que delimitan lúminas grandes e irregulares. 
Dimensiones (13 ejemplares). Ancho total, 34(60,3)95 $\mu \mathrm{m}$; cuerpo central, ancho $18(29,6) 34 \mu \mathrm{m}$ y $18(30,9) 40 \mu \mathrm{m}$ de largo; ancho del saco sobre cara proximal, 9(15,9)21 $\mu \mathrm{m}$ y sobre cara distal, 18(26)34 $\mu \mathrm{m}$; largo del saco, 23(35,9)50 $\mu \mathrm{m}$.

Principal material estudiado. BAPal 6165 (a) M71/0, S56/4, U47/0, W72/4, U60/0, P40/1, T71/3, U71/3, F42/4, G69/0.

Discusión. Bharadwaj et al. (1976) mencionaron sin describir a la especie Platysaccus densus Kar 1968 para el Subgrupo Itararé (superior) y la Formación Rio Bonito, de la Cuenca Paraná, siendo ésta la única cita de la especie para cuencas sudamericanas. Comparando dicha especie con $P$. queenslandi de Jersey (1962) no se hallaron diferencias significativas que justifiquen su separación, ya que a pesar que $P$. densus fue definida como formas diploxilonoides de cuerpo central liso y oval elongado transversalmente, $P$. queenslandi incluye formas con cuerpo central circular a oval, ya sea elongado longitudinal como transversalmente, y difiere de la especie $P$. papilionis por presentar los sacos aproximadamente equidimensionales respecto del cuerpo central, menos inflados que en dicha especie. Respecto de la amplia definición de $P$. queenslandi, quizás sea válido considerar sinónimo de la misma a P. katriensis Kar (1968), también presente en el Subgrupo Itararé y la Formación Rio Bonito, aunque la falta de descripción e ilutración de la misma impiden una consideración objetiva.

Por la forma del cuerpo central, cápula y del contorno general se entiende que el material referido a Plasatysaccus sp. por Archangelsky y Gamerro (1980b, lám. II, fig. 4) deber ser referido a $P$. quenslandii.

Registros previos. Platysaccus queenslandi fue descripta para Ipwich Coalfield (de Jersey, 1962). Esta especie está muy bien representada en sedimentos triásicos gondwánicos (véase Raine et al., 2006).

- Pennsylvaniano-Guadalupiano: Brasil: ilustrada para el Subgrupo Itararé (superior) y la Formación Rio Bonito, Cuenca Paraná (Bharadwaj et al., 1976).

- Cisuraliano-Guadalupiano: Argentina: ilustrada para la Biozona Cristatisporites, Cuenca Claromecó-Colorado (Archangelsky y Gamerro, 1980b).

- Guadalupiano: Australia: mencionada para la Formación Bandanna, Springsure Anticline (Rigby y Hekel, 1977). India: presente en Jharia Coalfield, Bihar (Kar, 1968). 
- Pérmico-Triásico: Israel: mencionada para las formaciones Arqov y Yamin (Eshet, 1990). Arabia: ilustrada para la Formación Al Khlata, Oman y Arabia Saudita (Stephenson et al., 2003). Australia: presente en la Cuenca Bowen (de Jersey, 1979).

- Triásico: Argentina: presente en las formaciones Cacheuta (Jain, 1968; Azcuy y Longobucco, 1983), Potrerillos (Azcuy y Longobucco, 1983; Zavattieri, 1987), Las Cabras (Zavattieri, 1990, 1991b), Los Rastros (Ottone et al., 2005) y Puesto Viejo (Ottone y Garcia, 1991), todas en la provincia de Mendoza, Cuenca Cuyana. En la provincia de Santa Cruz, ha sido mencionada para la Formación El Tranquilo (Zavattieri, 1992). En la provincia de Río Negro ha sido ilustrada para Formación Comallo (Zavattieri et al., 1994). Chile: ilustrada para la Formación Panguipulli (Zavattieri et al., 2003). Australia: presente en Ipwich Coalfield (de Jersey, 1962); Leigh Creek Coal Measures (Playford y Detmann, 1965), Tasmania (Playford, 1965); en las formaciones Blackstone, Tivoli y Cooneana, de Ipswish Coal Measures (de Jersey, 1962, 1964, 1970, 1971); Esk Beds (de Jersey, 1972); en el Grupo Rewan (de Jersey, 1968, 1979); las formaciones Moorooka y Tirigalpa (de Jersey y Hamilton, 1965) y Moolayember (de Jersey y Hamilton, 1967). Antártida: presente en la Formación Falla, Central Transactartic Mountains (Farabee et al., 1989). Pakistán: presente en Miembro Narmia, de la Formación Mianwali, y en la Formación Tredian (Balme, 1970). India: mencionada para la Formación Maitur, oeste de Bengal (Maheshwari y Banerjee, 1975); en el Grupo Panchet, Auranga Coalfield, Bihar (Banejee y Maheshwari, 1975).

\section{Platysaccus sp. A \\ Lámina XIV, figuras C y D}

Descripción. Grano de polen bisacado diploxilonoide, de similar forma y tamaño entre el cuerpo y los sacos. Cuerpo central liso y oscuro, oval elongado en sentido longitudinal. Cápula rectangular a ahusada, angosta, de 1,1(3,2)7 $\mu \mathrm{m}$ ancho respecto del cuerpo. Sacos mayores a 1/2 círculo, inflados, de inserción proximal ecuatorial y distal subecuatorial, inclinados distalmente. Sexina de los sacos delgada, con un retículo conformado por muros delgados que delimitan lúminas irregulares. 
Dimensiones (7 ejemplares). Ancho total, 46(57,6)82 $\mu \mathrm{m}$; cuerpo central, ancho $21(23,3) 25 \mu \mathrm{m}$ y $23(30,3) 37 \mu \mathrm{m}$ de largo; ancho del saco sobre cara proximal, 10(13,6)16 $\mu \mathrm{m}$ y sobre cara distal, 22(27)38 $\mu \mathrm{m}$; largo del saco, 25(31)38 $\mu \mathrm{m}$.

Principal material estudiado. BAPal 6152 (a) M75/1, Q46/2, Q66/0, G54/1.

Comentarios. Los ejemplares aquí estudiados son comparables con Platysaccus queenslandi de Jersey (1962), porque ambas son formas diploxilonoides, de similares dimensiones entre el cuerpo central y los sacos, de cuerpo central liso y oscuro. Sin embargo, los ejemplares agrupados en Platysaccus sp. A, poseen todos el cuerpo central oval elongado longitudinalmente, y presentan una cápula rectangular, angosta, elongada (de $1 / 8$ a $3 / 8$ respecto del ancho del cuerpo central); mientras que $P$. queenslandi presenta la cápula rectangular a oval, y siempre es de mayor tamaño (de 1/3 a 2/3 de ancho respecto del ancho del cuerpo central).

Género Pteruchipollenites Couper 1958

Especie tipo. Pteruchipollenites thomassi Couper, 1958.

Afinidad botánica. Gimnospermopsida-Caytoniales-Peltaspermaceae (véase Balme, 1995).

Pteruchipollenites sp. cf. P. gracilis (Segroves) Foster 1979

Lámina XIV, figura E

Descripción. Grano de polen bisacado, haploxilonoide, de contorno oval elongado en sentido transversal. Cuerpo central de contorno poco discernible, subcircular a oval transversalmente. Pared delgada, de coloración más clara a la de los sacos. Sacos semicirculares de inserción proximal ecuatorial y distal subecuatorial, de raíces poco marcadas. La zona de adherencia de los sacos al cuerpo es delgada, de forma semilunar, y rodean al cuerpo por todo el contorno ecuatorial. Por los extremos del cuerpo, se contactan los sacos entre sí por delgados puentes. Sexina de los sacos infrareticulada, con muros gruesos que limitan lúminas de márgenes irregulares.

Dimensiones (16 ejemplares). Ancho total, 39(53,6)76 $\mu \mathrm{m}$; cuerpo central, ancho $16(29,3) 50 \mu \mathrm{m}$ y $24(36,9) 58 \mu \mathrm{m}$ de largo; ancho del saco, 16(29,8)50 $\mu \mathrm{m}$; largo del saco, $25(34,6) 58 \mu \mathrm{m}$. 
Principal material estudiado. BAPal 6152 (a) E49/0, G45/2, J36/0, J58/3, L51/0, S39/1, W46/4, D58/4; BAPal 6152 (e) X44/0; BAPal 6165 (a) G60/3; BAPal 6165 (b) $\mathrm{C} 48 / 0$.

Comentarios. La pobre preservación y el escaso material estudiado impide una asignación específica, aunque el caracter de los sacos y la morfología general del cuerpo central permiten compararlos con la especie Pteruchipollenites gracilis (Segroves) Foster 1979.

Género Scheuringipollenites Tiwari 1973

Especie tipo. Scheuringipollenites maximus (Hart) Tiwari, 1973.

Afinidad botánica. Gimnospermas-Coniferales-Lebachiaceae (véase Balme, 1995; Quadros et al., 1996).

Scheuringipollenites circularis Césari, Archangelsky y Seoane 1995

Lámina XIV, figura F

Descripción. Grano de polen bisacado, haploxilonoide, de contorno oval longitudinal. Cuerpo central circular, de pared delgada, coloración más clara que los sacos y bordes del mismo poco discernibles. Cápula ancha de 6(10)16 $\mu \mathrm{m}$ de ancho, de lados rectos o levemente cóncavos, paralelos. Sacos mayores a 1/2 círculo de inserción proximal ecuatorial y distal bilateral. Sexina de los sacos infrareticulada, de muros delgados que delimitan lúminas irregulares, poco discernibles.

Dimensiones (4 ejemplares). Ancho total, 40(53,7)63 $\mu \mathrm{m}$; cuerpo central, ancho $28(32,7) 36 \mu \mathrm{m}$ y $30(34,2) 37 \mu \mathrm{m}$ de largo; ancho del saco sobre cara proximal, $11(12,6) 14 \mu \mathrm{m}$ y sobre cara distal, $20(25,2) 30 \mu \mathrm{m}$; largo del saco, 25(31)38 $\mu \mathrm{m}$.

Principal material estudiado. BAPal 6152 (a) S40/4, A38/03, V39/2. Redepósito: BAPal 6173 (a) D43/0.

Registros previos. Scheuringipollenites circularis fue descripto para la perforación Las Mochas, biozonas Potonieisporites-Lundbladispora y Cristatisporites, Carbonífero Superior-Cisuraliano de la Cuenca Chacoparaná (Césari et al., 1995).

- Cisuraliano: Argentina: presente en las formaciones Tasa Cuna, Cuenca Paganzo (Balarino y Gutiérrez, 2006) y Río Genoa, Cuenca Tepuel-Genoa (Gutiérrez et al., 
2007). Uruguay: presente en la Formación San Gregorio, Cuenca Paraná (Gutiérrez, et al., 2006).

- Cisuraliano-Guadalupiano: Uruguay: presente en la Formación Melo (Miembro Mangrullo), Cuenca Paraná (Mautino et al., 1998b; Gutiérrez et al., en prensa-b).

Scheuringipollenites maximus (Hart) Tiwari 1973

Lámina XIV, figura G

1977. Pityosporites maximus (Hart) Anderson, p. 116, pl. 148, figs. 1-16, pl. 149, figs. 1-23, pl. 150, figs 1-19.

Descripción. Grano de polen bisacado, haploxilonoide, de contorno circular a oval elongado en el sentido transversal. Cuerpo central de pared delgada, de coloración más clara a la de los sacos. Los bordes, cuando discernibles, delimitan un cuerpo central circular a levemente oval elongado transversalmente. Cápula angosta, de 1(7,4)16 $\mu \mathrm{m}$, de lados rectos paralelos, cóncavos o levemente convexos, de extremos divergentes. Sacos iguales a 1/2 círculo, de inserción proximal no discernible y distal bilateral. Sexina de los sacos infrareticulada, de muros gruesos generalmente dispuestos radialmente desde las zonas de adherencia, y de lúminas de contornos irregulares.

Dimensiones (20 ejemplares). Ancho total, 43(56,2)89 $\mu \mathrm{m}$; ancho del saco sobre cara distal, 14(25,2)39 $\mu \mathrm{m}$; largo del saco, 20(46,2)87 $\mu \mathrm{m}$.

Principal material estudiado. BAPal 6152 (a) N41/2, N67/1, K53/0, Q51/2, H65/0, P53/1, O64/0, Q68/0, L38/3; BAPal 6158 (a) G40/0; BAPal 6165 (b) J52/1, L44/4. Redepósito: BAPal 6174 (a) R63/3.

Comentarios. Parte de los ejemplares asignados a Pityosporites maximus (Hart) por Anderson (1977, p. 116, pl. 148, figs. 1-16, pl. 149, figs. 1-23, pl. 150, figs 1-19), del Cisuraliano de Sudáfrica, presentan las características diagnósticas de esta especie (forma y dimensiones generales, ancho de la cápula, características del cuerpo central, etc.).

Registros previos. Scheuringipollenites maximus fue descripto para (Tiwari, 1963), para el Valle del Río Mchuchuma, Pérmico de Tanzania, África.

- Pennsylvaniano: Brasil: ilustrada para el Subgrupo Itararé, Cuenca Paraná (Souza et al., 2000, di Pasquo et al., 2003b; Souza, 2006). 
- Cisuraliano: Argentina: presente en las formaciones Tasa Cuna, Cuenca Paganzo (Balarino y Gutiérrez, 2006) y Río Genoa, Cuenca Tepuel-Genoa (Gutiérrez et al., 2007). Uruguay: presente en la Formación San Gregorio, Cuenca Paraná (Gutiérrez et al., 2006b). Brasil: presente en la perforación 3-MC-3-SC, Santa Catarina, Cuenca Paraná (Quadros et al., 1996). Paraguay: mencionada para la sección inferior del Grupo Independencia (González et al., 1996) e ilustrada, Formación Tacuary, Grupo Independencia (Muff et al., 1999), Cuenca Chacoparaná. Antártida: ilustrada para Heimefrontfjella mountain-range (Lindström, 1995) y Fossilryggen, Vestfjella (Lindström, 1993, 1995, 1996, 2005, Playford, 1990); ambas localidades de Dronning Maud Land. Australia: presente en Blair Athol Coal Measures, Cuenca Bowen (Foster, 1975); mencionada para las cuencas Perth, Collie y Officer (Backhouse, 1993); para Fairbairn Dam, Cuenca Bowen (Fielding y McLoughlin, 1992) e ilustrada para la Formación Fossil Cliff, Cuenca Perth (Foster et al., 1985). India: mencionada por Tiwari (1973). India: mencionada para la Formación Barakar (Srivastava y Jha, 1998). Sudáfrica: presente en Cuenca Karroo (Anderson, 1977).

- Guadalupiano: Australia: presente para Baralaba Coal Measures, Cuenca Bowen (Foster, 1979).

- Lopingiano-Triásico Inferior: Australia: presente en la Formación Rewan, Cuenca Bowen (Foster, 1979; 1982a). India: ilustrada para la Formación Parsora, Cuenca Gondwana (Tiwari y Ram-Awatar, 1987); mencionada para las formaciones Raniganj y Panchet (Rana y Tiwari, 1980).

Scheuringipollenites medius (Burjack) Dias-Fabrício 1981

Lámina XIV, figura $\mathrm{H}$

Descripción. Grano de polen bisacado haploxilonoide, de contorno subcircular a levemente oval, elongado transversalmente. Cuerpo central de márgenes no discernibles. Cápula de $1(6,2) 15 \mu \mathrm{m}$, de contornos rectos y paralelos a convexos, de extremos divergentes. Sacos iguales o levemente menores a 1/2 círculo, de inserción distal bilateral. Sexina de los sacos infrareticulada, de muros delgados y lúminas irregulares. 
Dimensiones (17 ejemplares). Ancho total, 30(41,1)55 $\mu \mathrm{m}$; ancho del saco sobre cara distal, 10(6,2)15 $\mu \mathrm{m}$; largo del saco, 22(35,2)45 $\mu \mathrm{m}$.

Principal material estudiado. BAPal 6152 (a) G48/3, F39/1, P53/2, G72/1, A43/0, B43/0, M59/3, N49/0, O63/3; BAPal 6158 (a) N55/2; BAPal 6159 (a) P53/2.

Registros previos. Scheuringipollenites medius (Burjack) Dias-Fabrício (1981) fue descripto originalmente para la Formación Rio Bonito, Cisuraliano de la Cuenca Paraná, Brasil.

- Pennsylvaniano-Cisuraliano: Argentina: ilustrada para la Formación Río del Peñón, Cuenca Paganzo (Gutiérrez y Limarino, 2006).

- Cisuraliano: Argentina: presente en las formaciones Tasa Cuna, Cuenca Paganzo (Balarino y Gutiérrez, 2006) y Río Genoa, Cuenca Tepuel-Genoa (Gutiérrez et al., 2007) y en la Biozona Cristatisporites (Césari et al., 1995), Cuenca Chacoparaná. Uruguay: presente en la Formación San Gregorio, Cuenca Paraná (Gutiérrez et al., 2006b). Brasil: presente en la perforación 2-AO-1-RS, Río Grande do Sul (Quadros et al., 1996) e ilustrada para el Subgrupo Itararé (Dias, 1993), Cuenca Paraná. Paraguay: ilustrada para la Formación Tacuary, Grupo Independencia, Cuenca Chacoparaná (Muff et al., 1999).

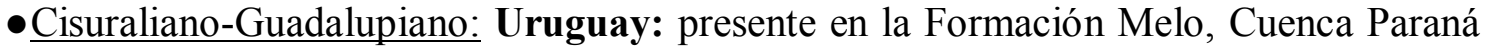
(Gutiérrez et al., en prensa-b).

Scheuringipollenites ovatus (Balme y Hennelly) Foster 1975

Lámina XV, figuras A y B; Lámina XVI, figura $\mathrm{H}$

1977. pars. Pityosporites ovatus (Balme y Hennelly) Anderson, 115, pl. 142, figs 1-55, pl. 144, figs. 45-48, pl. 146, figs 1-22.

Descripción. Grano de polen bisacado, haploxilonoide, de contorno general subcircular a levemente oval, elongado en sentido longitudinal. Cuerpo central oval longitudinal, de pared delgada de coloración más clara que la de los sacos y bordes generalmente poco discernibles. Cápula de 2(4)6 $\mu \mathrm{m}$ de ancho, de lados rectos paralelos a cóncavos, extendida por toda la longitud del cuerpo. Sacos iguales o levemente menores a medio círculo, de inserción proximal ecuatorial y distal bilateral, de leve inclinación distal. 
Sexina de los sacos infrareticulada, de muros delgados y lúminas irregulares, poco discernibles.

Comparación. Anderson (1977) incluyó dentro de Pityosporites ovatus (Balme y Hennelly) numerosos especímenes (pl. 142, figs 1-55, pl. 144, figs. 45-48, pl. 146, figs. 1-22) que pueden ser referidas a esta especie, por los rasgos que presentan (contorno general, características del cuerpo central, forma de la cápula, etc.). Bajo el mismo epíteto específico Anderson (1977) incluyó otros ejemplares que podrían ser incluídos en los géneros Alisporites, Falcisporites y Accinctisporites y en otras especies de Scheuringipollenites, aunque la discusión de estos últimos especímenes ya ha sido realizada previamente.

Dimensiones (5 ejemplares). Ancho total, 28(42)84 $\mu \mathrm{m}$; cuerpo central, ancho $15(18,2) 35 \mu \mathrm{m}$ y $21(37,5) 78 \mu \mathrm{m}$ de largo; ancho del saco sobre cara proximal, $7(9,8) 21$ $\mu \mathrm{m}$ y sobre cara distal, 11(21,4)37 $\mu \mathrm{m}$; largo del saco, 21(37,5)78 $\mu \mathrm{m}$.

Principal material estudiado. BAPal 6152 (a) L67/0, E42/4, B42/0, C50/1, J52/3.

Registros previos. Scheuringipollenites ovatus fue descripta para Blair Athol Coal Measures, Pérmico de Australia (Foster, 1975).

- Cisuraliano: Argentina: ilustrada en la Formación Tupe (miembro cuspidal), Cuenca Paganzo (Vergel, 2008). Uruguay: descripta para la Formación San Gregorio (Gutiérrez et al., 2006b), Cuenca Paraná. Brasil: presente en la perforación 3-MC-3-SC, Santa Catarina, Cuenca Paraná (Quadros et al., 1996). Australia: presente en Blair Athol Coal Measures (Foster, 1975); y en Springsure Anticline (Rigby y Hekel, 1977). Mencionada para las Cuencas Perth, Collie y Officer (Backhouse, 1993). Antártida: ilustrada para Heimefrontfjella mountain-range (Lindström, 1995) y Fossilryggen, Vestfjella, (Lindström, 1996, 2005, playford, 1990); ambas localidades de Dronning Maud Land. Sudáfrica: presente en Cuenca Karroo (Anderson, 1977).

- Cisuraliano-Guadalupiano: Uruguay: mencionada para la Formación Melo (Beri y Pecoits, 2001), Cuenca Paraná.

- Pérmico-Triásico: Australia: presente en la Formación Rewa, Cuenca Bowen (de Jersey, 1979).

Esta es la primera vez que se describe esta especie en la Argentina.

Subturma DISSACCITRILETI Leschik 1955

Género Colpisaccites Archangelsky y Gamerro 1979

Especie tipo. Colpisaccites granulosus Archangelsky y Gamerro, 1979. 
Afinidad botánica. Desconocida.

Colpisaccites granulosus Archangelsky y Gamerro 1979

Lámina XV, figura $\mathrm{C}$

Descripción. Grano de polen bisacado, haploxilonoide, de contorno subcircular, a levemente oval en sentido transversal. Cuerpo central poco discernible. Pared delgada, de coloración más clara que los sacos. Cápula de lados rectos a cóncavos que divergen en los extremos, de 1 a $10 \mu \mathrm{m}$ de ancho. Sacos iguales o menores a $1 / 2$ círculo, de inserción subecuatorial distal e inclinación distal. La inserción distal de los mismos presenta generalmente asociados pliegues exinales longitudinales, de forma ahusada, subparalelos, que no alcanzan los extremos del cuerpo central. Sexina de los sacos infrareticulada, con muros poco discernibles.

Dimensiones (6 ejemplares). Ancho total, 50(59)75 $\mu \mathrm{m}$; ancho del saco sobre cara distal, 23(24,5)27 $\mu \mathrm{m}$; largo del saco, 18(42,6)65 $\mu \mathrm{m}$.

Principal material estudiado. BAPal 6143 (a) H68/2; BAPal 6146 (b) M42/4; BAPal 6152 (a) O47/2, Q63/0; BAPal 6168 (a) H65/0; BAPal 6188(b) Z33/4.

Registros previos. Colpisaccites granulosus fue descripta originalmente por Archangelsky y Gamerro (1979) la Cuenca Chacoparaná, siendo una forma poco frecuente para la Biozona Cristatisporites y común en Striatites.

- Cisuraliano: Argentina: presente en las formaciones Bajo de Véliz (Gutiérrez y Césari, 2000) y Tasa Cuna, Cuenca Paganzo (Balarino y Gutiérrez, 2006). Uruguay: presente en la Formación San Gregorio (Beri y Daners, 1995; Gutiérrez et al., 2006b), Cuenca Paraná.

- Cisuraliano-Guadalupiano: Argentina: ilustrada para las biozonas Cristatisporites y Striatites, Cuenca Chacoparaná (Archangelsky y Gamerro, 1979; Vergel, 1987b; Césari et al., 1995). Mencionada para la Formación Yacimiento Los Reyunos, cuencas Oriental y Occidental, Bloque de San Rafael (Césari et al., 1996). Uruguay: mencionada para la Formación Melo (Mautino et al., 1998b), Cuenca Paraná.

Género Limitisporites Leschik emend. Klaus 1963

Especie tipo. Limitisporites rectus Leschik, 1956. 
Afinidad botánica. Gimnospermas-Coniferopsida (véase Balme, 1995).

Limitisporites amazonensis Playford y Dino 2000b

Lámina XV, figura D

Descripción. Grano de polen bisacado, haploxilonoide a levemente diploxilonoide, de contorno oval, elongado transversalmente. Cuerpo central subcircular a oval, elongado en sentido longitudinal. Marca de dehiscencia relictual dilete asimétrica en cara proximal, corta, de 1/4 del ancho del cuerpo. Pared del cuerpo gruesa y homogénea, lo que le otorga una oscura coloración al mismo. Cápula angosta, de lados rectos, delimitados por los pliegues asociados a la zona de adherencia de los sacos, de 6(8,4)11 $\mu \mathrm{m}$ de ancho. Sacos iguales a $1 / 2$ círculo, de implantación proximal ecuatorial y distal bilateral. Sexina infrareticulada.

Dimensiones (5 ejemplares). Ancho total, 80(100,8)130 $\mu \mathrm{m}$; cuerpo central, ancho $44(51,6) 68 \mu \mathrm{m}$ y $38(58,4) 83 \mu \mathrm{m}$ de largo; ancho del saco sobre cara proximal, 17(24,2)35 $\mu \mathrm{m}$ y sobre cara distal, 33(43,2)55 $\mu \mathrm{m}$; largo del saco, 43(62,6)97 $\mu \mathrm{m}$.

Principal material estudiado. BAPal 6143 (a) S49/4; BAPal 6183 (a) J42/0; BAPal 6189 (a) O43/3, K56/1. Redepósito: BAPal 6174 (b) C42/4.

Comentarios. Los ejemplares aquí estudiados son referidos a la especie Limitisporites amazonensis por presentar las características diagnósticas: contorno haploxilonoide a levemente diploxilonoide, extendido transversalmente, lesura monolete a dilete, recta a geniculada, sacos adheridos distalmente de manera bilateral, con pliegues asociados a sus bases, definiendo una ancha cápula (Playford y Dino, 2000b: p. 102, pl.5, figs. 7-9).

Registros previos. Limitisporites amazonensis fue descripta para la Formación Nova Olinda, Cuenca Amazona, para el Carbonífero Superior de Brasil (Playford y Dino, 2000b).

- Cisuraliano-Guadalupiano: Uruguay: presente en la Formación Melo (Miembro Mangrullo), Cuenca Paraná (Gutiérrez et al., en prensa-b).

Esta es la primera cita de la especie para la Argentina.

Limitisporites sp. cf. L. rectus Leschik 1956

Lámina $\mathrm{XV}$, figura $\mathrm{E}$ 
Descripción. Grano de polen bisacado, haploxilonoide, de contorno subcircular a levemente oval, elongado en sentido. Cuerpo central subcircular, de pared gruesa y homogénea, lo que le otorga una oscura coloración. Marca de dehiscencia relictual monolete en cara proximal, de 1/3 del ancho del cuerpo. Cápula angosta, de $18 \mu \mathrm{m}$ de ancho, de lados rectos, delimitados por los pliegues ahusados, asociados a la zona de adherencia distales de los sacos. Sacos menores a $1 \frac{1}{2}$ círculo, de implantación proximal ecuatorial y distal bilateral.

Dimensiones ( 1 ejemplar). Ancho total, $70 \mu \mathrm{m}$; cuerpo central, ancho $47 \mu \mathrm{m}$ y $46 \mu \mathrm{m}$ de largo; ancho del saco sobre cara proximal, $13 \mu \mathrm{m}$ y sobre cara distal, $23 \mu \mathrm{m}$; largo del saco, $56 \mu \mathrm{m}$.

Principal material estudiado. BAPal 6188 (b) Z33/4.

Comentarios. No se realiza una asignación específica certera por haberse hallado un solo ejemplar. Además, la marca monolete que se observa es más corta en la observada para la especie. Sin embargo, el resto de las características permiten una comparación con Limitisporites rectus Leschik 1956.

\section{Género Triadispora Klaus 1964}

Especie tipo. Triadispora plicata Klaus, 1964.

Afinidad botánica. Gimnospermas (Adloff et al., 1974).

Triadispora epigona Klaus 1964

Lámina XV, figuras $\mathrm{G}$ y $\mathrm{H}$

Descripción. Grano de polen bisacado, haploxilonoide. Cuerpo central de exina gruesa que le otorga una coloración oscura y homogénea, de contorno subrectangular a oval, elongado transversalmente. Capa lisa con una marca trilete claramente visible, de rayos algo sinuosos. Cápula extendida a lo largo de todo el cuerpo y de lados cóncavos, que acompañan el contorno del cuerpo, debido a la adherencia semilunar de los sacos. Sacos iguales a levemente mayores a $1 / 2$ círculo, de adherencia proximal ecuatorial y distal subecuatorial, de poca inclinación distal. Sexina de los sacos infrareticulada, conformando delgados muros que definen lúminas poco discernibles de márgenes 
irregulares. Puede observarse frecuentemente raíces marcadas radiales en la base de los sacos.

Dimensiones (2 ejemplares). Ancho total, 56-57 $\mu \mathrm{m}$; cuerpo central, ancho 36-40 $\mu \mathrm{m}$ y $37 \mu \mathrm{m}$ de largo; ancho del saco sobre cara proximal, 2-4 $\mu \mathrm{m}$ y sobre cara distal, 10-20 $\mu \mathrm{m}$; largo del saco, $35 \mu \mathrm{m}$.

Principal material estudiado. BAPal 6152 (a) O72/0; BAPal 6165 (a) H34/2.

Comentarios. Si bien los ejemplares aquí estudiados son escasos, los mismos presentan un buen estado de preservación donde se observan las características diagnósticas de la especie Triadispora epigona: cuerpo central bien definido, oval oscuro con una marca trilete o geniculada, cápula bien definida, ancha y sacos pequeños, de inclinación distal (Foster 1979: pp. 71-72, pl. 24, figs. 1-7).

Registros previos. Triadispora epigona fue descripta para Heilbronn, Triásico de Alemania (Klaus, 1964). Este es el primer registro de la especie T. epigona para cuencas sudamericanas, hallándose sí representadas otras especies del género.

- Guadalupiano: Australia: presente para Baralaba Coal Measueres, Cuenca Bowen (Foster, 1979).

Esta es la primera cita de la especie para la Argentina.

Género Vitreisporites Leschik emend. Jansonius 1962

Especie tipo. Vitreisporites signatus Leschik 1955.

Afinidad botánica. Gymnospermopsida-Caytoniales-Caytoniaceae (véase Balme, 1995).

Vitreisporites sp. A

Lámina $\mathrm{XV}$, figura $\mathrm{F}$

Descripción. Grano de polen bisacado haploxilonoide, de contorno general oval transversal. Cuerpo central de exina delgada que le otorga una coloración más clara que la de los sacos, de márgenes poco discernibles, de contorno oval elongado longitudinalmente. Cápula de 9-10 $\mu \mathrm{m}$ de ancho, extendia a lo largo de todo el cuerpo y de lados cóncavos, que acompañan el contorno del cuerpo. Sacos iguales a $1 \frac{1}{2}$ círculo, de adherencia proximal ecuatorial y distal subecuatorial, de poca inclinación distal. Sexina 
Lámina XII 


\section{Lámina XII}

A y B. Alisporites australis de Jersey 1962, BAPal 6155 (a) M69/0 (X 800); BAPal 6152 (a) J60/3 (X 800).

C Alisporites opii Daugherty 1941, BAPal 6145 (a) P44/0 (X 800).

D y E. Alisporites rioclarensis Menéndez 1976, BAPal 6152 (a) P51/0 (X 1000); BAPal 6165 (b) M40/2 (X 700).

F. Chordasporites sp. cf. C. australiensis de Jersey 1962, BAPal 6152 (c) P52/4 (X 800).

G y H. Falcisporites parvus (de Jersey) nov. comb., BAPal 6152 (a) X60/2 (53 $\mu \mathrm{m})$; $\mathrm{J} 73 / 4$ (X 800). 

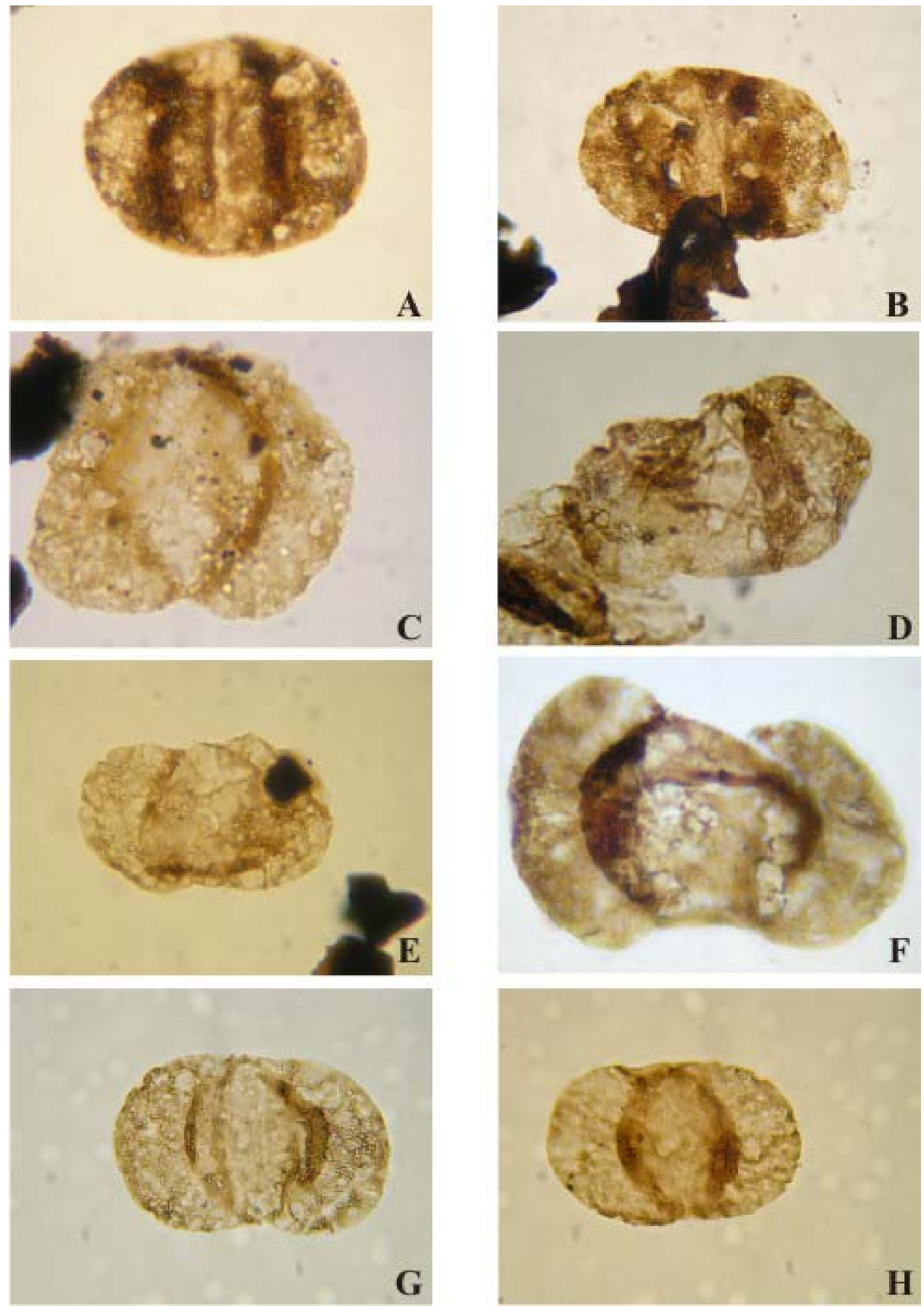
Lámina XIII 


\section{Lámina XIII}

A y B. Falcisporites similis (Balme) nov. comb., BAPal 6152 (a) F68/1 (X 900); S47/0 (X 650).

C. cf. Ibisporites sp., BAPal 6152(a) L64/0 (X 800).

D. Pityosporites sp. A, BAPal 6152 (a) H40/2 (X 750).

E. Platysaccus crassimarginatus Lakhanpal, Sah y Dube 1960, BAPal 6152 (a) H57/2 (X 700).

F. Platysaccus papilionis Potonié y Klaus 1954, BAPal 6150 O52/0 (X 850).

G y H. Platysaccus leschikii Hart 1960, BAPal 6173 (a) F60/0 (X 800); BAPal 6184 (b) E37/0 (X 350). 

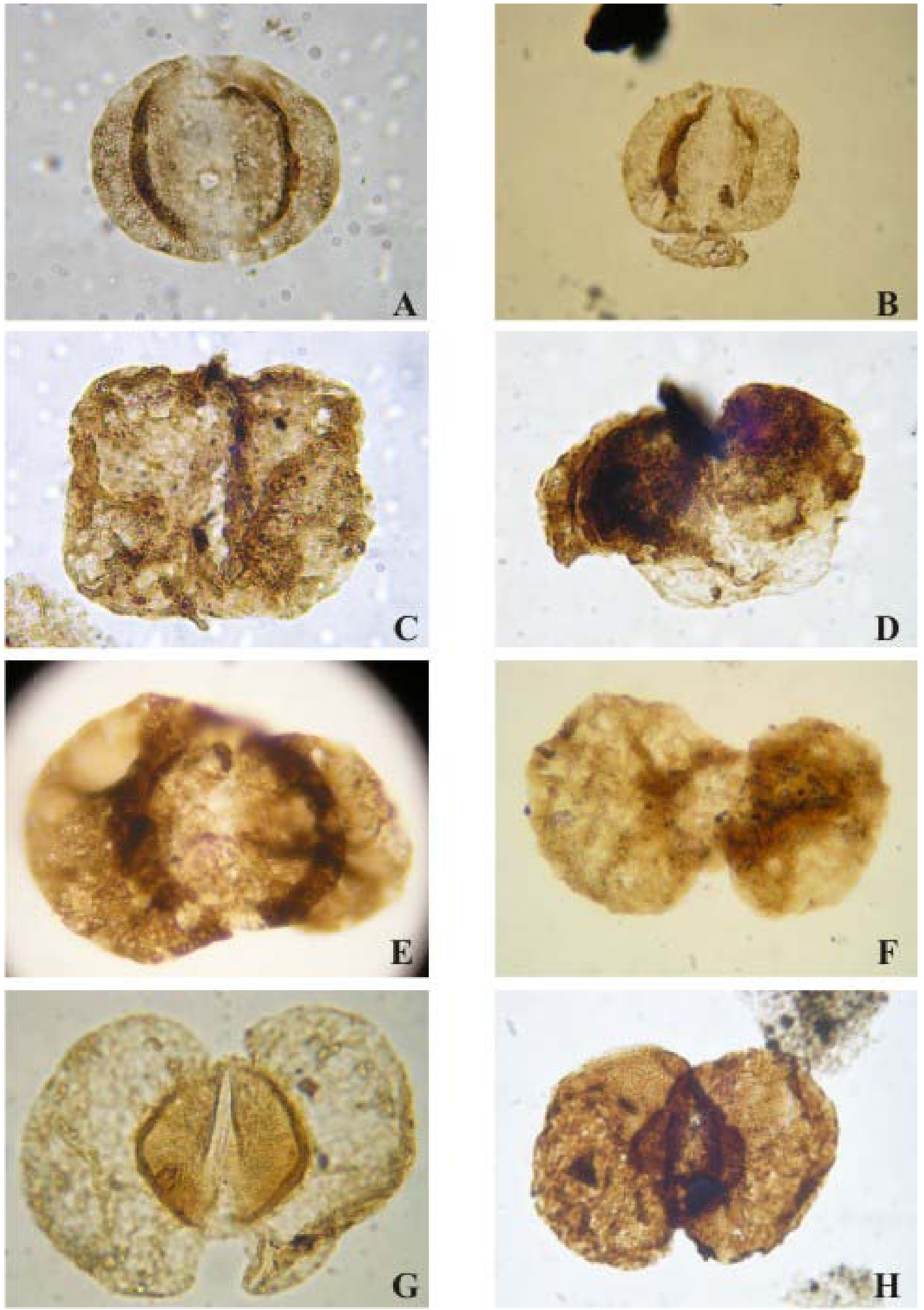


\section{Lámina XIV}

A y B. Platysaccus queenslandi de Jersey 1962, BAPal (X 500); BAPal 6187(a) Y37/2 (X 800).

C y D. Platysaccus sp. A, BAPal 6168 (a) V44/0 (X 850); BAPal 6158(b) H35/3 (X 850).

E. Pteruchipollenites sp. cf. P. gracilis (Segroves) Foster 1979, BAPal 6152 (a) D58/4 (X 650).

F. Scheuringipollenites circularis Césari, Archangelsky y Seoane 1995, BAPal 6173 (a) D43/0 (X 900).

G. Scheuringipollenites maximus (Hart) Tiwari 1973, BAPal 6165 (b) J52/1 (X 850).

H. Scheuringipollenites medius (Burjack) Dias-Fabrício 1981, BAPal 6152 (a) X43/0 (X 450). 


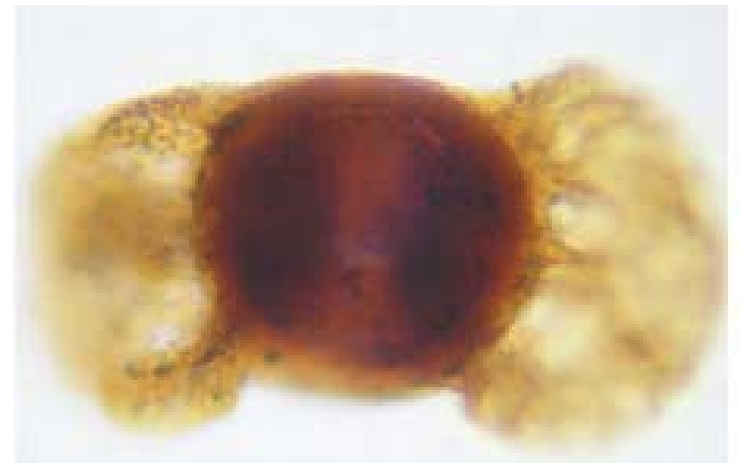

A
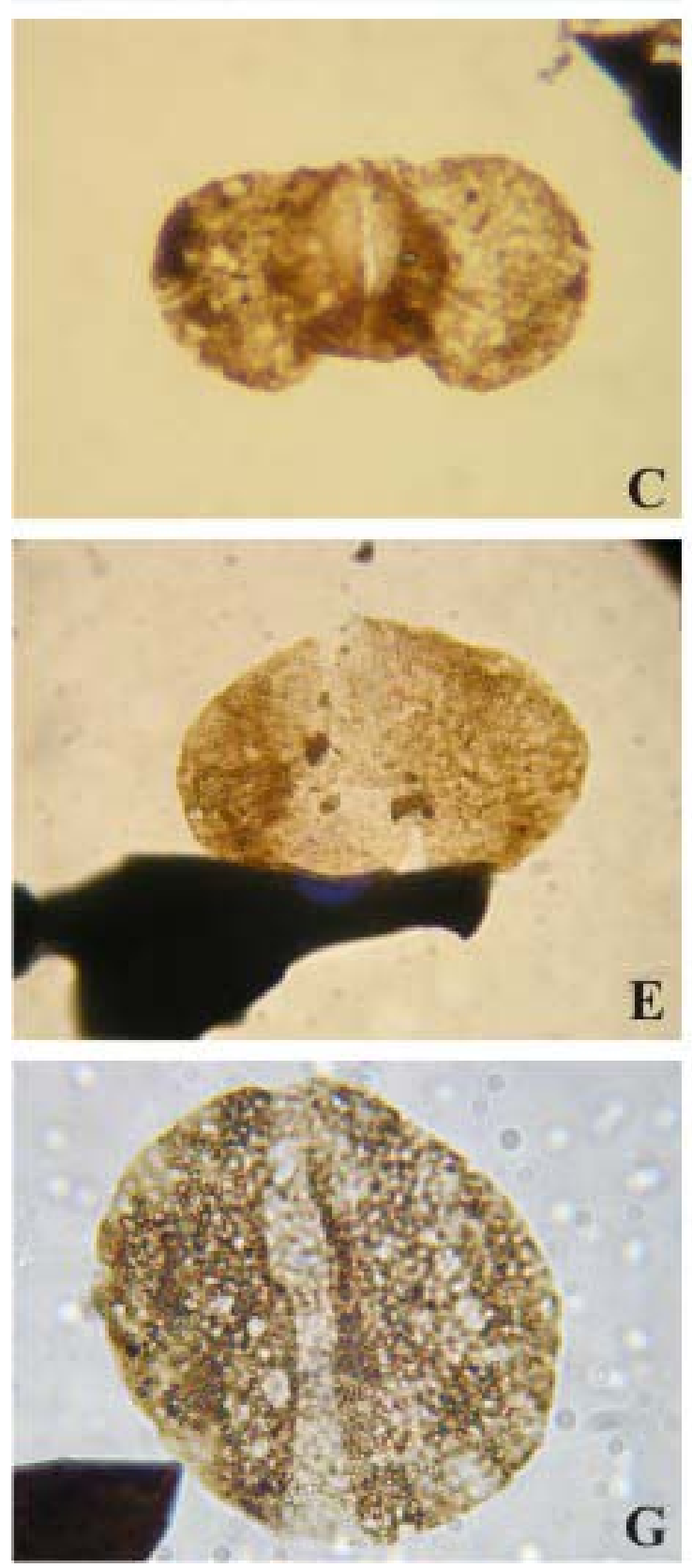
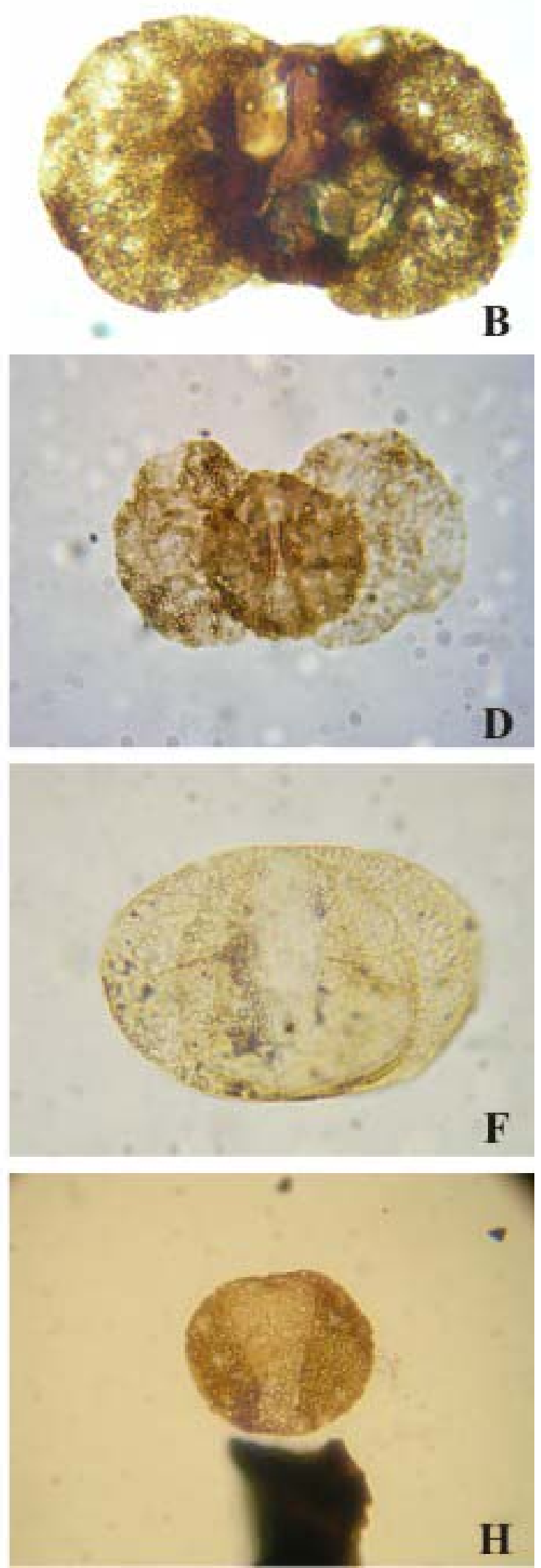
Lámina XV 


\section{Lámina XV}

A y B. Scheuringipollenites ovatus (Balme y Hennelly) Foster 1975, BAPal 6152 (a) N70/4 (X 800); BAPal 6159 (a) P53/2 (X 850).

C. Colpisaccites granulosus Archangelsky y Gamerro 1979, BAPal 6168 (a) H65/0 (X 850).

D. Limitisporites amazoniensis Playford y Dino 2000b, BAPal 6189 (a) K56/1 (X 350).

E. Limitisporites sp. cf. L. rectus Leschik 1956, BAPal 6188 (b) Z33/4 (X 900).

F. Vitreisporites sp. A, BAPal 6165 (a) F64/0 (X 850).

G y H. Triadispora epigona Klaus 1964, BAPal 6165 (a) H34/2 (X 900); BAPal 6152 (a) $\mathrm{O} 72 / 0$ (X 800). 

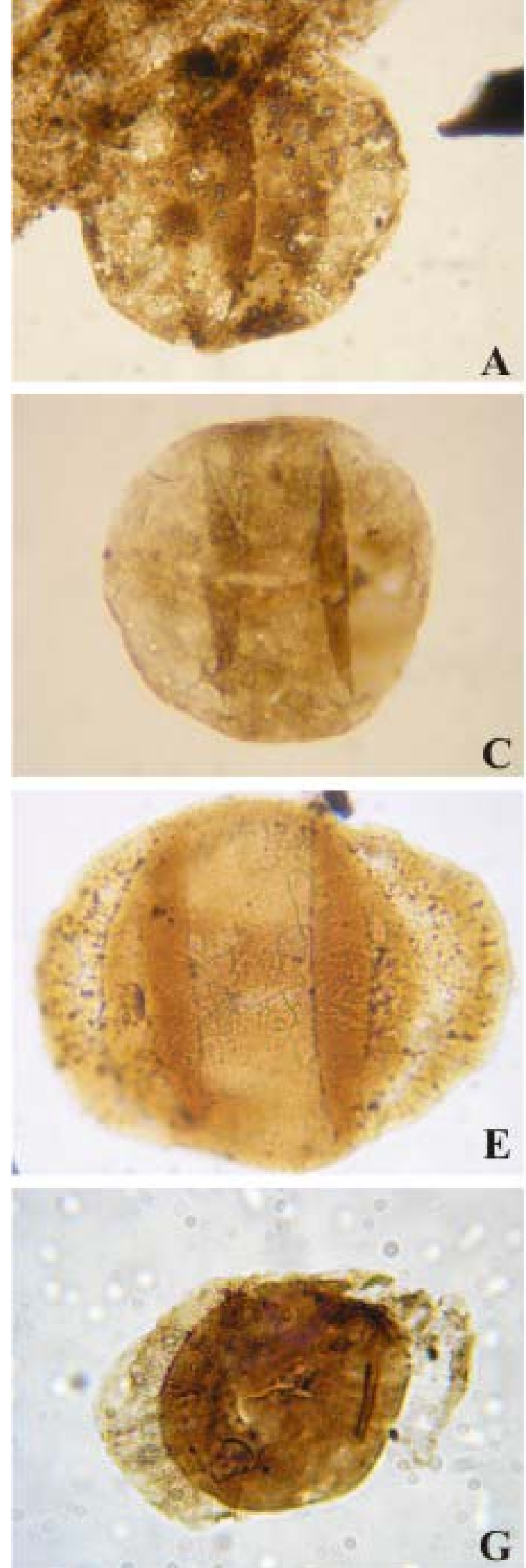
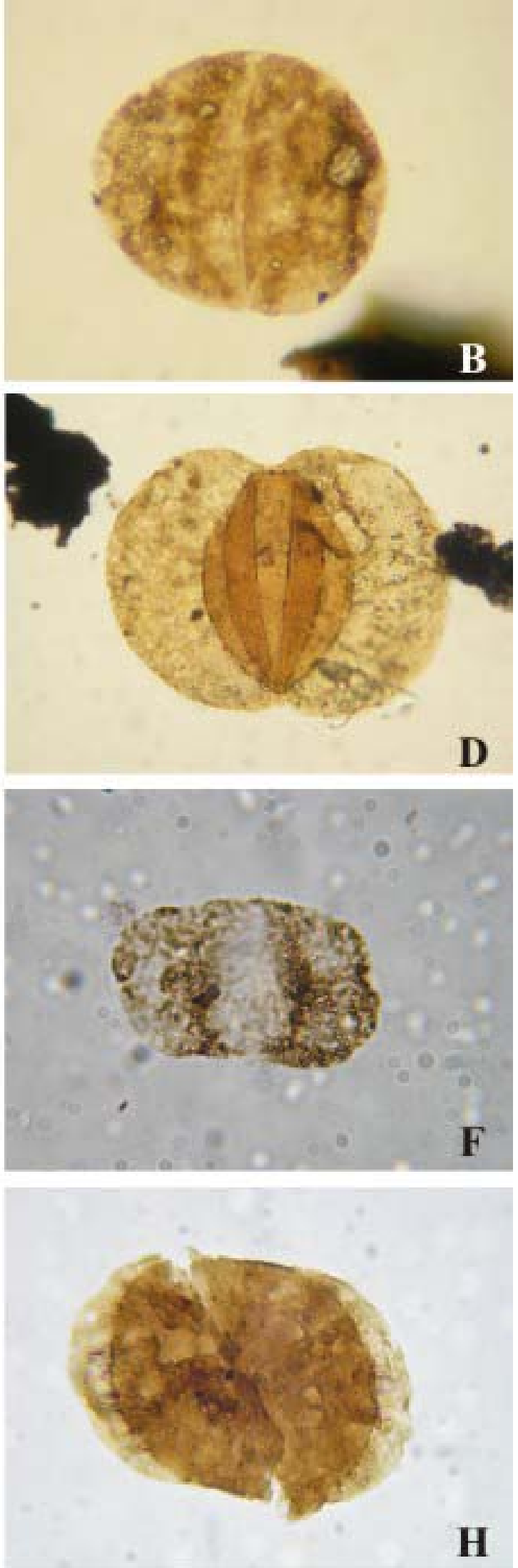
Lámina XVI 


\section{Lámina XVI}

A y B. Convolutispora archangelskyi Playford y Dino 2002

C y D. Convolutispora ordonezii Archangelsky y Gamerro 1979

E. Lophotriletes sp. A

F. Lophotriletes sp. A. Detalle de la ornamentación.

G. Alisporites australis de Jersey 1962

H. Scheuringipollenites ovatus (Balme y Hennelly) Foster 1975 

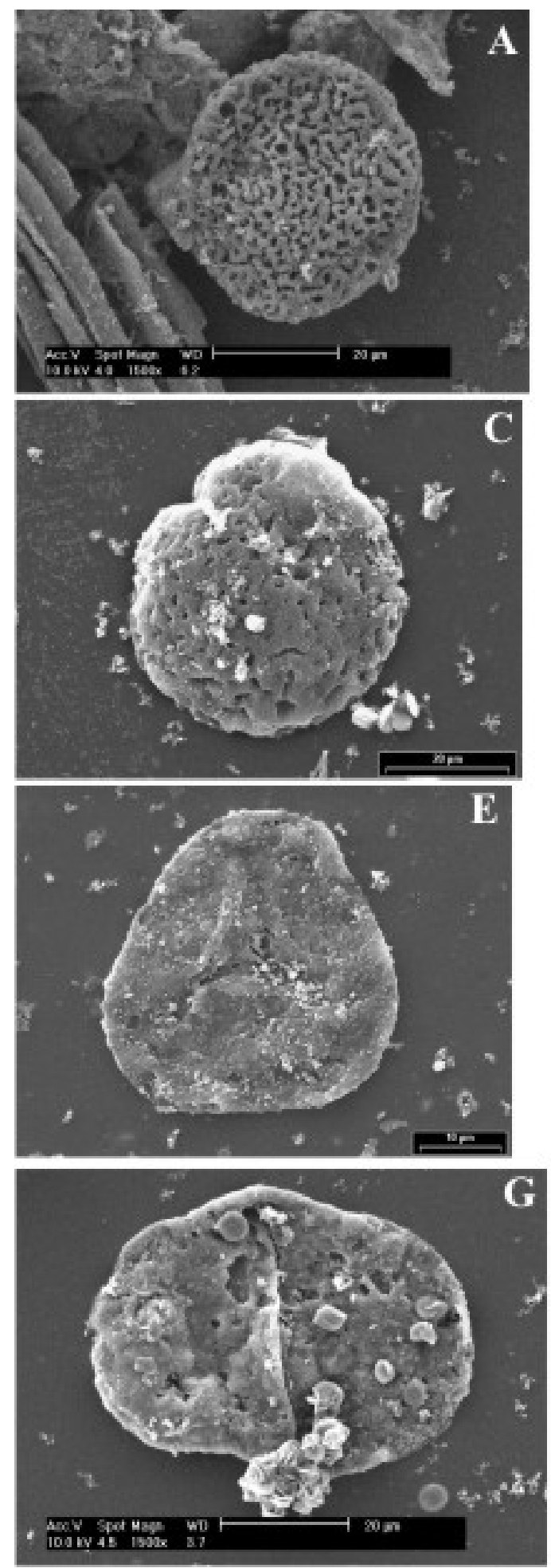
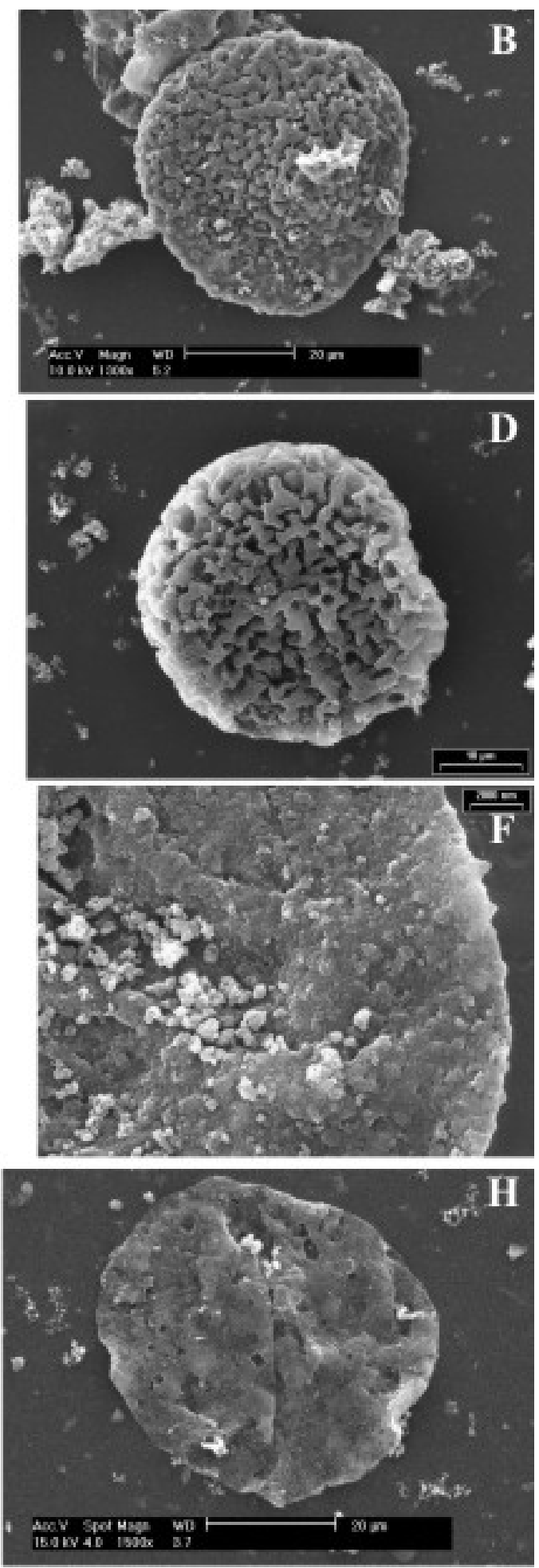
Lámina XVII 


\section{Lámina XVII}
A. Protohaploxypinus limpidus (Balme y Hennelly) Balme y Playford 1967
B. Staurosaccites cordubensis Archangelsky y Gamerro 1979
C. Lueckisporites sp.
D. Pityosporites sp. A
E. Striatopodocarpites cancellatus (Balme y Hennelly) Hart 1963
F y G. Vittatina subsaccata Samoilovich 1953
H. Lunatisporites variesectus Archangelsky y Gamerro 1979 

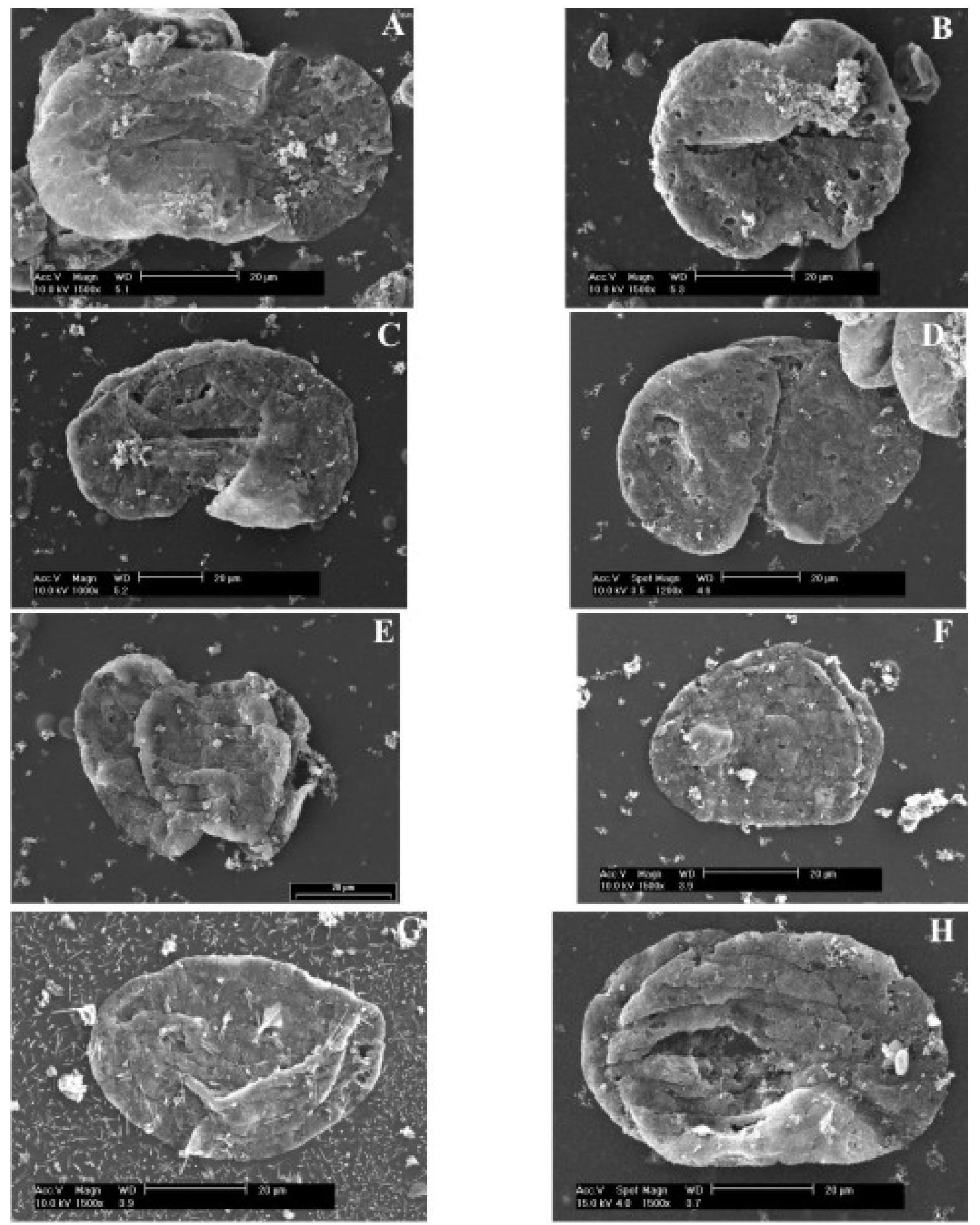
de los sacos infrareticulada, conformando delgados muros que definen lúminas poco discernibles de márgenes irregulares.

Dimensiones (2 ejemplares). Ancho total, 35-42 $\mu \mathrm{m}$; cuerpo central, ancho 17-18 $\mu \mathrm{m}$ y 21-24 $\mu \mathrm{m}$ de largo; ancho del saco sobre cara proximal, 7-8 $\mu \mathrm{m}$ y sobre cara distal, 11$13 \mu \mathrm{m}$; largo del saco, 21-24 $\mu \mathrm{m}$.

Principal material estudiado. BAPal 6152 (a) H70/4; BAPal 6165 (a) F64/0.

Comentarios. Los escasos ejemplares aquí observados, como así también la pobre preservación de éstos, impiden la asignación específica, aunque características tales como la forma general del grano, como del cuerpo central, permiten asignarlos al género Vitreisporites.

Subturma STRIATITES Pant 1954

Género Corisaccites Venkatachala y Kar 1966

Especie tipo. Corisaccites alutas Venkatachala y Kar 1966.

Afinidad botánica. Gimnospermas-Coniferopsida?

Corisaccites alutas Venkatachala y Kar 1966

Lámina XVIII, figura A

1970. pars. Lueckisporites densus Cauduro, pp. 20-21, pl. 16, figs. 112-113.

1977. pars. Lueckisporites nyakapendensis Hart; Anderson, p. 125, pl. 180, figs. 18-19, 21-22; pl. 181, fig. 3-4, 7, 9.

1977. pars. Lueckisporites welkomensis por Anderson, p. 126; pl. 182, figs 2, 6-9.

1980b. Corisaccites sp. Archangelsky y Gamerro, lám. II, fig. 5.

2000b. Lueckisporites virkkiae Potonié y Klaus emend. Clarke; Playford y Dino, pl. 8, fig. 17.

Sinonimia adicional. Balme (1970).

Descripción. Grano de polen bisacado, teniado, de contorno general subcircular, oval a subrectangular, elongado transversalmente, con variación desde formas haploxilonoides hasta fuertemente diploxilonoides. Cuerpo central circular, de pared delgada. La cara proximal presenta una cicatriz media, profunda, de orientación transversal, que alcanza los lados del cuerpo y lo bisecta, de 13 a $18 \mu \mathrm{m}$ de largo cada tenia resultante. Cápula rectangular, de lados longitudinales rectos a ligeramente cóncavos o convexos, de hasta 
1/5 respecto de los lados transversales. Sacos mayores a 1/2 círculo, con una amplia superficie de superposición, dejando una zona libre de los sacos de hasta 1/5 de ancho respecto del ancho total de los mismos. Adherencia proximal ecuatorial y distal bilateral. Sexina gruesa y oscura que conforma infragránulos dispuestos densamente, lo que le otorga una coloración siempre más oscura que el cuerpo. Márgenes de los sacos lisos.

Dimensiones ( 7 ejemplares). Ancho total, 63(79)99 $\mu \mathrm{m}$; cuerpo central, ancho $40(51,5) 60 \mu \mathrm{m}$ y $32(40,5) 56 \mu \mathrm{m}$ de largo; ancho del saco sobre cara proximal, 3(11)18 $\mu \mathrm{m}$ y sobre cara distal, $28(33,8) 47 \mu \mathrm{m}$; largo del saco, 52(57,2)62 $\mu \mathrm{m}$.

Principal material estudiado. BAPal 6149 (a) P63/0; BAPal 6152 (a) K48/0, J42/2, R57/0, T65/0; BAPal 6165 (a) D36/3.

Comparaciones. Algunos ejemplares referidos por Anderson (1977, p. 125, pl. 180, figs 18-19, 21-22; pl. 181, fig. 3-4, 7, 9) a Lueckisporites nyakapendensis Hart y a L. welkomensis por Anderson (1977, p. 126; pl. 182, figs 2, 6-9), presentan el cuerpo con dos tenias bien definidas y una cápula muy angosta, por lo que se entiende que hallarían una mejor ubicación sistemática en Corisaccites alutas. Parte del material descripto por Cauduro (1970, pp. 20-21, pl. 16, figs. 112-113) como L. densus, de la Formación Rio Bonito de Brasil, es reasignado a C. alutas, por no presentar diferencias significativas en cuanto a las características de la cápula y del cuerpo central. Del mismo modo Corisaccites sp. ilustrado por Archangelsky y Gamerro (1980b, lám. II, fig. 5), del Cisuraliano de la Cuenca Claromecó-Colorado, debe ser referido a C. alutas sobre la base de su angosto sulco, forma del cuerpo central y contorno de los sacos.

Registros previos. Corisaccites alutas fue descripto originalmente por Venkatachala y Kar (1966, p. 108, fig. 1-2, pl. 1; figs. 1-7), para Salt Range, Pérmico de Pakistán.

- Pennsylvaniano tardío-Guadalupiano: Brasil: presente en las formaciones Nova Olinda y Andirá, Grupo Trapajós, Cuenca Amazonas (Playford y Dino, 2000b).

- Cisuraliano-Guadalupiano: Argentina: presente en la Formación Victoriano Rodríguez, Biozona Striatites, Cuenca Chacoparaná (Playford y Dino, 2002); ilustrada para la Cuenca Claromecó-Colorado (Archangelsky y Gamerro, 1980b). Bolivia: ilustrada para la Formación Vitiacua (Sempere et al., 1992). Brasil: presente para la Formación Rio Bonito (Cauduro, 1970; Daemón y Quadros, 1970), ilustrada para la Formación Pedra do Fogo, Cuenca Parnaíba (Dino et al., 2002). Australia: ilustrada 
para la Formación Stockton, Cuenca Collie (Backhouse, 1991). Pakistán: presente para la Formación Amb, Grupo Zaluch (Balme, 1970). India: mencionada para la Formación Barajar (Srivastava y Jha, 1998). Arabia: ilustrada para la Formación Khuff (Stephenson y Filatoff, 2000b). Oman: presente en la Formación Gharif (Stephenson y Osterloff, 2002; Stephenson, 2008). África: en Cuenca del Karroo (Anderson, 1977; Weiss, 2001).

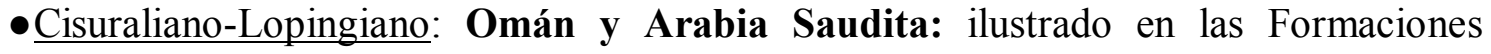
Gharif, Unayzah y Khuff(Stephenson et al., 2002).

- Guadalupian-Lopingiano: Brasil: presente en las formaciones Palermo, Iratí, Serra Alta y Teresina (Daemón y Quadros, 1970).

- Lopingiano: Argentina: mencionada para la Formación La Veteada, Cuenca Paganzo (Zavattieri et al., 2008). España: ilustrada para la Formación Alcotas, sección Landete (Doubinger et al., 1990; Diéguez y Barrón, 2005).

Género Distriatites Bharadwaj 1962

Especie tipo. Distriatites bilateralis Bharadwaj, 1964.

Afinidad botánica. Gymnospermopsida (Raine et al., 2008).

\section{Distriatites sp. A}

Lámina XVIII, figura B

Descripción. Grano de polen bisacado, teniado, diploxilonoide. Cuerpo central en vista polar circular a levemente oval, elongado longitudinalmente. Cara proximal con más de 5 tenias transversales, paralelas a subparalelas, completas, separadas por profundas estrías. Cápula subrectangular, dividida por 3 o más estrías profundas, perpendiculares a las proximales, de $8 \mu \mathrm{m}$ de ancho. Sacos mayores a $1 / 2$ círculo, de igual a mayor tamaño (alto y largo) que el cuerpo central, inclinados distalmente. Adherencia proximal ecuatorial y distal bilateral. Sexina delgada que conforma un retículo poco discernible.

Dimensiones (1 ejemplar). Ancho total, $56 \mu \mathrm{m}$; cuerpo central, ancho $28 \mu \mathrm{m}$ y $28 \mu \mathrm{m}$ de largo; ancho del saco, $25 \mu \mathrm{m}$; largo del saco, $36 \mu \mathrm{m}$.

Principal material estudiado. BAPal 6156 (c) C49/4. 
Comentarios. La pobre preservación del ejemplar identificado impide una asignación específica, sin embargo, la presencia de las tenias proximales y distales dispuestas perpendicularmente entre sí, permiten asignarlo al género Distritatites.

Género Illinites Kosanke 1950 emend. Jansonius y Hills 1976

Especie tipo. Illinites unicus Kosanke emend. Jansonius y Hills, 1976.

Afinidad botánica. Gimnospermopsida (Kosanke, 1950; Jizba, 1962; Staplin et al., 1967); Voltziales (Scheuring, 1970). Ullmannia frumentaria (Schlotheim). Véase más en Azcuy et al. (2002).

Illinites unicus Kosanke emend. Jansonius y Hills 1976 Lámina XVIII, figuras C y D

Descripción. Grano de polen bisacado a monosacado, teniado, haploxilonoide. Cuerpo central en vista polar oval, elongado longitudinalmente, de contorno a veces no discernible claramente. Capa con estrías dispuestas perpendiculares ú oblícuas al eje mayor del cuerpo, que delimitan tenias completas o incompletas, acuñadas entre sí. Cápula ahusada, de lados cóncavos que se contactan por los extremos. Sacos menores a iguales a 1/2 círculo, de mayor tamaño que el cuerpo central. Adherencia proximal ecuatorial y distal bilateral. Zona distal de adherencia con pliegues ahusados asociados, que delimitan la cápula. Sexina delgada que conforma un infraretículo poco discernible. Dimensiones (3 ejemplaes). Ancho total, 43(48,3)52 $\mu \mathrm{m}$; cuerpo central, ancho $22(26,5) 31 \mu \mathrm{m}$ y $42(42,5) 43 \mu \mathrm{m}$ de largo; ancho del saco sobre cara proximal, 8(9)10 $\mu \mathrm{m}$ y sobre cara distal, $22(25,3) 32 \mu \mathrm{m}$; largo del saco, 42(42,5)43 $\mu \mathrm{m}$.

Principal material estudiado. BAPal 6185 (b) V34/0; BAPal 6188 (b) U53/4. Redepósito: BAPal 6174 (a) V58/2.

Registros previos. Illinites unicus fue descripto originalmente para Coffee Creek, Wabash Country, Estados Unidos por Kosanke (1950).

- Pennsylvaniano: Perú: presente en la Formación Tarma, Pongo de Mainique (Azcuy et al., 2002).

- Pennsylvaniano-Cisuraliano: Brasil: presente en la perforación 3-MC-3-SC, Matos Costa, Santa Catarina, Cuenca Paraná (Quadros et al., 1996). 
- Cisuraliano: Argentina: presente en la Biozona Cristatisporites (media y superior) de la Cuenca Chacoparaná (Césari et al., 1995).

- Cisuraliano-Guadalupiano: Brasil: mencionada para la Formación Rio Bonito, Cuenca Paraná (Souza y Marques-Toigo, 2005).

Ampliamente distribuída para sedimentos del Carbonífero Superior y el Pérmico de Sudamérica, Estados Unidos, Europa, India y Medio Oriente (véase Azcuy et al., 2002, pp. 16-18).

Género Hamiapollenites Wilson emend. Tschudy y Kosanke 1966 Especie tipo. Hamiapollenites saccatus Wilson, 1962a.

Afinidad botánica. Gymnospermas (véase Quadros et al., 1996).

Hamiapollenites andiraensis Playford y Dino 2000b

Lámina XVIII, figura E

1966. Hamiapollenites karroensis (auct. non Hart) Hart 1964 [1964a]; Quadros et al., p. 64.

Descripción. Grano de polen bisacado, teniado, de contorno oval transversal, diploxilonoide. Cuerpo central dividido en la capa por finas estrías en 5 a 11 tenias completas, de ancho constante, entre $3(4,6) 7 \mu \mathrm{m}$ y extremos redondeados. Cápula lisa, bisectada longitudinalmente por una zona engrosada de ancho constante. Dicha área suele presentarse incompleta. Sacos mayores a 1/2 círculo, de igual a menor altura que el cuerpo y la mitad de ancho del mismo. Adherencia ecuatorial, con espesamientos de la exina asociados a dichas zonas. Sexina delgada que conforma una infragranulación visible en ciertas zonas. Sacos de contorno irregular y con dispersos pliegues radiales productos de la compresión.

Dimensiones (8 ejemplares). Ancho total, 50(58,2)68 $\mu \mathrm{m}$; cuerpo central, ancho 20(26,4)30 $\mu \mathrm{m}$ y 21(29,4)35 $\mu \mathrm{m}$ de largo; ancho del saco, 12(17,5)20 $\mu \mathrm{m}$; largo del saco, $22(25,2) 30 \mu \mathrm{m}$.

Principal material estudiado. BAPal 6152 (a) J69/1, U58/0, K65/0; BAPal 6152 (b) W74/1; BAPal 6156 (c) G46/2; BAPal 6165 (b) O65/4; BAPal 6168 (a) U51/0; BAPal 6189 (a) $C 47 / 3$. 
Comentarios. Los ejemplares aquí estudiados son asignados sin dudas a la especie Hamiapollenites andiraensis Playford y Dino 2000 b (p. 106, pl. 8, figs. 5-9; pl. 6, fig. 6; pl. 12, figs. 1, 2): cuerpo central oval transversal, con 6 a 8 estrías continuas subparalelas proximales, y una banda exinal distal de posición longitudinal de 4 a 10 $\mu \mathrm{m}$ de ancho; sacos pequeños de adherencia ecuatorial.

Registros previos. Hamiapollenites andiraensis fue descripta por Playford y Dino (2000b, p. 106, pl. 8, figs. 5-9, pl. 11, fig. 6, pl. 12, figs. 1, 2) para las formaciones Nova Olinda y Andirá, Carbonífero Superior-Pérmico, del Grupo Trapajós, Cuenca Amazona, Brasil. También es descripta para Chapéu do Sol, Cuenca Paraná (Quadros et al., 1996). - Cisuraliano-Lopingiano: Brasil: ilustrada para la Formación Pedra do Fogo, Cuenca Parnaíba (Dino et al., 2002).

Esta es la primera cita de la especie para la Argentina.

Hamiapollenites fusiformis Marques-Toigo emend. Archangelsky y Gamerro 1979 Lámina XVIII, figura F

Descripción. Grano de polen bisacado, teniado, de contorno oval trasversal, haploxilonoide. Cuerpo central más oscuro que los sacos, de exina gruesa. Cara proximal con 8 a 15 tenias de ancho constante, entre $2(3,3) 6 \mu \mathrm{m}$ de ancho, completas y de extremos redondeados. Cápula lisa con una franja engrosada que bisecta longitudinalmente al cuerpo, no siempre evidente por corrosión. Sacos menores o iguales a 1/2 círculo, de tamaño reducido, de hasta $2 / 3$ de la altura del cuerpo y de $1 / 4 \mathrm{de}$ ancho. Sexina delgada, que no desarrolla infraretículo evidente. Inserción de los sacos subecuatorial distal, levemente inclinados distalmente.

Dimensiones (10 ejemplares). Ancho total, 51(68,1)82 $\mu \mathrm{m}$; cuerpo central, ancho 12(37,1)55 $\mu \mathrm{m}$ y 30(42,4)55 $\mu \mathrm{m}$ de largo; ancho del saco, 5(21,4)55 $\mu \mathrm{m}$; largo del saco, $18(30,4) 35 \mu \mathrm{m}$.

Principal material estudiado. BAPal 6138 (b) D52/4, F44/2; BAPal 6140 (a) F69/0; BAPal 6142 (a) U55/1; BAPal 6152 (a) B37/1, G74/0, T43/0; BAPal 6152 (b) T46/0, U42/1. Redepósito: BAPal 6135 (a) V57/1; BAPal 6181 (a) P72/1. 
Registros previos. Hamiapollenites fusiformis fue descripta originalmente por Marques-Toigo (1974, p. 611, pl. III, figs. 7-10) para la Formación San Gregorio, Cisuraliano de Uruguay.

- Pennsylvaniano-Guadalupiano: Argentina: presente en las biozonas PotonieisporitesLundbladispora, Cristatisporites y Striatites, Cuenca Chacoparaná (Archangelsky y Gamerro, 1979; Vergel, 1987; Césari et al., 1995).

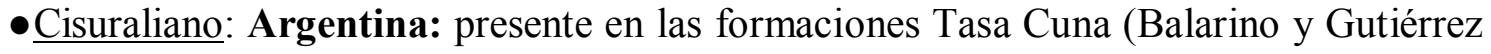
2006) y Bajo de Véliz (Gutiérrez y Césari, 2000), Cuenca Paganzo. Ilustrada para la Formación El Imperial, Cuenca San Rafael (García, 1996). Uruguay: presente en las formaciones San Gregorio (Marques-Toigo, 1974; Gutiérrez et al, 2006) y Tres Islas (Beri, 1988), Cuenca Paraná. Brasil: ilustrada para el Grupo Itararé (Dias, 1993); y presente en la perforación 3-MC-3-SC, Matos Costa, Santa Catarina (Quadros et al., 1996), Cuenca Paraná. Arabia: ilustrada para la Formación Al Khlata, Oman y Arabia Saudita (Stephenson et al., 2003) y mencionada para la Formación Khuff (Stephenson y Filatoff, 2000a, 2000b, 2003).

- Cisuraliano-Guadalupiano: Uruguay: ilustrada para la Formación Melo (Beri y Pecoits, 2001), Cuenca Paraná.

- Guadalupiano: Brasil: presente en la Formación Andirá, Grupo Trapajós, Cuenca Amazonas (Playford y Dino, 2000b).

\section{Hamiapollenites ruditaeniatus Qu y Wang 1986 Lámina XVIII, figuras $\mathrm{G}$ y $\mathrm{H}$}

Descripción. Grano de polen bisacado, teniado, de contorno oval transversal, haploxilonoide. Capa dividida por anchos surcos en 3 a 4 tenias completas, de hasta 12 $\mu \mathrm{m}$ de largo y extremos redondeados. Cápula lisa, bisectada longitudinalmente por una zona engrosada de forma ahusada. Sacos menores a 1/2 círculo, de menor altura que el cuerpo y la mitad de ancho del mismo. Adherencia proximal ecuatorial y distal bilateral. Sexina delgada que conforma una infragranulación visible en ciertas zonas.

Dimensiones (3 ejemplares). Ancho total, 84(90,3)95 $\mu \mathrm{m}$; cuerpo central, ancho 34(51,6)62 $\mu \mathrm{m}$ y 40-45 $\mu \mathrm{m}$ de largo; ancho del saco sobre cara proximal, 9-15 $\mu \mathrm{m}$ y sobre cara distal, $24(28,8) 32 \mu \mathrm{m}$; largo del saco, 50(61,5)68 $\mu \mathrm{m}$. 
Principal material estudiado. BAPal 6183 (a) K34/3; BAPal 6187 (b) Q36/3, R69/4.

Comentarios. Si bien los ejemplares hallados son pocos, los mismos presentan un buen grado de preservación en donde pueden verse los caracteres diagnósticos de la especie Hamiapollenites ruditaeniatus: cuerpo central oval longitudinal, capa dividida por anchos surcos en 3 a 4 tenias completas, cápula lisa dividida por una zona engrosada longitudinal, de forma ahusada y sacos iguales o menores a $1 / 2$ círculo.

Registros previo. Hamiapollenites ruditaeniatus fue descripta por Qu y Wang (1986) para el Triásico de China.

-Lopingiano-Triásico Inferior: China: Meishan, Changxing, Zhejiang (Ouyang Shu y Utting, 1990).

- Triásico Inferior: China: ilustrada para la Cuenca Junggar, Xinjiang, China (Ouyang Shu y Norris, 1999).

Esta es la primera cita de la especie para la Argentina.

Género Lunatisporites Leschik emend. Scheuring 1970

Especie tipo. Lunatisporites acutus Leschik, 1955.

Afinidad botánica. Gimnospermas, Coniferales, Podocarpaceae (véase Balme, 1995).

Lunatisporites noviaulensis (Leschik) Foster 1979

Lámina XIX, figuras A y B

1956. Taeniaesporites noviaulensis Leschik, p. 134, pl. 22, figs. 1-2.

Sinonimia adicional. VéaseFoster (1979).

Descripción. Grano de polen bisacado, teniado, de contorno oval elongado transversalmente, haploxilonoide a levemente diploxilonoide. Cuerpo central oval, elongado en el sentido del eje mayor del grano. Capa con una estría principal que bisecta al cuerpo transversalmente, completa, ancha en su parte media y que se afina hacia los extremos. Esta estría principal bisecta al cuerpo en 2 sectores, subdivididos a su vez por estrías secundarias que limitan generalmente 2 tenias, rara vez 3 , de extremos redondeados y de superficie finamente granulada. Cápula de lados cóncavos o convexos hacia el centro, de 9(17,7)28 $\mu \mathrm{m}$ de ancho. Sacos iguales a 1/2 círculo, adheridos al cuerpo por zonas de adherencia proximal ecuatorial y distal subecuatorial bilateral. Las 
zonas distales pueden estar asociadas a delgados pliegues semilunares que acompañan la forma del límite de la zona. Sexina infrareticulada, conformando delgados muros.

Dimensiones (8 ejemplares). Ancho total, 76(80,8)87 $\mu \mathrm{m}$; cuerpo central, ancho $46(53,3) 63 \mu \mathrm{m}$ y $43(41,2) 54 \mu \mathrm{m}$ de largo; ancho del saco sobre cara proximal, 9(14,2)20 $\mu \mathrm{m}$ y sobre cara distal, 30(33,1)40 $\mu \mathrm{m}$; largo del saco, 45(42,2)56 $\mu \mathrm{m}$.

Principal material estudiado. BAPal 6185 (b) U41/3, N51/3; BAPal 6187 (a) L60/3; BAPal 6188 (b) M61/1. Redepósito: BAPal 6174 (a) T63/0; BAPal 6175 (a) M58/3; BAPal 6178 (a) O34/4; V54/1.

Registros previos. Lunatisporites noviaulensis (Leschik) Foster fue descripta para Salzton von Neuhof (Bei Fulda), Pérmico de Alemania Leschik (1956).

- Pennsylvaniano: Brasil: presente en la perforación 3-MC-3-Sc, Matos Costa, Carbonífero Superior-Lopingiano, Santa Catarina, Cuenca Paraná (Quadros et al., 1996).

- Guadalupiano: Australia: presente en Baralaba Coal Measures (muy raro) (Foster, 1979). Presente en el Guadalupiano-superior de la Cuenca Sydney (Helby, 1973).

- Lopingiano: Argentina: mencionada para la Formación La Veteada, Cuenca Paganzo (Zavattieri et al., 2008).

- Permico Superio-Triásico Inferior: Australia: presente en la Formación Rewan, Cuenca Bowen (Foster, 1979; de Jersey, 1968, 1970); en el Pérmico de Chhidruan (Balme, 1963) y el Triásico del Salt Range (Balme, 1970). Distribución adicional: véase Foster (1979).

- Triásico Inferior: India: presente en la Formación Maitur, Grupo Panchet (Maheshwari y Banerjee, 1975).

Lunatisporites paliensis Tiwari y Ram-Awatar 1989

Lámina XIX, figura C

Descripción. Grano de polen bisacado, teniado, de contorno circular, levemente diploxilonoide. Cuerpo central subcircular a oval en sentido transversal. Capa con una estría principal que bisecta al cuerpo transversalmente, completa, ancha en su parte media y que se afina hacia los extremos. Esta estría principal divide al cuerpo en 2 sectores, subdivididos a su vez por estrías secundarias que limitan generalmente 2-3 
tenias, de extremos redondeados y ahusados. Cápula de lados convexos hacia el centro y extremos que se bifurcan, de $2 \mu \mathrm{m}$ de ancho en su parte central y hasta $32 \mu \mathrm{m}$ de ancho en los extremos. Sacos menores a iguales a 1/2 círculo, de adherenacia proximal ecuatorial y distal bilateral, inclinados distalmente. Sexina infrareticulada, conformando delgados muros.

Dimensiones (17 ejemplares). Ancho total, 67(84)116 $\mu \mathrm{m}$; cuerpo central, ancho 52(70,2)92 $\mu \mathrm{m}$ y 41(61,5)74 $\mu \mathrm{m}$ de largo; ancho del saco sobre cara proximal, $6(9,5) 13$ $\mu \mathrm{m}$ y sobre cara distal, $20(35,5) 50 \mu \mathrm{m}$; largo del saco, 51(68,3)96 $\mu \mathrm{m}$.

Principal material estudiado. BAPal 6148 (a) M39/1; BAPal 6152 (a) B50/3, C60/2; BAPal 6152 (c) X58/2; BAPal 6156 (c) W51/2; BAPal 6158 (a) Z60/1; BAPal 6189 (a) G71/1. Redepósito: BAPal 6174 (a) C51/1, D43/0, J56/0, X64/2; BAPal 6174 (b) F61/0; BAPal 6175 (a) X50/0; BAPal 6175 (b) M50/0, M63/4, P40/0, Y63/2.

Comentarios. El material aquí descripto presenta las características diagnósticas de la especie Lunatisporites paliensis: prominentes tenias, angosta cápula, sacos de similar altura que el cuerpo central que lo engloban, y su gran tamaño (110-140 $\mu \mathrm{m}$ de ancho total), caracteres estos que no se observan en otras especies también aquí estudiadas.

Registros previos. Lunatisporites paliensis fue descripta por Tiwari y Ram-Awatar (1989) para el Cisuraliano de Birsinghpur-Pali, Johilla Coalfield, India.

Esta es la primera cita de la especie para cuencas sudamericanas.

Lunatisporites variesectus Archangelsky y Gamerro 1979 Lámina XIX, figura D; Lámina XVII, figura $\mathrm{H}$

Descripción. Grano de polen bisacado, teniado, de contorno oval elongado transversalmente, haploxilonoide a levemente diploxilonoide. Cuerpo central circular a suboval, elongado en el sentido del eje mayor del grano. Pared del cuerpo delgada que le da una coloración clara, hialina. Capa con una estría principal que bisecta al cuerpo transversalmente, completa, ancha en su parte media y que se afina hacia los extremos. Puede observarse en algunos casos la presencia de una marca de monolete corta, recta o geniculada, de la mitad del diámetro transversal del cuerpo. Esta estría principal bisecta al cuerpo en 2 sectores, subdivididos a su vez por estrías completas e incompletas, finas, que pueden orientarse paralelas a la principal como así también oblicuamente a ésta. Las 
estrías secundarias limitan de 4 a 9 tenias de 5(6,3)10 $\mu \mathrm{m}$ ancho, el cual varía según la disposición de las estrías. Las tenias también pueden ser incompletas, los extremos siempre son redondeados y la superficie puede presentar una fina granulación de distribución dispersa. Cápula de lados rectos o cóncavos hacia el centro, de 9(17,7)28 $\mu \mathrm{m}$ de ancho. Sacos mayores a 1/2 círculo, adheridos al cuerpo por zonas de adherencia proximal ecuatorial y distal subecuatorial. Las mismas pueden estar asociadas a delgados pliegues semilunares que acompañan la forma del límite de la zona. Sexina infrareticulada, conformando muros orientados radialmente. Los sacos siempre son más oscuros que el cuerpo.

Dimensiones (15 ejemplares). Ancho total, 58(79,2)100 $\mu \mathrm{m}$; cuerpo central, ancho $36(50,4) 62 \mu \mathrm{m}$ y $38(45) 58 \mu \mathrm{m}$ de largo; ancho del saco sobre cara proximal, $12(16,1) 20$ $\mu \mathrm{m}$ y sobre cara distal, 16(27,7)39 $\mu \mathrm{m}$; largo del saco, 40(46,6)62 $\mu \mathrm{m}$.

Principal material estudiado. BAPal 6138 (a) E65/0; BAPal 6152 (a) B38/3, M50/2, M69/3, P65/1, M52/2; BAPal 6155 (a) J36/3; BAPal 6184 (b) J37/2; BAPal 6188 (a) C34/2. Redepósito: BAPal 6174 (a) K68/1; BAPal 6175 (b) J62/3.

Registros previos. Lunatisporites variesectus fue descripta originalmente por Archangelsky y Gamerro (1979) para 3 perforaciones que realizara YPF en la provincia de Córdoba, Biozona Striatites (Cisuraliano-Guadalupiano), raro en parte superior de Biozona Cristatisporites (Cisuraliano), Cuenca Chacoparaná.

- Cisuraliano: Argentina: presente en la Formación Tasa Cuna, Cuenca Paganzo (Balarino y Gutiérrez, 2006). Brasil: presente en la perforación 3-MC-3-SC Matos Costa, Santa Catarina (Quadros et al., 1996), ilustrada para el Grupo Itararé (Dias, 1993), Cuenca Paraná. Presente en el Grupo Trapajós, Cuenca Amazonas (Playford y Dino, 2000b). Uruguay: presente en la Formación San Gregorio (Marques-Toigo, 1974; Gutiérrez et al., 2006b), Cuenca Paraná. Paraguay: ilustrada para la Formación Tacuary, Grupo Independencia, Cuenca Chacoparaná (Muff et al., 1999).

- Cisuraliano-Guadalupiano: Argentina: presente en la Biozona Striatites (Archangelsky y Gamerro, 1979; Vergel, 1987b), Cristatisporites (Césari et al., 1995); y en la Formación Victoriano Rodríguez, biozonas Cristatisporites y Striatites (Playford y Dino, 2002), Cuenca Chacoparaná. Ilustrada para la Formación De La Cuesta (Aceñolaza y Vergel, 1987). Brasil: ilustrada para las formaciones Rio Bonito (Souza y Marques-Toigo, 2005) e Iratí (Premaor et al., 2006), Cuenca Paraná. Uruguay: 
ilustrada para la Formación Melo (Mautino et al., 1998b; Beri y Pecoits, 2001), Cuenca Paraná.

\section{Lunatisporites sp. A}

Lámina XIX, figuras E y F

Descripción. Grano de polen bisacado, teniado, haploxilonoide a levemente diploxilonoide, de contorno general oval elongado en sentido transversal. Cuerpo central subcircular a oval transversal, de contornos poco discernibles. Capa bisectada por una estría profunda, transversal, angosta y completa. A su vez, cada parte resultante de la división de esta estría principal se subdivide en 7 a 13 tenias, delimitadas por estrías más pequeñas, orientadas de manera subparalela a la estría principal, y las cuales no pueden observarse si son completas al no poder discernir claramente el contorno del cuerpo. Cápula de 4(16,6)27 $\mu \mathrm{m}$ de ancho, rectangular de lados rectos a levemente cóncavos hacia el centro del cuerpo. Sacos iguales a 1/2 círculo, levemente mas largos respecto del cuerpo, de implantación proximal ecuatorial y distal bilateral y leve inclinación distal. Zona de superposición de los sacos con el cuerpo ancha, de hasta 4/5 respecto del ancho del saco. Sexina de los sacos infrareticulada, conformando muros cortos, anchos e irregulares, que delimitan pequeñas lúminas, y dispuestos densamente, lo que otorga a los sacos una coloración más oscura respecto del cuerpo.

Dimensiones (14 ejemplares). Ancho total, 60(72,5)85 $\mu \mathrm{m}$; cuerpo central, ancho 22(45)60 $\mu \mathrm{m}$ y 35(44,9)50 $\mu \mathrm{m}$ de largo; ancho del saco sobre cara proximal, 6(11,1)15 $\mu \mathrm{m}$ y sobre cara distal, $15(25,9) 35 \mu \mathrm{m}$; largo del saco, 35(50,3)62 $\mu \mathrm{m}$.

Principal material estudiado. BAPal 6139 (a) E48/4; BAPal 6152 (a) F69/1, M60/3, S61/2; BAPal 6152 (b) N36/3, P64/0; BAPal 6155 (a) L51/1; BAPal 6156 (a) J49/1; BAPal 6161 (a) P58/1; BAPal 6163 (a) N57/4; BAPal 6166 (a) X46/0; BAPal 6167 (a) W46/1; BAPal 6186 (a) E39/0;.

Comentarios. Caracteres tales como la presencia de una estría principal transversa en el cuerpo central que divida en 2 al cuerpo central, y estas a su vez subdivididas por estrías mas pequeñas, de las que resulten numerosas tenias transversales y oblicuas, ubican a los ejemplares aquí estudiados sin dudas dentro del género Lunatisporites. Lunatisporites sp. A es comparable con las siguientes especies: 
Lunatisporites pellucidus (Goubin) Maheshwari y Banerjee (1975, pp. 166-167, pl. 5, fig. 74) es la forma más parecida a los ejemplares aquí descriptos, por su caracter haploxilonoide y su poca definición del contorno del cuerpo central. Sin embargo se diferencia por presentar un cuerpo oval-romboidal, elongado longitudinalmente, en sentido contrario del máximo desarrollo del cuerpo central de los ejemplares observados.

Lunatisporites tethyensis Vijaya y Tiwari (en Vijaya et al., 1988, p. 76, pl. V, 7, 8, 10, 11, 14, fig. 18), también presenta un contorno haploxilonoide, pero a diferencia de los ejemplares de la Cuenca Colorado, su cuerpo es oval longitudinal, los sacos son marcadamente menores y el número de tenias de la cápula es menor (5-6 en esta especie y 7-10 en Lunatisporites sp. B). Además presenta pliegues distales semilunares, elementos no visibles en estos ejemplares.

Lunatisporites paliensis Tiwari y Ram-Awatar (1989, p. 100, pl. 1, figs. 14, 15) también presenta un contorno haploxilonoide, pero el tamaño general es mucho mayor (varía entre los 110 y $140 \mu \mathrm{m}$, mientras que el rango de variación de los ejemplares de Cuenca Colorado de 73 a $89 \mu \mathrm{m}$ ), además, presenta menor cantidad de tenias (4 a 5) que en $L$. sp. A (7-13).

Lunatisporites variesectus Archangelsky y Gamerro (1979, pp. 453-454, lám. XI, figs. 9-13) esta forma también es haploxilonoide a levemente diploxilonoide, pero se diferencia por presentar un cuerpo central bien definido, una calle o estría central mas ancha, y los conjuntos de tenias resultantes tienen formas irregulares por las bifurcaciones de las estrías que los subdividen, lo que no ocurre con las subdivisiones de los conjuntos de tenias en los cuerpos de los ejemplares asignados como Lunatisporites sp. A.

Lunatisporites ovatus (Goubin) Maheshwari y Banerjee (1975, p. 167, pl. 5, fig. 68) esta especie tiene un cuerpo central oval longitudinal, presenta solo de 4 y 6 tenias proximales y pliegues distales semilunares, características no observadas aquí.

Los ejemplares descriptos e ilustrados como Lueckisporites asulcus (Bose y Kar) Anderson (1977, p. 124, pl. 175, figs. 1-9, pl. 176, figs. 1-21, pl. 177, figs. 1-12) presentan un contorno general oval haploxilonoide a levemente diploxilonoide, cuerpo central oval trasversal, dividido en dos por una estría principal, y cada uno de estos sectores presenta entre 3 y 6 tenias angostas, cápula de lados rectos y de ancho entre $1 / 4 \mathrm{a}$ 
$1 / 2$ de ancho respecto del ancho del cuerpo central. Dichos caracteres lo asemejan estrechamente con el material aquí descripto. Se debe mencionar por un lado que el material de Anderson debe ser ubicado en el género Lunatisporites y no en Lueckisporites, y por otro lado Lunatisporites asulcus Bose y Kar (1966, p. 52, pl. 16, figs. 1-2) presenta el cuerpo central marcadamente oval en sentido longitudinal con extremos ahusados, un ancho total que oscila entre 184 y $207 \mu \mathrm{m}$, cápula ahusada muy angosta. Además, la estría central característica de Lunatisporites, no es ni descripta ni se observa en el material ilustrado por Bose y Kar (1966).

\section{Lunatisporites sp. B}

Lámina XIX, figuras G y H

Descripción. Grano de polen bisacado, teniado, de contorno haploxilonoide a diploxilonoide, ovalmente elongado en sentido trasversal. Cuerpo central oval elongado trasversalmente, de pared delgada. Capa dividida en dos partes iguales por una profunda estría media. En cada área se observan alrededor de 2 tenias de ancho variable y orientadas paralelas al eje mayor del cuerpo. Cápula rectangular, de 4(8,6)13 $\mu \mathrm{m}$ de ancho, elongada longitudinalmente, de lados rectos subparalelos. Sacos iguales a mayores a 1/2 círculo, de inserción proxima ecuatorial y distal bilateral. Zona de adherencia distal asociada a pliegues ahusados subparalelos a los lados mayores de la cápula, y de 1/5 del ancho del cuerpo. Sexina de los sacos infrareticulada, con muros delgados que limitan lúminas de márgenes irregulares.

Dimensiones (6 ejemplares). Ancho total, 55(78)102 $\mu \mathrm{m}$; cuerpo central, ancho 24(43,3)56 $\mu \mathrm{m}$ y 30(37)48 $\mu \mathrm{m}$ de largo; ancho del saco sobre cara proximal, 11(19,8)25 $\mu \mathrm{m}$ y sobre cara distal, 28(33,6)47 $\mu \mathrm{m}$; largo del saco, 32(46,6)60 $\mu \mathrm{m}$.

\footnotetext{
Principal material estudiado. BAPal 6151 (a) S47/4; BAPal 6152 (a) V49/4; BAPal 6152 (b) R50/0; BAPal 6152 (e) Q41/1. Redepósito: BAPal 6173 (a) K56/0; BAPal 6175 (b) X61/0.
}

Comentarios. La pobre preservación de los ejemplares estudiados impide la observación detallada de las tenias de cada una de las zonas definidas en el cuerpo central, motivo por el cual, junto con el bajo número de ejemplares observados, dificultan la asignación específica, aunque sí puede hacerse una asignación genérica, 
por observarse características propias como la profunda estría del cuerpo, los sectores resultantes de la misma a su vez subdivididos en numerosas tenias longitudinales y coincidir también con la morfología general del grano.

Género Lueckisporites Potonié y Klaus emend. Klaus 1963

Especie tipo. Lueckisporites virkkiae Potonié y Klaus, 1954.

Afinidad botánica. Gimnospermas-Coniferopsida (véase Balme, 1995).

\section{Lueckisporites sp. cf. L. nyakapendensis Hart 1960}

Lámina XX, figura $\mathrm{C}$

Descripción. Grano de polen bisacado, biteniado, fuertemente diploxilonoide, de contorno general oval elongado en sentido transversal. Cuerpo central oval a subhexagonal, que alcanza su mayor desarrollo en igual sentido del grano. Capa bisectada por una estría transversal completa, que delimita 2 tenias anchas, en contacto entre sí, y sin una evidente ornamentación. Cápula angosta, de 40(47,8)53 $\mu \mathrm{m}$ de ancho, de lados rectos a levemente cóncavos hacia el centro del cuerpo, subparalelos. Sacos mayores a 1/2 círculo, 1/3 más grandes que el largo del cuerpo central, adheridos distalmente de manera bilateral. Zona de superposición entre sacos y cuerpo central de $1 / 2$ del ancho de los sacos. Sexina de los mismos infrareticulada, conformando muros cortos, irregulares y anchos, dispuestos densamente, lo que le otorga una coloración más oscura a los sacos respecto del cuerpo. Fuerte inclinación distal de los mismos.

Dimensiones (5 ejemplares). Ancho total, 64(80,6)100 $\mu \mathrm{m}$; cuerpo central, ancho $40(47,8) 53 \mu \mathrm{m}$ y $35(30,5) 35 \mu \mathrm{m}$ de largo; ancho del saco sobre cara proximal, 8(14,6)26 $\mu \mathrm{m}$ y sobre cara distal, 30(38,8)56 $\mu \mathrm{m}$; largo del saco, 36(44,5)60 $\mu \mathrm{m}$.

Principal material estudiado. BAPal 6138 (c) Q62/3; BAPal 6152 (a) M50/3; BAPal 6152 (b) P64/0; BAPal 6165 (a) X50/0. Redepósito: BAPal 6175 (b) P56/1.

Comentarios. La pobre preservación de los ejemplares aquí estudiados no permiten realizar una asignación específica certera. Sin embargo, caracteres tales como el aspecto general fuertemente diploxilonoide, el cuerpo central oval elongado transversalmente, la presencia de una estría central estrecha, ausencia de pliegues distales asociados a las zonas de adherencia y los sacos de mayor tamaño que el cuerpo central, permiten aproximar la asignación a la especie Lueckisporites nyakapendensis. 


\section{Lueckisporites singhii Balme 1970}

Lámina XX, figuras A y B

1964. Lueckisporites sp. Singh, p. 257, pl. 46, fig. 4.

Descripción. Grano de polen bisacado, biteniado, haploxilonoide, de contorno general oval elongado en sentido transversal. Cuerpo central claro, subcircular a oval, transversalmente elongado, de contornos en general poco definidos. Capa bisectada por una calle o amplia estría principal de extensión transversal, total o parcialmente completa, abierta hasta en 1/6 del largo del cuerpo, de lados rectos y extremos ahusados. Las 2 tenias resultantes son equidimensionales, y su superficie se observa ligeramente infragranulada. Cápula de 13(18,8)23 de ancho, contorno subrectangular, de lados mayores rectos a levemente cóncavos hacia el centro. Sacos iguales a 1/2 círculo, de implantación proximal ecuatorial y distal bilateral. Zona de superposición distal de los sacos con el cuerpo amplia, de $2 / 3$ del ancho del saco. Sexina de los sacos gruesa con una densa infragranulación, lo que les otorga a los sacos una coloración muy oscura.

Dimensiones ( 7 ejemplares). Ancho total, 54(65,5)75 $\mu \mathrm{m}$; cuerpo central, ancho 40(45)52 $\mu \mathrm{m}$ y 40(46,7)53 $\mu \mathrm{m}$ de largo; ancho del saco sobre cara proximal, 8-12 $\mu \mathrm{m}$ y sobre cara distal, $22(25,4) 31 \mu \mathrm{m}$; largo del saco, 43(49,7)57 $\mu \mathrm{m}$.

Principal material estudiado. BAPal 6152 (a) Q58/1, T57/4; BAPal 6155 (a) L72/4; BAPal 6165 (a) D62/1; BAPal 6165 (b) C52/2; BAPal 6189 (a) R56/0. Redepósito: BAPal 6172 (a) R70/2.

Registros previos. Lueckisporites singhii fue descripta por Balme (1970, p. 376, pl. 13, figs. 1-3) para las formaciones permo-triásicas Amb, Wargal Limestone y Chhidru, de Salt Range y Surghar Range, Oeste de Pakistán.

- Cisuraliano: Arabia Saudita: mencionada para la Formación Khuff (Stephenson y Filatoff, 2000b, 2003).

- Lopingiano: Argentina: mencionada para la Formación La Veteada, Cuenca Paganzo (Zavattieri et al., 2008).

Lueckisporites singrauliensis Sinha 1972

Lámina XX, figura D 
Descripción. Grano de polen bisacado, biteniado, fuertemente diploxilonoide. Cuerpo central subcircular, pequeño, de $2 / 3$ de largo respecto del largo total. Capa bisectada por una estría transversal completa, que delimita 2 tenias reñiformes, y sin una evidente ornamentación. Cápula angosta, de 3(8,1)11 $\mu \mathrm{m}$ de ancho, de lados rectos a levemente cóncavos hacia el centro del cuerpo, subparalelos. Sacos mayores a 1/2 círculo, de adherencia proximal ecuatorial y distal bilateral. Sexina de los mismos infrareticulada, conformando muros cortos, irregulares y anchos, dispuestos densamente, lo que le otorga una coloración más oscura a los sacos respecto del cuerpo, inclinados distalmente.

Dimensiones (8 ejemplares). Ancho total, 68(78,2)95 $\mu \mathrm{m}$; cuerpo central, ancho $26(38,1) 56 \mu \mathrm{m}$ y $15(34,8) 41 \mu \mathrm{m}$ de largo; ancho del saco sobre cara proximal, $15(26) 47$ $\mu \mathrm{m}$ y sobre cara distal, 30(33,8)41 $\mu \mathrm{m}$; largo del saco, 34(49,8)60 $\mu \mathrm{m}$.

Principal material estudiado. BAPal 6152 (a) F36/0, R58/3, W44/3; BAPal 6152 (b) Y60/0; BAPal 6152 (c) V41/0; BAPal 6158 (a) N64/1; BAPal 6165 (a) H52/4; BAPal 6188 (b) D48/1.

Comentarios. Los ejemplares aquí estudiados presentan las características que definen a la especie Lueckisporites singraulensis. Estas son: contorno fuertemente diploxilonoide, cuerpo central pequeño, de forma circular que porta 2 tenias reñiformes, cápula angosta de lados rectos y sacos inflados, de inclinación distal.

Registros previos. Lueckisporites singrauliensis fue descripto por Sinha (1972) para la perforación NCSJ-4, n ${ }^{\circ}$ 112, Jhingurdah Seam, Singrauli Coalfield, Madhya Pradesh, India.

-Lopingiano: India: presente en la Formación Raniganj (Tiwari y Vijaya, 1995).

Esta es la primera cita de la especie para la Argentina.

Lueckisporites virkkiae Potonié y Klaus emend. Klaus 1963

Lámina XX, figuras $\mathrm{E}$ y $\mathrm{F}$

Sinonimia. Balme (1970) y Raine et al. (2007).

Descripción. Grano de polen bisacado, biteniado, levemente diploxilonoide, de contorno general oval elongado en sentido transversal. Cuerpo central de circular a oval, elongado también transversalmente, de pared delgada y coloración clara. Cara proximal 
bisectada por una calle o amplia estría central transversa, completa y de ancho constante. La calle limita 2 tenias ovaladas a reniformes sin esculturación evidente. La cápula es rectangular, de lados rectos y un ancho de hasta 1/3 respecto del cuerpo. Sacos iguales a 1/2 círculo, 1/5 más largos que el cuerpo central, de implantación proximal ecuatorial y distal bilateral, e inclinación distal. Zona de superposición de los sacos con el cuerpo ancha, de hasta $3 / 4$ del ancho respecto de los sacos. Sexina de los sacos infrareticulada, conformando muros cortos, anchos e irregulares, que delimitan pequeñas lúminas, dispuestos densamente lo que le otorga una coloración más oscura a lo sacos respecto del cuerpo.

Dimensiones (6 ejemplares). Ancho total, 71(85)105 $\mu \mathrm{m}$; cuerpo central, ancho $25(51,3) 65 \mu \mathrm{m}$ y $38(43,2) 50 \mu \mathrm{m}$ de largo; ancho del saco sobre cara proximal, 15(24,6)43 $\mu \mathrm{m}$ y sobre cara distal, 20(27,5)43 $\mu \mathrm{m}$; largo del saco, 38(43,2)50 $\mu \mathrm{m}$.

Principal material estudiado. BAPal 6143 (a) J68/2; BAPal 6152 (a) G43/3, E44/0; BAPal 6158 (a) W58/0. Redepósito: BAPal 6175 (a) P41/0.

Registros previos. Lueckisporites virkkiae fue descripta por Potonié y Klaus (1954, p. 534, pl. 10, fig. 3) para Werra Solvaywerke Borth, Lopingiano de Alemania.

- Pennsylvaniano tardío-Cisuraliano: Brasil: descripta para las formaciones Nova Olinda y Andirá, Grupo Trapajós, Cuenca Amazonas (Playford y Dino, 2000b).

- Cisuraliano: Paraguay: ilustrada para la Formación Tacuary, Grupo Independencia, Cuenca Chacoparaná (Muff et al., 1999). Bolivia: ilustrada para la Formación Vitiacua (Sempere et al., 1992). Oman y Arabia Saudita: ilustrada para la Formación A1 Khlata, (Stephenson et al., 2003); mencionada para la Formación Khuff (Stephenson y Filatoff, 2003). África: ilustrada para sedimentos probablemente asignable a Dwyka, Cuenca de Gabón, atribuíbles a Karroo (Jardiné, 1974).

- Cisuraliano-Guadalupiano: Argentina: ilustrada para la Formación Piedra Shotel, Biozona Striatites, Cuenca Central Patagónica (Gamerro y Archangelsky, 1981a); presente en la Biozona Striatites, Cuenca Chacoparaná (Archangelsky y Gamerro, 1979); ilustrada para la Formación Yacimiento Los Reyunos, Cuenca Oriental (Césari et al., 1996). Brasil: presente en los Estratos con Mesosaurus, Formación Iratí (Menéndez, 1976; Premaor et al., 2006); ilustrada para las formaciones Rio Bonito (Souza y Marques-Toigo, 2005) y Pedra do Fogo, Cuenca do Parnaíba (Dino et al., 2002). 
- Guadalupiano: Pakistán: presente en Wargar Limestone, Grupo Zaluch (Balme, 1970).

- Guadalupiano-Lopingiano: Omán y Arabia Saudita: ilustrada para las Formaciones Ghariff, Unayzah y Khuff (Stephenson et al., 2003).

-Lopingiano: Brasil: presente en la perforación 3.MC-3-SC, Matos Costa, Santa Catarina, Cuenca Paraná (Quadros et al., 1996). Estados Unidos: presente en la Formación Flowerpot, Oklahoma (Wilson, 1962a; Clapham, 1970). Pakistán: presente en la Formación Chhidru, Grupo Zaluch (Balme, 1970). Inglaterra: Clarke, 1965. España: ilustrada para la Formación Alcotas, sección Landete (Diéguez y Barrón, 2005).

- Lopingiano-Triásico Inferior: Groenlandia: presente en Kap Stosch (Balme, 1979). Israel: mencionada para las formaciones Arqov y Yamin (Eshet, 1990). India: ilustrada para la Formación Parsora, Cuenca Gondwana (Tiwari y Ram-Awatar, 1987). Australia: presente en la Formación Rewan, Cuenca Bowen (de Jersey, 1979). Irlanda: ilustrada para las formaciones Kingscourt Gypsum y Kingscourt Sandstone (Vissher, 1971).

Género Protohaploxypinus Samoilovich emend. Morbey 1975

Especie tipo. Protohaploxypinus latissimus (Luber) Samoilovich, 1953.

Afinidad botánica. Gimnospermosida-Voltizales/Glossopteridales (véase Balme, 1995; Lindström et al., 1977).

Protohaploxypinus amplus (Balme y Hennelly) Hart 1964

Lámina $\mathrm{XX}$, figura $\mathrm{G}$

1955. pars. Lueckisporites amplus Balme y Hennelly, p. 93, pl. 3, figs. 24-27.

1980b. Protohaploxypinus sp. Archangelsky y Gamerro, lám. II, fig. 6.

Sinonimia adicional. Foster (1979).

Descripción. Grano de polen bisacado, teniado, de contorno general oval, elongado en sentido transversal, haploxilonoide. Cuerpo central subcircular a oval, elongado longitudinalmente. Capa dividida por finas estrías, en 9 a 10 tenias completas, perpendiculares al eje mayor del cuerpo central, de ancho constante y extremos redondeados. Las tenias nunca se bifurcan. Cápula rectangular, de $1 / 2$ de ancho respecto 
del cuerpo. Sacos iguales a $1 / 2$ círculo, de implantación proximal ecuatorial y distal bilateral. El área de adherencia distal de los mismos es de forma semilunar. En éstas zonas de adherencia pueden observarse áreas engrosadas, a modo de pliegues ubicados a los lados rectos de la cápula, pero no siempre están presentes. Sexina de los protosacos desarrolla granulación interna, que no alcanza a conformar un infraretículo, de disposición homogénea.

Dimensiones (6 ejemplares). Ancho total, 60(76,1)95 $\mu \mathrm{m}$; cuerpo central, ancho $32(47,6) 62 \mu \mathrm{m}$ y $34(47,6) 58 \mu \mathrm{m}$ de largo; ancho del saco sobre cara proximal, 15(17,5)19 $\mu \mathrm{m}$ y sobre cara distal, 15(24,3)42 $\mu \mathrm{m}$; largo del saco, 32(54)71 $\mu \mathrm{m}$.

Principal material estudiado. BAPal 6146 (a) U58/1; BAPal 6152 (a) D65/1; BAPal 6158 (a) U56/4; BAPal 6165 (a) L70/1; BAPal 6168 (a) V59/0BAPal 6183 (b) F47/3. Redepósito: BAPal 6174 (a) Q50/1; BAPal 6175 (b) H46/2.

Comentarios. Muy probablemente el material referido a Protohaploxypinus sp. por Archangelsky y Gamerro (1980b, lám. II, fig. 6) deba ser incluido en esta especie por la forma del cuerpo y del grano, la forma de la cápula y la cantidad de tenias que presentan.

Registros previos. Lueckisporites amplus fue descripta originalmente por Balme y Hennelly (1955, p. 93, pl. 3, figs. 24-27) para la perforación South Wallarah, South New Gales, Australia. Posteriormente dicha especie fue combinada al género Protohaploxypinus por Hart (1964).

- Pennsylvaniano cuspidal: Argentina: presente en la Formación Agua Colorada, Sierra de Famatina, Cuenca Paganzo (Gutiérrez, 1993) y en los Estratos de Mascasín (Pérez Loinaze y Césari, 2004). Brasil: presente en las formaciones Monte Grande, Itaituba y Nova Olinda, Grupo Trapajós, Cuenca Amazonas (Playford y Dino, 2000b); presente para el Subgrupo Itararé, Cuenca Paraná (di Pasquo et al., 2003b; Souza et al., 2003); e ilustrada para la Formación Piauí, Cuenca Paranaíba (Dino y Playford, 2002), presente en la perforación 2-CS-1-PR, Chapéu do Sol, Carbonífero Superior-Lopingiano, Cuenca Paraná (Quadros et al., 1996). Perú: mencionada para la Formación Tarma, Pongo de Mainique (Azcuy et al., 2002).

- Cisuraliano: Argentina: presente para la Biozona Cristatisporites, Cuenca Chacoparaná (Césari et al., 1995); presente en las formaciones Tasa Cuna (Balarino y Gutiérrez, 2006) y Bajo de Véliz (Menéndez, 1971; Gutiérrez y Césari, 2000), Cuenca 
Paganzo; ilustrada en la Formación Tupe (miembro cuspidal), Cuenca Paganzo (Vergel, 2008). Uruguay: ilustrada para la Formación Melo (Beri y Pecoits, 2001), Cuenca Paraná. Brasil: presente en el Grupo Trapajós, Cuenca Amazonas (Playford y Dino, 2000b). Ilustrada para el Grupo Itararé, Cuenca Paraná (Dias, 1993; Souza y Callegari, 2004). Paraguay: ilustrada para la Formación Tacuary, Grupo Independencia, Cuenca Chacoparaná (Muff et al., 1999). Australia: presente en Blair Athol Coal Measures (Foster, 1975) y mencionada para Fairbairn Dam (Fielding y McLoughlin, 1992), Cuenca Bowen. Ilustrada para las formaciones Stockton, Cuenca Collie (Backhouse, 1991) y Fossil Cliff, Cuenca Perth (Foster et al., 1985); las Cuencas Perth, Collie y Officer (Backhouse, 1993) y Formación Bandanna, Springsure Anticline (Rigby y Hekel, 1977). Antártida: presente para Prince Charles Mountains (Balme y Playford, 1967); ilustrada por Playford (1990). Mencionada para Vestfjella, Dronning Maud Land (Larsson et al., 1990; Lindström, 1993, 1996, 2005); Heimefrontfjella mountain-range, Dronning Maud Land (Lindströn, 1995). Arabia: ilustrada para la Formación Al Khlata, Oman y Arabia Saudita (Stephenson et al., 2003); y mencionada para la Formación Khuff (Stephenson y Filatoff, 2000a, 2000b, 2003). Sudáfrica: presente en Cuenca Karroo (Anderson, 1977).

- Cisuraliano-Guadalupiano: Argentina: ilustrada para la Biozona Cristatisporites, Cuenca Claromecó-Colorado (Archangelsky y Gamerro, 1980b). Uruguay: ilustrada para la Formación Melo (Beri y Pecoits, 2001), Cuenca Paraná. Brasil: presente en la Formación Rio Bonito (Ybert, 1975), ilustrada en la Formación Iratí (Premaor et al., 2006), Cuenca Paraná. Papúa: ilustrada para las formaciones Ainim y Aiduna (Playford y Rigby, 2008).

- Guadalupiano: Australia: presente en Baralaba Coal Measures, Cuenca Bowen (Foster, 1979); en Sue Coal Measures, Cuenca Perth (Segroves, 1969) y en la Formación Bandanna, Springsure Anticline (Rigby y Hekel, 1977).

- Lopingiano: Argentina: mencionada para la Formación La Veteada, Cuenca Paganzo (Zavattieri et al., 2008). Antártida: ilustrada para Buckley, Transantarctic Mountains (Farabee et al., 1991).

- Lopingiano-Triásico Inferior: Australia: presente en la Formación Rewan, Cuenca Bowen (Foster, 1979; de Jersey, 1979). 
- Triásico: Argentina: ilustrada para la Formación Puesto Viejo, San Rafael (Ottone y Garcia, 1991).

\section{Protohaploxypinus bharadwajii Foster 1979}

\section{Lámina XX, figura $\mathrm{H}$}

Sinonimia. Véase Foster (1979).

Descripción. Grano de polen bisacado, teniado, de contorno general oval, elongado transversalmente, haploxilonoide a levemente diploxilonoide. Cuerpo central subcircular a levemente oval longitudinal, de pared gruesa y oscura. Capa dividida por finas estrías en tenias de orientación transversal y ancho constante. Cápula angosta extendida a lo largo del cuerpo, de forma rectangular a ahusada, rodeada a los lados por pliegues anchos y semilunares, asociados a las bases distales de los sacos. Sacos con adherencia proximal ecuatorial y distal bilateral, inclinados distalmente. Sexina de los sacos infrareticulada conformando muros irregulares que delimitan lúminas de contorno irregular. Los muros se disponen densamente, otorgándole una coloración oscura a los mismos, aunque más clara que la de los pliegues distales.

Dimensiones (4 ejemplares). Ancho total, 58(70)82 $\mu \mathrm{m}$; cuerpo central, ancho $30(38,5) 45 \mu \mathrm{m}$ y $30(45,5) 58 \mu \mathrm{m}$ de largo; ancho del saco sobre cara proximal, 20-22 $\mu \mathrm{m}$ y sobre cara distal, 21(29,5)42 $\mu \mathrm{m}$; largo del saco, 32(46,7)58 $\mu \mathrm{m}$.

Principal material estudiado. BAPal 6152 (a) U51/2, J64/0; BAPal 6162 (a) E54/1, O53/0.

Comentarios.

Registros previos. Protohaploxypinus bharadwajii fue descripta por Foster (1979) para Blair Athol y Baralaba Coal Measures, Pérmico de Australia.

- Pennsylvaniano: Brasil: presente en las formaciones Itaituba y Nova Olinda,Grupo Trapajós, Cuenca Amazonas (Playford y Dino, 2000b) e ilustrada para la Formación Piauí, Cuenca Paranaíba (Dino y Playford, 2002).

- Pennsylvaniano-Cisuraliano: Argentina: ilustrada para la Formación Río del Peñón, Cuenca Paganzo (Gutiérrez y Limarino, 2006).

- Cisuraliano: Uruguay: presente en la Formación San Gregorio (Gutiérrez et al., 2006b). Brasil: presente en la perforación 2-UV-1-PR, União da Vitória, Cuenca Paraná 
(Quadros et al., 1996) e ilustrada para el Subgrupo Itararé, Cuenca Paraná (Dias, 1993; Souza y Callegari, 2004). Australia: presente en Blair Athol Coal Measures, Cuenca Bowen (Foster, 1979) y mencionada para Fairbairn Dam, Cuenca Bowen (Fielding y McLoughlin, 1992). Antártida: ilustrada por Playford (1990).

- Guadalupiano: Australia: presente en Baralaba Coal Measures, Cuenca Bowen (Foster 1979).

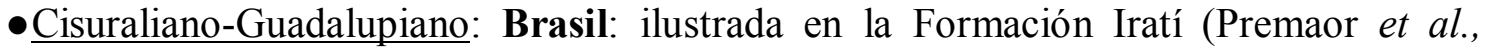
2006), Cuenca Paraná.

- Lopingiano-Triásico Inferior: Australia: ilustrada para la Formación Rewan, Cuenca Bowen (Foster, 1982).

\section{Protohaploxypinus diagonalis Balme 1970}

Lámina XXI, figuras A y B

1977. pars. Pityosporites amplus (Balme y Hennelly) Anderson, pl. 167, figs. 11, 13.

Descripción. Grano de polen bisacado, teniado, de contorno general oval elongado transversalmente, haploxilonoide. Cuerpo central oval longitudinal. Capa dividida en 8 a 10 tenias, por finas y profundas estrías. Estas tenias se disponen de manera oblicua respecto del eje mayor del cuerpo; son completas, a veces algo sinuosas, el ancho es constante, de 4 a $7 \mu \mathrm{m}$; y suelen afinarse en los extremos. Cápula extendida en todo el largo del cuerpo, de forma rectangular. Sacos iguales a 1/2 círculo, de inserción proximal ecuatorial y distal bilateral, de bordes rectos. Al área proximal de adherencia se asocian zonas engrosadas semilunares, que recorren ecuatorialmente al cuerpo, que se engrosan en la parte media y se afinan hacia los extremos alcanzando a contactarse entre sí. Sexina de los sacos infrareticulada, conformando muros anchos que delimitan aisladas lúminas subcirculares a irregulares.

Dimensiones (5 ejemplares). Ancho total, 70(77)83 $\mu \mathrm{m}$; cuerpo central, ancho $33(38,2) 45 \mu \mathrm{m}$ y $41(47,2) 52 \mu \mathrm{m}$ de largo; ancho del saco sobre cara proximal, 21(21,5)22 $\mu \mathrm{m}$ y sobre cara distal, $24(28,7) 34 \mu \mathrm{m}$; largo del saco, 40(47,2)56 $\mu \mathrm{m}$.

Principal material estudiado. BAPal 6146 (b) Y41/1; BAPal 6150 (a) P43/4; BAPal 6152 (a) L62/3. Redepósito: BAPal 6173 (a) K43/1; BAPal 6175 (b) L42/2. 
Comentarios. Tanto en la diagnosis (Balme 1970, pp. 364-365, pl. 10, figs. 6-8) como así también en la descripción e ilustración de los ejemplares citados en Foster (1979, pp. 87-88, pl. 29, figs. 4-5), no se observan ni se describen las zonas engrosadas asociadas a las zonas de adherencia proximal. Aunque dicho caracter está presente en los ejemplares aquí estudiados, son igualmente referidos a Protohaploxypinus diagonalis Balme (1970, pp. 364-365, pl. 10, figs. 6-8), por coincidir en el resto de los caracteres que la definen: morfología general, tamaño, forma oval-ahusada del cuerpo central, capa dividida en 8 a 10 tenias de disposición oblicua y contorno levemente sinuoso y cápula rectangular.

Parte del material referido por Anderson (1977, pl. 167, figs. 11, 13) como Pityosporites amplus (Balme y Hennelly) Anderson presenta las características diagnósticas de esta especie, por lo que se lo incluye en Protohaploxypinus diagonalis.

Registros previos. Protohaploxypinus diagonalis fue descripto por Balme (1970) para las formaciones permo-triásicas Amb, Wargal Limestone y Chhidru, de Salt Range y Surghar Range, Oeste de Pakistán.

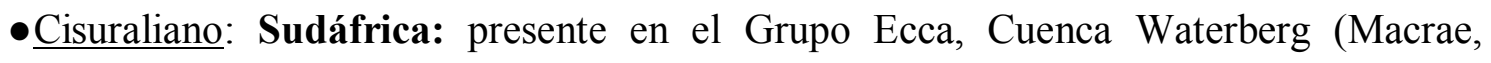
1988); ilustrado en la Cuenca del Karroo (Anderson, 1977).

- Guadalupiano: Australia: presente en Baralaba Coal Measures, Cuenca Bowen (Foster, 1979).

- Lopingiano-Triásico Inferior: Australia: presente en la Formación Rewan, Cuenca Bowen (Foster, 1979).

- Triásico: Argentina: ilustrada para la Formación Las Cabras, Cuenca Cuyana (Zavattieri, 1990, 1991b).

Protohaploxypinus goraiensis (Potonié y Lele) Hart 1964 Lámina XXI, figura D

1961. Lunatisporites goraiensis Potonié y Lele, p. 32, pl. 3, figs. 70-72.

1965. Faunipollenites perexiguus Bharadwaj y Salujha, p. 45, pl. 8, figs. 4-5.

1969. Protohaploxypinus rugatus Segroves, pp. 200-201, pl. 7, figs. G-H, pl. 9, figs. DI.

1979. Protohaploxypinus perexiguus (Bharadwaj y Salujha) Foster, p. 91, pl. 30, figs. 910. 
1991. Protohaploxypinus rugatus Segroves; Backhouse, p. 289, pl. XVII, figs. 1-5. 1996. Protohaploxypinus perexiguus (Bharadwaj y Salujha) Foster; Lindström, p. 40, pl. 1 , fig. 15.

Sinonimia adicional. Foster (1979).

Descripción. Grano de polen bisacado, teniado, de contorno general subcircular a levemente oval, elongado longitudinalmente. Cuerpo central de contorno no discernible, exina delgada que otorga una coloración más clara que los sacos. Capa dividida en numerosas tenias completas (de 6 a más de 10), de ancho constante y de extremos no visibles, limitadas por finas y profundas estrías. Las estrías se orientan tanto transversalmente como de manera oblicua. Cápula de 6(11,2)27 $\mu \mathrm{m}$ de ancho, subrectangular a suboval, con su eje mayor paralelo al mayor desarrollo del cuerpo. Sacos menores a 1/2 círculo de adherencia proximal ecuatorial y distal bilateral. Los sacos se pueden contactar entre sí bordeando los lados menores de la cápula por delgados puente. Intexina de los sacos infrareticulada, conformando muros que delimitan lúminas irregulares. Los muros se disponen de manera aislada.

Dimensiones (11 ejemplares). Ancho total, 41(50,9)60 $\mu \mathrm{m}$; largo del cuerpo central, 33(41,5)46 $\mu \mathrm{m}$; ancho del saco sobre cara distal, 13(18,3)20 $\mu \mathrm{m}$; largo del saco, $32(45,7) 60 \mu \mathrm{m}$.

Principal material estudiado. BAPal 6148 (a) J47/1; BAPal 6152 (a) F67/1, M35/4, T52/4; BAPal 6158 (b) K45/3; BAPal 6159 (a) O62/1; BAPal 6165 (a) D35/0, H44/4; BAPal 6168 (a) G43/0; BAPal 6169 (a) H58/0.

Comparaciones. Protohaploxypinus goriaensis (Potonié y Lelé) Hart (1964), incluye formas bisacadas de cuerpo estriado, de 100 a $126 \mu \mathrm{m}$ de ancho total, con más de 8 tenias, el cuerpo central oval longitudinal a subcircular, no discernible claramente, de cápula angosta y delgados puentes, que contactan por los extremos a los sacos entre sí. Hart combinó a la especie al género Protohaploxypinus, e incluye en la especie a formas con 7 a 8 tenias, una cápula de $1 / 5$ de ancho, sacos semicirculares sin puentes, aunque se juntan por los extremos.

En la descripción original de P. perexiguus (Bharadwaj y Salujha) Foster (1979), se incluyen formas de contorno subcircular, de cuerpo no discernible, con 7 a 10 tenias, una cápula angosta, sacos que se contactan entre sí por los extremos y con un ancho total de 54 a $74 \mu \mathrm{m}$. 
Protohaploxypinus rugatus Segroves (1969) fue propuesta para formas haploxilonoides, de cuerpo subcircular, con 4 a 7 tenias, de cápula de 1/8 a 1/10 de ancho, sacos semicirculares con puentes ocasionales, y con un ancho total de 29-40 $\mu \mathrm{m}$. Foster (1979, p. 92) diferenció esta especie de P. limpidus y $P$. perexiguus, porque presenta una cápula más angosta, sacos no estructurados y un margen limboide angosto (área libre del saco de forma semilunar proyectada en el borde ecuatorial del grano de polen). Este último caracter no resulta significativo para diferenciar las especies, porque se puede observar en granos de polen haploxilonoides, de sacos iguales o menores a medio círculo.

Protohaploxypinus rugatus, $P$. perexiguus y $P$. gorianensis presentan características similares: forma haploxilonoide de contorno general subcircular a oval transversal, cuerpo central poco discernible de forma subcircular a oval longitudianl, cápula angosta y sacos semicirculares que se contactan por los extremos del cuerpo o se fusionan por medio de puentes. Respecto al número de tenias: presentan de 4 a 7 tenias en $P$. rugatus, 7 a 10 tenias en $P$. perexiguus, y más de 8 en $P$. gorianensis.

En el material aquí estudiado se han observado ejemplares que gradan desde formas pequeñas con pocas tenias (41x33 $\mu \mathrm{m}$ con 6 tenias; BAPal 6165 (a) H44/4) a formas de mayor tamaño y número de tenias (60x44 $\mu$ m con 10 tenias; BAPal 6168 (a) G43/0). Si se consideran los extremos de estas variaciones morfológicas se pueden establecer claramente dos poblaciones, que podrían corresponderse con P. rugatus para los ejemplares más pequeños y $P$. gorianensis para el otro grupo. Sin embargo, los ejemplares ubicados en la media, en cuanto a las dimensiones y cantidad de tenias, podrían ser asignados arbitrariamente tanto a una como a otra especie, según el grado de proximidad a uno u otro extremo del conjunto general. Por lo tanto se consideran que todos ellos pertenecen a una única especie que debe ser $P$. gorianensis, por poseer dicha especie prioridad respecto del año de publicación, y los demás epítetos (P. rugatus y $P$. perexiguus) deben ser considerados sinónimo junior.

Hay que destacar que Foster (1979) asignó a P. perexiguus formas de tamaños un poco menores a los observados en el material tipo (Bharadwaj y Salujha, 1965, p. 45: 57 a $110 \mu \mathrm{m})$, caracter que quedaría comprendido al considerar a todas las especies.

Estudios realizados a partir de granos de granos de polen provenientes de esporangios (e.g. Lindström et al., 1997), demuestran que la diversidad morfológica obtenida de los 
mismos comprende a más de una morfoespecie reconocida de manera aislada (incluso más de un morfogénero), con lo que caracteres como un número exacto de número de tenias, como así también la presencia de un limbo en los sacos (caracter éste dado por los diferentes grados de maduración de los granos) no son relevantes en el momento de delimitar las distintas morfoespecies. Los mismos pueden variar según el tamaño de los ejemplares como así también por el grado de maduración.

Comentarios. Los ejemplares aquí estudiados presentan las características diagnósticas de la especie Protohaploxypinus goriaensis: granos de polen de contorno circular a levemente oval, marcadamente haploxilonoides, cuerpo central de pared delgada con 5 a 10 tenias, cápula angosta de lados paralelos a convexos, y sacos iguales a menores a $1 / 2$ círculo, conectados entre sí por puentes ubicados en los extremos del cuerpo.

Registros previos. Originalmente descripto como Lunatisporites goraiensis por Potonié y Lele (1961, p. 32, pl. 3, figs. 70-72).

- Cisuraliano: Brasil: presente en la Formación Rio do Sul, Grupo Itararé (MarquesToigo et al., 1990); presente en la perforación 3-MC-3-SC, Matos Costa, Cuenca Paraná (Quadros et al., 1996). Antártida: ilustrada para Fossilryggen, Vestfjella, Dronning Maud Land (Lindström, 1996). Namibia: ilustrada para el Grupo Dwyka en la perforación Strat Test 1 (Stapleton, 1977). Sudáfrica: presente en Cuenca Karroo (Anderson, 1977). Pakistán: presente en la Formación Amb, Grupo Zaluch (Balme, 1970). Australia: presente en Collie Coal Measures, Cuenca Collie (Backhouse, 1991).

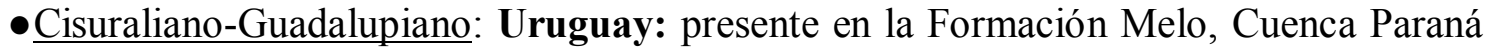
(Mautino et al., 1998b). Brasil: presente en la Formación Rio Bonito, Cuenca Paraná (Marques-Toigo, 1988).

- Guadalupiano: Australia: presente en Baralaba Coal Measures, Cuenca Bowen (Foster 1979). Australia: presente en las formaciones High Cliff, Carynginia y Wagina Sandstone, Cuenca Peth (Segroves, 1969).

- Lopingiano: Antártida: presente en Prince Charles Mountains (Balme y Playford, 1967).

- Lopingiano-Triásico Inferior: Australia: presente en la Formación Rewan, Cuenca Bowen (Foster 1979). India: presente en el piso Talchir, Cuenca Rewa (Potonié y Lelé 1961; Hart, 1964).

Esta es la primera cita de la especie para la Argentina. 
Protohaploxypinus limpidus (Balme y Hennelly) Balme y Playford 1967

Lámina XXI, figura C; Lámina XVII, figura A

1955. pars. Lueckisporites limpidus Balme y Hennelly, p. 94, pl. 3, figs. 29-30, pl. 4, figs. 34-35.

Sinonimia adicional. Foster (1979) y Raine et al. (2005).

Descripción. Grano de polen bisacado, teniado, de contorno general oval, elongado en sentido transversal, haploxilonoide. Cuerpo central de pared delgada, de coloración más clara que los sacos, y contornos dificilmente discernibles. Capa dividida por finas estrías que delimitan de 5 a 14 tenias completas de orientación transversal, de 3 a $8 \mu \mathrm{m}$ de ancho y de extremos no discernibles. Cápula rectangular, de 11(19,4)30 $\mu \mathrm{m}$ de ancho. Protosacos iguales a $1 / 2$ círculo, de inserción proximal ecuatorial y distal subecuatorial bilateral. Sexina de los sacos infrareticulada conformando anchos muros que delimitan pequeñas lúminas de contorno circular a oval. Los muros se orientan radialmente.

Dimensiones (11 ejemplares). Ancho total, 57(100)79,9 $\mu \mathrm{m}$; cuerpo central, ancho $37(46,1) 57 \mu \mathrm{m}$ y $28(45,3) 63 \mu \mathrm{m}$ de largo; ancho del saco sobre cara proximal, 14(15,5)21 $\mu \mathrm{m}$ y sobre cara distal, 14(30,5)43 $\mu \mathrm{m}$; largo del saco, 28(46,7)28 $\mu \mathrm{m}$.

Principal material estudiado. BAPal 6138 (a) W62/1; BAPal 6143 (a) W73/0; BAPal 6152 (a) N42/0, P35/2, Q458/1, R54/4, F50/4, D53/4; BAPal 6164 (a) W35/2; BAPal 6165 (a) D61/4.

Comentarios. Si bien los ejemplares aquí estudiados no presentan los pliegues distales longitudinales asociados a las zonas de adherencia bilaterales, la ausencia de éste caracter no impide su asignación específica, ya que puede o no estar presente. Además, características tales como aspecto general haploxilonoide, numerosas tenias proximales (alrededor de 10), sacos iguales a medio círculo y de implantación distal subecuatorial bilateral, confirman la asignación específica.

Registros previos. Protohaploxypinus limpidus (Balme y Hennelly) Balme y Playford fue descripto originalmente para el Cisuraliano de la Cuenca Collie (Balme y Hennelly, 1955).

- Pennsylvaniano: Argentina: presente en los Estratos de Mascasín (Pérez Loinaze y Césari, 2004). Brasil: mencionada para la Formación Rio do Sul, Subgrupo Itararé, Cuenca Paraná (Marques-Toigo et al., 1989); presente en la Formación Nova Olinda, 
Grupo Trapajós, Cuenca Amazonas (Playford y Dino, 2000b). Libia: ilustrada para el intervalo Ghzeliano-Asseliano (Brugman et al., 1985).

- Cisuraliano: Argentina: presente en las formaciones Tasa Cuna (Balarino y Gutiérrez 2006) y Bajo de Véliz (Gutiérrez y Césari, 2000), Cuenca Paganzo. Uruguay: presente en la Formación San Gregorio, Cuenca Paraná (Gutiérrez et al., 2006b). Australia: presente en las cuencas Collie (Balme y Hennelly, 1955; Backhouse, 1991) y Perth (Segroves, 1969); para Blair Athol Coal Measures, Cuenca Bowen (Foster, 1975); Mencionada para la Cuenca Officer (Backhouse, 1993); Fairbairn Dam, Cuenca Bowen (Fielding y McLoughlin, 1992) y la Formación Fossil Cliff, Cuenca Perth (Foster et al., 1985). Antártida: presente en Prince Charles Mountains (Balme y Playford, 1967). Mencionada para Vestfjella, Dronning Maud Land (Larsson et al., 1990; Lindström, 1993, 1996) y Heimefrontfjella mountain-range, Dronning Maud Land (Lindströn, 1995). Brasil: ilustrada para el Subgrupo Itararé, Cuenca Paraná (Souza y Callegari, 2004). Pakistán: presente en las formaciones Amb, Wargar Limestone y Chhidru, Grupo Zaluch (Balme, 1970). África: ilustrada para sedimentos probablemente asignables a Dwyka, Cuenca de Gabón, atribuíbles a Karroo (Jardiné, 1974); presente en Cuenca Karroo (Anderson, 1977). Sudáfrica: presente en el Grupo Ecca, Cuenca Waterberg (Macrae, 1988). Arabia Saudita: mencionada para la Formación Khuff (Stephenson y Filatoff, 2000a, 2000b, 2003).

- Cisuraliano-Guadalupiano: Brasil: ilustrada para la Formación Rio Bonito, Cuenca Paraná (Smaniotto et al., 2006). Papúa: ilustrada para las formaciones Ainim y Aiduna (Playford y Rigby, 2008).

- Guadalupiano: Australia: presente en la Formación Bandanna, Springsure Anticline (Rigby y Hekel, 1977) y en Baralaba Coal Measures, Cuenca Bowen (Foster, 1979).

-Lopingiano: Antártida: ilustrada para Buckley, Transantarctic Mountains (Playford, 1990; Farabee et al., 1991).

- Lopingiano-Triásico Inferior: Australia: presente en la Formación Rewan, Cuenca Bowen (Foster, 1979, 1982a; de Jersey, 1979). Israel: mencionada para las formaciones Arqov y Yamin (Eshet, 1990).

- Triásico Inferior: Argentina: mencionada para la Formación Los Rastros, Cuenca Cuyana (Ottone et al., 2005). 
Protohaploxypinus microcorpus (Schaarschmidt) Clarke 1955

Lámina XXI, figuras E y F

1963. Striatites microcorpus Schaarschmidt, p. 55, pl. 14, figs. 6, 7.

Sinonima adicional. Foster (1979) y Raine et al. (2005).

Descripción. Grano de polen bisacado teniado, haploxilonoide. Contorno general oval elongado transversalmente. Cuerpo central subcircular a levemente oval, elongado en sentido longitudinal, de márgenes poco discernibles. Capa con numerosas tenias (entre 6 y 11) pobremente definidas. Tenias completas que se extienden en todo el largo del grano o incompletas, acuñadas entre sí. Cápula ancha, de 5/7 del largo total del cuerpo, de márgenes cóncavos hacia el centro del cuerpo. Sacos menores a 1/2 círculo, unidos en algunos casos lateralmente por medio de delgados puentes exinales. Adherencia proximal ecuatorial y distal bilateral. Sexina de los sacos infrareticulada, con muros delgados y poco distinguibles, que delimitan lúminas de margenes irregulares.

Dimensiones (9 ejemplares). Ancho total, 56(72,3)83 $\mu \mathrm{m}$; cuerpo central, ancho $23(39,2) 58 \mu \mathrm{m}$ y $30(43) 54 \mu \mathrm{m}$ de largo; ancho del saco sobre cara proximal, $10(13,5) 18$ $\mu \mathrm{m}$ y sobre cara distal, $16(28,1) 39 \mu \mathrm{m}$; largo del saco, 34(47,7)57 $\mu \mathrm{m}$.

Principal material estudiado. BAPal 6139 (a) C57/1; BAPal 6152 (a) X57/0, V63/1;

BAPal 6161 (a) N56/3. Redepósito: BAPal 6171 (a) O64/3; BAPal 6172 (a) G34/4; BAPal 6175 (a) O56/3, R43/2; BAPal 6175 (b) C45/4.

Registros previos. Protohaploxypinus microcorpus (Schaarschmidt) Clarke fue descripta originalmente por Schaarschmidt (1963) para Franconian bay, Zechstein, Lopingiano de Alemania.

- Cisuraliano: Paraguay: ilustrada para la Formación Tacuary, Grupo Independencia, Cuenca Chacoparaná (Muff et al., 1999). Australia: mencionada para las cuencas Perth, Collie y Officer (Backhouse, 1993). Arabia: ilustrada para la Formación Al Khlata, Oman y Arabia Saudita (Stephenson et al., 2003) y mencionada para la Formación Khuff (Stephenson y Filatoff, 2003). Sudáfrica: presente en el Grupo Ecca, Cuenca Waterberg (Macrae, 1988).

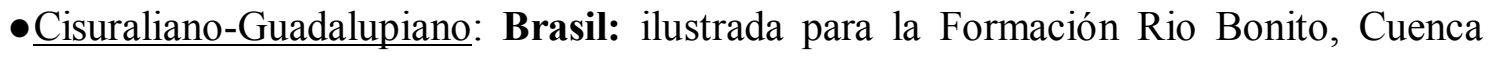
Paraná (Souza y Marques-Toigo, 2005). 
- Guadalupiano: Australia: presente en Baralaba Coal Measures, Cuenca Bowen (Foster, 1979) y en la Formación Bandanna, Cuenca Bowen (de Jersey, 1979).

- Guadalupiano-Lopingiano: Omán y Arabia Saudita: ilustrada para la Formación Khuff (Stephenson et al., 2003).

- Lopingiano: Antártida: ilustrada para Formación Buckley, Transantarctic Mountains (Farabee et al., 1991). Inglaterra: Clarke, 1965. España: ilustrada para la Formación Alcotas, sección Landete (Diéguez y Barrón, 2005).

- Lopingiano-Triásico Inferior: Australia: presente en la Formación Rewan, Cuenca Bowen (Foster 1979; de Jersey, 1979). Ilustrada para la Cuenca Sydney (Helby, 1973). India: mencionada en Raniganj Coalfield (Bharadwaj, 1962). Pakistán: presente en la Formación Chhidru, Salt Range y Trans-Indus Ranges (Balme, 1970). Europa: mencionada por Morbey (1975). Israel: mencionada para las formaciones Arqov y Yamin (Eshet, 1990). Arabia: ilustrada para la Formación Khuff (Stephenson y Filatoff, 2000b). España: ilustrada para las formaciones Boniches y Alcotas (Doubinger et al., 1990).

- Triásico Inferior: Argentina: presente en las formaciones Potrerillos y Cacheuta (Zavattieri y Rojo, 2005). Ilustrada para las formaciones Las Cabras (Zavattieri, 1990, 1991a), Puesto Viejo (Ottone y Garcia, 1991) y Los Rastros (Ottone et al., 2005), todas de Cuenca Cuyana.

Protohaploxypinus varius (Bharadwaj) Balme 1970

Lámina XXI, figura G

1962. Faunipollenites varius Bharadwaj, p. 95, pl. 18, fig. 230.

Sinonimia adicional. Véase Balme (1970).

Descripción. Grano de polen bisacado, teniado, de contorno general oval, elongado transversalmente, haploxilonoide a levemente diploxilonoide. Cuerpo central circular, de contorno no discernibles y pared delgada. Capa dividida en tenias transversales (de 8 a 12), completas, de 2 a $8 \mu \mathrm{m}$ de ancho y extremos redondeados, delimitadas por finas estrías. Cápula subrectangular longitudinal, de lados longitudinales rectos a levemente cóncavos hacia el centro del cuerpo. Inserción de los sacos proximal ecuatorial y distal 
subecuatorial bilateral. Intexina de los sacos infrareticulada conformando muros densamente dispuestos que delimitan lúminas de contorno irregular.

Dimensiones (8 ejemplares). Ancho total, 72(83,3)107 $\mu \mathrm{m}$; cuerpo central, ancho 40(45,5)50 $\mu \mathrm{m}$ y 42(51,6)65 $\mu \mathrm{m}$ de largo; ancho del saco sobre cara proximal, 16-20 $\mu \mathrm{m}$ y sobre cara distal, 23(31,1)44 $\mu \mathrm{m}$; largo del saco, 43(55)70 $\mu \mathrm{m}$.

Principal material estudiado. BAPal 6148 (a) R36/2; BAPal 6152 (a) E44/0, F46/0, H67/2, H67/2; BAPal 6152 (c) A59/3; BAPal 6165 (a) L59/1, K48/4.

Comentarios. Si bien los ejemplares aquí estudiados presentan un número un poco mayor de tenias respecto del referido para Protohaploxypinus varius (Bharadwaj) por Balme (1970, pp. 365-366, pl. 10, figs. 4-5; entre 8 y 12 tenias en los ejemplares aquí estudiados y 6 y 9 para los ejemplares de Balme), es posible la asignación específica ya que los granos presentan el resto de los caracteres diagnósticos: cuerpo central circular poco discernible, cápula subrectangular, ausencia de pliegues distales y aspecto general. Registros previos. Protohaploxypinus varius (Bharadwaj) Balme fue descripta originalmente para el Raniganj Coalfield, Cisuraliano de la India (Bharadwaj, 1962).

- Cisuraliano: Brasil: presente en la perforación 3-MC-3-SC, Matos Costa, Santa Catarina, Cuenca Paraná (Quadros et al., 1996). Bolivia: ilustrada para la Formación Vitiacua (Sempere et al., 1992). India: presente en Raniganj Coald-Field, Bhiar (Bharadwaj y Salujha, 1964). Pakistán: presente en la Formación Amb, Grupo Zaluch (Balme, 1970). Svalbard (Europa): ilustrada para la Formación Nodeskiöldbreen (Mangerud y Konieczny, 1991).

- Lopingiano-Triásico Inferior: Israel: mencionada para las formaciones Arqov y Yamin (Eshet, 1990). Pakistán: presente en la formaciones Wargar Limestone y Chhidru, Grupo Zaluch (Balme, 1970).

- Triásico: Argentina: mencionada para la Formación Los Rastros, Cuenca Cuyana (Ottone et al., 2005).

Género Staurosaccites Dolby 1976 en Dolby y Balme 1976 Especie tipo. Staurosaccites quadrifidus Dolby en Dolby y Balme 1976 Afinidad botánica. Gimnospermas-Coniferopsida (véase Quadros et al., 1996).

Staurosaccites cordubensis Archangelsky y Gamerro 1979 Lámina XVII, figura B; Lámina XXI, figura $\mathrm{H}$ 
1980b. Staurosaccites sp. Archangelsky y Gamerro, lám. II, fig. 11.

Sinonimia. Véase Archangelsky y Gamerro (1979).

Descripción. Grano de polen bisacado, haploxilonoide, de contorno general circular a levemente oval. Cuerpo central circular, claro, de pared delgada y capa dividida en 2 anchas tenias reniformes separadas por una estría central transversal, en la que, en algunos casos, puede observarse una marca monolete a levemente geniculada. En las tenias pueden observarse, una difusa ornamentación de verrugas de sección poligonal a irregular. Cápula angosta, de hasta 1/5 de ancho respecto del ancho general del grano, de lados convexamente opuestos, lo que hace que los extremos de la misma sean mas anchos respecto del centro. Sacos iguales a 1/2 círculo de inserción distal. La dispocisión longitudinal de las zonas distales de adherencia y la calle proximal transversal del cuerpo central dan un aspecto de un círculo cortado por 2 surcos perpendiculares entre sí. Sexina de los sacos delgada, con un pequeño infragranulado poco evidente.

Dimensiones (16 ejemplares). Ancho total, 25(52,9)65 $\mu \mathrm{m}$; tenias, 14(30,1)58 $\mu \mathrm{m}$ de largo; ancho del saco sobre cara distal, 12(21,9)35 $\mu \mathrm{m}$; largo del saco, 26(45)67 $\mu \mathrm{m}$.

Principal material estudiado. BAPal 6149 (b) G47/1; BAPal 6152 (a) K36/1, K41/0, L42/2, M42/3, N50/1, F47/4, N68/0, S51/4; BAPal 6156 (a) T48/2.

Registros previos. Staurosaccites cordubensis fue descripta por Archangelsky y Gamerro (1979, pp. 451-452, lám. X, figs. 8-9) para las biozonas Cristatisporites y Striatites, Cisuraliano-Guadalupiano, Cuenca Chacoparaná.

- Cisuraliano-Guaduliapiano: Argentina: ilustrado para la Biozona Striatites, Cuenca Claromecó-Colorado (Archangelsky y Gamerro, 1980b); presente en la Formación Victoriano Rodríguez, Biozona Striatites, Cuenca Chacoparaná (Vergel, 1987b; Playford y Dino, 2002). Presente en la Formación Santa Máxima, Cuenca calingastaUspallata (Ottone, 1989); ilustrado en la Formación De La Cuesta, Cuenca Paganzo (Aceñolaza y Vergel, 1987). Brasil: presente en pozo 2-CS-1-PR, Chapéu do Sol, Cuenca Paraná (Quadros et al., 1996); ilustrada para las formaciones Rio Bonito, Cuenca Paraná (Souza y Marques-Toigo, 2005) e Iratí (Premaor et al., 2006), Cuenca Paraná. Uruguay: ilustrado para la Formación Melo, Cuenca Paraná (Mautino et al., 1998b). 
- Lopingiano: Argentina: mencionada para la Formación La Veteada, Cuenca Paganzo (Zavattieri et al., 2008).

Género Striatopodocarpites Zoricheva y Sedova ex Sedova emend. Hart 1964 Especie tipo. Striatopodocarpites tojmensis Sedova, 1956.

Afinidad botánica. Gimnospermosida-Voltizales/Glossopteridales (véase Balme, 1995; Lindström et al., 1977; Rigby y Chandra, 1990).

Striatopodocarpites cancellatus (Balme y Hennelly) Hart 1963

Lámina XVII, figura E; Lámina XXII, figura A

1955. Lueckisporites cancellatus Balme y Hennelly, pp. 92-93, pl. 2, figs. 11-15. 1987a. Striatopodocarpites sp. Vergel, p. 73, lám. II, fig. 19.

Sinonimia adicional. Foster (1979) y Raine et al. (2005).

Descripción. Grano de polen bisacado, teniado, diploxilonoide, de contorno general oval elongado en sentido trasversal. Cuerpo central circular, de pared gruesa. Capa dividida entre 8 a 10 tenias trasversales, completas, de 2 a $5 \mu \mathrm{m}$ de ancho y extremos redondeados delimitadas por profundas y angostas estrías. El contorno ecuatorial levemente ondulado, dado por la altura de las tenias en los laterales. Cápula de $3(11,9) 20 \mu \mathrm{m}$, de forma rectangular, con lados rectos y ornamentación no discernible. Sacos iguales a levemente mayores a 1/2 círculo, de inserción proximal ecuatorial, distal bilateral y fuerte inclinación distal. Contorno de los sacos irregular y intexina infrareticulada, conformando un infrapunctuado laxamente dispuesto. En las bases de los sacos pueden observarse algunos pliegues radiales producto de la compresión de los mismos.

Dimensiones (12 ejemplares). Ancho total, 40(70)107 $\mu \mathrm{m}$; cuerpo central, ancho $19(35,5) 53 \mu \mathrm{m}$ y $15(36) 59 \mu \mathrm{m}$ de largo; ancho del saco sobre cara proximal, 9(15,6)29 $\mu \mathrm{m}$ y sobre cara distal, 20(30,1)47 $\mu \mathrm{m}$; largo del saco, 18(43,6)63 $\mu \mathrm{m}$.

Principal material estudiado. BAPal 6138 (a) J51/4; BAPal 6152 (a) R61/1; BAPal 6152 (b) H60/2; BAPal 6156 (a) V36/2; BAPal 6158 (a) V54/4; BAPal 6165 (b) D50/3; BAPal 6184 (b) M42/1; BAPal 6187 (b) S67/0. Redepósito: BAPal 6173 (a) H51/2; BAPal 6175 (b) F70/3, Q73/1, U73/3. 
Registros previos. Striatopodocarpites cancellatus (Balme y Hennelly) Hart fue descripto originalmente para el Cisuraliano de la Cuenca Collie (Balme y Hennelly, 1955).

- Cisuraliano: Argentina: presente en la Biozona Cristatisporites, Cuenca Chacoparaná (Césari et al., 1995). Brasil: ilustrada para el Grupo Itararé, Cuenca Paraná (Dias, 1993). Australia: presente en la Cuenca Perth (Segroves, 1969). Ilustrada para Blair Athol Coal Measures, Cuenca Blair Athol (Foster, 1975) y Stockton, Cuenca Collie (Backhouse, 1991). Mencionada en Fairbairn Dam, Cuenca Bowen (Fielding y McLoughlin, 1992). Antártida: mencionada para Vestfjella, Dronning Maud Land (Lindström, 1993, 1996, 2005); ilustrada (Playford, 1990). Pakistán: presente en la Formación Amb, Grupo Zaluch (Balme, 1970). Sudáfrica: presente en el Grupo Ecca, Cuenca Waterberg (Macrae, 1988) y en Cuenca Karroo (Anderson, 1977). Ilustrada para el Keetewa-Mchuchuma Coalfield en Tanzania (Manum y Duc Tien, 1973). Omán y Arabia Saudita: ilustrada para el Grupo Huashi (Love, 1994) y para la Formación Ghariff (Stphenson et al., 2003); mencionada para la Formación Khuff (Stephenson y Filatoff, 2000b, 2003).

- Guadalupiano: Australia: presente en Baralaba Coal Measures, Cuenca Bowen (Foster, 1979) y en la Formación Bandanna, Springsure Anticline (Rigby y Hekel, 1977).

- Cisuraliano-Guadalupiano: Brasil: ilustrada en la Formación Iratí, Cuenca Paraná (Premaor et al., 2006). Papúa: descripta para las formaciones Ainim y Aiduna (Playford y Rigby, 2008).

- Lopingiano: Antártida: ilustrada para Buckley, Transantarctic Mountains (Farabee et al., 1991); Pakistán: presente en la Formación Chhidru, Grupo Zaluch (Balme, 1970). Inglaterra: Clarke (1965).

- Lopingiano-Triásico Inferior: Australia: ilustrada para la Formación Rewan, Cuenca Bowen (Foster, 1979, 1982a).

Striatopodocarpites fusus (Balme y Hennelly) Potonié 1958

Lámina XXII, figuras C y D

1955. pars. Lueckisporites fusus Balme y Hennelly, p. 92, pl. 1, figs. 7, 8, 9 (cf.), 10. 
Sinonimia adicional. Foster (1979) y Raine et al. (2005).

Descripción. Grano de polen bisacado, teniado, fuertemente diploxilonoide. Cuerpo central subcircular, de pared gruesa, que en el contorno ecuatorial se engrosa y adopta una forma irregular. Capa dividida en 7 a 9 tenias pobremente discernibles, de ancho poco variable y extremos redondeados, delimitadas por finas estrías completas, transversales y levemente sinuosas. Cápula ahusada, que recorre todo el largo del cuerpo central, y de 1/4 de ancho respecto del ancho del cuerpo, de 2(6)12 $\mu \mathrm{m}$ de ancho. Sacos 1/3 mas grandes que el cuerpo, mayores a medio círculo, de inserción proximal ecuatorial, distal bilateral recta y fuerte inclinación distal. Zona de superposición entre los sacos y el cuerpo amplia, de hasta la mitad del ancho del saco. Sexina de los sacos gruesa, infrareticulada, conformando muros gruesos, cortos e irregulares, dispuestos radial y densamente, lo que le otorga una coloración más oscura a los sacos respecto del cuerpo. Lúminas circulares, pequeñas e irregulares.

Dimensiones (11 ejemplares). Ancho total, 45(84,5)145 $\mu \mathrm{m}$; cuerpo central, ancho $25(43,6) 80 \mu \mathrm{m}$ y $26(44,1) 74 \mu \mathrm{m}$ de largo; ancho del saco sobre cara proximal, 11(14,7)22 $\mu \mathrm{m}$ y sobre cara distal, $22(36,7) 62 \mu \mathrm{m}$; largo del saco, 33(58,3)97 $\mu \mathrm{m}$.

Principal material estudiado. BAPal 6148 (a) H50/0; BAPal 6152 (a) Q58/4; BAPal 6158 (a) L57/4; BAPal 6165 (a) O61/2; BAPal 6165 (b) G45/0; BAPal 6168 (a) G47/0. Redepósito: BAPal 6174 (b) S55/3; BAPal 6175 (a) O44/3; BAPal 6178 (a) $\mathrm{R} 60 / 1$.

Comentarios. A pesar de no poder observar claramente todas las tenias presentes en la capa, características tales como el margen general del grano fuertemente diploxilonoide, la relación cuerpo central-saco, la cápula angosta y ahusada y la presencia en la misma de esa línea de dehiscencia permiten la asignación específica.

Registros previos. Striatopodocarpites fusus (Balme y Hennelly) Potonié fue descripto originalmente para el Cisuraliano de la Cuenca Collie (Balme y Hennelly, 1955).

- Pennsylvaniano: Brasil: presente en la Formación Nova Olinda, Grupo Trapajós, Cuenca Amazonas (Playford y Dino, 2000b). Perú: presente en la Formación Tarma, Pongo de Mainique (Azcuy et al., 2002).

- Cisuraliano: Argentina: presente en la Biozona Cristatisporites de la Formación Victoriano Rodríguez, Cuenca Chacoparaná (Playford y Dino, 2002). Uruguay: presente en la Formación San Gregorio, Cuenca Paraná (Gutiérrez et al., 2006b). 
Brasil: presente en la perforación 2-AO-1-RS, Atanásio, Rio Grande do Sul (Quadros et al., 1996), Cuenca Paraná. Antártida: ilustrada para Fossilryggen, Vestfjella, Dronning Maud Land (Lindström, 1996); Heimefrontfjella mountain-range, Dronning Maud Land (Playford, 1990; Lindströn, 1995). Australia: presente en Blair Athol Coal Measures (Foster, 1975), Fairbairn Dam, Cuenca Bowen (Fielding y McLoughlin, 1992) y en la Formación Stockton, Cuenca Collie (Backhouse, 1991). India: mencionada e ilustrada, Barakar Sediments, Karapura Coalfield (Bharadwaj y Dwivedi, 1981). Sudáfrica: presente en Cuenca Karroo (Anderson, 1977) e ilustrada para el Keetewa-Mchuchuma Coalfield en Tanzania (Manum y Duc Tien, 1973).

- Guadalupiano: Australia: presente en Baralaba Coal Measures, Cuenca Bowen (Foster, 1979). Ilustrada para la Formación Bandanna, Springsure Anticline (Rigby y Hekel, 1977).

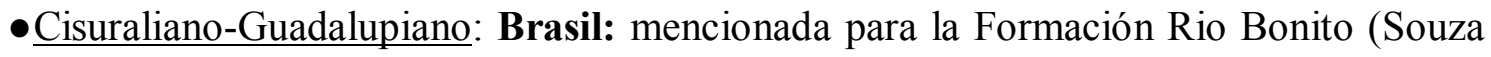
y Marques-Toigo, 2005) e ilustrada en la Formación Iratí, Cuenca Paraná (Premaor et al., 2006). Papúa: ilustrada para las formaciones Ainim y Aiduna (Playford y Rigby, 2008).

- Lopingiano: Antártida: ilustrada para la Formación Buckley, Transantarctic Mountains (Farabee et al., 1991). Inglaterra: Clarke (1965).

- Lopingiano-Triásico Inferior: Australia: presente en la Formación Rowen, Cuenca Bowen (de Jersey, 1979; Foster, 1979, 1982a). Israel: mencionada para las formaciones Arqov y Yamin (Eshet, 1990).

Striatopodocarpites gondwanensis Lekhanpal, Sah y Dube 1960 Lámina XXII, figura B

Sinonimia. Véase Foster (1979).

Descripción. Grano de polen bisacado, teniado, diploxilonoide, de contorno general oval elongado en sentido transversal. Cuerpo central oval a ahusado longitudinalmente. Capa dividida en más de 7 tenias transversales, completas o acuñadas, separadas por delgadas estrías. Cápula angosta, $1(10,7) 14 \mu \mathrm{m}$, de forma subrectangular a ahusada. Sacos mayores a 1/2 círculo, de similar altura que el cuerpo central, de inserción proximal ecuatorial, distal bilateral e inclinación distal. Intexina infrareticulada, 
conformando un retículo irregular y poco discernible. En las bases de los sacos pueden observarse pliegues radiales.

Dimensiones (8 ejemplares). Ancho total, 71(81,3)91 $\mu \mathrm{m}$; cuerpo central, ancho $22(36,2) 48 \mu \mathrm{m}$ y $38(42,1) 50 \mu \mathrm{m}$ de largo; ancho del saco sobre cara proximal, 18(20,5)25 $\mu \mathrm{m}$ y sobre cara distal, $29(33,3) 43 \mu \mathrm{m}$; largo del saco, 44(39)67 $\mu \mathrm{m}$.

Principal material estudiado. BAPal 6149 (a) J58/0; BAPal 6159 (a) H65/3; BAPal 6165 (a) N45/3; BAPal 6184 (b) V47/1; BAPal 6187 (a) K50/4, S42/3. Redepósito: BAPal 6175 (b) D65/2.

Comentarios. Foster (1979, p. 98) describió a la especie con las tenias paralelas o acuñadas, irregularmente divididas en pequeños bloques cuadrados. Dicho caracter no se observa en la mayoría de los ejemplares aquí estudiados ni en los ilustrados por Foster (1979, pl. 35, figs. 1a-b). Sin embargo caracteres tales como la forma del cuerpo oval-ahusado longitudinalmente; la cápula abierta ocupando de $1 / 2$ a $1 / 3$ de ancho respecto del cuerpo; el contorno general diploxilonoide y de similar largo entre el cuerpo y los sacos, permiten realizar la asignación específica.

Registros previos. Striatopodocarpites gondwanensis fue descripta por Lekhanpal, Sah y Dube (1960) para el Pérmico de la India.

- Cisuraliano: Australia: presente en Blair Athol Measures (Foster, 1979); mencionada (Foster, 1975; Segroves, 1969). África: presente en Serie Agoula, Gabon (Jardiné, 1974).

- Guadalupiano: Australia: presente en Baralaba Coal Measures, Cuenca Bowen (Foster, 1979).

- Lopingiano: Antártida: presente en Formación Bukley (Farabee et al., 1991).

Esta es la primera cita de la especie para la Argentina.

Striatopodocarpites sp. cf. S. phaleratus (Balme y Hennelly) Foster 1979

Lámina XXII, figura E

Descripción. Grano de polen bisacado, teniado, diploxilonoide. Cuerpo central oval, elongado longitudinalmente, de pared gruesa y coloración oscura. Capa dividida por estrías, que delimitan de 6 a $9 \mu \mathrm{m}$ tenias transversales, completas. Cápula de 16(19,6)22 de ancho, extendida por todo el largo del cuerpo, rectangular a oval, elongada 
longitudinalmente. Sacos mayores a 1/2 círculo, de adherencia proximal ecuatorial y distal bilateral, inclinados distalmente. A las zonas distales de adherencia de los sacos se asocian pliegues extendidos en todo el largo de la cápula, ahusados. Sexina de los sacos infrareticulada, conformando gránulos densamente dispuestos.

Dimensiones (3 ejemplares). Ancho total, 99(116,6)136 $\mu \mathrm{m}$; cuerpo central, ancho $52(55) 59 \mu \mathrm{m}$ y $61(71,6) 84 \mu \mathrm{m}$ de largo; ancho del saco sobre cara proximal, $21(25,5) 33$ $\mu \mathrm{m}$ y sobre cara distal, 40(48)64 $\mu \mathrm{m}$; largo del saco, 56(72,3)95 $\mu \mathrm{m}$.

Principal material estudiado. BAPal 6188 (a) T60/0. Redepósito: BAPal 6174 (a) R42/0; BAPal 6175 (a) T61/3.

Comentarios. Si bien características tales como aspecto general, forma y número de tenias, la presencia de los pliegues distales y la forma de los sacos permiten comparar a los ejemplares aquí estudiados con Striatopodocarpites phaleratus (Balme y Hennelly) Hart (1964, p. 1193; text-fig. 23), la presencia de una cápula mayor a la observada para la especie y un bajo número de ejemplares estudados, impiden una asignación específica certera. Dicha especie presenta como característica diagnóstica también, una cápula ahusada, de lados cóncavos que se contactan por sus extremos, rasgo no observado en estos ejemplares.

Striatopodocarpites sp. cf. S. solitus (Bharadwaj y Salujha) Foster 1979 Lámina XXII, figura $\mathrm{F}$

Descripción. Grano de polen bisacado, teniado, haploxilonoide a levemente diploxilonoide. Cuerpo central oval transversal. Capa dividida por estrías que delimitan más de 6 tenias trasversales, completas, de $7(4,6) 7 \mu \mathrm{m}$ de ancho y extremos redondeados. Cápula lisa, de contorno rectangular. El contorno ecuatorial del cuerpo central presenta un anillo o reborde completo o incompleto, engrosado, más oscuro que el cuerpo. Sacos iguales a 1/2 círculo, de inserción proximal ecuatorial y distal subecuatorial bilateral. Tamaño de los sacos similar o levemente mayor al del cuerpo central. Las zonas de adherencia distales son amplias, cubriendo alrededor de las 4/5 partes del ancho del cuerpo central. Sexina de los sacos infrareticulada, conformando gránulos laxamente dispuestos. 
Dimensiones (5 ejemplares). Ancho total, 71(84)99 $\mu \mathrm{m}$; cuerpo central, ancho $30(34,2) 38 \mu \mathrm{m}$ y $20(40,4) 50 \mu \mathrm{m}$ de largo; ancho del saco sobre cara proximal, 14(17)22 $\mu \mathrm{m}$ y sobre cara distal, $30(34,2) 38 \mu \mathrm{m}$; largo del saco, $40(52,6) 58 \mu \mathrm{m}$.

Principal material estudiado. BAPal 6152 (a) Q62/0; BAPal 6152 (d) J40/3; BAPal 6159 (a) W33/3. Redepósito: BAPal 6175 (a) U57/0; BAPal 6175 (b) H55/4.

Comentarios. La pobre preservación de los ejemplares aquí estudiados impiden una asignación específica certera, aunque características tales como el aspecto general, la similar proporción de los tamaños entre el cuerpo y los sacos, las tenias proximales, y el anillo engrosado ecuatorial permiten confrontar los ejemplares con la especie Striatopodocarpites solitus (Bharadwaj y Salujha) Foster (1979, p. 100, pl. 35, figs. 2, 9, pl. 37, figs. 12-13). El anillo engrosado antes mencionado es un caracter descripto e ilustrado en la descripción original de la especie (Bharadwaj y Salujha, 1964, p. 201, pl. 6, figs. 101-103, pl. 7, fig. 104). Si bien dicha especie es descripta e ilustrada por Foster (1979, p. 100, pl. 35, figs. 2, 9, pl. 37, figs, 12, 13), éste caracter diagnóstico es mencionado pero no posible observar en las figuras que lo ilustran. Si se considera dicho caracter como diagnóstico para definir la especie, es posible que, al menos, los ejemplares ilustrados por Foster no deban ser incluídos dentro de S. solitus.

\section{Género Tornopollenites Morgan 1972}

Especie tipo. Tornopollenites toreutos Morgan, 1972.

Afinidad botánica. Gymnospermas (véase Quadros et al., 1996).

Tornopollenites toreutos Morgan 1972

Lámina XXII, figuras G y H

Descripción. Grano de polen bisacado, teniado, de contorno general subrectangular, de lados rectos y ángulos fuertemente redondeados, de mayor desarrollo en sentido transversal, haploxilonoide a levemente diploxiolonoide. Cuerpo central subrectangular, de lados rectos y ángulos redondeados, elongado en igual sentido que el contorno general. Exina del cuerpo gruesa, dividida en ambas caras por estrías espiraladas de hasta $1 \mu \mathrm{m}$ de ancho en porciones centrales del cuerpo, que se ahusan en los extremos y delimitan tenias de ancho constantes. Las mismas pueden observarse en número de 6 a 8 
por cada cara. Sacos pequeños, mayores a medio círculo, de inserción lateral al cuerpo. Sexina infragranulada. Se forman algunos pliegues radiales por compresión de los sacos.

Dimensiones (4 ejemplares). Ancho total, 75(84,2)93 $\mu \mathrm{m}$; cuerpo central, ancho 40(45)50 $\mu \mathrm{m}$ y $26(30,7) 37 \mu \mathrm{m}$ de largo; ancho del saco, $16(20,7) 30 \mu \mathrm{m}$; largo del saco, $25(29,2) 34 \mu \mathrm{m}$.

Principal material estudiado. BAPal 6146 (b) F56/1; BAPal 6152 (a) B48/1, O58/2; BAPal 6152 (b) V70/3.

Comentarios. Los ejemplares estudiados son asignados sin dudas a la especies Tornopollenites toreutos por presentar los caracteres diagnósticos: cuerpo central oval a surectangular, elongado en sentido transversal, tenias espiraladas y sacos menores a $1 / 2$ círculo, de implantación ecuatorial.

Registros previos. Tornopollenites toreutos ha sido descripta por Morgan (1972, pp. 481-482, pl. 1, figs. 1-2) para la perforación Matador, Pérmico (Wolfcampiano) de Texas, Estados Unidos.

- Cisuraliano-Lopinigiano: Brasil: presente en la perforación 2-AO-1-RS, Anastásio, Rio Grande do Sul, Cuenca Paraná (Quadros et al., 1996). Ilustrada para la Formación Pedra do Fogo, Cuenca Parnaíba (Dino et al., 2002).

- Cisuraliano: África: ilustrada para sedimentos probablemente asignable a Dwyka, Cuenca de Gabón, atribuíbles a Karroo (Jardiné, 1974).

- Guadalupiano-Lopingiano: Brasil: presente en la Formación Andirá, Grupo Trapajós, Cuenca Amazonas (Playford y Dino, 2000b).

Esta es la primera cita de la especie para la Argentina.

Turma PLICATES Naumova emend. Potonié 1960

Subturma POLYPLICATES Erdtman 1952

Género Vittatina Luber ex Wilson 1962

Especie tipo. Vittatina subsaccata Samoilovich emend. Jansonius, 1962.

Afinidad botánica. Gimnospermas-Coniferopsida (véase Quadros et al., 1996).

Vittatina corrugata Marques-Toigo 1974

Lámina XXIII, figuras A y B 
Descripción. Grano de polen teniado, de contorno general oval elongado en sentido transversal. Cara proximal dividida por finas estrías en más de 14 tenias, orientadas transversalmente, extendidas hacia los márgenes del cuerpo, completas, de 2 a $3 \mu \mathrm{m}$ de ancho, con sus extremos son redondeados. Cara distal con por lo menos una costilla longitudinal, poco marcada. Las tenias se particionan longitudinalmente generando un patron de verrugas densamente dispuestas.

Dimensiones (3 ejemplares). Cuerpo central, ancho 41(47,3)58 $\mu \mathrm{m}$ y $28(33,6) 38 \mu \mathrm{m}$ de largo.

Discusión. Vittatina corrugata Marques-Toigo (1974) se diferencia del resto de las especies por presentar sobre la cara proximal, una serie de tenias de disposición transversal, subdivididas a su vez por estrías menores, resultando una ornamentación conformada por verrugas subrectangulares, dispuestas en forma densa densa y alineadas. La cara distal solo presenta costillas dispuestas longitudinalmente, esta última permite incluir a la especie en el género Vittatina. Sin embargo al observar las ilustraciones originales y la descripción del material tipo (Marques-Toigo, 1974, pl. IV, figs. 4-6), así como el descripto y/o ilustrado por Quadros et al. (1996, p. 136), Beri (1988, fig 28) y Beri y Goso (1996, lám. III, fig, 9), la presencia de varias costillas no se observa con claridad. De la misma manera en el material aquí estudiado dicho carácter (presencia de varias cotillas longitudinales) no es claramente visible, apreciándose una sola. A pesar de ello entendemos, que por el momento y hasta no revisar el material tipo, que nuestro material debería incluirse en $V$. corrugata por su escultura proximal, ausencia de sacos y presencia de un costilla distal.

Por otra parte debemos mencionar que $V$. corrugata comparte una serie de caracteres con el género Tiwarisporis, como ser la forma general del cuerpo y, en cara proximal, la cantidad de tenias, forma y disposición de las verrugas. Sin embargo, el género Tiwarisporis incluiría (sensu Foster 1975) formas que presentan en su cara distal verrugas de contorno irregular, densamente dispuestas, a modo de pavimento, además de la tenias segmentadas sobre la cara proximal.

Principal material estudiado. BAPal 6164 (a) D49/0, J64/4; BAPal 6169 (a) N40/3.

Registros previos. Vittatina corrugata fue descripta por Marques-Toigo (1974) para la Formación San Gregorio, Cisuraliano, Cuenca Paraná, Uruguay. 


\section{Lámina XVIII}




\section{Lámina XVIII}

A. Corisaccites alutas Venkatachala y Kar 1966, BAPal 6152 (a) T65/0 (X 500).

B. Distriatites sp. A, BAPal 6156(c) C49/4 (X 850).

C y D. Illinites unicus Kosanke emend. Jansonius y Hills 1976, BAPal 6188 (b) U53/4 (X 800); BAPal 6174 (a) V58/2 (X 800).

E. Hamiapollenites andiraensis Playford y Dino 2000b, BAPal 6165 (b) O65/4 (X 850).

F. Hamiapollenites fusiformis Marques-Toigo emend. Archangelsky y Gamerro 1979, BAPal 6152 (a) T43/0 (X 800).

G y H. Hamiapollenites ruditaeniatus Qu y Wang 1986, BAPal 6187 (b) Q36/3 (X 650); R69/4 (X 650). 

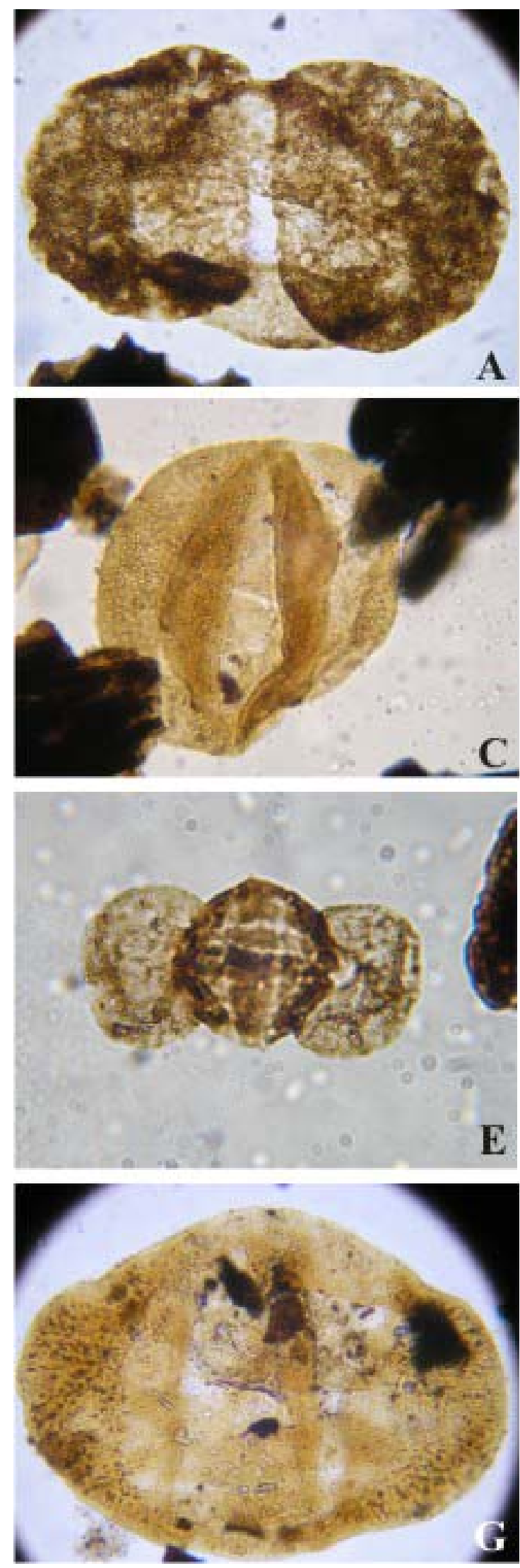
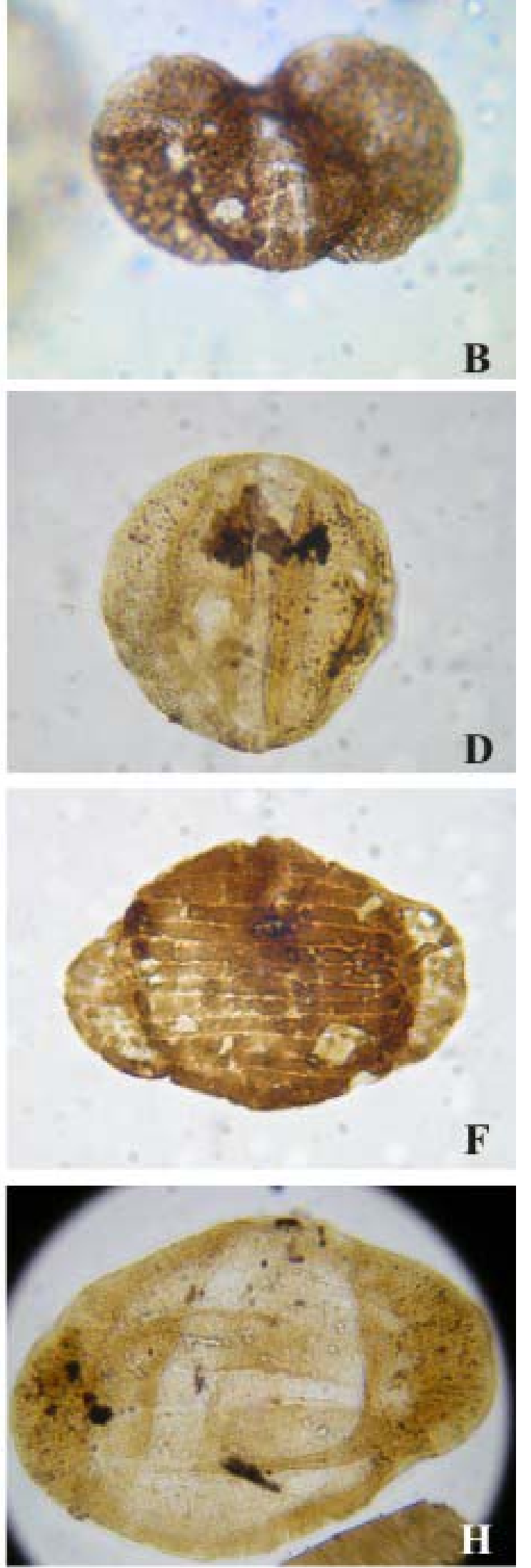


\section{Lámina XIX}

A y B. Lunatisporites noviaulensis (Leschik) Foster 1979, BAPal 6174 (a) T63/0 (X 800); BAPal 6178 (a) V54/1 (X 800).

C. Lunatisporites paliensis Tiwari y Ram-Awatar 1989, BAPal6175 (a) X50/0 (X 350).

D. Lunatisporites variesectus Archangelsky y Gamerro 1979, BAPal 6152 (a) M52/2 (X $850)$.

E y F. Lunatisporites sp. A, BAPal 6152 (a) M60/3 (X 650); BAPal 6152 (b) N36/3 (X 1000).

G y H. Lunatisporites sp. B, BAPal 6151 (a) S47/4 (X 750); BAPal 6152 (b) R50/0 (X 850). 

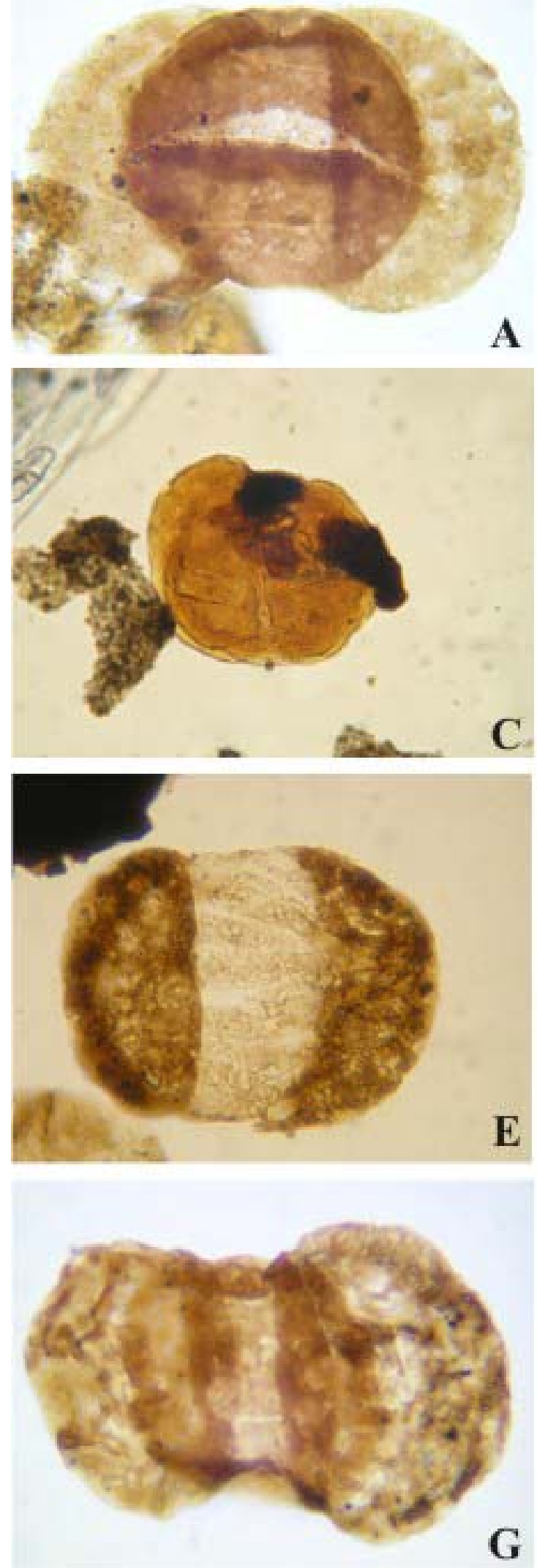
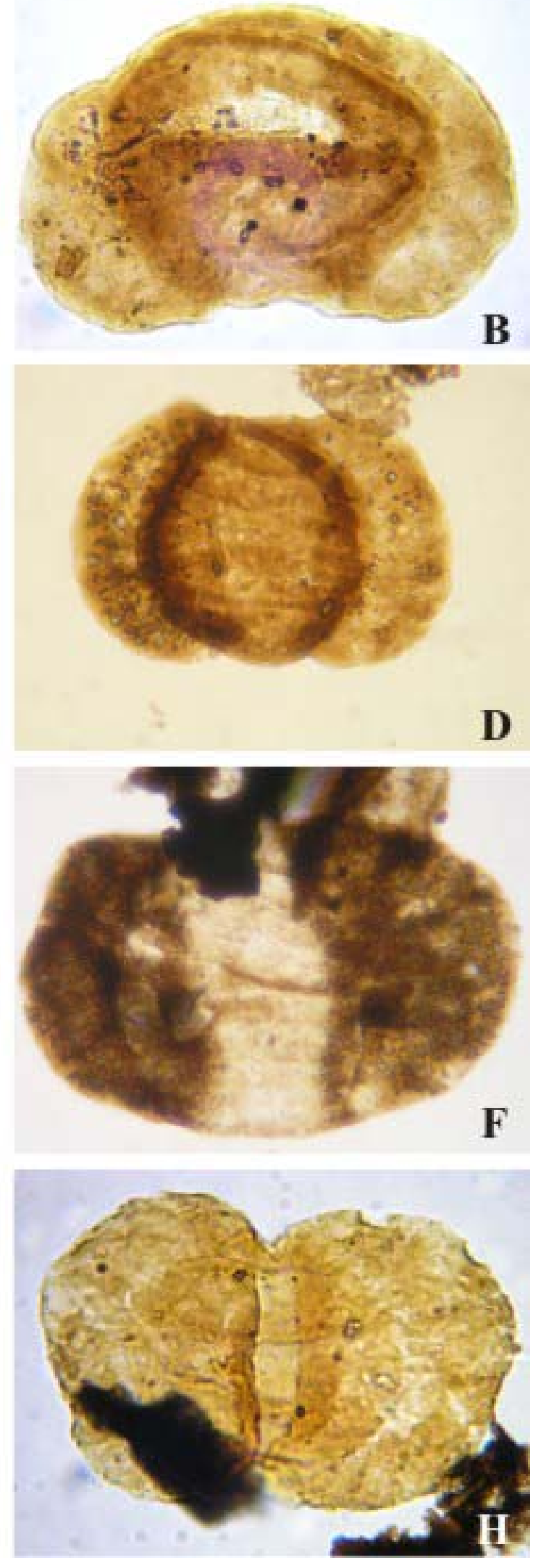


\section{Lámina XX}




\section{Lámina XX}

A y B. Lueckisporites singhii Balme 1970, BAPal 6152 (a) Q58/1 (X 700); BAPal 6155 (a) L72/4 (X 850).

C. Lueckisporites sp. cf. L. nyakapendensis Hart 1960, BAPal 6152 (a) M50/3 (X 700).

D. Lueckisporites singrauliensis Sinha 1972, BAPal 6152 (a) W44/3 (X 750).

E y F. Lueckisporites virkkiae (Potonié y Klaus) emend. Klaus 1963, BAPal 6158 (a) W58/0 (X 350); BAPal 6178 (b) F68/1 (X 850).

G. Protohaploxypinus amplus (Balme y Hennelly) Hart 1964, BAPal 6158 (a) U56/4 (X 850).

H. Protohaploxypinus bharadwajii Foster 1979, BAPal 6152 (a) U51/2 (X 750). 

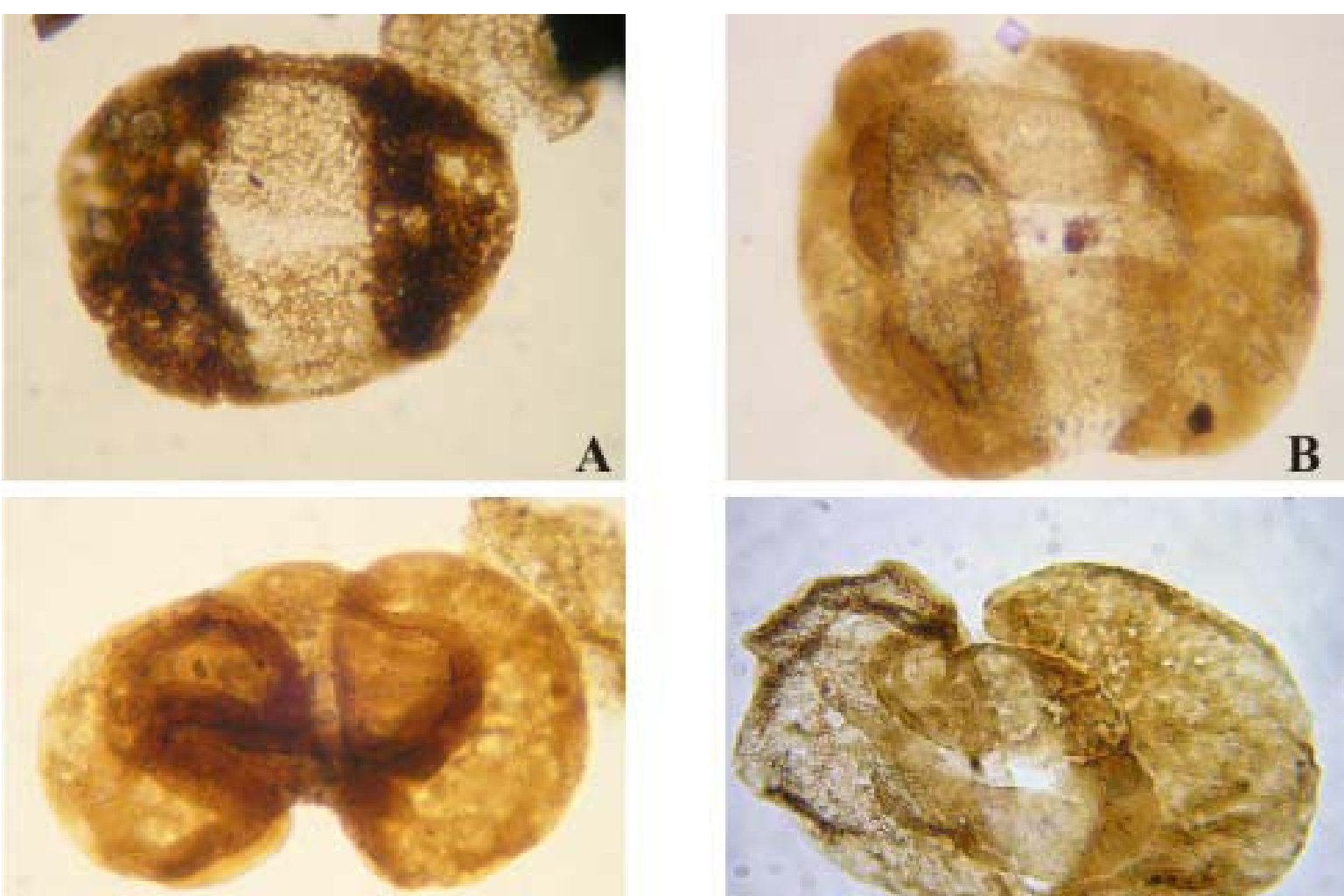

C
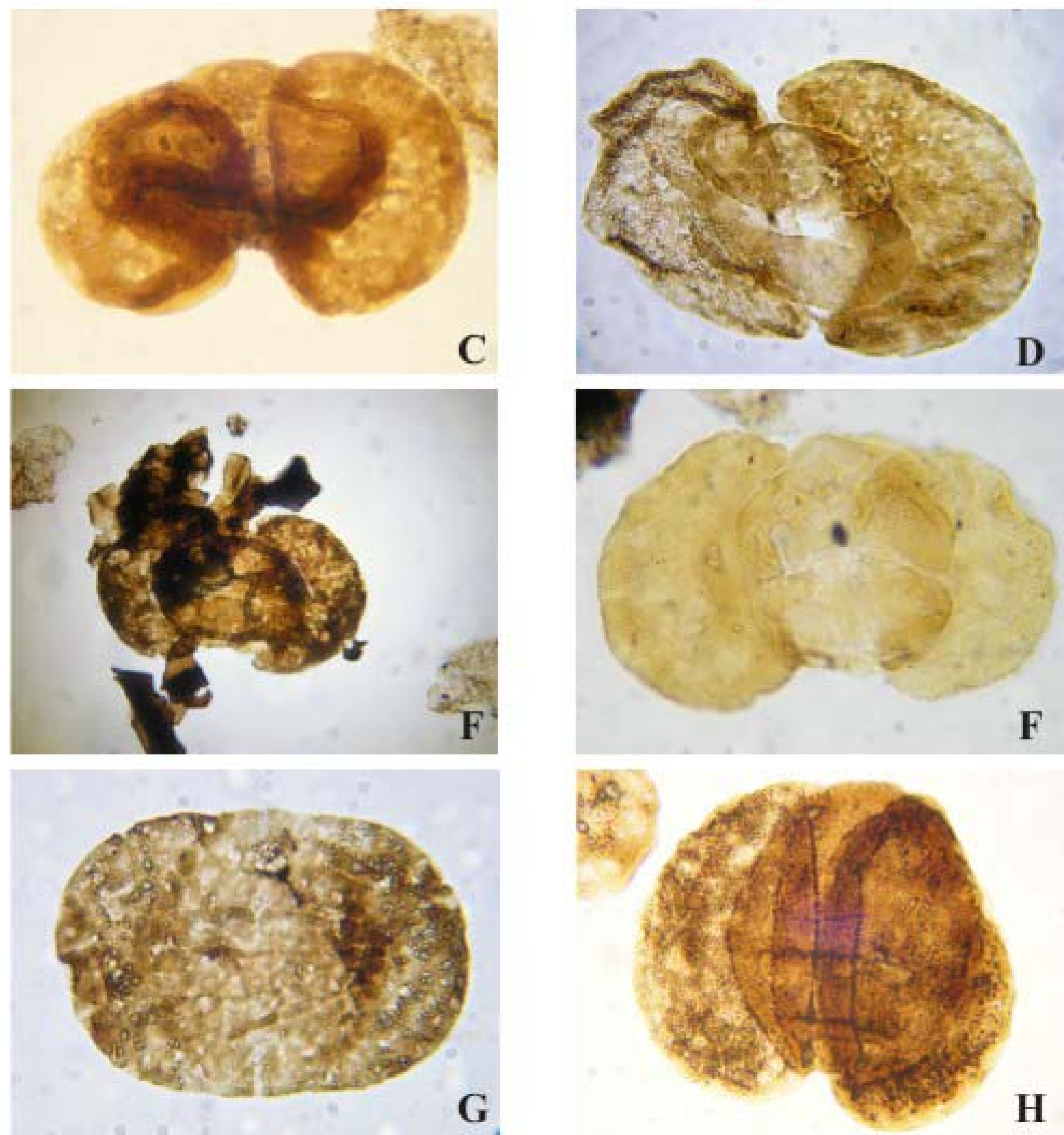


\section{Lámina XXI}




\section{Lámina XXI}

A y B. Protohaploxypinus diagonalis Balme 1970, BAPal 6152 (a) L62/3 (X 800); BAPal 6150 (a) P43/4 (X 750).

C. Protohaploxypinus limpidus (Balme y Hennelly) Balme y Playford 1967, BAPal 6164 (a) W35/2 (X 750).

D. Protohaploxypinus goraiensis (Potonié y Lele) Hart 1964, BAPal 6165 (a) D35/0 (X 700).

E y F. Protohaploxypinus microcorpus (Schaarschmidt) Clarke 1955, BAPal 6139 (a) C57/1 (X 850); BAPal 6172 (a) G34/4 (X 750).

G. Protohaploxypinus varius (Bharadwaj) Balme 1970, BAPal 6152 (a) E44/0 (X 850).

H. Staurosaccites cordubensis Archangelsky y Gamerro 1979, BAPal 6152 (a) F75/1 (X 700). 

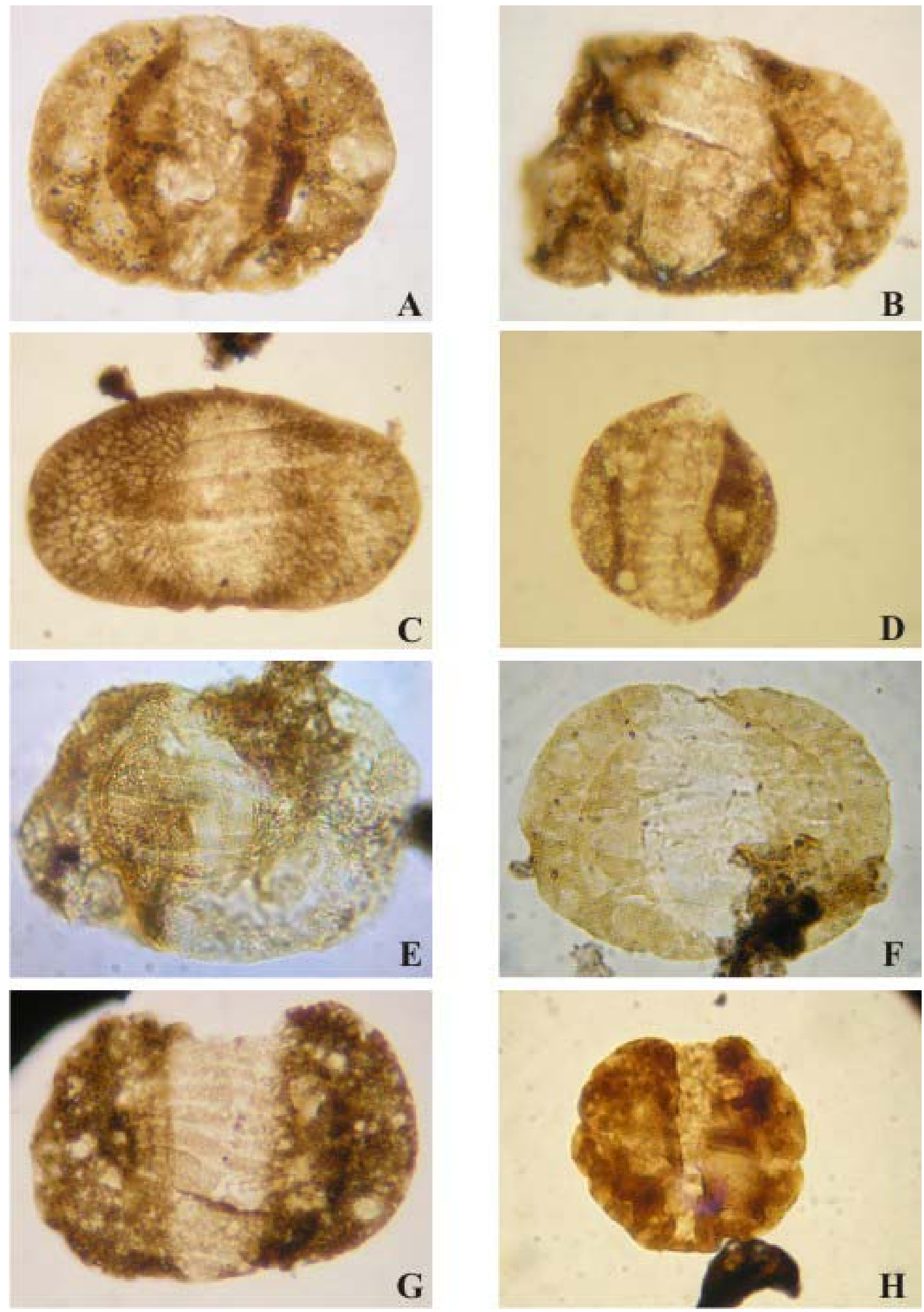
Lámina XXII 


\section{Lámina XXII}

A. Striatopodocarpites cancellatus (Balme y Hennelly) Hart 1963, BAPal 6187 (b) $\mathrm{S} 67 / 0$ (X 1200).

B. Striatopodocarpites gondwanensis Lekhanpal, Sah y Dube 1960, BAPal 6187 (a) S42/3 (X 800).

C y D. Striatopodocarpites fusus (Balme y Hennelly) Potonié 1958, BAPal 6178 (a) R60/1 (X 800).

E. Striatopodocarpites sp. cf. S. phaleratus (Balme y Hennelly) Foster 1979, BAPal 6174 (a) R42/0 (X 350).

F. Striatopodocarpites sp. cf. S. solitus (Bharadwaj y Salujha) Foster 1979, BAPal 6175 (b) $\mathrm{H} 55 / 4$ (X 750).

G y H. Tornopollenites toreutos Morgan 1972, BAPal 6152 (a) O58/2 (X 850); BAPal 6152 (b) $\mathrm{V} 70 / 3$ (X 700). 

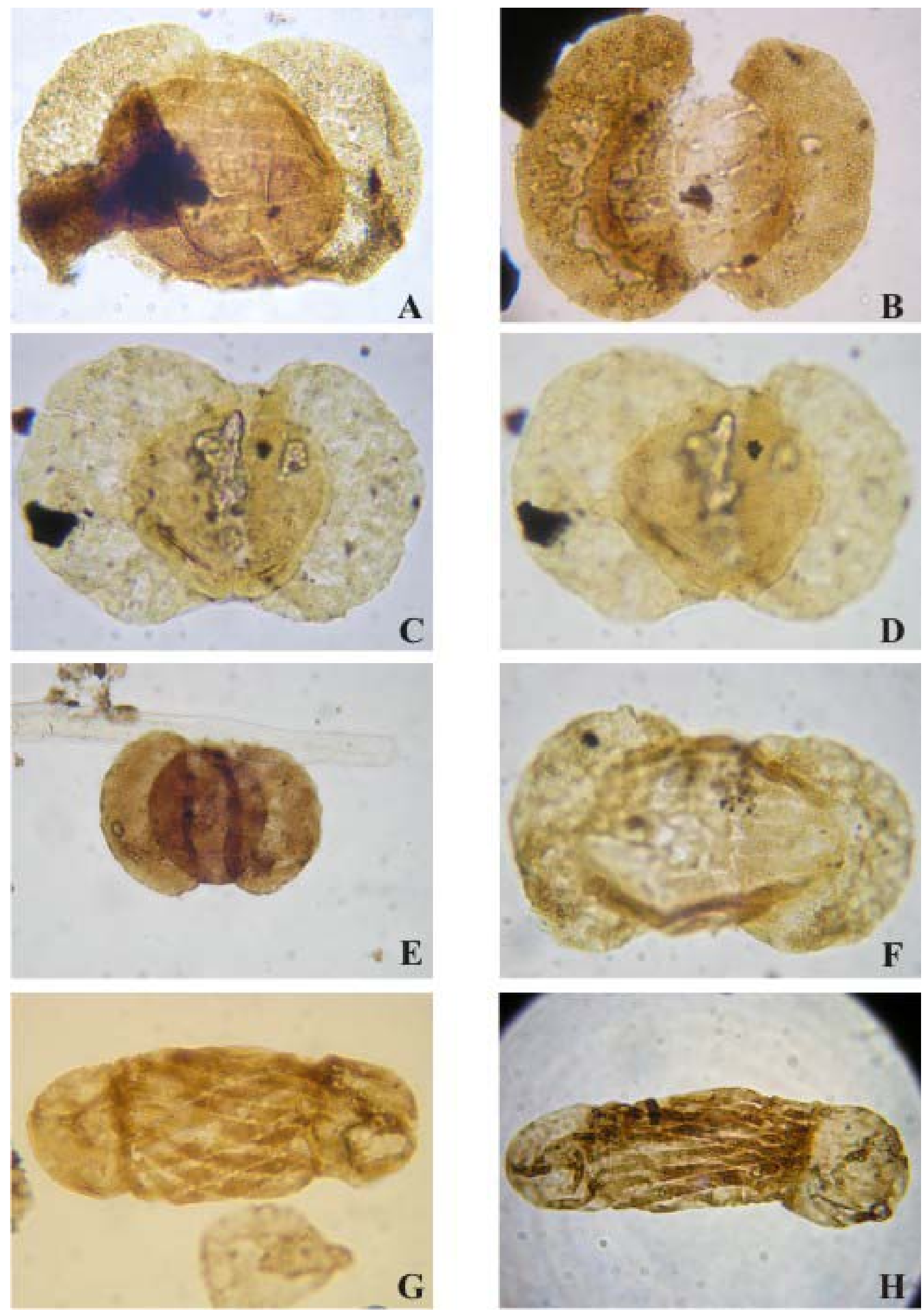
- Cisuraliano: Argentina: presente en la Formación Victoriano Rodríguez, Biozona Cristatisporites, Cuenca Chacoparaná (Playford y Dino, 2002). Uruguay: mencionadas y/o ilustradas para las formaciones Tres Islas (Beri, 1988; Beri et al., 2000) y San Gregorio (Beri y Daners, 1996; Beri y Goso, 1996; Beri et al., 2006), Cuenca Paraná. Brasil: mencionada para el Subgrupo Itararé, Cuenca Paraná (Souza y Callegari, 2004). - Cisuraliano-Guadalupiano: Uruguay: presente en la Formación Melo (Mautino et al., 1998b; Beri y Pecoits, 2001), Cuenca Paraná. Brasil: presente en la perforación 3-MC3-SC, Matos Costa, Santa Catarina, Cuenca Paraná (Quadros et al., 1996).

\section{Vittatina costabilis Wilson 1962 \\ Lámina XXIII, figura C}

Sinonimia. Gutiérrez et al. (2006b).

Descripción. Grano de polen teniado, protobisacado, de contorno general de circular a levemente oval elongado transversal o longitudinalmente. Cara proximal dividida por finas estrías en 8 a más de 12 tenias, orientadas transversalmente, extendidas hacia los márgenes del cuerpo, completas, de $2(3,8) 10 \mu \mathrm{m}$ de ancho, con sus extremos son redondeados. Cara distal bisectada por una ancha franja engrosada central longitudinal, de forma ahusada a subrectangular. Protosacos muy reducidos, que no siempre se distinguen del margen del cuerpo del grano.

Dimensiones (19 ejemplares). Ancho total, 45(51,3)68 $\mu \mathrm{m}$; cuerpo central, ancho $35(40,5) 45 \mu \mathrm{m}$ y $38(48,1) 57 \mu \mathrm{m}$ de largo; ancho del saco, 5(7,5)10 $\mu \mathrm{m}$; largo del saco, $12(29,5) 37 \mu \mathrm{m}$.

Principal material estudiado. BAPal 6138 (a) E56/4; BAPal 6140 (a) K37/2; BAPal 6143 (b) Q42/1; BAPal 6147 (a) O45/2; BAPal 6148 (a) P41/1; BAPal 6152 (a) B48/3, D47/2, D39/3, G70/0, M43/0, N40/1, V62/0; BAPal 6152 (c) D46/4; BAPal 6165 (a) C47/3, F69, E55/4; BAPal 6185 (a) J51/3; BAPal 6188 (b) Y41/2.

Registros previos. Vittatina costabilis fue descripta por Wilson (1962, pp. 25-26, pl. III, fig. 12) para la Formación Flowerpot, Lopingiano, del Oeste de Oklahoma, Estados Unidos.

- Pennsylvaniano-Cisuraliano: Brasil: presente en las formaciones Nova Olinda y Andirá, Grupo Trapajós, Cuenca Amazonas (Playford y Dino, 2000b) y mencionada para Subgrupo Itararé, Cuenca Paraná (Marques-Toigo et al., 1989). Kazakhstan: ilustrada para Aidaralash Creek (Dunn, 2001). 
Francia y Alemania: ilustrada para Autun y Palatinat (Doubinger, 1974). Polonia: ilustrada para la Cuenca Itrasudetic (Jerzykiewicz, 1987).

- Cisuraliano: Argentina: presente para la Biozona Cristatisporites (Césari et al., 1995) presente en la Formación Victoriano Rodríguez, Biozona Cristatisporites, Cuenca Chacoparaná (Playford y Dino 2002); ilustrada en la Formación Tupe (miembro cuspidal), Cuenca Paganzo (Vergel, 2008). Uruguay: presente para la Formación San Gregorio, Cuenca Paraná (Gutiérrez et al., 2006b). Brasil: presente para la perforación 2-CS-1-PR, Chapéu do Sol, Cuenca Paraná (Quadros et al., 1996). África: ilustrada para la serie Dwyka (Stapleton, 1977). Estados Unidos: presente en muestras de pozo, Texas (Tschudy y Kosanke, 1966). Arabia Saudita: mencionada para la Formación Khuff(Stephenson y Filatoff, 2000b, 2003). Omán: presente en la Formación Gharif(Stephenson y Osterloff, 2002).

- Cisuraliano-Guadalupiano: Uruguay: ilustrada para la Formación Melo (Mautino et al., 1998b; Beri y Pecoits, 2001), Cuenca Paraná. Brasil: ilustrada para las formaciones Rio Bonito (Dias, 1993; Souza y Callegari, 2004; Souza y Marques-Toigo, 2005; Smaniotto et al., 2006) e Iratí (Premaor et al., 2006), Cuenca Paraná y la Formación Pedra do Fogo, Cuenca Parnaíba (Dino et al., 2002).

- Lopingiano: Estados Unidos: presente en la Formación Flowerpot, Oklahoma (Clapham, 1970).

- Lopingiano-Triásico Inferior: Groenlandia: presente en Kap Stosch (Balme 1979).

Vittatina fasciolata (Balme y Hennelly) Bharadwaj 1962 Lámina XXIII, figura D

1956. Marsupipollenites fasciolatus Balme y Hennelly; pp. 62, pl. 3, fig. 42-45.

Descripción. Grano de polen teniado, de contorno general subcircular a circular, con 10 a 15 tenias proximales que se extiende transversalmente al cuerpo. Las tenias son completas y de $3(4,4) 8 \mu \mathrm{m}$ de ancho, y alcanzan los bordes del cuerpo sin ahusarse. Próximos a los extremos de las tenias se observan también sobre la cara proximal, dos pliegues verticales. Sobre los laterales de la cara opuesta se observan escasas tenias perpendiculares a las anteriores.

Dimensiones (11 ejemplares). Ancho total, 36(45,9)55 $\mu \mathrm{m}$; largo total 31(39,8)45 $\mu \mathrm{m}$.

Principal material estudiado. BAPal 6146 (b) G46/4; BAPal 6152 (a) M50/0, M49/0, P62/1; BAPal 6162 (b) H62/1, U42/1; BAPal 6168 (a) L67/3; BAPal 6183 (a) L48/2; BAPal 6187 (a) U57/0; BAPal 6189 (a) R43/0. Redepósito: BAPal 6179 (a) 56/3. 
Registros previos. Vittatina fasciolata (Balme y Hennelly) Bharadwaj fue descripto originalmente para el Cisuraliano de la Cuenca Collie (Balme y Hennelly, 1956, pp. 62, pl. 3, figs. 42-45).

- Cisuraliano: Argentina: presente en la Formación Tasa Cuna, Cuenca Paganzo (Balarino y Gutiérrez, 2006. Australia: presente en la Cuenca Collie (Balme y Hennelly, 1956; Backhouse, 1991). Mencionada para Fairbairn Dam, Cuenca Bowen (Fielding y McLoughlin, 1992) y para las cuencas Perth, Collie y Officer (Backhouse, 1993). Antártida: ilustrada para Heimefrontfjella mountain-range, Dronning Maud Land (Lindströn, 1995) y mencionada para Vestfjella, Dronning Maud Land (Lindström, 1993, 1996). Sudáfrica: presente en Cuenca Karroo (Anderson, 1977).

- Cisuraliano-Guadalupiano: Argentina: presente en la Biozona Striatites, Cuenca Chacoparaná (Césari et al., 1995). Uruguay: presente en la Formación Melo, Cuenca Paraná (Mautino et al., 1998b).

- Guadalupiano: Australia: ilustrada para la Formación Bandanna, Springsure Anticline (Rigby y Hekel, 1977).

- Lopingiano: Argentina: mencionada para la Formación La Veteada, Cuenca Paganzo (Zavattieri et al., 2008). India: presente en Coals Raniganj Stage (Bharadwaj 1962).

Vittatina subsaccata Samoilovich 1953

Lámina XXIII, figuras E y F; Lámina XVII, figuras G y H

Sinonimia. Véase Playford y Dino (2000b).

Descripción. Grano de polen teniado, de contorno general oval. Cara proximal dividida por finas estrías en 8 a más de 15 tenias, orientadas transversalmente y extendidas hasta los márgenes del cuerpo, y de $2(3,6) 5 \mu \mathrm{m}$ ancho. Las tenias son completas y no se bifurcan ni se ahusan en los extremos. En ejemplares bien conservados pueden presentar pequeñas verrugas dispuestas espaciadamente. En la cara distal puede observarse en la mayoría de los casos una banda o zona engrosada (dependiendo esto del grado de definición del área), posicionada longitudinalmente, que bisecta al cuerpo. Los protosacos son pequeños, siempre menores a 1/2 círculo. Bases de los mismos rectas, la sexina conforma pequeños muros que no alcanzan a formar un infraretículo. 
Dimensiones (11 ejemplares). Ancho total, 45(55,1)65 $\mu \mathrm{m}$; cuerpo central, ancho 27(40)55 $\mu \mathrm{m}$ y 37(42,8)47 $\mu \mathrm{m}$ de largo; ancho del saco, 8(8,5)12 $\mu \mathrm{m}$; largo del saco, $8(25) 33 \mu \mathrm{m}$.

Principal material estudiado. BAPal 6146 (a) M52/3, X56/2, J72/2; BAPal 6152 (a) H63/0, L58/3, P70/3; BAPal 6157 (a) K53/4; BAPal 6161 (a) K40/; BAPal 6162 (a) K72/2; BAPal 6169 (a) E43/2; BAPal 6187 (b) P58/2.

Registros previos. Vittatina subsaccata ha sido descripta por Samoilovich (1953, p. 44, pl. IX, figs. 4a, b) para depósitos pérmicos de las áreas Cherdyn y Akt'unbinsk, Urales.

- Pennsylvaniano-Pérmico: Argentina: presente en la Cuenca Chacoparaná (Vergel, 1987). Brasil: presente en las formaciones Nova Olinda y Andirá, Grupo Trapajós, Cuenca Amazonas (Playford y Dino, 2000b). Kazakhstan: ilustrada para Aidaralash Creek (Dunn, 2001).

- Cisuraliano: Argentina: presente en las formaciones Bajo de Véliz (Gutiérrez y Césari, 2000) y Tasa Cuna, ambas del ámbito de Cuenca Paganzo (Balarino y Gutiérrez, 2006); ilustrada para la Biozona Cristatisporites, Cuenca Chacoparaná (Césari et al., 1995); ilustrada en la Formación Tupe (miembro cuspidal), Cuenca Paganzo (Vergel, 2008). Uruguay: presente en la Formación San Gregorio, Cuenca Paraná (Gutiérrez et al., 2006b). Brasil: presente en la perforación 2-CS-1-PR, Chapéu do Sol (Quadros et al., 1996) e ilustrada para el Grupo Itararé, Cuenca Paraná (Dias, 1993). África: ilustrada en la serie Dwyka (Stapleton, 1977). Arabia Saudita: mencionada para la Formación Khuff (Stephenson y Filatoff, 2000a, 2000b, 2003).

- Cisuraliano-Guadalupiano: Argentina: presente en la Formación Victoriano Rodríguez, biozonas Cristatisporites y Striatites, Cuenca Chacoparaná (Playford y Dino, 2002). Ilustrada para la Formación Yacimiento Los Reyunos, Cuenca Oriental (Césari et al., 1996). Uruguay: presente en la Formación Melo (Mautino et al., 1998b), Cuenca Paraná. Brasil: presente en la Formación Rio Bonito (Ybert, 1975; Dias Fabrício, 1981; Souza y Marques-Toigo, 2005).

- Lopingiano-Triásico Inferior: Groenlandia: presente en Kap Stosch (Balme, 1979).

Vittatina vittifera (Luber y Waltz) Samoilovich 1953

Lámina XXIII, figuras $\mathrm{G}$ y $\mathrm{H}$ 
Descripción. Grano de polen teniado, de contorno general suboval, elongado en sentido transversal, con 8 a 15 tenias proximales que se extiende transversalmente al cuerpo. Las tenias son completas, de 3(3,6)4 $\mu \mathrm{m}$ de ancho, y alcanzan los bordes del cuerpo sin ahusarse. Cara distal lisa.

Dimensiones (3 ejemplares). Ancho total, 51(52,3)54 $\mu \mathrm{m}$; largo total 34(36,3)38 $\mu \mathrm{m}$.

Principal material estudiado. BAPal 6152 (a) K48/0; BAPal 6185 (b) S48/3; BAPal 6187 (b) M39/4.

Comentarios. Si bien los ejemplares estudiados se hallaron en un bajo número, los mismos presentan las características diagnósticas de la especie Vittatina vittifera, y es por ello que la asignación específica se hace sin dudas. Las mismas son: cuerpo central con 12 a 15 tenias transversales, completas, borde ecuatorial más oscuro a modo de anilloy ausencia de sacos.

Registros previos. Vittatina vittifera (Luber y Waltz) Samoilovich 1953 fue descripta originalmente para la región de Solikamsk, Pre-Urales Occidental, Pérmico de Rusia.

- Límite Pennsylvaniano-Pérmico: Kazajstán: ilustrada para el estratotipo del límite, Aidaralash (Dunn, 2001).

- Cisuraliano: Brasil: presente en la perforación 3-MC-3-SC, Matos Costa, Santa Catarina, Cuenca Paraná (Quadros et al., 1996). Svalbard (Europa): ilustrada para las formaciones Nodeskiöldbreen, Gipshuken y Kappstarostin (Mangerud y Konieczny, 1991).

- Cisuraliano-Guadalupiano: Brasil: mencionada para la Formación Rio Bonito, Cuenca Paraná (Souza y Marques-Toigo, 2005). Uruguay: ilustrada para la Formación Melo (Beri y Petcoits, 2001).

Esta es la primera cita de la especie para la Argentina.

Género Tiwarisporis Maheshwari y Kar 1967

Especie tipo. Tiwarisporis flavatus Maheshwari y Kar, 1967.

Afinidad botánica. Gimnospermas-Coniferopsida?.

Tiwarisporis anaverrucosus (Archangelsky y Gamerro) nov. comb. Lámina XXIV, figuras A y B 
1979. Striatoabieites anaverrucosus Archangelsky y Gamerro, pp. 454-457, lám. XII, figs. 1-5.

Descripción. Grano de polen bisacado, multiteniado, de contorno general oval, elongado transversalmente, haploxilonoide a levemente diploxilonoide. Cuerpo oval elongado en sentido transversal, de exina gruesa dividida en numerosas tenias, aproximadamente 26 , de 2 a $4 \mu \mathrm{m}$ de ancho, de contorno irregular, que se ahusan en los extremos. A menudo las tenias están parcialmente divididas por estrías más delgadas longitudinales, que generan un patrón de segmentos rectangulares a irregulares en cada tenia. Algunas tenias son incompletas y se acuñan entre las tenias completas. Cara distal amplia subrectangular, cubierta en su totalidad por verrugas planas, de contorno irregular, dispuestas densamente y en contacto entre sí, conformando un pavimento compacto. Sacos menores a medio círculo de contorno irregular. Adherencia al cuerpo lateral recta, con una leve inclinación distal. Sexina levemente infrareticulada, sin conformar muros evidentes, aunque sí se observa una granulometría fina y densa. Pliegues radiales formados por compresión.

Dimensiones (6 ejemplares). Ancho total, 65(79,8)109 $\mu \mathrm{m}$; cuerpo central, ancho $40(52,8) 80 \mu \mathrm{m}$ y $33(53,5) 84 \mu \mathrm{m}$ de largo; ancho del saco, 7(20,3)26 $\mu \mathrm{m}$; largo del saco, $25(43,1) 80 \mu \mathrm{m}$.

Principal material estudiado. BAPal 6152 (a) O68/0, J68/3; BAPal 6157 (a) H59/3; BAPal 6162 (a) M43/0; BAPal 6160 (a) N51/4. Redepósito: BAPal 6174 (a) N66/3.

Discusión. Tiwarisporis anaverrucosus (Archangelsky y Gamerro) nov. comb. fue descripta por Archangelsky y Gamerro (1979, pp. 454-457, lám. XII, figs. 1-5) como una especie nueva del género Striatoabieidites debido a las numerosas tenias proximales que presentaban los ejemplares (entre 18 y 30), y por su aspecto general. Si bien dichas características son compartidas por las distinas especies del género, en particular $S$. anaverrucosus se diferencia de las demás debido a la presencia en su cara distal de gránulos o verrugas de contorno irregular densamente dispuestos, a modo de pavimento. Estos rasgos definen al género Tiwarisporis (Maheshwari y Kar, 1967) por lo que se considera que $S$. anaverrucosus encuentra mejor ubicación sistemática dentro de Tiwarisporis, además su diagnosis (Maheshwari y Kar 1967, pp. 369-370, figs. 1-7), permite incluír ejemplares con sacos rudimentarios (protosacos). Tiwarisporis anaverrucosus representaría un caso de máximo desarrollo en la gradación de tamaños 
de dichos sacos o protosacos, ya que si bien se presentan bien desarrollados no poseen una sexina infrareticulada (Archangelsky y Gamerro 1979; p. 454). Dicho caracter permite separar a esta especie del resto de las especies incluídas en Tiwarisporis. Otro caracter considerado en la diagnosis de Tiwarisporis es la presencia de una marca monolete proximal. Si bien dicho caracter no está presente en T. anaverrucosus, tampoco fue descripta en las otras especies del género: Tiwarisporis simplex (Tiwari) Maheswari y Kar (1967, p. 370, figs. 5-6), y T. novus Bharadwaj y Dwived (1981, p. $39 ;=T$. gondwanensis Srivastava, 1970, p. 159, pl. 2, figs. 22-23).

Registros previos. Striatoabieites anaverrucosus fue descripta originalmente por Archangelsky y Gamerro (1979), Biozona Striatites, Cuenca Chacoparanense, Argentina.

- Cisuraliano: Brasil: ilustrada para el Grupo Itararé, Cuenca Paraná (Pons, 1979; Dias, 1993).

- Cisuraliano-Guadalupiano: Argentina: presente en la Formación Victoriano Rodríguez, Biozona Striatites, Cuenca Chacoparaná (Playford y Dino 2002); ilustrada para la Formación De La Cuesta, Cuenca Paganzo (Aceñolaza y Vergel, 1987). Uruguay: ilustrada para la Formación Melo, Cuenca Paraná (Beri y Pecoits, 2001; Gutiérrez et al., en prensa-b).

\section{Tiwarisporis simplex (Tiwari) Maheshwari y Kar 1967}

Lámina XXIV, figuras C, D y E

1965. Welwitschiapites simplex Tiwari, p. 206, pl. 8, fig. 193, pl. 9, figs 200-201. 1977. Vittatina simplex (Tiwari) Anderson, p. 104, pl. 128, figs. 1-19.

Descripción. Grano de polen multiteniado, de contorno general oval, elongado transversalmente. Exina gruesa dividida en numerosas tenias, más de 35, de 2 a $4 \mu \mathrm{m}$ de ancho, de contorno irregular, de extremos redondeados. Las tenias están subdivididas por delgadas estrías longitudinales, que generan un patrón de segmentos rectangulares a irregulares en cada tenia. Algunas tenias son incompletas y se acuñan entre las tenias completas. Cara distal cubierta en su totalidad por verrugas planas, de contorno irregular, dispuestas densamente y en contacto entre sí, conformando un pavimento compacto. 
Dimensiones (4 ejemplares). Ancho total, 100(103,2)110 $\mu \mathrm{m}$; largo total, 83(88)95 $\mu \mathrm{m}$. Principal material estudiado. BAPal 6148 (a) W53/1; BAPal 6151 (a) O61/3; BAPal 6168 (a) U45/0; BAPal 6187 (a) S56/4.

Comentarios. Características diagnósticas de la especie Tiwarisporis simplex, tales como las numerosas tenias transversales proximales, las verrugas bajas y densamente dispuestas distales y la ausencia de marca monolete y de saco permiten asignar sin duda a los ejemplares aquí estudiados.

Registros previos. Descripta originalmente por Tiwari (1965) para el Barakar Stage fue luego sinonimizada por Maheshwari y Kar (1967, p. 370; figs 5-6).

- Cisuraliano: Australia: presente en Blair Athol Coal Measures (Foster, 1975, 1979). África: Región Ecca, Congo (Bose y Maheshwari, 1968). India: presente en Barakar Stage (Tiwari, 1965). Sudáfrica: presente en Cuenca Karroo (Anderson, 1977).

- Cisuraliano-Guadalupiano: Uruguay: presente en la Formación Melo, Cuenca Paraná (Mautino et al., 1998b).

- Guadalupiano: Australia: presente en Baralaba Coal Measures, Cuenca Bowen (Foster, 1975, 1979).

Para mayor información sobre sus registros previos, véase Foster (1979, p. 103).

Esta es la primera cita de la especie para cuencas sudamericanas.

Género Weylandites Bharadwaj y Srivastava 1969a

Especie tipo. Weylandites lucifer (Bharadwaj y Salujha) Foster, 1975.

Afinidad botánica. Gimnospermosida-Voltizales/Glossopteridales (véase Balme, 1995).

Weylandites lucifer (Bharadwaj y Salujha) Foster 1975

Lámina XXIV, figuras $\mathrm{G}$ y $\mathrm{H}$

1964. Decussatisporites lucifer Bharadwaj y Salujha; p. 213, pl. 12, figs. 169-171.

1977. Vittatina lucifera (Bharadwaj y Salujha) Anderson, p. 105, pl. 129, figs. 1-71, 8093, pl. 130, figs. 1-54.

Sinonimia adicional. Véase Foster (1975) y Quadros et al. (1996).

Descripción. Grano de polen teniado, de contorno oval, elongado transversalmente. Cuerpo central de exina gruesa, dividida por finas estrías en angostas tenias que se 
continúan por todo el grano. En la cara proximal se observan más de 17 tenias dispuestas en sentido transversal, de ancho variable. En la cara distal se continúan las mismas ubicándose longitudinalmente, siguiendo el contorno del sulco. Sulco distal medio, poco visible por compresión.

Dimensiones (3 ejemplares). Ancho total, 39-65 $\mu \mathrm{m}$; largo total, 39-57 $\mu \mathrm{m}$.

Principal material estudiado. BAPal 6152 (a) E58/0; BAPal 6188 (a) H55/3; BAPal 6189 (a) $\mathrm{V} 34 / 0$.

Registros previos. Esta especie fue originalmente descripta por Bharadwaj y Salujha (1964) para Raniganj, Lopingiano de Bihar, y luego combinada por Foster (1975, p. 20, pl. 7, fig. 2).

- Cisuraliano: Uruguay: presente en la Formación San Gregorio (Gutiérrez et al., 2006b), Cuenca Paraná. Australia: presente en Blair Athol Coal Measures (Foster, 1975). Ilustrada para la Formación Stockton, Cuenca Collie (Backhouse, 1991) y mencionada para las Cuencas Perth, Collie y Officer (Backhouse, 1993). Antártida: mencionada para Vestfjella, Dronning Maud Land (Lindström, 1993, 1996, 2005). India: presente en la Formación Barakar, Karapura Coalfield (Bharadwaj y Dwivedi, 1981) e ilustrada para Barren Measures, Jharia Coalfield, Bihar (Kar, 1968). África: presente en el Grupo Ecca, en Cuenca Karroo (Anderson, 1977) y Cuenca Waterberg (Macrae, 1988). Arabia Saudita: mencionada para la Formación Khuff (Stephenson y Filatoff, 2000b, 2003). Oman: presente en la Formación Gharif (Stephenson y Osterloff, 2002). Sudáfrica: presente en Cuenca Karroo (Anderson, 1977).

- Cisuraliano-Guadalupiano: Argentina: presente en las biozonas Cristatisporites y Striatites, Cuenca Chacoparaná (Césari et al., 1995). Uruguay: ilustrada para la Formación Melo (Mautino et al., 1998b; Beri y Pecoits, 2001), Cuenca Paraná. Brasil: presente en la Formación Iratí (Menéndez, 1976; Premaor et al., 2006) y en la perforación 2-AO-1-RS, Anastásio, Rio Grande do Sul, Cuenca Paraná (Quadros et al., 1996). Papúa: ilustrada para las formaciones Ainim y Aiduna (Playford y Rigby, 2008).

- Guadalupiano: Australia: presente en Baralaba Coal Measures, Cuenca Bowen (Foster, 1979).

- Lopingiano-Triásico Inferior: Australia: presente en la Formación Rowen, Cuenca Bowen (de Jersey, 1979; Foster, 1979, 1982a). 
Weylandites magmus (Bose y Kar) Backhouse 1991

Lámina XXIV, figura F

1966. Decussatisporites magmus Bose y Kar, p. 120, pl. 128, figs. 7-9; pl. 29, fig. 14.

1977. Vittatina magma (Bose y Kar) Anderson, p. 106, pl. 130, figs. 55-62, pl. 131, figs. $1-38$.

Sinonimia adicional. Véase Backhouse (1991) y Gutiérrez et al. (2006b).

Descripción. Grano de polen de contorno subcircular a oval. Cuerpo central dividido por finas estrías en 12 a 15 tenias transversales, de 3 a 5 de ancho $\mu \mathrm{m}$, paralelas en la cara proximal, algunas más cortas y acuñadas entre las mayores. En la cara distal se continúan las mismas pero se ubican en sentido longitudinal, en los lados longitudinales del grano. Sulco distal medio, poco visible por compresión.

Dimensiones (3 ejemplares). Ancho total, 41(45,6)51 $\mu \mathrm{m}$; largo total, 46-47 $\mu \mathrm{m}$.

Principal material estudiado. BAPal 6152 (b) P59/4; BAPal 6143 (a) M41/1. Redepósito: BAPal 6170 (a) T67/1.

Registros previos. Weylandites magmus fue descripta originalmente para el Cisuraliano de Congo (Bose y Kar, 1966).

- Cisuraliano: Argentina: presente en la Formación Tasa Cuna, Cuenca Paganzo (Balarino y Gutiérrez, 2006). Uruguay: presente en la Formación San Gregorio (Gutiérrez et al., 2006b). Australia: presente en la Cuenca Collie (Backhouse, 1991). África: presente en las zonas de microfloras $3^{\mathrm{a}}$ a 7, Cuenca de Karoo (Anderson, 1977). Antártida: ilustrada para Heimefrontfjella (Lindström 1995) y mencionada para Fossilryggen Vestfjella, Dronning Maud Land (Lindström 1996). India: presente en Bihar (Bharadwaj y Dwivedi, 1981).

- Cisuraliano-Guadalupiano: Argentina: mencionada para la Formación Yacimiento Los Reyunos (Césari et al., 1996). Uruguay: presente en la Formación Melo, Cuenca Paraná (Beri y Pecoits, 2001; Gutiérrez et al., en prensa-b).

Subturma PRAECOLPATES Potonié y Kremp 1954

Género Marsupipollenites Balme y Hennelly emend. Balme 1970

Espacie tipo. Marsupipollenites triradiatus (Balme y Hennelly) Hart, 1965.

Afinidad botánica. Gimnospermosida-Voltizales/Glossopteridales (véase Balme, 1995). 
Marsupipollenites striatus (Balme y Hennelly) Hart 1965

Lámina XXV, figura A

1956b. Marsupipollenites triradiatus f. striatus Balme y Hennelly, p. 61, pl. 2, figs. 3637.

1977. Vittatina triradiata (Balme y Hennelly) Anderson, p. 109, pl. 134, figs. 1-66, pl. 135, figs. 1-36.

Sinonimia adicional. Véase Raine et al. (2005).

Descripción. Grano de polen monosulcado, de contorno general circular a suboval. Cara proximal con marca trilete de rayos cortos y rectos. Exina dividida por finas estrías que conforman tenias (alrededor de 15) de ancho constante, y contorno curvo, ya que rodean la marca trilete sin cortarla. Bordes del cuerpo replegados hacia la cara distal, conformando un sulco de forma subrectangular a oval.

Dimensiones (52 ejemplares). Diámetro mayor, 33(39,7)57 $\mu \mathrm{m}$; dimámetro menor, 29(35,7)47 $\mu \mathrm{m}$.

Principal material estudiado. BAPal 6152 (a) F67/3; F70/3; H37/0, K51/4, K74/4, N54/0, V60/0, V44/4, H37/0, E63/3, F53/2, F55/2, F44/4; BAPal 6188 (a) F60/0;

BAPal 6188 (b) K36/0.

Comentarios. El material referido a Vittatina triradiata (Balme y Hennelly) por Anderson (1977, p. 109, pl. 134, figs. 1-66, pl. 135, figs. 1-36) es incluido en M. striatus porque exhibe las características diagnósticas de la especie (por ejemplo las estrías proximales).

Registros previos. Descripta originalmente en la Cuenca Collie por Balme y Hennelly (1956) como una forma de Marsupipollenites triradiatus fue luego propuesta originalmente como M. striatus por Hart (1965, p. 104, fig. 250).

- Pennsylvaniano cuspidal-Guadalupiano: Argentina: presente en las biozonas Potonieisporites-Lundbladispora, Cristatisporites y Striatites, Cuenca Chacoparaná (Archangelsky y Gamerro, 1979; Césari et al., 1995).

- Cisuraliano: Argentina: presente en la Formación Bajo de Véliz, Cuenca Paganzo (Gutiérrez y Césari, 2000). Uruguay: presente en la Formación San Gregorio, Cuenca Paraná (Gutiérrez et al., 2006b). Brasil: ilustrada para el Grupo Itararé (Dias, 1993), Cuenca Paraná. Australia: ilustrada para las cuencas Collie (Backhouse, 1991; 
Backhouse, 1993), Perth (Foster et al., 1985; Backhouse, 1993) y Officer (Backhouse, 1993). Antártida: mencionada para Fossilryggen, Vestfjella, Dronning Maud Land (Lindström, 1993; Lindström, 1996) y Heimefrontfjella mountain-range, Dronning Maud Land (Lindströn, 1995); ilustrada (Playford, 1990). Arabia Saudita: mencionada para la Formación Khuff (Stephenson y Filatoff, 2000a, 2000b, 2003). Sudáfrica: presente en Cuenca Karroo (Anderson, 1977).

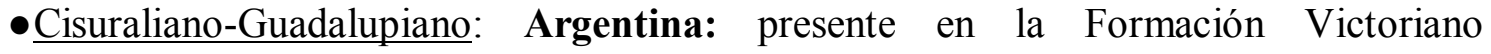
Rodríguez, biozonas Cristatisporites y Striatites, Cuenca Chacoparaná (Playford y Dino, 2002). Ilustrada para las formaciones De La Cuesta, Cuenca Paganzo (Aceñolaza y Vergel, 1987), El Imperial, Cuenca San Rafael (García, 1996) y Yacimiento Los Reyunos, Cuenca Oriental (Césari et al., 1996). Uruguay: presente en la Formación Melo, Cuenca Paraná (Anzótegui et al., 1998b). Brasil: presente en la perforación 2CS-1-PR, Chapéu do Sol (Quadros et al., 1996) e ilustrada para la Formación Rio Bonito, Grupo Guatá, Supergrupo Tubarão (Dias Fabrício, 1981) e Iratí (Premaor et al., 2006), todos de Cuenca Paraná. Papúa: ilustrada para las formaciones Ainim y Aiduna (Playford y Rigby, 2008).

- Guadalupiano: Australia: presente en Baralaba Coal Measures, Cuenca Bowen (Foster, 1979).

- Lopingiano: Antártida: ilustrada para Buckley, Transantarctic Mountains (Farabee et al., 1991). Estados Unidos: presente en la Formación Flowerpot, Oklahoma (Clapham, 1970).

-Lopingiano-Triásico Inferior: Australia: ilustrada para la Formación Rewan, Cuenca Bowen (Foster, 1979, 1982a).

Marsupipollenites triradiatus Balme y Hennelly $1956 \mathrm{~b}$

Lámina XXV, figura B

Sinonimia. Véase Raine et al. (2005).

Descripción. Grano de polen monosulcado, de contorno general circular. Cara proximal con una pequeña marca trilete de rayos cortos y rectos. Exina gruesa conformando una superficie de verrugas o gránulos densamente dispuestos. Los mismos son pequeños y 
de contornos irregulares. Borde del cuerpo replegado hacia la cara distal, conformando un sulco amplio de contorno subrectangular.

Dimensiones (12 ejemplares). Diámetro mayor, 35(43,8)62 $\mu \mathrm{m}$; dimámetro menor, $27(36,2) 43 \mu \mathrm{m}$.

Principal material estudiado. BAPal 6152 (a) E49/1, R65/0, T58/4, P58/4, O64/0, T66/3; BAPal 6152 (b) F51/1; BAPal 6158 (a) J67/1; BAPal 6162 (b) V41/0; BAPal 6165 (a) K42/0; BAPal 6165 (b) Q40/0, Q59/4.

Registros previos. Marsupipollenites triradiatus fue descripta originalmente por Balme y Hennelly (1956b, pp. 60-61, pl. 2, figs. 29-35) para la perforación no 5, Pérmico de Andar New Castle, Australia.

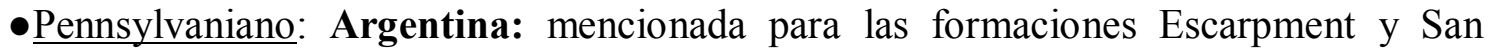
Telmo, Grupo Mandiyutí, Cuenca Tarija (di Pasquo et al., 2001; di Pasquo, 2003a). Brasil: ilustrada para el Subgrupo Itararé, Cuenca Paraná (di Pasquo et al., 2003b).

- Pennsylvaniano cuspidal-Cisuraliano: Argentina: presente en la Formación El Imperial, Cuenca San Rafael (García, 1996).

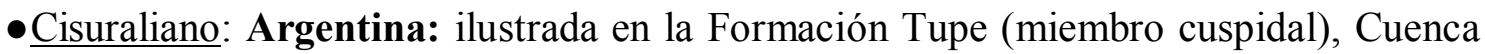
Paganzo (Vergel, 2008). Brasil: presente en la perforación 2-AO-1-RS, Atanásio, Río Grande do Sul, Cuenca Paraná (Quadros et al., 1996). Australia: presente en Blair Athol Coal Measures (Foster, 1975). Ilustrada para la Formación Stockton, Cuenca Collie (Backhouse, 1991) y la Formación Bandanna, Springsure Anticline (Rigby y Hekel, 1977). Mencionada para las Cuencas Perth, Collie, Officer (Backhouse, 1993) y Fairbairn Dam, Cuenca Bowen (Fielding y McLoughlin, 1992). Antártida: presente en Prince Charles Mountains (Balme y Playford, 1967) y mencionada para Vestfjella, Dronning Maud Land (Lindström, 1993, 1996); ilustrada (Playford, 1990). Pakistán: presente para la Formación Chhidru, Grupo Zaluch (Balme, 1970). África del Sur: ilustrada para el Keetewa-Mchuchuma Coalfield en Tanzania (Manum y Duc Tien, 1973).

- Cisuraliano-Guadalupiano: Uruguay: ilustrada para la Formación Melo, Cuenca Paraná (Mautino et al., 1998b; Beri y Pecoits, 2001). Brasil: ilustrada para la Formación Iratí, Cuenca Paraná (Premaor et al., 2006). Papúa: ilustrada para las formaciones Ainim y Aiduna (Playford y Rigby, 2008).

- Guadalupiano: Australia: Baralaba Coal Measures, Cuenca Bowen (Foster, 1979). 
- Lopingiano: Antártida: ilustrada para Buckley, Transantarctic Mountains (Farabee et al., 1991).

- Lopingiano-Triásico Inferior: Australia: presente en la Formación Rewan, Cuenca Bowen (Foster, 1979; de Jersey, 1979).

Género Praecolpatites Bharadwaj y Srivastava 1969a

Especie tipo. Praecolpatites nidpurensis Bharadwaj y Srivastava 1969a.

Afinidad botánica. Gnetopsida-Ephedrales?.

Praecolpatites sinuosus (Balme y Hennelly) Bharadwaj y Srivastava 1969a Lámina XXV, figura $\mathrm{C}$

1956b. Marsupipollenites sinuosus Balme y Hennelly, p. 61, pl. 2, figs. 25-28.

Sinonimia adicional. Véase Raine et al. (2006).

Descripción. Grano de polen poliplicado, de contorno general oval, elongado longitudinalmente, de contornos convexos y extremos redondeados a levemente agudos. Exina compuesta por 2 capas, de aproximadamente $1 \mu \mathrm{m}$ de espesor, con alrededor de 5 prominentes pliegues longitudinales. Los mismos son continuos, levemente sinuosos, tienen un contorno ahusado y generalmente no alcanzan los extremos del grano. Puede observarse en algunos sectores marginales de los pliegues una leve crenulación. Los pliegues están separados entre sí por unos surcos longitudinales, profundos, que se extienden a lo largo de todo el grano. Los pliegues son más oscuros que las zonas que los separan.

Dimensiones (6 ejemplares). Eje mayor, 38(41,4)47 $\mu \mathrm{m}$; eje menor, 23(26,3)30 $\mu \mathrm{m}$.

Principal material estudiado. BAPal 6152 (a) J64/4, M58/1; BAPal 6156 (a) K36/2; BAPal 6162 (b) Q59/0; BAPal 6165 (a) F68/2, J35/0.

Comentarios. Los ejemplares aquí estudiados presentan las características diagnósticas de la especie Praecolpatites sinuosus: son formas poliplicadas, de contorno oval a ahusado longitudinalmente, con aproximadamente 5 pliegues notorios, longitudinales.

Registros previos. Esta especie fue descripta originalmente por Balme y Hennelly (1956b, pp. 60-61, pl. 2, figs. 29-35) para el Pérmico de Australia y posteriormente combinada por Bharadwaj y Srivastava (1969a, pp. 141-142, pl. 29, fig. 125). 
- Cisuraliano: Australia: presente en Blair Athol Coal Measures (Foster, 1975). Ilustrada para la Formación Stockton, Cuenca Collie (Backhouse, 1991). Mencionada para Fairbairn Dam, Cuenca Bowen (Fielding y McLoughlin, 1992) y para las cuencas Perth, Collie y Officer (Backhouse, 1993). Antártida: mencionada para Vestfjella, Dronning Maud Land (Lindström, 1993, 1996, 2005); ilustrada por Playford (1990). Pakistán: presente en la Formación Chhidru, Grupo Zaluch (Balme, 1970). India: presente en Coal Raniganj, Serie Damuda (Bharadwaj, 1962). Sudáfrica: presente en la Cuenca Karroo (Anderson, 1977).

- Guadalupiano: Australia: presente en Baralaba Coal Measures, Cuenca Bowen (Foster, 1979). Ilustrada para la Formación Bandanna, Springsure Anticline (Rigby y Hekel, 1977).

- Lopingiano: Antártida: ilustrada para Buckley, Transantarctic Mountains (Farabee et al., 1991).

- Lopingiano-Triásico Inferior: Australia: presente en la Formación Rewan, Cuenca Bowen (Foster, 1979; de Jersey, 1979).

- Triásico Inferior: India: presente en Nidpur microflora assemblage, Serie Panchet (Bharadwaj y Srivastava, 1969a).

Esta es la primera cita de la especie para la Argentina.

Subturma MONOCOLPATES Iverson y Tröels-Smith 1950

Género Pakhapites Hart 1965

Especie tipo. Pakhapites fasciolatus (Balme y Hennelly) Hart, 1965.

Afinidad botánica. Desconocida.

Pakhapites fusus (Bose y Kar) Menéndez 1971

Lámina XXV, figuras E y F

1966. Fusacolpites fusus Bose y Kar, p. 118; lám. 28, figs 10-12, lám. 29, figs 1-8, 17 18.

Descripción. Grano de polen monocolpado, estriado, de contorno general oval a ahusado, elongado en sentido longitudinal. Cara proximal dividida por finas estrías transversales, rectas a levemente curvadas hacia los extremos, poco discernibles, y se extienden de un lado a otro del grano. Las estrías limitan alrededor de 10 a 20 tenias equidimensionales, de 1,5 a $4 \mu \mathrm{m}$ de ancho. El colpo es claro y está desarrollado a lo 
largo del eje longitudinal del grano. Es de contorno variable, desde subrectangular a lados convexos hacia el centro, que se bifurcan hacia los extremos.

Dimensiones (19 ejemplares). Diámetro ecuatorial, 30(42,8)58 $\mu \mathrm{m}$; diámetro polar, $40(52,1) 63 \mu \mathrm{m}$; ancho del colpo $1(9,3) 15 \mu \mathrm{m}$.

Principal material estudiado. BAPal 6152 (b) X59/0; BAPal 6160 (a) G50/0; BAPal 6165 (b) O58/0, W49/4; BAPal 6182 (a) W40/4;BAPal 6183 (b) K46/1; BAPal 6186

(a) X64/2; BAPal 6187 (a) O71/3, U69/3; BAPal 6188 (b) O70/4, R67/0; BAPal 6189

(a) E34/0, R61/0, O50/4. Redepósito: BAPal 6171 (a) J66/3; BAPal 6173 (a) P39/0; BAPal 6180 (a) Q66/4.

Registros previos. Esta especie fue descripta originalmente para la región Walikale, Pérmico de Congo, África (Bose y Kar, 1966, p. 118; lám. 28, figs 10-12, lám. 29, figs 1-8, 17-18). Luego fue combinada por Menédez (1971, p. 297; lám. VI, fig. 7).

- Pennsylvaniano-Cisuraliano: Brasil: presente en las formaciones Nova Olinda y Andirá, Grupo Trapajós, Cuenca Amazonas (Playford y Dino, 2000b).

- Cisuraliano: Argentina: presente en las formaciones Bajo de Véliz (Menéndez, 1971; Gutiérrez y Césari, 2000) y Tasa Cuna (Balarino y Gutiérrez, 2006) ambas de Cuenca Paganzo; presente en las formaciones Santa Máxima, Cuenca Calingasta-Uspallata (Ottone, 1989) y El Imperial, San Rafael (García, 1996). También presente en las Biozona Cristatisporites (Césari et al., 1995), Cuenca Chacoparaná. Ilustrada en la Formación Tupe (miembro cuspidal), Cuenca Paganzo (Vergel, 2008). Uruguay: presente en las formaciones Tres Islas (Fasolo y Vergel, 1994) y San Gregorio, Cuenca Paraná (Gutiérrez et al., 2006b). Namibia: ilustrada para el Grupo Dwyka en la perforación Strat Test 1 (Stapleton, 1977). India: presente en la Formación Talchir, Cuenca Rewa Gondwana (Chandra y Lele, 1980).

- Cisuraliano-Guadalupiano: Argentina: presente en la Formación Victoriano Rodríguez, biozonas Cristatisporites y Striatites, Cuenca Chacoparaná (Playford y Dino, 2002) Ilustrada para la Formación Yacimiento Los Reyunos, Cuenca Oriental (Césari et al., 1996). Brasil: presente en la Cuenca Maranhão (Bharadwaj et al., 1976); en la perforación 2-CS-1-PR, Chapéu do Sol, Cuenca Paraná (Quadros et al., 1996); en la Formación Rio Bonito (Días-Fabricio, 1981) y en el área de Trombudo Central (MarquesToigo et al., 1990).

Pakhapites ovatus (Bose y Kar) García 1996

Lámina XXV, figura D 
1966. Fusacolpites ovatus Bose y Kar; pp. 119-120, lám. XXVIII, figs. 13-14.

1996. Pakhapites ovatus (Bose y Kar) García; p. 19, lám. IV, fig. 4.

2000b. Pakhapites ovatus (Bose y Kar) Playford y Dino, p. 115, pl. 13, fig. 11.

Descripción. Grano de polen monocolpado, estriado, de contorno general oval a fusiforme, elongado en sentido longitudinal. Cara proximal dividida por finas estrías transversales, rectas a levemente curvadas hacia los extremos, que se extienden de un lado a otro del grano de forma subhorizontal a oblícua. Las estrías limitan de 8 a 10 tenias de 2 a $7 \mu \mathrm{m}$ de ancho. El colpo es angosto, de lados paralelos casi en contacto entre sí, que se bifurcan hacia los extremos.

Dimensiones (4 ejemplares). Diámetro ecuatorial, 23(29,5)37 $\mu \mathrm{m}$; diámetro polar, $30(38,5) 45 \mu \mathrm{m}$; ancho del colpo $1(6,6) 10 \mu \mathrm{m}$.

Principal material estudiado. BAPal 6152 (a) V57/1; BAPal 6162 (a) G64/1; BAPal 6165 (b) L49/0; BAPal 6187 (a) E58/0.

Comentarios. En este trabajo y siguiendo el criterio exhibido en Gutiérrez et al. (2006a, p. 627) se seguirá la enmienda realizada por García (1996) que es previa a la propuesta de Playford y Dino (2000b).

Registros previos. Esta especie fue descripta originalmente para la región Walikale, Pérmico de Congo, África (Bose y Kar, 1966).

- Pennsylvaniano-Cisuraliano: Brasil: presente en las formaciones Nova Olinda y Andirá, Grupo Trapajós, Cuenca Amazonas (Playford y Dino, 2000b).

- Cisuraliano: Argentina: presente en la Formación El Imperial, Cuenca San Rafael (García, 1996).

Uruguay: presente en la Formación San Gregorio, Cuenca Paraná (Gutiérrez et al., 2006b).

\section{Género Cycadopites Wodehouse 1933}

Especie tipo. Cycadopites follicularis Wilson y Webster, 1946.

Afinidad botánica. Probablemente Peltaspermaceas, Cycadales, Ginkgoales y Benetitales (véase Quadros et al., 1996).

Cycadopites crassimarginis (de Jersey) de Jersey 1964

Lámina XXV, figura $\mathrm{G}$

1960. Entylissa crassimarginis de Jersey; p. 9, pl. 2, figs. 15-16. 
Sinonima adicional. Véase de Jersey (1964).

Descripción. Grano de polen monocolpado, de contorno general oval a ahusado. Lados fuertemente convexos y ápices agudos. Colpo angosto, de hasta $1 / 3$ de ancho respecto del ancho del grano, de forma ahusada. Márgenes del colpo engrosados por repliegues de la exina de hasta $5 \mu \mathrm{m}$ de espesor. Exina gruesa, lisa y oscura.

Dimensiones (9 ejemplares). Diámetro ecuatorial, 20(25,7)32 $\mu \mathrm{m}$; diámetro polar, 30(38)49 $\mu \mathrm{m}$; ancho del colpo 2(6)8 $\mu \mathrm{m}$.

Principal material estudiado. BAPal 6146 (b) O64/0; BAPal 6152 (a) J68/0, M64/3, U52/1, E61/1; BAPal 6162 (a) E62/3, O62/0; BAPal 6166 (a) D43/2.

Comentarios. De Jersey (1964, pp. 10-11) combinó a la especie dentro del género Cycadopites por presentar similitud con Cycadopites follicularis. La especie se caracteriza por presentar engrosamientos en el contorno del colpo, de aproximadamente $3 \mu \mathrm{m}$. Zavattieri y Rojo (2005, p. 521) discuten el origen de esos engrosamientos y consideran que los mismos se deben a un repliegue del margen del colpo.

Los ejemplares observados en Cuenca Colorado, son similares a las formas asignadas como C. follicularis, pero presentan ese caracter, motivo por el cual se los asigna a $C$. crassimarginalis. Esta sería la cita más antigua de la especie.

Registros previos. Esta especie fue descripta por De Jersey (1960) para el Jurásico del Rosewood coalfield.

- Triásico: Argentina: presente en las formaciones Potrerillos y Cacheuta, Cuenca Cuyana (Zavattieri y Rojo, 2005). Australia: ilustrada para Esk Beds, Moreton Basin (de Jersey, 1972).

Cycadopites follicularis Wilson y Webster 1946

Lámina XXV, figura $\mathrm{H}$

Sinonimia. Véase Raine et al. (2006).

Descripción. Grano de polen monocolpado, de contorno general oval a ahusado, de lados convexos y extremos aguzados. La relación ancho/largo de 3:2. Colpo extendido a lo largo de todo el cuerpo, de ancho variable, generalmente angosto en el centro y extremos abiertos. Exina levigada, generalmente corroída. 


\section{Lámina XXIII}




\section{Lámina XXIII}

A y B. Vittatina corrugata Marques-Toigo 1974, BAPal 6169 (a) N40/3 (X 850); BAPal 6164 (a) J64/4 (X 850).

C. Vittatina costabilis Wilson 1962, BAPal 6152 (a) V62/0 (X 1000).

D. Vittatina fasciolata (Balme y Hennelly) Bharadwaj 1962, BAPal 6152 (a) P62/1 (X 800).

E y F. Vittatina subsaccata Samoilovich 1953, BAPal 6169 (a) E43/2 (X 850); BAPal 6148 (a)O62/1 (X 750).

G y H. Vittatina vittifera (Luber y Waltz) Samoilovich 1953, BAPal 6185 (b) S48/3 (X 700). 

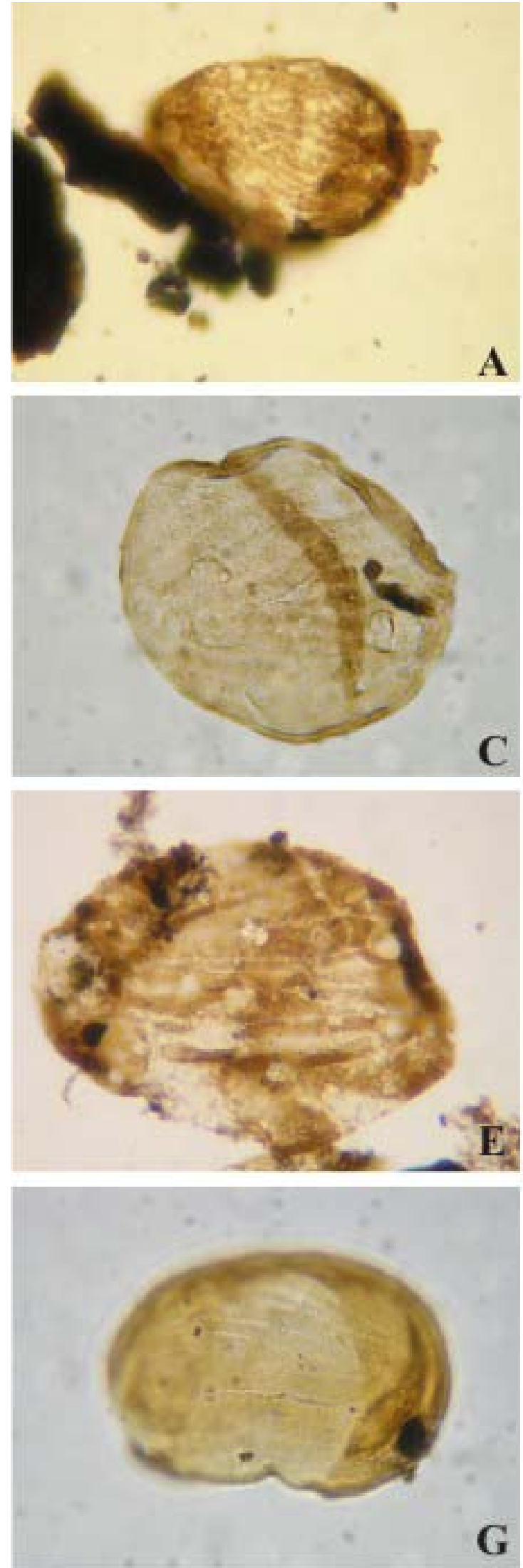
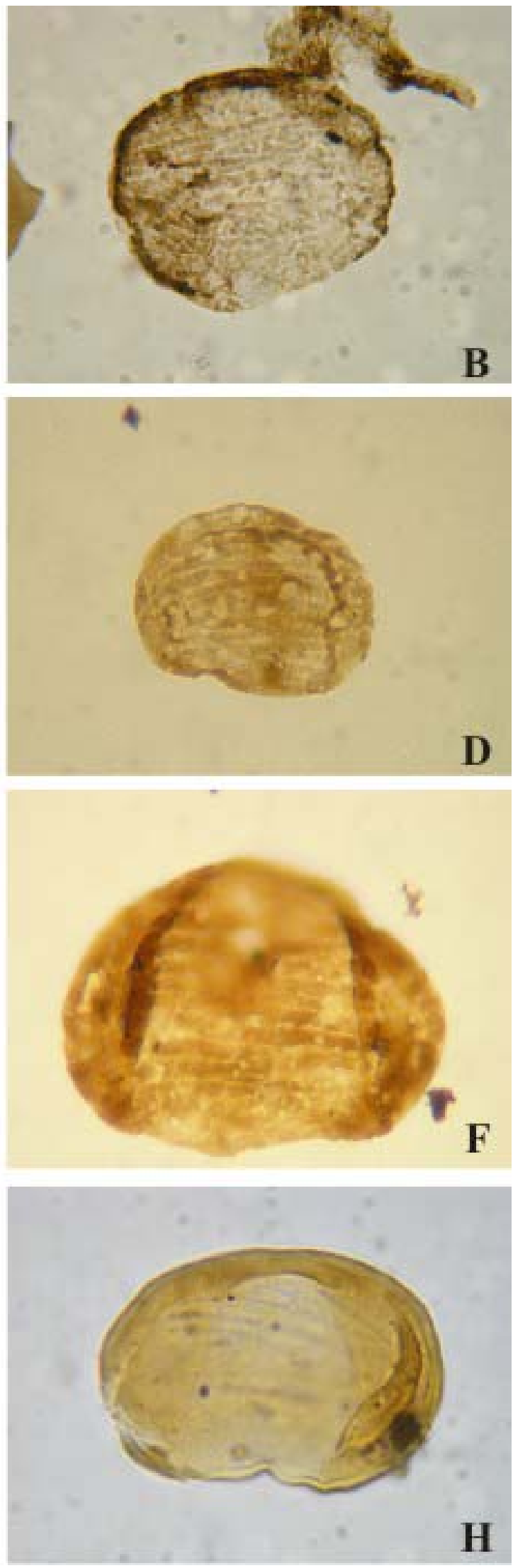
Lámina XXIV 


\section{Lámina XXIV}

A y B. Tiwarisporis anaverrucosus (Archangelsky y Gamerro) nov. comb., BAPal 6181 (a) $\mathrm{M} 59 / 0$ (X 850).

C. Tiwarisporis simplex (Tiwari) Maheshwari y Kar 1967, BAPal 6187 (a) S56/4 (X $350)$.

D y E. Tiwarisporis simplex (Tiwari) Maheshwari y Kar 1967, BAPal 6187 (a) S56/4 (X 1000).

F. Weylandites magmus (Bose y Kar) Backhouse 1991, BAPal T67/1 (X 850).

G y H. Weylandites lucifer (Bharadwaj y Salujha) Foster 1975, BAPal 6152 (a) E58/0 (X 800); BAPal 6189 (a) V34/0 (X 900). 

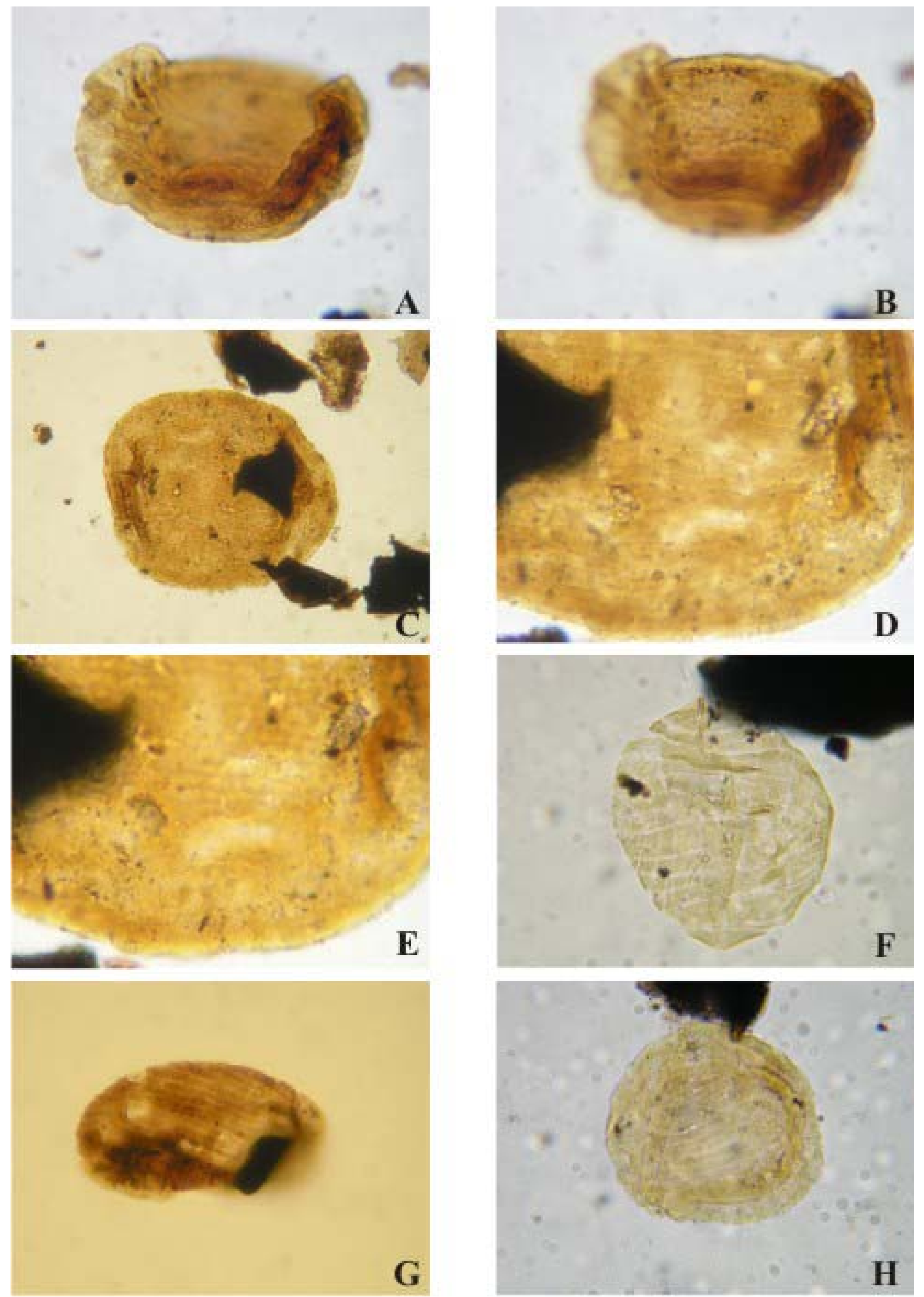
Lámina XXV 


\section{Lámina XXV}

A. Marsupipollenites striatus (Balme y Hennelly) Hart 1965, BAPal 6188 (a) F60/0 (X 850).

B. Marsupipollenites triradiatus Balme y Hennelly 1956b, BAPal 6152 (b) F51/1 (X 950).

C. Praecolpatites sinuosus (Balme y Hennelly) Bharadwaj y Srivastava 1969a, BAPal 6152 (a) M58/1 (X 1200).

D. Pakhapites ovatus (Bose y Kar) García 1996, BAPal 6165 (b) L49/0 (X 1200).

E y F. Pakhapites fusus (Bose y Kar) Menéndez 1971 BAPal 6186 (a)X64/2 (X 750); BAPal 6180 (a) Q66/4 (X 800).

G. Cycadopites crassimarginis (de Jersey) de Jersey 1964, BAPal 6166 (a) D43/2 (X 850).

H. Cycadopites follicularis Wilson y Webster 1946, BAPal 6152 (b) V70/0 (X 850). 

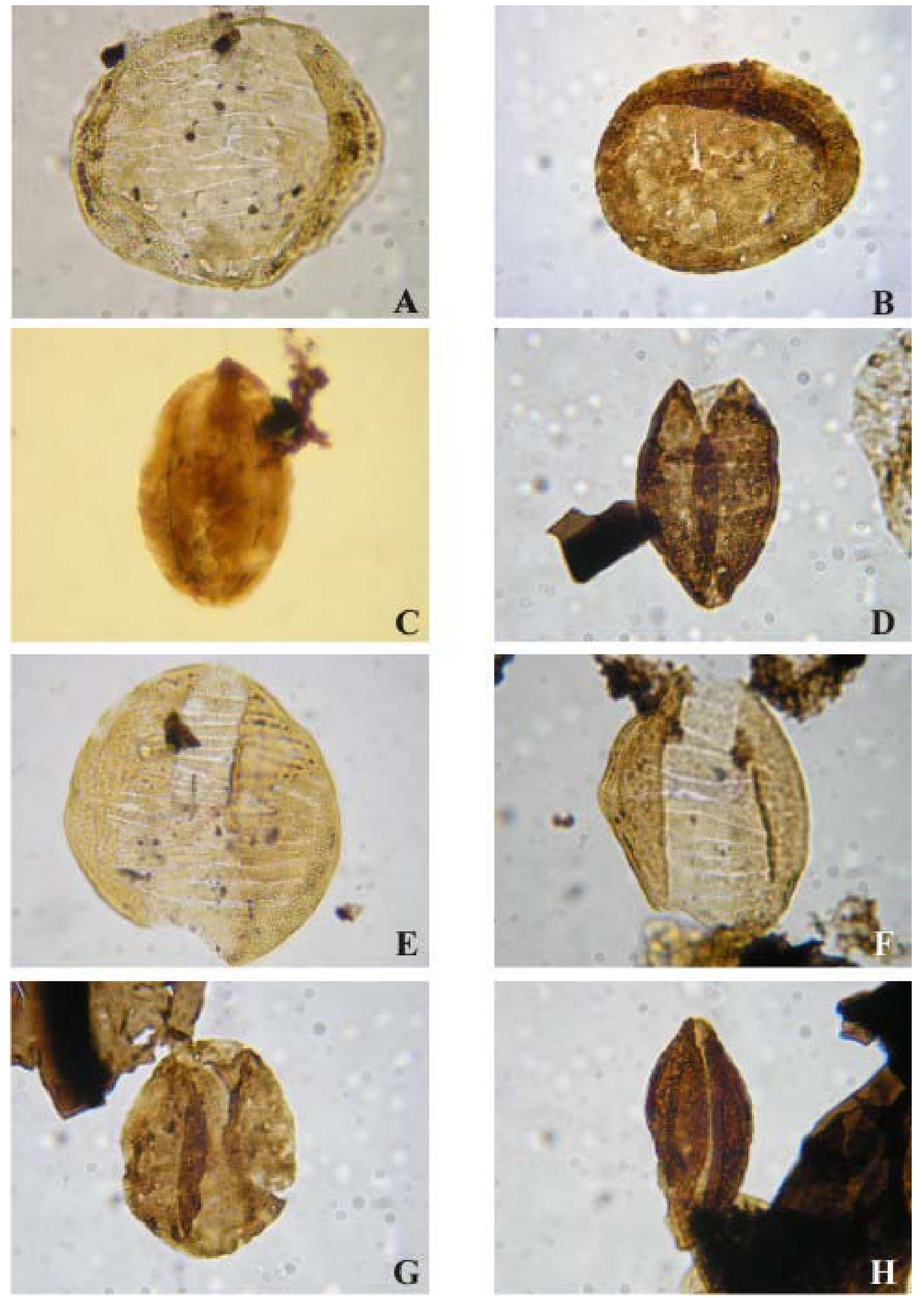
Dimensiones (18 ejemplares). Diámetro ecuatorial, 20(26,9)34 $\mu \mathrm{m}$; diámetro polar, $37(43,3) 55 \mu \mathrm{m}$; ancho del colpo 3(7,2)15 $\mu \mathrm{m}$.

Principal material estudiado. BAPal 6143 (a) L71/4; BAPal 6143 (b) H73/2; BAPal 6152 (a) D35/2, C41/1, H42/1, J54/0, W38/1, M71/3, N60/0; BAPal 6152 (b) V70/0; BAPal 6155 (a) W47/0; BAPal 6158 (b) W69/0; BAPal 6165 (a) O43/2, S70/1. Redepósito: BAPal 6136 (a) X69/0.

Registros previos. Cycadopites follicularis fue descripta por Wilson y Webster (1946, p. 274, pl. 1, fig. 7) para Fort Union coal, Montana.

- Pennsylvaniano-Cisuraliano: Argentina: presente en la Formación Tupe, Cuenca Paganzo (Césari, 1984). Brasil: presente en las formaciones Itaituba, Nova Olinda y Andirá, Grupo Trapajós, Cuenca Amazonas (Playford y Dino, 2000b).

- Cisuraliano: Australia: presente en Blair Athol Coal Measures (Foster, 1975). Arabia Saudita: mencionada para la Formación Khuff (Stephenson y Filatoff, 2000b, 2003).

Pakistán: presente en las Formación Amb, Grupo Zaluch (Balme, 1970).

- Guadalupiano: Australia: presente en Baralaba Coal Measures, Cuenca Bowen (Foster, 1979). Pakistán: presente en la Formación Wargar Limestone, Grupo Zaluch (Balme, 1970).

- Lopingiano: Antártida: ilustrada para Buckley, Transantarctic Mountains (Farabee et al., 1991).

- Lopingiano-Triásico Inferior: Australia: presente en la Formación Rewan, Cuenca Bowen (Foster, 1979). Pakistán: presente en la Formación Chhidru, Grupo Zaluch (Pérmico), y en las formaciones Mianwali y Tredian (Triásico) (Balme, 1970). Groenlandia: presente en Kap Stosch (Balme 1979). India: mencionada para Raniganj Coal Measures (Lopingiano) y la Formación Maitur, Grupo Panchet (Triásico Inferior) (Rana y Tiwari, 1980). Australia: ilustrada para la Cuenca Sydney (Helby, 1973).

- Triásico: Argentina: presente en la Formación Potrerillos (Zavattieri, 1987) e ilustrada para las formaciones Las Cabras (Zavattieri, 1990, 1991a) y Los Rastros (Ottone et al., 2005), todas de Cuenca Cuyana. Australia: ilustrada para Esk Beds, Cuenca Moreton (de Jersey, 1972). Antártida: presente en la Formación Falla, Central Transactartic Mountains (Farabee et al., 1989). 
Grupo ACRITARCHA Evitt 1963

Subgrupo ACANTHOMORPHITAE Downie, Evitt y Sarjeant 1963

Género Buedingiisphaeridium Schaarschmidt 1963

Especie tipo. Buedingiisphaeridium permicum Schaarschmidt 1963.

Buedingiisphaeridium permicum Schaarschmidt 1963

Lámina XXVI, figuras A y B

1998a. Micrhystridium sp. cf. M. teichertii Sarjeant, Mautino et al., p. 312; lám. III, fig. Q.

Descripción. Vesícula subcircular a subpoligonal, de contorno irregular dado por la compresión. Línea ecuatorial lisa, con 8 a 12 elementos ornamentales proyectados. Pared gruesa e hialina, de hasta $2 \mu \mathrm{m}$ de ancho, ornamentada con aproximadamente 20 elementos verrucosos a cónicos, macizos, de 1 a $2 \mu \mathrm{m}$ de diámetro de sus bases de contorno irregular y de hasta $3 \mu \mathrm{m}$ de alto, dispuestos espaciadamente. Pliegues irregulares semilunares a rectos, formados por la compresión de la vesícula, ubicados hacia los márgenes.

Dimensiones (34 ejemplares). Diámetro de la vesícula, 15(20,5)25 $\mu \mathrm{m}$; procesos, ancho $1(1,6) 2,5 \mu \mathrm{m}$ y $1(1,8) 3 \mu \mathrm{m}$ de largo.

Principal material estudiado. BAPal 6152 (a) F61/0, G63/1, G39/4, H47/2, J52/4, M62/2, N62/0, R70/2, S69/0, T57/2, U36/4, V53/2, W46/3, X58/1.

Discusión y comparaciones. El género Buedingiisphaeridium fue propuesto originalmente por Schaarsmidt (1963) para incluír a vesículas con paredes ornamentadas con numerosos procesos cónicos, dispuestos de manera dispersa. Sarjeant y Stancliffe (1994, p. 24) al enmendar la diagnosis, incluyen formas ornamentadas con numerosas verrugas bajas o tuberculos cónicos, cerrados en la punta, a menudo con engrosamientos o sólidos, a veces huecos, o en parte, y con cavidades comunicadas con el interior de la vesícula. De las especies conocidas para Buedingiisphaeridium, referimos el material de la Cuenca Claromecó-Colorado a B. permicum Schaarsmidt (1963) por sus dimensiones generales (diámetro de la vesícula, entre 15 y $25 \mu \mathrm{m}$ ) y por la cantidad de procesos ornamentales que se proyectan sobre su contorno (20). 
Se diferencia de B. triassicum (Jansonius) Staplin et al. (1965) porque esta presenta una vesícula de $12 \mu \mathrm{m}$ de diámetro, ornamentación compuesta por gránulos, verrugas y conos, de pequeño tamaño y forma irregular, que se proyectan sobre el contorno en un número mayor (entre 20 y 50). Micrhystridium microspinosum Schaarsmidt (1963) se diferencia por presentar un diámetro menor $(14-16 \mu \mathrm{m})$, de pared más delgada y una ornamentación conformada por espinas, sólidas o huecas, de desarrollo variable.

Por otra parte el material referido a Micrhystridium sp. cf. M. teichertii Sarjeant por Mautino et al. (1998b, p. 312, lám. III, fig. Q) es incluida en B. permicum, por el tipo y tamaño de la escultura (apéndices romos, fuertes y de base amplia) y las dimensiones generales. Este tipo de escultura caracteriza al género Buedingiisphaeridium, mientras que las espinas a género Micrhystridium.

Registros previos. Buedingiisphaeridium permicum fue descripta por Schaarschmidt (1963) para Franconian bay, Zechstein, Lopingiano de Alemania.

- Cisuraliano-Guadalupiano: Uruguay: presente en la Formación Melo, Cuenca Paraná (Mautino et al., 1998b).

Esta es la primera cita de la especie para la Argentina.

Género Circulisporites de Jersey emend. Norris 1965

Especie tipo. Circulisporites parvus de Jersey, 1962.

Circulisporites parvus de Jersey 1962

Lámina XXVI, figuras C y D

Descripción. Microfosil subcircular a elipsoidal, de contorno irregular por compresión del cuerpo. Pared delgada hialina, menos de $1 \mu \mathrm{m}$ de ancho, con numerosas estrías ecuatoriales continuas (más de 6). El cuerpo generalmente se halla comprimido, pudiendo observarse pliegues sobre el ecuador, por lo que las estrías no pueden observarse en todo el recorrido.

Dimensiones (4 ejemplares). Diámetro de la vesícula, 23(28,3)33 $\mu \mathrm{m}$.

Principal material estudiado. BAPal 6138 (a) C45/0, O69/4; BAPal 6138 (c) P70/0. Redepósito: BAPal 6176 (a) F44/0. 
Comentarios. Características diagnósticas presentes en el material aquí estudiado tales como la forma general subcircular a elipsoidal, la pared delgada hialina y las numerosas estrías ecuatoriales continuas permiten asignarlos a la especie Circulisporites parvus sin duda.

Registros previos. Circulisporites parvus fue descripta originalmente por de Jersey (1962) para el Triásico Medio-Superior de Ipswich Coalfield, Australia.

- Cisuraliano: Australia: presente en la Cuenca Collie (Backhouse, 1991) e ilustrada para Blair Athol Coal Measures (Foster 1979). Antártida: mencionada para Vestfjella, Dronning Maud Land (Lindström, 1996). India: presente en Singrauli Coalfield, Barakar Stage (Sinha, 1969). Sudáfrica: presente en la Cuenca Karoo (Anderson, 1977).

- Guadalupiano: Australia: ilustrada para Baralaba Coal Measures, Cuenca Bowen (Foster 1979).

- Triásico: Antártida: presente en las formaciones Fremouw y Falla, Grupo Victoria (Norris, 1965; Kyle y Fasola, 1978).

Esta es la primera cita de la especie para cuencas sudamericanas.

Género Micrhystridium Deflandre emend. Sarjeant y Stancliffe 1994

Especie tipo. Micrhystridium insconspiccum Deflandre emend. Deflandre y Sarjent, 1970.

Micrhystridium fragile Deflandre 1947

Lámina XXVI, figuras E y F

1987. Micrhystridium sp. Cazzulo-Klepzig y Días Fabricio, estampa I, fig. 7.

1981. Micrhystridium tipo 3 Marques-Toigo, Días Fabricio y Mendes Piccoli, estampa 1 ,

figs 6-8.

2002. Micrhystridium toigae Quadros, p. 45, estampa 3, figs. 21-24.

Descripción. Vesícula subpoligonal a subcircular. La pared es delgada, menor al micrón de ancho, con numerosos e irregulares pliegues producto de la compresión del cuerpo. De 12 a 15 procesos regularmente distribuídos, proyectados desde el contorno, de bases 
angostas, curvados, quebrados y plegados. Los mismos tienen una extensión de hasta ancho del radio de la vesícula.

Dimensiones (10 ejemplares). Diámetro mayor de la vesícula, 15(18,5)22 $\mu \mathrm{m}$; diámetro menor de la vesícula, $11(15,8) 20 \mu \mathrm{m}$; procesos, base $1(1,6) 2 \mu \mathrm{m}$ y $3(5,9) 9 \mu \mathrm{m}$ de largo.

Principal material estudiado. BAPal 6149 (a) H48/2, BAPal 6149 (b) H47/1; BAPal 6152 (a) B39/2, G73/1, H58/1, O69/0, U57/0; BAPal 6162 (a) F46/2; BAPal 6165 (a) $\mathrm{V} 50 / 0$.

Observaciones. En los ejemplares aquí estudiados se ha observado una variación en la formas de las vesículas, desde poligonales a subcirculares; en las primeras dicha forma sería generada por las anchas bases de los procesos ornamentales que al aproximarse entre sí por compresión generan lados rectos; meintras que las formas subcirculares dominan entre los ejemplares que exhiben procesos con bases menores.

Comparaciones. Si bien Micrhystridium fragile es una especie característica del Jurásico Medio (Deflandre, 1947; Valensi, 1953; Fensome et al., 1990), Jansonius (1962) describió e ilustró ejemplares comparables con dicha especie pertenecientes a las formaciones Toad y Grayling, de Peace River, del Triásico de Canadá. Los ejemplares asignados por Jansonius presentan un número mayor de procesos (alrededor de 30) comparado con el número que presenta el material tipo (según la diagnósis entre 8 y 15 procesos, raramente 30). Los ejemplares de Cuenca Claromecó-Colorado coinciden en todas las características con los descriptos por Jansonius (1962, pp. 85-86, pl. 16, fig. 64, text-fig. 3-e), en especial el tamaño y la forma del quiste, el número, la forma y los tamaños de los procesos. Entendemos que el material aquí descripto así como el de Jansonius (1962) pueden ser incluidos en M. fragile porque están comprendidos por su diagnosis.

Considerando los rangos de tamaño de la vesícula (diámetro, 13-20 $\mu \mathrm{m}$ ), el número de procesos y sus dimensiones (entre 20 a 30 procesos, de 1,5 a $4 \mu \mathrm{m}$ de base y 10 a $20 \mu \mathrm{m}$ de largo) que presenta M. toigae Quadros (2002), propuesta para la Formación Palermo, Guadalupiano de la Cuenca Paraná, debería incluirse en M. fragile.

Registros previos. Micrhystridium fragile fue descripto por Deflandre (1947) para el Jurásico Medio de Francia.

- Cisuraliano-Guadalupiano: Uruguay: presente en la Formación Melo, Cuenca Paraná (Mautino et al., 1998b). Brasil: ilustrada para las formaciones Rio Bonito (Marques- 
Toigo et al., 1981) y Palermo (Cazzulo-Klepzig y Dias Fabrício, 1987; Quadros 2002), Cuenca Paraná.

Esta es la primera cita de la especie para la Argentina.

\author{
Micrhystridium sp. cf. M. ? sp. B Foster 1979 \\ Lámina XXVI, figuras $\mathrm{G}$ y $\mathrm{H}$
}

Descripción. Vesícula hueca, de contorno subcircular irregular, debido a hallarse plegada. Pared formada por 2 capas. Capa interna de 1 a 1,5 $\mu \mathrm{m}$ de espesor, levigada. Capa externa delgada, hialina, con procesos pequeños y filiformes, de ápices redondeados. Las bases, levemente más anchas que los procesos, se contactan entre sí. La vesícula presenta pliegues irregulares y concéntricos dados por la compresión. No se observa abertura, sino ruptura de desenquistamiento.

Dimensiones ( 1 ejemplar). Diámetro mayor de la vesícula, $60 \mu \mathrm{m}$; diámetro menor de la vesícula, $46 \mu \mathrm{m}$; procesos, base de $1 \mu \mathrm{m}$ y 2-5 $\mu \mathrm{m}$ de largo.

Principal material estudiado. BAPal 6138 (b) K51/4.

Comparaciones. Los ejemplares de Cuenca Colorado han sido comparados con las ilustraciones realizadas por Foster (1979, p. 110, pl. 40, figs. 2, 3). El rango de diámetros observados en dicho trabajo oscila entre 30(32)38 $\mu \mathrm{m}$, y entre 60 y $46 \mu \mathrm{m}$ en los primeros. Por haberse hallado un solo ejemplar y además diferir en el tamaño, se asigna con dudas a la especie.

Género Mehlisphaeridium Segroves 1967

Especie tipo. Mehlisphaeridium fibratum Segroves, 1967.

Mehlisphaeridium fibratum Segroves 1967

Lámina XXVII, figura A

Descripción. Vesícula subcircular a oval, deformada por ruptura. Pared lisa, dividida en 2 capas. Capa interna densa y oscura, de $1 \mu \mathrm{m}$ de ancho. Capa externa delgada y clara, proyectada conformando procesos cónicos, de bases anchas, lados rectos y ápices agudos a levemente redondeados. Los mismos generan crestas longitudinales por 
plegamiento. Sus bases se contactan en la mayoría de los casos. La vesícula puede hallarse rota irregularmente.

Dimensiones (1 ejemplar). Diámetro mayor de la vesícula, $30 \mu \mathrm{m}$; diámetro menor de la vesícula, $27 \mu \mathrm{m}$; procesos, base de 2-4 $\mu \mathrm{m}$ y 3-5 $\mu \mathrm{m}$ de largo.

Principal material estudiado. BAPal 6143 (b) M40/0.

Comentarios. Si bien se ha hallado un solo ejemplar, la asignación específica se puede realizar por presentar todos los caracteres diagnósticos de la especie Mehlisphaeridium fibratum: forma y tamaño de vesícula y procesos.

Registros previos. Mehlisphaeridium fibratum fue descripta por Segroves (1967) para el Cisuraliano de la Formación Carynginia (Artinskiano: Cisuraliano), Cuenca Perth, Australia.

- Cisuraliano: Australia: presente en la Cuenca Collie (Backhouse, 1991) e ilustrada para Back Alley Shale y Baralaba Coal Measures (Foster 1979). Mencionada para la Formación Carynginia, Cuenca Perth y en el Artinskiano de la Cuenca Bowen (Rigby y Heckel, 1977). Sudáfrica: presente en las zonas Microflorales 3b a 5a, Cuenca Karoo (Anderson, 1977).

- Guadalupiano: Australia: ilustrada para la Formación Bandanna, Springsure Anticline (Rigby y Hekel, 1977) y Baralaba Coal Measures, Cuenca Bowen (Foster 1979).

Esta es la primera cita de la especie para cuencas sudamericanas.

Mehlisphaeridium regulare Anderson 1977

Lámina XXVII, figuras C y D

Descripción. Vesícula circular, pequeña, pared oscura, de 1,2 a $3 \mu \mathrm{m}$ de ancho. Ornamentación compuesta por procesos cortos y romos. Algunos elementos pueden fusionarse por sus bases, y se proyectan sobre por sobre el contorno de la vesícula. Se disponen de manera densa e irregular, con lo que quedan áreas de la vesícula descubiertas.

Dimensiones (4 ejemplares). Diámetro de la vesícula con la ornamentación, 30(34)39 $\mu \mathrm{m}$; diámetro de la vesícula sin la ornamentación, 21(25,9)29 $\mu \mathrm{m}$; procesos, base de $1(2,5) 4 \mu \mathrm{m}$ у $2(3,2) 5 \mu \mathrm{m}$ de largo. 
Principal material estudiado. BAPal 6182 (a) J65/1; BAPal 6185 (a) O38/0; BAPal 6187 (a) Q60/0; BAPal 6188 (a) L46/0.

Comentarios. Características diagnósticas de la especie Mehlisphaeridium regulae tales como la forma circular de la vesícula y la ornamentación compuesta por cortos procesos despuestos densa e irregularmente, permiten la asignación específica de los ejemplares aquí estudiados sin dudas.

Registros previos. Mehlisphaeridium regulare fue descripta por Anderson (1977) para el Pérmico de la Cuenca Karroo, Sudáfrica.

- Cisuraliano: Australia: presente en la Cuenca Collie (Backhouse, 1991); en la Formación Fossil Cliff Member, Cuenca Perth (Foster et al., 1985) y en el Grupo Grant, Cuenca Canning (Foster y Waterhouse, 1988). Sudáfrica: presente en las zonas Microflorales 2a a 5b, Cuenca Karoo (Anderson, 1977).

- Cisuraliano-Guadalupiano: Papúa: ilustrada para las formaciones Ainim y Aiduna (Playford y Rigby, 2008).

Esta es la primera cita de la especie para cuencas sudamericanas.

\section{Grupo FUNGI}

Género Reduviasporonites Wilson 1962 emend. Foster et al., 2002

Especie tipo. Reduviasporonites catenulatus Wilson, 1962b.

\section{Reduviasporonites chalastus (Foster) Elsik 1999}

Lámina XXVII, figura E, F, G y H

1979. Chordecystia chalasta Foster, pp. 109-110, pl. 41, figs. 3-9; text-figs. 22.

Sinonimia adicional. Véase Foster et al. (2002).

Descripción. Microfosil compuesto por células agregadas en forma de cadena, aunque pueden hallase también de manera aislada. Contorno de las células de forma variada, desde formas rectangulares de lados rectos $\mathrm{y}$ esquinas redondeadas a formas subcirculares. Las células se hallan completas, rara vez rotas. La pared es simple, menor al micrón de ancho, levigada, finamente foveada, debido a la corrosión. Pliegues 
irregulares formados por compresión de la célula, paralelos a los lados en el caso de formas rectangulares y concéntricos en las formas circulares.

Dimensiones (4 ejemplares en cadena). Largo de cada elemento, 32(65,5)118 $\mu \mathrm{m}$; ancho de cada elemento, 24(41,6)51 $\mu \mathrm{m}$.

Principal material estudiado. BAPal 6143 (a) G56/0; BAPal 6143 (b) W40/0; BAPal 6145 (a) G36/3. Redepósito: BAPal 6172 (a) O58/0.

Registros previos. Descripta originalmente para la Formación Rewan (Foster 1979) presenta un amplio registro para fines del Paleozoico y el Triásico Inferior.

- Pennsylvaniano: Perú: Wood y Elsik (1999).

- Guadalupiano-Lopingiano: Omán y Arabia Saudita: ilustrada para la Formación Ghariff (Stephenson et al., 2003).

- Lopingiano: Argentina: mencionada para la Formación La Veteada, Cuenca Paganzo (Zavattieri et al., 2008). Australia: presente en la Formación Rewan, Cuenca Bowen (Foster, 1979); mencionada para Billawock, Cuenca Bonaparte (Helby, 1992). Estados Unidos: presente en la Formación Flowerpot, Oklahoma (Wilson, 1962a; Morgan, 1967; Clapham, 1970). Arabia Saudita y Oman: Formación Khuff (Stephenson y Filatoff, 2000a).

- Lopingiano-Triásico Inferior: China: mencionada para la Formación Guodikeng, Cuenca Junggar (Li et al., 1986). Rusia: presente en las Series Vetlugian (Lozovskiy, 1992), Krassilov et al. (1999). Groenlandia: Kap Stosch. Inglaterra: Conisborough y Hilton Plant Beds. Arabia Saudita: presente en "Basal Khuff clastics" (Stephenson et al., 2003).

Para mayor información acerca de los registros previos véase Eshet et al. (1995), Visscher et al. (1996), Wood y Elsik (1999) y Foster et al. (2002). 


\section{Lámina XXVI}




\section{Lámina XXVI}

A y B. Buedingiisphaeridium permicum Schaarschmidt 1963, BAPal 6152 (a) U56/3 (X 750); N54/2 (X 750).

C y D. Circulisporites parvus de Jersey 1962, BAPal 6138 (a) C45/0 (27 $\mu \mathrm{m})$; BAPal 6176 (a) F44/0 (X 700).

E y F. Micrhystridium fragile Deflandre 1947, BAPal 6152 (a) G73/1 (15 $\mu \mathrm{m})$; BAPal 6149 (a) H48/2 (X 1000).

G y H. Micrhystridium sp. cf. M. ? sp. B Foster 1979, BAPal 6138(b) K51/4 (X 700). 

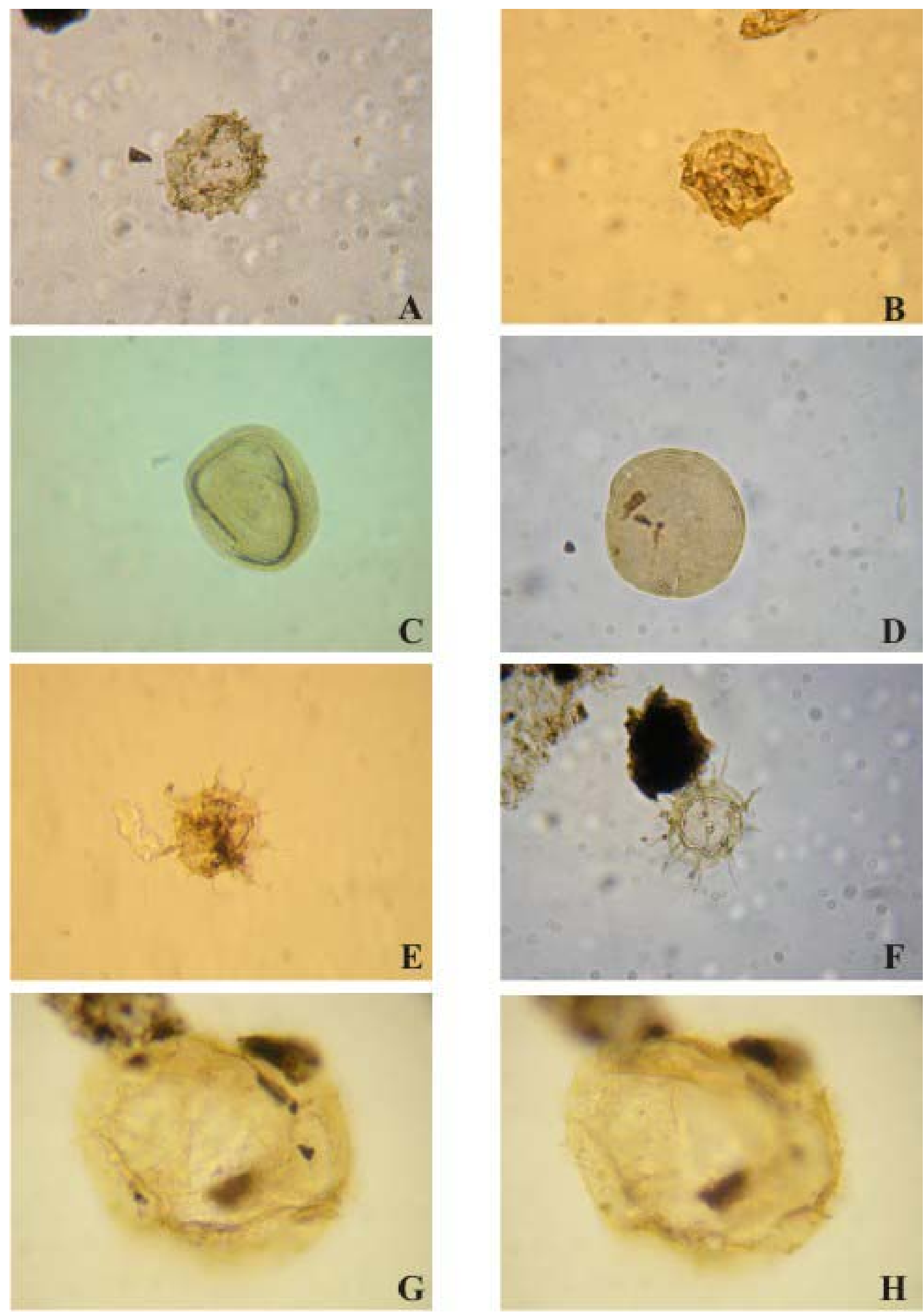


\section{Lámina XXVII}

A. Mehlisphaeridium fibratum Segroves 1967, BAPal 6143(b) M40/0 (X 950).

B. Mehlisphaeridium regulae Anderson 1977, BAPal 6188 (a) L46/0 (X 900).

C y D. Mehlisphaeridium regulae Anderson 1977, BAPal 6185 (a) O38/0 (X 1000).

E y G. Reduviasporonites chalastus (Foster) Elsik 1999, BAPal 6145 (a) G36/3 (X 500); BAPal 6143 (a) G56/0 (X 550).

F y H. Reduviasporonites chalastus (Foster) Elsik 1999, BAPal 6143 (b) W40/0 (X 750); BAPal 6172 (a) O58/0 (X 900). 

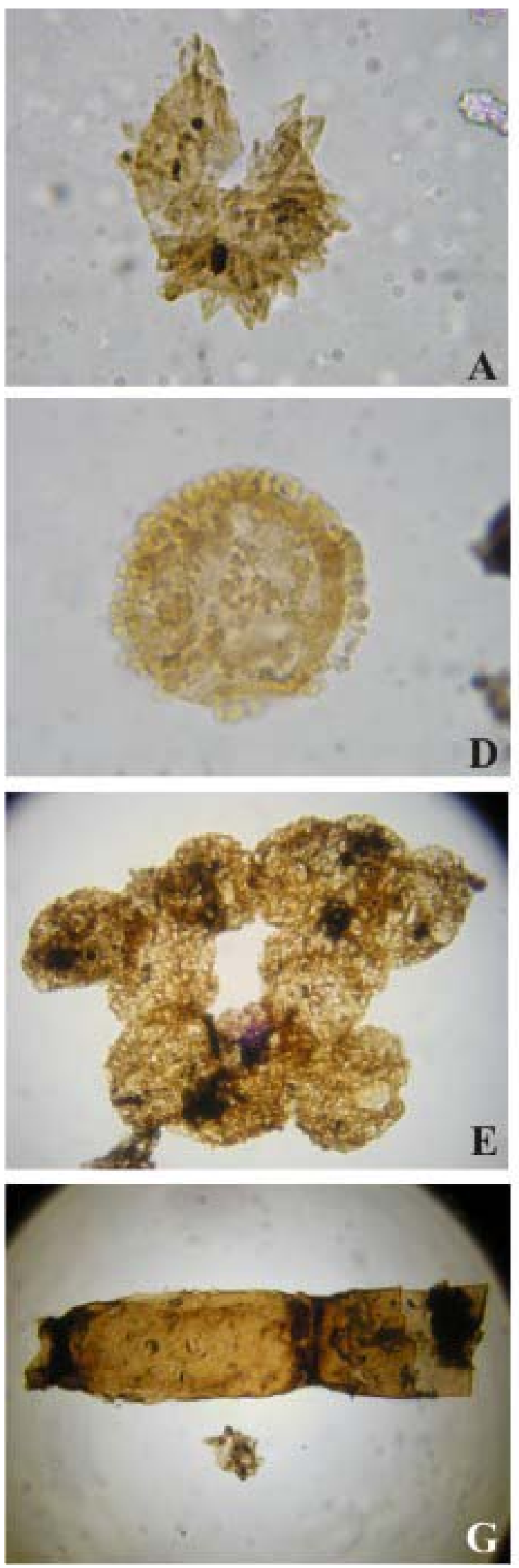
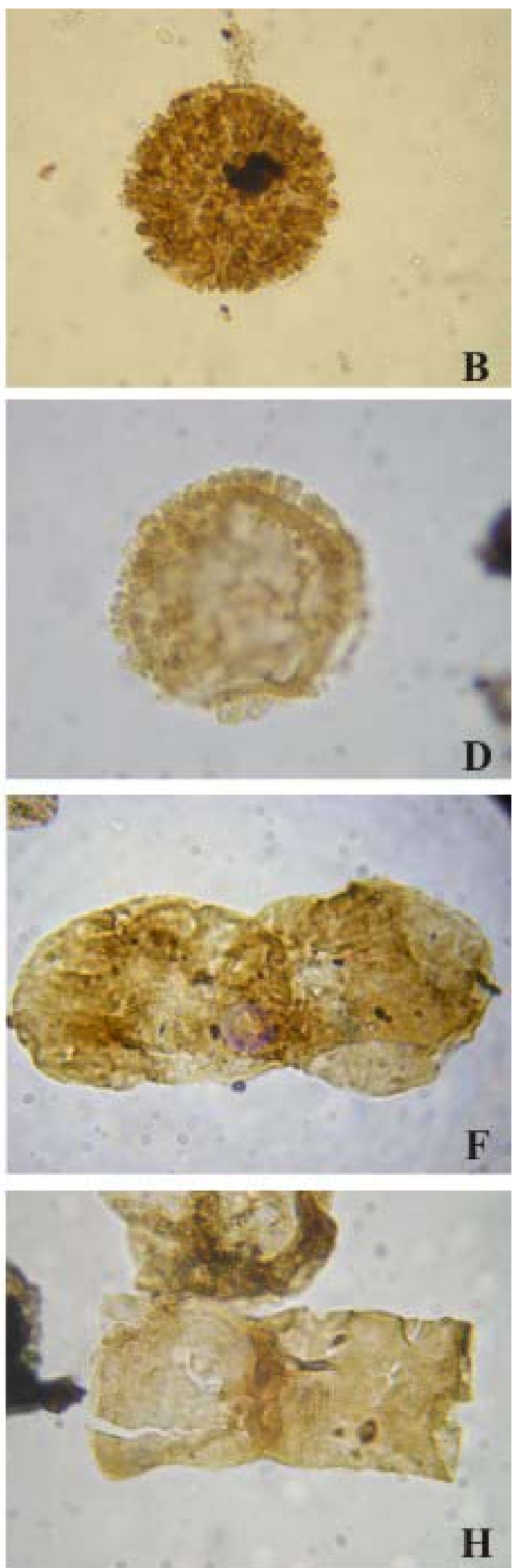


\section{V.2. Retrabajo}

En ambas perforaciones se ha identificado material pérmico retrabajado en sedimentitas mesozoicas, que se superponen al Grupo Pillahuincó, en especial entre 3995 y los 2900 mbnm, en la perforación Cruz del Sur x-1 y entre 2988 y los 2940 mbnm en la perforación La Estrella x-1. Este aspecto fue previamente resaltado, entre otros, por Schümann (2004, p. 1), en especial en la perforación Cruz del Sur x-1.

El redepósito incluye fundamentalmente (véase Figuras 12 y 13) formas que presentan registros en las sedimentitas referidas al Grupo Pillahuincó en ambas perforaciones. Estas formas han sido incluidas en las descripciones sistemáticas del material autóctono.

Un segundo grupo lo conforman un pequeño número de palinomorfos que no muestran registros en las sedimentitas pérmicas infrayacentes. Este grupo también ha sido descripto e ilustrado, y se presenta a continuación.

\section{V.2.1. Diatomozonotriletes townrowii Segroves 1970 (Lámina XXVIII, figura A)}

Descripción. Espora radial trilete, de contorno triangular, de lados rectos a levemente convexos y ápices redondeados. Margen liso, con la ornamentación proyectada en algunas partes. Lesura simple, de rayos rectos, extendidos hasta el margen ecuatorial. Cara proximal plana y levigada. Cara distal piramidal, ornamentada por gránulos de base circular y disposición espaciada, menores al micrón de diámetro. Zonas interradiales con hileras de más de 20 báculas filiformes, próximas al margen ecuatorial, de $0,5 \mu \mathrm{m}$ de ancho basal y hasta 3 $\mu \mathrm{m}$ de alto, con ápice redondeado o trunco. La altura de las báculas disminuye levemente hacia los ápices. Exina delgada, menor al micrón de espesor.

Dimensiones ( 1 ejemplar). Diámetro ecuatorial, $39 \mu \mathrm{m}$; espesor de la exina, 0,5$1 \mu \mathrm{m}$.

\section{Principal material estudiado. BAPal 6172 (a) S49/2.}

Registros previos. Diatomozonotriletes townrowii fue descripta originalmente por Segroves (1970) para la Formación Fossil Cliff, Cuenca Perth, Cisuraliano de Australia. Cisuraliano: Australia: ilustrada para la Formación Stockton y Collie Coal Measures, Cuenca Collie (Backhouse, 1991). CisuralianoGuadalupiano: Uruguay: descripta para la Formación Melo, Cuenca Paraná 
(Mautino et al., 1998a). A pesar de ser material redepositado esta constituye la primera cita para la Arentina.

\section{V.2.2. Lundbladispora sp. A (Lámina XXVIII, figura B)}

Descripción. Espora radial trilete cingulicavada, de contorno subcircular a subcircular. Margen liso y levemente irregular por proyección de la ornamentación. Lesura bien definida, de rayos rectos extendidos hasta el borde interno del cíngulo, con labios delgados. Exina dividida en dos capas, generándose entre ambas capas un cavum claramente distinguible. Intexina bien definida, de contorno similar al contorno general de la espora, exoexina ornamentada en cara distal y borde ecuatorial, con verrugas, gránulos y en menor medida conos densamente distribuidos, que coalescen por sus bases frecuentemente. Los elementos ornamentales miden de 1 a 1,5 $\mu \mathrm{m}$ de diámetro basal. Cara distal fuertemente convexa.

Dimensiones ( 1 ejemplar). Diámetro ecuatorial, $51 \mu \mathrm{m}$; diámetro del cuerpo, 42 $\mu \mathrm{m}$; ornamentación, $1-1,5 \mu \mathrm{m}$ de ancho basal y menores a $1 \mu \mathrm{m}$ de altura; intexina $1 \mu \mathrm{m}$ de espesor.

Principal material estudiado. BAPal 6180 (a) J53/1.

Comentarios. El ejemplar estudiado presenta una marcada similitud con los ejemplares asignados a Lundbladispora? sp. A asignados por Foster (1979, p. 54, pl. 13, fig. 8), en especial por el tipo y distribución de la ornamentación (verrugas, granos y en menor medida conos, dispuestos densamente en la exoexina), por ser una espora cingulicavada (pared exinal separada sobre el ecuador en dos capas: exoexina e intexina, formando un marcado cavum) y su contorno subcircular. Una mayor precisión en la asignación específica se ve dificultada por haber observado un solo ejemplar.

Lundbladispora sp. A se diferencia de Lundbladispora brevicula Balme (1963, pp. 23-24, pl. 4, figs. 8-9) por presentar una escultura de menor dimensión y más densamente dispuesta.

V.2.3. Thymospora cicatricosa (Balme y Hennelly) Hart 1965 (Lámina XXVIII, figura C) 
1956b. Verrucosisporites cicatricosus Balme y Hennelly, p. 57, pl. 1, figs. 1418. Sinonimia adicional. Véase Foster (1979).

Descripción. Espora bilateral monolete, de contorno general subcircular a oval y de margen ondulado por proyección de la ornamentación. Lesura simple, bien definida, de hasta $2 / 3$ de extensión respecto del radio ecuatorial mayor. Cara proximal levigada, cara distal ornamentada por verrugas-rugulas, conformando un retículo denso y oscuro. Entre los elementos ornamentales se generan áreas poligonales levigadas. Exina de 2 a $5 \mu \mathrm{m}$ de espesor.

Dimensiones ( 1 ejemplar). Diámetro mayor, $35 \mu \mathrm{m}$; diámetro menor, $22 \mu \mathrm{m}$; ornamentación, $4 \mu \mathrm{m}$ de ancho basal y hasta $2 \mu \mathrm{m}$ de alto.

Principal material estudiado. BAPal 6170 (a) R53/0.

Comentarios. La naturaleza de la ornamentación asì como las dimensiones que presenta el ejemplar aquí estudiado permiten referirlo a Thymospora cicatricosa (Balme y Hennelly) Hart (1965, p. 57, pl. 1, figs. 14-18).

Registros previos. Thymospora cicatricosa (Balme y Hennelly) Hart fue descripta originalmente para Greta Seam, Hebburn No. 2, Newcastle Stage, Pérmico de Australia (Balme y Hennelly, 1956b). Guadalupiano: Australia: ilustrada para Baralaba Coal Measures, Cuenca Bowen (Foster, 1979). Lopingiano-Triásico Inferior: Australia: ilustrada la Formación Rewan, Cuenca Bowen (Foster, 1979). Esta es la primera cita de la especie para Argentina.

\section{V.2.4. Potonieisporites magnus Lele y Karim 1971 (Lámina XXVIII, figura D)}

Descripción. Grano de polen monosacado, de simetría bilateral, de contorno general ovalado. Cuerpo central subcircular a oval longitudinal, marca monolete a dilete proximal. Cara distal con 2 pliegues ahusados, semilunares, que se contactan en los extremos del cuerpo y que delimitan un área libre distal suboval a subrectangular en sentido transversal. Saco de adherencia proximal ecuatorial y distal subecuatorial. Raíces dispuestas radialmente. Sexina del saco infrareticulada, conformando muros irregulares en forma y ancho que delimitan lúminas irregulares. 
Dimensiones ( 1 ejemplar). Ancho total, $79 \mu \mathrm{m}$; cuerpo central, ancho $56 \mu \mathrm{m}$ y $53 \mu \mathrm{m}$ de largo; ancho del saco sobre cara proximal, $13 \mu \mathrm{m}$; ancho del saco sobre cara distal, $28 \mu \mathrm{m}$; ancho de pliegues $2-4 \mu \mathrm{m}$.

Principal material estudiado. BAPal 6178 (a) D56/4.

Registros previos. Potonieisporites magnus fue descripta por Lelé y Karim (1971) para Patharjore Nala, Jayanti Coalfield, Bihar, India. Pennsylvaniano: Argentina: presente en las formaciones Agua Colorada (Gutiérrez 1993) y Guandacol (Ottone y Azcuy, 1989), Cuenca Paganzo; y en la Formación San Telmo, Cuenca Tarija (Azcuy y di Pasquo, 2000). Brasil: mencionada para el Subgrupo Itararé, Cuenca Paraná (Souza et al., 2003). Perú: ilustrada para la Formación Tarma, Pongo de Mainique (Azcuy et al., 2002). Cisuraliano: Argentina: presente en la Formación Bajo de Véliz, Cuenca Paganzo (Gutiérrez y Césari, 2000).

V.2.5. Lueckisporites sp. cf. L. stenotaeniatus Menéndez 1976 (Lámina XXVIII, figura E)

Descripción. Grano de polen bisacado, teniado, de contorno fuertemente diploxilonoide, ovalmente elongado en sentido trasversal. Cuerpo central oval transversal. Capa dividida en 2 tenias transversales, de 1/4 de largo respecto del largo total del cuerpo, curvadas y extendidas sin alcanzar la línea ecuatorial. Cápula subrectangular, de lados longitudianes cóncavos, de 14-15 $\mu \mathrm{m}$ de ancho. Sacos mayores a 1/2 círculo, de inserción proxima ecuatorial y distal bilateral. Zona de adherencia distal asociada a pliegues ahusados subparalelos a los lados mayores de la cápula. Sexina de los sacos infrareticulada, con muros delgados que limitan lúminas de márgenes irregulares.

Dimensiones (2 ejemplares). Ancho total, 72-87 $\mu \mathrm{m}$; cuerpo central, ancho 51$62 \mu \mathrm{m}$ y 30-33 $\mu \mathrm{m}$ de largo; ancho del saco sobre cara proximal, 7-18 $\mu \mathrm{m}$ y sobre cara distal, 30-37 $\mu \mathrm{m}$; largo del saco, 47-49 $\mu \mathrm{m}$.

Principal material estudiado. BAPal 6175 (b) O57/3, T55/0.

Cometarios. La pobre preservación de los escasos ejemplares estudiados impider asignar específicamente y $\sin$ dudas a los mismos. Sin embargo, características tales como la presencia de las tenias delgadas, extendidas en la 
cara proximal, sin que alcancen la línea del ecuador, como así también la forma general del grano, permiten compararlo con la especie Lueckisporites stenotaeniatus Menéndez (1976, pp. 13-14, lám. II, fig. 8-9).

\section{V.2.6. Verticipollenites sp. A (Lámina XXVIII, figura F)}

Descripción. Grano de polen bisacado, teniado, fuertemente diploxiolonoide. Cuerpo central subcircular a subromboidal. Exina del cuerpo fina y clara, dividida por finas estrías en aproximadamente 8 tenias, de disposición transversal, que se conectan entre sí por estrías menores, perpendiculares a las mayores. Sacos mayores a 1/2 círculo, de inserción proximal ecuatorial y distal bilateral. Cápula ahusada, de hasta $9 \mu \mathrm{m}$ de ancho, de contornos levemente cóncavos y extremos próximos o en contacto. Sexina delgada que conforma infraretículo denso, radialmente dispuesto.

Dimensiones ( 1 ejemplar). Ancho total, $71 \mu \mathrm{m}$; cuerpo central, ancho $34 \mu \mathrm{m}$ y $35 \mu \mathrm{m}$ de largo; ancho del saco sobre cara proximal, $20 \mu \mathrm{m}$ y sobre cara distal, $31 \mu \mathrm{m}$; largo del saco, $43 \mu \mathrm{m}$.

\section{Principal material estudiado. BAPal 6178 (a) K44/1.}

Comentarios. El ejemplar hallado puede referirse sin dudas al género Verticipollenites, por presentar las características tenias subdivididas, y el contorno general fuertemente diploxilolonide. Sin embargo, características tales como la forma de la cápula ahusada, un tamaño menor al de las especies del género y la presencia de sacos si bien mayores a $1 / 2$, menos inflados que para las especies conocidas, impiden referirlo a alguna de ellas.

V.2.7. Peltacystia sp. cf. P. monile Balme y Segroves 1966 (Lámina XXVIII, figura G) Descripción. Microfosil de contorno circular, oblado, de pared levigada y oscura, de $1 \mu \mathrm{m}$ de ancho. La pared queda separada del centro por una zona anular de debilidad, de coloración más clara. El borde interno del cuerpo presenta pequeños gránulos laxamente dispuestos, no observables en todo el contorno. En el polo del cuerpo se puede observar un área más clara, subcircular, de margenes poco discernibles, de $1 / 3$ de ancho respecto del radio total del cuerpo. 
Dimensiones ( 1 ejemplar). Diámetro total del cuerpo, $27 \mu \mathrm{m}$; diámetro interno del cuerpo, $22 \mu \mathrm{m}$; ancho de la pared, $1 \mu \mathrm{m}$.

Principal material estudiado. BAPal 6173 (a) J46/3.

Comentarios. No se puede realizar una asignación precisa por haberse hallado un solo ejemplar, al que no se le observan claramente los elementos ornamentales. Sin embargo, se lo compara estrechamente con Peltacystia monile Balme y Segroves (1966) por el tipo y distribución de la ornamentación (discreta y laxamente dispuesta).

Registros previos. Peltacystia monile fue descripta originalmente por Balme y Segroves (1966) para el Lopingiano de Wagina Sandstone, Australia.

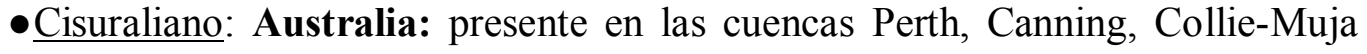
(Segroves, 1967) y Collie (Backhouse, 1991). Antártida: mencionada para Vestfjella, Dronning Maud Land (Lindström, 1996). A pesar de tratarse de material retrabajado esta es la primera cita para la Argentina. 
Lámina XXVIII 


\section{Lámina XXVIII}

\section{Retrabajo}

\section{Palinomorfos pérmicos:}
A. Diatomozonotriletes townrowii Segroves 1970, BAPal 6172(a) S49/2 (X 800).
B. Lundbladispora sp. A, BAPal 6180(a) J53/1 (X 650).
C. Thymospora cicatricosa (Balme y Hennelly) Hart 1965, BAPal 6170(a) R53/0 (X 700).
D. Potonieisporites magnus Lele y Karim 1971, BAPal 6187(a) D56/4 (X 600).
E. Lueckisporites sp. cf. L. stenotaeniatus Menéndez 1976, BAPal (X 550).
F. Verticipollenites sp. A, BAPal 6178(a) K44/1 (X 700).

\section{Palinomorfos jurásico-cretácicos:}

G. Peltacystia sp. cf. P. monile Balme y Segroves 1966, BAPal 6173(a) J46/3 (X 650).

H. Cedripites sp. BAPal 6173 T69/4 (X 650).

I. Schematophora sp. BAPal 6173 (a) C44/4 (X 850).

J. Spiniferites sp. BAPal 6177 (a) Q69/4 (X 400).

K. Spiniferites sp. BAPal 6177 (a) Q69/4 (X 1200).

L. Alphorosphaeridium sp. BAPal 6171 (a) L51/2 (X 800).

M. Dinoflagelado indeterminado 1. BAPal 6173 (a) J60/3 (X 600).

N. Dinoflagelado indeterminado 2. BAPal 6174 (a) F42/0 (X 700).

N. Dinoflagelado indeterminado 3. BAPal 6178 (b) W59/1 (X 600). 

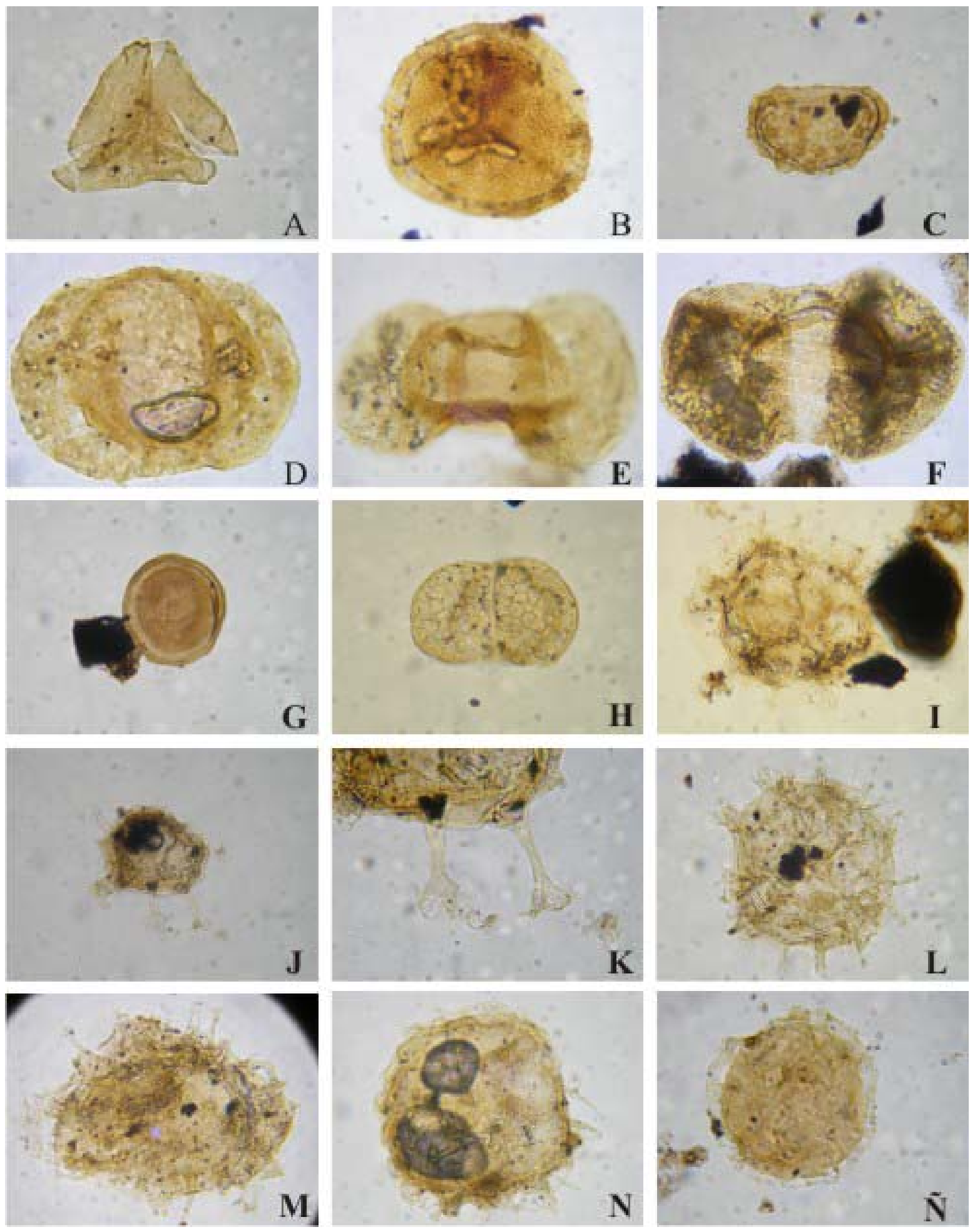


\section{VI.1. Bioestratigrafía}

Los datos aquí obtenidos a partir del estudio de las asociaciones de las perforaciones La Estrella x-1 y Cruz del Sur x-1, han sido analizados utilizando el modelo de Correlación Gráfica (GC, Graphic Correlation), donde los mismos son volcados en un gráfico de 2 dimensiones en el que se ubican en el eje vertical las distintas profundidades de donde provienen las muestras (testigos y cutting) y en el eje horizontal los diferentes taxones. Este método permite la construcción de rangos de distribución (Range Chart, véase Figuras 13 y 14) ya sea temporales o estratigráficos, pudiendo establecerse "Asociaciones de Unidad" o "Asociaciones de Sección" (Edwards y Guex, 1996).

Los rangos de distribución resultantes de gráficos de correlación representan hipótesis estratigráficas de relación entre los taxones, y, como todas las hipótesis, están sujetas a posteriores o adicionales observaciones (por ejemplo, en aquellos casos de distribuciones representadas por datos provenientes de muestras de cutting que serán consideradas particularmente).

Otro método que se utiliza para el estudio de los datos obtenidos de las asociaciones es el de Asociaciones Unitarias (UAs, Unitary associations; Edwards y Guex, 1996), en el cual el énfasis se da sobre las presencias, no así considerando las ausencias. Para el tipo de análisis de datos requeridos para nuestro estudio, es necesario considerar las ausencias como datos, ya que existen taxones que dejan de observarse a determinadas profundidades y es considerado el dato como característico también de la asociación (además de los registros exclusivos, las primeras apariciones y las presencias). Por lo tanto, se considera que el método UAs no se adecúa al tipo de información aquí analizada.

\section{VI.1.1. Perforación La Estrella x-1}

A partir de la distribución de los taxones descriptos para la perforación La Estrella se pueden establecer dos asociaciones de unidad (Figura 13), considerando las distribuciones exclusivas de las especies, como así también las primeras apariciones, últimos registros y las distribuciones que se continúan desde niveles inferiores hacia los superiores. 


\section{VI.1.1.1. Listado de especies}

En el Cuadro 4 se presenta el listado de los palinomorfos identificados en la perforación La Extrella x-1. Entre ellas se destacan las primeras descripciones para la Argentina de: Calamospora breviradiata, Leiotriletes ulutus, Baculatisporites bharadwaji, Converrucosisporites pustulatus, Verrucosisporites microtuberosus, Verrucosisporites surangei, Horriditriletes filiformis, Phidiasporites fosteri, Didecitriletes uncinatus, Lundbladispora willmotti, Laevigatosporites flexus, L. plicatus, Thymospora cruciumensis, Leiosphaeridia crescentica, L. talchirensis, Cymatiosphaera gondwanensis, Crutaesporites globosus, Alisporites opii, A. rioclarensis, Platysaccus crassimarginatus, Limitisporites amazonensis, Triadispora epigona, Hamiapollenites andiraensi, H. ruditaeniatus, Lunatisporites paliensis, Lueckisporites singraulensis, Protohaploxypinus goriaensis, Striatopodocarpites gondwanensis, Tornopollenites toreutos, Vittatina vittifera, Tiwarisporis simplex, Praecolpatites sinuosus, Buedingiisphaeridium permicum, Circulisporites parvus, Micrhystridium fragile, Mehlisphaeridium fibratum y M. regulare. 


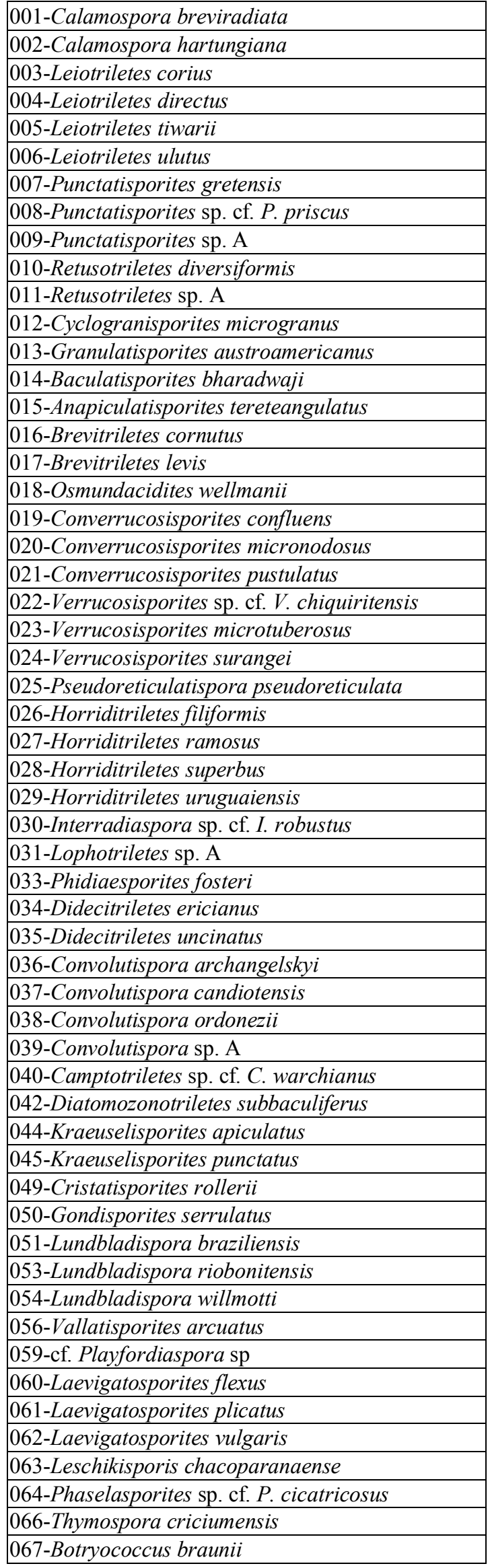

068-Brazilea scissa

069-Brazilea sp. A

070-Leiosphaeridia crescentica

071-Leiosphaeridia talchirensis

073-Portalites gondwanensis

074-Quadrisporites granulatus

076-Cymatiosphaera gondwanensis

077-Cannanorpollis sp. cf. C. densus

078-Cannanoropollis janakii

081-Potonieisporites brasiliensis

082-Potonieisporites densus

083-Potonieisporites lelei

085-Potonieisporites sp. cf. P. pyriferus

086-Potonieispoirtes triangulatus

088-Cahenisaccites densus

089-Caheniasaccites elongatus

090-Crucisaccites latisulcatus

091-Crucisaccites $\mathrm{sp}$.

092-Bascanisporites sp A

093-Gondwanapollis frenguellii

094-Stellapollenites sp. cf. S. talchirensis

095-Accinctisporites excentricus

096-Accinctisporites sp. A

097-Meristocorpus sp. A

098-Meristocorpus sp. B

099-Striomonosaccites cicatricosus

100-Crustaesporites globosus

101-Polarisaccites bilateralis

102-Alisporites australis

103-Alisporites opii

104-Alisporites rioclarensis

105-Chordasporites australiensis

106-Falcisporites parvus

107-Falcisporites similis

108-cf. Ibisporites sp.

109-Pityosporites $\mathrm{sp}$. A

110-Platysaccus crassimarginatus

111-Platysaccus leschikii

112-Platysaccus papilionis

113-Platysaccus queenslandi

114-Platysaccus sp. A

115-Pteruchipollenites sp. cf. P. gracilis

116-Scheuringipollenites circularis

117-Scheuringipollenites maximus

118-Scheuringipollenites medius

119-Scheuringipollenites ovatus

120-Colpisaccites granulosus

121-Limitisporites amazoniensis

122-Limitisporites sp. cf. L. rectus

123-Triadispora epigona

124-Vitreisporites $\mathrm{sp}$. A

125-Corisaccites alutas

126-Distriatites sp. A

128-Hamiapollenites andiraensis

129-Hamiapollenites fusiformis

132-Lunatisporites paliensis 
133-Lunatisporites variesectus

134-Lunatisporites sp. A

135-Lunatisporites sp. B

136-Lueckisporites sp. cf. L. nyakapendensis

137-Lueckisporites singhii

138-Lueckisporites singrauliensis

140-Lueckisporites virkkiae

141-Protohaploxypinus amplus

142-Protohaploxypinus bharadwajii

143-Protohaploxypinus diagonalis

144- Protohaploxypinus limpidus

145-Protohaploxypinus microcorpus

146-Protohaploxypinus goriaensiss

147-Protohaploxypinus varius

148-Staurosaccites cordubensis

149-Striatopodocarpites cancellatus

150-Striatopodocarpites fusus

151-Striatopodocarpites gondwanensis

153-Striatopodocarpites sp. cf. S. solitus

154-Tornopollenites toreutos

156-Vittatina corrugata
157-Vittatina costabilis

158-Vittatina fasciolata

159-Vittatina subsaccata

160-Vittatina vittifera

161-Tiwarisporis anaverrucosus

162-Tiwarisporis simplex

163-Weylandites magmus

164-Weylandites lucifer

165-Marsupipollenites striatus

166-Marsupipollenites triradiatus

167-Praecolpatites sinuosus

168-Pakhapites fusus

169-Pakhapites ovatus

170-Cycadopites crassimarginis

171-Cycadopites follicularis

172-Buedingiisphaeridium permicum

173-Circulisporites parvus

174-Micrhystridium fragile

175-Micrhystridium sp. cf. M.? sp. B

176-Mehlisphaeridium fibratum

179-Reduviasporonites chalastus

Cuadro 4. Listado de las especies identificadas en la perforación La Estrella X-1.

\section{VI.1.1.2. Distribución estratigráfica de las especies identificadas}

Las asociaciones microflorísticas identificadas en el Pérmico de la perforación La Estrella x-1 (Cuadro 4) provienen de 35 muestras (10 testigos y 25 cutting), cuya distribución fue graficada en la Figura 13.

Las mismas incluyen abundantes elementos de variado grado de preservación permitiendo así su asignación específica o aproximaciones sistemáticas, en aquellos casos con material regularmente conservado (afectado por corrosión fîsica y química, en especial por la presencia de evidencia de piritización).

Las asociaciones palinológicas observadas provienen desde los $3549 \mathrm{mbnm}$ hasta los 2940 mbnm; asignables al Grupo Pillahuincó desde 3549 hasta 2986 mbnm, mientras que el intervalo 2896-2940 mbnm se corresponde al Cretácico Inferior indiferenciado.

A partir de la distribución de las especies identificadas en la perforación La Estrella x-1, se ha podido diferenciar dos Asociaciones de Unidad bien características: I (3549$3231 \mathrm{mbnm})$ y II (3231-2986 mbnm); mientras que el segmento que incluye los $2986 \mathrm{y}$ 2940 mbnm, aparecen microfloras marinas del Cretácico con retrabajo de las asociaciones pérmicas (Figura 13). 
La Asociación I (Cuadros 4 y 5) se caracteriza por la una gran diversidad genérica y específica (82 géneros y 155 especies), y por la presencia exclusiva, entre otras, de Converrucosisporites confluens y Vittatina vittifera, que permiten nominarla.

A partir de los $3231 \mathrm{mbnm}$, se observa una marcada disminución en la diversidad de las microfloras, aunque aparecen nuevos taxones (27 especies, véase Figura $13 \mathrm{y}$ Cuadros 4 y 5) que van a caracterizar a las asociaciones del intervalo superior 32312986 mbnm (Asociación II), destacándose la presencia, entre otras, de Tornopollenites toreutos y Reduviasporonites chalastus, que le dan el nombre.

Por otra parte hay conjunto de especies, entre ellas Platysaccus queenslandi, $P$. papilionis, Alisporites australis, Scheuringipollenites maximus, Lueckisporites virkkiae, Protohaploxypinus limpidus, Staurosaccites cordubensis, Convolutispora ordonezii, Vittatina subsaccata, Leiotriletes directus, que aparecen bien representadas a lo largo de toda la perforación analizada (Figura 13 y Cuadro 5). 


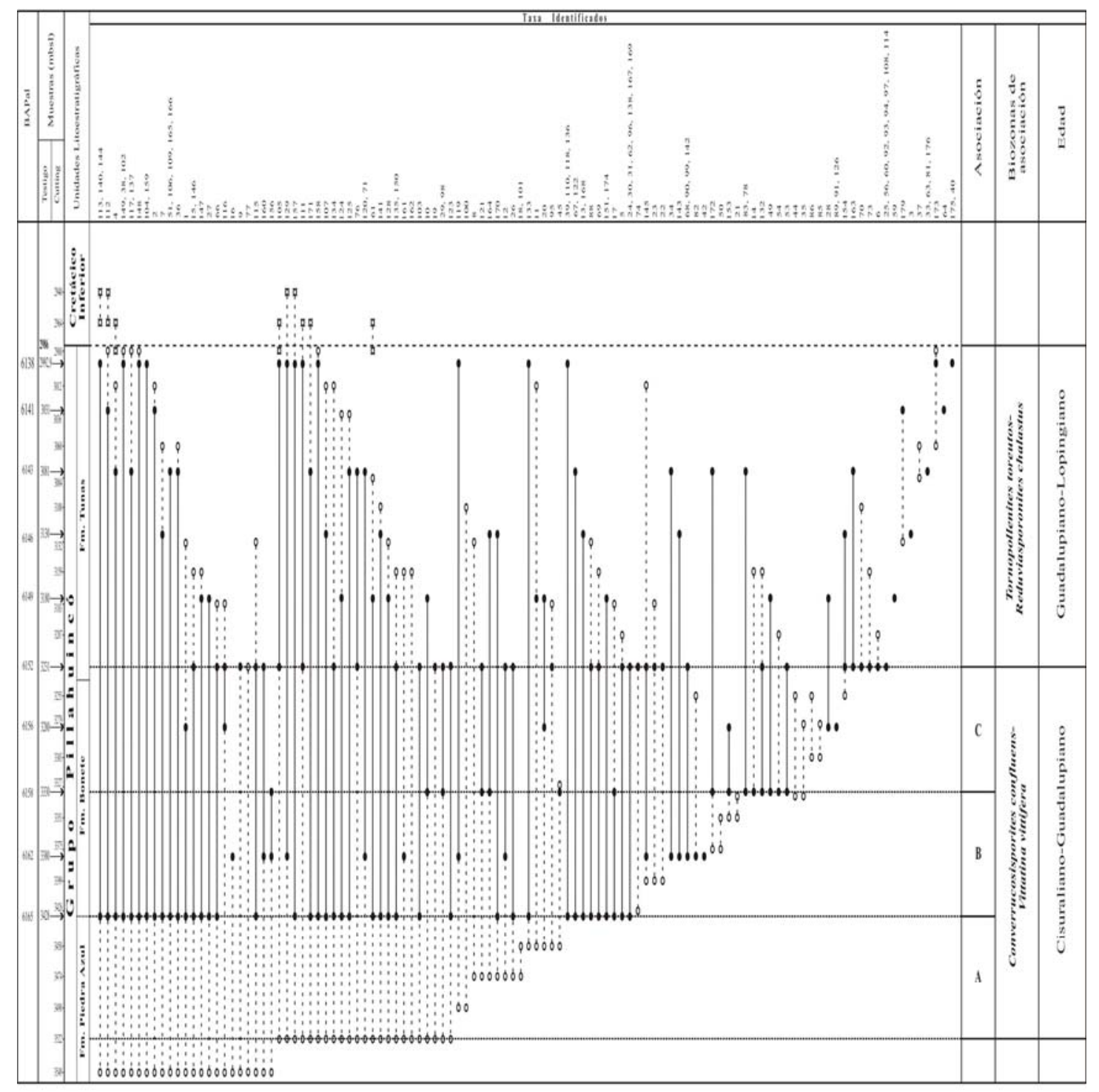

Figura 13. Distribución estratigrafica de las especies presentes en La Estrella x-I (niveles testigo y cutting). Referencias: (o) mustra de testigo; (0) nuestra de cutting, (a) redepósitio. 


\begin{tabular}{|c|c|}
\hline ESPECIES / BIOZONAS & \begin{tabular}{l|l|l|}
$\mathrm{CV}$ & $\mathrm{TC}$ \\
\end{tabular} \\
\hline 012-Cyclogranisporites microgranus & \\
\hline 018-Osmundacidites wellmanii & \\
\hline 019-Converrucosisporites confluens & \\
\hline 021-C. pustulatus & \\
\hline 022-Verrucosisporites sp. cf. $V$. chiquiritensis & \\
\hline 024-V. surangei & \\
\hline 026-Horriditriletes filiformis & \\
\hline 029-H. uruguaiensis & \\
\hline 030-Interradiaspora sp. cf. I. robustus & \\
\hline 031-Lophotriletes sp. A & \\
\hline 035-Didecitriletes uncinatus & \\
\hline 042-Diatomozonotriletes subbaculiferus & \\
\hline 044-Kraeuselisporites apiculatus & \\
\hline 045-K. punctatus & \\
\hline 050-Gondisporites serrulatus & \\
\hline 053-Lundbladispora riobonitensis & \\
\hline 062-Laevigatosporites vulgaris & \\
\hline 068-Brazilea scissa & \\
\hline 074-Quadrisporites granulatus & \\
\hline 082-Potonieisporites densus & \\
\hline 085-P. sp. cf. P. pyriferus & \\
\hline 086- $P$. triangulatus & \\
\hline 089-Caheniasaccites elongatus & \\
\hline 090-Crucisaccites latisulcatus & \\
\hline 091-C. sp. & \\
\hline 096-Accinctisporites sp. A & \\
\hline 098-Meristocorpus sp. B & \\
\hline 099-Striomonosaccites cicatricosus & \\
\hline 101-Polarisaccites bilateralis & \\
\hline 103-Alisporites opii & \\
\hline 121-Limitisporites amazoniensis & \\
\hline 123-Triadispora epigona & \\
\hline 126-Distriatites sp. A & \\
\hline 138-Lueckisporites singrauliensis & \\
\hline 142-Protohaploxypinus bharadwajii & \\
\hline 153-Striatopodocarpites sp. cf. S. solitus & \\
\hline 156-Vittatina corrugata & \\
\hline $160-V$. vittifera & \\
\hline 167-Praecolpatites sinuosus & \\
\hline 169-Pakhapites ovatus & \\
\hline 001-Calamospora breviradiata & \\
\hline 002-C. hartungiana & \\
\hline 004-Leiotriletes directus & \\
\hline 005-L. tiwarii & \\
\hline 007-Punctatisporites gretensis & \\
\hline 008-P. sp. cf. P. priscus & \\
\hline 009-P.sp. A & \\
\hline 010-Retusotriletes diversiformis & \\
\hline 011-R. sp. A & \\
\hline 013-Granulatisporites austroamericanus & \\
\hline 014-Baculatisporites bharadwaji & \\
\hline 015-Anapiculatisporites tereteangulatus & \\
\hline 016-Brevitriletes cornutus & \\
\hline
\end{tabular}

017-B. levis

020-Converrucosisporites micronodosus

023-Verrucosisporites microtuberosus

027-Horriditriletes ramosus

028-H. superbus

034-Didecitriletes ericianus

036-Convolutispora archangelskyi

038-C. ordonezii

039-C. sp. A

049-Cristatisporites rollerii

051-Lundbladispora braziliensis

054-L. willmotti

061-Laevigatosporites plicatus

066-Thymospora criciumensis

067-Botryococcus braunii

069-Brazilea sp. A

071-Leiosphaeridia talchirensis

076-Cymatiosphaera gondwanensis

077-Cannanorpollis sp. cf. C. densus

078-C. janakii

083-Potonieisporites lelei

088-Cahenisaccites densus

095-Accinctisporites excentricus

100-Crustaesporites globosus

102-Alisporites australis

104-A. rioclarensis

105-Chordasporites australiensis

106-Falcisporites parvus

107-F. similis

109-Pityosporites $\mathrm{sp}$. A

110-Platysaccus crassimarginatus

111-P. leschikii

112-P. papilionis

113-P. queenslandi

115-Pteruchipollenites sp. cf. $P$. gracilis

116-Scheuringipollenites circularis

117-S. maximus

118-S. medius

119-S. ovatus

120-Colpisaccites granulosus

122-Limitisporites sp. cf. L. rectus

124-Vitreisporites $\mathrm{sp}$. A

125-Corisaccites alutas

128-Hamiapollenites andiraensis

129-H. fusiformis

132-Lunatisporites paliensis

133-L. variesectus

134-L. sp. A

135-L. sp. B

136-Lueckisporites sp. cf. L. nyakapendensis

137-L. singhii

140-L. virkkiae

141-Protohaploxypinus amplus

143-P. diagonalis

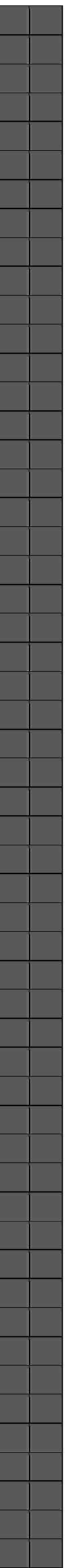




\begin{tabular}{|l|l|l|}
\cline { 2 - 3 } $144-P$. limpidus & & \\
\hline $145-$ P. microcorpus & & \\
\hline $146-P$. perexiguus & & \\
\hline $147-P$. varius & & \\
\hline $148-$ Staurosaccites cordubensis & & \\
\hline $149-$ Striatopodocarpites cancellatus & & \\
\hline $150-$ S. fusus & & \\
\hline $151-$ S. gondwanensis & & \\
\hline $154-$ Tornopollenites toreutos & & \\
\hline $157-$ Vittatina costabilis & & \\
\hline $158-$ Vasciolata & & \\
\hline $159-$. subsaccata & & \\
\hline $161-$ Tiwarisporis anaverrucosus & & \\
\hline $162-$. simplex & & \\
\hline $164-$ Weylandites lucifer & & \\
\hline $165-$ Marsupipollenites striatus & & \\
\hline $166-$ M. triradiatus & & \\
\hline $168-$ Pakhapites fusus & & \\
\hline $170-$ Cycadopites crassimarginis & & \\
\hline $171-$ C. follicularis & & \\
\hline $172-$ Buedingiisphaeridium permicum & & \\
\hline $174-$ Micrhystridium fragile & \\
\hline $003-$ Leiotriletes corius & \\
\hline $006-$ L. ulutus & \\
\hline
\end{tabular}

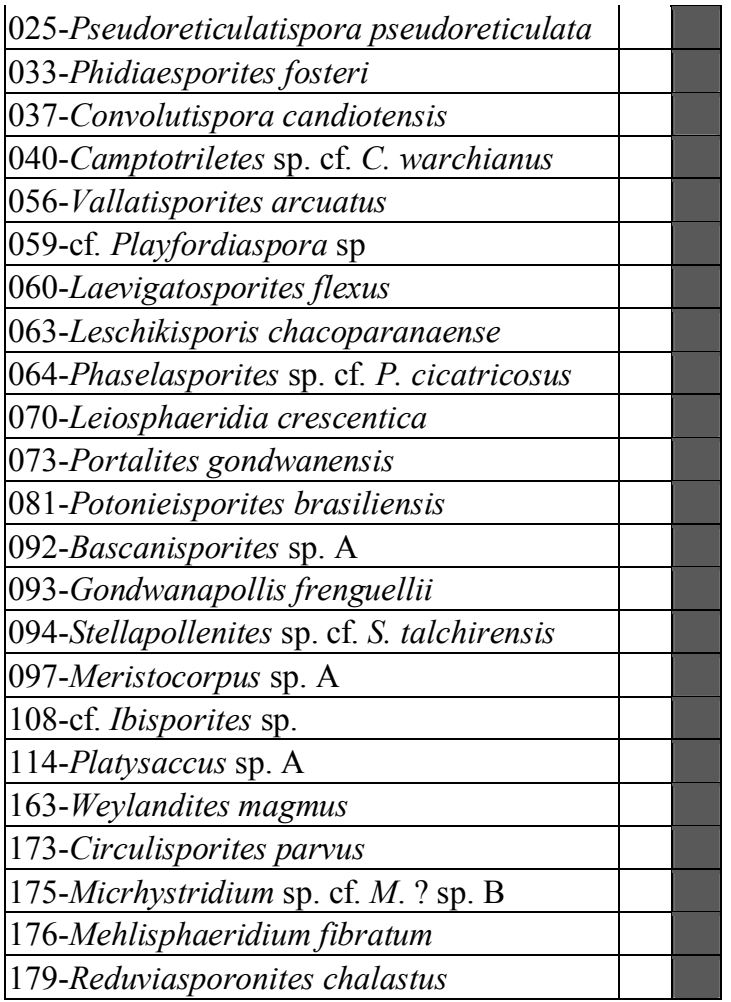

Cuadro 5. Listado de especies de las Asociaciones CV y TC de la perforación La Estrella x-1. 


\section{VI.1.2. Perforación Cruz del Sur x-1}

\section{VI.1.2.1. Listado de especies}

En el Cuadro 6 se presenta el listado de los palinomorfos identificados en la perforación Cruz del Sur x-1. A diferencia de la perforación La Estrella x-1, en Cruz del Sur se han identificado 102 especies de 54 géneros, y para La Estrella x-1 155 especies, completando un total de 179 especies para ambas perforaciones. Se identificaron en forma exclusiva en Cruz del Sur: Diatomozonotriletes ponticulus, Lundbladispora iphilegma, Indotriradites reidii, Spelaeotriletes triangulus, Pilasporites sp. B, Costatacyclus crenatus, Hamiapollenites ruditaeniatus, Lunatisporites noviaulensis, Striatopodocarpidites sp. cf. S. phaleratus, Mehlisphaeridium regulare, Lundbladispora sp. A, Thymospora cicatricosa y Peltacystia monile, estos 3 últimos solo aparecen como redepósito en Jurásico-Cretácico.

Del total de las especies identificadas en la perforación Cruz del Sur x-1 se destacan las descripciones por primera vez para la Argentina de Calamospora breviradiata, Baculatisporites bharadwaji, Pseudoreticulatispora pseudoreticulata, Diatomozonotriletes ponticulus, Lundbladispora iphilegna, Indotriradites reidii, Laevigatosporites flexus, Leiosphaeridia talchirensis, Maculatasporites minimus, Costatacyclus crenatus, Limitisporites amazonensis, Hamiapollenites andiraensis, $H$. ruditaeniatus, Lunatisporites paliensis, Lueckisporites singraulensis, Protohaploxypinus gorianensis, Striatopodocarpites gondwanensis, Vittatina vittifera, Tiwarisporis simplex, Buedingiisphaeridium permicum, Circulisporites parvus y Mehlisphaeridium regulare.

Entre el intervalo 3686-2900 mbnm se han identificado 31 especies pérmicas redepositadas en el Jurásico-Cretácico indiferenciado (Figura 14, Cuadro 6). 
Balarino, M. Lucía

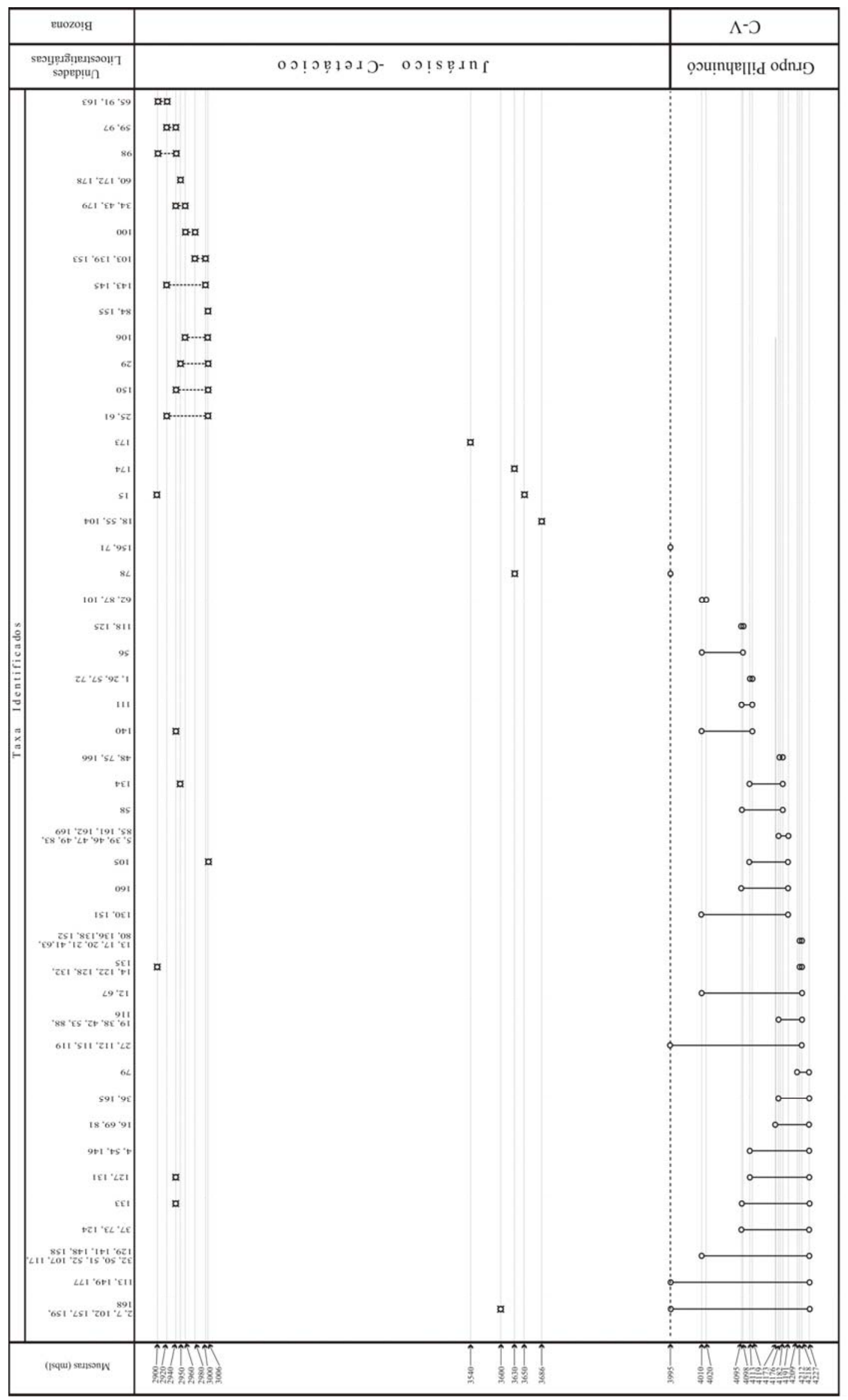




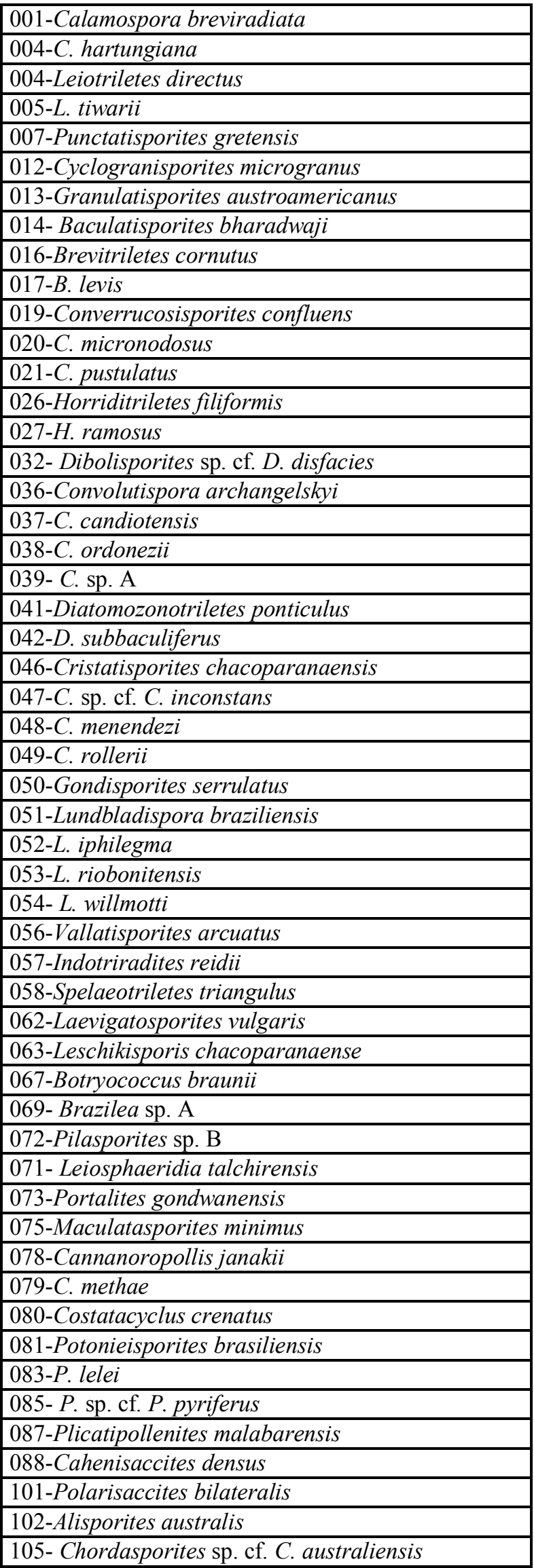

107-Falcisporites similis

111- Platysaccus leschikii

112- P. papilionis

113-P. queenslandi

115-Pteruchipollenites sp. cf. P. gracilis

116-Scheuringipollenites circularis

118-S. medius

117-S. maximus

119-S. ovatus

122-Limitisporites sp. cf. L. rectus

125-Corisaccites alutas

127-Illinites unicus

128-Hamiapollenites andiraensis

129-H. fusiformis

130-H. ruditaeniatus

131-Lunatisporites noviaulensis

132-L. paliensis

133-L. variesectus

134- L. sp. A

135- L. sp. B

136- Lueckisporites sp. cf. L. nyakapendensis

138- L. singrauliensis

140-L. virkkiae

141- Protohaploxypinus amplus

144-P. limpidus

145-P. microcorpus

146- $P$. goraiensis

148-Staurosaccites cordubensis

149-Striatopodocarpites cancellatus

150-S. fusus

151-S. gondwanensis

152-S. sp. cf. S. phaleratus

153-S. sp. cf. S. solitus

156-Vittatina corrugata

157-V. costabilis

158- $V$. fasciolata

159-V. subsaccata

160-V. vittifera

161-Tiwarisporis anaverrucosus

162- Tiwarisporis simplex

163-Weylandites magmus

165-Marsupipollenites striatus

166-M. triradiatus

168-Pakhapites fusus

169-P. ovatus

177-Mehlisphaeridium regulare

015-Anapiculatisporites tereteangulatus*

018- Osmundacidites wellmanii *

025- Pseudoreticulatispora pseudoreticulata *

029-Horriditriletes uruguaiensis*

034- Didecitriletes ericianus *

043-Diatomozonotriletes townrwoi *

055-Lundbladispora sp. $\mathrm{A}^{*}$ 


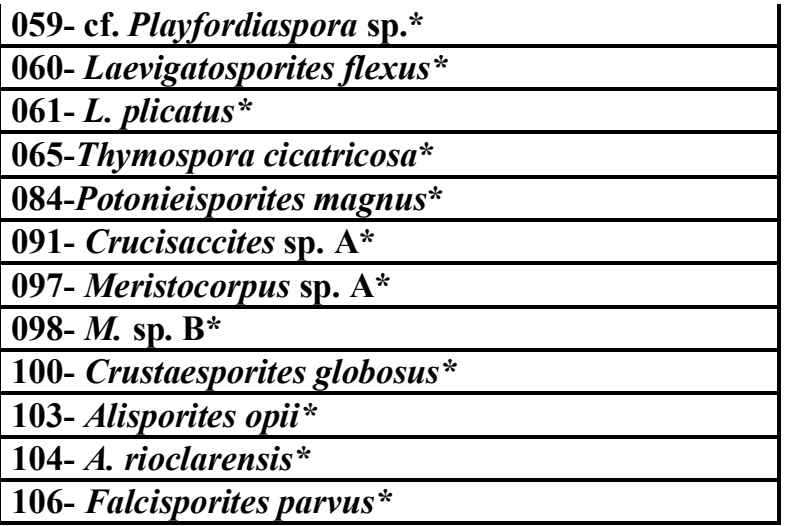

139-Lueckisporites sp. cf. L. stenotaeniatus* 143-Protohaploxypinus diagonalis* 145-P. microcorpus* 150- Striatopodocarpites fusus* 153- S. sp. cf. S. solitus* 155-Verticipollenites sp. A* 163-Weylandites magmus * 172- Buedingiisphaeridium permicum * 173-Circulisporites parvus* 174- Micrhystridium fragile* 178-Peltacystia monile* 179-Reduviasporonites chalastus*

Cuadro 6. Lista de especies identificadas en la perforación Cruz del Sur x-1. Para su distribución véase Figura 13. *, Retrabajo.

\section{VI.1.2.2. Distribución estratigráfica de las especies identificadas}

Las muestras de cutting estudiadas provenientes de la perforación Cruz del Sur (Figura 14) corresponden a 13 niveles que van desde los 4227 a los 2900 mbnm; el intervalo 4227-3994 mbnm corresponde a pelitas y areniscas referibles al Grupo Pillahuincó de donde se obtuvieron 8 muestras, todas ellas cutting. Las mismas presentan microfloras en su mayoría abundantes y en general bien preservadas, permitiéndose en todos los casos las asignaciones específicas ó genéricas, o aproximaciones sistemáticas en aquellos ejemplares con mala preservación. Por su parte el intervalo 3994-2550 mbnm, corresponde al syn-rift (Jurásico-Cretácico) donde se han observado microfloras marinas que incluye abundantes palinomorfos pérmicos redepositados.

En el intervalo 4227-3994 mbnm, las microfloras incluyen formas distribuidas en todo el intervalo (véase Figura 14) como Cyclogranisporites microgranus, Baculatisporites bharadwaji, Convolutispora ordonezii, Horriditriletes ramosus, Diatomozonotriletes subbaculiferus, Converrucosisporites confluens, Lundbladispora riobonitensis, Spelaeotriletes triangulus, Botryococcus braunii, Platysaccus papilionis, Pteruchipollenites sp. cf. P. gracilis, Scheuringipollenites ovatus, S. circularis, Limitisporites sp. cf. L. rectus y Hamiapollenites andiraensis.

Por su parte entre las especies cuya distribución aparece más restringida (Figura 14), se pueden mencionar: Calamospora breviradiata, Leiotriletes tiwarii, Convolutispora ordonezii, C. sp. A, Converrucosisporites confluens, Cristatisporites chacoparanaensis, C. menendezi, C. rollerii, C. sp. cf. C. inconstans, Cyclogranisporites microgranus, 
Spelaeotriletes triangulus, Baculatisporites bharadwaji, Horriditriletes ramosus, $H$. filiformis, Indotriradites reidii, Diatomozonotriletes subbaculiferus, Lundbladispora riobonitensis, Vallatisporites arcuatus, Laevigatosporites vulgaris, L. plicatus, Botryococcus braunii, Leiosphaeridia talchirensis, Maculatasporites minimus, Potonieisporites lelei, P. sp. cf. P. pyriferus, Plicatipollenites malabarensis, Cannanoropollis janakii, Cahenisaccites densus, Polarisaccites bilateralis, Crustaesporites globosus, Platysaccus papilionis, P. leschikii, Pteruchipollenites sp. cf. P. gracilis, Chordasporites australiensis, Scheuringipollenites circularis, Limitisporites sp. cf. L. rectus, Corisaccites alutas, Lunatisporites paliensis, L. sp. A, Lueckisporites virkkiae, Hamiapollenites ruditaeniatus, Striatopodocarpites gondwanensis, Tiwarisporis anaverrucosus, T. simplex, Vittatina vittifera y $V$. corrugata.

Entre 3686 y 3540 mbnm aparece material Pérmico redepositado; un primer conjunto incluye formas con registro restringido a este intervalo, tales como Osmundacidites wellmanii, Lundbladispora sp. A, Alisporites rioclarensis, Micrhystridium fragile, Circulisporites parvus. Un segundo conjunto incluye formas con registros en el intervalo interior, tales como Calamospora hartungiana, Punctatisporites gretensis, Alisporites australis, Vittatina costabilis, V. subsacatta, Pakhapites fusus y Cannanorpollis janakii. Por último completa Anapiculatisporites tereteangulus que también aparece registrado en el intervalo 3006-2900 mbnm.

En éste intervalo se observa abundante material pérmico redepositado exclusivo del mismo (Figura 14). Entre esos taxones se puede mencionar Pseudoreticulatispora pseudoreticulata, Laevigatosporites plicatus, L. flexus, Striatopodocarpites fusus, Horriditriletes uruguaiensis, Falcisporites parvus, Potonieisporites magmus, Protohaploxypinus diagonalis, P. microcorpus, Alisporites opii, Lueckisporites sp.cf. L. stenotaeniatus, Striatopodocarpites cf. solitus, Crustaesporites globosus, Didecitriletes ericianus, Diatomozonotriletes townrwoii, Reduviasporonites chalastus, Buedingisphaeridium permicum, Peltacystia monile, Thymospora cicatricosa y Weylandites magmus. Completa otro conjunto de formas también pérmicas que muestran registro en el intervalo 4227-3995 mlbs tales como Lunatisporites variesectus, L. nouviaulensis, L. paliensis, Illinites unicus, Baculatisporites bharadwaji, Hamiapollenites andiraensis y Lueckisporites virkkiae. 
Entre todo este material redepositado se destacan Diatomozonotriletes townrowii, Lundbladispora sp. A, Thymospora cicatricosa, Potonieisporites magnus, Lueckisporites sp. cf. L. stenotaeniatus, Verticipollenites sp. A, Peltacystia sp. cf. P. monile porque aparecen solamente en esta perforación y como redepósito (Lámina XXVIII).

\section{VI.2. Propuesta de Biozonación}

\section{V.2.1. Biozona de Asociación Converrucosisporites confluens-Vittatina vittifera (CV; Figuras 13 y 20; Cuadros 4 y 5)}

La Biozona Converrucosisporites confluens-Vittatina vittifera (CV) presenta su sección tipo en la perforación La Estrella x-1 entre los 3549 y los 3231 mbnm (que incluye los niveles testigo 3428, 3380, 3280 y $3231 \mathrm{mbnm})$. Se caracteriza por la abundancia de granos de polen bisacados de cuerpo central liso (51,6-55,6\%), acompañanado por esporas triletes $(12,7-20,6 \%)$ y granos de polen plicados $(12,1$ 18,5\%). Los demás grupos de palinomorfos están presente en bajas proporciones: granos de polen estriados (7,0-12,3\%), monosulcados $(0,2-3,7 \%)$, monosacados $(0,6-$ $2,2 \%)$, algas $(0-3,9 \%)$ y acritarcas $(0-0,4 \%)$. Presenta una alta diversidad específica, identificándose para esta asociación 130 especies (Cuadro 5).

La base de esta biozona está definida por el FOB (First occurrence biohorizon ó biohorizonte de primera presencia) de Converrucosisporites confluens, Horriditriletes uruguaiensis, Retusotriletes diversiformis, Laevigatosporites plicatus, Meristocorpus sp. B, Chordasporites australiensis, Colpisaccites granulosus, Alisporites opii, Falcisporites similis, Platysaccus leschikii, Triadispora epigona, Vitreisporites sp., Lunatisporites sp. A, L. sp. B, Corisaccites alutas, Hamiapollenites fusiformis, $H$. andiraensis, Protohaploxypinus amplus, Striatopodocarpites fusus, Vittatina costabilis, V. fasciolata, Tiwarisporis anaverrucosus, T. simplex, Cycadopites follicularis, Cymatiosphaera gondwanensis y Leiosphaeridia talchirensis.

El límite superior de esta biozona está marcado por la desaparición de Converrucosisporites confluens, Cyclogranisporites microgranus, Horriditriletes filiformis, H. uruguaiensis, Interradiaspora sp. cf. I. robustus, Laevigatosporites 
vulgaris, Lophotriletes sp. A, Verrucosisporites sp. cf. V. chiquiritensis, V. surangei, Punctatisporites sp. A., Accinctisporites sp. A, Cannanorpollis sp. cf. C. densus, Crucisaccites latisulcatus, Meristocorpus sp. B, Striomonosaccites cicatricosus, Alisporites opii, Limitisporites amazoniensis, Triadispora epigona, Lueckisporites singrauliensis, Protohaploxypinus bharadwajii, Vittatina vittifera, Praecolpatites sinuosus, Pakhapites ovatus, Brazilea scissa y Quadrisporites granulatus.

Este límite también aparece indicado por los primeros registros de Leiotriletes ulutus, L. corius, Convolutispora candiotensis, Tornopollenites toreutos, Weylandites magmus, Leiosphaeridia crescentica, Portalites gondwanensis (Figura 12), que van a caracterizar la biozona superior.

Caracterizan a esta bizona, además de los taxones de amplio registro, la presencia exclusiva de Converrucosisporites confluens, Diatomozonotriletes subbaculiferus, Osmundacidites wellmanii, Verrucosisporites surangei, Verrucosisporites sp. cf. V. chiquiritensis, Horriditriletes uruguaiensis, H. filiformis, Interradiaspora sp. cf. I. robustus, Lophotriletes sp. A, Didecitriletes uncinatus, Cyclogranisporites microgranus, Kraeuselisporites punctatus, K. apiculatus, Gondisporites serrulatus, Lundbladispora riobonitensis, Laevigatosporites vulgaris, Brazilea scissa, Potonieisporites densus, P. triangulatus, P. sp. cf. P. pyriferus, Caheniasaccites elongatus, Crucisaccites sp. A, Bascanisporites sp. A, Gondwanapollis frenguellii, Stellapollenites sp. cf. S. talchirensis, Accinctisporites sp. A, Crucisaccites latisulcatus, Meristocorpus sp. A, M. sp. B, Striomonosaccites cicatricosus, Polarisaccites bilateralis, Alisporites opii, cf. Ibisporites sp., Platysaccus sp. A, Limitisporites amazoniensis, Triadispora epigona, Distriatites sp. A, Lueckisporites singrauliensis, Protohaploxypinus bharadwajii, Striatopodocarpites sp. cf. S. solitus, Praecolpatites sinuosus y Pakhapites ovatus.

Esta biozona también es identificada en la perforación Cruz del Sur x-1 42273995 mbnm (Figura 14) a partir de la presencia de Converrucosisporites confluens, Vittatina vittifera, Cyclogranisporites microgranus, Horriditriletes filiformis, Diatomozonotriletes subbaculieferus, Gondisporites serrulatus, Vallatisporites arcuatus, Laevigatosporites vulgaris, Potonieisporites cf. pyriferus, Lueckisporites singrauliensis, Striatopodocarpites cf. solitus y Pakhapites ovatus. 
La Biozona CV puede ser dividida a su vez en 3 Asociaciones informales (A, B, C), a partir de la distribución de los taxones que las conforman (Figura 13). Las mismas son:

*Asociación A (3549-3428 mbnm): se caracteriza por la presencia exclusiva de Osmundacidites wellmanii y Polarisaccites bilateralis. En este intervalo (Figura 13) se observan las primeras apariciones de Converrucosisporites confluens, Cyclogranisporites microgranus, Horriditriletes filiformis, $H$. uruguaiensis, Laevigatosporites plicatus, Punctatisporites sp. cf. P. priscus, Retusotriletes diversiformis, Crustaesporites globosus, Meristocorpus sp. B, Alisporites opii, Chordasporites cf. australiensis, Colpisaccites granulosus, Falcisporites similis, Limitisporites amazoniensis, Platysaccus leschikii, Scheuringipollenites ovatus, Triadispora epigona, Vitreisporites sp. A, Corisaccites alutas, Hamiapollenites andiraensis, H. fusiformis, Lunatisporites sp. A, L. sp. B, Protohaploxypinus amplus, Striatopodocarpites fusus, Vittatina costabilis, $V$. fasciolata, Tiwarisporis anaverrucosus, T. simplex, Weylandites lucifer, Cycadopites crassimarginis, Cycadopites follicularis, Cymatiosphaera gondwanensis y Leiosphaeridia talchirensis.

Completa la Asociación A un numeroso conjunto de especies que muestran un amplio registro vertical en el pozo, entre ellas se destacan Anapiculatisporites tereteangulatus, Brevitriletes cornutus, Calamospora breviradiata, Convolutispora archangelskyi, C. ordonezii, Horriditriletes ramosus, Thymospora criciumensis, Alisporites australis, A. rioclarensis, Falcisporites parvus, Platysaccus papilionis, $P$. queenslandi, Scheuringipollenites circularis, S. maximus, Lueckisporites singhii, L. virkkiae, Protohaploxypinus limpidus, P. goraiensis, P. varius, Staurosaccites cordubensis, Striatopodocarpites cancellatus, Marsupipollenites striatus, $M$. triradiatus, Vittatina corrugata, $V$. subsaccata y $V$. vittifera.

El techo lo conforma la aparición de las especies que marcan la base de la Asociación superior (Figura 13).

*Asociación B (3428-3330 mbnm): caracterizada por la presencia exclusiva de Converrucosisporites pustulatus, Diatomozonotriletes subbaculiferus, Gondisporites serrulatus y Kraeuselisporites punctatus. Además por el primer registo en su base de Brevitriletes levis, Convolutispora sp. A, Didecitriletes ericianus, Granulatisporites austroamericanus, Interradiaspora sp. cf. I. robustus, Laevigatosporites vulgaris, 
Leiotriletes tiwarii, Lophotriletes sp. A, Verrucosisporites microtuberosus, V. surangei, Accinctisporites sp. A, Cahenisaccites densus, Crucisaccites latisulcatus, Potonieisporites densus, Striomonosaccites cicatricosus, Limitisporites sp. cf. L. rectus, Platysaccus crassimarginatus, Scheuringipollenites medius, Lueckisporites sp. cf. L. nyakapendensis, L. singrauliensis, Protohaploxypinus bharadwajii, P. diagonalis, P. microcorpus, Striatopodocarpites gondwanensis, Pakhapites fusus, P. ovatus, Praecolpatites sinuosus, Botryococcus braunii, Brazilea scissa, B. sp. A, Buedingiisphaeridium permicum, Micrhystridium fragile y Quadrisporites granulatus. El techo aparece marcado por la última aparición de Brevitriletes cornutus y Vittatina corrugata.

*Asociación C (3330-3231 mbnm): definida por la presencia de exclusiva de Converrucosisporites pustulatus, Didecitriletes uncinatus, Kraeuselisporites apiculatus, Lundbladispora riobonitensis, Caheniasaccites elongatus, Crucisaccites sp., Potonieisporites sp. cf. $P$. pyriferus, $P$. triangulatus, Distriatites $\mathrm{sp}$. A y Striatopodocarpites sp. cf. S. solitus. Su base aparece marcada además por la aparición de Baculatisporites bharadwaji, Cristatisporites rollerii, Horriditriletes superbus, Lundbladispora willmotti, Potonieisporites lelei y Lunatisporites paliensis.

Por su parte el techo aparece indicado por la desaparición de Converrucosisporites confluens, Cyclogranisporites microgranus, Horriditriletes filiformis, H. uruguaiensis, Interradiaspora sp. cf. I. robustus, Laevigatosporites vulgaris, Lophotriletes sp. A, Verrucosisporites sp. cf. V. chiquiritensis, V. surangei, Punctatisporites sp. A., Accinctisporites sp. A, Cannanorpollis sp. cf. C. densus, Crucisaccites latisulcatus, Meristocorpus sp. B, Striomonosaccites cicatricosus, Alisporites opii, Limitisporites amazoniensis, Triadispora epigona, Lueckisporites singrauliensis, Protohaploxypinus bharadwajii, Vittatina vittifera, Praecolpatites sinuosus, Pakhapites ovatus, Brazilea scissa y Quadrisporites granulatus.

\section{VI.2.2 Biozona de Asociación Tornopollenites toreutos-Reduviasporonites chalastus (TC, Figura 13 y Cuadro 5)}

La Biozona de Asociación Tornopollenites toreutos-Reduviasporonites chalastus (TC) presenta su sección tipo en la perforación La Estrella x-1, entre los 3231 y 2986 mbnm. Está caracterizada por un cambio abrupto en la composición cuantitativa 
de los distintos grupos de palinomorfos, respecto de la Biozona CV (Cuadro 5). De este modo en la Biozona TC los granos de polen bisacados (74,3-88,9\%) aparecen como los componenetes dominantes, mientras que el resto de los grupos constituyen conjuntos relictuales: esporas $(2,4-10,9 \%)$, granos de polen estriados $(3,4-9,4)$, plicados $(0,2-$ $4,3 \%)$, monosacados $(0,7-3,0 \%)$, monosulcados $(0-0,9 \%)$, algas $(0-0,9 \%)$ y acritarcas (0-0,4\%). En contraposición a la Bizona CV (con 130 especies identificadas) en esta biozona se observa una disminución de la diversidad específica (con 114 especies para la Biozona TC).

La base de esta biozona está definida por el FOB (Figura 13) de las siguientes especies: Leiotriletes ulutus, L. corius, Convolutispora candiotensis, Tornopollenites toreutos, Weylandites magmus, Leiosphaeridia crescentica y Portalites gondwanensis.

Se destacan como componentes exclusivos de la Biozona TC, las siguientes especies: Camptotriletes sp. cf. C. warchianus, Convolutispora candiotensis, Laevigatosporites flexus, Leiotriletes corius, L. ulutus, Leschikisporis chacoparanaense, Phaselisporites sp. cf. P. cicatricosus, Phidiaesporites fosteri, cf. Playfordiaspora sp., Pseudoreticulatispora pseudoreticulata, Vallatisporites arcuatus, Bascanisporites sp A, Gondwanapollis frenguellii, Meristocorpus sp. A, Stellapollenites sp. cf. S. talchirensis, Potonieisporites brasiliensis, cf. Ibisporites sp., Platysaccus sp. A, Tornopollenites toreutos, Weylandites magmus, Circulisporites parvus, Leiosphaeridia crescentica, Mehlisphaeridium fibratum, M. sp. cf. M.? sp. B, Portalites gondwanensis y Reduviasporonites chalastus.

Completa la Biozona un conjunto de numerosas especies que aparecieron en la Biozona CV y continúan (Figura 13), tales como: Anapiculatisporites tereteangulatus, Baculatisporites bharadwaji, Brevitriletes levis, Calamospora breviradiata, $C$. hartungiana, Converrucosisporites micronodosus, Convolutispora archangelskyi, C. ordonezii, C. sp. A, Cristatisporites rollerii, Didecitriletes ericianus, Granulatisporites austroamericanus, Horriditriletes ramosus, H. superbus, Laevigatosporites plicatus, Leiotriletes directus, L. tiwarii, Lundbladispora braziliensis, L. willmotti, Punctatisporites gretensis, P. sp. cf. P. priscus, Retusotriletes diversiformis, $R$. sp. A, Thymospora criciumensis, Verrucosisporites microtuberosus, Accinctisporites excentricus, Cahenisaccites densus, Cannanoropollis janakii, Potonieisporites lelei, Alisporites australis, A. rioclarensis, Chordasporites australiensis, Colpisaccites 
granulosus, Falcisporites parvus, F. similis, Limitisporites sp. cf. L. rectus, Pityosporites sp. A, Platysaccus crassimarginatus, P. leschikii, P. papilionis, $P$. queenslandi, Scheuringipollenites circularis, S. maximus, S. medius, S. ovatus, Pteruchipollenites sp. cf. P. gracilis, Vitreisporites sp. A, Corisaccites alutas, Hamiapollenites andiraensis, H. fusiformis, Lueckisporites sp. cf. L. nyakapendensis, L. singhii, L. virkkiae, Lunatisporites paliensis, L. variesectus, L. sp. A, L. sp. B, Protohaploxypinus amplus, P. diagonalis, P. limpidus, P. microcorpus, P. goraiensis, P. varius, Staurosaccites cordubensis, Striatopodocarpites cancellatus, S. fusus, S. gondwanensis, Marsupipollenites striatus, M. triradiatus, $V$. costabilis, $V$. fasciolata, $V$. subsaccata, Tiwarisporis anaverrucosus, T. simplex, Weylandites lucifer, Cycadopites crassimarginis, C. follicularis, Pakhapites fusus, Botryococcus braunii, Brazilea sp. A, Buedingiisphaeridium permicum, Cymatiosphaera gondwanensis, Leiosphaeridia talchirensis y Micrhystridium fragile.

\section{VI.3. Edad de las Biozonas}

Para el análisis estratigráfico de las asociaciones se confeccionó el Cuadro 7 donde se volcó la información resumida en los ítems registros previos del Capítulo VI (Sistemática), donde se incluyen las referencias bibliográficas de los taxones aquí considerados.

\section{Biozona de Asociación Converrucosisporites confluens-Vittatina vittifera}

(CV). Entre los componentes de las asociaciones caracterizadas como Biozona CV (Cuadros 5 y 7 y Figura 13) se destaca Converrucosisporites confluens, ampliamente distribuida en el Cisuraliano de Argentina, Uruguay, Brasil, Antártida, Omán y Arabia Saudita y Vittatina vittifera, presente desde el límite Pennsylvaniano-Pérmico de Kazajstán y en el Cisuraliano-Guadalupiano de la Cuenca Paraná, Brasil.

Otras especies con registros restringidos al Cisuraliano-Guadalupiano, son $V$. corrugata, Lunatisporites variesecctus, Polarisaccites bilateralis, Striomonosaccites cicatricosus, Convolutispora archangelsyki, Converrucosisporites micronodosus, Horriditriletes superbus, Leschikisporites chacoparanaense, Colpisaccites granulosus, Tiwarisporis anaverrucosus y Gondisporites serrulatus, que han sido descriptas para las cuencas Chacoparaná (Argentina y Paraguay) y Paraná (Uruguay, Brasil); así como en 
Omán y Arabia Saudita. En este conjunto también se incluyen a Horriditriletes filiformis, Converrucosisporites pustulatus, Leiosphaeridia talchirensis y Didecitriletes uncinatus, cuyo registro se restringen al Cisuraliano de Australia, India, Brasil.

También se destaca un conjunto de especies (Anapiculatisporites tereteangulus, Brevitriletes cornutus, Lueckisporites singhii, Staurosaccites cordubensis, Vittatina fasciolata Tiwarisporites simplex y Buedingiisphaeridium permicum) ampliamente registradas en el Cisuraliano-Guadalupiano del Gondwana.

En esta biozona también aparece un conjunto de especies con registros en todo el Pérmico y que se extienden hasta el Triásico Inferior, como por ejemplo Osmundacidites wellmanii, Krauselisporites punctatus, K. apiculatus, Baculatisporites bharadwaji, Protohaploxypinus bharadwajii, P. goraiensis, P. varius, P. microcorpus, P. diagonalis, Striatopodocarpites gondwanensis, Alisporites australis, Falcisporites parvus, F. similis, Scheuringipollenites ovatus, Weylandites lucifer, Preacolpatites sinuosus y Micrhystridium fragile); como así también taxones que se registran desde el Pennsylvaniano hasta el Pérmico, como lo son Brevitriletes levis, Horriditriletes uruguaiensis, Convolutispora ordonezii, Cyclogranisporites microgranus, Didecitriletes ericianus, Cristatisporites rollerii, C. chacoparanensis, Vallatisporites arcuatus, Verrucosisporites microtuberosus, Granulatisporites austroamericanus, Diatomozonotriletes subbaculiferus, Lundbladispora riobonitensis, Crucisaccites latisulcatus, Potonieisporites triangulatus, P. densus, P. lelei, Caheniasaccites elongatus, C. densus, Limitisporites amazoniensis, Crucisaccites latisulcatus, Scheuringipollenites circularis, Hamiapollenites fusiformis, Corisaccites alutas, Pakhapites ovatus, P. fusus, Laevigatosporites vulgaris, Quadrisporites granulatus, Brazilea scissa, Cymatiosphaera gondwanensis (véase Cuadro 7).

Por último se debe destacar que Thymospora criciumensis y Alisporites rioclarensis solo han sido descriptas para Cisuraliano-Guadalupiano de Brasil; y Hamiapollenites andiraensis, si bien presenta una distribución cosmopolita sólo ha sido mencionada para asociaciones del Cisuraliano.

Por lo tanto se entiende que a partir de la presencia Anapiculatisporites tereteangulus, Brevitriletes cornutus, Converrucosisporites confluens, C. micronodosus, C. pustulatus, Convolutispora archangelskyi, Didecitriletes uncinatus, D. ericianus, Gondisporites serrulatus, Horriditriletes superbus, H. filiformis, Striomonosaccites 
cicatricosus, Colpisaccites granulosus, Lunatisporites variesecctus, Lueckisporites singhii, Staurosaccites cordubensis, Vittatina vittifera, V. corrugata, V. fasciolata, Tiwarisporites simplex, T. anaverrucosus, Polarisaccites bilateralis, Leiosphaeridia talchirensis y Buedingiisphaeridium permicum es posible asignar para la Biozona CV una edad pérmica temprana a media (Cisuraliano-Guadalupiano temprano).

\begin{tabular}{|c|c|c|c|c|c|}
\hline & Carbonífero & Pérmico & & & Triásico \\
\hline Especies seleccionadas / & \begin{tabular}{|l|} 
Pennsylvan \\
\end{tabular} & \begin{tabular}{|l|l|} 
Cisuraliano & Guadalupiano \\
\end{tabular} & Lopingiano & Inferior & Medio-Superior \\
\hline \multicolumn{6}{|l|}{ 027-Horriditriletes ramosus } \\
\hline \multicolumn{6}{|l|}{ 171-Cycadopites follicularis } \\
\hline \multicolumn{6}{|l|}{ 004-Leiotriletes directus } \\
\hline \multicolumn{6}{|l|}{ 007-Punctatisporites gretensis } \\
\hline \multicolumn{6}{|l|}{ 010-Retusotriletes diversiformis } \\
\hline \multicolumn{6}{|l|}{ 060-Laevigatosporites flexus } \\
\hline \multicolumn{6}{|l|}{ 067-Botryococcus braunii } \\
\hline \multicolumn{6}{|l|}{ 068-Brazilea scissa } \\
\hline \multicolumn{6}{|l|}{ 074-Quadrisporites granulatus } \\
\hline \multicolumn{6}{|l|}{ 078-Cannanoropollis janakii } \\
\hline 093-Gondwanapollis frenguellii & & & & & \\
\hline 111-Platysaccus leschikii & & & & & \\
\hline \multicolumn{6}{|l|}{ 112-Platysaccus papilionis } \\
\hline \multicolumn{6}{|l|}{ 113-Platysaccus queenslandi } \\
\hline \multicolumn{6}{|l|}{ 117-Scheuringipollenites maximus } \\
\hline \multicolumn{6}{|l|}{ 131-Lunatisporites noviaulensis } \\
\hline \multicolumn{6}{|l|}{ 140-Lueckisporites virkkiae } \\
\hline \multicolumn{6}{|l|}{ 141-Protohaploxypinus amplus } \\
\hline \multicolumn{6}{|l|}{ 144-Protohaploxypinus limpidus } \\
\hline \multicolumn{6}{|l|}{ 150-Striatopodocarpidites fusus } \\
\hline \multicolumn{6}{|l|}{ 157-Vittatina costabilis } \\
\hline \multicolumn{6}{|l|}{ 159-Vittatina subsaccata } \\
\hline \multicolumn{6}{|l|}{ 165-Marsupipollenites striatus } \\
\hline \multicolumn{6}{|l|}{ 166-Marsupipollenites triradiatus } \\
\hline \multicolumn{6}{|l|}{ 005-Leiotriletes tiwarii } \\
\hline 034-Didecitriletes ericianus & & & & & \\
\hline 051-Lundbladispora braziliensis & & & & & \\
\hline 053-Lundbladispora riobonitensis & & & & & \\
\hline 062-Laevigatosporites vulgaris & & & & & \\
\hline 125-Corisaccites alutas & & & & & \\
\hline 002-Calamospora hartungiana & & & & & \\
\hline 012-Cyclogranisporites microgrant & & & & & \\
\hline 013-Granulatisporites austroameric & & & & & \\
\hline 017-Brevitriletes levis & & & & & \\
\hline 023-Verrucosisporites microtubero. & & & & & \\
\hline 029-Horriditriletes uruguaiensis & & & & & \\
\hline 038-Convolutispora ordonezii & & & & & \\
\hline 042-Diatomozonotriletes subbaculif & & & & & \\
\hline 046-Cristatisporites chacoparanaen & & & & & \\
\hline 056-Vallatisporites arcuatus & & & & & \\
\hline 073-Portalites gondwanensis & & & & & \\
\hline 087-Plicatipollenites malabarensis & & & & & \\
\hline 088-Cahenisaccites densus & & & & & \\
\hline
\end{tabular}




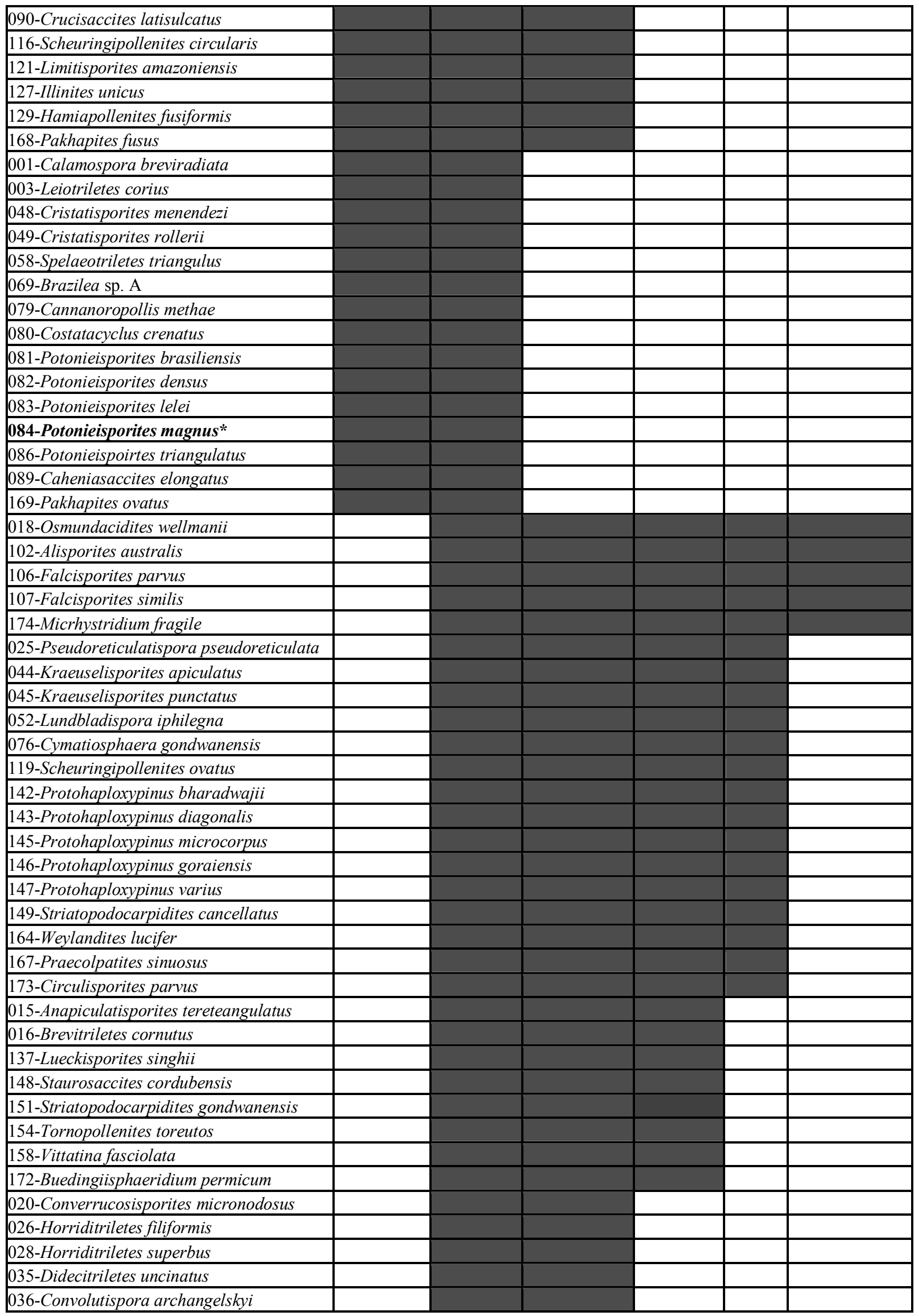




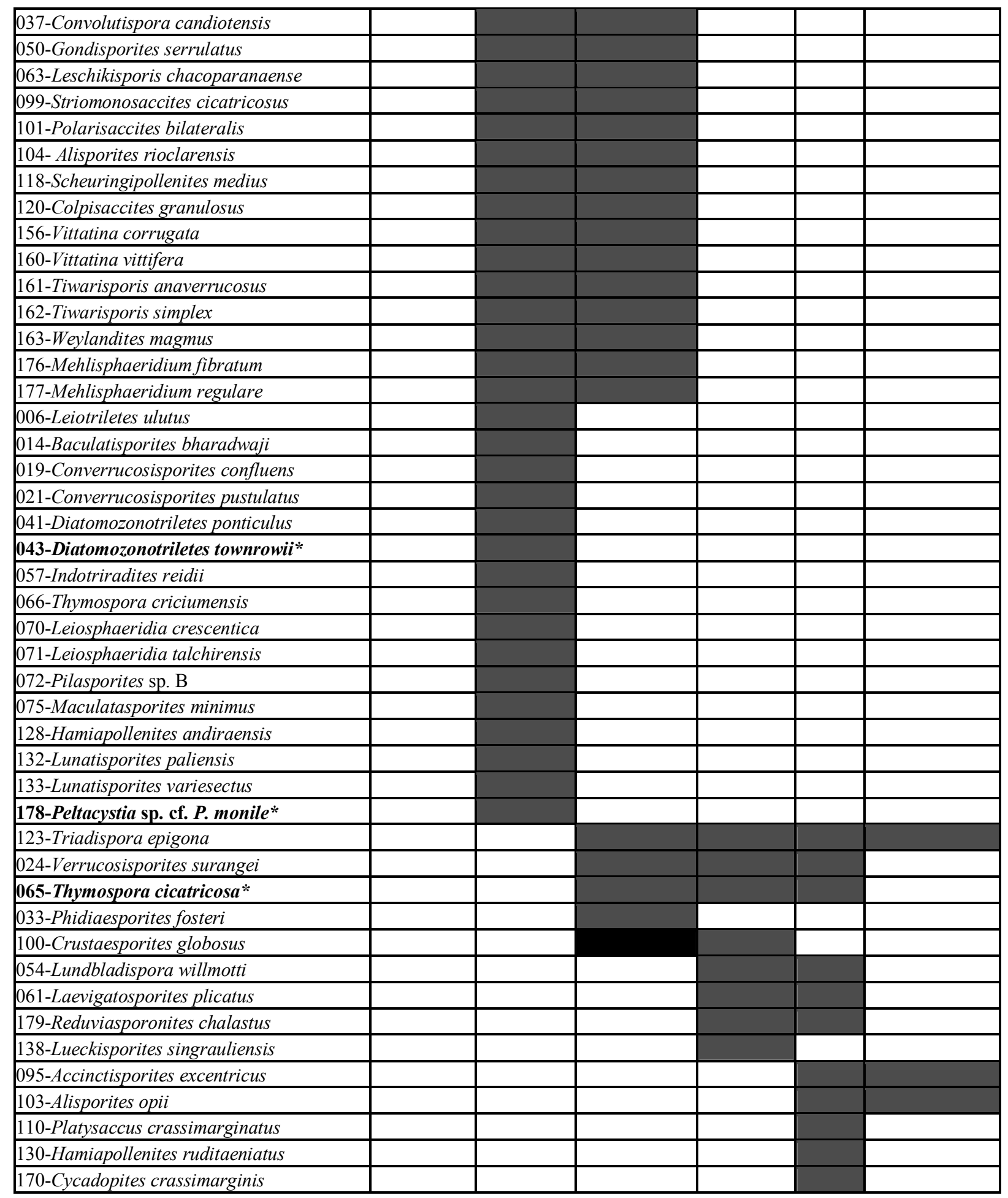

Cuadro 7. Distribución estratigráfica de las especies identificadas en la Cuenca Claromecó-Colorado. *Retrabajo. 


\section{Biozona de Asociación Tornopollenites toreutos-Reduviasporonites chalastus}

(TC). Entre los componentes de la Biozona que presentan valor estratigráfico (Cuadro 7) se destacan la presencia de Tornopollenites toreutos (con registros en el Pérmico de Estados Unidos, Brasil y Sudáfrica) y Reduviasporonites chalastus (células fúngicas aisladas o asociadas en forma de cadena, especie restringida al Lopingiano-Triásico Inferior y ampliamente registrada, tanto en Australia, China, Rusia, Groenlandia, Inglaterra y Arabia Saudita (véase Foster et al., 2002; Stephenson et al., 2003), como en Argentina (Formación La Veteada, Zavattieri et al., 2008).

Entre las especies con presencia exclusiva en la biozona, Phidiaesporites fosteri es característica del Guadalupiano de Australia (Foster, 1979). El resto de las especies registradas para la asociación presentan una distribución más amplia, ya sea abarcando todo el Pérmico, como Anapiculatisporites tereteangulatus, Brevitriletes cornutus, Didecitriletes ericianus, Lueckisporites singhii, Staurosaccites cordubensis, Vittatina fasciolata y Buedingiisphaeridium permicum.

Otro conjunto lo conforman las especies con registro que abarca todo el Pérmico y el Triásico Inferior, como Pseudoreticulatispora pseudoreticulata, Circulisporites parvus, Baculatisporites bharadwajii, Falcisporites parvus, F. similis, Scheuringipollenites ovatus, Protohaploxypinus goraiensis, P. microcorpus, $P$. diagonalis, P. varius, Striatopodocarpites gondwanensis, Weylandites lucifer y Micrhystridium fragile.

Por su parte Lundbladispora willmotti y Laevigatosporites plicatus presentan un registro que va del Lopingiano al Triásico Inferior. Mientras Portalites gondwanensis, Vallatisporites arcuatus, Leiotriletes corius, Potonieisporites lelei y P. brasiliensis, Pennsylvaniano-Cisuraliano. Los biocrones de dichas especies se extenderían a partir de estos registros.

Sobre la base de la presencia de taxones característicos del Lopingiano (Crustaesporites globosus), del límite Permo-Triásico (Reduviasporonites chalastus), como así también del Guadalupiano (Phidiaesporites fosteri) es posible asignar a la Biozona TC una edad de rango que va del Guadalupiano tardío al Lopingiano temprano. 


\section{VI.4. Comparaciones con biozonas de cuencas sudamericanas}

\section{VI.4.1. Cuenca Chacoparaná}

La Cuenca Chacoparaná (Figuras 15) presenta un desarrollo en el subsuelo del centro-este de Argentina y se extiende en sentido norte sur. La mayor parte del conocimiento de la palinología de esta cuenca se alcanzó a través de distintas perforaciones realizadas por YPF e YCF en las provincias de Córdoba, Santa Fe, Santiago del Estero y Chaco (véase Archangelsky et al., 1987, 1996). Russo et al. (1980) definieron para las formaciones Ordoñez y Victoriano Rodríguez, las Biozonas Potonieisporites-Lundbladispora (PL), Cristatisporites (C) (Asseliano-Kunguriano) y Striatites (S) (Kunguriano?-Kazaliano). Posteriormente este esquema fue completado y ajustado en varias ocasiones (Vergel, 1993, 1986, 1987a, 1987b; Archangelsky y Vergel, 1996; Césari et al., 1995; Gutiérrez et al., 2003b). En el Cuadro 8 se incluye un listado de los componentes de las biozonas indentificadas en la Cuenca ClaromecóColorado (CV y TC, ya sea en la perforación La Estrella como Cruz del Sur) y que comparte con las biozonas Cristatisporites y Striatites de Cuenca Chacoparaná. 


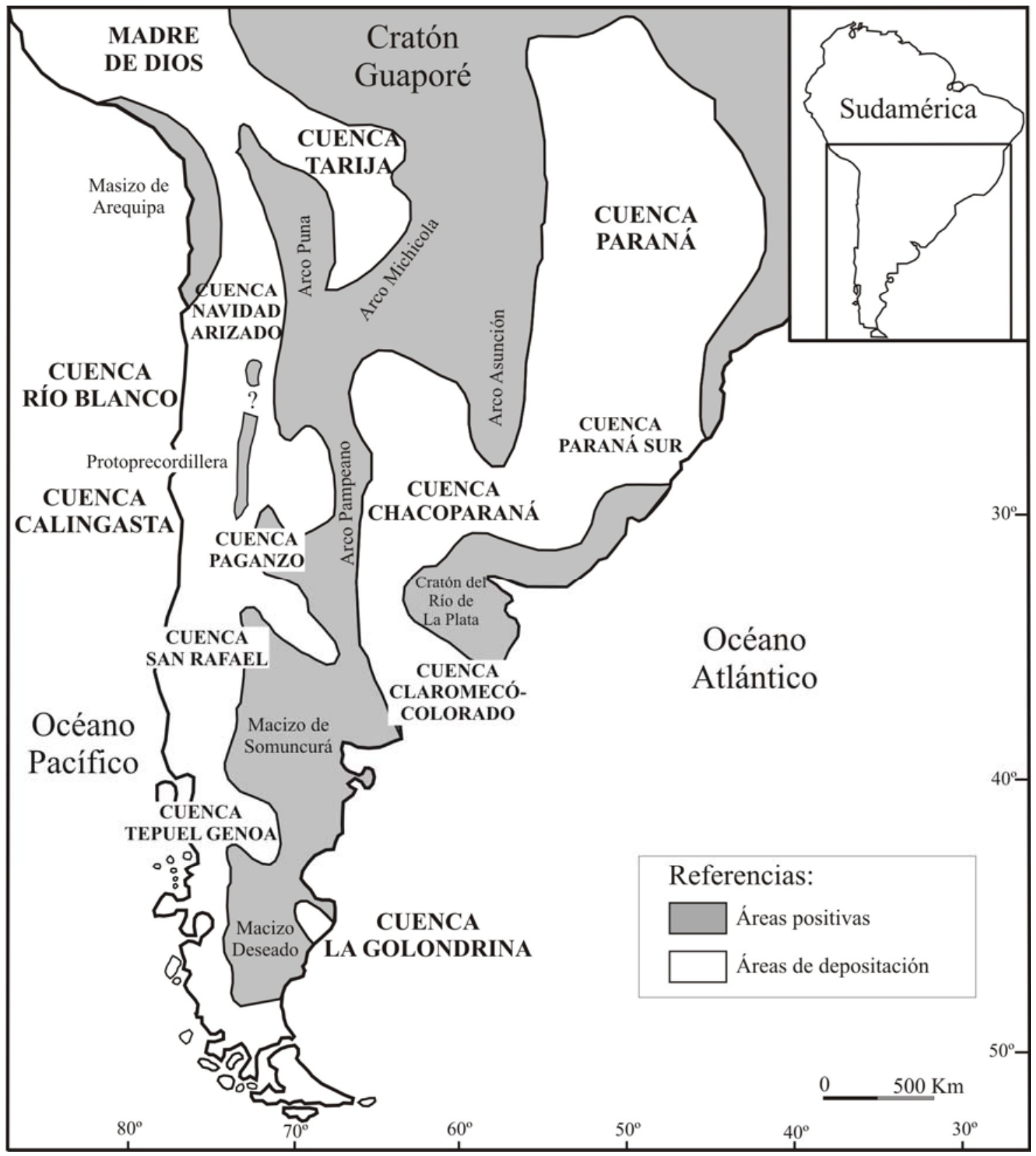

Figura 15. Principales cuencas sedimentarias de Sudamérica del Neopaleozoico. 


\begin{tabular}{|c|c|c|c|c|c|}
\hline Cuencas & \multicolumn{2}{|c|}{ Chacoparaná } & \multicolumn{3}{|c|}{ Claromecó-Colorado } \\
\hline Taxones / Biozonas & $\mathbf{C}$ & $\mathbf{S}$ & $\mathbf{C V}$ & TC & CVs \\
\hline 12- Cyclogranisporites microgranus & & & & & \\
\hline 13-Granulatisporites austroamericanus & & & & & \\
\hline 16-Brevitriletes cornutus & & & & & \\
\hline 20-Converrucosisporites micronodosus & & & & & \\
\hline 25- Pseudoreticulatispora pseudoreticulata & & & & & \\
\hline 29- Horriditriletes uruguaiensis & & & & & \\
\hline 37- Convolutispora candiotensis & & & & & \\
\hline 50- Gondisporites serrulatus & & & & & \\
\hline 53-Lundbladispora riobonitensis & & & & & \\
\hline 56-Vallatisporites arcuatus & & & & & \\
\hline 63- Leschikisporis chacoparanaense & & & & & \\
\hline 67- Botryococcus braunii & & & & & \\
\hline 68-Brazilea scissa & & & & & \\
\hline 73-Portalites gondwanensis & & & & & \\
\hline 77- Cannanorpollis sp. cf. C. densus & & & & & \\
\hline 79- Cannanoropollis methae & & & & & \\
\hline 90- Crucisaccites latisulcatus & & & & & \\
\hline 101-Polarisaccites bilateralis & & & & & \\
\hline 116- Scheuringipollenites circularis & & & & & \\
\hline 144- Protohaploxypinus limpidus & & & & & \\
\hline 157- Vittatina costabilis & & & & & \\
\hline 168-Pakhapites fusus & & & & & \\
\hline 7- Punctatisporites gretensis & & & & & \\
\hline 19- Converrucosisporites confluens & & & & & \\
\hline 38-Convolutispora ordonezii & & & & & \\
\hline 42- Diatomozonotriletes subbaculiferus & & & & & \\
\hline 47-Cristatisporites sp. cf. C. inconstans & & & & & \\
\hline 51-Lundbladispora braziliensis & & & & & \\
\hline 81- Potonieisporites brasiliensis & & & & & \\
\hline 87- Plicatipollenites malabarensis & & & & & \\
\hline 99- Striomonosaccites cicatricosus & & & & & \\
\hline 120-Colpisaccites granulosus & & & & & \\
\hline 129- Hamiapollenites fusiformis & & & & & \\
\hline 133- Lunatisporites variesectus & & & & & \\
\hline 148-Staurosaccites cordubensis & & & & & \\
\hline 149-Striatopodocarpidites cancellatus & & & & & \\
\hline 159-Vittatina subsaccata & & & & & \\
\hline 165-Marsupipollenites striatus & & & & & \\
\hline 36- Convolutispora archangelskyi & & & & & \\
\hline 119- Scheuringipollenites ovatus & & & & & \\
\hline 140- Lueckisporites virkkiae & & & & & \\
\hline 161- Tiwarisporis anaverrucosus & & & & & \\
\hline 125-Corisaccites alutas & & & & & \\
\hline
\end{tabular}

Cuadro 8. Especies comunes entre las biozonas de Cuenca Claromecó-Colorado (CV y TC: perforación La Estrella x-1; CVs: perforación Cruz del Sur x-1) y Cristatisporites (C) y Striatites (S) de Cuenca Chacoparaná. 
La Biozona Converrucosisporites confluens-Vittatina vittifera (CV) comparte con la Biozona Cristatisporites 29 especies (Cuadro 8), entre las que se destacan Converrucosisporites micronodosus, C. confluens, Gondisporites serratus, Convolutispora ordonezi, C. candiotensis, Striomonosaccites cicatricosus, Polarisaccites bilateralis, Pakhapites fusus y Striatopodocarpites cancellatus. También se destacan Cyclogranisporites microgranus, Brevitriletes cornutus, Horriditriletes uruguaiensis, Gondisporites serrulatus, Lundbladispora riobonitensis, Brazilea scissa, Crucisaccites latisulcatus y Polarisaccites bilateralis, especies que comparten y que son exclusivas de ambas biozonas ( $\mathrm{Cr}$ y CV). Por otro lado, la Biozona CV comparte con la Biozona Striatites, 18 especies (C. confluens, Striomonosaccites cicatricosus, Lunatisporites varisectus, Convolutispora archangelskyi, Lueckisporites virkkiae, Tiwarisporis anaverrucosus, Leschiskisporis chacoparanaense, Scheuringipollenites ovatus y Staurosaccites cordubensis, etc.), y no presentan formas exclusivas compartidas entre ambas bizonas (S y CV).

La presencia de formas exclusivas tanto de la Biozona $\mathrm{Cr}$ como de la $\mathrm{S}$ en la Biozona $\mathrm{CV}$ no permite realizar una estrecha comparación con una u otra biozona en particular, aunque sí se puede destacar que la Biozona $\mathrm{Cr}$ está caracterizada por la abundancia de formas cingulizonadas (en especial los géneros Cristatisporites, Vallatisporites y Lublandispora), lo que no se observa en ninguna de las asociaciones de Cuenca Claromecó-Colorado.

Por su parte la Biozona Tornopollenites toreutos-Reduviasporonites chalastus (TC) comparte con la Biozona Cristatisporites 23 especies (Cuadro 8) (tales como Convolutispora ordonezii, Lunatisporites variesectus, Staurosaccites cordubensis, Vittatina costabilis), siendo compartidas en forma exclusiva por ambas Biozonas (TC y Cr), 5 especies: Pseudoreticulatispora pseudoreticulata, Convolutispora candiotensis, Vallatisporites arcuatus, Leschikisporis chacoparanaense y Portalites gondwanensis. Mientras que comparte 16 especies con la Biozona Striatites (Convolutispora ordoñezii, Diatomozonotriletes subbaculiferus, Striomonosaccites cicatricosus, Marsupipollenites striatus, Lunatisporites variesectus, Staurosaccites cordubensis, Striatopodocarpites cancellatus, etc.). 
Se puede observar cierta afinidad entre las composiciones de las Biozonas TC y Striatites, ya que entre las especies en común se destacan aquellas que caracterizan a ambas biozonas: Convolutispora archangelskyi, Scheuringipollenites ovatus, Leschiskisporites chacoparanaense, Tiwarisporis anaverrucosus, y Corisaccites alutas, y a su vez, todas estas formas son exclusivas de la Biozona S.

Por lo tanto, y teniendo en cuenta las composiciones de las asociaciones identificadas en la Cuenca Claromecó-Colorado no es posible referirlas a ninguna de las biozonas del Pérmico de la Cuenca Chacoparaná, ya que las especies características de las biozonas Cristatisporites y Striatites, se hallan mayoritariamente compartidas por las Biozonas CV y TC (véase Cuadro 8).

Además se debe señalar que para la Biozona Cristatisporites se estableció (Archangelsky y Vergel, 1996) que su límite inferior está indicado por los primeros registros de Hamiapollenites bullaeformis y Protohaploxypinus limpidus. Si bien esta última especie aparece en ambas asociaciones de La Estrella, H. bullaeformis no ha sido hallada en ninguna de las perforaciones estudiadas. En la Biozona Cr también domina el polen del tipo monosacado, las esporas triletes apiculadas y cingulizonadas y en particular existe una importante diversidad específica dentro del género Cristatisporites. Esta última característica aparece insinuada en la asociación de Cruz del Sur, ya que aparecen escasos ejemplares de Cristatisporites chacoparanaensis, C. menendezi y $C$. rollerii. Con respecto a los granos de polen monosacados, no dominan las asociaciones aquí estudiadas, aunque sí están presentes.

\section{VI.4.2. Cuencas del centro-oeste de Argentina}

Para las cuencas que se desarrollaron en el intervalo Carbonífero-Pérmico en el centro-oeste de Argentina (Paganzo, Río Blanco, Calingasta-Uspallata y San Rafael, véase Figura 15), Césari y Gutiérrez (2000) propusieron un esquema bioestratigráfico, definiendo para el Pérmico las biozonas de asociación Fusacolpites fusus-Vittatina subsaccata (FS) y Lueckisporites-Weylandites (LW) (véase Figura 2). En el Cuadro 9 se incluyeron las especies que comparten las biozonas propuesta para Claromecó-Colorado con las biozonas FS y LW, observándose un comportamiento similar a las biozonas de Chacoparaná. 


\begin{tabular}{|c|c|c|c|}
\hline Cuencas & Centrooeste & Claromecó- & rado \\
\hline Taxones / Biozonas & \begin{tabular}{l|l} 
FS & LW \\
\end{tabular} & \begin{tabular}{l|l} 
CV & TC \\
\end{tabular} & CVs \\
\hline 07- Punctatisporites gretensis & & & \\
\hline 16- Brevitriletes cornutus & & & \\
\hline 48-Cristatisporites menendezi & & & \\
\hline 49- Cristatisporites rollerii & & & \\
\hline 51- Lundbladispora braziliensis & & & \\
\hline 53-Lundbladispora riobonitensis & & & \\
\hline 73-Portalites gondwanensis & & & \\
\hline 79- Cannanoropollis methae & & & \\
\hline 109- Pityosporites sp. A & & & \\
\hline 115- Pteruchipollenites sp. cf. P. gracilis & & & \\
\hline 144- Protohaploxypinus limpidus & & & \\
\hline 4- Leiotriletes directus & & & \\
\hline 29- Horriditriletes uruguaiensis & & & \\
\hline 68-Brazilea scissa & & & \\
\hline 77- Cannanorpollis sp. cf. C. densus & & & \\
\hline 78- Cannanoropollis janakii & & & \\
\hline 81- Potonieisporites brasiliensis & & & \\
\hline 87- Plicatipollenites malabarensis & & & \\
\hline 88- Cahenisaccites densus & & & \\
\hline 102- Alisporites australis & & & \\
\hline 120- Colpisaccites granulosus & & & \\
\hline 122- Limitisporites sp. cf. L. rectus & & & \\
\hline 129- Hamiapollenites fusiformis & & & \\
\hline 141- Protohaploxypinus amplus & & & \\
\hline 158- Vittatina fasciolata & & & \\
\hline 159- Vittatina subsaccata & & & \\
\hline 163- Weylandites magmus & & & \\
\hline 165-Marsupipollenites striatus & & & \\
\hline 168- Pakhapites fusus & & & \\
\hline 169- Pakhapites ovatus & & & \\
\hline 38-Convolutispora ordonezii & & & \\
\hline 46- Cristatisporites chacoparanaensis & & & \\
\hline 118- Scheuringipollenites medius & & & \\
\hline 133- Lunatisporites variesectus & & & \\
\hline 140-Lueckisporites virkkiae & & & \\
\hline 148-Staurosaccites cordubensis & & & \\
\hline 153- Striatopodocarpidites sp. cf. S. solitus & & & \\
\hline 161- Tiwarisporis anaverrucosus & & & \\
\hline 164- Weylandites lucifer & & & \\
\hline
\end{tabular}

Cuadro 9. Especies de las biozonas de Cuenca Claromecó-Colorado (CV y TC: perforación La Estrella; CVs: perforación Cruz del Sur) compartidas con las biozonas FS (Fusacolpites fusus-Vittatina subsaccata) y LW (Lueckisporites-Weylandites) de las cuencas del Centro-Oeste de Argentina. 
De este modo la Biozona Converrucosisporites confluens-Vittatina vittifera (CV) comparte con la Biozona FS un total de 26 especies (véase Cuadro 9), entre ellas se destacan Vittatina fasciolata, Weylandites magmus, Brevitriletes cormutus y Pakhapites ovatus; presentando solo las siguientes especies exclusivas en común: Brevitriletes cormutus, Lundbladispora riobonitensis y Pakhapites ovatus. Por su parte comparte 24 especies con la Biozona LW, entre ellas Protohaploxypinus amplus, Pakhapites fusus y V. subsacatta; y no comparten especies exclusivas de ambas biozonas (CV y LW).

Dentro de las especies que caracterizan a la Biozona LW, Convolutispora ordonezii, Weylandites lucifer, Tiwarisporis anaverrucosus, Staurosaccites cordubensis, Lunatisporites variesectus, Lueckisporites virkkiae, Scheuringipollenites medius, se han identificado en la Biozona CV.

Por lo tanto no se puede establecer una estrecha correlación entre la biozona $\mathrm{CV}$ con las biozonas del oeste argentino, porque la correspondencia de especies es alta con ambas biozonas de la Cuenca Claromecó-Colorado.

Por su parte la Biozona Tomopollenites toreutos-Reduviasporonites chalastus (TC) comparte con la Biozona FS, 20 especies (Cuadro 9), entre ellas algunas formas diagnóticas: Hamiapollenites fusiformis, Colpisaccites granulosus, Vittatina subsaccata, Marsupipollenites striatus, y solo comparten como única especie exclusiva de ambas biozonas (TC y FS) Portalites gondwanernsis, aunque de escaso valor estratigráfico por su amplio registro.

Con la Biozona LW también comparte 20 especies (entre ellas Tiwarisporis anaverrucosus, Staourosaccites cordubensis, Lunatisporites variesectus, Convolutispora ordonezii). La Biozona LW se define por la primera aparición de especies de Lueckisporites, y la dominancia de especies de los géneros Vittatina, Marsupipollenites, Weylandites, etc. Esta última característica ha sido observada en la Biozona TC; mientras que la presencia de Lueckisporites spp. ya ha sido registrada para la biozona inferior (CV).

Por todo ello ambas biozonas propuestas para la Cuenca Claromecó-Colorado (CV y TC), presentan las mismas similitudes en cuanto a su composición específica con las biozonas del centro oeste argentino (FS y LW). Además algunas de las especies que caracterizan a las Biozonas FS y LW, están presentes en las biozonas aquí propuestas (Cuadro 9).

\section{VI.4.3. Cuenca Paraná, Brasil}

La Cuenca Paraná (Figura 15) se halla en el centro-este de Sudamérica, comprende unos $1.700 .000 \mathrm{~km}^{2}$ y se desarrolla en su gran mayoría en Brasil aunque alcanza zonas de Uruguay, Argentina y Paraguay. Milani (1997) reconoció 6 supersecuencias para esta cuenca, denominando desde la más antigua: Rio Ivaí (relacionada con el Grupo Río Ivaí, 
Ordovícico-Silúrico), Paraná (Grupo Paraná, Devónico); Gondwana I (grupos Tubaraõ y Passa Dois, Carbonífero-Pérmico); Gondwana II (formaciones triásicas), Gondwana III (Grupo San Benito, Jurásico-Cretácico) y la Supersecuencia Bauru (Grupo Bauru, Cretácico). La Supersecuencia Gondwana I corresponde a un ciclo transgresivo-regresivo, y está representado en su mayoría en el Grupo Tubaraõ. La sección inferior está constituida por el Subgrupo Itararé, seguidos por las formaciones Rio Bonito y Palermo (Subgrupo Guatá). El Grupo Passa Dios lo componen las formaciones Irati, Serra Alta, Teresina y Rio do Rastro. La palinología de la Supersecuencia Gondwana I ha sido ampliamente estudiada, y se ha propuestos esquemas bioestratigráficos, destacándose los Daemón y Quadros (1970) y Marques-Toigo (1988, 1991); éste último ha sido ajustado y modificado en repetidas oportunidades (Daemón y Marques-Toigo, 1991; Souza y Marques-Toigo, 2003, 2005) (Cuadro 16). Estos esquemas plantean particularmente para las formaciones Rio Bonito, Palermo e Irati, las biozonas de intervalo Vittatina costabilis (Vc) y Lueckisporites virkkiae (Lv). La Biozona Vc se divide en las subzonas Protohaploxypinus goriaensis (Pg) y Hamiapollenites karooensis (Hk).

En el Cuadro 6 se han incluido las especies en común identificadas en las biozonas pérmicas de la Cuenca Paraná (Vc y Lv) y en las biozonas propuestas para la Cuenca Claromecó-Colorado (CV y TC). La Biozona Converrucosisporites confluens-Vittatina vittifera $(\mathrm{CV})$ comparte con la Biozona Vc, 35 especies, entre ellas Protohaploxypinus goraiensis, Diatomozonotriletes subbaculiferus, Laevigatosporites vulgaris, Granulatisporites austroamericanus, Converrucosisporites confluens. Ambas biozonas (CV, Vc) comparten 7 formas exclusivas: Horriditriletes ramosus, H. uruguaiensis, Cristatisporites inconstans, Vallatisporites arcuatus, D. subbaculiferus, Kraeuselisporites apiculatus, K. punctatus, Lundbladispora riobonitensis, Quadrisporites granulatus, Illinites unicus, Stellapollenites talchirensis y Maculatasporites minimus. A su vez comparte con la Biozona Lv, 27 especies, destacándose Lueckisporites virkkiae, Protohaploxypinus microcorpus y Weylandites lucifer, aunque no compraten ninguna especie exclusivas. 


\begin{tabular}{|c|c|c|c|c|c|c|}
\hline \multirow{3}{*}{$\begin{array}{c}\text { Cuencas } \\
\text { Especies / Biozonas }\end{array}$} & \multicolumn{3}{|c|}{ Paraná } & \multirow{2}{*}{\multicolumn{3}{|c|}{ Claromecó-Colorado }} \\
\hline & \multicolumn{2}{|c|}{$\mathbf{V e}$} & \multirow[t]{2}{*}{$\mathbf{L v}$} & & & \\
\hline & $\mathbf{P g}$ & Hk & & $\mathrm{CV}$ & TC & CVs \\
\hline 4- Leiotriletes directus & & & & & & \\
\hline 17-Brevitriletes levis & & & & & & \\
\hline 146- Protohaploxypinus goraiensis & & & & & & \\
\hline 27-Horriditriletes ramosus & & & & & & \\
\hline 47-Cristatisporites sp. cf. C. inconstans & & & & & & \\
\hline 29-Horriditriletes uruguaiensis & & & & & & \\
\hline 13- Granulatisporites austroamericanus & & & & & & \\
\hline 56-Vallatisporites arcuatus & & & & & & \\
\hline 19- Converrucosisporites confluens & & & & & & \\
\hline 74-Quadrisporites granulatus & & & & & & \\
\hline 129- Hamiapollenites fusiformis & & & & & & \\
\hline 127-Illinites unicus & & & & & & \\
\hline 122-Limitisporites sp. cf. L. rectus & & & & & & \\
\hline 42-Diatomozonotriletes subbaculiferus & & & & & & \\
\hline 44- Kraeuselisporites apiculatus & & & & & & \\
\hline 45-Kraeuselisporites punctatus & & & & & & \\
\hline 53-Lundbladispora riobonitensis & & & & & & \\
\hline 73-Portalites gondwanensis & & & & & & \\
\hline 94- Stellapollenites sp. cf. S. talchirensis & & & & & & \\
\hline 118-Scheuringipollenites medius & & & & & & \\
\hline 5-Leiotriletes tiwarii & & & & & & \\
\hline 7- Punctatisporites gretensis & & & & & & \\
\hline 12- Cyclogranisporites microgranus & & & & & & \\
\hline 20-Converrucosisporites micronodosus & & & & & & \\
\hline 23-Verrucosisporites microtuberosus & & & & & & \\
\hline 26- Horriditriletes filiformis & & & & & & \\
\hline 37- Convolutispora candiotensis & & & & & & \\
\hline 51-Lundbladispora braziliensis & & & & & & \\
\hline 67- Botryococcus braunii & & & & & & \\
\hline 81- Potonieisporites brasiliensis & & & & & & \\
\hline 87- Plicatipollenites malabarensis & & & & & & \\
\hline 102-Alisporites australis & & & & & & \\
\hline 141- Protohaploxypinus amplus & & & & & & \\
\hline 144- Protohaploxypinus limpidus & & & & & & \\
\hline 159- Vittatina subsaccata & & & & & & \\
\hline 160- Vittatina vittifera & & & & & & \\
\hline 168- Pakhapites fusus & & & & & & \\
\hline 169- Pakhapites ovatus & & & & & & \\
\hline 149-Striatopodocarpidites cancellatus & & & & & & \\
\hline 117-Scheuringipollenites maximus & & & & & & \\
\hline 76- Cymatiosphaera gondwanensis & & & & & & \\
\hline 75- Maculatasporites minimus & & & & & & \\
\hline 157-Vittatina costabilis & & & & & & \\
\hline 165-Marsupipollenites striatus & & & & & & \\
\hline 62- Laevigatosporites vulgaris & & & & & & \\
\hline 66- Thymospora criciumensis & & & & & & \\
\hline 133-Lunatisporites variesectus & & & & & & \\
\hline 148-Staurosaccites cordubensis & & & & & & \\
\hline 150-Striatopodocarpites fusus & & & & & & \\
\hline 140-Lueckisporites virkkiae & & & & & & \\
\hline 145-Protohaploxypinus microcorpus & & & & & & \\
\hline 164- Weylandites lucifer & & & & & & \\
\hline 166-Marsupipollenites triradiatus & & & & & & \\
\hline
\end{tabular}

Cuadro 10. Especies de las biozonas de Cuenca Claromecó-Colorado (CV y TC: perforación La Estrella; CVs: perforación Cruz del Sur) compartidas con las biozonas Vc (Vittatina costabilis) y Lv (Lueckisporite virkkiae) de la Cuenca Paraná, Brasil 
La Biozona Tornopollenites toreutos-Reduviasporonites chalastus (TC) comparte con la Biozona Vc 32 especies, destacandose entre ellas Staurosaccites cordubensis, Vittatina vittifera, Hamiapollenites fusiformis, Scheuringipollenites maximus, Striatopodocarpites fusus. Se destacan por compartir Lundbladispora riobonitensis, Portalites gondwanensis y Stellapollenites sp. cf. S. talchirensis como especies exclusivas, aunque ninguna de ellas tienen un significado estratigráfico. Por último, comparte 24 especies con la Biozona Lv, sin especies exclusivas.

La Biozona $V c$ comienza con las primeras apariciones de diversas especies de los géneros Vittatina ( $V$. saccata, $V$. subsaccata, $V$. costabilis y $V$. vittifera) y Protohaploxypinus (P. goraiensis y P. micros) e Illinites unicus. Además, se destaca la abundancia de los granos de polen, tanto monosacados como bisacados, respecto de las esporas. Las microfloras de TC presentan dichos géneros y la abundancia de granos de polen respecto de las esporas también se ve claramente reflejada. La Biozona de Intervalo Lueckisporites virkkiae se define por la primera aparición de la especie junto con L. angoulaensis, junto con Weylandites lucifer y especies de Staurosaccites. Además están bien representados los géneros Protohaploxypinus, Striatopodocarpites, Striatoabieidites, Lunatisporites y Marsupipollenites. También están presentes los géneros de esporas Convolutispora y Thymospora. En este caso también concuerda con la composición TC, ya que dichos géneros están presentes, en algunos casos, con una diversidad específica importante.

Considerando las composiciones de ambas biozonas (CV y TC) y las de la Cuenca Paraná (Vc y Lv), no puede establecerse estrechas comparación entre sí, ya que las especies que caracterizan a cada biozona, están presentes en una y otra asociación.

\section{VI.4.4. Cuenca Amazonas, Brasil}

La Cuenca Amazonas (Figura 17) se ubica en el norte de Brasil, desarrollada en el subsuelo de los estados de Amazonas y Paraná, y se extiende en sentido este-oeste, en la misma dirección del Río Amazonas. La secuencia carbonífera-pérmica de la misma comprende al Grupo Trapajós, extendida en su mayoría en subsuelo, y conocida a partir de perforaciones petroleras. Lo conforman, de base a techo, las formaciones Monte Alegre, Itaituba, Nova Olinda y Andirá, con una potencia total de $2671 \mathrm{~m}$. 


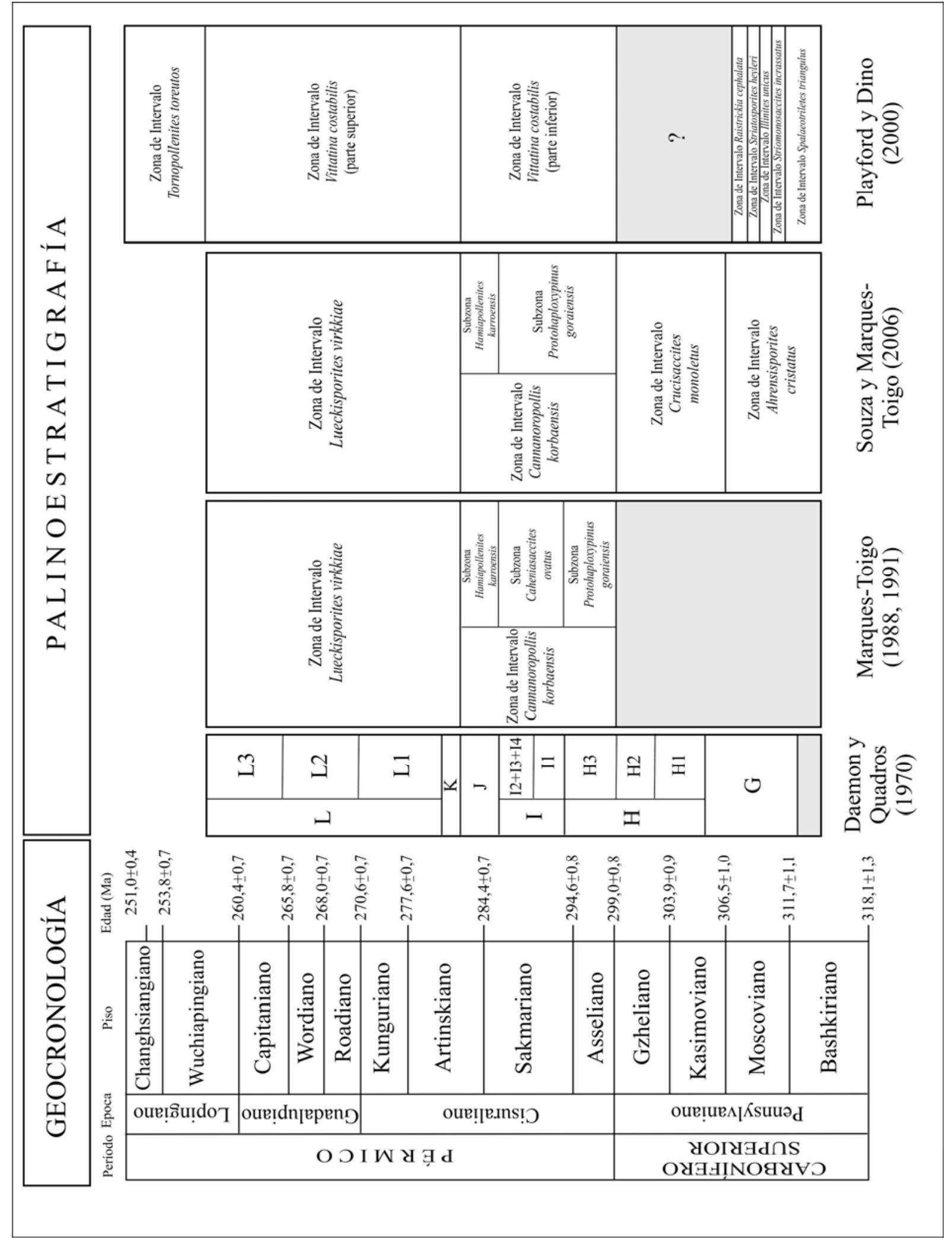

Figura 16. Cuadro palinoestratigráfico de la Cuenca Paraná. 


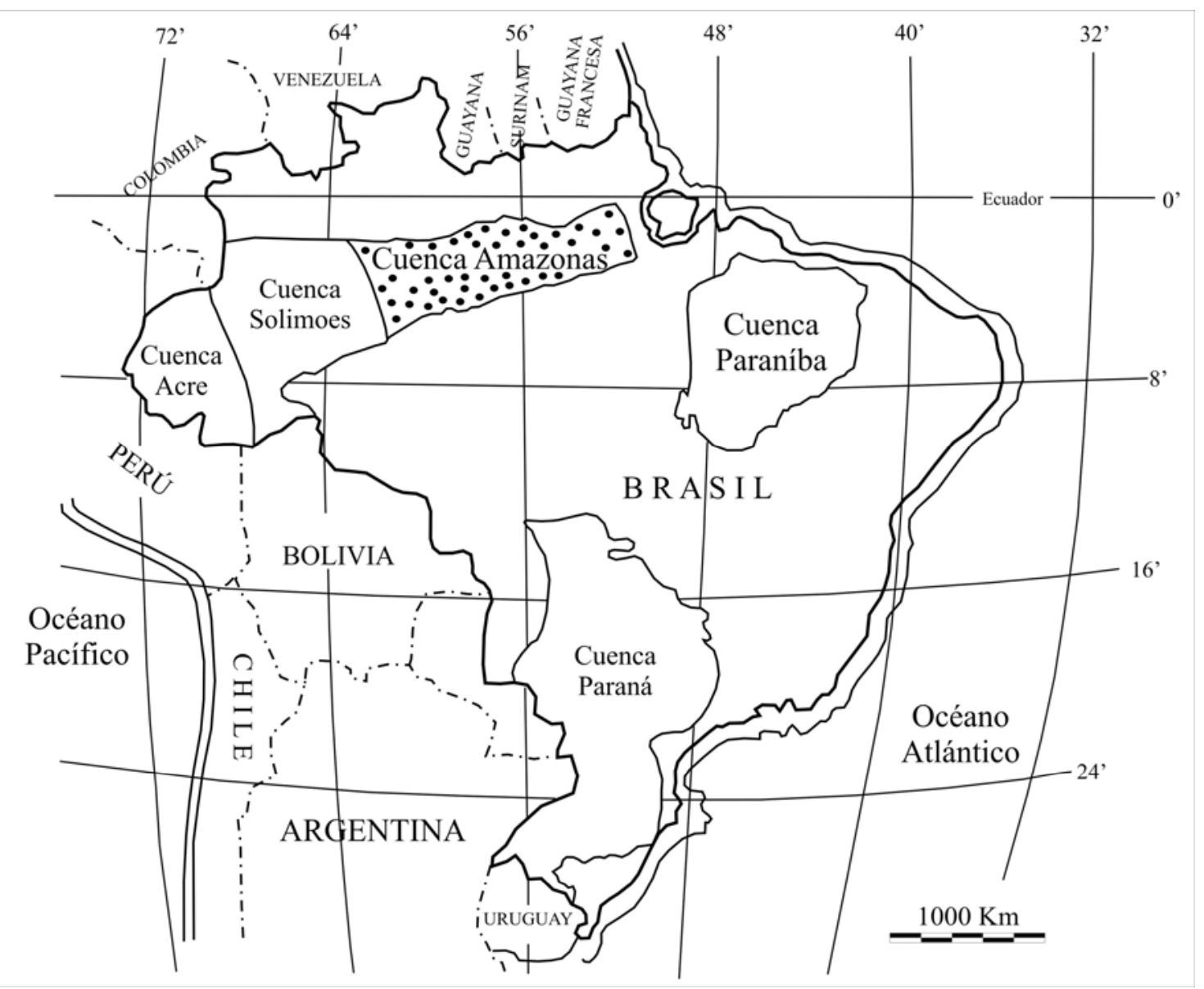

Figura 17. Cuenca Amazonas (Brasil).

La palinología de esta cuenca ha sido estudiada primero por Daemón y Contreiras (1971) y luego por Playford y Dino (2000a, 2000b), quienes establecieron un esquema bioestratigráfico (Cuadro 18) que comprende las biozonas Speleaotriletes triangulus, Striomonosaccites incressatus, Illinites unicus, Striatosporites heyleri, Raistrickia cephalata, Vittatina costabilis (parte inferior), Vittatina costabilis (parte superior) y Tornopollenites toreutos. La mayoría de estas biozonas están referidas al Carbonífero Superior, siendo únicamente pérmicas las biozonas Vittatina costabilis (Vc) y Tornopollenites toreutos $(\mathrm{Tt})$. Las especies compartidas por esta dos últimas biozonas y aquellas propuestas para la Cuenca Claromecó-Colorado ( $\mathrm{CV}$ y $\mathrm{TC}$ ) han sido graficadas en el Cuadro 11. 


\begin{tabular}{|c|c|c|c|c|}
\hline \multirow{2}{*}{\begin{tabular}{|l|} 
Cuencas \\
Especies / Biozonas \\
\end{tabular}} & Amazonas & \multicolumn{3}{|c|}{ Claromecó-Colorado } \\
\hline & Vc & CV & TC & CVs \\
\hline 062- Laevigatosporites vulgaris & & & & \\
\hline 087- Plicatipollenites malabarensis & & & & \\
\hline 125-Corisaccites alutas & & & & \\
\hline 128- Hamiapollenites andiraensis & & & & \\
\hline 129- Hamiapollenites fusiformis & & & & \\
\hline 140- Lueckisporites virkkiae & & & & \\
\hline 157- Vittatina costabilis & & & & \\
\hline 159- Vittatina subsaccata & & & & \\
\hline 160- Vittatina vittifera & & & & \\
\hline 168-Pakhapites fusus & & & & \\
\hline 171- Cycadopites follicularis & & & & \\
\hline 073-Portalites gondwanensis & & & & \\
\hline 078- Cannanoropollis janakii & & & & \\
\hline 121- Limitisporites amazoniensis & & & & \\
\hline 127-Illinites unicus & & & & \\
\hline 154- Tornopollenites toreutos & & & & \\
\hline 087- Plicatipollenites malabarensis & & & & \\
\hline
\end{tabular}

Cuadro 11. Especies de las biozonas de Cuenca Claromecó-Colorado (CV y TC: perforación La Estrella; CVs: perforación Cruz del Sur) compartidas con las biozonas Vc (Vittatina costabilis) y Tt (Tornopollenites toreutos) de la Cuenca Amazonas, Brasil

La Biozona Converrucosisporites confluens-Vittatina vittifera (CV) comparte con la Biozona Vc 13 especies, entre las que se destacan Hamiapollenites andiraensis, Lueckisporites virkkiae, Cycadopites follicularis, y Laevigatosporites vulgaris, solamente Limitisporites amazoniensis, aparece como especie exclusiva en ambas biozonas (CV y Vc). Con la Biozona Tt comparte 10 especies, aunque sin especies exclusivas en común para ambas biozonas (Cvy Tt).

La Biozona CV no parecen mostrar estrechas relaciones con estas biozonas, aunque si hay que considerar que la Biozona Vc fue definida por un conjunto de especies, sin presencias exclusiva, de las cuales se han identificado en la Biozona CV: Laevigatosporites vulgaris, Corisaccites alutas, Hamiapollenites andiraensis, $H$. fusiformis, Lueckisporites virkkiae, Vittatina costabilis, $V$. subsaccata, $V$. vittifera, Pakhapites fusus, Cycadopites follicularis, Cananoropollis janakii y Limitisporites amanzoniensis.

La Biozona Tornopollenites toreutos-Reduviasporonites chalastus (TC) comparte con la Biozona Vittatina costabilis 11 especies, siendo las más importantes desde el punto de vista estratigráfico Corisaccites alutas y Pakhapites fusus, aunque solo comparten como especie exclusiva de ambas biozonas (TCy Vc) Portalites gondwanensis.

A su vez, comparte también 9 especies con la Biozona Tt, destacándose la presencia de la especie que da nombre a la biozona que es exclusiva de ambas biozonas (TC y Tt), además de Vittatina subsaccata, V. costabilis, Hamiapollenites andiraensis, H. fusiformis, etc. 
Se debe destacar que la Biozona Tt fue definida sobre la base de 4 especies de distribución exclusiva (Vernucosisporites insuetus, Thymospora obscura, Laevigatosporites minor y Tornopollenites toreutos) y solo una se halla presente en la Biozona TC. Además las especies cuya distribución comienza en la parte superior de la Biozona Vittatina costabilis, y que se hacen dominantes en la Biozona $\mathrm{Tt}$ (Hamiapollenites andiraensis, Corisaccites alutas y Lueckisporites virkkiae) también están presentes en la Biozona TC.

A partir de lo discutido se entiende que teniendo en cuenta la composición de las biozonas no es posible referir las biozonas aquí propuestas con las del Cuenca Amazonas, ya que comparten las mismas especies que definen a las biozonas de Brasil. La única especie que sí se encuentra restringida a dos biozonas (TCy Tt) es Tomopollenites toreutos.

\section{VI.4.5. Consideraciones (Figura 18)}

A partir de las comparaciones realizadas entre las biozonas propuestas para Cuenca ClaromecóColorado y aquellas definidas para el centro oeste de Argentina, Chacoparaná, Paraná y Amazonas puede concluirse que las asociaciones palinológicas aquí referidas a las biozonas Converrucosisporites confluensVittatina vittifera y Tomopollenites toreutos-Reduviasporonites chalastus no pueden ser asignadas a ninguna de las biozonas propuestas para las cuencas antes mencionadas.

La Biozona CV (Figura 18) sería equivalente temporal a todas las biozonas propuestas para el Cisuraliano, ya sea para el Asseliano-Kunguriano medio (biozonas Cristatisporites para Chacoparaná, Cannanoropollis korbaensis para Cuenca Paraná y Vittatina costabilis (parte inferior) para Cuenca Amazonas) o para el Asseliano-Sakmariano, como lo es la Biozona Pakhapites fusus-Vittatina subsaccata para las cuencas del centro oeste de Argentina. Además sería parcialmente equivalente en tiempo a las biozonas propuestas para la parte superior del Cisuraliano-Guadalupiano como son las biozonas Striatites (Chacoparaná) Lueckisporites-Weylandites (centro-oeste argentino), Lueckisporites virkkiae (Paraná) y la parte superior de Vittatina costabilis (Amazonas).

Por su parte, la Biozona TC (Figura 18), sería en parte equivalente a la biozona Striatites, a parte de Lueckisporites virkkiae, a la parte superior de Vittatina costabilis y a toda la biozona Tornopollenites toreutos, definida para el Lopingiano. 


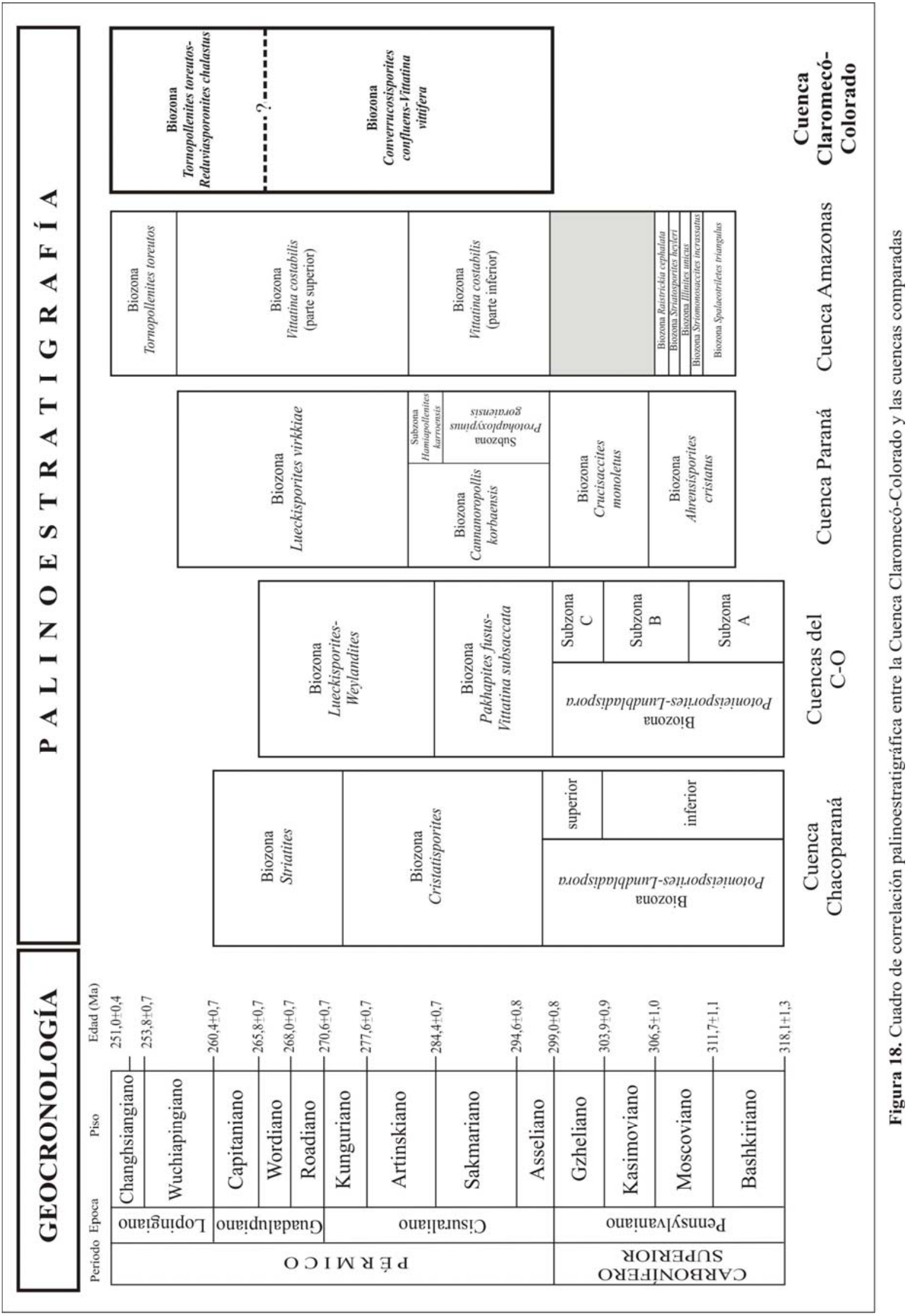




\section{VI.5. Correlaciones}

En este capítulo se realizará una valoración regional del esquema palinoestratigráfico aquí propuesto para la Cuenca Claromecó-Colorado. En primer lugar se sintetizará la información publicada en los últimos años para las cuencas relacionadas a la aquí considerada, como son las Cuencas Paganzo, Río Blanco, Calingasta-Uspallata, San Rafael, Chacoparaná y Tepuel-Genoa.

\section{VI.5.1. Cuencas Paganzo, Río Blanco, Calingasta-Uspallata, San Rafael}

En la actualidad para esta zona de la Argentina se acepta el esquema propuesta por Césari y Gutiérrez (2001), ligeramente modificado en los aspectos cronológicos por Gutiérrez et al. (2003a, 2008b) y Césari (2007) (Figura 2). Posteriormente al primer trabajo se produjeron una serie de hallazgos que permitieron aportar datos al conocimiento del Pérmico de estas cuencas. La mayoría de estos trabajos corresponden a listados publicados en resúmenes o trabajos, siendo escasos los aportes desde el punto de vista sistemático. En este sentido podemos mencionar:

Cuenca Paganzo. En los últimos años se amplió el conocimiento sobre la palinología del Neopaleozoico de esta cuenca, tanto de unidades litoestratigráficas conocidas palinológicamente, como de nuevos hallazgos en otras unidades. Entre las primeras se destacan los registros en las formaciones Bajo de Véliz (Gutiérrez y Césari, 2000; Césari y Gutiérrez, 2001) y Tupe. Para ésta última unidad, se mencionaron nuevas asociaciones palinológicas provenientes de los afloramientos de la provincia de San Juan (Vergel y Fasolo, 1999; Cisterna et al., 2001, 2002; Vergel y Cisterna, 2001; Vergel, 2008) que permitieron referir los términos superiores de la unidad a niveles cercanos al límite Carbonífero-Pérmico y al Cisuraliano, reforzado esto por la presencia de una fauna asociada (Cisterna et al., 2001, 2002) que indicarían esa edad. Se destacan como novedosos los hallazgos de asociaciones en las formaciones Tasa Cuna (Césari et al., 1999a; Balarino y Gutiérrez, 2006), Andapaico (Carrevedo et al., 2008; Correa et al., 2008, en prensa), La Veteada (Gutiérrez et al., 2008a; Zavattieri et al., 2008) y en sedimentitas neopaleozoicas del área Dique Los Sauces (Vergel et al., 2000).

Cuenca Río Blanco. En esta cuenca los hallazgos de microfloras en la Formación Volcán (Césari et al., 1999b, 2002) permitieron referirla al Carbonífero Superior-Pérmico Inferior. Por su parte, en el norte de la provincia de La Rioja, 
recientemente el hallazgo de varios niveles con palinomorfos en la Formación Río del Peñón (Gutiérrez y Limarino, 2006), posibilitó ubicar dicha unidad en el Carbonífero Superior-Pérmico Inferior. Dataciones vinculadas con esta unidad (Fauqué et al., 1999; Coughlin, 2000) así como la información brindada por los invertebrados marinos asociados (Cisterna y Simanauskas, 2000; Simanauskas y Cisterna, 2000) concuerdan con dichos resultados.

Cuenca Calingasta-Uspallata. Para esta Cuenca se destacan los primeros hallazgos de asociaciones palinológicas en la Formación Loma de Los Morteritos (Gutiérrez en Pazos et al., 2002; Carbonífero Superior-Pérmico Inferior) y recientemente la Formación Agua de Jagüe (Césari et al., 2008).

\section{Bioestratigrafía}

Desde el punto de vista bioestratigráfico, para las Cuencas Paganzo, Río Blanco, Calingasta-Uspallata y San Rafael, Césari y Gutiérrez (2001) propusieron un esquema de biozonación palinoestratigráfica (ver Cuadro 2), que integra los esquemas precedentes definidos para la Cuenca Paganzo (Azcuy, 1979, 1986; Azcuy y Jelín, 1980; Césari, 1986b, 1986c, Archangelsky et al., 1987a, 1987b, 1987c, 1996a, 1996b). Para el Pérmico el mismo incluye las Biozonas Pakhapites fusus-Vittatina subsaccata (FS) y Lueckisporites-Weylandites (LW).

La Biozona de intervalo Fusacolpites fusus-Vittatina subsaccata (FS), fue reconocida en las formaciones El Imperial, Bajo de Véliz, Tasa Cuna y La Puerta, en los términos superiores de las formaciones Santa Máxima, El Imperial, Río del Peñón (La Rioja), Loma de Los Morteritos y Tupe; y recientemente en el miembro inferior de la Formación Andapaico. La base de la biozona está marcada por la primer aparición de Fusacolpites fusus, y el marcado incremento de los granos de polen estriados, y coincide con la base de la Biozona de Gangamopteris (megaflora). Son considerados taxones característicos de esta biozona Distriatites insolitus, Vittatina subsaccata, Hamiapollenites fusiformis, Striatoabieites multistriatus, Marsupipollenites striatus, Latusipollenites quadrisaccatus, Barakarites rotatus, Converrucosisporites confluens, Horriditriletes rectus, Kraeuselisporites sanluisensis, Lophotriletes rarus, L. cursus y Brevitriletes cornutus. El techo de la unidad está marcado por la aparición de Lueckisporites spp. Originalmente fue referida a los términos basales del Cisuraliano, 
teniendo en cuenta los datos geocronológicos existentes (Formación Patquía: 302 \pm 6 y 288 \pm 7 Ma, Thompson y Mitchell, 1972) y su equivalencia con la Biozona Gangamopteris. Césari (2007) y Gutiérrez et al. (2008b) confirman una edad cisuraliana temprana para la unidad.

Por su parte la Biozona de Asociación Lueckisporites-Weylandites (LW), fue reconocida en las formaciones Yacimiento Los Reyunos, Santa Máxima, De La Cuesta (= parte inferior de la Formación La Veteada, véase Gutiérrez et al., 2008a) y en los niveles superiores de las formaciones El Imperial y Andapaico (véase Césari y Gutiérrez, 2001; Correa et al., en prensa). Se caracteriza por el dominio de los granos de polen estriados, tipo Lueckisporites, Lunatisporites, Weylandites, Vittatina, Marsupipollenites, Corisaccites, Staurosaccites. En base a la edad absoluta obtenida de una toba (Miembro Toba Vieja Gorda), vinculada con el nivel palinológico de la

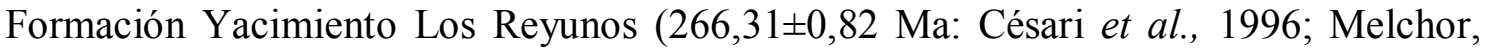
2000), esta unidad fue referida por Césari y Gutiérrez (2001) a la parte superior del Cisuraliano (no más viejo que el Artinskiano). Una edad cisuraliana tardía-guadalupiana fue confirmada por Césari (2007) y Gutiérrez et al. (2008b).

\section{VI.5.2. Cuenca Chacoparaná}

Para el Neopaleozoico de esta Cuenca se destacan como novedades los estudios palinológicos de los pozos Las Mochas (Césari et al., 1995), Árbol Blanco (Gutiérrez et al., 1997, 2002, en prensa-a; Vergel, 1998) y Ordóñez (Winn y Steinmetz, 1998; Playford y Dino, 2002) que brindan información, en especial los dos primeros sondeos, sobre las asociaciones neocarboníferas, que exhiben una estrecha afinidad con aquellas descriptas para las cuencas del centro-oeste argentino.

El esquema propuesto originalmente por Russo et al. (1980), fue modificado por Vergel (1993), Césari et al. (1995), Archangelsky et al. (1996) y Archangelsky y Vergel (1996), quedando para el Pérmico el mismo integrado por la Biozona de Asociación Cristatisporites (Cr), referida al Cisuraliano (Asseliano-Kunguriano). Esta unidad ha sido subdividida por Vergel (1993) en tres Sub-biozonas de Asociación: Cristatisporites inferior (Ci, Asseliano-Artinskiano inferior), Cristatisporites media (Cm, ArtinskianoKunguriano inferior) y Cristatisporites superior (Cs, Kunguriano). Si bien Césari et al. (1995) reconocen a la Biozona Cr dividida en tres subunidades en la perforación Las 
Mochas, no coinciden con los taxones diagnósticos propuestos para definir dicha subdivisión. Por su parte, Gutiérrez et al. (2002), también reconocen esta biozona completa en la perforación Árbol Blanco, aunque incluyendo sólo dos subunidades. Esta información llevaría a plantear dudas respecto a los criterios utilizados para la subdivisión propuesta por Vergel (1993).

Para el Pérmico también fue definida la Biozona de Asociación de Striatites (S), referida originalmente al Guadalupiano-Loginpiano? (Kunguriano?-Kazaniano). La misma fue localizada únicamente en la Subcuenca de San Cristóbal-Las Breñas Oriental, en las perforaciones Ordóñez (sudeste de Córdoba), Josefina (sudeste de Santa Fe) y Las Mochas (noroeste de Santa Fe) (Vergel, 1993; Césari et al., 1995).

\section{VI.5.3. Cuencas Claromecó-Colorado y Tepuel-Genoa}

Con respecto a estas cuencas los nuevos hallazgos (Gutiérrez et al., 2003b, 2005, 2007; Balarino, 2006, 2008; Vergel y Cuneo, 2006); aportan información que sugieren que los esquema propuestos por Archangelsky (1996b), Archangelsky et al. (1996) y Andreis y Archangelsky (1996), deberían ser modificados. En este trabajo se plantea un nuevo esquema.

\section{VI.5.4. Cuadro de correlación general}

A partir de la información disponible se sugiere el esquema de biozonación y correlación palinoestratigráfico para el Neopaleozoico argentino, representado en la Figura 18.

A partir de la nueva información obtenida de las asociaciones palinológicas provenientes de las perforaciones La Estrella x-1 y Cruz del Sur x-1, y considerando la secuencia estratigráfica de la que provienen (Grupo Pillahuincó) así como los datos litoestratigráficos hasta ahora publicados (véase Archangelsky, 1996b, Fryklund et al., 1996; Juan et al., 1996b y Lesta y Sylwan, 2005) se pueden proponer las siguientes modificaciones a las edades de las unidades litoestratigráficas que atraviesan dichas perforaciones (Figura 20); en especial las formaciones Bonete y Tunas.

Con respecto al esquema planteado por Archangeslky y Gamerro (1980b) y Archangelsky (1996b), para la perforación YPF Puelches x-1, lamentablemente no podemos establecer correlaciones para los intervalos 2440-2700 mbnm (referido 
originalmente a la Biozona Striatites) y 2800-3200 mbnm (referido a la Biozona Cristatisporites) debido al caracter preliminar del análisis palinológico realizado por los mencionados autores y por la ausencia de muestras provenientes de sedimentitas referibles a la Formación Sauce Grande en el estudio aquí realizado. Una revisión de las microfloras de Puelches X-1, permitirá avanzar en éste sentido.

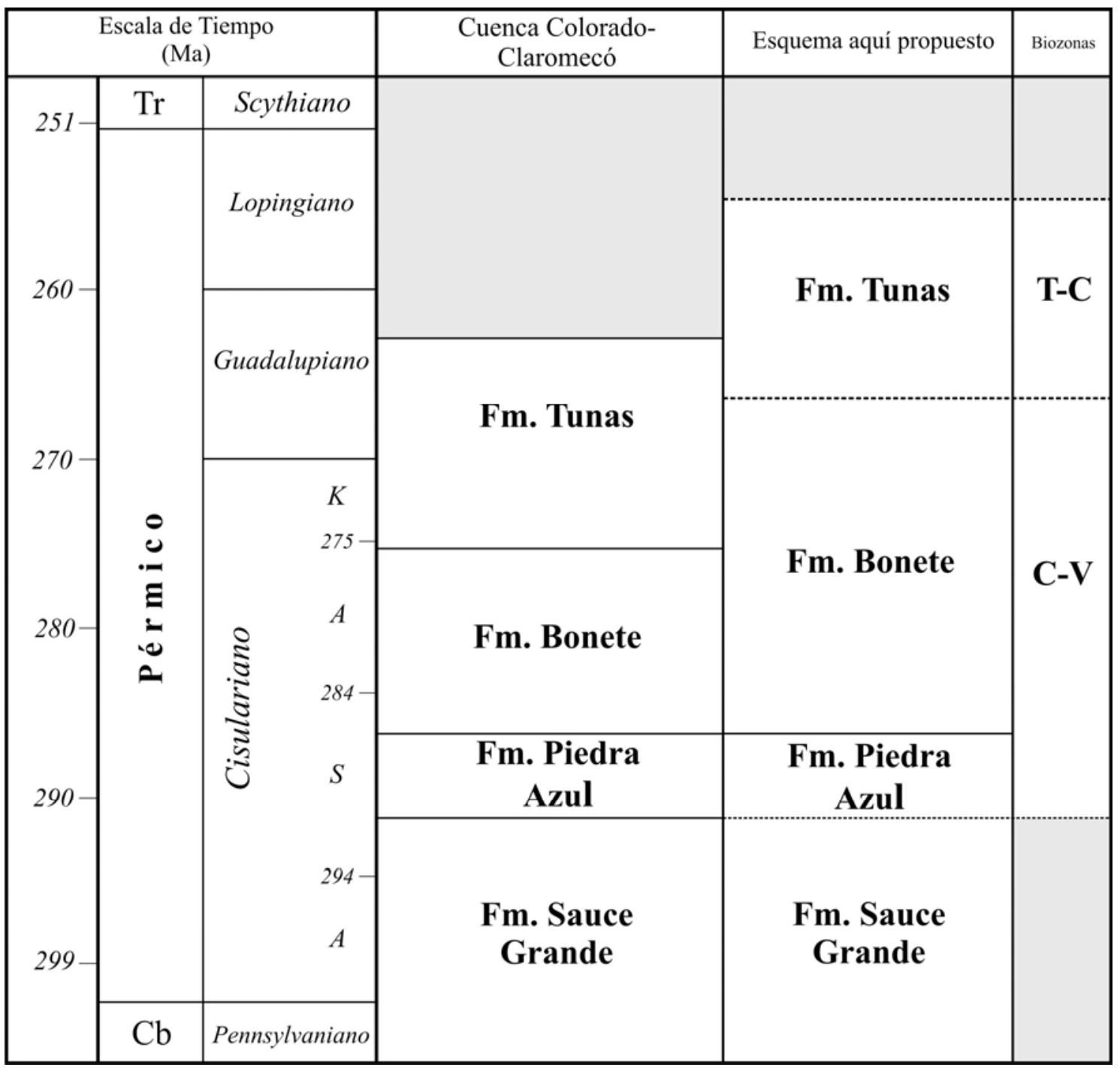

Figura 19. Grupo Pillahuincó: ajuste cronoestratigráfico de las unidades que lo integran a partir de la información palinológica. 


\section{CARACTERÍSTICAS DE LAS MICROFLORAS}

\section{VII.1. Composición de las microfloras}

Tal como fuera detallado en los capítulos anteriores la sección atravesada por la perforación La Estrella x-1 corresponde al Grupo Pillahuincó y comprende el lapso que va del Cisuraliano al Lopingiano temprano: Biozonas Converrucosisporites confluensVittatina vittifera (entre los 3549 y $3231 \mathrm{mbnm}$ ) y Tornopollenites toreutosReduviasporonites chalastus (entre los 3231 y 2940 mbnm).

Teniendo en cuenta las posibles afinidades de los palinomorfos que componen las microfloras (Cuadro 12), podemos señalar que la Biozona Converrucosisporites confluens-Vittatina vittifera (Cisuraliano-Guadalupiano temprano) incluye asociaciones (Cuadros 12, 13 y 14 y Figura 21) que se caracterizan por la abundancia de granos de polen bisacados de cuerpo central liso vinculados a las Caytoniales: 33,25-43,66\% (Alisporites, 8,33-13,38\%; Vittatina, 3,40-8,79\%), asociados a los granos de polen bisacados y monosacados afin a las Coniferopsidas (20,78-31,21\%) y granos de polen estriados relacionados a las Glossopteridales/Voltziales (16,01-18,7\%). Las Coniferospidas aparecen representadas por Scheuringipollenites (11,07-18,45\%), Platysaccus (2,67-8,35\%) y Pityosporites (1,31-5,05\%); mientras que las Glossopteridales-Voltziales por Marsupipollenites (7,24-12,14\%) y Protohaploxypinus $(2,18-6,37 \%)$.

Complementan las esporas derivadas de las Pteridophyta (7,25-13,59\%) y Sphenophyta $(3,42-7,68 \%)$. Los demás grupos de plantas están presente en muy bajas proporciones, Lycophyta $(0,66-1,2 \%)$ y Cycadales $(0,00-1,87 \%)$. Los acritarcas aparecen en los niveles $3428 \mathrm{mbnm}$ (0,40\%), $3380 \mathrm{mbnm}(0,37 \%)$ y $3231 \mathrm{mbnm}$ $(0,22 \%)$. Las prasinofitas sólo aparecen representados en los niveles $3428 \mathrm{mbnm}$ $(0,20 \%)$ y $3231 \mathrm{mbnm}(3,96 \%)$, mientras que las Ephedrales solo se encuentran en el nivel $3231 \mathrm{mbnm}(0,44 \%$ del espectro).

Por su parte la Biozona Tornopollenites toreutos-Reduviasporonites chalastus TC (Guadalupiano tardío-Lopingiano temprano), incluye asociaciones palinológicas que muestran ligeros cambios en cuanto a la participación de los distintos grupos de plantas, respecto de la Biozona CV (Figura 20). Como en ella, la Biozona TC también se encuentra fuertemente dominada por los granos de polen bisacados de cuerpo central 
liso vinculados a las Caytoniales $(47,01-69,00 \%)$, asociados a los granos de polen bisacados y monosacados vinculados a las Coniferales $(21,49-38,31 \%)$, mientras que los granos de polen estriados vinculadas a las Glossopteridales/Voltziales (2,90-10,26\%) y las esporas vinculadas a las Pteridophyta $(0,72-5,97 \%)$ y a las Sphenophyta $(1,36-$ 4,69\%), disminuyen su participación en la composición de las asociaciones, en especial hacia los términos superiores del pozo.

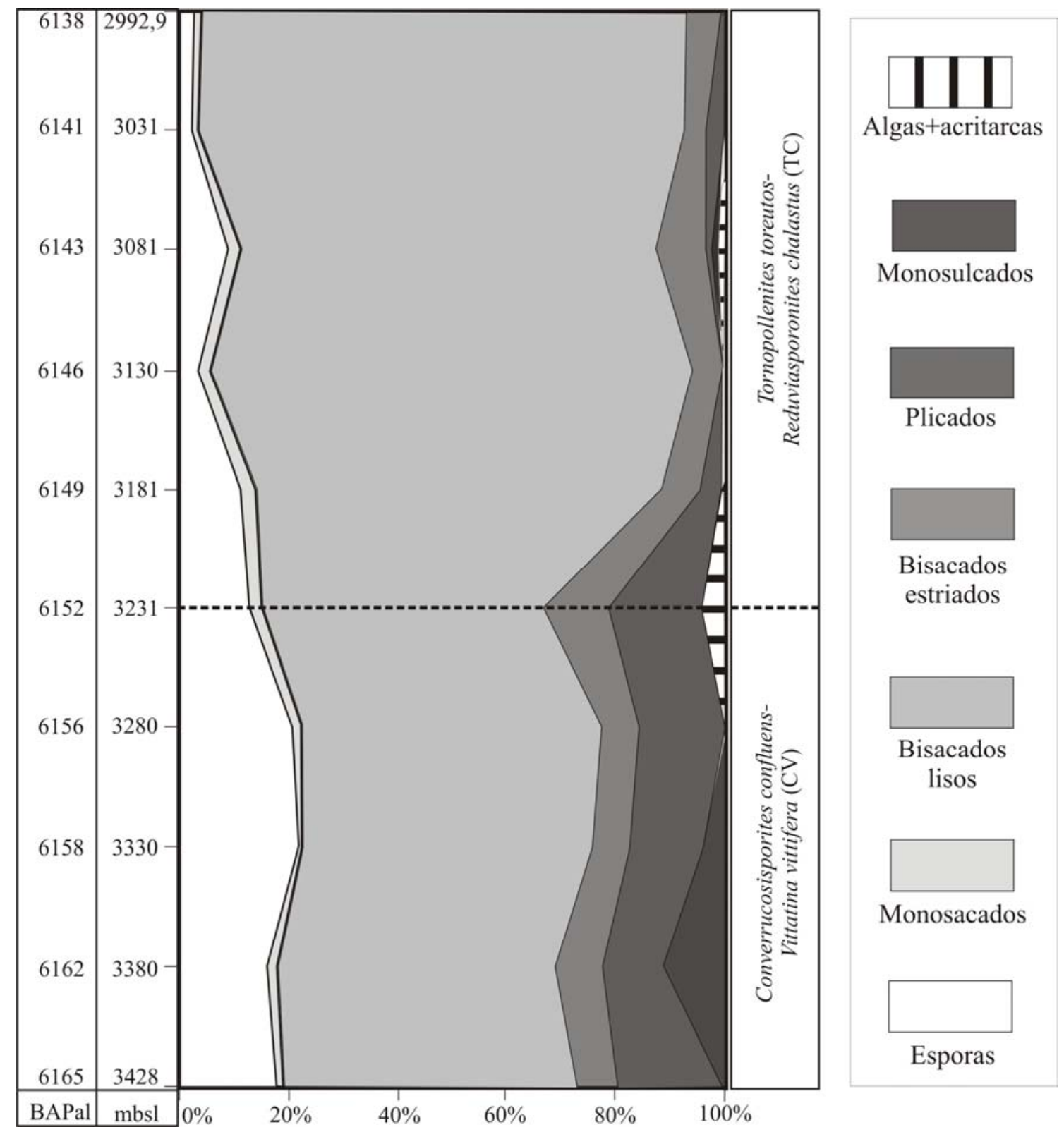

Figura 20. Gráfico de abundancia relativa de los grupos de palinomorfos en las muestras testigo de la perforación La Estrella x-1. 
Los granos de polen de Caytoniales (Cuadros 13 y 14) constituyen el componente dominante de las asociaciones (47,01 \% del espectro en el nivel 3180 mbnm y 69,00 \% en 2992,9 mbnm), principalmente el género Alisporites (10,3918,80\%). Por su parte las Coniferopsidas están representadas por Scheuringipollenites (8,27-15,22\%), Platysaccus (9,15-13,73\%) y Pityosporites (1,13-5,30\%). Los helechos (Pteridophyta) constituyen elementos con poca representación en el espectro polínico (entre 0,72 y 5,77\%), destacandose el género Convolutispora (0,48-2,46\%). También es baja la participación de las Sphenophyta (entre 1,36 y 4,69\%; Calamospora, 0,002,68\%). Las Lycophyta en contraste con la Bizona CV casi desaparecen en las microfloras, hallandose únicamente presentes en el nivel $3180 \mathrm{mbnm}$ con un bajo porcentaje relativo $(1,07 \%)$.

\begin{tabular}{|c|c|c|}
\hline & & Morfogénero \\
\hline \multirow[t]{2}{*}{ Lycophyta } & Licofitas herbáceas-subherbáceas & $\begin{array}{l}\text { Cristatisporites, Vallatisporites, } \\
\text { Kraeuselisporites, Gondisporites?, } \\
\text { Playfordiaspora?, Intotriradites? }\end{array}$ \\
\hline & Licofitas arbóreas & Lundbladispora \\
\hline \multirow[t]{2}{*}{ Pteridophyta } & Filicopsida & $\begin{array}{l}\text { Anapiculatisporites, Punctatisporites, } \\
\text { Leiotriletes, Brevitriletes, Horriditriletes, } \\
\text { Granulatisporites, Cyclogranisporites, } \\
\text { Convolutispora, Lophotriletes, } \\
\text { Converrucosisporites, Verrucosisporites, } \\
\text { Diatomozonotriletes, Interradispora?, } \\
\text { Dibolisporites, Didecitriletes, } \\
\text { Camptotriletes, Leschikisporites, } \\
\text { Phaselisporites, Thymospora } \\
\end{array}$ \\
\hline & Pteridohyta s.l. & $\begin{array}{l}\text { Retusotriletes, Baculatisporites?, } \\
\text { Osmundacidites, Spelaeotriletes, } \\
\text { Pseudoreticulatispora, Phidiaesporites }\end{array}$ \\
\hline Sphenophyta & & Calamospora, Laevigatosporites \\
\hline \multirow[t]{5}{*}{ Gimnospermosida } & Caytoniales-Corystopermaceae & Alisporites, Falcisporites, \\
\hline & Caytoniales-Caytoniaceae & Vitreisporites \\
\hline & Caytoniales-Peltaspermaceae & $\begin{array}{l}\text { Pteruchipollenites, Vittatina, } \\
\text { Hamiapollenites }\end{array}$ \\
\hline & Voltizales/Glossopteridales & $\begin{array}{l}\text { Striomonosaccites, Crustaesporites, Illinites, } \\
\text { Protohaploxypinus, Striatopodocarpites, } \\
\text { Meristocorpus?, Weylandites, } \\
\text { Marsupipollenites, Pakhapites?, Triadispora } \\
\text { Striatoabieites, Tiwarisporis, } \\
\text { Tornopollenites } \\
\end{array}$ \\
\hline & Gimnospermosida & $\begin{array}{l}\text { Ibisporites?, Distriatites, Accinctisporites, } \\
\text { Polarisaccites }\end{array}$ \\
\hline \multirow[t]{4}{*}{ Coniferopsida } & Coniferopsida s.l. & $\begin{array}{l}\text { Corisaccites, Lueckisporites, Staurosaccites, } \\
\text { Stellapollenites, Crucisaccites, } \\
\text { Bascanisporites, Gondwanapollis?, } \\
\text { Colpisaccites?, }\end{array}$ \\
\hline & Coniferales-Ferugliocladaceae & Cannanoropollis \\
\hline & Coniferales-Lebachiaceae & Scheuringipollenites \\
\hline & Coniferales-Pinaecea & Pityosporites, Platysaccus, Chordasporites \\
\hline
\end{tabular}


Balarino, M. Lucía

\begin{tabular}{|c|c|c|}
\hline & Coniferales-Podocarpaceae & Lunatisporites \\
\hline & Coniferales-Ullmanaceae & Limitisporites \\
\hline & $\begin{array}{l}\text { Coniferales-Emporiaceae-Rufloriaceae- } \\
\text { Utrechteaceae }\end{array}$ & Potonieisporites \\
\hline & Cordaitales & $\begin{array}{l}\text { Plicatipollenites, Caheniasaccites, } \\
\text { Costatacyclus? }\end{array}$ \\
\hline Cycadales-Gynkgoales & & Cycadopites \\
\hline Gnetopsida-Ephedrales & & Praecolpatites \\
\hline Algae-Clorophyceae & & Botryococcus \\
\hline Algae indeteterminado & & Quadrisporites, Pilasporites? \\
\hline Acritarcas & & $\begin{array}{l}\text { Buedingiisphaeridium, Circulisporites, } \\
\text { Micrhystridium, Mehlisphaeridium, }\end{array}$ \\
\hline Prasinophyta & & $\begin{array}{l}\text { Brazilea, Leiosphaeridia, Cymatiosphaera, } \\
\text { Maculatasporites }\end{array}$ \\
\hline Fungi & & Portalites, Reduviasporonites \\
\hline
\end{tabular}

Cuadro 12. Afinidad botánica de los palinomorfos que integran las palinofloras identificadas en las perforaciones La Estrella x-1 y Cruz del Sur x-1 (véase Balme, 1995; de Jersey y Raine, 1990; Zamuner et al., 2001; Zavattieri, 2002; Rojo y Zavattieri, 2005; Zavattieri y Rojo, 2005; Raine et al., 2008). 


\begin{tabular}{|c|c|c|c|c|c|c|c|c|c|c|c|c|c|c|c|c|c|c|c|c|}
\hline \multirow{2}{*}{$\begin{array}{l}\text { Géneros/ Biozonas } \\
\text { morfogrupos }\end{array}$} & \multicolumn{10}{|c|}{ CV } & \multicolumn{10}{|c|}{ TC } \\
\hline & \multirow{2}{*}{\multicolumn{2}{|c|}{$\begin{array}{l}3428 \mathrm{mbnm} \\
\text { BA Pal } 6165\end{array}$}} & \multirow{2}{*}{\multicolumn{2}{|c|}{$\begin{array}{c}3380 \mathrm{mbnm} \\
\text { BA Pal } 6162\end{array}$}} & \multirow{2}{*}{\multicolumn{2}{|c|}{$\begin{array}{c}330 \mathrm{mbnm} \\
\text { BA Pal } 6158\end{array}$}} & 3280 & & 3231 & mbnm & 3180 & mbnm & 3130 & $\mathrm{nbnm}$ & 3081 & $\mathrm{nbnm}$ & 3031 & $\mathrm{mbnm}$ & 2992 , & mbnm \\
\hline & & & & & & & BA F & 16156 & BA P & 16152 & BA P & 16149 & BA Pr & 16146 & BA P & 16143 & BA P & 16141 & $\mathrm{BAP}$ & al 6138 \\
\hline Calamospora & 9 & 1,81 & 6 & 1,12 & 11 & 2,41 & 10 & 2,43 & 3 & 0,66 & 0 & 0,00 & 4 & 0,96 & 12 & 2,68 & 0 & 0,00 & 3 & 0,68 \\
\hline Laevigatosporites & 0 & 0,00 & 0 & 0,00 & 1 & 0,22 & 0 & 0,00 & 1 & 0,22 & 0 & 0,00 & 0 & 0,00 & 0 & 0,00 & 1 & 0,24 & 0 & 0,00 \\
\hline ETL indet & 8 & 1,61 & 24 & 4,49 & 23 & 5,04 & 16 & 3,88 & 18 & 3,96 & 19 & 4,06 & 5 & 1,20 & 9 & 2,01 & 6 & 1,45 & 3 & 0,68 \\
\hline Sphenophyta & & 3,42 & & 5,62 & & 7,68 & & 6,31 & & 4,84 & & 4,06 & & 2,17 & & 4,69 & & 1,69 & & 1,36 \\
\hline Anapiculatisporites & 2 & 0,40 & 4 & 0,75 & 0 & 0,00 & 3 & 0,73 & 4 & 0,88 & 2 & 0,43 & 0 & 0,00 & 1 & 0,22 & 0 & 0,00 & 0 & 0,00 \\
\hline Brevitriletes & 3 & 0,60 & 0 & 0,00 & 1 & 0,22 & 0 & 0,00 & 0 & 0,00 & 0 & 0,00 & 0 & 0,00 & 0 & 0,00 & 0 & 0,00 & 0 & 0,00 \\
\hline Convolutispora & 0 & 0,00 & 15 & 2,81 & 15 & 3,29 & 15 & 3,64 & 8 & 1,76 & 7 & 1,50 & 3 & 0,72 & 11 & 2,46 & 2 & 0,48 & 5 & 1,13 \\
\hline Converrucosisporites & 27 & 5,43 & 0 & 0,00 & 2 & 0,44 & 0 & 0,00 & 0 & 0,00 & 0 & 0,00 & 0 & 0,00 & 0 & 0,00 & 0 & 0,00 & 0 & 0,00 \\
\hline Horriditriletes & 4 & 0,80 & 4 & 0,75 & 3 & 0,66 & 4 & 0,97 & 2 & 0,44 & 1 & 0,21 & 0 & 0,00 & 1 & 0,22 & 0 & 0,00 & 0 & 0,00 \\
\hline Leiotriletes & 20 & 4,02 & 17 & 3,18 & 12 & 2,63 & 12 & 2,91 & 6 & 1,32 & 6 & 1,28 & 0 & 0,00 & 2 & 0,45 & 1 & 0,24 & 0 & 0,00 \\
\hline Lophotriletes & 0 & 0,00 & 0 & 0,00 & 7 & 1,54 & 0 & 0,00 & 0 & 0,00 & 0 & 0,00 & 0 & 0,00 & 0 & 0,00 & 0 & 0,00 & 0 & 0,00 \\
\hline Punctatisporites & 6 & 1,21 & 1 & 0,19 & 3 & 0,66 & 12 & 2,91 & 6 & 1,32 & 2 & 0,43 & 0 & 0,00 & 0 & 0,00 & 0 & 0,00 & 1 & 0,23 \\
\hline Retusotriletes & 0 & 0,00 & 0 & 0,00 & 1 & 0,22 & 0 & 0,00 & 0 & 0,00 & 0 & 0,00 & 0 & 0,00 & 0 & 0,00 & 0 & 0,00 & 0 & 0,00 \\
\hline Thymospora & 2 & 0,40 & 2 & 0,37 & 2 & 0,44 & 0 & 0,00 & 0 & 0,00 & 0 & 0,00 & 0 & 0,00 & 0 & 0,00 & 0 & 0,00 & 0 & 0,00 \\
\hline ETV indet & 3 & 0,60 & 0 & 0,00 & 15 & 3,29 & 8 & 1,94 & 3 & 0,66 & 9 & 1,92 & 0 & 0,00 & 0 & 0,00 & 0 & 0,00 & 0 & 0,00 \\
\hline ETA indet & 0 & 0,00 & 15 & 2,81 & 0 & 0,00 & 2 & 0,49 & 4 & 0,88 & 0 & 0,00 & 1 & 0,24 & 5 & 1,12 & 0 & 0,00 & 0 & 0,00 \\
\hline Pteridophyta & & 13,48 & & 10,86 & & 13,38 & & 13,59 & & 7,25 & & 5,77 & & 0,96 & & 4,46 & & 0,72 & & 1,36 \\
\hline Lundbladispora & 4 & 0,80 & 4 & 0,75 & 2 & 0,44 & 3 & 0,73 & 3 & 0,66 & 4 & 0,85 & 0 & 0,00 & 0 & 0,00 & 0 & 0,00 & 0 & 0,00 \\
\hline ETCz indet & 1 & 0,20 & 2 & 0,37 & 1 & 0,22 & 0 & 0,00 & 0 & 0,00 & 1 & 0,21 & 0 & 0,00 & 0 & 0,00 & 0 & 0,00 & 0 & 0,00 \\
\hline Lycophyta & & 1,00 & & 1,12 & & 0,66 & & 0,73 & & 0,66 & & 1,07 & & 0,00 & & 0,00 & & 0,00 & & 0,00 \\
\hline Cannanaropollis & 0 & 0,00 & 0 & 0,00 & 0 & 0,00 & 0 & 0,00 & 0 & 0,00 & 0 & 0,00 & 1 & 0,24 & 0 & 0,00 & 0 & 0,00 & 0 & 0,00 \\
\hline Cahenisaccites & 0 & 0,00 & 0 & 0,00 & 0 & 0,00 & 0 & 0,00 & 0 & 0,00 & 3 & 0,64 & 1 & 0,24 & 0 & 0,00 & 0 & 0,00 & 0 & 0,00 \\
\hline Chordasporites & 0 & 0,00 & 0 & 0,00 & 0 & 0,00 & 0 & 0,00 & 1 & 0,22 & 0 & 0,00 & 0 & 0,00 & 0 & 0,00 & 0 & 0,00 & 1 & 0,23 \\
\hline Corisaccites & 1 & 0,20 & 0 & 0,00 & 0 & 0,00 & 0 & 0,00 & 0 & 0,00 & 0 & 0,00 & 1 & 0,24 & 0 & 0,00 & 0 & 0,00 & 0 & 0,00 \\
\hline Lueckisporites & 2 & 0,40 & 3 & 0,56 & 1 & 0,22 & 0 & 0,00 & 5 & 1,10 & 3 & 0,64 & 4 & 0,96 & 8 & 1,79 & 4 & 0,97 & 0 & 0,00 \\
\hline Lunatisporites & 0 & 0,00 & 0 & 0,00 & 1 & 0,22 & 0 & 0,00 & 3 & 0,66 & 0 & 0,00 & 2 & 0,48 & 2 & 0,45 & 0 & 0,00 & 1 & 0,23 \\
\hline Pityosporites & 22 & 4,43 & 7 & 1,31 & 10 & 2,19 & 17 & 4,13 & 23 & 5,05 & 20 & 4,27 & 22 & 5,30 & 22 & 4,91 & 16 & 3,86 & 5 & 1,13 \\
\hline Platysaccus & 17 & 3,42 & 25 & 4,68 & 15 & 3,29 & 11 & 2,67 & 38 & 8,35 & 43 & 9,19 & 57 & 13,73 & 41 & 9,15 & 53 & 12,80 & 46 & 10,41 \\
\hline Scheuringipollenites & 55 & 11,07 & 76 & 14,23 & 77 & 16,89 & 76 & 18,45 & 62 & 13,63 & 65 & 13,89 & 63 & 15,18 & 55 & 12,28 & 63 & 15,22 & 37 & 8,37 \\
\hline Staurosaccites & 2 & 0,40 & 2 & 0,37 & 0 & 0,00 & 1 & 0,24 & 0 & 0,00 & 0 & 0,00 & 0 & 0,00 & 0 & 0,00 & 1 & 0,24 & 0 & 0,00 \\
\hline GPML indet & 4 & 0,80 & 11 & 2,06 & 3 & 0,66 & 7 & 1,70 & 10 & 2,20 & 11 & 2,35 & 8 & 1,93 & 6 & 1,34 & 3 & 0,72 & 5 & 1,13 \\
\hline Coniferopsida & & 20,72 & & 23,23 & & 23,46 & & 27,18 & & 31,21 & & 30,98 & & 38,31 & & 29,91 & & 33,82 & & 21,49 \\
\hline Alisportes & 69 & 13,88 & 64 & 11,99 & 38 & 8,33 & 50 & 12,14 & 45 & 9,89 & 69 & 14,74 & 78 & 18,80 & 47 & 10,49 & 43 & 10,39 & 60 & 13,57 \\
\hline Falcisporites & 5 & 1,01 & 7 & 1,31 & 5 & 1,10 & 3 & 0,73 & 15 & 3,30 & 0 & 0,00 & 6 & 1,45 & 5 & 1,12 & 9 & 2,17 & 5 & 1,13 \\
\hline Hamiapollenites & 4 & 0,80 & 1 & 0,19 & 0 & 0,00 & 2 & 0,49 & 8 & 1,76 & 0 & 0,00 & 2 & 0,48 & 0 & 0,00 & 2 & 0,48 & 1 & 0,23 \\
\hline Pteruchipollenites & 1 & 0,20 & 3 & 0,56 & 0 & 0,00 & 0 & 0,00 & 0 & 0,00 & 0 & 0,00 & 0 & 0,00 & 1 & 0,22 & 0 & 0,00 & 0 & 0,00 \\
\hline Vittatina & 40 & 8,05 & 24 & 4,49 & 30 & 6,58 & 14 & 3,40 & 40 & 8,79 & 0 & 0,00 & 0 & 0,00 & 5 & 1,12 & 13 & 3,14 & 19 & 4,30 \\
\hline Vitreisporites & 2 & 0,40 & 0 & 0,00 & 0 & 0,00 & 0 & 0,00 & 0 & 0,00 & 0 & 0,00 & 1 & 0,24 & 0 & 0,00 & 0 & 0,00 & 0 & 0,00 \\
\hline BL indet & 96 & 19,32 & 115 & 21,54 & 97 & 21,27 & 68 & 16,50 & 51 & 11,21 & 151 & 32,26 & 139 & 33,49 & 170 & 37,95 & 184 & 44,44 & 220 & 49,77 \\
\hline Caytoniales & & 43,66 & & 40,08 & & 37,28 & & 33,25 & & 34,95 & & 47,01 & & 54,47 & & 50,89 & & 60,63 & & 69,00 \\
\hline Marsupipollenites & 52 & 10,46 & 41 & 7,68 & 33 & 7,24 & 50 & 12,14 & 34 & 7,47 & 17 & 3,63 & 2 & 0,24 & 1 & 0,22 & 1 & 0,24 & 0 & 0,00 \\
\hline Meristocorpus & 0 & 0,00 & 0 & 0,00 & 0 & 0,00 & 0 & 0,00 & 0 & 0,00 & 0 & 0,00 & 0 & 0,00 & 2 & 0,45 & 0 & 0,00 & 0 & 0,00 \\
\hline Pakhapites & 1 & 0,20 & 1 & 0,19 & 10 & 2,19 & 0 & 0,00 & 0 & 0,00 & 1 & 0,21 & 0 & 0,00 & 0 & 0,00 & 0 & 0,00 & 1 & 0,23 \\
\hline Protohaploxypinus & 21 & 4,23 & 15 & 2,81 & 10 & 2,19 & 9 & 2,18 & 29 & 6,37 & 14 & 2,99 & 7 & 1,69 & 7 & 1,56 & 0 & 0,00 & 3 & 0,68 \\
\hline Striatopodocarpites & 1 & 0,20 & 0 & 0,00 & 0 & 0,00 & 1 & 0,24 & 1 & 0,22 & 1 & 0,21 & 0 & 0,00 & 5 & 1,12 & 0 & 0,00 & 2 & 0,45 \\
\hline GPME indet & 0 & 0,00 & 1 & 0,19 & 0 & 0,00 & 0 & 0,00 & 0 & 0,00 & 0 & 0,00 & 0 & 0,00 & 0 & 0,00 & 0 & 0,00 & 0 & 0,00 \\
\hline BE indet & 10 & 2,01 & 32 & 5,99 & 20 & 4,39 & 17 & 4,13 & 10 & 2,20 & 15 & 3,21 & 7 & 1,69 & 20 & 4,46 & 11 & 2,66 & 21 & 4,75 \\
\hline Glossopt.-Voltziales & & 17,10 & & 16,85 & & 16,01 & & 18,70 & & 16,26 & & 10,26 & & 3,61 & & 7,81 & & 2,90 & & 6,11 \\
\hline Cycadopites & 0 & 0,00 & 10 & 1,87 & 7 & 1,54 & 1 & 0,24 & 1 & 0,22 & 1 & 0,21 & 0 & 0,00 & 4 & 0,89 & 0 & 0,00 & 0 & 0,00 \\
\hline Cycadales & 0 & 0,00 & 10 & 1,87 & 7 & 1,54 & 1 & 0,24 & 1 & 0,22 & 1 & 0,21 & 0 & 0,00 & 4 & 0,89 & 0 & 0,00 & 0 & 0,00 \\
\hline Praeacolpatites & 0 & 0,00 & 0 & 0,00 & 0 & 0,00 & 0 & 0,00 & 2 & 0,44 & 0 & 0,00 & 0 & 0,00 & 0 & 0,00 & 0 & 0,00 & 0 & 0,00 \\
\hline Ephedrales & 0 & 0,00 & 0 & 0,00 & 0 & 0,00 & 0 & 0,00 & 2 & 0,44 & 0 & 0,00 & 0 & 0,00 & 0 & 0,00 & 0 & 0,00 & 0 & 0,00 \\
\hline Botryococcus & 0 & 0,00 & 0 & 0,00 & 0 & 0,00 & 0 & 0,00 & 0 & 0,00 & 0 & 0,00 & 1 & 0,24 & 2 & 0,45 & 0 & 0,00 & 0 & 0,00 \\
\hline Clorophyceae & 0 & 0,00 & 0 & 0,00 & 0 & 0,00 & 0 & 0,00 & 0 & 0,00 & 0 & 0,00 & 1 & 0,24 & 2 & 0,45 & 0 & 0,00 & 0 & 0,00 \\
\hline Buedingiisphaeridium & 1 & 0,20 & 0 & 0,00 & 0 & 0,00 & 0 & 0,00 & 1 & 0,22 & 0 & 0,00 & 0 & 0,00 & 1 & 0,22 & 0 & 0,00 & 0 & 0,00 \\
\hline Circulisporites & 0 & 0,00 & 0 & 0,00 & 0 & 0,00 & 0 & 0,00 & 0 & 0,00 & 0 & 0,00 & 0 & 0,00 & 0 & 0,00 & 0 & 0,00 & 2 & 0,45 \\
\hline Micrhystridium & 1 & 0,20 & 2 & 0,37 & 0 & 0,00 & 0 & 0,00 & 0 & 0,00 & 2 & 0,43 & 0 & 0,00 & 1 & 0,22 & 1 & 0,24 & 0 & 0,00 \\
\hline Acritarcas & & 0,40 & & 0,37 & & 0,00 & & 0,00 & & 0,22 & & 0,43 & & 0,00 & & 0,45 & & 0,24 & & 0,45 \\
\hline Brazilea & 0 & 0,00 & 0 & 0,00 & 0 & 0,00 & 0 & 0,00 & 2 & 0,44 & 0 & 0,00 & 1 & 0,24 & 0 & 0,00 & 0 & 0,00 & 0 & 0,00 \\
\hline Leiosphaeridia & 1 & 0,20 & 0 & 0,00 & 0 & 0,00 & 0 & 0,00 & 16 & 3,52 & 1 & 0,21 & 0 & 0,00 & 2 & 0,45 & 0 & 0,00 & 1 & 0,23 \\
\hline Prasinophyta & & 0,20 & & 0,00 & & 0,00 & & 0,00 & & 3,96 & & 0,21 & & 0,24 & & 0,45 & & 0,00 & & 0,23 \\
\hline TOTAL & 497 & 100 & 534 & 100 & 456 & 100 & 412 & 100 & 455 & 100 & 468 & 100 & 415 & 100 & 448 & 100 & 414 & 100 & 442 & 100,00 \\
\hline
\end{tabular}

Cuadro 13. Abundancia relativa de géneros según afinidades botánicas en las distintas muestras testigo de la perforación La Estrella x-1. 


\begin{tabular}{|c|c|c|c|c|c|c|c|c|c|c|}
\hline Biozona & \multicolumn{5}{|c|}{ CV } & \multicolumn{5}{|c|}{ TC } \\
\hline $\begin{array}{r}\text { mbnm } \\
\text { Grupo parental / BA Pal }\end{array}$ & \begin{tabular}{|l|}
3428 \\
6165
\end{tabular} & \begin{tabular}{|l|}
3380 \\
6162
\end{tabular} & \begin{tabular}{|l|}
3330 \\
6158 \\
\end{tabular} & \begin{tabular}{|l|}
3280 \\
6156
\end{tabular} & \begin{tabular}{|l|}
3231 \\
6152 \\
\end{tabular} & $\begin{array}{l}3180 \\
6149\end{array}$ & \begin{tabular}{|l|}
3130 \\
6146
\end{tabular} & $\begin{array}{l}3081 \\
6143\end{array}$ & $\begin{array}{l}3031 \\
6141\end{array}$ & $\begin{array}{c}2992,9 \\
6138\end{array}$ \\
\hline Sphenophyta & 3,42 & 5,62 & 7,68 & 6,31 & 4,84 & 4,06 & 2,17 & 4,69 & 1,69 & 1,36 \\
\hline Pteridophyta & 13,48 & 10,86 & 13,38 & 13,59 & 7,25 & 5,77 & 0,96 & 4,46 & 0,72 & 1,36 \\
\hline Lycophyta & 1,00 & 1,12 & 0,66 & 0,73 & 0,66 & 1,07 & 0,00 & 0,00 & 0,00 & 0,00 \\
\hline Coniferopsida & 20,78 & 23,23 & 23,46 & 27,18 & 31,21 & 30,98 & 38,31 & 29,91 & 33,82 & 21,49 \\
\hline Caytoniales & 43,66 & 40,08 & 37,28 & 33,25 & 34,95 & 47,01 & 54,47 & 50,89 & 60,63 & 69,00 \\
\hline Glossopteridales-Voltziales & 17,10 & 16,85 & 16,01 & 18,7 & 16,26 & 10,26 & 3,61 & 7,81 & 2,90 & 6,11 \\
\hline Cycadales & 0,00 & 1,87 & 1,54 & 0,24 & 0,22 & 0,21 & 0,00 & 0,89 & 0,00 & 0,00 \\
\hline Ephedrales & 0,00 & 0,00 & 0,00 & 0,00 & 0,44 & 0,00 & 0,00 & 0,00 & 0,00 & 0,00 \\
\hline Clorophyceae & 0,00 & 0,00 & 0,00 & 0,00 & 0,00 & 0,00 & 0,24 & 0,45 & 0,00 & 0,00 \\
\hline Acritarca & 0,40 & 0,37 & 0,00 & 0,00 & $\mathbf{0 , 2 2}$ & 0,43 & 0,00 & $\mathbf{0 , 4 5}$ & 0,24 & 0,45 \\
\hline Prasinophyta & 0,20 & 0,00 & 0,00 & 0,00 & 3,96 & 0,21 & 0,24 & $\mathbf{0 , 4 5}$ & 0,00 & 0,23 \\
\hline & 100 & 100 & 100 & 100 & 100 & 100 & 100 & 100 & 100 & 100 \\
\hline
\end{tabular}

Cuadro 14. Abundancia relativa de los grupos parentales en la perforación La Estrella x-1.

\begin{tabular}{|c|c|c|c|c|c|c|c|c|}
\hline $\begin{array}{l}\text { mbnm } \\
\text { BAPal }\end{array}$ & TOTAL & E & GPM & GPB & GPBE & GPP & GPS & AAPF \\
\hline $\mathbf{2 9 9 2 , 9}$ & 442 & 12 & 5 & 374 & 28 & 19 & 1 & 3 \\
$\mathbf{6 1 3 8}$ & & 2,7 & 1,1 & 84,6 & 6,3 & 4.3 & 0,2 & 0,6 \\
\hline $\mathbf{3 0 3 1}$ & 414 & 10 & 3 & 368 & 18 & 14 & 0 & 1 \\
$\mathbf{6 1 4 1}$ & & 2,4 & 0,7 & 88,9 & 4,3 & 3,4 & 0 & 0,2 \\
\hline $\mathbf{3 0 8 1}$ & 448 & 41 & 8 & 341 & 42 & 6 & 4 & 6 \\
$\mathbf{6 1 4 3}$ & & 9,1 & 1,8 & 76,1 & 9,4 & 1,3 & 0,9 & 1,3 \\
\hline $\mathbf{3 1 3 0}$ & 415 & 13 & 10 & 366 & 23 & 1 & 0 & 2 \\
$\mathbf{6 1 4 6}$ & & 3,1 & 2,4 & 88,2 & 5,5 & 0,2 & 0 & 0,5 \\
\hline $\mathbf{3 1 8 1}$ & 468 & 51 & 14 & 348 & 33 & 17 & 2 & 3 \\
$\mathbf{6 1 4 9}$ & & 10,9 & 3 & 74,3 & 7 & 3,6 & 0,4 & 0,6 \\
\hline $\mathbf{3 2 3 1}$ & 455 & 58 & 10 & 235 & 56 & 74 & 3 & 19 \\
$\mathbf{6 1 5 2}$ & & 12,7 & 2,2 & 51,6 & 12,3 & 16,3 & 0,6 & 4,1 \\
\hline $\mathbf{3 2 8 0}$ & 412 & 85 & 7 & 225 & 30 & 64 & 1 & 0 \\
$\mathbf{6 1 5 6}$ & & 20,6 & 1,7 & 54,6 & 7,3 & 15,5 & 0,2 & 0 \\
\hline $\mathbf{3 3 3 0}$ & 456 & 99 & 3 & 242 & 32 & 63 & 17 & 0 \\
$\mathbf{6 1 5 8}$ & & 21,7 & 0,6 & 53 & 7 & 13,8 & 3,7 & 0 \\
\hline $\mathbf{3 3 8 0}$ & 534 & 94 & 12 & 297 & 53 & 65 & 11 & 2 \\
$\mathbf{6 1 6 2}$ & & 17,6 & 2,2 & 55,6 & 9,9 & 12,1 & 12,1 & 0,4 \\
\hline $\mathbf{3 4 2 8}$ & 497 & 89 & 4 & 267 & 41 & 92 & 1 & 3 \\
$\mathbf{6 1 6 5}$ & & 17,9 & 0,8 & 53,7 & 8,2 & 18,5 & 0,2 & 0,6 \\
\hline
\end{tabular}

Cuadro 15. Abundancia relativa de grupos en las muestras testigo de la perforación La Estrella $\mathrm{x}-1$. REFERENCIAS: E (esporas), GPM (granos de polen monosacados), GPB (granos de polen bisacados lisos), GPBE (granos de polen bisacados estriados), GPP (granos de polen plicados), GPM (granos de polen monosulcados), AAPF (algas+acritarcas+prasinophytas+fungii). 
En este contexto se observa que durante el Cisuraliano-Guadalupiano temprano (Biozona $\mathrm{CV}$ ) las microfloras presentan una alta diversidad genérica y específica en los granos de polen vinculados a las pteridospermas (Caytoniales), GlossopteridalesVoltziales y Coniferospidas. En contraste la diversidad es mucho menor entre los componentes vinculados a las Pteridpophyta, Sphenophyta y Lycophyta.

Por lo tanto se puede señalar que estas microfloras de la Biozona CV incluyen (Cuadro 13) una baja representación de componentes de la flora local (autóctona) fundamentalmente de hábitos hidro-higrófilos (en especial las Pteridophyta que dominan en forma clara en este grupo, y la muy escasa presencia de Sphenophyta y Lycophyta); por otra parte estas microfloras estan dominadas por elementos que representan a la vegetación que vivía en áreas más alejadas (alóctona) con requerimientos xerófilos y/o mesófilos (Coniferospida, Caytoniaes, Glossopteridales/Voltziales; Knoll y Nicklas, 1987) cuyo polen fue transportads por los cursos de agua o por el viento desde los centros de origen a las zonas de depositación.

Como la abundancia de granos bisacados en general (Cuadro 14) es la característica distintiva de estas microfloras, se puede señalar que la flora alóctona habría estado integrada principalmente por Caytoniales, y en menor medida por las Glossopteridales/Voltziales y Coniferales.

Los niveles correspondientes a las profundidades 3428, 3380, $3231 \mathrm{mbnm}$ estarían evidenciando la presencia de cuerpos de agua salobres (evento transgresivo?), a partir de la participación del grupo Acritarca-Prasinophyta. Los más notorios son los niveles 3380 mbnm (Micrhystridium 0,37\%) y 3428 mbnm (Micrhystridium 0,20\% y Leiosphaeridia 0,20\%) y en menor medida el nivel $3231 \mathrm{mbnm}$ (Leiosphaeridia 3,52\%, Brazilea 0,44\%, Buedingiisphaeridium 0,22\%).

Por su su parte hacia el Guadalupiano tardío-Lopingiano temprano, las asociaciones microflorísticas (Biozona TC), reflejan ligeros cambios en la composición de la flora parental, también desarrollada en un paleoambiente predominantemente continental. Estas microfloras incluyen abundantes granos de polen bisacados, también con una escasa participación de los elementos acuáticos: acritarcas y prasinofitas (3180 mbnm; Micrhystridium con 0,43\% y Leiosphaeridia 0,21\%; $3081 \mathrm{mbnm}$ con Leiosphaeridia 0,45\%, Micrhystridium 0,22\% y Buedingiisphaeridium 0,22\% y 2992,9 mbnm con Circulisporites 0,45\% y Leiosphaeridia 0,43\%). 
Para estos momentos las Caytoniales constituyen el componente mejor representado de la megaflora en las asociaciones microflorísticas (Cuadro 14), y los bosques de Coniferas de las tierras altas (elementos alóctonos) estarían caracterizadas en las microfloras por las Lebachiaceae (Scheuringipollenites) y Podocarpaceae/Pinnaceae (Platysaccus y Pityosporites). Por su parte los elementos que representan a las Glossopteridales-Voltziales decrecen en su participación de las microfloras. En este sentido, también los elementos representativos de la flora auctóctona, en especial aquellos con requerimientos hidro a higromesófilos, como los helechos (Pteridophyta) y Sphenophyta, aparecen pocos representados (Pteridophyta, 0,72-5,77\%; Sphenophyta, 1,36-4,69\%), incluso las Lycophyta llegan a desaparece en el espectro polínico (1,07\% en el nivel 3180 mbnm a $0,00 \%$ en los restantes niveles).

El empobrecimiento de la flora (autóctona) con requerimeintos higrohidromesófilos, como las Pteridophyta, Sphenophyta y Lycophyta, hacia el Guadalupiano tardío-Lopingiano temprano, podría estar reflejando un período de aridización y disminución de las fuentes de agua, que ya se estaba insinuando para el Cisuraliano-Guadalupiano temprano.

Otro aspecto a destacar es la alta diversidad específica que presentan las asociaciones aquí estudiadas podría interpretarse como indicadora de la estabilidad del ecosistema. También podría indicar un alto aporte de elementos alóctonos en la microflora (Frederiksen, 1983), ya que dentro de un área particular de depositación, los sedimentos detríticos contienen una elevada diversidad de palinomorfos (debido al aporte de componentes alóctonos) comparada con los carbones, que por lo general, reflejan principalmente los elementos de la flora autóctona.

\section{VII.2. Consideraciones paleogeografícas y paleoclimáticas}

\section{VII.2.1. Marco general}

El lapso Devónico Tardío-Lopingiano estuvo caracterizado a nivel mundial por una era glacial, que según Scotese et al. (1999) estuvo compuesta por dos eventos glaciares (Fameniano-Tournaisiano y Namuriano-Sakmariano) separadas por un período cálido. La segunda glaciación sería la más importante, ya que durante el Pennsylvaniano-Cisuraliano se alcanzó la máxima extensión de los terrenos englazados (véase Frakes y Crowell, 1969; Martini, 1997), ya que éstos habrían cubierto la mitad 
sur del América del Sur, la mayor parte (2/3) de África, India, Antártida y Australia (Scotese et al., 1999). Este evento glaciario estuvo asociado a varios pulsos transgresivos de los mares epicontinentales (Veevers y Powell, 1987; Scotese et al., 1999), también a una progresiva aridización (vinculada a un calentamiento global) que alcanzó su climax hacia el límite Pérmico-Triásico y que se continuó hasta fines del Jurásico (Scotese et al., 1999).

Durante el Cisuraliano el clima tuvo un comportamiento muy variable y dinámico, caracterizado por un calentamiento global evidenciado por el retroceso de los glaciares (el máximo rectroceso se habria registrado hacia el Sakmariano tardíoArtinskiano temprano) y el desarrollo de transgresiones glacieustáticas, que provocaron la disminución del albedo global y resultaron en un calentamiento que se aceleró quedando los centros glaciares restringidos a las altas latitudes. Luego de este evento, el calentamiento se desaceleró y aunque los centros glaciares continuaban preservados hacia fines del Cisuraliano en las altas latitudes.

Por su parte en las bajas latitudes, durante el Cisuraliano, se instalaron condiciones de climas áridos a semiáridos, probablemente por la formación de nuevos cordones montañosos. La máxima aridización se habría dado hacia el Kunguriano (fines del Cisuraliano). El incremento de la evaporación, habría acentuado el calentamiento global. Las sucesivas regresiones de los mares internos y la relevante reducción de las fuentes de humedad podrían haber representado otras causas del avance del clima árido.

Todos estos factores climáticos (avances y retrocesos glaciarios, retrocesos y avances de los mares epicontinetales, aridización de las zonas ubicadas en las bajas latitudes vinculados a los procesos orogénicos coetáneos) van a generar sucesivos y drásticos cambios paleogeográfico que van a afectar la biota, en especial la flora, que van a tratar de ser analizados en este aporte a partir del registro microflorístico.

En este aspecto podemos mencionar que a escala global los eventos paleogeográficos, bióticos, climáticos $\mathrm{y}$ sedimentológicos han sido ampliamente discutidos y resumidos (véase Martín et al., 1997; Ziegler et al., 1997; Rees et al., 1999; Chumakov y Zharkov, 2002). Es así como en el Gondwana Occidental los sucesivos eventos glaciarios e interglaciarios, se dan en un marco de un calentamiento global, que hacia fines del Pérmico genera la implantación de un clima marcadamente árido (Scotese et al., 1999). 
En este contexto las evidencias observadas indican que durante el CarboníferoPérmico la concentración de $\mathrm{CO}_{2}$ era de aproximadamente $0,03 \%$, mientras que los niveles de $\mathrm{O}_{2}$ eran altos, originados por la fotosíntesis y diversificación de las plantas terrestres, pudiendo haber alcanzado los 35\% (Beerling et al., 2002). Estos niveles altos de $\mathrm{O}_{2}$ pudieron haber favorecido la diversificación biótica (Graham et al., 1995) y un incremento en la producción de $\mathrm{O}_{3}$, y por lo tanto un mejor escudo protector contra los rayos UV (Berner y Canfiekd, 1989; Burgoyne et al., 2005). Por su parte durante el Pennsylvaniano las temperaturas eran más bajas que las del Mississippiano, con una caída de aproximadamente de $15^{\circ} \mathrm{C}$ en el promedio de la temperatura global (Anderson et al., 1999; Burgoyne et al., 2005). Las altas precipitaciones del Mississippiano decrecen significativamente hacia el Pennsylvaniano mientras que los niveles de $\mathrm{O}_{2}$ en la atmósfera se incrementan abruptamente (Frakes, 1979; Burgoyne et al., 2005).

Al inicio del Pérmico todavía prevalece un clima frío con condiciones glaciares (Scott et al., 1997), que hacia fines del mismo por los efectos del calentamiento global y el derretimiento de los glaciares, se instalan condiciones más áridas (Veevers et al., 1994; Anderson et al., 1999), probablemente por la corriente cálida marina (Frakes, 1979; Burgoyne et al., 2005).

Las floras del Pennsylvaniano en el Reino Florístico Gondwana se habrían desarrollado solo a lo largo de las regiones cálidas de la periferia de Sudamérica y Australia, donde se habían establecido hábitats favorables para el desarrollo de la vegetación, ya que la mayor parte del continente se hallaba cubierta por los glaciares. Esta vegetación remplazó a aquella que caracterizaron el fin del Devónico y el Mississippiano. Esta nueva flora, más pobre y con baja diversidad, dominó los nuevos ambientes caracterizados por condiciones climáticas extremas (Morris, 1975; Retallack, 1980; Archangelsky et al., 1987a; Azcuy et al., 1987; Burgoyne et al., 2005) y fue caracterizada como Flora Nothorhacopteris-Botrychiopsis (Anderson et al., 1999). En estos tiempos se produce una primer y gran radiación de las Gimnospermas (Anderson et al., 1999). Este nuevo ecosistema estuvo dominado por las pteridospermasgimnospermas-helechos y fue explotado intensamente por los insectos (Anderson et al., 1999).

Durante el Cisuraliano, con la retracción de los glaciares y el calentamiento global, las glossopteridales colonizaron el Gondwana. El Reino Florístico Gondwana, 
aparece por lo tanto dominado por las Glossopteridales. Las Glossopteridales habrían experimentado en el Pérmico un moderada radiación (Anderson et al., 1999). Esta flora también incluye licofitas, esfenofitas, helechos, pteridospermas, ginkgoales, cordaitales y coníferas. En regiones más próximas a los centros glaciares (cuencas Chacoparaná, Paraná, Antártida, Karro, etc.) se habrían desarrollado bosques que generaron la formación de mantos de carbones de considerables espesores, en especial hacia fines del Cisuraliano (Artinskiano-Kunguriano).

Esta flora eopérmica se caracterizó además por la diversificación de las gimnospermas (pequeñas, hojas a veces simples y con incremento de la venación) y la aparición de otras innovaciones evolutivas (los óvulos formaron clusters o estructuras tipo cono). Entre las gimnospermas de caracteriza la aparición de las Voltziales, grupo que sobrevive a la extinción de fines del Pérmico y del que habrían evolucionado las coníferas en el Triásico Temprano (Taylor y Taylor, 1993; Anderson et al., 1999; Kerp et al., 2006). Esta flora también es aprovechada por los insectos (Anderson et al., 1999).

\section{VII.2.2. Litoestratigrafía y evolución ambiental}

En este marco general del Gondwana occidental debemos mencionar que las secciones del Pennsylvaniano en el oeste argentino, están integradas por lo general por depósitos continentales y glacimarinos con depósitos interglaciarios, productos de la expansión y retracción de los glaciares, acompañados por fluctuaciones glacieustáticos del nivel del mar y cambios glacioeustáticos en la topografía del continente (véase Limarino et al., 2002, 2006; Limarino y Spalletti, 2006). Durante el momento que va del fines del Pennsylvaniano y el Cisuraliano, estos eventos son registrados en la en las Cuenca Karroo- Kalahari-Karasburg (África del Sur), Paraná (Brasil: Subgrupo Itararé y Uruguay: Formación San Gregorio), Chacoparaná (formaciones Sachayoj y Charata) y Claromecó-Colorado (Formación Sauce Grande).

Hacia el este en las cuencas del Karroo, Kalahari y Karasburg (sur de África) aparecen más de 700 m (Grupo Dwyka) de depósitos glaciarios continentales que intercalan con glacimarinos (Visser, 1983a, 1983b, 1989, 1990, 1993, 1994, 1996, 1997; Visser y Loock, 1982; Wopfen, 1999, 2002; Wopfen y Diekmann, 1996; Stollhofen et al., 2000). Según Chumakov y Zharkov (2002) se habrían producido dos avances (Asseliano y Sakmariano) y retorcesos (límite Asseliano-Sakmariano, inicios del 
Arinskiano) glaciarios.

El Grupo Dwyka incluye importantes depósitos glacigénicos, aunque su edad está en discusión. Los estudios palinológicos de esta cuenca (Anderson, 1977; McRae, 1989; Weiss y Wopfner, 1997; Key et al., 1998) sugieren una edad que va del Pennsylvaniano-Cisuraliano (302-280 según Key et al., 1998), datos confirmados por la evidencia dada por la macrofauna (Dickin, 1961; Martín y Wilczewski, 1970; Martín et al., 1970; McLachlan y Anderson, 1973). Dataciones obtenidas sobre circón magmático de horizontes tufíticos por Bangert et al. (1999), brindan edades $208 \mathrm{~Pb} / 238 \mathrm{U}$ de 302,0+/-3,0 y 299,2+/-3,2 Ma (Gzheliano) para la parte inferior del Grupo Dwyka, y 288,0+/-3,0-289,6 +/- 3,8 Ma (Sakmariano) para la parte basal de la Formación Prince Albert del Grupo Ecca que lo sobreyace; del mismo Grupo Ecca, la Formación Collinghan ha sido datada en 270 +/- 1 Ma (límite Cisuraliano-Guadalupiano; Chatuneau et al., 2002).

En secciones de Namibia y Sudáfrica del Grupo Dwyka se han reconocido 4 eventos intergalaciaros (Theron y Blignault, 1975; Visser, 1977; Wopfner, 1999, Wopfner y Diekmann, 1996). Visser (1977) estimó que la duración de cada evento de deglaciación comprende entre 9 y $11 \mathrm{Ma}$, mientras Bangert et al. (1999) estimaron de 5 a 7 Ma para cada evento. También calcularon una edad de aproximadamente $307 \mathrm{Ma}$ (Moscoviano tardío) para la base del Grupo, $302 \mathrm{Ma}$ (Gzheliano) para el fin del segundo interglaciario, $297 \mathrm{Ma}$ (Asseliano) para el tope del tercero, y $290 \mathrm{Ma}$ (Sakmariano) para el contacto entre los Grupos Dwyka y Ecca.

Durante el Asseliano, y simultáneamente al avance glaciario, en las partes marginales de las cuencas Paraná, Chacoparaná y Claromecó/Sierras Australes se habrían depositados tillitas galciarias y sedimentos glacilacustre y glacifluvial. Durante el máximo glaciaro del Asseliano-Sakmariano, habrian coalescido los glaciares del Gab ón, Zaire y Península Arábiga.

En la Cuenca Paraná, la porción más basal del Subgrupo Itararé representa depósitos glaciarios de la cuenca, con una potencia superior a los 1400 metros. La misma está conformada por las formaciones Lagoa Azul o Campo do Tenente, según los distintos autores y estaría marcando una edad Bashkiriano-Moscoviano (Limarino y Spalletti, 2006). La sección más sur de la cuenca evidencia dicho evento con las sedimentitas que conforman la Formación San Gregorio, siendo estas diamictitas y 
depósitos transgresivos. La parte superior del subgrupo (aproximadamente $1200 \mathrm{~m}$ de potencia) es referida al Cisuraliano (Asseliano-Sakmariano según Santos et al., 1996; Stephenson y McLean, 1999; o Asseliano-Artinskiano, según França, 1994; Holz, 1998, 1999, 2003). Esta unidad exhibe la misma alternancia de depósitos continentales y glacimarinos, formados durante los episodios glaciares e interglaciares. Éste evento sería el responsable de la acumulación de carbones. Culmina la secuencia con los depósitos de la Formación Río Bonito, sedimentitas depositadas durante el Artinskiano y el Kunguriano temprano, correspondiente a sedimento fluviales (véase Limarino y Spalletti 2006).

Este mismo modelo se puede observar en la Cuenca Chacoparaná. Durante el Carbonífero Superior-pre Kasimoviano, se depositan las sedimentitas correspondientes a la Formación Sachayoj, unidad conformada por alternancia de pelitas y areniscas depositadas en ambientes marinos y transicionales. Hacia el sur de la cuenca, los depósitos de areniscas, pelitas carbonosas y diamictitas continentales y marinas poco profundas, están representadas por la Formación Ordóñez, de edad Moscoviana. El intervalo correspondiente al Cisuraliano superior está representado por depositos marinos poco profundos que corresponden a la parte más superior de la Formación Ordóñez y a la porción más basal de la Formación Victoriano Rodríguez (véase Winns y Steimann, 1988; Limarino y Spalletti, 2006).

El modelo que se observa para la Cuenca Claromecó-Colorado (véase Andreis y Japas, 1996; Limarino y Spalletti, 2006), comienza con los depósitos de diamictitas interrumpidos por pobres depósitos de areniscas y pelitas, que corresponden a los depósitos de la Formación Sauce Grande (Pennsylvaniano-Cisuraliano temprano), los cuales son reemplazados gradualmente por secuencias transgresivas de pelitas y arenicas finas correspondientes a la Formación Piedra Azul (Cisuraliano). Las mismas representan, al menos en parte a ambientes marinos abiertos. El ciclo continúa con los depósitos de la Formación Bonete, de edad cisuraliana tardía-guadalupiana temprana, compuesta por areniscas y pelitas características de depósitos marinos poco profundos. El ciclo culmina con la Formación Tunas, de edad guadalupiana tardía-lopingiana (véase Capítulo II y Figura 20). 


\section{VII.2.3. Características de la Flora}

En este modelo glacial (Visser 1987, 1991a, 1991b) propuesto para el Pennsylvaniano-Cisuraliano, se habrían desarrollado principalmente dos floras, una interglacial y otra periglacial.

Las floras periglaciares marginales e incluso las de las zonas centrales, se habrían acumulado en los pantanos formando turba, posteriormente transformadose en capas de carbón. La flora interglaciaria y carbones son conocidas en Pennsylvaniano del oeste argentino (Flora NBG y carbones tupenses) y en el Cisuraliano del Brasil (Cuenca Paraná). Se asume que los carbones se acumulan luego de una transgresión glacioeustática en pantanos costaneros y planicies fluviales durante la elevación isostática del área (Santos et al., 1996; Bustin, 1997; Cazzulo-Klepzig et al., 2005) o glacioeustático por ascenso del nivel del mar (Michaelson y Henderson, 2000). El clima interglacial era suficientemente frío tal como lo demuestran las afinidades de la vegetación primaria (resistente a condiciones frías, tales como las gimnospermas y coníferas.

Durante el Pérmico las floras periglaciales (véase Guerra-Sommer y Cazzulo Klepzig, 2000, Holz et al., 2000, Jasper et al., 2003) habrían estado integradas por pteridospermas de hábito herbáceo y arbustivo (Botrychiopsis, Nothorhacopteris), helechos y esfenofitas de porte subherbáceos y principalmente por glossopteridales con un hábito de árbol pequeño (afinidad de taiga), integrada principalmente por Gangamopteris (decíduas) que habría vivido en áreas de permafrost.

La Flora de Gangamopteris (Cúneo et al., 1993; Wnuk, 1996; Cúneo, 1996), incluye a este género que representa una planta resistente al frío que aparece localmente (Australia, Antártida, África, India) asociada con tillitas (Chandra, 1992) y a registros de permafrost (Retallack, 1980). En la India aparece asociada a conchostracos y pequeños insectos (Chandra, 1992), mientras que en Antártida, los depósitos interglaciares incluyen cangrejos de agua dulce, que según Bacbock et al. (1998) podrían indicar un máximo de temperatura para los interglaciarios que oscilaría entre los $10^{\circ}$ y $20^{\circ} \mathrm{C}$. Durante el retroceso glaciario y la degradación del permafrost la vegetación es reemplazada por la Flora de Glossopteris (componente principal de las floras interglaciarias), la que debe haber sido más termofílica. La Flora de Glossopteris habría prevalecido en los momentos en que se produce una degradación de la glaciación 
eopérmica.

En Sudamérica, en especial en la Patagonia, la vegetación fue más diversa y termofílica desde el inicio del Pérmico (Cúneo, 1996) a pesar de la proximidad del cinturón glacial y su penetración en Sudamérica (Cuencas Paraná y Chacoparaná) de las lenguas glaciarias (Santos et al., 1996).

Durante el fin del Sakmariano e inicios del Artinskiano (fines de Cisuraliano) se habría producido la máxima retracción glaciaria quedando ésta restringida a la Antártida, y un cinturón angosto de 10 a $15^{\circ}$ de latitud $\mathrm{S}$, donde prevalecían condiciones climáticas templadas a frías, formada inmediatamente al norte de las zonas glaciarias. Numerosos depósitos de carbones de esta edad son identificados en Australia, India, Sudáfrica y Brasil (parte alta del Subgrupo Itararé, Formaciones Río Bonito e Itararé). La elevación del área, por rebote isostático, habría permitido la formación de centros locales de glaciación (Sudáfrica y Antártida) (Eyles et al., 1993; Visser, 1996, 1997). Durante estos momentos, la flora intreglaciaria se caracterizaba por los bosques de Glossopteris (que fueron habitados por anfibios, reptiles y grandes insectos neuroperidos, Chandra, 1992) y por bosques deciduos con helechos y esfenofitas de porte subherbáceos (Retallack, 1980; Chandra, 1992). En las zonas más áridas, las coníferas representan un componente subordinado.

Durante este mismo lapso, se habría desarrollado un angosto cinturón semiárido (de $5^{\circ}-15^{\circ}$ de ancho) que aparece entre $\operatorname{los} 40^{\circ}-45^{\circ}$ y $50^{\circ}-55^{\circ} \mathrm{S}$, donde las tierras altas estaban englazadas y se depositaron red beds (véase Limarino y Spalletti, 1986, 2006; López-Gamundí et al., 1992; Limarino et al., 1993, 2002, 2006). Prevalecía un clima árido, con cortas estaciones humedas, responsables de la formación de lagos y pantanos efímeros. La temperatura probablemente habría sido moderada en las zonas proximas a los englazamientos, tal como lo demostrarían la presencia de la flora de Glossopteris (Wnuk, 1996) y el amplio desarrollo de la fauna Notal (Grunt, 1995) en las plataformas marinas, donde los conodontes son escasos o están ausentes.

En este contexto en la Cuenca Claromecó-Colorado la flora parece exhibir una correspondencia respecto de la evolución de las asociaciones florísticas en el tiempo y el incremento de aridización. Las asociaciones siempre aparecen dominadas por granos de polen de cuerpo central liso, y con una presencia importante del grupo de los estriado (vinculados a la Coniferopsidas y Caytoniales los primeros, y a las Glossopteridales- 
Voltziales, los segundos). Mientras que en la biozona TC, si bien los granos de polen bisacados lisos continúan siendo las formas predominantes en las asociaciones, las esporas desaparen casi por completo del espectro polinico.

Los altos niveles de formas biscadas lisas en la composición de las microfloras y los bajos a nulos porcentajes de palinomorfos asociados a cuerpos de agua como lo son las esporas de Lycophyta y Sphenophyta, estarían corroborando el deterioro de las condiciones climáticas, que culminarían en condiciones más secas hacia el Lopingiano temprano.

En este sentido se analizará este aspecto (empobrecimiento de la flora en el lapso Cisuraliano tardío-Lopingiano tempranbo) en un contexto temporal-geográfico, para poder evaluar su importancia.

En una primera etapa, se restringe el análisis a la flora con requerimientos higromesófilos a xerófilos (flora alòctona) que se habría desarrollado en el centro-oeste de la Argentina (cuencas Paganzo, San Rafael, Calingasta-Uspallata, Rio Blanco, para el Pennsylvaniano-Pérmico y las cuencas Cuyana, Llantenes, Ischigualasto-Villa Unión, Marayes-Carrizal, San Rafael y Cordillera Principal Sanjuanina; para el Triásico; véase Artabe et al., 2001; Stipanicic y Marsicano, 2002; Zavattieri, 2002). Siendo ésta la zona con que cuenta con la mayor densidad de información para el lapso considedrado (Pennsylvaniano-Triásico) y poder considerar las observaciones realizadas en la Cuenca Claromecó-Colorado, en un marco geogràfico y temporal más amplio.

En el Cuadro 16 se ha representando la distribución de los granos de polen monosacados, bisacados, porados, plicados, colpados y poliplicados agrupados según su posible afinidad botánica.

\begin{tabular}{|c|c|c|c|c|c|c|c|c|c|c|c|}
\hline & & \multicolumn{3}{|c|}{$\begin{array}{c}\text { Pensylvanniano } \\
\text { DM }\end{array}$} & \multirow{2}{*}{$\begin{array}{c}\text { C- } \\
\text { G } \\
\text { FS } \\
\end{array}$} & \multirow{2}{*}{$\begin{array}{c}\begin{array}{c}\text { G- } \\
\text { Lo }\end{array} \\
\text { LW } \\
\end{array}$} & \multirow[t]{2}{*}{ Lo } & \multirow[t]{2}{*}{ TI } & \multirow[t]{2}{*}{ TM } & \multirow[t]{2}{*}{ TS } & \multirow[t]{2}{*}{ TSs } \\
\hline & Biozonas & $\mathbf{A}$ & $\mathrm{B}$ & $\mathrm{C}$ & & & & & & & \\
\hline \multicolumn{12}{|l|}{ GIMNOSPERMOSIDAS } \\
\hline \multirow{11}{*}{ Gymnospermopsida s.l. } & Ibisporites & & & & & & & & & & \\
\hline & Accinctisporites & & & & & & & & 3 & 7 & 2 \\
\hline & Angustisulcites & & & & & & & & 1 & 1 & \\
\hline & Cuneatisporites & & & & & & & & & 1 & \\
\hline & Granamocolpites & & & & & & & & & 1 & \\
\hline & Grebespora & & & & & & & & 1 & 1 & \\
\hline & Megamonoporites & & & & & & & & 3 & 4 & \\
\hline & Parcisporites & & & & & & & & & 1 & \\
\hline & Peroaletes & & & & & & & & & 1 & \\
\hline & Psilomonoporites & & & & & & & & 1 & 2 & 1 \\
\hline & Punctamonoaperturites & & & & & & & & & 1 & \\
\hline
\end{tabular}




\begin{tabular}{|c|c|c|c|c|c|c|c|c|c|c|c|}
\hline & Punctamonocolpites & & & & & & & & & 1 & \\
\hline & & & & & 1 & 1 & $\mathbf{0}$ & $\mathbf{0}$ & 12 & 28 & 4 \\
\hline \multicolumn{12}{|l|}{ O. CAYTONIALES } \\
\hline \multirow[t]{4}{*}{$\overline{\overline{\text { F. CAYTONIACEAE }}}$} & Klausipollenites & & & & & 1 & 1 & & 3 & 6 & 1 \\
\hline & Vitreisporites & & & & & & 1 & & 3 & 2 & \\
\hline & Minutosaccus & & & & & & 1 & & 2 & 2 & \\
\hline & Vesicaspora & & & & & & & & 2 & 3 & \\
\hline \multirow{6}{*}{ F. CORYSTOPERMACEAE } & Chordasporites & 1 & & 1 & 1 & & & & 2 & 3 & 1 \\
\hline & Pteruchipollenites & & 2 & 1 & 1 & 2 & & & 2 & 3 & 1 \\
\hline & Alisporites & & & & 2 & 6 & 4 & & 8 & 14 & 5 \\
\hline & Falcisporites & & & & & & 2 & & 3 & 2 & 2 \\
\hline & Sulcosaccispora & & & & & & & & & 1 & \\
\hline & & 1 & 2 & 2 & 4 & 8 & 9 & & 25 & 36 & 10 \\
\hline \multirow[t]{17}{*}{ O. GLOSSOPTERIDALES } & Meristocorpus & 1 & 1 & 1 & 2 & & & & & & \\
\hline & Marsupipollenites & 2 & 1 & & 2 & 2 & 1 & & 1 & & \\
\hline & Protohaploxypinus & & 5 & 4 & 8 & 8 & 3 & & 5 & 8 & 3 \\
\hline & $\begin{array}{l}\text { Striatoabieites } \\
\end{array}$ & & 1 & & 2 & 2 & & & 4 & 6 & \\
\hline & Striatopodocarpites & & & 1 & 6 & 3 & & & 1 & 3 & \\
\hline & Striomonosaccites & & & & 1 & 2 & & & & 1 & \\
\hline & Mabuitasaccites & & & & 1 & 1 & & & & & \\
\hline & Illinites & & & & 1 & 2 & & & 1 & & \\
\hline & Weylandites & & & & 1 & 2 & & & & & \\
\hline & Pakhapites & & & & 2 & 3 & & & & & \\
\hline & Crustaesporites & & & & & 1 & & & & 1 & \\
\hline & Goubinispora & & & & & & & & 1 & 1 & \\
\hline & Tenuisaccites & & & & & & & & & 2 & \\
\hline & Paraillinites & & & & & & & & 2 & & \\
\hline & Infernopollenites & & & & & & & & 1 & & \\
\hline & Striapollenites & & & & & 1 & & & & & \\
\hline & Tornopollenites & & & & & 2 & & & & & \\
\hline \multirow[t]{2}{*}{ O. VOLTZIALES } & Triadispora & & & & & & & & 2 & 5 & \\
\hline & & 3 & 8 & 6 & 26 & 29 & 4 & & 18 & 27 & 3 \\
\hline \multicolumn{12}{|l|}{ O. PELTASPERMALES } \\
\hline \multirow{5}{*}{ F. PELTASPERMACEAE } & Vittatina & & & 1 & 6 & 7 & 2 & & & & \\
\hline & Hamiapollenites & & & & 2 & 5 & & & & & \\
\hline & Distriatites & & & & 1 & & & & & & \\
\hline & Tiwarisporis & & & & & 1 & & & & & \\
\hline & & $\mathbf{0}$ & $\mathbf{0}$ & 1 & 9 & 13 & 2 & & $\mathbf{0}$ & $\mathbf{0}$ & $\mathbf{0}$ \\
\hline \multicolumn{12}{|l|}{ O. CONIFERALES } \\
\hline \multirow[t]{8}{*}{ Coniferales s.l. } & Brachysaccus & & & & & & & & 1 & 2 & \\
\hline & Daughertyspora & & & & & & & & 1 & 1 & \\
\hline & Gondwanapollis & 2 & 3 & 2 & & & & & & & \\
\hline & Latusipollenites & & & & 2 & 1 & & & & & \\
\hline & Dacrycarpites & & & & & & & & 1 & 1 & \\
\hline & Colpisaccites & & 2 & 1 & 2 & 1 & & & & & \\
\hline & Bascanisporites & & & & & & & 1 & & & \\
\hline & & 2 & 5 & 3 & 4 & 2 & & 1 & 3 & 4 & \\
\hline \multirow[t]{2}{*}{ F. ARAUCARIACEA } & Araucariacites & & & & & & & & 3 & 2 & \\
\hline & & $\mathbf{0}$ & $\mathbf{0}$ & $\mathbf{0}$ & $\mathbf{0}$ & $\mathbf{0}$ & & $\mathbf{0}$ & 3 & 2 & $\mathbf{0}$ \\
\hline F. CUPRESÁCEA & Inaperturopllenites & & & & & & 1 & & 4 & 7 & 1 \\
\hline & & $\mathbf{0}$ & $\mathbf{0}$ & $\mathbf{0}$ & $\mathbf{0}$ & $\mathbf{0}$ & 1 & $\mathbf{0}$ & 4 & 7 & $\mathbf{1}$ \\
\hline F. EMPORIACEAE-RUFLORIACEAE- & Potonieisporites & 11 & 12 & 9 & 7 & 2 & & & 1 & & \\
\hline & Variapollenites & & & & & & & & & 3 & 3 \\
\hline & Vestigisporites & 1 & & 1 & 1 & & & & & & \\
\hline & & 12 & 12 & 10 & 8 & 2 & $\mathbf{0}$ & $\mathbf{0}$ & 1 & 3 & 3 \\
\hline F. FERUGLIOCLADACEAE & Barakarites & & & & 1 & 1 & & & & & \\
\hline & Cannanoropollis & 6 & 6 & 6 & 5 & 3 & 1 & & & & \\
\hline & Parasaccites & 2 & 2 & & & & & & & & \\
\hline & Crucisaccites & 3 & 3 & 2 & 3 & 1 & & & & & \\
\hline & Divarisaccus & 1 & 1 & & 1 & & & & & & \\
\hline & Circumplicatipollis & 1 & 2 & 1 & 1 & 1 & & & & & \\
\hline & Tuberisaccites & & & 1 & & 1 & & & & & \\
\hline & Valialasaccites & & & & 1 & 1 & & & & & \\
\hline & & 14 & 14 & 10 & 12 & 8 & 0 & 0 & 0 & $\mathbf{0}$ & 0 \\
\hline F. PODOCARPACEAE- & Platysaccus & 4 & 3 & 3 & 3 & 2 & & & 3 & 4 & 3 \\
\hline & $\begin{array}{l}\text { Lunatisporites } \\
\text { (Taeniasporites) }\end{array}$ & & & & 1 & 4 & 2 & & 1 & 3 & \\
\hline
\end{tabular}




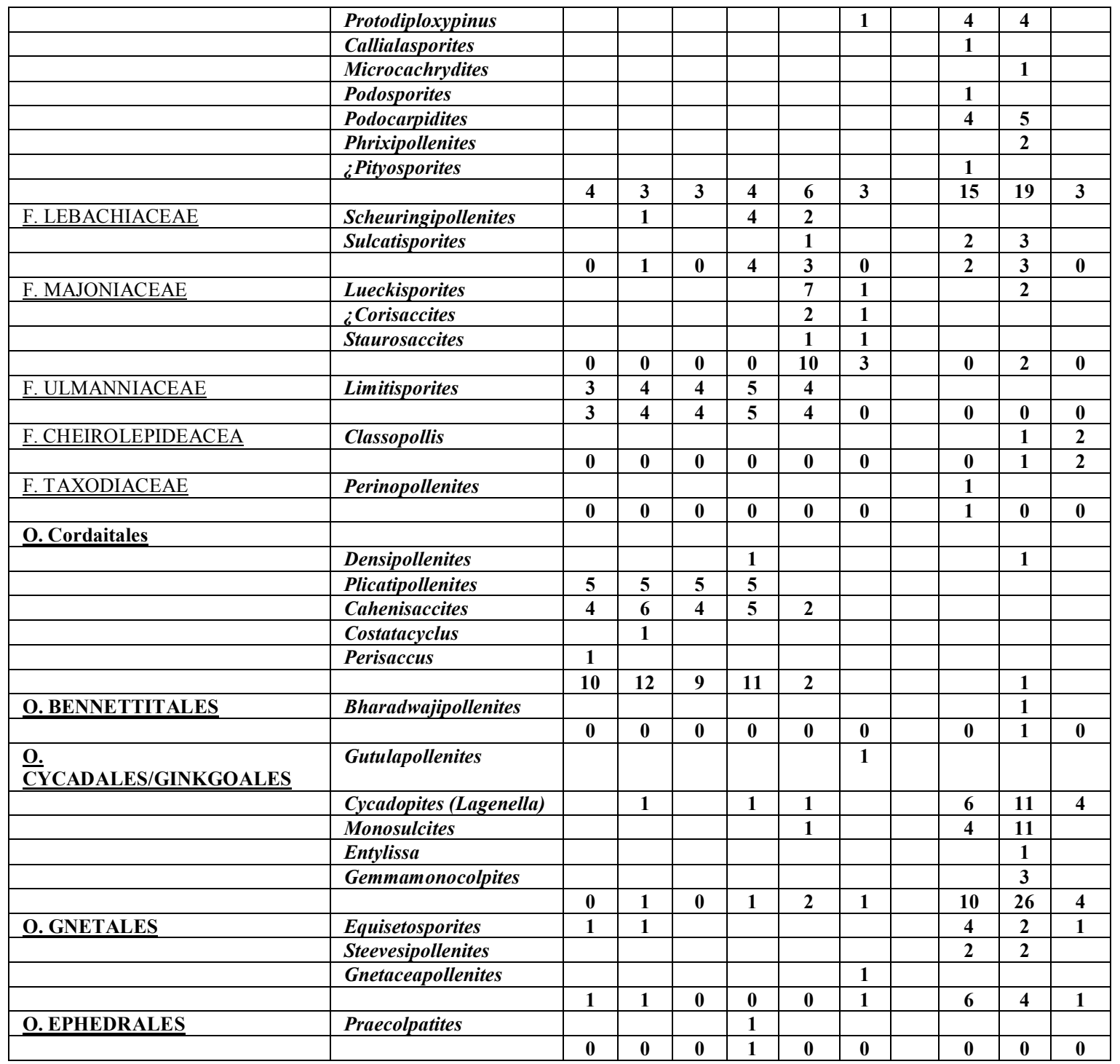

Cuadro 16. Registro de los granos de polen durante el Pennsylvaniano-Triásico en el centro-oeste argentino. Los números indican las cantidades de especies conocidas hasta el momento. Referencia: DM (Biozona Raistrickia densa-Convolutispora muriornata; Sub-biozonas: A, B, C), FS (Biozona Pakhapites fusus-Vittatina subsaccata); LW (Biozona Lueckisporites-Weylandites); C-G (Cisuraliano-Guadalupiano temprano); G-Lo (Guadalupiano tardío-Lopingiano temprano); Lo (Lopingiano tardío); TI (Triásico Inferior); TM (Triásico Medio); TS (Triásico Superior); TSs (Triásico Superior alto). Bibliografía utilizada para el Paleozoico Superior: Azcuy y Gutiérrez (1985); Azcuy et al. (1982); Balarino y Gutiérrez (2006); Barredo y Ottone (2003); Césari (1984, 1986a); Césari y Bercowski (1997); Césari y Gutiérrez (1985); Césari y Limarino (2002); Césari y Vazquez Nístico (1988); Césari et al. (1987, 1996, 1999a); di Pasquo et al. (2004); Ezpeleta y Gutiérrez (2006); García (1995, 1996); González Amicón (1973); Gutiérrez (1993); Gutiérrez y Barreda (2006); Gutiérrez y Césari (1989); Gutiérrez y Limarino (2001, 2006); Gutiérrez et al. (1987); Menéndez (1965, 1971); Menéndez y González Amicón (1979); Ottone (1989, 1991); Ottone y Azcuy (1988, 1990, 1991); Ottone y García (1996); Ottone y Rossello (1996); Pérez Loinaze y Césari (2004); Vergel (2008); Vergel y Lechn (2001); Vergel y Luna (1992); Vergel et al. (1993, 2000);. Bibliografía utilizada para el Triásico: Azcuy y Longobucco (1983); Herbst (1965, 1970, 1972); Jain (1968); Ottone y García (1991); Ottone y Mancuso (2006); Ottone y Rodríguez Amenábar (2001); Ottone et al. (1992, 2005); Raine et al. (2008); Rojo y Zavattieri (2005); Stipanicic et al. (2007); Volkheimer y Zavattieri (1985); Yorigoyen y Stover (1970); Zavattieri (1986, 1987, 1991a, 1991b; 1992; 2002); Zavattieri y Melchor (1999); Zavattieri y Papú (1993); Zavattieri y Volkheimer (1992). 
Durante el Pennsylvaniano (Biozona DM; sub-biozonas A, B, C; véase Césari y Gutiérrez, 2001), entre los granos de polen dominan los monosacados lisos (con 13 géneros), especialmente aquellos vinculados a las Cordaitales (Plicatipollenites, Caheniasaccites) y Coniferales (Potonieisporites, Gondwanapollis, Cannanoropollis, Crucisaccites); en forma complementaria los bisacados lisos (vinculados a las Coniferales), que también aparecen en la sub-biozona A con Platysaccus, Limitisporites y Chordasporites?, incluyen 8 especies reconocibles en contraste con las 37 entre los monosacados.

En la sub-biozona B, se registran 38 especies de granos de polen monosacados contra 12 de los bisacados para pasar a 31 y 10 respectivamente en la sub-biozona C (fines del Pennsylvaniano).

Durante el Pennsylvaniano también se destaca la aparición de los granos de polen vinculados a las Glossoperidales-Voltziales, como son los granos monosacados estriados (Meristocorpus) en la sub-biozona A y la de los granos de polen bisacados estriados (Protohaploxypinus: 5 especies y Striatoabieites: 1 especie) en la Sub-biozona B. Es llamativo el registro de los géneros Marsupipollenites, Equisetosporites (Subbiozona A), Cycadopites (Sub-biozona B) y Vittatina (Sub-biozona C), para el Pennsylvaniano de este sector de la Argentina, taxones caracterìsticos del Pérmico. Algunas de estas presencia deberían ser confirmadas.

A comienzos del Pérmico, se produce una diversificación entre los granos de polen bisacados lisos, apareciendo las primeras citas de los géneros vinculados a las Caytoniales tales como Alisporites (Biozona FS), Klausipollenites, Vitreisporites y Minutasaccus (Biozona LW); los generos vinculados a las Coniferales (Platysaccus, Limitisporites, Colpisaccites) continúan su registro. Entre las Caytoniales, se registran 3 géneros y 4 especies en la Biozona FS, mientras que 5 géneros y 11 especies en la Biozona LW. Entre las Coniferales, 4/14 (FS) y 4/9 (LW).

Por su parte, entre los granos de polen mosocados lisos (vinculados a las Coniferales y Cordaitales) se produce una disminución en la diversidad específica durante el Cisuraliano, así por ejemplo se registran 12 géneros con 33 especies para la Biozona FS (destacándose la aparición de los géneros Barakarites, Valialasaccites y Latusipollenites), y 9 géneros y 13 especies para la Biozona LW. Esta tendencia se va incrementar hacia fines del Pérmico llegando a desaparecer la mayoría de los 
representantes de este grupo hacia el Triásico donde se produce un cambio composicional.

Hacia el Cisuraliano, los granos de polen monosacados estriados incrementan su diversidad, apareciendo los géneros Striomonosaccites, Mabuitasaccites y Crustaesporites. Mientras que entre los granos de polen bisacados estriados se produce una importante diversificación, principalmente entre aquellos vinculados a las Glossopteridales-Voltziales, representados por los géneros Protohaploxypinus (8 especies), Striatopodocarpites (6 especies), Illinites (1 especie) y Striatoabieites (2 especies), en la Biozona FS. Hacia fines del Guadalupiano e inicio del Lopingiano (Biozona LW) aparecen en este grupo los géneros: Tornopollenites y Striapollenites. Acompañan esta novedad, otra diversificación importante entre los granos bisacados vinculados a las Coniferales, aparecen Lueckisporites (con 7 especies), Lunatisporites (4 especies), Corisaccites (2 especies) y Staurosaccites (1 especie).

Para este mismo lapso (Cisuraliano-Lopingiano temprano), entre el resto de los granos de polen relacionados a las Glossopteridales/Voltziales y Coniferales se destacan las apariciones de los primeros registros de Weylandites, Pakhapites, Polarisaccites, Hamiapollenites, Distriatites, Preacolpatites, Monosulcites, Tiwarisporis, y una alta diversidad específica para los géneros Vittatina (6 especies en la Biozona FS y 7 en LW) y Hamiapollenites (2 y 5, respectivamente).

La escasa información de registros para el resto del Lopingiano y en especial para el Triásico Temprano (ausente hasta el momento) no nos permite observar el comportamiento de los diferentes grupos polínicos. Recién hacia el Triásico Medio, se vuelve a registrar un notorio incremento tanto de géneros como de especie entre los granos de polen bisacados lisos, las Caytoniales aparecen con 8 géneros y 25 especies, para pasar a 9 géneros y 39 especies en el Triásico Tardío; comportamiento que disminuye hacia fines del Triásico e inicio del Jurásico, con 5 géneros y 10 especies.

Entre los granos de polen bisacados vinculados a las Coniferales se registran 9 géneros y 21 especies en el Triásico Medio, 8 géneros y 22 especies en el Triásico Tardío y 1 género y 3 especies hacia fines del Triásico-inicio del Jurásico. La mayoría de estos géneros son primeros registros.

Entre los granos de polen bisacados estriados, monosacados estriados y plicados vinculados a las Glossopteridales/Voltziales, se produce una leve disminución en su 
diversidad, con 9 géneros y 18 especies para el Triásico Medio, 8 géneros y 27 especies para el Triásico Tardío, hasta casi desaparecer hacia fines del Triásico-inicios del Jurásico, con un solo género y 3 especies.

Otro cambio ocurrido son las drásticas reducciones que sufren los granos de polen monosacados (Potonieisporites, 1 especie; Variapollenites, 3 especies y Densipollenites, 1 especie) y bisacados estriados vinculados a las Coniferales (Lunatisporites, 3 especies, Lueckisporites, 2 especies), durante el Triásico.

En contraste hacia el Triásico Medio se observa una marcada diversidad entre los ganos de polen plicados vinculados a las Cycadales/Gynkgoales, con 2 géneros y 10 especies para el Triásico Medio y 4 géneros y 26 especies para el Triásico Tardío, hasta casi desaparecen a fines del Triásico (1 género y 4 especies).

En este contexto las microfloras obtenidas de la perforación La Estrella x-1 incorporan más información a la conocida para el Cisuraliano, y aportan datos novedosos para el lapso Guadalupiano tardío-Lopingiano temprano, muy poco conocidos para las cuencas sudamericanas (Cuadros 12 a 15 y Figura 18).

A partir de las asociaciones estudiadas se observa que la Biozona $\mathrm{CV}$ (Cisuraliano-Guadalupiano temprano) en correspondencia a lo que sucede con las floras antes analizadas presentan una dominancia de granos de polen bisacados lisos (aproximadamente un 50\% ) vinculados a las Caytoniales (con diversidad específica de los géneros Alisporites, Falcisporites, Chordasporites, etc.) y Coniferales (Platysaccus, Pityosporites, etc). Las formas plicadas representan un alto porcentaje en las asociaciones (que oscilan de los 12 a 18,5\%), están vinculadas a GlossopteridalesVolztiales y representadas por los géneros Weylandites y Pakhapites).

Las esporas vinculadas a Pteridophyta, Sphenophyta, y Lycophyta aparecen en la asociación, con valores que van desde los 21,7 a 12\%. Si bien para la Biozona TC (Guadalupiano tardío-Lopingiano temprano) los grupos antes mencionados están presentes en las asociaciones, los granos de polen de cuerpo liso pasan a ser mayoritarios, alcanzando valores relativos próximos al 90\% en detrimento las esporas, que decrecen abruptamente hasta casi desaparecer en las asociaciones provenientes de los niveles más altos (la presencia de las mismas en cercana al 3\%).

Los granos de polen estriados (Glossopteridales-Volztiales) se mantienen en una proporción constante en ambas biozonas, con rangos de porcentajes relativos que 
oscilan entre 6 y 12\%, aunque se insinúa una disminución de los mismos en los niveles superiores. Con respecto a los granos de polen plicados (Glossopteridales-Volztiales), también decrecen abruptamente en los porcentajes en las asociaciones, conformando solo un 0,2 a 4,3 \% respecto del total. Los granos de polen monosacados (ConiferalesCordaitales) son elementos de baja representación tanto en la Biozona CV como en la $\mathrm{TC}$, tanto como los granos de polen monosulcados, las algas y acritarcas.

Considerando la evolución de los principales grupos representada en el Cuadro 16, que corresponde principalmente a lo que en esta tesis agrupamos como "flora alóctona", se observa una concordancia con las tendencias que se manifiestan en el mencionado cuadro:

1) Las Glossopteridales se mantienen constantes durante el lapso CisuralianoLopingiano temprano.

2) Las Caytoniales comienzan a dominar en las floras.

3) Dentro de las Coniferales-Cordaitales se observan diferentes comportamientos: las Emporiaceae (Potonieisporites) y Cordaitales tienden a disminuír su representación hacia el Lopingiano temprano; las Podocarpaceae se mantienen constante (Platysaccus) o aumentan (Lunatisporites) y las Majoniaceae (Lueckisporites, Corisaccites, Staurosaccites) aparecen y dominan hacia el GuadalupianoLopingiano temprano.

\begin{tabular}{|l|c|c|}
\hline \multicolumn{1}{|r|}{ Edad } & Ci-Gu & Gu-Lo \\
\hline Generos-Grupo parental / Biozonas & CV & TC \\
\hline Lycophyta & 7 & $\mathbf{5}$ \\
\hline Kraeuselisporites & 2 & 0 \\
\hline Cristatisporites & 1 & 1 \\
\hline Gondisporites & 1 & 0 \\
\hline Lundbladispora & 3 & 2 \\
\hline Vallatisporites & 0 & 1 \\
\hline cf. Playfordiaspora & 0 & 1 \\
\hline & $\mathbf{3 4}$ & $\mathbf{2 9}$ \\
\hline Leiotriletes & 2 & 4 \\
\hline Punctatisporites & 3 & 3 \\
\hline Retusotriletes & 2 & 2 \\
\hline Cyclogranisporites & 1 & \\
\hline Granulatisporites & 1 & 1 \\
\hline Baculatisporites & 1 & 1 \\
\hline Anapiculatisporites & 1 & 1 \\
\hline Brevitriletes & 2 & 2 \\
\hline Osmundacidites & 1 & \\
\hline Converrucosisporites & 3 & 1 \\
\hline Verrucosisporites & 3 & 1 \\
\hline
\end{tabular}




\begin{tabular}{|c|c|c|}
\hline Pseudoreticulatispora & 0 & 1 \\
\hline Horriditriletes & 4 & 2 \\
\hline Interradiaspora & 1 & 0 \\
\hline Lophotriletes & 2 & 0 \\
\hline \begin{tabular}{|l|} 
Phidiaesporites \\
\end{tabular} & 0 & 1 \\
\hline Didecitriletes & 2 & 1 \\
\hline Convolutispora & 3 & 4 \\
\hline Camptotriletes & 0 & 1 \\
\hline Diatomozonotriletes & 1 & 0 \\
\hline Leschikisporis & 0 & 1 \\
\hline Phaselasporites & 0 & 1 \\
\hline Thymospora & 1 & 1 \\
\hline Sphenophyta & 4 & 4 \\
\hline Calamospora & 2 & 2 \\
\hline Laevigatosporites & 2 & 2 \\
\hline Chlorophycaea & 1 & 1 \\
\hline Botryococcus & 1 & 1 \\
\hline Algae & 1 & 0 \\
\hline Quadrisporites & 1 & 0 \\
\hline Prasinophyta & 4 & 4 \\
\hline Brazilea & 2 & 1 \\
\hline Leiosphaeridia & 1 & 2 \\
\hline Cymatiosphaera & 1 & 1 \\
\hline Fungii & 0 & 2 \\
\hline Portalites & 0 & 1 \\
\hline Reduviasporonites & 0 & 1 \\
\hline Acritarcas & 2 & 5 \\
\hline Buedingiisphaeridium & 1 & 1 \\
\hline Circulisporites & 0 & 1 \\
\hline Micrhystridium & 1 & 2 \\
\hline Mehlisphaeridium & 0 & 1 \\
\hline Cordaitales & 2 & 1 \\
\hline Cahenisaccites & 2 & 1 \\
\hline Coniferales & 27 & 20 \\
\hline Cannanorpollis & 2 & 2 \\
\hline Potonieisporites & 4 & 2 \\
\hline Limitisporites & 2 & 1 \\
\hline Chordasporites & 1 & 1 \\
\hline \begin{tabular}{|l|} 
Pityosporites \\
\end{tabular} & 1 & 1 \\
\hline Platysaccus & 4 & 5 \\
\hline Scheuringipollenites & 4 & 4 \\
\hline Lunatisporites & 4 & 4 \\
\hline Coniferopsida & 9 & 10 \\
\hline Crucisaccites & 2 & 1 \\
\hline Bascanisporites & 0 & 1 \\
\hline Gondwanapollis & 0 & 1 \\
\hline Stellapollenites & 0 & 1 \\
\hline Colpisaccites & 1 & 1 \\
\hline Corisaccites & 1 & 1 \\
\hline Lueckisporites & 4 & 3 \\
\hline Staurosaccites & 1 & 1 \\
\hline Gimnospermopsida & 4 & 2 \\
\hline Accinctisporites & 2 & 1 \\
\hline Polarisaccites & 1 & 0 \\
\hline cf. Ibisporites & 0 & 1 \\
\hline Distriatites & 1 & 0 \\
\hline
\end{tabular}




\begin{tabular}{|c|c|c|}
\hline Glossopteridales/Voltziales & 23 & 19 \\
\hline Meristocorpus & 1 & 1 \\
\hline Striomonosaccites & 1 & 0 \\
\hline Crustaesporites & 1 & 1 \\
\hline Triadispora & 1 & 0 \\
\hline Protohaploxypinus & 7 & 6 \\
\hline Striatopodocarpites & 4 & 3 \\
\hline Tornopollenites & 1 & 1 \\
\hline Tiwarisporis & 2 & 2 \\
\hline Weylandites & 1 & 2 \\
\hline Marsupipollenites & 2 & 2 \\
\hline Pakhapites & 2 & 1 \\
\hline Caytoniales & 14 & 14 \\
\hline Alisporites & 3 & 2 \\
\hline Falcisporites & 2 & 2 \\
\hline Pteruchipollenites & 1 & 1 \\
\hline Vitreisporites & 1 & 1 \\
\hline Hamiapollenites & 2 & 2 \\
\hline Vittatina & 5 & 3 \\
\hline Ephedrales & 1 & 0 \\
\hline Praecolpatites & 1 & 0 \\
\hline Cycadales/Ginkgoales & 2 & 2 \\
\hline Cycadopites & 2 & 2 \\
\hline
\end{tabular}

Cuadro 17. Número de géneros y especies presentes en cada biozona propuesta para Cuenca Colorado. Referencias: CV (Biozona Converrucosisporites confluens-Vittatina costabilis); TC (Biozona Tornopollenites toretus-Reduviosporites chalastus); Ci-Gu (Cisuraliano-Guadalupiano temprano); Gu-Lo (Guadalupiano tardío-Lopingiano temprano).

Un segundo ámbito para el análisis resulta la Cuenca Chacoparaná (véase Figura 15), para ella también se resume la distribución de las diferentes especies ordenadas según su afinidad botánica en los Cuadros 18 y 19.

\begin{tabular}{|c|c|c|c|c|c|}
\hline & Edad & Pen & Límite & $\mathbf{C i}$ & Gu \\
\hline & & & & Gu & \\
\hline & Biozonas & PL & PL & $\mathrm{Cr} \mathbf{s}$ & $\mathbf{S}$ \\
\hline \multicolumn{6}{|l|}{ GIMNOSPERMOPSIDAS } \\
\hline $\begin{array}{l}\text { GYMNOSPERMOPSIDA S.L. } \\
\text { Polarisaccites bilateralis } \\
\text { Polarisaccites triradiatus }\end{array}$ & \multirow{5}{*}{ O. CAYTONIALES } & & \multirow[t]{2}{*}{1} & \multirow[t]{2}{*}{$\begin{array}{l}X \\
X\end{array}$} & \multirow[t]{2}{*}{$\begin{array}{l}X \\
X\end{array}$} \\
\hline & & & & & \\
\hline F. CORYSTOPERMACEAE & & & & & \\
\hline $\begin{array}{l}\text { Chordasporites sp. A } \\
\text { Pteruchipollenites gracilis }\end{array}$ & & & $\mathrm{X}$ & $\begin{array}{l}X \\
X\end{array}$ & $\begin{array}{l}X \\
X\end{array}$ \\
\hline Pteruchipollenites sp. A & & & & $\mathrm{X}$ & $\mathrm{X}$ \\
\hline Alisporites australis & \multirow{14}{*}{ O. GLOSSOPTERIDALES } & \multirow{14}{*}{$\mathrm{X}$} & \multirow{3}{*}{$\mathrm{X}$} & $\mathrm{X}$ & $\mathrm{X}$ \\
\hline Alisporites sp. & & & & $\mathrm{x}$ & \\
\hline Allsporites sp. A & & & & & \\
\hline $\begin{array}{l}\text { Marsupipollenites striatus } \\
\text { Marsupipollenites triradiatus }\end{array}$ & & & $\mathrm{X}$ & $\begin{array}{l}X \\
X\end{array}$ & $\begin{array}{l}X \\
X\end{array}$ \\
\hline Protohaplolypinus limpidus & & & $\mathrm{X}$ & $\mathrm{X}$ & $\mathrm{X}$ \\
\hline Protohaploxypinus amplus & & & & $\mathrm{X}$ & $\mathrm{X}$ \\
\hline Protohaploxypinus bharadwajii & & & & $\mathrm{X}$ & $\mathrm{X}$ \\
\hline Protohaploxypinus goraiensis & & & $\mathrm{X}$ & $\mathrm{X}$ & $\mathrm{X}$ \\
\hline Protohaploxypinus perfectus & & & $\mathrm{X}$ & $\mathrm{X}$ & $\mathrm{X}$ \\
\hline Protohaploxypinus rugatus & & & & $\mathrm{X}$ & $\mathrm{X}$ \\
\hline Striatoabieites multistriatus & & & & $\mathrm{X}$ & $\mathrm{X}$ \\
\hline Striatopodocarpites cancellatus & & & & $\mathrm{X}$ & $\mathrm{X}$ \\
\hline Striatopodocarpites fusus & & & & & $\mathrm{X}$ \\
\hline Striatopodocarpites $s p$. & & & & $\mathrm{X}$ & \\
\hline
\end{tabular}


Striomonosaccites cicatricosus

Striomonosaccites ovatus

Striomonosaccites sp. A

Striomonosaccites sp. B

Mabuitasaccites crucistriatus

Illinites spp.

Illinites unicuus

Pakhapites fusus

Pakhapites ovatus

Weylandites lucifer

Weylandites magmus

Vittatina vittifera

Vittatina corrugata

Vittatina costabilis

Vittatina fasciolata

Vittatina ovalis Klaus

Vittatina $s p$.

Vittatina sp. Cesari et al.

Vittatina subsaccata

Hamiapollenites fusiformis

Hamiapollenites insolitus

Striatoabieites anaverrucosus

CONIFERALES S.L.

Colpisaccites granulosus

Colpisaccites sp.A

Latusipollenites quadrisaccatus

Pepperisporites sp. A

Gondwanapollis frenguellii

F. EMPORIACEAE-RUFLORIACEAE-UTRECHT ACEAE

Potonieisporites brasiliensis o

Potonieisporites magnus

Potonieisporites neglectus

Potonieisporites novicus

Potonieisporites triangulatus

Sahnites sp. A

Sahnites thomasii

F. FERUGLIOCLADACEAE

Barakarites rotatus

Cannanoropollis densus

Cannanoropollis janakii

Cannanoropollis korbahensis

Cannanoropollis mehtae

Cannanoropollis triangularis

Circumplicatipollis plicatus

Crucisaccites latisulcatus

Tuberisaccites sp. A

Tuberisaccites tuberculatus

F. PODOCARPACEAE/PINACEAE

Platysaccus papilionis

Lunatisporites variesectus

F. LEBACHIACEAE

Scheuringipollenites circularis

Scheuringipollenites maximus

Scheuringipollenites medius

Scheuringipollenites ovatus

F. MAJONIACEAE

Lueckisporites angoulensis

Lueckisporites brasiliensis

Lueckisporites latisaccus

Lueckisporites stenotaeniatus

Lueckisporites virkkiae

Staurosaccites cordubensis

F. ULLMANACIAE

Limitisporites elongatus

Limitisporites hexagonalis

Limitisporites rectus

Plicatipollenites densus

Plicatipollenites gondwanensis

Plicatipollenites malabarensis

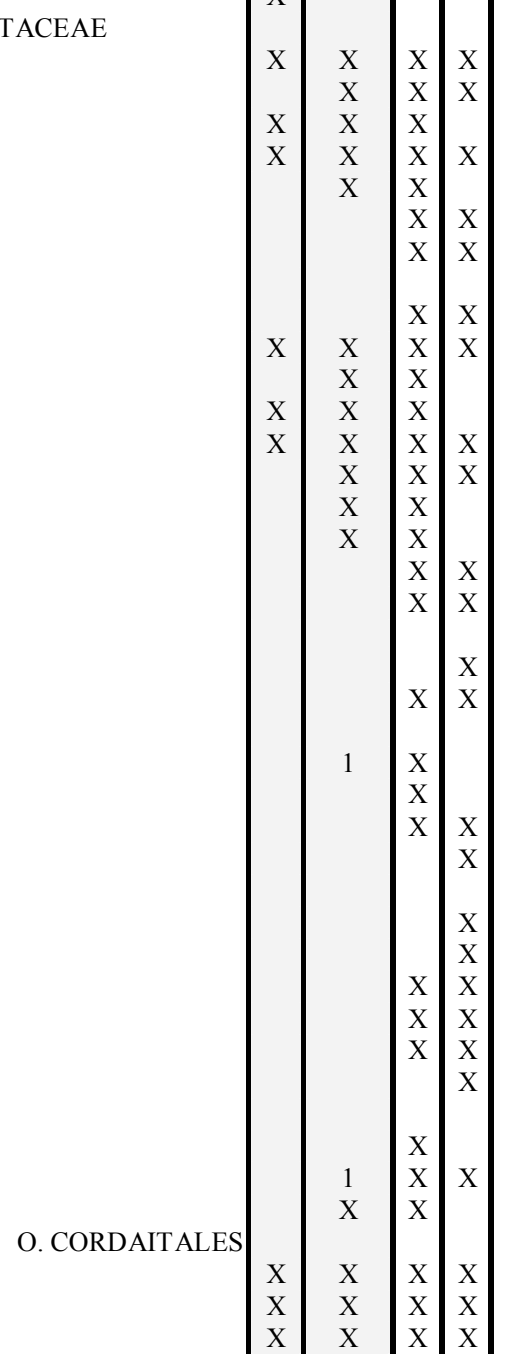



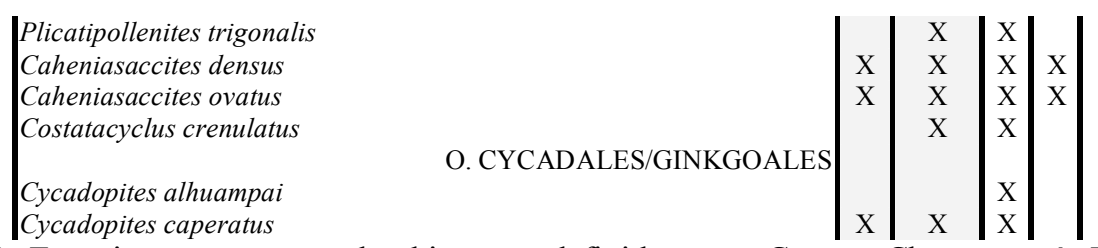

Cuadro 18. Especies presentes en las biozonas definidas para Cuenca Chacoparaná. Referencias: PL (Biozona Plicatipollenites-Lublandispora); Cr (Biozona Cristatisporites); S (Biozona Striatites); Pen (Pennsylvaniano); Límite (Pennsylvaniano tardío-Cisuraliano basal); Ci-Gu (Cisuraliano-Guadalupiano temprano); Gu (Guadalupiano tardío).

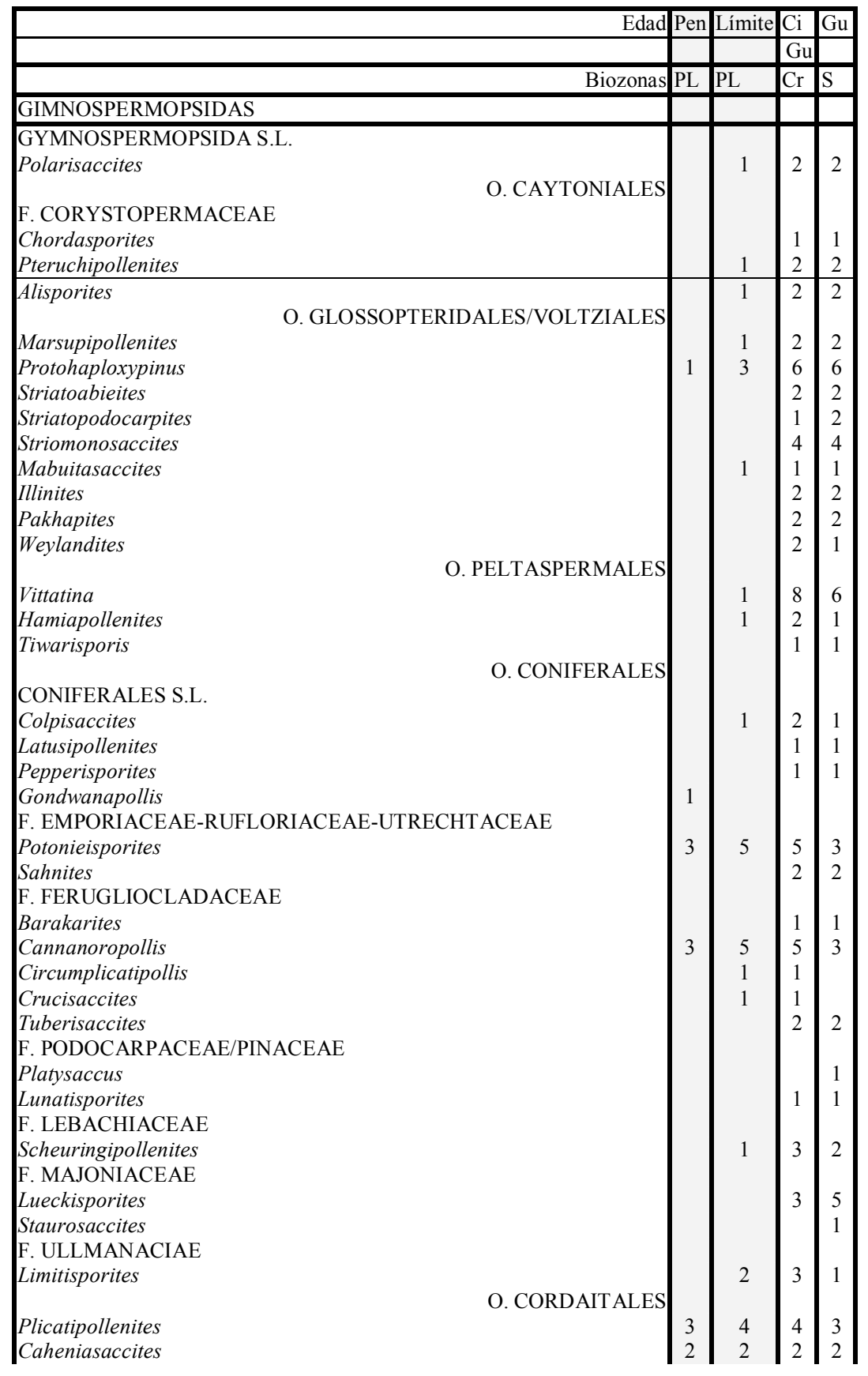




$$
\mid \begin{aligned}
& \text { Costatacyclus } \\
& \text { Cycadopites }
\end{aligned}
$$

O. CYCADALES/GinkgOALES $\left|\begin{array}{l|l|l}1 & 1 \\ 1 & 1 & 1\end{array}\right|$

Cuadro 19. Número de especies por género ordenados según afinidad botánica, presentes en las biozonas definidas para Cuenca Chacoparaná. Referencias: PL (Biozona Plicatipollenites-Lublandispora); $\mathrm{Cr}$ (Biozona Cristatisporites); S (Biozona Striatites); Pen (Pennsylvaniano); Límite (Pennsylvaniano tardíoCisuraliano basal); $\mathrm{Ci}-\mathrm{Gu}$ (Cisuraliano-Guadalupiano temprano); Gu (Guadalupiano tardío).

En esta Cuenca también se puede observar un comportamiento similar para el Pennsylvaniano medio-tardío, con el dominio de los granos de polen monosacados vinculados a las Cordaitales y las Coniferales. El inicio del Pérmico también muestra una diversidad entre los granos de polen bisacados estriados vinculados a las Glossopteridales/Voltziales, Peltaspermales y Coniferales. La diversidad entre los granos de polen bisacados no estriados, al contrario de lo que ocurre en el centro-oeste argentino y en la Cuenca Colorado, se mantiene relativamente constante durante el Cisuraliano-Guadalupiano. 


\section{CONCLUSIONES}

La realización de esta Tesis Doctoral ha permitido alcanzar una serie de conclusiones a partir de los materiales estudiados. Entre ellas se destacan:

1- Las asociaciones microflorísticas provenientes del subsuelo de la Cuenca Claromecó-Colorado fueron analizadas durante la década del '80, y sus resultados solo se dieron a conocer como informes inéditos y muy escasos trabajos publicados que incluían listas sistemáticas y algunas ilustraciones. A partir de éste estudio, más el aporte de nuevos preparados, se ha podido realizar un estudio sistemático de detalle de las asociaciones, ampliando el conocimiento sistemático y plantear un nuevo esquema palinoestratigráfico para la cuenca.

2- Se estudiaron asociaciones microflorísticas provenientes de 2 perforaciones: UTAL.CMM1.La Estrella x-1 (10 niveles testigo y 25 muestras de cutting) y UTAL.CMM1.Cruz del Sur x-1 (13 muestras de cutting).

3- Se describieron e ilustraron 179 especies: 135 determinadas a nivel específico, 23 confrontadas con determinadas especies y 21 determinadas a nivel genérico.

4- Se propusieron las siguientes combinaciones: Falcisporites parvus (de Jersey) nov. comb., Falcisporites similis (Balme) nov. comb. y Tiwarisporis anaverrucosus (Archangelsky y Gamerro) nov. comb.

5- 47 de las especies son nuevos registros para Argentina: Calamospora breviradiata Kosanke 1950, Leiotriletes ulutus Utting 1994, Baculatisporites bharadwaji Hart 1963b, Converrucosisporites pustulatus Backhouse 1988, Verrucosisporites microtuberosus (Loose) Smith y Butterworth 1967, Verrucosisporites surangei Maheshwari y Banerjee 1975, Horriditriletes filiformis (Balme y Hennelly) Backhouse 1991, Phidiaesporites fosteri Foster 1979, Didecitriletes uncinatus (Balme y Hennelly) Venkatachala y Kar 1965, Diatomozonotriletes ponticulus Foster 1975, Lundbladispora iphilegna Foster 1979, Lundbladispora willmotti Balme 1963, Indotriradites reidii Foster 1979, Laevigatosporites flexus Segroves 1970, Laevigatosporites plicatus Kar 1968, Thymospora criciumensis Quadros, MarquesToigo y Krepzig 1996, Leiosphaeridia crescentica Sinha 1969, Leiosphaeridia talchirensis Lele y Karim 1971, Maculatasporites minimus Segroves 1967, 
Cymatiosphaera gondwanensis (Tiwari) Backhouse 1991, Costatacyclus crenatus Felix y Burbridge emend. Urban 1971, Crustaesporites globosus Leschik 1956, Alisporites opii Daugherty 1941, Alisporites rioclarensis Menéndez 1976, Platysaccus crassimarginatus Lakhanpal, Sah y Dube 1960, Scheuringipollenites ovatus (Balme y Hennelly) Foster 1975, Limitisporites amazonensis Playford y Dino 2000b, Triadispora epigona Klaus 1964, Hamiapollenites andiraensis Playford y Dino 2000b, Hamiapollenites ruditaeniatus Qu y Wang 1986, Lunatisporites noviaulensis (Leschik) Foster 1979, Lunatisporites paliensis Tiwari y Ram-Awatar 1989, Lueckisporites singhii Balme 1970, Lueckisporites singrauliensis Sinha 1972, Protohaploxypinus bharadwajii Foster 1979, Protohaploxypinus goraiensis (Potonié y Lele) Hart 1964, Striatopodocarpites gondwanensis Lekhanpal, Sah y Dube 1960, Tornopollenites toreutos Morgan 1972, Vittatina vittifera (Luber y Waltz) Samoilovich 1953, Tiwarisporis simplex (Tiwari) Maheshwari y Kar 1967, Praecolpatites sinuosus (Balme y Hennelly) Bharadwaj y Srivastava 1969a, Buedingiisphaeridium permicum Schaarschmidt 1963, Circulisporites parvus de Jersey 1962, Micrhystridium fragile Deflandre 1947, Mehlisphaeridium fibratum Segroves 1967, Mehlisphaeridium regulare Anderson 1977 y Reduviasporonites chalastus (Foster) Elsik 1999.

6- Los ejemplares hallados solamente como redepósito en asociaciones cretácicas en la perforación Cruz del Sur x-1: Diatomozonotriletes townrowii Segroves 1970, Thymospora cicatricosa (Balme y Hennelly) Hart 1965 y Lueckisporites sp. cf. L. stenotaeniatus Menéndez 1976.

7- Se propone un nuevo esquema palinoestratigráfico con 2 biozonas para el Pérmico de la Cuenca Claromecó-Colorado:

7-a.) Biozona de asociación Converrucosisporites confluens-Vittatina vittifera (CV), presenta su sección tipo en la perforación La Estrella x-1 (3549- $3231 \mathrm{mbnm}) \mathrm{y}$ ha sido identificada en la perforación Cruz del Sur x-1 (4227-3995 mbnm), referida al Cisuraliano-Guadalupiano temprano y aparecería representada en las formaciones Piedra Azul y Bonete.

Se caracteriza por la presencia exclusiva de Converrucosisporites confluens, Diatomozonotriletes subbaculiferus, Osmundacidites wellmanii, Verrucosisporites surangei, Verrucosisporites sp. cf. V. chiquiritensis, Horriditriletes uruguaiensis, $H$. filiformis, Interradiaspora sp. cf. I. robustus, Didecitriletes uncinatus, 
Cyclogranisporites microgranus, Kraeuselisporites punctatus, K. apiculatus, Gondisporites serrulatus, Lundbladispora riobonitensis, Laevigatosporites vulgaris, Brazilea scissa, Potonieisporites densus, P. triangulatus, P. sp. cf. P. pyriferus, Caheniasaccites elongatus, Gondwanapollis frenguellii, Stellapollenites sp. cf. $S$. talchirensis, Accinctisporites sp. A, Crucisaccites latisulcatus, Striomonosaccites cicatricosus, Polarisaccites bilateralis, Alisporites opii, Limitisporites amazoniensis, Triadispora epigona, Distriatites sp. A, Lueckisporites singrauliensis, Protohaploxypinus bharadwajii, Striatopodocarpites sp. cf. S. solitus, Praecolpatites sinuosus y Pakhapites ovatus. El límite superior de esta biozona está marcado por la desaparición tanto de éstas especies como de Cannanorpollis sp. cf. C. densus, Crucisaccites latisulcatus, Vittatina vittifera, Brazilea scissa y Quadrisporites granulatus.

Ha sido subdividida a su vez en 3 asociaciones informales: A, B y C.

Desde el punto de vista de grupos morfológicos, la biozona CV está caracterizada por la abundancia de granos de polen bisacados lisos (51,6-55,6\%), acompañado por esporas triletes $(12,7-20,6 \%)$ y granos de polen plicados $(12,1-18,5 \%)$. Los granos de polen estriados (7,0-12,3\%), monosulcados (0,2-3,7\%), monosacados $(0,6-2,2 \%)$, algas $(0-3,9 \%)$ y acritarcas $(0-0,4 \%)$ aparecen como elementos subordinados.

7. b) Biozona de Asociación Tornopollenites toreutos-Reduviasporonites chalastus (TC), asignada al Guadalupiano tardío-Lopingiano temprano, presenta su sección tipo en la perforación La Estrella x-1 (3231-2986 mbnm). Aparecería representada en la Formación Tunas. La base está definida por los primeros registros de Leiotriletes ulutus, L. corius, Convolutispora candiotensis, Tornopollenites toreutos, Weylandites magmus, Leiosphaeridia crescentica y Portalites gondwanensis y se define por la presencia exclusiva de Tornopollenites toreutos, Reduviasporonites chalastus, Camptotriletes sp. cf. C. warchianus, Convolutispora candiotensis, Laevigatosporites flexus, Leiotriletes corius, L. ulutus, Leschikisporis chacoparanaense, Phaselisporites sp. cf. P. cicatricosus, Phidiaesporites fosteri, Pseudoreticulatispora pseudoreticulata, Vallatisporites arcuatus, Potonieisporites brasiliensis, Weylandites magmus, Circulisporites parvus, Leiosphaeridia crescentica, Mehlisphaeridium fibratum y $M$. sp. cf. M.? sp. B. 
Presenta un cambio abrupto en la composición cuantitativa de los distintos grupos de palinomorfos, respecto de la Biozona $\mathrm{CV}$ : los granos de polen bisacados (74,3-88,9\%) aparecen como los componenetes dominantes, mientras que el resto de los grupos constituyen conjuntos relictuales: esporas (2,4-10,9\%), granos de polen estriados $(3,4-9,4)$, plicados $(0,2-4,3 \%)$, monosacados $(0,7-3,0 \%)$, monosulcados $(0-0,9 \%)$, algas $(0-0,9 \%)$ y acritarcas $(0-0,4 \%)$.

8- La Biozona CV sería equivalente temporalmente a las biozonas Cristatisporites y parte de Striatites (Cuenca Chacoparaná), Cannanoropollis korbaensis y parte inferior de Lueckisporites virkkiae (Cuenca Paraná), la mayor parte de Vittatina costabilis (Cuenca Amazonas) y Pakhapites fusus-Vittatina subsaccata y Lueckisporites-Weylandites (centro oeste de Argentina). Por su parte, la Biozona TC, sería en tiempo a la parte superior de las biozonas Striatites, Lueckisporites virkkiae, Vittatina costabilis y a toda la biozona Tornopollenites toreutos.

9- Durante el Cisuraliano-Guadalupiano temprano (Biozona CV) las microfloras incluyen una alta representación de elementos de la vegetación que vivía en áreas más alejadas (alóctona) con requerimientos xerófilos y/o mesófilos (Coniferospida, Caytoniaes, Glossopteridales/Voltziales), y una baja representación de componentes de la flora autóctona (de hábitos hidro-higrófilos; en especial las Pteridophyta que dominan en forma clara en este grupo, y la muy escasa presencia de Sphenophyta y Lycophyta).

Las profundidades 3428, 3380, 3231 mbnm representarían cuerpos de agua salobres (evento transgresivo?), a partir de la participación del grupo AcritarcaPrasinophyta (3380 mbnm: Micrhystridium 0,37\%; 3428 mbnm: Micrhystridium 0,20\% y Leiosphaeridia 0,20\%; 3231 mbnm: Leiosphaeridia 3,52\%, Brazilea 0,44\%, Buedingiisphaeridium 0,22\%).

10- Hacia el Guadalupiano tardío-Lopingiano temprano, las microfloras (Biozona TC) reflejan ligeros cambios en la composición de la flora parental, también desarrollada en un paleoambiente predominantemente continental, incluyendo abundantes granos de polen bisacados, y una escasa participación de los elementos acuáticos (3180 mbnm: Micrhystridium, 0,43\% y Leiosphaeridia 0,21\%; $3081 \mathrm{mbnm:}$ Leiosphaeridia, 0,45\%, Micrhystridium, 0,22\% y Buedingiisphaeridium 0,22\% y 2992,9 mbnm: Circulisporites, 0,45\% y Leiosphaeridia 0,43\%). Al igual que en la Biozona $\mathrm{CV}$, probablemente reflejen la presencia de cuerpos de agua salobres. 
Las Caytoniales constituyen el grupo dominante de la megaflora en las asociaciones microflorísticas, y los bosques de Coniferas (elementos alóctonos) estarían caracterizados en las microfloras por las Lebachiaceae (Scheuringipollenites) y Podocarpaceae/Pinnaceae (Platysaccus y Pityosporites); las Glossopteridales-Voltziales decrecen en su participación de las microfloras. También los elementos representativos de la flora auctóctona aparecen pocos representados (Pteridophyta, 0,72-5,77\%; Sphenophyta, 1,36-4,69\%). Las Lycophyta llegan a desaparece en el espectro polínico.

11- El empobrecimiento de la flora (autóctona) con requerimeintos higrohidromesófilos, como las Pteridophyta, Sphenophyta y Lycophyta, hacia el Guadalupiano tardío-Lopingiano temprano, podría estar reflejando un período de aridización y disminución de las fuentes de agua, que ya se estaba insinuando para el Cisuraliano-Guadalupiano temprano.

12- Dentro de la flora alóctona, los diferentes grupos presentan comportamiento variable para este mismo intervalo: las Glossopteridales no presentan cambios en su representación en las microfloras; las Caytoniales dominan y dentro de las ConiferalesCordaitales, las Emporiaceae (Potonieisporites) y Cordaitales tienden a disminuír su representación en las microfloras; las Podocarpaceae se mantienen constante (Platysaccus) o aumentan (Lunatisporites) y las Majoniaceae (Lueckisporites, Corisaccites, Staurosaccites) aparecen y dominan.

Este comportamiento es coherente con las tendencias evolutivas de la paleoflora (evidenciada a traves del registro palinológico) observadas en las cuencas paleozoicas y triásicas del centro-oeste de Argentina.

De esta manera el análisis del contenido palinológico de las sedimentitas pérmicas del subsuelo de la Cuenca Claromecó-Colorado (Grupo Pillahuincó) permitió proponer un esquema de biozonación para Cuenca Colorado, compararlo $\mathrm{y}$ correlacionarlo con los esquemas ya existentes hasta el momento para la Argentina y áreas vecinas (principalmente Brasil y Uruguay), aportar elementos al conocimiento de la flora desarrollada durante el Cisuraliano-Lopingiano tardío en este sector de Argentina en un contexto paleogeográfico y paleoclimático. 


\section{AGRADECIMIENTOS}

A mi director de Tesis Doctoral, Pedro R. Gutiérrez, quien no solo me enseñó de qué se trataba el mundo de la paleopalinología, me guió en cada uno de estos nuevos pasos, sino que además me dió esta gran oportunidad. Gracias a su incondicional y constante ayuda este trabajo ha podido desarrollarse. Además, por hacer también de este laboratorio, un increíble y cordial lugar de trabajo.

Al Dr. Sergio Archangelsky por haber cedido el material con el que se llevó a cabo este estudio, así como también, haber permitido utilizar su bibliografía que ha resultado de indispensable ayuda.

Al Dr. Claudio Sylwan por la importante información suministrada para el desarrollo de esta Tesis.

A mi familia, Luis y Ana, Damián y Leopoldo, quienes siempre me alentaron a estudiar y trabajar en lo que me gustaba, y nunca dejaron de apoyarme en los buenos y malos momentos, en las idas y en las vueltas.

A Javier Ardouin, por su compañía, su paciencia, su aliento constante y por ayudarme a ver el mundo siempre con los mejores ojos.

A mis antiguos compañeros de laboratorio y ahora nuevos y grandes amigos: Leticia Povilauskas, Bárbara Cariglino, Laura Carrevedo, Valeria Pérez Loinaze, Carolina Panti, Eliana Coturel, Gustavo Correa, Luis Palazzesi, Roberto Pujana y Ezequiel Vera, quienes han hecho que cada instante compartido haya estado lleno de risa y buenos momentos, y que hacen cada día que éste sea un lugar único.

A la Dra Sara Balent, quien me brindó su desinteresada ayuda y colaboración en esta Tesis. 
A las Dras. Viviana Barreda y Silvia Césari por las palabras de aliento como asi también la bibliografía cedida para la consulta.

A la Ing Agrónoma Amalia González por la confección de numerosas ilustraciones que permitieron mejorar la información gráfica de esta Tesis.

Al Lic. Fabián Tricárico por las fotografías de MEB realizadas en el Museo Argentino de Ciencias Naturales.

A la Agencia Nacional de Promoción Científica y Tecnológica y al CONICET porque a traves de las becas obtenidas, se ha podido llevar a cabo el desarrollo de esta Tesis; y porque a traves de los subsidios ANPCyT-PICT 2002-11817 y 2005-32693. CONICET-PIP 5723 financiaron parte de los gastos.

Al Museo Argentino de Ciencias Naturales "B. Rivadavia" en cuyo ámbito se ha realizado este trabajo de Tesis.

A la Facultad de Ciencias Naturales y Museo, de la Universidad Nacional de La Plata, ámbito que me permitió formarme en esta increíble carrera. 


\section{BIBLIOGRAFÍA}

ACEÑOLAZA, F.G. y VERGEL, M.M. 1987. Hallazgo del Pérmico Superior fosilífero en el Sistema de Famatina. $10^{\circ}$ Congreso Geológico Argentino (San Miguel de Tucumán), Actas 3: 125-129.

ADlOFF, M.C., DOUBINGER, J. y PALAIN, C. 1974. A contribution to the Palynology of the Triassic and Lower Lias in Portugal. "Silves Sandstone from Northern Tage”. Com. Serv. Geol. Portugal (Lisboa): 91-144.

AĞRALI, B. y AKYOL, E. 1967 Hazro kömürlerinin palinolojik incelenmesi ve Permo-Karboniferdeki gölsel horizonların yaşı hakkında düşünceler. Maden Tetkik ve Arama Enstitüsü Dergisi 68, pp. 1-26.

ALPERN, B. y DOUBINGER, G. 1973. Microfossiles organiques du Paléozoïque. 6 Les Miospores Monoletes du Paléozoïque, Paris. CIMP/CNRS. 103 pp.

ALVAREZ, G.T. 2007. Extensión noroccidental de la Cuenca paleozoica de Claromecó, provincia de Buenos Aires. Revista de la Asociación Geológica Argentina, 62 (1): 86-91.

AMARAL, P.G.C.; RICARDI-BRANCO, F.; SOUZA, P.A. y BERNARDES-DEOLIVEIRA, M.E.C. 2001. Macro and microphytofossils study of the Itararé Subgroup at Km 96 of Bandeirantes Highway, Campinas Municipality, SP. Anais da Academia Brasileira de Ciências, 73(3): 462-3.

AMOS, A.J. 1972. Las cuencas carbónicas y pérmicas de Argentina. Simp. Intern. Sist. Carbónico-Pérmico America do Sul. Anais da Academia brasileira de Ciençias, 44 (Supl.) : 27-36.

AMOS, A.J., 1980. La fauna de invertebrados en la cronología del Carbónico y Pérmico de Argentina. $2^{\circ}$ Congreso Argentino de Paleontología y Bioestratigrafía y $I^{\circ}$ Congreso Latinoamericano de Paleontología. 1978. Actas 4: 231-234. Buenos Aires.

AMOS, A. B., QUARTINO, B. J. y ZARDINI, R. A. 1972. El Grupo de La Tinta, Provincia de Buenos Aires, Argentina. Paleozoico o Precámbrico. Annais XXV Congreso Brasilero de Geología: 211-221. San Pablo.

AMENÁBAR R., C. DI PASQUO, M., CARRIZO, H.A. y AZCUY, C.L. 2006. Palynology of the Chigua (Devonian) and Malimán (Carboniferous) formations in 
the Volcán Range, San Juan Province, Argentina. Part I. Paleomicoplankton and acavate smooth and ornamented spores. Ameghiniana, 43(2): 339-375.

ANDERSON, J.M. 1977. The biostratigraphy of the Permian and Triassic. Part 3. A Review of Gondwana Permian palynology with particular reference to the Northern Karoo Basin South Africa. Memoirs of the Botanical Survey of South Africa, No. 41, $401 \mathrm{pp}$; Johannesburg.

ANDERSON, J.M., ANDERSON, H.M., ARCHANGELSKY, S., BAMFORD, M., CHANDRA, S., DETTMANN, M., HILL, R., MCLOUGHLIN S. y ROSLER, O. 1999. Patterns of Gondwana plant colonisation and diversification. Journal of African Earth Sciences, 28(1): 145167.

ANDREIS, R.R. 1984. Análisis litofacial de la Formación Sauce Grande (Carbónico superior?), Sierras Australes, Provincia de Buenos Aires. An. Meet. Proj. 211-IGCP, Abstract: 28-29. San Carlos de Bariloche.

ANDREIS, R.R. y ARCHANGELSKY, S., 1996. The Neo-Paleozoic Basins on southern South America. En: Moullade, M. y Nairn, A.E.M. (Eds.), The Phanerozoic Geology of the World. The Paleozoic, B., 339-650, Elsevier, Amsterdam.

ANDREIS, R.R y JAPAS, M.S. 1996. Cuencas Sauce Grande y Colorado. En: El Sistema pérmico en la República Argentina y en la República Oriental del Uruguay (S. Archangelsky, ed), Academia Nacional de Ciencias: 45-64.

ANDREIS, R.R. y TORRES RIBEIRO, M. 2003. Estratigrafía, facies y evolución deposicional de la Formación Sauce Grande (Carbonífero Superior), Cuenca Sauce Grande, Sierras Australes, Buenos Aires, Argentina. Revista de la Asociación Geológica Argentina, 58(2): 137-165.

ANDREIS, R.R., AMOS, A.J., ARCHANGELSKY, S. y GONZÁLEZ, C.R. 1987. Capítulo IX: Cuencas Sauce Grande (Sierras Australes) y Colorado. En: Archangelsky, S. (ed.), El Sistema Carbonífero en la República Argentina, Academia Nacional de Ciencias, pp. 213-223.

ANDREIS, R.R., ÍÑIGUEZ, A.M., LLUCH, J.L. y RODRÍGUEZ, S. 1990. Cuenca Paleozoica de Ventania, Sierras Australes, provincia de Buenos Aires. En: G. Chebli y L. Spalletti (eds.), Cuencas Sedimentarias Argentinas. Serie de Correlación Geológica 6(1989): 265-298. Universidad Nacional de Tucumán. 
ARCHANGELSKY, S. 1996a. A correlation chart for Carboniferous-Permian zones in Argentina, Uruguay and Bolivia. Newsletter on Carboniferous Stratigraphy, I.U.G.S. Subcommission on Carboniferous Stratigraphy, 14: 10-11.

ARCHANGELSKY, S. 1996b. Capítulo 4. Palinoestratigrafía de la Plataforma Continental. En: V.A Ramos y M.A. Turic (eds.), Relatorio del $13^{\circ}$ Congreso Geológico Argentino y $3^{\circ}$ Congreso de Exploración de Hidrocarburos (Buenos Aires), Geología y Recursos naturales de la Plataforma Continental Argentina, pp. 67-72.

ARCHANGELSKY, S. 1996c. Aspect to Gondwana paleobotany: Gimnosperms of the Paleozoic-Mesozoic transition. Review of Palaeobotany and Palynology, 90: 287302.

ARCHANGELSKY, S. 1998. Informe palinológico pozo Paragüil $x$-1. Barranca Sur S.A. (informe inédito).

ARCHANGELSKY, S. 1999. Informe palinológico pozo Paragüil x-1. Barranca Sur S.A. (informe inédito).

ARCHANGELSKY, S. y CÚNEO, N.R. 1984. Zonación del Pérmico continental de Argentina sobre la base de sus plantas fósiles. Memoria $3^{\circ}$ Congreso Latinoamericano de Paleontología, México, pp. 143-154.

ARCHANGELSKY, S. y CÚNEO, N.R. 1987. Ferugliocladaceae, a new conifer family from the Permian of Gondwana. Review of Palaeobotany and Palynology, 51: 3-30.

ARCHANGELSKY, S. y GAMERRO, J.C. 1979. Palinología del Paleozoico Superior en el subsuelo de la Cuenca Chacoparanense, República Argentina. I. Estudio sistemático de los palinomorfos de tres perforaciones de la Provincia de Córdoba. Revista Española de Micropaleontología, 11(3): 417-478.

ARCHANGELSKY, S. y GAMERRO, J.C. 1980a. Informe final del estudio palinológico de los pozos YPF CCMI, Ra $x-y$ y $P u x-1$ (Ranquel y Puelches). Informe inédito, CIRGEO, Buenos Aires.

ARCHANGELSKY, S. y GAMERRO, J.C. 1980b. Palinomorfos pérmicos del subsuelo de la Cuenca Colorado, en la Plataforma del Mar, Argentina, Provincia Buenos Aires. Boletim IG Instituto de Geociências USP 11: 119-124.

ARCHANGELSKY, S. y VERGEL, M.M. 1996. Paleontología, bioestratigrafía y paleoecología. En: Archangelsky, S. (ed.), El sistema pérmico en la República 
Argentina y en la República Oriental del Uruguay, Academia Nacional de Ciencias. Córdoba, pp. 40-44.

ARCHANGELSKY, S., GAMERRO, J.C. y LEGUIZAMÓN, R.R. 1980a. Estudios palinológicos de las perforaciones YCF CO1, CO2 y CO3 (Paleozoico Superior) Santiago Temple, provincia de Córdoba. II Congreso Argentino de Paleontología y Bioestratigrafía y I Congreso Latinoamericano de Paleontología (Buenos Aires, 1978), Actas IV: 45-49. Argentina

ARCHANGELSKY, S., AZCUY C.L., PINTO, I.D., GONZÁLEZ, C.R., MARQUES TOIGO, M., ROSLER, O. y WAGNER, R.H. 1980b. The Carboniferous and early Permian of the South American Gondwana Area: A summary of biostratigraphic information. II Congreso Argentino de Paleontología y Bioestratigrafía y I Congreso Latinoamericano de Paleontología (Buenos Aires, 1978) Actas IV: 257269. Argentina.

ARCHANGELSKY, S., AZCUY, C.L., GONZÁLEZ, C.R. y SABATTINI, N. 1987a. V. Paleontología, bioestratigrafía y paleoecología de las Cuencas Paganzo, CalingastaUspallata y Río Blanco. En: ARCHANGELSKY, S. (ed.), El Sistema Carbonífero en la República Argentina, Academia Nacional de Ciencias, pp. 133-168.

ARCHANGELSKY, S., AZCUY, C.L., GONZÁLEZ, C.R. y SABATTINI, N. 1987b. XIII. Correlación general de biozonas. En: ARCHANGELSKY, S. (ed.), El Sistema Carbonifero en la República Argentina, Academia Nacional de Ciencias, pp. 281-292. ARCHANGELSKY, S., AZCUY, C.L., GONZÁLEZ, C.R. y SABATTINI, N. 1987c. XIV. Edad de las biozonas. En: ARCHANGELSKY, S. (ed.), El Sistema Carbonifero en la República Argentina, Academia Nacional de Ciencias, pp. 293-301.

ARCHANGELSKY, S., CÚNEO, R. y VILLAR DE SEOANE, L. 1990. Estudios sobre megasporas pérmicas argentinas. I. Sublagenicula brasileinsis (Dijkstra) DybováJachowickz et al. Ameghiniana 26(1989): 209-217.

ARCHANGELSKY, S., GUERSTEIN, G.R. y QUATTROCCHIO, M.E. 1997. [Pejerrey $x$-1 offshore well, Informe técnico presentado a Shell Capsa, Buenos Aires, 19 pp.].

ARCHANGELSKY, S., AZCUY, C.L., CÉSARI, S.N., GONZÁLEZ, C.R., HÜNICKEN, M.A., MAZZONI, A. y SABATTINI, N. 1996a. Correlación y edad de las biozonas. En: S. Archangelsky (ed.), El Sistema Pérmico en la República 
Argentina y en la República Oriental del Uruguay, pp. 203-226. Academia Nacional de Ciencias, Córdoba

ARCHANGELSKY, S., SABATTINI, N., ACEÑOLAZA, F., BUATOIS, L., GONZÁleZ, C., GARCÍA, G., CÉSARI, S., OTTONE, E., CÚNEO, N., HÜNICKEN, M., MAZZONI, A. y GUTIÉRREZ, P. 1996b. Capítulo X. Paleontología y bioestratigrafía de las Cuencas Paganzo, Calingasta-Uspallata y San Rafael. En: El Sistema Pérmico en la República Argentina y en la República Oriental del Uruguay (S. Archangelsky. ed.), Academia Nacional de Ciencias, Córdoba, pp. 177-201.

ARJANG, B. 1975. Die Rato-Jurassischen Floren des Iran und Afghanistans. Palaeontographica B, 152(4-6): 85-148.

ARTABE, A.E., MOREL, E.M., SPALLETTI, L.A. 2001. Paleoecología de las de las floras triásicas argentinas. En: El Sistema Triásico en la Argentina (Artabe, A.E., Morel, E.M.; Zamuner, A.E.; eds). Fundación Museo de La Plata "Francisco P. Moreno": 199-225. La Plata.

AZCUY, C.L. 1975. Miosporas del Namuriano y Westfaliano de la comarca MalanzánLoma Larga, provincia de La Rioja, Argentina. I. Localización geográfica y geológica de lacomarca y descripcion es sistemáticas. Ameghiniana, 12(1): 1-69.

AZCUY, C.L.1979. A review of the Gondwana palynology of Argentina and South America. $4^{\circ}$ Int. Palynol. Conf. (Lucknow 1976/1977), Proc. 2: 175-185.

AZCUY, C.L. 1986. Algunas precisiones sobre las palinozonas Carbónico-Pérmicas de la Cuenca Paganzo. Ameghiniana, 23(1-2): 97-100.

AZCUY, C.L. y DI PASQUO, M. 2000. Palynology of the Late Carboniferous from the Tarija Basin, Argentina: A systematic review of monosaccate pollen genera. Palaeontographica Abt. B, 254: 107-137.

AZCUY, C.L. y DI PASQUO, M. 2005. Early Carboniferous palynoflora from Ambo Formation, Pongo de Mainique, Peru. Review of Palaeobotany and Palynology, 134: 153-184.

AZCUY, C.L. y GUTIÉRREZ, P.R. 1985. Palinología de sedimentitas carbónicas de la Cuenca San Rafael. Ameghiniana, 22(1):97-109. 
AZCUY, C.L. y JELIN, R. 1980. Las palinozonas del límite Carbónico-Pérmico en la Cuenca Paganzo. II Congreso Argentino de Paleontología y Bioestratigrafía y I Congreso Latinoamericano de Paleontología, Actas 2: 51-67. Buenos Aires.

AZCUY, C.L. y LONGOBUCCO, M.I. 1983. Palinología de las formaciones Potrerillos y Cacheuta, provincia de Mendoza, Argentina. Ameghiniana, 20(3-4): 297-316. AZCUY, C.L., GUTIÉRREZ, P.R. y BARREDA, V.D. 1982. Algunas miosporas carbónicas de la Formación Agua Colorada, Provincia de La Rioja. Ameghiniana, 19(3-4): 289-302.

AZCUY, C.L., ANDREIS, R., CUERDA, A., HÜNICKEN, M., PENSA, M., VALENCIO, D.A. y VILAS, J.F. 1987 "El Sistema Carbonifero en la República Argentina", III Cuenca Paganzo: 41-99, IUGS (SCCS - Proy. 211 IGCP), Córdoba.

AZCUY, C.L., DI PASQUO, M. y VALDIVIA AMPUERO, H. 2002. Late Carboniferous miospores from the Tarma Formation, Pongo de Mainique, Peru. Review of Palaeobotany and Palynology, 118: 1-28.

BABCOCK, L.E., MILLER, M.F., ISBELL, J.L., COLLINSON, J.W. y HASIOTIS, S.T. 1998. Paleozoic-Mesozoic crayfish from Antarctica: Earliest evidence of freshwater decapod crustaceans. Geology; 26(6): 539-542.

BACKHOUSE, J. 1988. Permian trilete spores from the Collie Basin, Western Australia. Mem. Ass. Australas. Palaeontols, 5: 53-72.

BACKHOUSE, J. 1991. Permian palynostratigraphy of the Collie Basin, Western Australia. Review of Palaeobotany and Palynology, 67: 237-314.

BACKHOUSE, J. 1993. Palynology and correlation of Permian sediments in the Perth, Collie, and Officer Basins, Western Australia. Geological Survey of Western Australia, report 34: 111-128.

BALARINO, M.L. 2006. Granos de polen bisecados de la Cuenca Colorado (Pérmico), Argentina: diversidad y discusión sobre su registro. $9^{\circ}$ Congreso Argentino de Paleontología y Bioestratigrafía, Resúmenes: 176.

BALARINO, M.L. 2008. Acritarcas de Cuenca Colorado (Pérmico): Diversidad, nuevos registros y distribución estratigráfica. V Simposio Argentino del Paleozoico Superior, Buenos Aires, Ameghiniana 45(4-suplemento): 5R. 
BALARINO, M.L. y GUTIÉRREZ, P.R. 2006. Palinología de la Formación Tasa Cuna (Pérmico Inferior), Córdoba, Argentina: sistemática y consideraciones bioestratigráficas. Ameghiniana, 43(2): 437-460.

BALME, B.E. 1957. Spores and pollen grains from the Mesozoic of Western Australia. C.S.I.R.O. Aust. Coal Res. Sect. T.C. 25: 1-48.

BALME, B.E. 1963. Plant microfossils from the Lower Triassic of Western Australia. Palaeontology, 6(1): 12-40.

BALME, B.E. 1964. The palynological record of Australian Pre-Tertiary Floras. En: Ancient pacific floras, the pollen story, Cranwell, L.M. (ed.). University Hawaii Press, Honolulu: 49-80.

BALME, B.E. 1970. Palynology of Permian and Triassic strata in the Salt Range and Surghar Range, West Pakistan. En: B. Kummel y C. Teichert (eds), Stratigraphic Boundary problems: Permian and Triassic of West Pakistan. University of Kansas, Special Publication 4: 305-453.

BALME, B.E. 1979. Palynology of Permian-Triassic Boundary beds at Kap Stosch, East Greenland. Meddelelser om GrØnland, 200(6): 4-37.

BALME, B.E. 1995. Fossil in situ spores and pollen grains: an annotated catalogue. Review of Palaeobotany and Palynology, 87: 81-323.

BALME, B.E. y HENNELLY, J.P.F. 1955. Bisaccate sporomorphs from Australian Permian Coal. Australian Journal of Botany, 3: 89-98.

BALME, B.E. y HENNELLY, P.F. 1956a. Trilete sporomorphs from Australian Permian Sediments. Australian Journal of Botany, 4: 240-260.

BALME, B.E. y HENNELLY, P.F. 1956b. Monolete, monocolpate, and alete sporomorphs from australian permian sediments. Australian Journal of Botany, 4(1): 54-67.

BALME, B.E. y PLAYFORD, G. 1967. Late permian plant microfossils from the Prince Charles Mountains, Antarctica. Revue de Micropaléntologie, 10(3): 179-192.

BANGERT, B., LORENZ, V., ARMOSTRONG, R.L. 1999. The geochronology and significance of ash-fall tuffs in the glacigenic, Carboniferous-Permian Dwyka Group of Namibia and South Africa. Journal of African Earth Sciences, 29: 33-49. 
BARREDO, S y OTTONE, E.G. 2003. Formación Ciénaga Larga del Tontal, nomen novum para la Formación Casa de Piedra, Carbonífero, Precordillera de San Juan. Revista de la Asociación Geológica Argentina, 58(2): 267-270.

BECKER, D. y BERTELS, A. 1980. Micropaleontología de la Secuencia Terciárica de la Perforación Puelche (Margen Continental Argentino). $2^{\circ}$ Congreso Argentino de Paleontología y Bioestratigrafía y $1{ }^{\circ}$ Congreso Latinoamericano de Paleontología. (Buenos Aires) Actas, 2: 315-333.

BEERLING, D.J., LAKE, J.A., BERNER, R.A., HICKEY, L.J., TAYLOR, D.W., y ROYER, D.L., 2002. Carbon isotope evidence implying high O2/CO2 ratios in the Permo-Carboniferous atmosphere: Geochimica et Cosmochimica Acta, v. 66, p. 3757-3767.

BERGGREN, M.A. 1962. Some planktonic foraminifera from the Maestrichtian and type Danian Stages of southern Scandinavian. Stockholm Contributions to Geology, 9: 1-106.

BERI, A. 1988. Estudio sistemático del contenido palinológico de una muestra de la Formación Tres Islas (Pérmico Inferior) del Uruguay. Paula-Coutiana, 3: 27-48.

BERI, A. y DANERS, G. 1995. Palinología de la perforación N. 221, Pérmico, R. O. del Uruguay. Revista Geociências 14: 145-160. Sâo Paulo.

BERI, A. y DANERS, G. 1996. Palinomorfos de la perforación Cerro Largo Sur Nº14, Pérmico Inferior, Uruguay. Revista Chilena de Historia Natural, 69: 163-170.

BERI, Á. y GOSO, C.A. 1996. Análisis palinológico y estratigráfico de la Fm. San Gregorio (Pérmico Inferior) en el área de los cerros Guazunambi, Cerro Largo, Uruguay. Revista Española de Micropaleontología, 28: 211-223.

BERI, A. y GOSO AGUILAR, C. 1998. Resultados palinológicos y estratigráficos de la Formación San Gregorio (Pérmico Inferior), Uruguay. Geociências, 3(6): 108-119.

BERI, A. y PECOITS, E. 2001. Palinología y sedimentología de la Formación Melo (Pérmico) en la cañada "El Barón", departamento de Cerro Largo, Uruguay. Ameghiniana, 38(4): 419-428.

BERI, Á., GUTIÉRREZ, P.R., CERNUSCHI, F. y BALARINO, M. L. 2006. Palinología del Pérmico Inferior en la perforación DCLS-24 (Formación San Gregorio), departamento de Cerro Largo, Uruguay. Parte I: esporas, algas, prasinofitas y acritarcas. Ameghiniana, 43(1): 227-244. 
BERNER, R.A. y CANFIELD, D.E., 1989. A new model of atmospheric oxygen over Phanerozoic time. Am. J. Sci. 289: 333-361.

BHARADWAJ, D.C. 1957. The palynological investigation in the Saar Coals, Part I: morphography of Sporae dispersae. Paleontographica Abt. B. 105(5-6): 73-125.

BHARADWAJ, D.C. 1962. The miospore genera in the coals of Raniganj Stage (Upper Permian), India. The Palaeobotanist 9 (1960): 68-106.

BHARADWAJ, D.C. 1964. Potonieisporites Bharadwaj, ihre Morphologie, Systematik und Stratigraphie. Fortschritte der Geologie Reheindland und Westfalen, 12: 45-54. Kreffeld.

BHARADWAJ, D.C. 1975. Palynology in biostratigraphy and palaecology in India Lower Gondwana Formations. The Palaeobotanist, 22(2): 150-157.

BHARADWAJ, D.C. y DWIVEDI, A. 1981. Sporae dispersae of the Barakar sediments from South Karanpura Coalfield, Bihar, India. The Palaeobotanist, 27(1): 21-84.

BHARADWAJ, D.C. y SALUJHA, S.K. 1964. Sporogical study of Seam VIII in Raniganj Coald-Field, Bhiar (India) Part I. Description of sporae dispersae. The Paleobotanist 12(2): 181-215.

BHARADWAJ, D.C. y SALUJHA, S.K. 1965. A sporoligicial study of seam VII (Jote Dhemo Colliery) in the Raniganj Coalfield, Bihar (India). The Palaeobotanist, 13(1): 30-41.

BHARADWAJ, D.C. y SINGH, H.P. 1956. An Upper Triassic miospores assemblage from the Coals of Lunz, Austria. The Palaeobotanist, 12: 28-44.

BHARADWAJ, D.C. y SRIVASTAVA, S.C. 1969a. Some new miospores from Barakar Stage, lower Gondwana, India. The Paleobotanist, 17(2): 220-229.

BHARADWAJ, D.C. y SRIVASTAVA, S.C. 1969b. A Triassic microflora from India. Palaeontographica Abt. B, 125: 119-149.

BHARADWAJ, D.C., KAR, R.K. y NAVALE, K.B. 1976. Palynostratigraphy of Lower Gondwana deposits in Paraná and Maranhão Basins, Brazil. Biological Memoirs, 1 (1-2): 56-103.

BHARADWAJ, D.C., SRIVASTAVA, S.C. y ANAND-PRAKASH 1979. Palynostratigraphy of the Talchir Formation from Manendragarh, Madhya Pradesh, India. Geophytology, 8(2): 215-225. 
BISWAS, B. 1962. Stratigraphy of the Mahadeo, Langpar, Cherra and Tura formations, Assam, India. Bulletin of the Geological, Mining and Metallurgical Society, 25: 148.

BOSE, M.N. y KAR, R.K. 1966. Paleozoic sporae dispersae from Congo. I-Kindu Kalima and Walekale Regions. Annales de Musée Royal de l'Afrique Centrale, Série 8, Sciences géologiques, 53: 1-238.

BOSE, M.N. y MAHESHWARI, H.K. 1968. Paleozoic sporae dispersae from Congo. VIII. Area in he vicinity of Lake Tanganyke, South Alberville. Annales de Musee Royal de l'Afrique Centrale, Serie 8, Sciences géologiques, 60:1-116.

BRUGMAN, W.A., EGGINK, J.W., LOBOZIAK, S. y VISSCHER, H. 1985. Late Carboniferous-Early Permian (Ghzelian-Artinskian) Palynomorphs. Journal of Micropalaeontology, 4(1): 93-106.

BURJACK, M.I de A. 1978. Estudo palinológico da jazida carbonífera de Charqueadas. Goiânia. Universidade Federal de Goiás, 231 pp.

BURKE, K. 1976. Development of the tectonic trench associated with the rifting of the Atlantic Ocean. Tectonophysics, 36: 93-112.

BUSHNELL, D.C., BALDI, J.E., BETTINI, F.H., FRANZIN, H., KOVAS, E., MARINELLI, R. y WARTENBURG, G.J. 2000. Petroleum systems analysis of the eastern Colorado Basin, offshore northern Argentina. En: MELLO, M.R. y KATZ, B.J. (ed.), Petroleum systems of South Atlantic margins, AAPG Memoir 73 pp. $403-$ 415. American Association of Petroleum Geologists.

BUSTIN, R.M. 1997. Cold-temperate peats and coals: their sedimentology and composition. En: I.P. Martini, Editor, Late Glacial and Postglacial Environmental Changes: Quaternary, Carboniferous-Permian and Proterozoic, Oxford Univ. Press, New York (1997), pp. 294-310.

CACCAVARI, M.A. y GULER, M.V. 2006. Acaciapollenites acaciae sp. nov., una nueva políade de mimosoidea del Neógeno, en la Cuenca del Colorado, Argentina. Ameghiniana, 43(3): 585-590.

CARAMÉS, A. y MALUMIÁN, N. 2000. Foraminíferos bentónicos del Cenozoico del pozo Estrella x-1, Cuenca del Colorado, plataforma continental argentina. Ameghiniana, 37(4): 387-419. 
CAUDURO, A.D. 1970. Lower Gondwana Miospores from São Sepé Outcrop (Rio Grande do Sul, Brasil). Escola de Geologia, Universidade Federal de Rio Grande do Sul, Publicaçâo Especial, 17: 1-34.

CARREVEDO M.L., CORREA G.A., GUTIÉRREZ, P.R. y DE INUNCIAGA, M.F. 2008. Primeras evidencias de edad pérmica para la Formación Andapaico (San Juan, Argentina). V Simposio Argentino del Paleozoico Superior, Buenos Aires, Ameghiniana 45(4-suplemento): 5R-6R.

CASADÍO, S., MANERA, T., PARRAS, A., MONTALVO, C. y CORNACHIONE, G. 1999. Primer registro en superficie de sedimentos continentales del Cretácico Superior en la cuenca del Colorado, sureste de La Pampa. $14^{\circ}$ Congreso Geológico Argentino, Salta, Actas 1: 59.

CASADÍO, S., MANERA, T., PARRAS, A., MONTALVO, C. y CORNACHIONE, G. 2000. Primer registro en superficie de sedimentos continentales del Cretácico Superior en la Cuenca del Colorado. Revista de la Asociación Geológica Argentina, 55(1-2):129-133.

CAZZULO-KLEPZIG, M., MENEGAT, R. y GUERRA-SOMMER, M. 2005. Palynology and paleobotany in the reconstruction of landscape units from the Candiota Coalfield, Permian of Paraná Basin, Brazil. Revista Brasilera de Paleontología, 8(1): 83-98.

CÉSARI, S.N. 1984. Palinología de la Formación Tupe (Paleozoico Superior), Sierra de Maz, provincia de La Rioja. Ameghiniana, 21(1): 85-102.

CÉSARI, S.N. 1986a. Palinología de la Formación Tupe (Paleozoico Superior), Sierra de Maz, provincia de La Rioja. Parte II. Ameghiniana, 22(3-4): 197-212.

CÉSARI, S.N. 1986b. La palinozona Potonieisporites-Lundbladispora de la Cuenca Paganzo. Revista de la Asociación Geológica Argentina, 40(1985): 293-296.

CÉSARI, S.N. 1986c. Zonación palinológica del Carbonífero tardío en Argentina. IV Congreso Argentino de Paleontología y Bioestratigrafía, Mendoza; Actas I: 228230.

CÉSARI, S.N. 2007. Palynological biozones and radiometric data at the CarboniferousPermian boundary in Western Gondwana. Gondwana Research 11: 529-536. 
CÉSARI, S.N. y BERCOWSKI, F. 1997. Palinología de la Formación Jejenes (Carbonífero) en la Quebrada de Las Lajas, provincia de San Juan, Argentina. Nuevas inferencias paleoambientales. Ameghiniana, 34(4): 497-509.

CÉSARI, S.N. y GUTIÉRREZ, P.R. 1985. Microflora de la localidad de Los Mogotes Colorados (Paleozoico superior), provincia de La Rioja, República Argentina. Boletim Instituto de Geociências, Universidade de Saõ Paulo 15: 20-31

CÉSARI, S.N. y GUTIÉRREZ, P.R. 2001. Palynostratigraphy of Upper Paleozoic sequences in Central-Western Argentina. Palynology, 24: 113-146.

CÉSARI, S.N. y LIMARINO, C.O. 2002. Palynology of glacial sediments from the Guandacol Formation (Middle Carboniferous) in the Cerro Bola area, Paganzo Basin, Argentina. Alcheringa 26: 159-176.

CÉSARI, S.N. y VÁZQUEZ NÍSTICO, B. 1988. Palinología de la Formación Guandacol (Carbonífero), provincia de San Juan, República Argentina. Revista Española de Micropaleontología, 20(1): 39-58.

CÉSARI, S.N., GUTIÉRREZ, P.R. Y AMOS, A.J. 1987 Revisión bioestratigráfica de la Formación Jejenes (Carbónico), Provincia de San Juan. Primeras Jornadas sobre Geología de Precordillera, San Juan, Actas I: 174-180.

CÉSARI, S.N., MEZA, J.C. y MELCHOR, R.N. 1996. Primer registro palinológico de la Cuenca pérmica Oriental (Fm. Yacimiento Los Reyunos), Mendoza, Argentina. XIII Congreso Geológico Argentino y III Congreso de Exploración de Hidrocarburos, Actas V: 49-63.

CÉSARI, S.N., GUTIÉRREZ, P.R., MARTÍNEZ, M. y POPRIDKIN, C. 1999a. Primer registro palinológico de la Formación Tasa Cuna (Pérmico Inferior), provincia de Córdoba, Argentina. Actas $10^{\circ}$ Simposio Argentina de Paleobotánica y Palinología (Mendoza 1997), Asociación Paleontológica Aregentina, Publicación Especial 7: 19-22.

CÉSARI, S., FAUQUÉ, L., ESCOSTEGUY, L., CEGARRA, M. y LIMARINO, C. 1999b. Palinomorfos de la Formación Volcán en la Precordillera de San Juan. Ameghiniana-Resúmenes 36(4-Suplemento): 31R.

CÉSARI, S., ARCHANGELSKY, S. y DE SEOANE, L.V. 1995. Palinología del Paleozoico Superior de la Perforación Las Mochas, provincia de Santa Fe, Argentina. Ameghiniana, 32(1): 73-106. 
CÉSARI, S.N., GUTIÉRREZ, P.R. y NET, L. 2001. Nuevos registros palinologicos en la Formación Malanzán (Carbonífero), provincia de La Rioja. Su importancia bioestratigráfica. $2^{o}$ Simposio Argentino del Paleozoico Superior, Trelew, Resúmenes: 6.

CÉSARI, S.N., PÉREZ LONAIZE, V.S., LIMARINO, C.O. y FAUQUÉ, L. 2002. Palinología de la sección inferior de la Formación Volcán (Carbonífero-Pérmico Inferior), provincia de San Juan. Implicancias estratigráficas y paleoambientales. $8^{\circ}$ Congreso Argentino de Paleontología y Bioestratigrafía (Corrientes), Resúmenes: 68.

CÉSARI, S.N., PÉREZ LOINAZE, V.S., LIMARINO, C.O., TEDESCO, A.M. y CICCIOLI, P.L. 2008. Primer registro palinológico relacionado a la Biozona Costatumulus amosi en el Pérmico de la Provinica de Mendoza, Argentina. $V$ Simposio Argentino del Paleozoico Superior, Buenos Aires, Ameghiniana 45(4suplemento): 6R-7R.

CHANDRA, S. 1992. Changing Patterns of the Permian Gondwana Vegetation. The Palaeobotanist, 40: 73-100.

CHANDRA, A., KAR, R.K. y LACEY, W.S. 1977. Palynological studies in the Lower Karroo of Rhodesia and republic of South Africa. The Palaeobotanist, 24(2): 71-95. CHANDRA, A. y LELE, K.M. 1980. Talchir miofloras from South Rewa Gondwana Basin, India and their biostratigraphical significance. Proceedings of the $I V$ International Palynological Conference (Lucknow 1976-77) 2: 117-151.

CHUMAKOV, N.M. y ZHARKOV M.A. 2002. Climate during Permian-Triassic Biosphere Reorganizations, Article 1: Climate of the Early Permian. Stratigraphy and Geological Correlation, 10(6): 586-602.

CINGOLANI, C.A., 2005. Unidades Morfoestructurales (y estructuras menores) de la Provincia de Buenos Aires. En: De Barrio, R., Etcheverry, R., Caballé, M y Llambías, E. (Eds.) Geología y Recursos Minerales de la Provincia de Buenos Aires. Relatorio XVI Congreso Geológico Argentino, La Plata, 21-30

CISTERNA, G.A. y SIMANAUSKAS, T. 2000. Brachiopods from the Río del Peñón Formation, Río Blanco basin, Upper Palaeozoic of Argentina. Revista Española de Paleontología, 15: 129-151. 
CISTERNA, G.A., SIMANAUSKAS, T., ARCHBOLD, N.W., VERGEL, M.M., MARTÍNEZ, M. y STERREN, A. 2001. El intervalo marino de la Formación Tupe en la quebrada de La Herradura (Cuenca Paganzo): nuevas interpretaciones sobre su edad, bioestratigrafía y relaciones paleobiogeográficas. $2^{\circ}$ Simposio Argentino de Paleozoico Superior (Trelew), Resúmenes: 9.

CISTERNA, G.A., SIMANAUSKAS, T. y ARCHBOLD, N.W. 2002. Permian brachiopods from the Tupe Formation, La Herradura Creek, San Juan Province, Precordillera, Argentina. Alcheringa, 26: 177-200.

CLAPHAM, W.B. 1970. Permian miospores from the Flowerpot Formation of western Oklahoma. Micropaleontology, 16(1): 15-36.

CLARKE, R.F.A. 1965. British Permian saccate and monosulcate miospores. Palaeontology, 8(2): 322-354.

CLEMENT-WESTERHOF, J.A. 1984. Aspects of Permian palaeobotany and palynology. IV. The conifer Ortiseia Florin from the Val Gardena Formation of the Dolomites and Vicentinian Alps (Italy) with special references to a revised concept of the Walchiaceae (Göppert) Schimper. Review of Palaeobotany and Palynology, 41: 51-166. Amsterdam.

CLENDENING, J.A. 1969. Gillespieisporites gen. nov. and Laevigatosporites plicatus sp. nov. from Dunkard Strata of the Appalachian Basin. Proceedings of the Virginia Academy of Science, 40: 262-269.

CLENDENING, J.A. 1970. Laevigatosporites dunkardensis, new name for Laevigatosporites plicatus Clandening, 1969. Journal of Paleontology, 44(4): 188.

COATES, D.A. 1969. Stratigraphy and sedimentation of the Sauce Grande Formation, Sierra de la Ventana, Southern Buenos Aires Province. I Simp. Intern. Gondw., (Mar del Plata, 1967), Actas 2: 799-816.

COLBATH, G.K.1996. Chapter 7. Green and Blue-Green Algae. Itroduction. En: Jansonius, J. y McGregor, D.C. (eds.), Palynology: Principles and aplications; American Association of Stratigraphic Palynolosgists Foundation, I: 171-172.

COOKSON, I.C. 1947. Plant microfossils from the lignites of Kerguelen Archipelago. B.A.N.Z. Anctartic Research Expedition 1929-1931. B.A.N.Z.R.E., 85a, serie A. Adelaide [s.n.] 2:127-142. 
CORNET, B. 1989. Late Triassic angiosperm-like pollen from the Richmond Rift Basin of Virginia, U.S.A. Palaeontographica Abt. B, 213(1-3): 37-87.

CORREA, G.A., CARREVEDO, M.L., GUTIÉRREZ, P.R. y COTUREL, E.P. 2008. Consideraciones sobre la edad del miembro inferior de la Formación Andapaico (Paleozoico Superior, San Juan, Argentina). V Simposio Argentino del Paleozoico Superior, Buenos Aires, Ameghiniana 45(4-Resúmenes): 7R-8R.

CORREA, G.A., CARREVEDO, M.L. y GUTIÉRREZ, P.R. 2008. Age and Palaeoenvironment of Andapaico Formation (Lower Permian, San Juan, Argentina): palynological and sedimentological evidences. En prensa.

COUGHLIN, T.J. 2000. Linked orogen-oblique zones in the central Argentine Andes: the basis of a new model for Andean orogenesis and metallogenesis. Thesis University of Queensland, St. Lucia. 145 pp. Inédito.

COUPER, R.A. 1953. Upper Mesozoic and Cainozoic spores and pollen grains from New Zealand. New Zealand Geological Survey Paleontological Bulletin, 22: 1-77.

COUPER, R.A. 1958. British Mesozoic microspores and pollen grains. A systematic and stratigraphic study. Palaeontographica B 103: 75-179.

COUSMINER, H.L. 1965. Permian spores from Apillapampa, Bolivia. Journal of Paleontology, 39(6): 1097-1111.

CÚNEO, N.R. 1996. Permian phytogeography in Gondwana. Palaeogeogr. Palaeoclimatol. Palaeoecol. 125: 75-104.

CÚNEO, N.R., ISBELL, J., TAYLOR, E.L. y TAYLOR, T.N. 1993. The Glossopteris flora from Antarctica: taphonomy and paleoecology. 12th International Congress on Carboniferous/Permian Stratigraphy and Geology (Buenos Aires, 1991) 2: 13-40.

DAEMÓN, R.F. y CONTREIRAS, C.J.A. 1971. Zoneamento palinológico da Bacia do Amazonas. $25^{\circ}$ Congreso Brasileiro Geología, São Paulo, Annais 3: 79-88.

DAEMÓN, R.F. y MARQUES-TOIGO, M. 1991. An integrated biostratigraphic column for the Paraná Basin, Brazil. $12^{\circ}$ International Congress on CarboniferousPermian Geology, Buenos Aires, 1991: p. 13.

DAEMÓN, R.F. y QUADROS, L.P. 1970. Bioestratigrafia do Neopaleozóico da Bacia do Paraná. $24^{\circ}$ Congresso Brasileiro da Geologia, Brasilia, Annais: 359-412.

DAUGHERTY, L.H. 1941. The Upper Triassic Flora of Arizona. Carnegie Institute of Washington, Publications 526: 1-108. 
DEFLANDRE, G. 1947. Le problème des Hystrichosphères. Bulletin de l'Institut Océanographique de Monaco, 921: 1-23.

DE JERSEY, N.J. 1960. Jurassic spores and pollen grains from the Rosewood coalfield.

Geologycal Survey of Queensland, Publication 294: 1-14.

DE JERSEY, N.J. 1962. Triassic spores and pollen grains from the Ipswich Coalfield. Geologycal Survey of Queensland, Publication 307: 1-20.

DE JERSEY, N.J. 1964. Triassic spores and pollen grains from the Bundamba Group. Geologycal Survey of Queensland, Publication 313: 15 pp.

DE JERSEY, N.J. 1968. Triassic spores and pollen grains from the Clematis Sandstone.

Geologycal Survey of Queensland, Publication, 345, Palaeont. Pap. 22: 41 pp.

DE JERSEY, N.J. 1970a. Triassic miospores from the Blackstone Formation. Aberdare Conglomerate and Raceview Formation. Publs. Geol. Surv. Qd., 348, Palaeont. Pap. 22: 41 pp.

DE JERSEY, N.J. 1971. Triassic miospores from the Tivoli Formation and Kholo SubGroup. Geologycal Survey of Queensland, Publication, 353, Paleont. Pap. 28: 40 pp.

DE JERSEY, N.J. 1972. Triassic miospores from Esk Beds. Geologycal Survey of Queensland, Publication, 357, Palaeont. Pap. 32: 40 pp.

DE JERSEY, N.J. 1979. Palynology of the Permian-Triassic transition in the western Bowen, Basin. Geologycal Survey of Queensland, Publication 374: 1-39.

DE JERSEY, N.Y. y HAMILTON, M. 1965. Triassic microfloras of the Moorooka and Tirigalpa Formations. Qd. Govt. Min. J, 66: 327-332.

DE JERSEY, N.J. y HAMILTON, M. 1967. Triassic spores and pollen grain from the Moolayember Formation. Publs. Geol. Surv. Qd., 336, Paleont. Pap. 10: 61 pp.

DE JERSEY, N.J. y RAINE, J.I. 1990. Triassic and earliest Jurassic miospores from the Murihiku Supergroup, New Zealand. New Zealand Geological Survey Paleontological Bulletin 62: 1-164.

DELlAZZANA, J.G. 1976. Contribuiçao à palinologia da Formaçao Iratí (Permiano), Rio Grande do Sul, Brasil. Ameghiniana 13(1): 1-42.

DE SANTA ANA, H.B. 2004. Análise Tectono-estratigráfica das Seqüências PermoTriássicas e Jurocretácea da Bacia Chacoparanense Uruguaia ("Cuenca Norte”). 
Tese de Doutorado. Instituto de Geociencias e Ciencias Esatas, Universidade Stadual Paulista, 274 pp.

DETTMANN, M.E. 1963. Upper Mesozoic microfloras from South-Eastern Australia. Royal Society of Victoria, vol. 77, part 1: 148 pp.+ XXVII plates.

DI PASQUO, M. 2002. The Crassispora kosankei-Cystoptychus azcuyi Palynozone from the Upper Carboniferous Tupambi Formation, Tarija basin, northern Argentine. Rev. of Palaeob. and Palynol. 118: 47-76.

DI PASQUO, M. 2003. Avances sobre palinología, bioestratigrafía y correlación de los grupos Macharetí y Mandiyutí, Neopaleozoico de la Cuenca Tarija, provincia de Salta, Argentina. Ameghiniana, 40(1): 3-32.

DI PASQUO, M. 2007. Asociaciones palinológicas en las formaciones Los Monos (Devónico) e Itacua (Carbonífero Inferior) en Balapuca (Cuenca Tarija), sur de Bolivia. Parte 2. Asociaciones de la Formación Itacua e interpretación estratigráfica y cronología de las formaciones Los Monos e Itacua. Revista Geológica de Chile, 34(2): 163-198.

DI PASQUO, M. y AZCUY, C.L. 1997. Palinología del Grupo Mandiyuti, Carbonífero Superior, Cuenca Tarija, Argentina. VIII Congreso Geológico Chileno, Antofagasta, Actas, I: 475-479.

DI PASQUO, M.M. y DEL PAPA, C. 2004. Miospores from the Tarija Formation (Upper Carboníferous) at Zanja Honda creek (Salta province, Argentina) and its palaeoenvironmental significance. $32^{\circ}$ International Geological Congress (Florence, 2004), Italia. Abstracts part 2: 962

DI PASQUO, M. AZCUY, C.L. y STARCK, D. 2001. Palinología de la Formación San Telmo (Carbonífero Superior) de la sierra San Antonio, provincia de Salta, Argentina. Ameghiniana, 38(1): 85-98.

DI PASQUO, M., AZCUY, C.L. y SOUZA, P.A. 2003a. Palinología del Carbonífero Superior del Subgrupo Itararé en Itaporanga, Cuenca Paraná, Estado de São Paulo, Brasil. Parte 1: sistemática de esporas y paleofitoplancton. Ameghiniana, 40(3): 277-296.

DI PASQUO, M., AZCUY, C.L. y SOUZA, P.A. 2003b. Palinología del Carbonífero Superior del Subgrupo Itararé en Itaporanga, Cuenca Paraná, Estado de São Paulo, 
Brasil. Parte 2: sistemática de polen y significado paleoambiental y estratigráfico. Ameghiniana, 40(3): 297-313.

DI PASQUO, M.M., OWENS, B., STEPHENSON, M., FILATOFF, J. 2004. Vallatisporites and related cingulizonate genera from the late Carboniferous - early Permian of Saudi Arabia and South America. $11^{\circ}$ International Palynological Congress, (Granada, 2004), España. Polen, v. 14, p. 168-169.

DI PASQUO, M., MARTÍNEZ, M.A. y FREIJE, H. 2008. Primer registro palinológico de la Formación Sauce Grande (Pennsylvaniano-Cisuraliano) en las Sierras Australes, provincia de Buenos Aires, Argentina. Ameghiniana, 45(1): 69-81.

DIAS, M.E.R. 1993. Palinología do Grupo Itararé na Porção Centro-Sul do Rio Grande do Sul, Permiano da Bacia do Paraná, Brasil. Pesquisas, 20(2): 119-131.

DIAS-FABRÍCIO, M.E. 1981. Palinologia da Formação Rio Bonito na Área de Gravataí-Morungava, Rio Grande do Sul. Pesquisas, Porto Alegre, 14: 69-130.

DIBNER, A.F. 1971. Cordaites pollen of Angaraland. Uchenye Zapiski, Nauchno Issled Institut Geolgii Artsakhskij, 32:5-66. Moscow.

DICKINS, J.M. 1961. The gastropod Platyteichum in the Permian of Western Australia. Palaeontology, 4(1): 131-137.

DIÉGUEZ, C. y BARRÓN, E. 2005. Late Permian flora and vegetation changes near the Permian-Triassic boundary in the Landete section of the Alcotas Formation (SE Iberian Ranges, Spain). Palaeogeography, Palaeoclimatology, Palaeoecology; 229: 54-68.

DINO, R. y PLAYFORD, G. 2002. Stratigraphic and palaeoenvironmental significanc of Pennsylvanian (Upper Carboniferous) palynoflora from the Piauí Formation, Paranaíba Basin, northeastern Brazil. Paleontological Research, 6(1): 23-40.

DINO, R., ANTONIOLI, L. y BRAZ, S.M.N. 2002. Palynological data from the Trisidela Member of Upper Pedra de Fogo Formation ("Upper Permian") of the Parnaíba Basin, northeastern Brazil. Revista Brasileira de Paleontologia, 3: 24-35.

DOLBY, J.H. y BALME, B.E. 1976. Triassic palynology of the Carnarvon Basin, Western Australia. Review of Palaeobotany and Palynology, 22: 105-168.

DOUBINGER, J. 1974. Études palynologiques dans l'Autinien. Review of Palaeobotany and Palynology, 17: 21-38. 
DOUBINGER, J. y ADLOFF, M.C. 1977. Etude palynologiques dans le Trias de la bordure sud-est du Massif Central Français (Bassin de Largentere, Aredeche). Sci. Geol., Bull 30(1): 59-74.

DOUBINGER, J. y BUHMAN, D. 1981. Rott bei Borken und bei Schluchtern (Hessen, Deutschland) Palynologie und Tonmineralogie. Z. dt. geol. Ges. 132: 421-449.

DOUBINGER, J. y MAROCCO, R. 1981. Contenu Palynologique du Groupe Copacabana (Permien Inférieur et Moyen) sur la Bordure Sud de la Cordillère de Vilcabamba, Régin de Cuzco (Pérou). Sonderdruck aus der Geologischen Rundschau Band, 70(3): 1086-1099.

DOUBINGER, J., LÓPEZ-GÓMEZ y ARCHE, A. 1990. Pollen ans spores from the Permian and Triassic sediments of the Southeastern Iberian ranges, Cuesta de Hierro (Cuenca) to Chela-Manzanera (Valencia-Teruel) regiuon, Spain. Review of Palaeobotany and Palynology, 66(1): 25-45.

DOWNIE, C. y SARJEANT, W.A.S. 1963. On the interpretation and status of some hystrichosphere genera. Palaeontology, 6: 83-96.

DOWNIE, C., EVITT, W.R. y SARJEANT, W.A.S. 1963. Dinoflagellates, hystrichospheres, and the classification of the acritarchs. Standford University Publications, Geological Sciences 7: 1-16.

DUNN, M.T. 2001. Palynology of the Carboniferous-Permian boundary stratotype, Aidaralash Creek, Kazakhstan. Review of Palaeobotany and Palynology, 116: 175194.

DYBOVÁ, S. y JACHOWICZ, A. 1957. Mikrospory górno-śląskiego karbonu produktywnego. Prace Instytut Geologiczny 23: 1-328.

EDWARDS, L.E. y GUEX, J. 1996. Chapter 25. Analytical biostratigraphy and correlation. En: Jansonius, J. y McGregor, D.C. (eds.), Palynology: principles and applications; American Asociation of Stratigraphic Palynologist Fundation, 3: 9851009.

EISENACK, A. 1958. Tasmanites Newton 1875 und Leiosphaeridia N.G. as Gattungen der Hystrichosphaeridia. Palaentographica A, 110: 1-19.

ELORRIAGA, E.E. y VISCONTI, G. 2005. Estratigrafía de la Cuenca del Colorado en la provincia de La Pampa $16^{\circ}$ Congreso Geológico Argentino, La Plata, Actas: 351358. 
ELORRIAGA, E.E. y VISCONTI, G. 2006. Características de la Cuenca del Colorado en la provincia de La Pampa. 9० Jornadas Pampeanas de Ciencias Naturales, Resúmenes: No29. EdUNLpam (Ed.) ISBN950-863-079-5.

ELSIK, W.C. 1999. Reduviasporonites Wilson 1962: synonymy of the fungal organism involved in the Late Permian crisis. Palynology, 23: 37-41.

ERDTMAN, G. 1947. Suggestions for the classification of fossil and recent pollen grains and spores. Svensk Botanisk Tidskrift, 41: 104-114. Uppsala.

ERDTMAN, G. 1952. Pollen Morphology and Plant Taxonomy. Angiosperms. Almqvist and Wiksell, Stockholm: 539 pp.

ESHET, Y. 1990. Paleozoic-Mesozoic palynology of Israel. I. Palynological Aspects of the Permo-Triassic Succession in the Subsurface of Israel. Geological Survey of Israel Bulletin, 81: 1-57. Jerusalem.

ESHET, Y, RAMPINO, M R, y VISSCHER, H. 1995. Fungal event and palynological record of ecological crisis and recovery across the Permian-Triassic boundary. Geology, Vol. 23, 967-970.

EVITT, W.R. 1963. A discussion and proposals concerning fossil dinoflagellates, hystrichospheres, and acritarchs. I. Proceedings of the National Academy of Science of the United States of America, 49: 158-164.

EYLES, C.H., EYLES, N. y FRANÇA, A.B. 1993. Glaciation and tectonics in an active intracratonic basin: the Late Palaeozoic Itarare Group, Parana Basin, Brazil. Sedimentology, 40(1): 1-25.

EZPELETA, M.; GUTIÉRREZ, PR. 2006. Nuevos elementos de la microflora de la Formación Agua Colorada (Pensylvaniano), sistema de Famatina, La Rioja, Argentina. IX Congreso Argentino de Paleontología y Bioestratigrafía, IV Simposio del Paleozoico Superior, Actas 1:183 p. Córdoba.

FALCON, R.M.S. 1975. Palyno-stratigraphy of the Lower Karroo Sequence in the Central Sebungwe District, Mid-Zambezi Basin, Rhodesia. Palaeont Afr, 18: 1-29.

FALCON, R.M.S. 1978, New Permian miospores from Rhodesia. Arnoldia Rhodesia 8: 10-32.

FARABEE, M.J., TAYLOR, E.L. y TAYLOR, T.N. 1989. Pollen and spore assemblages from the Falla Formation (Upper Triassic), Central Transactartic Mountains, Antarctica. Review of Palaeobotany and Palynology, 61: 101-138. 
FARABEE, M.J., TAYLOR, E.L. y TAYLOR, T.N. 1991. Late Permian palynomorphs from the Buckley Formation, central Transantarctic Mountains, Antarctica. Review of Palaeobotany and Palynology, 69: 353-368.

FASOLO, Z. y VERGEL, M.M. 1994. Palinología de la perforación Fraile Muerto (FM2), Formación Tres Islas (Pérmico Inferior) de la Cuenca Paraná de Uruguay. Acta Geológica Leopoldensia, 17(39/2): 679-689.

FASOLO, Z., VERGEL, M.M., OLLER, J. y AZCUY, C. 2006. Nuevos datos palinológicos de la Formación Kaka (Eoserpukhoviano) en la Encañada de Beu, Subandino Norte de Bolivia. Revista Brasileira de Paleontología, 9(1): 53-62.

FAUQUÉ, L., LIMARINO, O., CINGOLANI, C., VARELA, R. 1999. Los movimientos intracarboníferos en la Precordillera riojana. XIV Congreso Geológico Argentino, Actas, Vol. 1, p. 421-424. Salta.

FELIX, C.J. y BURBRIDGE, P.P. 1967. Palynology of the Springer Formation of southern Oklahoma, U.S.A. Palaeontology, 10: 349-425.

FÉLIX, C.M., PREMAOR, E., HERMANY, G. y SOUZA, P.A. 2006. Análise palinotaxonômica e bioestratigráfica da Subturma Monosaccites na Bacia do Paraná, Brasil. I: Plicatipollenites Lele 1964 e Crucisaccites Lele \& Maithy 1965. Revista Brasileira de Paleontologia 9: 63-72.

FIELDING, C.R. y MCLOUGHLIN, S. 1992. Sedimentology and palynostratigraphy of Permian rocks exposed at Fairbairn Dam, central Queensland. Australian Journal of Earth Sciences, 39: 631-649.

FIGUEROA, D., MARSHALL, P. y PRAYITNO, W. 2005. Cuencas atlánticas de aguas profundas: principales plays. En: CHEBLI, G.A., CORTIÑAS, J. S.; SPALLETTI, L.A., LEGARRETA, L. y VALLEJOS, E.L. (eds.), Frontera exploratoria, VI Congreso de Exploración y Desarrollo de Hidrocarburos, IAPG, Buenos Aires, pp. 325-335.

FILATOFF, J. 1972, Stratigraphy and palynology of the Baralaba Coal Measures, Theodore, Queensland. Proceedings of the Royal Society of Queensland, 83: 21-34. FISHER, M.J. 1979. The Triassic palynofloral succesion in the Canadian Arctic Archipielago. American Asociation of Stratigraphic Palynologist Fundation, Contribution Series 5B: 83-100. 
FOSTER, C.B. 1975. Permian plant microfossils from the Blair Athol Coal Measures, central Queensland, Australia. Palaeontographica B, 154(5-6): 121-171.

FOSTER, C.B. 1979. Permian plant microfossils of the Blair Athol Coal Measures, Baralaba Coal Measures, and basal Rewan Formation of Queensland. Geologycal Survey of Queensland, Publication 372: 1-244.

FOSTER, C.B. 1982a. Spore-Pollen assemblages of the Bowen Basin, Queensland (Australia): their relationship to the Permian/Triassic Boundary. Review of Palaeobotany and Palynology, 36: 165-183.

FOSTER, C.B. y WATERHOUSE, J.B. 1988. The Granulatisporites confluens Oppelzone and Early Permian marine faunas from the Grant Formation on the Barbwire Terrace, Canning Basin, Western Australia. Australian Journal of Earth Sciences, 35: 135-157.

FOSTER, C.B., PALMIERI, V. y FLEMING P.J.G. 1985. Plant microfossils, Foraminiferida, and Ostracoda, from the Fossil Cliff Formation (Early Permian, Sakmarian), Perth Basin, Western Australia. Spec. Publ., S. Austr. Dept Mines and Energy, 5: 61-105.

FOSTER, C.B., STEPHENSON, M.H., MARSHALL, C. LOGAN, G.A. y GREENWOOD, P.F. 2002. A revision of Reduviasporonites Wilson 1962: description, illustration, comparison and biological affinities. Palynology, 26: 35-58.

FRAKES, L.A. y CROWELL, J.C. 1969. Late Paleozoic glaciation: I, South America. Geological Society of America. Bulletin, 80: 1007-1042.

FRAKES, L.A. 1979. Climates Throughout Geologic Time. Elsevier; 310 pp.

FRANÇA, A.B. 1994. Itararé Group: Gondwanan Carboniferous-Permian of the Paraná Basin, Brazil. En: Earth's Glacial Record (Deynoux, et al., eds). Cambridge University Press: 70-82.

FRANKE, D., NEBEN, S., SCHRECKENBERGER, B., SCHULZE, A. STILLER, M. y KRAVCZYK, C. 2006. Crustal structure across the Colorado Basin, offshore Argentina. Geophysical Journal International 165 (3), 850-864. doi: 10.1111/j.1365-246X.2006.02907.

FRANKE, D., NEBEN, S., LADAGE, S., SCHRECKENBERGER, B. y HINZ, K. 2007. Margin segmentation and volcano-tectonic architecture along the volcanic margin off Argentina/Uruguay, South Atlantic. Marine Geology, 244(1-4): 46-67. 
FREDERIKSEN, N.O. 1983. Angiosperm pollen and miscellanea. En: Middle Eocene palynomorphs from San Diego, California. (Fredereksen, N.O., Lowe, R.D. y Wosika, E.P., eds.). American Association of Stratigraphic Palynologists. Contributions Series, $\mathrm{n}^{\circ} 12: 32-109$.

FRYKLUND, B., MARSHALL, A. y STEVENS, J. 1996. Cuenca del Colorado. En: Ramos, V. A. y Turic, M. A. (eds.), Geología y Recursos Naturales de la Plataforma Continental Argentina. $13^{\circ}$ Congreso Geológico Argentino y $3^{\circ}$ Congreso de Exploración de Hidrocarburos, Relatorio, 8: 135-158. Buenos Aires.

FURQUE, G. 1965. Nuevos afloramientos del Paleozoico en la provincia de Buenos Aires. Revista Museo de La Plata (NS) Sección Geología 5(35): 239-243.

FURQUE, G. 1967. Estratigrafía de la región de Pillahuincó, provincia de Buenos Aires. Acta Geológica Lilloana, 9: 79-114. Tucumán.

FURQUE, G. 1973. Descripción geológica de la Hoja 34n, Sierra de Pillahuincó. Provincia de Buenos Aires. Servicio Nacional Minero Geológico, Boletín 141, 70 pp.

GAMERRO, J.C. y ARCHANGELSKY, S. 1981a. Hallazgo de palinomorfos pérmicos en sedimentitas de la Formación Piedra Shotel, Estancia La Casilda y en la perforación Cañadón Pastos Blancos (YPF Ch CPB es-1), Chubut, Argentina. $2^{\circ}$ Congresso Latino-Americano de Paleontología, Porto Alegre 1978, Actas 1: 169179.

GAMERRO, J.C. y ARCHANGELSKY, S. 1981b. Palinozonas neocretácicas y terciarias de la plataforma continental Argentina en la Cuenca del Colorado. Revista Española de Micropaleontología, 13: 119-140.

GARCÍA, G.B. 1995. Palinología de la Formación El Imperial, Paleozoico Superior, Cuenca San Rafael, Argentina. Parte I: esporas. Ameghiniana, 32(4): 315-339.

GARCÍA, G.B. 1996. Palinología de la Formación El Imperial, Paleozoico Superior, Cuenca San Rafael, República Argentina. Parte II: granos de polen, incertae sedis, acritarcas. Ameghiniana, 33(1): 7-33.

GEBHARD, I. 2005. Geología y aspectos exploratorios de la Cuenca del Colorado. En: Geología y Recursos minerales de la Provincia de Buenos Aires (de Barrio, R.E., Etcheverry, R.O., Caballé, M.F. y Llambías, E., eds.). Relatorio del XVI Congreso Geológico Argentino, La Plata.Capítulo XXX: 447-458. 
GONZÁLEZ, C.R. 1981. El Paleozoico Superior marino de la República Argentina. Bioestratigrafía y Paleoclimatología. Ameghiniana, 18(1-2): 51-65.

GONZÁLEZ, C.R. 1993. Late Paleozoic faunal succesion in Argentina. $12^{\circ}$ International Congress on Carboniferous and Permien Geology (Buenos Aires 1991), Comptes Rendus_1: 537-550.

GONZÁleZ, M.E., MUFF, R., VERGEL, M., HERBST, R. y FASOLO, Z. 1996. Nuevas investigaciones en la sección inferior del Grupo Independencia (Pérmico), Paraguay Oriental. GEOPAR, Ministerior de Obras Públicas y Comunicaciones, 1: 28-49.

GONZALEZ AMICÓN, O.R. 1973. Microflora carbónica de la localidad El Retamito, provincia de San Juan. Ameghiniana, 10(1): 1-35.

GRADSTEIN, F.M., OGG, J.G., SMITH, A.G. 2004. A Geologic Time scale 2004. Cambridge University Press, Cambridge, 589 pp.

GRAHAM, J.B., AGUILAR, N.M., DUDLEY, R. y GANS, C. 1995. Implications of the late Palaeozoic oxygen pulse for physiology and evolution. Nature, 375: 117 120

GRUNT, T.A. 1995. Biogeography of Permian Sea Basins. Paleontol.Zh., 4: 10-25.

GUERRA-SOMMER, M. y CAZZULO-KLEPZIG, M. 2000. Early Permian palaeofloras from Southern Brazilian Gondwana: A Palaeoclimatic approach. Revista Brasileira de Geociencias 30(3):486-490.

GUERSTEIN, G.R. 1990a. Palinología Estratigráfica del Terciario de la Cuenca del Colorado, República Argentina. Parte I: especies terrestres de la perforación Nadir N 1. Revista Española de Micropaleontología, 22(1): 33-61.

GUERSTEIN, G.R. 1990b Palinología Estratigráfica del Terciario de la Cuenca del Colorado, República Argentina. Parte II: especies marinas de la perforación Nadir N 1. Revista Española de Micropaleontología, 22(2): 167-182.

GUERSTEIN, G.R. 1990c Palinología Estratigráfica del Terciario de la Cuenca del Colorado, República Argentina. Parte III: Estudio sistemático y estadístico de la perforación Puerto Belgrano 20. Revista Española de Micropaleontología, 22(3): 459-480. 
GUERSTEIN, G.R. y GULER, M.V. 2000. Bioestratigrafía basada en quistes de dinoflagelados del Eoceno-Mioceno del pozo (YPF) Ombucta x-1, Cuenca del Colorado, Argentina. Ameghiniana, 37(1):81-90.

GUERSTEIN, G.R y JUNCIEL, G.L. 2001. Quistes de dinoflagelados del Cenozoico de la Cuenca del Colorado, Argentina. Ameghiniana, 38(3): 299-316.

GUERSTEIN, G.R. y QUATTROCCHIO, M.E. 1988. Palinozonas e interpretación estratigráfica mediante análisis de agrupamiento del Terciario de la Cuenca del Colorado, República Argentina. II Jornadas Geológicas Bonaerenses, Actas: 27-35.

GUERSTEIN, G.R. y QUATTROCCHIO, M.E. 1991. Datos paleoambientales basados en el estudio estadístico de las palinofloras de la perforación Nadir $\mathrm{N} 1$ (Eoceno-Mioceno), Cuenca del Colorado, República Argentina. Revista de la Asociación Geológica Argentina. 46(1-2) 136-149.

GUERSTEIN, G.R., QUATTROCCHIO, M.E., DESCHAMPS, C. y RUÍZ, L. 1995. Cenozoic (pre-Pliocene) paleoenvironmental trends based on palynomorphs fron the Colorado Basin, Argentina. En: Paleógeno de América del Sur, Asociación Paleontológica Argentina, Publicación especial 3: 63-73.

GUERSTEIN, G.R., WILLIAMS, G.L. y FENSOME, R.A. 2001. Cannosphaeropsis quattrocchiae, a new species of dinoflagellate cyst from the mid Cenozoic of the Colorado Basin, Argentina Micropaleontology; 47(2): 155-167. DOI: 10.2113/47.2.155.

GUERSTEIN, G.R., JUNCIEL, G.L., GULER, M.V. y DANERS, G. 2005. Diconodinium lurense, una nueva especie de quiste de dinoflagelado del Maastrichtiano Tardío-Daniano del Atlántico sudoccidental. Ameghiniana, 42(2): 329-338.

GULER, M.V. 2003. Quistes de dinoflagelados de la familia Protoperidiniaceae del Neógeno de la cuenca del Colorado, Argentina. Ameghiniana, 40(3), 457-467

GULER, M.V. y GUERSTEIN, G.R. 2002. Bioestratigrafía del Oligoceno-Plioceno Temprano de la Cuenca del Colorado (Argentina), basada en quistes de dinoflagelados. Revista Española de Micropaleontología 34(3): 359-371.

GULER, M.V. y GUERSTEIN, G.R. 2003. Quistes de dinoflagelados (Cladopyxiaceae, Gonyaulacaceae, Goniodomaceae e Incerta) del Oligoceno - Plioceno de la Cuenca 
del Colorado, Argentina. Familias e Incierta. Revista Española de Paleontología 18(1): 23-47.

GULER, M.V., GUERSTEIN, G.R. y QUATTROCCHIO, M.E. 2001. Palinología del Neógeno de la perforación Cx-1, Cuenca del Colorado, Argentina. Revista Española de Micropaleontología, 33(2): 183-204.

GULER, M.V., GUERSTEIN, G.R. y MALUMIÁN, N. 2002. Bioestratigrafía de la Formación Barranca Final, Neógeno de la Cuenca del Colorado, Argentina. Ameghiniana 39(1): 103-110.

GUTIÉRREZ, P.R. 1988. Análisis paleoflorístico, bioestratigráfico y aspectos paleoambientales de la Formación Agua Colorada en la sección sudoriental de la Sierra del Famatina, provincia de La Rioja, República Argentina. Tesis Doctoral, Faculta de Ciencias Exactas y Naturales, Universidad de Buenos Aires. 885 pp. (Inédita).

GUTIÉRREZ, P.R. 1993. Palinología de la Formación Agua Colorada (Carbonífero Superior), Sierra de Famatina, Provincia de La Rioja, Argentina. I. Granos de polen. Ameghiniana, 30(2): 163-212.

GUTIÉRREZ, P.R. y CÉSARI, S.N. 1989. Nuevas microfloras de la Formación Lagares (Carbonífero), provincia de La Rioja, República Argentina. Ameghiniana 25(1): 8596.

GUTIÉRREZ, P.R. y CÉSARI, S.N. 2000. Palinología de la Formación Bajo de Véliz (Pérmico Inferior), San Luis, Argentina: revisión sistemática y consideraciones estratigráficas. Ameghiniana, 37(4): 439-462.

GUTIÉRREZ, P.R. y BARREDA, V.D. 2006. Palinología de la Formación El Trampeadero (Carbonífero Superior), La Rioja, Argentina: significado bioestratigráfico. Ameghiniana, 43(1): 71-84.

GUTIÉRREZ, P.R. y LIMARINO, C.O. 2001. Palinología de la Formación Malanzán (Carbonífero Superior), La Rioja, Argentina: nuevos datos y consideraciones paleoambientales. Ameghiniana, 38(1): 99-118.

GUTIÉRREZ, P.R. y LIMARINO, C.O. 2006. El perfil del sinclinal del Rincón Blanco (noroeste de La Rioja): el límite Carbonífero-Pérmico en el noroeste argentino. Ameghiniana 43(4):687-703. 
GUTIÉRREZ, P.R. y CÉSARI, S.N. 1987. Nuevos elementos microflorísticos de la Formación Jejenes (Carbónico) provincia de San Juan. Asociación Geológica Argentina, Serie A, Monografías y Reuniones 2 (1986): 168-173.

GUTIÉRREZ, P.R., CÉSARI, S.N. y ARCHANGELSKY, S. 1997. Deusilites tenuistriatus sp. nov. (acritarca) en el Pérmico Inferior de la Cuenca Chacoparanense (Argentina). Ameghiniana 34(2): 247-250.

GUTIÉRREZ, P.R., CÉSARI, S.N. y ARCHANGELSKY, S. 2002. Revisión palinológica del pozo Árbol Blanco (YPF.SE.AB.x-1) (Paleozoico Superior), Santiago del Estero, Cuenca Chacoparanense, Argentina. . $8^{\circ}$ Congreso Argentino de Paleontología y Bioestratigrafía (Corrientes), Resúmenes: 72.

GUTIÉRREZ, P.R., DI PASQUO, M. y VERGEL, M.M. 2003a. Palinoestratigrafía del Carbonífero-Pérmico de la Argentina: estado actual del conocimiento. Revista del Museo Argentino de Ciencias Naturales, n.s. 5(2): 185-196.

GUTIÉRREZ, P.R., ARCHANGELSKY, S y Césari, S.N. 2003b. Contribución al conocimiento palinológico del Pérmicodel pozo UTAL-La Estrella 1, Cuenca del Colorado, Plataforma argentina. $3^{\circ}$ Simp. Arg. del Paleoz. Sup. (La Plata 09/03). Res.:15.

GUTIÉRREZ, P.R., BALARINO, M.L., ESCAPA, I. y CÚNEO, R. 2005. Formación Río Genoa (Pérmico Inferior): nuevos datos sobre su contenido palinológico. Reunión Anual de Comunicaciones y Simposio del 50 Aniversario de la Asociació Paleontológica Argentina y $1^{\circ}$ Simposio de Paleontología y Geología de la Península de Valdés, Ameghiniana 42(4) Suplemento, Resúmenes :32R.

GUTIÉRREZ, P.R., OTTONE, E.G. y JAPAS, S.M. (Eds.), 2006a. Léxico Estratigráfico de la Argentina. Volumen VII. Pérmico. Asociación Geológica Argentina, Serie B (Didáctica y Complementaria) 28: 368 pp.

GUTIÉRREZ, P.R., BERI, A., BALARINO, M.L. y CERNUSCHI, F. 2006b Palinología del Pérmico Inferior en la Perforación CLS-24 (Formación San Gregorio), departamento de Cerro Largo, Uruguay. Parte II: granos de polen. Ameghiniana, 43(3): 611-635.

GUTIÉRREZ, P.R., BALARINO, M.L., ESCAPA, I. y CÚNEO, R. 2007. Formación Río Genoa (Pérmico Inferior, Cuenca Tepuel-Genoa, Chubut): nuevos datos sobre 
su contenido palinológico. Revista del Museo Argentino de Ciencias Naturales, nueva serie, $9(2): 125-152$.

GUTIÉRREZ, P.R., ZAVATTIERI, A.M., EZPELETA, M. y ASTINI, R.A. 2008a. Nuevos elementos de la microflora de la Formación La Veteada (Pérmico) en los afloramientos de la sierra de Narváez (Catamarca), Argentina. Ameghiniana 45(4Resúmenes) en prensa.

GUTIÉRREZ P.R., ZAVATTIERI, A.M. y BALARINO, M.L. 2008b. Palinología del Pérmico en Argentina: estado actual del conocimiento. XII Simpósio Brasileiro de Paleobotânica e Palinologia, Resumos: 93.

GUTIÉRREZ, P.R., CÉSARI, S.N. y ARCHANGELSKY, S. (en prensa, a). A Palynological revision of the Árbol Blanco Well, Upper Paleozoic of the Chacoparaense Basin, Santiago del Estero Province, Argentina. Revista Española de Micropaleontología.

GUTIÉRREZ, P.R., BALARINO, M.L. y BERI, A. (en prensa, b). Palynology of the Lower Permian of Paraná Basin, Uruguay.

HABIB, D. 1968. Spore and pollen paleoecology of the Redstone seam (Upper Pennsylvanian) of West Virginia. Micropaleontology 14: 199-220.

HACQUEBARD, P.A. 1957. Plants spores in coal from the Horton Group (Mississippian) of Nova Scotia. Micropaleontology, 3: 301-324.

HARRINGTON, H.J. 1933. Sobre la presencia de restos de la flora de Glossopteris en las Sierras Australes de Buenos Aires. Rev. Mus. La Plata, 34: 303-338.

HARRINGTON, H.J. 1941. Investigaciones geológicas en las Sierra de Villavicencio y Mal País, prov. de Mendoza. Dirección Nacional de Minería y Geología, Boletín 49, pp. Buenos Aires.

HARRINGTON, H.J. 1947. Explicación de las Hojas Geológicas 33 m y 34 m, Sierras de Curamalal y de la Ventana, Provincia de Buenos Aires. Bol. Dir. Min. Geol., 61, $43 \mathrm{p}$ Buenos Aires.

HARRINGTON, H.J. 1955. The Permian Eurydesma fauna of eastern Argentina. J. Pal. 29(1): 112-128.

HARRINGTON, H.J. 1970. Las Sierras Australes de Buenos Aires, República Argentina: Cadena aulacogénica. Rev. Asoc. Geol. Arg. 25 (2): 151-181. 
HARRINGTON, H.J. 1972. Sierras Australes de la Provincia de Buenos Aires. En: A.F. Leanza. (Dir. y Ed.), I Simp. Geol. Reg. Arg. Acad. Nac. Cienc. 2: 967-984. Córdoba.

HARRINGTON, H.J. 1980. Sierras Australes de la provincia de Buenos Aires. En: $2^{\circ}$ Simposio Argentino de Geología Regional Argentina, Academia Nacional de Ciencias, 1: 967-983. Córdoba

HART, G.F. 1960. Microfloral investigations of the Lower Coal Measures (K2); Ketewaka-Mchuchuma Coalfield, Tanganyika. Bulletin Geological Survey Tanganyika, 36: $27 \mathrm{pp}$.

HART, G.F. 1963a. A probable pre-glossopteris micro-floral assemblage from Lower Karroo Sediments. South African Journal of Science: 135-146.

HART, G.F. 1963b. Microflora from the Ketewaka - Mchuchuma Coalfield, Tanganyika. Bulletin Geological Survey Tanganyika, 36: 1-27 (1965).

HART, G.F. 1964. A review of the classification and distribution of Permian miospores: Disaccate Striatiti. $5^{\circ}$ Congres International du Stratigraphie et de Geologie $d u$ Carbonifere, Paris 1963, Compte Rendu 3: 1171-1199.

HART, G.F. 1965. The systematics and distribution of Permian miospores. Witwatersrand University Press, 252 pp. Johannesburgo.

HELBY, R. 1973. Review of Late Permian and Triassic palynology of New South Wales. Geological Society of Australia, special publication 4: 141-155.

HELBY, R. 1992. BHP Petroleum Billawock - 1, Palynological Report, (no publicado). HEMER, D.O. y NYGREEN, P.W. 1967. Algae, acritarchs, and other microfossils incertae sedis from the Lower Carboniferous of Saudi Arabia. Micropaleontology 13: 183-194.

HERBST, R. 1965. Algunos esporomorfos del Triásico de Argentina. Ameghiniana, 4(5): 141-155.

HERBST, R. 1970. Estudio palinológico de la Cuenca Ischigualasto - Villa Unión, (Triásico), provincias de San Juan - La Rioja. Ameghiniana, 7(1): 83-97.

HERBST, R. 1972. Estudio palinológico de la Cuenca Ischigualasto-Villa Unión (Triásico), provs. San Juan-La Rioja. III. Esporas triletes. Ameghiniana, 9: 280-288. 
HOFFMEISTER, W., STAPLIN, F.L. y MALLOY, R. 1955. Mississipian plant spores from the Kardinsberg Formation of Illinois and Kentucky. Journal of Paleontology, 29(3): 372-399.

HOLZ, M. 1998. The Eopermian Coals of the Paraná basin in Southernmost Brazil: an analysis of the depositional conditions using sequence stratigraphy concepts. International Journal of Coal Geology, 36:141-163

HOLZ, M. 1999. Early Permian sequence stratigraphy and the palaeophysiographic evolution of the Paraná Basin in southernmost Brazil. Journal of African Earth Sciences 29(1): 51-61.

HOLZ, M. 2003. Sequence stratigraphy of a lagoonal estuarine system - an example from the lower Permian Rio Bonito Formation, Paraná Basin, Brazil. Sedimentary Geology, 162: 301-327.

HOLZ, M., VIEIRA, P.E. y KALKREUTH, W. 2000. The Early Permian coalbearing succession of the Paraná Basin in southernmost Brazil: depositional model and sequence stratigraphy. Revista Brasileira de Geociências, 30 (3): 420-422.

HOROWITZ, A. 1973. Triassic miospores from southern Israel. Review of Palaeobotany and Palynology, 16: 175-207.

HUGHES, N.F. y PLAYFORD, G. 1961. Palynological reconnaissence of the Lower Carboniferous of Spitzbergen. Micropaleontology, 7: 27-44.

IBRAHIMN, A.C. 1932. Sporomorfen aus den Floezen Agir und Bismark des Ruhrgebietes. Neus Jarbuch fur Mineralogie Monatshefte, 47: 438-454.

IBRAHIM, A.C. 1933. Sporenformen des Aegirhorizonts des Ruhr-Reviers. Konrad Triltsch, Würzburg: $47 \mathrm{pp}$.

I.A.P.G. 2005. Situación actual de la exploración y explotación de petróleo y gas en la Argentina. Petrotecnia, junio: 8-14.

IÑIGUEZ, A., ANDREIS, R. y ZALBA, P., 1988. Eventos piroclásticos en la Formación Tunas (Pérmico), Sierras Australes, provincia de Buenos Aires, República Argentina.

Segundas Jornadas Geológicas Bonaerenses, Actas 383-395.

INTROCASSO, A. 1982. Características de la corteza en el positivo bonaerense: Tandilia-Cuenca interserrana-Ventania, a través de datos de gravedad. Instituto de Física, Publicación 8: 1-26, Rosario. 
IVERSEN, J y TRÖELS SMITH, J. 1950. Pollenmorfologiske definiotioner og typer. Danmarks Geologiske Unders, 4: 1-54.

JAIN, R.K. 1968. Middle Triassic pollen grains and spores from Minas de Petroleo beds of the Cacheuta Formation (Upper Gondwana), Argentina. Palaeontographica Abt. $B, 122: 1-47$.

JANSONIUS, J. 1962. Palynology of Permian and Triassic sediments, Peace river area, western Canadá. Palaeontographica Abt. B, 110 (1-4): 35-98.

JANSONIUS, J. 1971. Emended diagnosis of Alisporites Daugherty 1941. Pollen et Spores, 13(2): 349-357.

JANSONIUS, J. y HILLS, L.V. 1976. Genera file of fossil spores and pollen. Special Publication, Department of Geology, University of Calgary, Canadá.

JARDINÉ, S. 1974. Microflores des formations du Gabon attribuées au Karroo. Review of Palaeobotany and Palynology, 17: 75-112.

JASPER, A., GUERRA-SOMMER, M., CAZZULO-KLEPZIG, M. e IANNUZZI, R. 2003. Biostratigraphic and paleoclimatic significance of Botrychiopsis fronds in the Gondwana realm. En: Wong, Th. E. (Ed.): Proceedings of the XVth International Congress on Carboniferous and Permian Stratigraphy. Utrecht, the Netherlands, pp. 379-388.

JASPER, A., MENEGAT, R., GUERRA-SOMMER. M., CAZZULO-KLEPZIG, M. y SOUZA, P.A. 2006. Depositional cyclicity and paleoecological variability in an outcrop of Rio Bonito formation, EarlyPermian, Parana Basin, Rio Grande do Sul, Brazil. Journal of South American Earth Sciences, 21:276-293.

JERZYKIEWICZ, J. 1987. Latest Carboniferous (Stephanian) and Early Permian (Autunian) Palynological assemblages from the Intrasudetic Basin, Southwestern Poland. Palynology, 11: 117-131.

JIZBA, K.M.M. 1962. Late Paleozoic bisaccate pollen from the United States midcontinent area. J. Paleont., 36: 871-887.

JONES, M.J. y TRUSWELL, E.M. 1992 Late Caboniferous and Early Permian palynostratigraphy of the Joe Joe Group, southern Galilee Basin, Queensland, and implications for Gonwanan stratigraphy. Journal of Australian Geology \& Geophysics, 13: 143-185. 
JUAN, R.C., DE JAGER, L. y RUSSELL, J. 1996a. The North-eastern Colorado Basin new insights from new seismic. $13^{\circ}$ Congreso Geológico Argentino y $3^{\circ}$ Congreso de Exploración de Hidrocarburos, Buenos Aires, Actas 1:143-144.

JUAN, R. DEL C, DE JAGER, J. RUSSELL, J. y GEBHARD, I. 1996b. Flanco norte de la cuenca del Colorado. En: RAMOS, A.V. y TURIC, M.A. (eds.), Geología y Recursos Naturales de la Plataforma Continental Argentina. $13^{\circ}$ Congreso Geológico Argentino y $3^{\circ}$ Congreso de Exploración de Hidrocarburos, Buenos Aires, Relatorio 7:117-133.

KAASSCHIETER, J.P.H. 1963. Geology of the Colorado basin. Tulsa Geological Society Digest 31: 177-187.

KAASSCHIETER, J.P.H. 1965. Geología de la Cuenca del Colorado. $2^{\circ}$ Jornadas Geológicas Argentinas, Tucumán, Actas 3:251-269.

KAR, R.K. 1968. Palynology of the Barren measures sequence from Jharia Coalfield, Bihar, India. 2. General palynology. The Palaeobotany, 16(2): 115-140.

KAR, R.K. y BOSE, M.N. 1967.Palaeozoic sporae dispersae from Congo. III.-Assise des schistes noirs de la Lukuga. Annales de Musee Royal de l'Afrique Centrale, Serie 8, Sciences géologiques 53: 1-238.

KAR, R.K, KIESER, G. y JAIN, K.P. 1972. Permo-Triassic subsurface palynology from Libya. Pollen et Spores, 14(4): 389-453.

KEELEY, M.L. y LIGHT, M.P.R. 1993. Basin evolution and prospectivity of the Argentine continental margin. Journal of Petroleum Geology 16(4), 451-464.

KEELEY, M.L., LIGHT, M.P.R., HOGG, S. y URIEN, C. 1992. Argentina's exploration licensing round covers 145 tracts in 15 basins. Oil \& Gas Journal 90(41).

KEIDEL, H. 1916. La geología de las Sierras de la Provincia de Buenos Aires y sus relaciones con las montañas de Sud África y los Andes. Min. Agric., Secc. Geol., Mineral. y Min., Anales 11 (3): 5-77.

KEIDEL, J. 1938. Über die "Gondwaniden” Argentiniens. Geologische Rundschau, Stuttgart 30(1-2), pp. 225-227, Abb. 7. Stuttgart.

KERP, H. HAMAD, A.A., VÖRDING, B. y BANDEL, K. 2006. Typical Triassic Gondwanan floral elements in the Upper Permian of the paleotropics Geology, 34(4):265-268; doi: 10.1130/G22187.1. 
KEY, R.M., TIDI, J., MC GEORGE, I., AITKEN, G., CADMAN, A., ANSCOMBE, J., 1998. The lower Karoo supergroup geology of the southwestern part of the Gemsbok sub-basin of the Kalahari Basin, Botswana. S. Afr. J. Geol., 101: 225-236. KHAN, A.M. y MARTIN, A.R.H. 1971. A note on genus Polypodiisporites R. Potonie. Pollen et Spores 13: 475-480.

KLAUS, W. 1960. Sporen der karnischen Stufe der ostalpinen Trias. Jahresbericht der geologischen Bundensanstalt, Sonderband 5: 107-184.

KLAUS, W. 1963. Sporen aus dem südalpinen Perm. Jahrbuch der Geologischen Bundensanstalt, Wien, 106: 229-361.

KLAUS, W. 1964. Zur sporenstratigraphischen Einstufung von Gips führenden Schichten in Bohrungen. Geologische Bundesanstalt, Wien II, Rasumofskygasse, 23: $1-16$.

KNOLL, J. y NICKLAS, E. 1987. Adaptation and fossil record of plants. American Journal of Botany, 72: 886-887.

KOSANKE, R.M. 1950. Pennsylvanian spores of Illinois and their use in correlation. Illinois State Geological Survival, Bulletin 74, 128 pp. Urbana.

KOSTADINOFF, J. 1993. Geophysical evidence of a Paleozoic basin in the interhilly area of Buenos Aires province, Argentina. $13^{\circ}$ International Congress on the Carboniferous and Permian Systems (Buenos Aires), Comptes Rendus, 1: 397-404.

KOSTADINOFF, J. 2007. Evidencia geofísica del umbral de Trenque Lauquen en la extensión norte de la Cuenca de Claromecó, provincia de Buenos Aires. Revista de la Asociación Geológica Argentina 62 (1): 69-75.

KOSTADINOFF, J. y FONT DE AFFOLTER, G. 1982. Cuenca Interserrana Bonaerense, Argentina. $5^{\circ}$ Congreso Latinoamericano de Geología, Buenos Aires, Actas 4: 105-121.

KOSTADINOFF, J. y PROZZI, C. 1998. Cuenca de Claromecó. Revista de la Asociación Geológica Argentina 53(4): 461-468.

KRÄUSEL, R. y LESCHIK, G. 1955. Die Keuperflora von Neuewelt bei Basel, II. Die Iso-und Mikrosporen. Schweizeirische Paläontologische Abhandlungen, 72: 1-10.

KRASSILOV, V A, AFONIN, S A, y BARINOVA, S S. 1999. Tympanicysta and the terminal Permian events. Permophiles, 35, 16-17.

KÜTZING, F.T. 1849. Species algarum. Brockhaus, Leipzing, 922 pp. 
KYLE, R.A. y FASOLA, A. 1978. Triassic palynology of the Beardmore Glacier Area of Antarctica. Palinología, num. extraord. 1. Madrid.

LAKHANPAL, R.N., SAH, S.C.D. y DUBE, S.N. 1960. Further observations on plant microfossils from a carbonaceous shale (Krols) near Naini Tal, with a discussion on the age of the beds. The Palaeobotanist, 7(2): 111-120.

LARSSON, K., LINDSTRÖM, S. y GUY-OHLSON, D. 1990. An Early Permian palynoflora from Milorgfjella, Dronning Maud Land, Antarctica. Antarctic Science, 2(4): 331-344.

LELE, K.M. 1964. Studies in the Talchir flora of India: 2. Resolution of the spore genus Nuskoisporites Pot. \& K1. The Palaeobotanist, 12: 147-168. Lucknow.

LELE, K.M. 1965. Studies in the Talchir flora of India: 3. Stellapollenites - a new monosaccate pollen genus from the South Rewa Gondwana basin. The Palaeobotanist, 13(1): 109-113.

LELE, K.M. 1975. Studies in the Talchir Flora of India. 10. Early and late Talchir microfloras from the West Bokaro Coalfield, Bihar. The Palaeobotanist, 22(3): 219235.

LELE, K.M. y KARIM, R. 1971. Studies in Talchir Flora of India. 6. Palynology of the Talchir Boulder Bed in Jayanti Coalfield, Bihar. The Palaeobotanist, 19(1): 52-69.

LELE, K.M. y MAITHY, P.K. 1964. An unusual monosaccate spore from the Karharbari Stage, Giridh Coalfield, India. The Palaeobotanist, 12(3): 307-312.

LELE, K.M. y MAITHY, P.K. 1969. Miospore assemblage of the Ganjra Nalla Beds, South Rewa Gondwana Basin, with some remarks on the age of the beds. The Palaeobotanist, 17(3): 298-309.

LELE, K.M. y MAKADA, R. 1972. Studies in the Talchir Flora of India - 7. Palynology of the Talchir Formation in the Jayanti Coalfield, Bihar. Geophytology, 2(1): 41-73.

LESCHIK, G.F. 1955. Die Keuperflora von Neuewelt bei Basel. II. Die Iso-und Mikrosporen. Schweizerische Paläontologische Abhandlungen 72: 1-70.

LESCHIK, G.F. 1956. Sporen aus dem Salzton des Zechsteins von Neuhof (Bei Fulda). Palaeontografica Abt. B, 100: 122-142.

LESTA, P. 2002. La exploración de la plataforma continental argentina: pasado, presente y futuro. Petrotecnia, 3: 16-23. 
LESTA, P. y SYLWAN, C. 2005. Cuenca de Claromecó. En Chebli, G.A., Cortiñas, J.S., Spalletti, L.A., Legarreta, L. y Vallejo, E.L. (eds.) Frontera Exploratoria de la Argentina, 6 a Congreso de Exploración y Desarrollo de Hidrocarburos, 10: 217-231, Mar del Plata.

LESTA, P., TURIC, M.A. y MAINARDI, E. 1978. Actualización de la información estratigráfica en la Cuenca del Colorado. Actas $7^{\circ}$ Congreso Geológico Argentino, 1: 701-713. Neuquén.

LESTA, P., MAINARDI, E. y STUBELJ, R. 1980. Plataforma continental argentina. $2^{\circ}$ Simposio Argentino de Geología Regional Argentina, 2: 1577-1602. Acad. Nac. Cienc. Córdoba.

LI, P.X., ZHANG, Z.M. y WU, S.Z. 1986. Stratigraphy. En: Permian and Triassic strata and fossil assemblages in the Dalongkou area of Jimsar, Xinjiang Geological Memoir Series 2, Geological Publishing House, Beijing: 2-38 (en chino con sumario en inglés).

LIMARINO, C.O. y CÉSARI, S.N. 2007. Paleoenvironmental evolution and biostratigraphy of Late Paleozoic Andean Gondwana basins. I Workshop. Problems in Western Gondwana Geology, Gramado 2007: 86.

LIMARINO, C.O. y GUTIÉRREZ, P.R. 1990. Diamictites in the Agua Colorada Formation (northwestern Argentina): new evidence of Carboniferous glaciation in South America. Journal of South American Earth Sciences 3: 9-20.

LIMARINO, C.O. y SPALLETTI, L.A. 1986. Eolian Permian deposits in West and northwest Argentina. Sedimentary Geology, 49: 129-137.

LIMARINO, C.O. y SPALLETTI, L.A. 2006. Paleogeography of the upper Paleozoic basins of southern South America: An overview. Journal of South American Earth Sciences, 22: 134-155.

LIMARINO, C.O., SPALLETTI, L.A. y SIANO, C. 1993. A Permian arid paleoclimatic phase in West and northwest Argentina. En: Compte Rendus XII Congres International Stratigraphie et Geologie du Carbonifere et Permien, 2: 453-468.

LIMARINO, C.O., MASSABIE, A.M., ROSSELlO, E., LÓPEZ GAMUNDÍ, O., PAGE, R. y JALFIN, G. 2000. Capítulo 13: El Paleozoico de Ventania, Patagonia e Islas Malvinas. En: Caminos, T. (ed.), Geología Argentina, Anales 29 (13): 319347. 
LIMARINO, C.O., CÉSARI, S., NET, L., MARENSSI, S., GUTIÉRREZ, P.R. y TRIPALDI, A. 2002. The Late Carboniferous postgalcial transgression in the Paganzo and Río Blanco Basins (northwestern Argentina): facies and stratigraphic significance. Journal of South American Earth Sciences 15:445-460.

LIMARINO, C.O., TRIPALDI, A., MARENSSI, S. y FAUQUE, L. 2006. Tectonic, sea-level, and climatic controls on Late Paleozoic sedimentation in the western basins of Argentina. Journal of South American Earth Sciences, 22 :205-226

LINDSTRÖM, S. 1993. Early Late Permian palynostratigraphy and palaeobiogeography of Vestfjella, Dronning Maud Land, Antarctica. Review of Palaeobotany and Palynology, 86: 157-173.

LINDSTRÖM, S. 1995. Early Permian palynostratigraphy of the northern Heimefrontfjella mountain-range, Dronning Maud Land, Antarctica. Review of Palaeobotany and Palynology, 89: 359-415.

LINDSTRÖM, S. 1996. Late Permian palynology of Fossilryggen, Vestfjella, Dronning Maud Land, Antarctica. Palynology, 20: 15-48.

LINDSTRÖM, S. 2005. Palynology of Permian shale, clay and sandstone clasts from the Basen till in northern Vestjella, Dronning Maud Land. Antarctic Science, 17(1): 87-96.

LINDSTRÖM, S., MCLOUGHLIN, S. y DRINNAN, A.N. 1997. Intraspecific variation of taeniate bisaccate pollen within permian glossopterid sporangia, from the Prince Charles Mountains, Antarctica. International Journal of Plant Sciences, 158(5): 673-684.

LLAMBÍAS, E. y PROZZI, C.R. 1975. Ventania. En: Geología de la provincia de Buenos Aires. $6^{\circ}$ Congreso Geológico Argentino, Relatorio 79-102, Bahía Blanca.

LÓPEZ GAMUNDI, O.R. 1989. Postglacial transgressions in Late Paleozoic basins of western Argentina. A record of glacio-eustatic sea level rise. Palaeogeography, Palaeoclimatology, Palaeoecology 71: 257-270.

LÓPEZ-GAMUNDÍ, O.R. 1997. Glacial-postglacial transitionin the Late Paleozoic basins of southern South America. En: Martini, I.P. (ed.), Late Glacial and Postglacial Environmental Changes-Quaternary, Carboniferous-Permian, and Proterozoic. Oxford University Press, New York, pp. 147-168. 
LÓPEZ-GAMUNDÍ, O.R. y ROSSELLO, E.A. 1992. En la cuenca intraserrana de Claromeco, Argentina: un ejemplo de cuenca de antepais herciniana. III Congreso Geológico de España y VIII Congreso Geoldgico Latinoamericano (Salamanca, España), Actas: 55-59.

LÓPEZ-GAMUNDÍ, O. y ROSSELLO, E.A. 1993. Devonian-Carboniferous unconformity in Argentina and its relation to Eo-Hercynian orogeny in southern South America. Geologische Rundschau, 82:136-147.

LÓPEZ-GAMUNDÍ, O.R. y ROSSELLO, E.A 1998. Common evolutionary patterns along the Samfrau geosynclinc: the Sauce Grande Basin-Ventana foldbelt (Argentina) and Karoo Basin-Cape foldbelt (South África) revisited. Geologische Rundschau.

LÓPEZ-GAMUNDÍ, O.R., LIMARINO, C.O. y CÉSARI, S.N. 1992. Late Paleozoic paleoclimatology of central western Argentina. Palaeogeography, Palaeoclimatology, Palaeoecology 91: 305-329.

LÓPEZ-GAMUNDÍ, O.R., ESPEJO, I.S., CONAGHAN, P.J. y POWELL, C. McA. 1994. Southern South America. En: J.J. Veevers y C. McA. Powell (eds.), Permian-Triassic Basins and Foldbelts along the Panthalassan Margin of Gondwanaland, Geological Society of America Memoir 184: 281-330.

LÓPEZ GAMUNDI, O.R., CONAGHAN, P.J., ROSELLO, E.A. y COBBOLD, P.R. 1995. The Tunas Formation in the Sierras Australes Foldbelt. East Central Argentina: evidence for syntectonic sedimentation in a foreland basin. Journal of South American Earth Sciences 8(2): 129-142.

LOVE, C.F. 1994. 3. The palynostratigraphy of the Haushi Group (WestphalianArtinskian) in Oman. En: Micropalaeontology and Hydrocarbon Exploration in the Middle East, Simmons (Ed.). pp. 23-39.

LOZOVSKIY, V.R. 1992. The Permian-Triassic boundary in continental series of Laurasia and its correlation with the marine scale. International Geology Review, 34: 1008-1014.

LUBER, A.A. y WALTZ, I.E. 1941. Atlas of microspores and pollen of the Palaeozoic of U.S.S.R. Trudy Tsent. Nauchno-issled. Geologo-razv. Instit. 139, 107 pp. (en ruso).

MACRAE, C.S. 1988. Palynostratigraphic correlation between the Lower Karoo sequence of the Waterberg and Pafuri Coal-Bearing Basin and the Hammanskraal 
plant macrofossil locality, Republic of South Africa. Department of Mineral and Energy Affairse, Geological Survey, Memoir 75. 217 pp.

MAHESHWARI, H.K. 1967. Studies in the Glossopteris flora of India. 29. Miospora assemblage from the Lower Gondwana Exposures along Bansloi river in Rajmahal Hills, Bihar. The Palaeobotanist, 15(3): 258-280.

MAHESHWARI, H.K. y BANERJEE, J. 1975. Lower Triassic palynomorphs from the Maitur Formation, West Bengal, India. Palaeontographica, Abt. B, 152: 149-190.

MAHESWARI, H.K. y KAR, R.K. 1967. Tiwarisporis gen. nov., a new spore genus from the Permian of Congo and India. Current Science, 36 (14): 369-370.

MAINARDI, E., STUBELJ, R. y TURIC, M. 1979. Cuencas costas afuera de la Argentina. $4^{\circ}$ Congreso Latinoamericano de Geología Económica, Actas 2: 385404.

MAITHY, P.K. 1965. Studies in the Glossopteris flora of India - 33. Sporae dispersae from the Karharbari Beds in the Giridih Coalfield, Bihar. The Palaeobotanist, 13(3): 291-307.

MALUMIÁN, N. 1970. Bioestratigrafía del Terciario marino del subsuelo de la provincia de Buenos Aires (Argentina). Ameghiniana, 7: 173-204

MALUMIÁN, N. 1972. Foraminíferos del Oligoceno y Mioceno del subsuelo de la provincia de Buenos Aires. Ameghiniana, 9(2): 97-137.

MALUMIÁN, N. y NÁÑEZ, C. 1996. Microfósiles y nanofósiles calcáreos de la plataforma continental. En: RAMOS, A.V. y TURIC, M.A. (eds.), Geología y Recursos Naturales de la Plataforma Continental Argentina. XIII Congreso Geológico Argentino y III Congreso de Exploración de Hidrocarburos, Relatorio 5:73-93.

MALUMIÁN, N., SURIANO, J.M. y COBOS, J.C. 1998. La Formación Barranca Final en su localidad tipo. Mioceno, Cuenca del Colorado. X Congreso Latinoamericano de Geología y VI Congreso Nacional de Geología Económica (Buenos Aires), Actas 1: $125-130$.

MANCILLA, O., SALINAS, A. y SOUBIES, E.D. 2002. Exploración en aguas profundas en la Cuenca del Colorado, República Argentina. Utilización del modelado estratigráfico numérico. Congreso de Exploración y Desarrollo de Hidrocarburos 2, Mar del Plata. 
MANGERUD, G. y KONIECZNY, R.M. 1991. Palynological investigations of Permian rock from Nordaustlandet, Svalbard. Polar Research 9(2): 155-167.

MANUM, S. 1962. On the genus Pityosporites Seward 1914, with a new description of Pityosporites antarcticus Seward. Nytt magasin for botanik 8: 11-15.

MANUM, S.B. y DUC TIEN, N. 1973. Palynostratigraphy of the Ketewaka Colafield (Lower Pwermian), Tanzania. Review of Palaeobotany and Palynology, 16: 213227.

MARQUES-TOIGO, M. 1972. Ammonoids vs. pollen and the Carboniferous or Permian age of San Gregorio Formation of Uruguay, Paraná Basin. Anais da Academia Brasileira da Ciências (suplemento) 44: 237-241.

MARQUES-TOIGO, M. 1974. Some new species of spores and pollen of Lower Permian age from the San Gregorio Formation in Uruguay. Anais da Academia Brasileira da Ciências, 46(3-4): 602-616.

MARQUES-TOIGO, M. 1988. Palinología Bioestratrigrafica e Paleoecologia do Neopaleozóico do Bacia do Paraná nos Estados do Rio Grande do Sul e Santa Catarina, Brasil. Programa de Pós Graduação em Geologia Regional, Universidade Federal do Rio Grande do Sul. Tesis doctoral, 259 pp. No publicada.

MARQUES-TOIGO, M. 1991. Palynobiostratigraphy of the southern Brazilian Neopalaeozoic Gondwana sequence. Pp. 503-515; En: H. Ulbrich y A.C. RochaCampos (eds), Gondwana Seven Proceedings, Instituto de Geociências, Universidade de São Paulo.

MARQUES-TOIGO, M. y PICCARELLI, A.T. 1985. On the morphology and botanical affinities of Lundbladispora Balme, 1963, in the Permian of the Paraná Basin, Brazil. Boletim do Instituto de Geociências da Universidade de São Paulo, São Paulo, 15 (1984): 24-52.

MARQUES-TOIGO, M., DIAS-FABRÍCIO, M.E. y MENDES PICCOLI, A.E. 1981. Ocorrência de microfósseis marinhos no Região de Gravataí, RS., Permiano Inferior, Bacia do Paraná. Congreso Latinoamericano de Paleontología, Porto Alegre, Anales, 2: 200-209.

MARQUES-TOIGO, M.; DIAS-FABRÍCIO, M.E.; GUERRA-SOMMER, M.; CAZZULO-KLEPZIG, M. y PICCOLI, A.E.M. 1989. Afloramentos da área deTrombudo Central, Permiano Inferior, Santa Catarina: palinologia,icnologia e 
sedimentologia. XI Congresso Brasileiro de Paleontologia, 11, 1989. Anais, Curitiba: $125-150$.

MARQUES-TOIGO, M., DIAS-FABRÍCIO, M.E., GUERRA-SOMMER, M. y MENDES PICCOLI, A.E. 1990. Afloramentos da área de Trombudo Central, Permiano Inferior, Santa Catarina: palinologia e sedimentologia. XI Congresso Brasileiro de Paleontologia, Curitiba, 1989, Anais; 125-150.

MARTÍN, H. y WILCZEWSKI, N.1970. Palaeocology, conditions of deposition and the palaeogeography of the marine Dwyka beds of South West Africa. Proceedings and Papers of the Second Gondwana Symposium, South Africa: 225-232.

MARTIN, L., BERTAUX, J., CORREGE, T., LEDRU, M.P., MOURGUIART, P., SIFEDDINE, A., SOUBIES, F., WIRRMANN, D., SUGUIO, K. y TURCQ, B. 1997. Astronomical forcing of contrasting rainfall changes in tropical South America between 12,400 and 8800 cal yr B.P. Quaternary Research, 47: 117-122.

MARTINI, E.P. (ed.) 1997. Late Glacial and Postglacial Environmental ChangesQuaternary, Carboniferous-Permian and Proterozoic. Oxford University Press, New York: 342 pp.

MAUTINO, L.R., VERGEL, M.D.M. y ANZOTEGUI, L.M. 1998a. Palinología de la Formación Melo (Pérmico Inferior) en Arroyo Seco, Departamento Rivera, República Oriental del Uruguay. Parte IV: Esporas. Ameghiniana, 35(1): 67-79.

MAUTINO, L.R., VERGEL, M.D.M. y ANZOTEGUI, L.M. 1998b. Palinología de la Formación Melo (Pérmico Inferior) en Arroyo Seco, Departamento Rivera, Uruguay. Parte V: granos de polen, acritarcas e incertae sedis. Ameghiniana, 35(3): 299-314.

MASSABIE, A., ROSSELLO, E.A. y LÓPEZ GAMUNDI, O.R., 2005. Cubierta Paleozoica-Mesozoica de las Sierras Australes de la Provincia de Buenos Aires. En: Geología y Recursos Naturales de la Provincia de Buenos Aires (deBarrio, R.E., Etcheverry, R.O., Caballé, M.F. y Llambías, E. eds.). Relatorio del XVI Congreso Geológico Argentino, La Plata, Cap. 6: 85-100.

MCLACHLAN, I.R y ANDERSON, A. 1973. A review of the evidence for marine conditions in Southern Africa during Dwyka times. Palaont. Afr., 15: 37-64.

MCNEILL, J., BARRIE, F.R., BURDET, H. M., DEMOULIN, V., HAWKSWORTH, D.L., MARHOLD, K., NICOLSON, D.H., PRADO, J., SILVA, P.C., SKOG, J.E., 
WIERSEMA, J.H. \& TURLAND, N.J. 2006. International Code of Botanical Nomenclature (Vienna Code). Electronic version of the original English text. aadopted by the Seventeenth International Botanical Congress, Vienna, Austria, July 2005. http://ibot.sav.sk/icbn/main.htm.

MACRAE, C.S. 1989. Palynostratigraphic identification of an uniconformity in borehole KNP 7 from the north-eastern part of the Soutpansberg Coalfield (Permian Period), South Africa. S. Af. J. Geol., 92: 261-271.

MELCHOR, R.N. 2000. Stratigraphic and biostratigraphic consequences of a new 40Ar/39Ar date for the base of the Cochicó Group (Permian), Eastern Permian Basin, San Rafael, Mendoza, Argentina. Ameghiniana 37(3): 271-282.

MELO, J.H. y LOBOZIAK, S. 2003. Devonian-Early Carboniferous miospore biostratigraphy of the Amazon Basin, Northern Brazil. Review of Palaeobotany and Palynology, 124: 131-202.

MENENDEZ, C.A. 1965. Contenido palinológico en sedimentos con "Rhacopteris ovata" (McCoy) Walk. de la Sierra de Famatina, La Rioja. Revista del Museo Argentino de Ciencias Naturales "Bernardino Rivadavia" e Instituto Nacional de Investigación de las Ciencias Naturales, Paleontología, 1(3): 45-80.

MENÉNDEZ (C.A.), 1966. Fascículo II. Plantas fósiles. En: A.V. Borrello (ed.), Paleontología bonaerense. Comisión de Investigación Científica, 35 pp. Buenos Aires.

MENENDEZ, C.A. 1971. Estudio palinológico del Pérmico de Bajo de Vélez, provincia de San Luis. Revista del Museo Argentino de Ciencias Naturales "Bernardino Rivadavia" e Instituto Nacional de Investigación de las Ciencias Naturales, Paleontología 1(9): 263-306.

MENENDEZ, C.A. 1976. Contenido palinológico de estratos pérmicos con "Mesosaurus" de Río Claro, São Paulo, Brasil. Revista del Museo Argentino de Ciencias Naturales "Bernardino Rivadavia” e Instituto Nacional de Investigación de las Ciencias Naturales, Paleontología 2(1): 1-30.

MENENDEZ, C.A. y AZCUY, C.L. 1969. Microflora carbónica de la Localidad de Paganzo, Provincia de La Rioja. Parte I. Ameghiniana, 6(2): 77-97. 
MENÉNDEZ, C.A. y GONZÁLEZ-AMICÓN, O.R. 1979. Nuevos elementos de la microflora carbónica de "Las Pircas" (Formación Agua Colorada) sierra de Famatina, La Rioja. Ameghiniana, 16: 65-79

MICHAELSON, R. y HENDERSON, R.A. 2000. Facies relationships and cyclicity of high-latitude, Late Permian, coal measures, Bowen Basin, Australia. International Journal of Coal Geology, 44: 19-48.

MILANI, J.E. 1997. Evolução tectono-estratigráfica da bacia do Paraná e seu relacionamento com a geodinâmica fanerozóica do Gondwana sul-oriental. Programa de Pós-Graduação em Geociências, Universidade Federal do Rio Grande do Sul, Tesis Doctoral, 255 pp.

MORBEY, S.J. 1975. The palynostratigraphy of the Rhaetian Stage, Upper Triassic in the Kendelbachgraben, Austria. Palaeontographica Abt. B, 152(1-3): 1-75.

MORGAN, B E. 1967. Palynology of a portion of the El Reno Group (Permian), southwest Oklahoma. Unpublished $\mathrm{PhD}$ thesis, University of Oklahoma.

MOREL, E. y GUTIÉRREZ, P.R. 2000. Malanzania nana Archangeslky, Azcuy y Wagner (Lycophyta) en el Carbonífero Superior de Buenos Aires, Cuenca Claromecó, Argentina. Ameghiniana, 37(2): 247-250.

MORELLI, J. LIMARINO, C.O., CÉSARI, S.N. y AZCUY, C.L. 1984. Características litoestratigráficas y paleontológicas de la Formación Lagares en los alrededores de la Mina Margarita, Prov. de La Rioja. IX Congreso Geológico Argentino, San Carlos de Bariloche, Actas, 4: 337-347.

MORGAN, B.E. 1972. Tornopollenites n. gen. from Permian of Texas. Pollen et Spores, 13: 481-484.

MORRIS , N.1975. The Rhacopteris flora in New South Wales. En: Gondwana Geology (Campbell, K.S.W., ed.), Australian National University Press, Canberra: 99-108.

MOY, C. y TRAVERSE, A. 1986. Palynofloras of the subsurface Eagle Mills Formation of Texas. Palynology, 10: 257-287.

MUFF, R., GONZÁLEZ, M.E. VERGEL. M.M., HERBST, R. y FASOLO, Z. 1999. Palynological investigations and biostratigraphic correlations of Permian sedimentary rocks from eastern Paraguay. Newsletters on stratigraphy, 37(1/2): 2135 . 
NAHUYS, J.P., ALPERN, B. e YBERT, J.P. 1968. Estudo palinologico e petrográfico de alguns carvôes do sul do Brasil. Instituto Tecnologico do Rio Grande do Sul, Boletim 46: 3-61.

NAKOMAN, E. 1975. Études palynologiques des veines d'age Namurien et de Westphalien à des secteurs de Karadon et d'Üzülmez du Bassin Houiller de Zonguldak. 1. Etude qualitative. Maden Tetkik ve Arama Enstitüsü (Turkey), 85: 45128.

NAUMOVA, S.N. 1953. Sporovo-pyltsevye kompleksy verkhnego devona Russkoi platformy I $\mathrm{ikh}$ znachenie dlya stratigrafii (Complexes sporo-polliniques $\mathrm{du}$ Dévonien supérieur de la plateforme russe et leur valeur stratigraphique). Trudy Instituta Geologischeskikh Nauk, Akademiya Nauk SSSR 143, Seriya Geologischeskaya 60 1-204 (en ruso).

NEVES, R. y OWENS, B. 1966. Some Namurian Camerate Miospores from the English Pennines. Pollen et Spores, 8: 337-360.

NILSSON, T. 1958. Uber das Vorkommen eines mesozoischen Sapropelgesteins in Schonen. Lunds Universitets Arsskrift 2, 54 (10): 1-112.

NORRIS, G. 1965. Triassic and Jurassic miospores and acritarchs from the Becon and Ferrar Groups, Victoria Land, Antarctica. N.Z. Jl. Geol. Geophys., 8: 236-277.

NYGREEN, P.W. y BOURN, O.P. 1967. Morphological variation of Potonieisporites in a late Pennsulvanian florule. Review of Palaeobotany y Palynology, 3: 325-332.

OTTONE, E.G. 1989. Palynoflores de la Formation Santa Maxima, Paléozoïque supérieur, République Argentine. Palaeontographica B, 213: 89-187.

OTTONE, E.G. 1991. Palynologie du Carbonifère súperieur de la coupe de Mina Esperanza, Bassin Paganzo, Argentine. Revue de Micropaléontologie, 34(2): 118135.

OTTONE, E.G. y AGUIRRE-URRETA, M.B. 2000. Palinomorfos cretácicos de la Formación Springhill en Estancia El Salitral, Patagonia austral, Argentina. Ameghiniana, 37(3): 379-382.

OTTONE E.G. y AZCUY C.L. 1988. "Circumplicatipollis, nuevo género de polen monosacado del Paleozoico superior de Argentina". Revista Española de Micropaleontología, XX (2): 245-249. 
OTTONE, E.G. y AZCUY, C.L. 1990. Datos palinológicos de la Formación Guandacol (Carbonífero) en la quebrada La Delfina, provincia de San Juan, Argentina. Ameghiniana 26(3-4, 1989): 191-208.

OTTONE, E.G. y AZCUY, C.L. 1991. Palinología del carbón de Agua Hedionda (Carbonífero). Huaco, provincia de San Juan, Argentina. Ameghiniana, 27(1-2, 1990): 3-18.

OTTONE, E.G. y GARCÍA, G.B. 1991. A Lower Triassic miospore assemblage from the Puesto Viejo Formation, Argentina. Review of Palaeobotany and Palynology, 68: 217-232.

OTTONE, E. y GARCÍA, G. 1996. Organic walled microphytoplankton from the lower seccion of the Santa Máxima Formation, Upper Carboniferous, Argentina.

Ameghiniana, 33(1): 103-106.

OTTONE, E.G. y MANCUSO, A.C. 2006. Algas Chlorococcales como indicadores paleoambientales: nuevos datos de la Formación Los Rastros, Triásico del centrooeste de Argentina. Revista del Museo Argentino de Ciencas Naturales "B.

Rivadavia”, n.s. 8(2): 209-220.

OTTONE, E. G. y RODRIGUEZ AMENÁBAR, C. 2001. A new disaccate pollen grain from the Triassic of Argentina. Ameghiniana, 38(2): 157-161.

OTTONE, E.G. y ROSSELLO, E. 1996. Palinomorfos pérmicos de la Formación La Puerta, Cordillera Frontal, Argentina. Ameghiniana 33(4): 453-455.

OTTONE, E.G., ÁlVAREZ, P.P. y BENOIT, S.V. 1992. Late Triassic plant microfossils from the Rancho de Lata Formation, Main Cordillera, Argentina. Micropaleontology, 38(3): 261-278.

OTTONE, E.G., MANCUSO, A.C. y RESANO, M. 2005. Miospores and chlorococcalean algae from the Los Rastros Formation, Middle to Upper Triassic of central-western Argentina. Ameghiniana, 42(2): 347-362.

OTTONE, E.G., ROSSELlO, E.A., SIMANAUSKAS, T. y VACHARD, D. 1998. Palaeontology and biostratigraphy of the Late Palaeozoic Copacabana Group at the Angosto del Beu, Bolivia. Ameghiniana, 35(1): 87-96.

OUYANG SHU y NORRIS, G. 1999. Earliest Triassic (Induan) spores and pollen from the Junggar Basin, Xinjiang, northwestern China. Review of Palaeobotany and Palynology 106(1): 1-56. 
OUYANG SHU y UTTING, J. 1990. Palynology of Upper Permian and Lower Triassic rocks, Meishan, Changxing County, Zhejiang Province, China. Review of Palaeobotany and Palynology, 66: 65-103.

PAGANI, M.A. 1998. Braquiópodos y gastrópodos pérmicos de las formaciones Piedra azul y Bonete (provincia de Buenos Aires). Ameghiniana, 35(3): 265-270.

PAGANI, M.A. 2000. Bivalvos del Pérmico Inferior de la Formación Bonete, Sierras Australes (provincia d Buenos Aires, Argentina). Ameghiniana, 37(3): 301-320.

PANT, D.D. y SRIVASTAVA, G.K. 1965. Some Lower Gondwana miospores from Brazil. Micropaleongology, 11(4): 468-478.

PAPÚ, O.H. 1990. Contribución a la palinología estratigráfica de la Formación Malargüe, Cretácico superior, sur de la provincia de Mendoza, Argentina. Parte 1: Especies terrestres y de aguas continentales. Ameghiniana, 27(3-4): 289-303.

PACHER, A. 1914. Über Flagellaten und Algae und Algen. Veröffentlichung Deutsche Botanische Gesselschanft, Berlin 32: 136-160.

PAZOS, P.J., ETCHEVARRÍA, M. y FOLGUERA, A. 2002. La Formación Loma de los Morteritos (Cordillera Frontal, Mendoza): rasgos sedimentarios y posición estratigráfica. $9^{\circ}$ Reunión Argentina de Sedimentología, Córdoba. Resúmenes: 35.

PEPPERS, R.A. 1997. Palynology of the Lost Branch Formation of Kansas-new insights on the major floral transition at the Middle-Upper Pennsylvanian boundary. Review of Palaeobotany and Palynology, 98: 223-246.

PÉREZ LOINAZE, V.S. 2007. A mississippian miospore Biozone for Southern Gondwana. Palynology, 31 (1): 101-117.

PÉREZ LOINAZE, V. 2008. Systematic palynological study of the Cortaderas Formation, (Mississippian) Río Blanco Basin, Argentina. Part Two. Ameghiniana, 45(2): 421-441.

PÉREZ LOINAZE, V.S. y CÉSARI, S.N. 2004. Palynology of the Estratos de Mascasín, Upper Carboniferous, Paganzo Basin, Argentina: systematic descriptions and stratigraphic considerations. Revista Española de Micropaleontología, 36(3): 407-438.

PLAYFORD, G. 1963. Lower Carboniferous microfloras of Spitsebergen - Part 2. Palaeontology, 5(4): 619-678. 
PLAYFORD, G. 1965. Plant microfossils from Triassic sediments near Poatina, Tasmania. Journal of the Geological Society of Australia, 12(2): 173-210.

PLAYFORD, G. 1978. Lower Carboniferous spores from the Ducabrook Formation, Drummond Basin, Queensland. Palaeontographica, Abt. B, 167: 195-160.

PLAYFORD, G. 1990. 6. Proterozoic and Paleozoic Palynology of Antarctica: A Review. En: Antarctic Paleobiology. Its Role in the Reconstruction of Gondwana (Taylor, T.N y Taylor, E.L., eds). Springer-Verlag New York Berlin Heidelberg London Paris Tokyo Hong Kong. Pp. 51-70.

PLAYFORD, G. y DETTMANN, M.E. 1965. Rhaeto-Liassic Plant Microfossils from the Leigh Creek Coal Measures, South Australia. Senckenbergische Naturforschend Gesellschaft, 46 (2/3): 127-181.

PlAYFORD, G., y DETTMANN, M.E., 1996. Spores. En: Palynology: Principles AND Applications (Vol. 1) (Jansonius, J., y McGregor, D.C. (Eds.). College Station, TX, Am. Assoc. Stratigraphic Palynol. Found: 227-260

PLAYFORD, G. y DINO, R. 2000a. Palynoestratigraphy of upper Palaeozoic strata (Trapajós Group), Amazonas Basin, Brazil: Part One. Palaeontographica Abt. B, 255: $1-46$.

PLAYFORD, G. y DINO, R. 2000b. Palynoestratigraphy of upper Palaeozoic strata (Trapajós Group), Amazonas Basin, Brazil: Part Two. Palaeontographica Abt. B, 255: 87-145.

PLAYFORD, G. y DINO, R. 2002. Permian palynofloral assemblages of the ChacoParaná Basin, Argentina: systematics and stratigraphic significance. Revista Española de Micropaleontología, 34(3): 235-288.

PLAYFORD, G. y RIGBY, J.F. 2008. Permian palynofloral of the Ainim and Aiduna formations, West Papua. Revista Española de Micropaleontología, 40(1-2): 1-57.

PLAYFORD, G., DINO, R. y MARQUES-TOIGO, M. 2001. The Upper Paleozoic miospore genus Spelaeotriletes Neves and Owens, 1966, and constituuent Gondwana species. Journal of South American Sciences, 14: 593-608.

PLOSZKIEWICZ, J.V. 1999. ¿Será Buenos Aires una nueva provincia petrolera? Antecedentes, hipótesis y certezas. Boletín de Informaciones Petroleras, 58: 139168. 
PONS, M.E.H. 1977: Estudo palinologico do Sub-grupo Itarare, na "Coluna White" Permiano Inferior, Santa Catarina, Brasil. III Parte. Ameghiniana, 13 (2)(1976): 109-125.

PONS, M.E.H. 1979. Estudo palinológico do Sub-grupo Itararé, na "Coluna White" Permiano Inferior, Santa Catarina, Brasil. III Parte. Ameghiniana 14(1977): 87-99.

POTONIÉ, R. 1956. Synopsis der Gattunger der Sporae dispersae. I. Teil: Sporites. Geologisches Jahrbuch Beihefte, 23: 1-103.

POTONIÉ, R. 1958. Synopsis der sporae dispersae. II Teil: Sporites (Nachträge), Saccites, Aletes, Preacolpate, Polyplicates, Monocolpates. Geologischen Jahrbuch, 31:1-114.

POTONIÉ, R. 1970. Synopsis der Guttenger der Sporae dispersae. Teil V. Nachträge zu allen Gruppen (Turmae). Beihefte zum Geologischen Jahrbuch, 87: 1-222.

POTONIÉ, R. y KLAUS, W. 1954. Einige Sporegattungen des alpinen Salzgebirges. Geologisches Jahrbuch, 68: 517-546.

POTONIE, R. y KREMP, G. 1954. Die Gattungen der Paläozoischen sporae dispersae und ihre stratigraphie. Beihefte zum Geologisches Jahrbuch, 69: 111-194.

POTONIÉ, R. y KREMP, G. 1955. Die Sporae dispersae des Ruhrkarbonns. Ihre Morphographie und Stratigraphie mit Ausblicken auf Arten anderen Gebiete und Zeitabschnitte. Teil I. Palaeontographica B, 98: 1-136.

POTONIÉ, R. y LELE, K.M. 1961. Studies in the Talchir Flora of India - 1. Sporae dispersae from the Talchir Beds of South Rewa Gondwana Basin. The Palaeobotanist, 8: 22-37.

POTONIÉ, R. y SAH, S.C.D. 1960. Sporae dispersae of the Lignites from Cannanore Beach on the Malbar Coast of India. The Palaeobotanist, 7(2):121-135.

PRÁMPARO, M.B. y VOLKHEIMER, W. 1999. Palinología del Miembro Avilé (Formación Agrio, Cretácico Inferior) en el cerro de la Parva, Neuquen. Ameghiniana, 36(2): 217-227.

PRÁMPARO, M.B. y VOLKHEIMER, W. 2002. Nuevos hallazgos de palinomorfos en la Formación La Amarga, Miembro Bañados de Caichigüe, cuenca Neuquina sudoriental, Argentina. Ameghiniana, 39(4): 395-404. 
PREMAOR, E., FISCHER, T.V. y SOUZA, P.A. 2006. Palinologia da Formação Irati (Permiano Inferior da Bacia do Paraná), em Montividiu, Goiás, Brasil. Revista Museo Argentino de Ciencias Naturales, 8(2): 221-230.

PRICE, P.L. 1984. A Permian palynostratigraphy for Queensland. Pp. 155-211; en Proceedings of the Symposium on the Permian geology of Queensland, Brisbane 1982, Geological Society of Australia. Queensland Division.

PUCCI, J.C. 1995. Exploration Argentina's Claromeco basin needs further exploration. Oil \& Gas Journal 93(39):

PUCCI, J.C. 2006. Situación de las cuencas marinas de la República Argentina. Petrotecnia, 7: 16-26.

PUNT, W., HOEN, P.P., BLACKMORE, S., NILSOON, S. y LE THOMAS, A. 2007. Glossary of Pollen and Spore Terminology. Review of Palaeobotany and Palynology, 143 (1-2): 1-81. http://www.bio.uu.nl/ ppalaeo/glossary/

QU, L.F. y WANG, Z. 1986. Triassic spore and pollen. En: Geol. Mem., Ser. 2, 3, Geol. Publ. House, Beijing, pp. 113-173 (en chino con resumen en inglés).

QUADROS, L.P. 2002. Acritarcos e Tasmanites do Permo-Carbonífero da Bacia do Paraná. Revista do Instituto Geológico, São Paulo, 23(1): 39-50.

QUADROS, L.P., MARQUES-TOIGO, M. y CAZZULO-KLEPZIG, M. 1996. Catálogo de esporos e pólen fósseis do Paleozoico. Boletim de Geociências da Petrobrás 9 (1995): 1-151.

QUATTROCCHIO, M.E. y GUERSTEIN, G.R. (1988) Evaluación paleoambiental y paleoclimática del Terciario de la Cuenca del Colorado, República Argentina. Palinofloras. Revista de la Asociación Geológica Argentina, XLIII (3): 375-387.

QUATTROCCHIO, M. y GUERSTEIN, G.R. 1994. Palynological analysis of Cruz del Sur x-1 Borehole. Colorado Basin, Argentina. Informe técnico inédito presentado a Union Texas Petroleum Co.

QUATTROCCHIO, M.E. y SARJEANT, W.A.S. 1996. Early Palaeocene (Danian)

Dinoflagellates from the Colorado Basin, Argentina. Revista Española de Micropaleontología, 28(3):111-138

QUATTROCCHIO, M.E. y RUIZ, L.C. 1999. Paleoambiente de la Formación Pedro Luro (Maastrichtiano?-Paleoceno) en base a palinomorfos, cuenca del Colorado, Argentina. Ameghiniana 36: 37- 47. 
QUATTROCCHIO, M.E., GUERSTEIN, G.R. y SBARDELLATI, M.S. 1986. Neogene dinoflagellate cysts from the Colorado Basin, Argentina. American Association of Stratigraphic Palynologist Contribution Series, 17: 151-157.

QUATTROCCHIO, M.E., GUERSTEIN, G.R. y DESCHAMPS, C.M. 1988 "Fluctuaciones climáticas del Terciario de la Cuenca del Colorado. Palinomorfos y vertebrados". II Jornadas Geológicas Bonaerenses, Actas: 27-35

QUATTROCCHIO, M.E., RUIZ, L.C. y VOLKHEIMER, W. 2000. Palynological zonation

of the Paleogene of the Colorado and Salta Group basins. Revista Española de Micropaleontología, 32(1):61-78.

RAINE, J.I., MILDENHALL, .M. y KENNEDY, E.M. 2005. New Zealand fossil spores and pollen: an illustrated catalogue. Institute of Geological and Nuclear Sciences $\begin{array}{lllll}\text { Information } & \text { Series } & 68, & \text { version }\end{array}$ http://www.gns.cri.nz/what/earthist/fossils/spore_pollen/catalog/index.htm. Institute of Geological \& Nuclear Sciences Limited, 2005.

RAMOS, V.A. 1984. Patagonia: un continente paleozoico a la deriva. $9^{\circ}$ Congreso Geológico Argentino (San Carlos de Bariloche), Actas 2: 311-325, Buenos Aires.

RAMOS, V.A. y KOSTADINOFF, J. 2005. La cuenca de Claromecó. Relatorio del $16^{\circ}$ Congreso Geológico Argentino, pp. 471-480.

RANA, V. y TIWARI, R.S. 1980. Palynological succesion in Permian-Triassic sediments in bore-hole RNM-3, East Raniganj Coalfield, W. Bengal. Geophytology, 10(1): 108-123.

RAVN, R.L. 1979. An introduction to the stratigraphic palynology of the Cherokee Group (Pennsylvanian) coal of Iowa. Iowa Geological Survey, Technical Paper 6: 1-117. Iowa City.

RAVN, R.L. 1986. Palynostratigraphy of the lower and middle Pennsylvanian coal of Iowa. Iowa Geological Survey, Technical Paper 7: 1-245. Iowa City.

RAVN, R.L. y FITZGERALD, D.J. 1982. A Morrowan (Upper Carboniferous) miospore flora from eastern Iowa, U.S.A. Palaeontographica, Abt. B, 183: 108-172; Stuttgart. 
REES, P., Mc, A., GIBBS, M.T., KUTZBACH, J.E., y BEHLING, P.J. 1999 Permian Climates: Evaluating Model Predictions Using Global Paleobotanical Data. Geology, 27(10): 891-894.

RETALLACK, G.J. 1980. Late Carboniferous to Middle Triassic Megafossil Floras From Sidney Basin. Bull. Geol. Surv. New S. Wales, 26: 385-430.

RETALLACK G. 2002. Triassic-Jurassic atmospheric CO2 spike. Nature,415: 387-388. RICCARDI, A. 1988. The Cretaceous System of Southern South America. Geological Society of America, Memoir $168: 1-161$.

RIGBY, J.F. Y CHANDRA, S. 1990. THE late Permian sporangiate fructification Nesowalesia edwardsii Pant, 1977, from Kattomba, New South Wales, Australia. Review of Palaeobotany and Palynology, 65(2): 175-178.

RIGBY, J.F. y HEKEL, H. 1977. Palynology of the Permian sequence in the Springsure anticline, central Queensland. Geological Survey of Queensland Publication 363, Palaeontological Papers, 37, 76 pp.

RIGGI, A. 1935. Geología de la Sierra de "Las Tunas" y sus relaciones con las demás sierras australes de la provincia de Buenos Aires. Anales del Museo Argentino de Ciencias Naturales "Bernardino Rivadavia", 38, Geología, 26: 313-332. Buenos Aires.

ROBLES, D.E. 2003. Reglamentación y uso correcto. Las siglas de los pozos. Petrotecnia, octubre: 62-67.

ROBLES, D.E. 2005. Un necesario reordenamiento o reclasificación actualizada de pozos argentinos de gas y/o petróleo y de servicio. Petrotecnia, abril: 80-84.

ROCHA-CAMPOS (A.C.) y CARVALHO (R.G.), 1975. Two new bivalves and gastropods from the Permian "Eurydesma fauna" of eastern Argentina. Boletim Instituto de Geoçiencias, Universidade de Sâo Paulo, 6: 185-191.

ROJO, L.D. y ZAVATTIERI, A.M. 2005. Estudio microfloristico de las formaciones Potrerillos y Cacheuta (Triásico) en el sur del cerro Cacheuta, Mendoza, Argentina. Parte 1. Ameghiniana 42(1): 3-20.

ROLLERI, E.O. 1975. Provincias geológicas bonaerenses. $5^{\circ}$ Congreso Geológico Argentino, Relatorio: 24-54. Buenos Aires. 
RUÍZ, L. y BIANCO, T.M. de 1989. Presencia de restos de Licópsidas arborescentes en Las Mostazas, Paleozoico Superior de la Sierras Australes, provincia de Buenos Aires. $1^{\circ}$ Jornadas de Geología Bonaerense (Tandil 1985), Actas: 935-938.

RUIZ, L.C. y QUATTROCCHIO, M.E. 1996. Stratigraphic palynology of the Pedro

Luro Formation (¿Maastrichtian-Paleocene), Colorado Basin, Argentina. En: Geologie de l'Afrique et de l'Atlantique Sud, Actes Colloques Angers 1994, Pau; Elf Aquitaine Edition, Memoire 16: 361-371.

RUIZ, L.C. y QUATTROCCHIO, M.E. 1997a. Estudio palinológico de la Formación Pedro Luro (¿Maasatrichtiano-Paleoceno) en la Cuenca del Colorado, Rep\{ublica Argentina. Parte 1. esporas triletes, Laevigati, Murornati, Tricrassati, Cingulati y Zonati. Revista Española de Micropaleontología, 29: 13-29.

RUIZ, L.C. y QUATTROCCHIO, M.E. 1997b. Estudio palinológico de la Formación Pedro Luro (¿Maasatrichtiano-Paleoceno) en la Cuenca del Colorado, Rep\{ublica Argentina. Parte 2. Turma Saccites, Alicates, Poroses e insertae sedis. Revista Española de Micropaleontología, 29: 115-137.

RUNNEGAR, N. 1972. Late Paleozoic bivalvia from South America: Provincial affinities and age. Anales Academia brasileira da Ciencias (suplemento): 295-312.

RUSSO, A., ARCHANGELSKY, S. y GAMERRO, J.C. 1980. Los depósitos suprapaleozoicos en el subsuelo de la llanura Chaco-Pampeana, Argentina. II Congreso Argentino de Paleontología y Bioestratigrafía y I Congreso Latinoamericano de Paleontología. Actas. Buenos Aires (1978), T. IV: 157-173.

ROUND, F.E. 1971. The taxonomy of the Chlorophyta II. British Phycological Journal, 6: $235-264$.

SAKSENA, S. 1971. On fossil flora of Granjra Nalla Beds: Part II - Microflora (A) dispersed spores and pollen grains. The Palaeobotanist, 18: 237-257.

SAMOILOVICH, S.R. 1953. Pollen and spores from the Permian deposits of the Cherdyn' and Akt'ubinsk areas, Cis-Urals. Travau del' Institut Petrographyque de l'Academie des Sciences de l'URSS, Moscou, 75: 5-57.

SANCHEZ DE POSADA, L.C., VILLA, E. MARTÍNEZ CHACÓN, L. RODRÍGUEZ, R.M., RODRÍGUEZ, S. y COQUEL, R. 1999 Contenido paleontológico y edad de la sucesión de Demués (Carbonífero, Zona Cantábrica). Universidad de La Rioja, Trabajos de geología, $N^{o} 21: 339-352$ 
SANTOS, P.R., ROCHA-CAMPOS, A.C. y CANUTO, J.R. 1996. Patterns of late Paleozoic deglaciation in the Paraná Basin, Brazil. Palaeogeography, Palaeoclimatology, Palaeocology, 125: 165-184.

SAXENA, R.K. 1993. New names for some palynofossil later homonyms from India. Geophytology, 23(1): 195-196.

SCHAARSCHMIDT, F. 1963. Sporen und Hystrichosphaerideen aus dem Zechstein von Bödingen in der Wetterau. Palaeontographica B, 113(1-4): 38-91.

SCHEURING, B.W. 1974. Krauselisporites Leschik and Thomsonisporites Leschik a revision of the type material of two disputed genera. Review of Palaeobotany and Palynology, 17: 187-204.

SCHMIDT, S. 2004. The Petroleum Potential of the Passive Continental Margin of South-Western Africa - A Basin Modelling Study. Fakultät für Georessourcen und Materialtechnik der Rheinisch-Westfälischen Technischen Hochschule Aachen, Doktors der Naturwissenschaften, $430 \mathrm{pp}$.

SCHOPF, J.M., WILSON, R.L. y BENTALL, R. 1944. An annotated synopsis of Paleozoic fossil spores and definition of generic groups. Illinois Geological Survey, Report 91: 66 pp.

SCHULZ, E. 1967. Sporen palaontologische Untersuchungen rateliassischer Schichten im Zentralteil des Germainschen Beckens. Palaontographica Abh., B-2(3): 542-633. SCHÜMANN, T.K., 2002. The hydrocarbon potential of the deep offshore along the Argentine volcanic rifted margin - a numerical simulation. Docteral Thesis RWTH Aachen, 244 pp.

SCHÜMANN, T., ELlOUZ, N., FRANKE, D., HINZ, K. y LITTKE, R. 2002. The Hydrocarbon Potential of the Deep Offshore along the Argentine Passive Volcanic Margin-A Basin Modelling Study. AAPG HEDBERG CONFERENCE, Hydrocarbon Habitat of Volcanic Rifted Passive Margins, September 8-11, Stavanger, Norway, 4 pp.

SCOTESE, C.R., BOUCOT, A.J. y MCKERROW, W.S. 1999. Gondwanan palaeogeography and palaeoclimatology. Journal of African Earth Sciences, 28(1): 99-114.

SCOTT, L., ANDERSON, H.M. y ANDERSON, J.M. 1997. Vegetation history. En: Cowling, R.M., Richardson, D.M., Pierce, S.M. (eds.), Vegetation of Southern Africa. Cambridge University Press, Cambridge. 
SEDOVA, M.A. 1956. The definition of 4 genera of Disaccate Striatiti. Palynology Translations: 1-10.

SEGROVES, K.L. 1967. Cutinized microfossils of probable non vascular origin from the Pemian of Western Australia. Micropaleontology, 13: 289-305.

SEGROVES, K.L. 1969. Saccate plant microfossils from the Permian of Western Australia. Grana Palynologica, 10(1): 43-73.

SEGROVES, K.L. 1970. Permian spores and pollen grains from the Perth Basin, Western Australia. Grana Palynologica, 10: 43-73.

SEGROVES, K.L. 1972. The sequence of palynological assemblages in the Permian of the Peth Basin, Western Australia. Proc. Pap. Second Gondwana Symp, South Africa, 1970: 511-529.

SEMPERE, T., AGUILERA, E., DOUBINGER, J., JANVIER, P., LOBO, J., OLLER, J. y WENZ, S. 1992. La Formation de Vitiacua (Permien moyen à supérieur - Trias? inférieur, Bolivie du Sud): stratigraphie, palynologie et paléontologie. Neues Jahrbuch fur Geologie und Paläontologie. Abhandlungen, 185(2): 239-253.

SEWARD, A.C. 1914. Antarctic fossil plants. En: British Antarctic ("Terra Nova") Expedition, 1910. Natural History Report, British Museum (Natural History), Geology, 1: 1-49.

SHU, O. y NORRIS, G. 1999. Earliest Triassic (Induan) spores and pollen from the Junggar Basin, Xinjiang, northewestern China. Review of Palaeobotany and Palynology, 106: 1-56.

SIMANAUSKAS, T. y CISTERNA, G. 2000. A paleo-opportunistic brachiop from the Early Permian Argentina. Alcheringa, 24: 45-53.

SINHA, V. 1969. Some "acritarchs" and other microfossils from Barakar Stage of Lower Gondwanas, India. The Palaeobotanist, 17(3): 326-331.

SINHA, V. 1972. Sporae dispersae from Jhingurdah Seam, Singrauli Coalfield (M.P.), India. The Palaeobotany, 19(2): 175-201.

SINGH, H.P. 1964. A miospore assemblage form the Permian of Iraq. Palaeontology, 7: 240-265.

SMANIOTTO, L.P., FISCHER, T.V., SOUZA, P.A. e IANNUZZI, R. 2006. Palinologia do Morro de Papaléo, Mariana Pimentel (Permiano Inferior, Bacia do 
Paraná), Rio Grande do Sul, Brasil. Revista brasileira de Paleontologia, 9(3): 311322.

SMITH, A.V.H. 1971. Le genere Verrucosisporites Ibrahim 1933 emend. En: Microfossiles organiques du Paléozoique. 4 Les Spores CIMP-CNRS (ed.) 2: 35-87. SMITH, A.V.H. y BUTTERWORTH, M.A. 1967. Miospores in the coal seams of the Carboniferous of Great Britain. Special Papers in Palaeontology, 1: 1-324.

SOUZA, P.A. 2006. Late Carboniferous palynostratigraphy of the Itararé Subgroup, northeastern Paraná Basin, Brazil. Review of Palaeobotany and Palynology, 138: 929.

SOUZA, P.A. y CALLEGARI, L.M. 2004. An Early Permian palynoflora from the Itararé Subgoup, Paraná Basin, Brazil. Revista Española de Micropaleontología, 36(3): 439-450.

SOUZA, P. A. y MARQUES-TOIGO, M. 2003. An overview on the Palynostratigraphy of the Upper Paleozoic strata of the Brazilian Paraná Basin. Revista del Museo Argentino de Ciencias Naturales, n.s., 5(2): 205-2014.

SOUZA, P.A. y MARQUES-TOIGO, M. 2005. Progress on the palynostratigraphy of the Permian strata in Rio Grande do Sul State, Paraná Basin, Brazil. Anais da Academia Brasileira de Ciências, 77(2): 353-365.

SOUZA, P.A., SAAD, A.R. y LIMA, M.R. 1997. Palinologia dos carvões do Estado de São Paulo. II- O carvão de Monte Mor. Revista do Instituto Geológico São Paulo, 18(1-2): 7-21.

SOUZA, P.A., PETRI, S. y DINO, R. 2003. Late Carboniferous palynology from the Itararé Subgroup (Paraná Basin) at Araçoiaba da Serra, São Paulo State, Brazil. Palynology, 27: 39-74.

SOUZA, P.A., BATEZELLI, C.V.B., DI PASQUO, M., AZCUY, C.L., SAAD, A.R. y PERINOTTO, J.A.J. 2000. Ocorrência de palinomorfos no Subgrupo Itararé (Carbonífero-Permiano da Bacia do Paraná) na Região de Jundiaí (Sp, Brasil). Geociências 5 ( $\mathrm{n}^{\mathrm{o}}$ especial): 28-32.

SRIVASTAVA, S.C. 1970. Microfloral investigations in some Coals of Talcher Coalfield (Orissa) India. The Palaebotanist, 18(2): 154-166. 
SRIVASTAVA, S.C. y JHA, N. 1998. Palynology of Lower Gondwana sediments in the Bhopalpalli area, Godavari Graben. Journal of The Palaeontological Society of India, 43: 41-48.

STAPLETON, R.P. 1977. Early Permian miospores from a borehole in Southest Africa. Pollen et Spores, 19(1): 143-162.

STAPLIN, F.I. 1960. Upper Missisippian plant spores from the Golata Formation, Alberta, Canadá. Palaeontographica Abt. B, 107: 1-40.

STAPLIN, F.L. y JANSONIUS, J. 1964. Elucidation of some Paleozoic densospores. Palaeontographica, Abt. B 114: 95-117.

STAPLIN, F.L., JANSONIUS, J. y POCOCK, S.J. 1965. Evaluation of some acritarchous hysrtichosphere genera. Neues Jahrbuch für Geologie und Paläontologie, Abhandlungen, 123(2): 167-201.

STAPLIN, F.L., POCOCK, S.J. y JANSONIUS, J. 1967. Relationships among gymnospermous pollen. Review of Palaeobotany and Palynology, 3: 293-310.

STARLING, A. 1994. Geochemical evaluation of the Cruz del Sur X-1 well, offshore Argentina - Final report. Core laboratories, Western Atlas.

STEEL, M. 1964. Une association de spores du Givétien infériur de la Vesdre, à Goé (Belgique). Annales de la Société Géologique de Belgique, 87: 233-262.

STEPHENSON, M.H. 1998. Preliminary correlation of palynological assemblages from Oman with the Granulatisporites confluens Oppel Zone of the Grant Formation (Lower Permian), Canning Basin, Western Australia. Journal of African Earth Sciences, 26: 521-526.

STEPHENSON, M.H. 2004. Early Permian spores from Oman and Saudi Arabia. En: M.I. Al-Husseini (ed.), Carboniferous, Permian and Early Triassic Arabian Stratigraphy, GeoArabia Special Publication 3, Gulf PetroLink, Bahrain, pp. 185215.

STEPHENSON, M.H. 2008. Spores and pollen from the middle and upper Gharif Members (Permian) of Oman. Palynology, 32: 157-182.

STEPHENSON, M.H. y FILATOFF, J. 2000a. Correlation of Carboniferous-Permian Palynological Assemblages from Oman and Saudi Arabia. En: Stratigraphic Palynology of the Palaeozoic of Saudi Arabia (Hajri, S y Owens, B. eds). Pp. 168191. 
STEPHENSON, M.H. y FILATOFF, J. 2000b. Description and Correlation of Late Permian Palynological Assemblages from the Khuff Formation, Saudi Arabia and Evidence for Duration of the pre-Khuff Hiatus. En: Stratigraphic Palynology of the Palaeozoic of Saudi Arabia (Hajri, S y Owens, B. eds). Pp. 192-215

STEPHENSON, M.H. y FILATOFF, J. 2003. Description and Correlation of Late Permian Palynological Assemblages from the Khuff Formation, Saudi Arabia and Evidence for the Duration of the pre-Khruff Hiatus. GeoArabia, 8(3): 192-215.

STEPHENSON, M.H. y MCLEAN, D. 1999. International correlation of Early Permian palynofloras from the Karoo sediments of Morupule, Botswana. South Afr. J. Geol. 102: 3-14.

STEPHENSON, M.H. y OSTERLOFF, P.L. 2002. Palynology of the deglaciation sequence represented by the Lower Permian Rahab and Lower Gharif members, Oman. American Association of Stratigraphic Palynologist Contribution Series 40: $1-32$.

STEPHENSON, M.H., OSTERLOFF, P.L. y FILATOFF, J. 2003. Palynological biozonation of the Permian of Oman and Saudi Arabia: progress and challenges. GeoArabia, 8(3): 467-496.

STIPANICIC, P.N. y MARSICANO, C.A. 2002. Léxico Estratigráfico de la Argentina: Triásico, Volumen VIII, Asociación Geológica Argentina, Serie "B" (Didáctica y Complementaria), $370 \mathrm{pp}$.

STIPANICIC, P.N., GONZÁLEZ DÍAZ, E.F. y ZAVATTIERI, A.M. 2007 Grupo Puesto Viejo nom. transl. por Formación Puesto Viejo González Díaz, 1964, 1967: nuevas interpretaciones paleontológicas, estratigráficas y cronológicas. Ameghiniana, 44(4): 759-761.

STOAKE, EA., CAMPBELL, CV., CASS, R. y UCHA, N. 1991. Seimic Stratigraphic Analysis of the Punta del Este Basin, Offshore Uruguay, South America. The American Arsociation of Petroleum, Bulletin, 75(2): 219-240.

STOLlHOFEN, H., STANISTREET, I.G., BANGERT, B., GRILL, H. 2000. Tuff, tectonism and glacially-related sea-level changes, Carboniferous-Permian, southern Namibia. Palaeogeography, Palaeoclimatology, Palaeoecology,. 161: 127-150.

STRÖTHER, O.K. 1991. A classification schema for the cryptospores. Palynology, 15: 219-236. 
SUNDARAM, D. 1986. Palinologia do Subgrupo Itararé (Neopaleozóico), Bacia do Paraná, no Estado de São Paulo, Brasil. Tesis Doctoral. Universidade de São Paulo, São Paulo, 1987: 311 pp.

TANKARD, A.J., ULIANA, M.A., WELSINK, H.J., RAMOS, V.A., TURIC, M., FRANÇA, A.B., MILANI, E. J., DE BRITO NEVES, B. B., EYLES, M. y DE SANTA ANA, H. 1995. Tectonic controls of basin evolution in southwestern Gondwana. En: TANKARD, A.J., SUÁREZ, R.S. y WELSINK, H.J. (eds.), Petroleum basins of South America: American Association of Petroleum Geologists Memoir, 62: 5-52.

TAYLOR, T.N. 1982. Ultrastructure studies of Paleozoic seed fern pollen: sporoderm development. Review of Palaeobotany and Palynology, 37: 21-53. Amsterdam.

TAYLOR, T.N. y TAYLOR, E.L. 1993. The Biology and Evolution of Fossil Plants. Prentice Hall, NJ, USA.: 982pp.

THE PALEOBILOGY DATA BASE, 2008. http://paleodb.geology.wisc.edu/cgibin/bridge.pl?action $=$ checkTaxonInfo\&taxon name $=$ Crustaesporites + globulus\&is $r$ $\underline{\text { eal_user }=1}$ (Última consulta diciembre 2008).

THERON, J. N. y BLIGNAULT, H. J. A model for sedimentation of the Dwyka glacials in the south-western En: Gondwana geology, Proceedings and Papers of the 3rd Gondwana Symposium (Cape. Jji Campbell, K. S. W., eds.): 347-56. Canberra: Australian National University Press, Australia.

THOMSON, P.W. y PFLUG, H. 1953. Pollen und Sporen des mitteleuropäischen Tertiärs: Gesamtübersicht über die stratigraphisch uns paläontologisch wichtigen Formen. Palaeontographica, Bd. 94, Abd. B: 1-138.

THOMPSON, R. y MITCHELL, J.C. 1972. Paleomagnetic and radiometric evidence for the age of the lower boundary of the Kiaman magnetic interval. Geophysics Journal 27: 207-214.

TIWARI, R.S. 1964. New miospore genera in the coals of Barakar Stage (Lower Gondwana) of India. The Palaeobotanist, 12(3): 250-259.

TIWARI, R.S. 1965. Miospores assemblage in some coals of Barakar Stage (Lower Gondwana) of India. The Palaeobotanist 13(2): 168-214.

TIWARI, R.S. 1968. Palynological investigations of some coal seams in the Ib-River Coalfield (Orissa), India. The Palaeobotanist, 16(3): 168-269. 
TIWARI, R.S. 1973. Scheuringipollenites, a new name for the Gondwana palynomorphs so far assigned to "Sulcatisporites Leschik 1955". Senckenbergiana Lethaea, 54: 105-117.

TIWARI, R.S. y NAVALE, G.K.B. 1967. Pollen and spore assemblages in some coals if Brasil. Pollen et Spores, 9: 583-606.

TIWARI, R.S. y RAM-AWATAR. 1987. A palynology assemblage from Parsora Formation, Johilla Coalfield, South Rewa Gondwana Basin, Madhya Pradesh. Geophytology, 17(1): 104-109.

TIWARI, R.S. y RAM-AWATAR. 1989. Sporae dispersae and correlation of Gondwana sediments in Johilla Coalfield, Son Valley Graben. Madhya Pradesh. The Palaeobotanist, 37: 94-114.

TIWARI, R.S.; VIJAYA, 1995: Differential morphographic identity of Gondwanic palynomorphs. The Palaeobotanist, 44: 62-115.

TOMEZZOLI, R.N. 1999. La Formación Tunas en las Sierras Australes de la provincia de Buenos Aires. Relaciones entre sedimentación y deformación a través de su estudio paleomagnético. Revista de la Asociación Geológica Argentina, 54(3): 220228.

TSCHUDY, R.H. y KOSANKE, R.M. 1966. Early Permian vesiculate pollen from Texas, USA. The Palaeobotanist, 1: 59-72.

TURIC, M. 2002. Actividades exploratorias en el margen continental argentino: perspectivas. Petrotecnia, 3: 24-29.

URBAN, J.B. 1971. Palynology and the Independence Shale of Iowa. Bulletin of American Paleontology, 266: 103-189.

URIEN, C.M. y ZAMBRANO, J.J. 1996. Estructura del margen continental. En: Geología y Recursos Naturales de la Plataforma Continental Argentina.(Ramos, A.V. y Turic, M.A., eds.), XIII Congreso Geológico Argentino y III Congreso de Exploración de Hidrocarburos, Relatorio 3:29-65.

URIEN, C.M., ZAMBRANO, J.J. y MARTINS, L.R. 1981. The basins of southeastern South America (southern Brazil, Uruguay and eastern Argentina) including the Malvinas Plateau and Southern South Atlantic paleogeographic evolution. En: Cuencas sedimentarias del Jurásico y Cretácico de América del Sur (Volkheimer, 
W. y Musacchio, E.A. eds.); Comité Sudamericano del Jurásico y Cretácico 1: 45125.

URIEN, C.M., ZAMBRANO, J.J. y YRIGOYEN, M.R. 1995. Petroleum basins of South America-an ovcrvicw. En: TANKARD, A.J., SUÁREZ SORUCO, R. y WELSINK, H.J. (eds.), Petroleum basins of South America. Tulsa: American Association of Petroleum Geologists Memoir 62, p. 63-78.

UTTING, J. 1978. Lower Karroo pollen and spore assemblages from the Coal Measures and underlying sediments of the Siankondobo Coalfield, mid-Zambezi Valley, Zambia. Palynology 2: 53-68.

UTTING, J. 1978. Karoo stratigraphy of the northern part of the Luangwa valley, Zambia. Memoir Geological Survey Zambia,4, 64 pp, Lusaka.

UTTING, J. 1994. Palynostratigraphy of Permian and Lower Triassic rocks, Sverdrup Basin, Canadian Artic Archipielago. Geological Survey of Canada. Bulletin 478: $107 \mathrm{pp}$.

VALENSI, L. 1953. Microfossiles des silex du Jurassique moyen. Remarques pétrographiques. Mémories de la Société Géologique de France, 68: 1-100.

VAN DER EEM, J.G.I.A. 1982. Palynological investigations in the Ladinian and Lower Karnian of the Western Dolomites, Italy. Review of Palaeobotany and Palynology, 39(3-4):189-300. Amsterdam.

VAZQUEZ NÍSTICO, B. y CÉSARI, S. 1987. Nuevos elementos paleoflorísticos de la Formación Guandacol (Carbonífero) en la Cuesta de Huaco, Provincia de San Juan. VII Simposio Argentino de Paleobotánica y Palinología. Actas. Buenos Aires: 1315.

VEEVERS, J.J. y POWELL, C.McA. 1987. Late Paleozoic glacial episodes in Gondwanaland reflected in transgressive-regressive depositional sequences in Euramerica. Geological Society of America Bulletin 98: 475-487.

VEEVERS, J.J., POWELL, C.McA., COLLINSON, J.W.y LÓPEZ-GAMUNDÍ, O.R. 1994. Synthesis. En: VEEVERS, J.J. y POWELL, C.M.A (eds.) Permian-Triassic Pangean basins and foldbelts along the Panthalassan margin of Gondwanaland. Boulder, Geological Society of America, Memoir 184: 331-353.

VENKATACHALA, B.S. y KAR, R.K. 1965. Two new trilete spore genera from the Permian of India. The Palaeobotanist, 13: 337-340. 
VENKATACHALA, B.S. y KAR, R.K. 1966. Corisaccites gen. nov., a new saccate pollen genus from the Permian of Salt Range, West Pakistan. The Palaeobotanist, 15: 107-109.

VERGEL, M.M. 1986. Palinología del Paleozoico Superior en la Perforación YPF J1 (Josefina), provincia de Santa Fe, Argentina. I. Anteturma Proximegerminantes. Ameghiniana, 23(3-4): 141-153.

VERGEL, M.M. 1987a. Palinología del Paleozoico Superior en la perforación YPF SF J (Josefina), provincia de Santa Fe, Argentina. II Anteturma Variegerminantes, Grupo Acritarcha e Incertis Sedis. Ameghiniana, 24(1-2): 67-80.

VERGEL, M.M. 1987b. Consideraciones sobre el contenido microflorístico de la perforación YPF SE Ab (Paleozoico Superior), Árbol Blanco, provincia de Santiago del Estero, Argentina. VII Simposio Argentino de Paleobotánica y Palinología, Actas, Buenos Aires: 13-15.

VERGEL, M.M. 1990. Leschikisporis chacoparanaense sp. nov. (espora monolete), en el Paleozoico Superior de la Cuenca Chacoparanense, Argentina. V Congreso Argentino de Paleontología y Bioestratigrafía, Tucumán, 1990, Actas I: 195-198.

VERGEL, M.M. 1993. Palinoestratigrafía de la secuencia neopaleozoica en la Cuenca Chacoparanense, Argentina. $12^{\circ}$ Congrès International de la Stratigraphie et Géologie du Carbonifére et Permien (Buenos Aires 1991), Comptes Rendus 1: 201212.

VERGEL., M.M. 1998. Palinología del Paleozoico Superior (Formación Sachayoj) en tres perforaciones de la subcuenca de Alhuampa, Cuenca Chacoparanense (Argentina). Parte I: Esporas. Ameghiniana, 35(4): 387-403.

VERGEL., M.M. 2008. Palynology of late Palaeozoic sediments (Tupe Formation) at La Herradura Creek, San Juan province, Argentina. Alcheringa, 32: 339-352.

VERGEL, M.M. y CISTERNA, G. 2001. La Formación Tupe en el sector occidental de la Cuenca Paganzo: Bioestratigrafía en base a su fauna de braquiópodos y contenido palinológico. $5^{\circ}$ Jorn. de Comunic. Cient., Fac. Cienc. Nat. e Instit. M. Lillo (UNT), Tucumán: 88 .

VERGEL, M.M. y CÚNEO, R. 2006. Microflora pérmica temprana en la Formación Río Genoa, Ferraroti, Chubut, Argentina. $13^{\circ}$ Simposio Argentino de Paleobotánica y Palinolología (Bahía Blanca), Resúmenes, p. 9. 
VERGEL, M.M. y FASOLO, Z.R. 1999. Datos palinológicos en la Formación Tupe (Paleozoico Superior), quebrada La Herradura, San Juan, Argentina. AmeghinianaResúmenes 36(4-Suplemento): 37R-38R.

VERGEL, M.M. y LECH, R.R. 2001. Aspectos sedimentarios y palinología de la Formación Agua Colorada (Carbonífero Superior) en la quebrada El Arbolito, departamento Tinogasta, Catamarca, Argentina. Acta Geológica Lilloana, 18: 229239.

VERGEL, M.M. y LUNA, F. 1992. Registros palinológicos en sedimentos del neopaleozoico de la Sierra de Paiman, La Rioja, Argentina. Acta Geológica Lillioana, 17(2): 161-168.

VERGEL, M.M, BUATOIS, L.A. y MANGANO, M.G. 1993. Primer registro palinológico en el Carbonífero Superior del margen norte de la Cuenca Paganzo, Los Jumes, Catamarca, Argentina. $12^{\circ}$ Congrès International de la Stratigraphie et Géologie du Carbonifére et Permien (Buenos Aires 1991), Comptes Rendus, 1: 213227.

VERGEL, M.M., PIERONI, E. y CARRIZO, H. 2000a. Registro palinológico en sedimentitas neopaleozoicas del área del dique Los Sauces, provincia de La Rioja, Argentina. $11^{\circ}$ Simposio Argentino de Paleobotánica y Palinología (Tucumán) Ameghiniana-Resúmenes 37(4-Suplemento): 64R.

VEROSLAVKY, G., DANERS, G. y DE SANTA ANA, H. 2003. Rocas sedimentarias pérmicas de la plataforma continental uruguaya: el prerift de la Cuenca Punta del Este. Geogaceta, 34: 203-206.

VIGRAN, J.O., MANGERUD, G., MØRK, A.,BUGGE, T. y WEITSCHAT, W. 1998. Biostratigraphy and Sequence Stratigraphy of the Lower and Middle Triassic Deposits from the Svalis Dome, Central Barents Sea, Norway. Palynology, 22: 89141

VIJAYA, KUMAR, S., SINGH, M.P. y TIWARI, R.S. 1988. A Middle to Late Triassic palynoflora from the Kalapani Limestone Formation, Malla Johar Area, Tethys Himalaya, India. Review of Palaeobotany and Palynology, 54: 55-83.

VIMAL, K.P. 1952: Spores and pollen from Tertiary lignites from Dandot, West Punjab (Pakistan). Proceedings of the Indian Academy of Sciences, section B, 36: 135-147. 
VISCONTI, G., ELORRIAGA, E. DE, PARRAS, A., FERNÁNDEZ, M. y CAMILLETTI, C. 2000. Afloramientos del Terciario marino (Formación Barranca Final) en el sudeste de la provincia de La Pampa. Jornada de Ciencia y Técnica, UNLPam, Trabajos de Investigación, Resúmenes: 73-74. Santa Rosa.

VISCONTI, G., ELORRIAGA, E.E. DE y PARRAS, A. 2003. Sedimentitas marinas de la Formación Barranca Final (Mioceno medio-superior de la cuenca del Colorado), aflorantes en el sureste de la provincia de La Pampa, Argentina. Revista de la Asociación Geológica Argentina, 58 (2): 187-193.

VISSER, J.N.J. 1983a. Submarine debris flow deposits from the Upper Carboniferous

Dwyka Tillite Formation in the Kalahari Basin, South Africa. Sedimentology, 30:511-523. Elsevier. Amsterdam.

VISSER, J.N.J. 1983b. Glacial-marine sedimentation in the Late Paleozoic Karoo Basin, southern Africa. In: B.F. Molnia (Ed.), Glacial-marine Sedimentation, 667701. Plenum Publ. Co, Sudafrica.

VISSER, J.N.J. 1987. The palaeography of part of southwestern Gondwana during the

Permo-Carboniferous Glaciation. Palaeogeography, Palaeoclimatology, Palaeoecology, 61: 205-219. Elsevier, Amsterdam.

VISSER, J.N.J. 1989. The Permo-Carboniferous Dwyka Formation of southern Africa: deposition by a predominantly subpolar marine ice sheet. Palaeogeographie, Palaeoclimatology, Palaeoecology, 70: 377-391.

VISSER, J.N.J. 1990. The age of the late Palaeozoic glacigene deposits in southern Africa. South African Journal of Geology 93, 366-375.

VISSER, J.N.J. 1991a. Geography and climatology of the Late Carboniferous to Jurassic Karoo Basin in south-western Gondwana. Ann. S. Afr. Museum 99, 415431.

VISSER, J.N.J. 1991b. The paleoclimatic setting of the Late Paleozoic marine ice sheet in the Karoo Basin of Southern Africa. In: Anderson, J.B., Ashley, G.M. (Eds.), Glacial Marine Sedimentation: Paleoclimatic Significance. Geological Society of America Special Paper 261, pp. 181-189.

VISSER, J.N.J. 1993. The Tectono-geographic Evolution of part of southwestern Gondwana during the Carboniferous and Permian. Comptes Rendus 12 Congreso 
Internacional de Estratigrafía y Geología del Carbónico y Pérmico, 1: 447-454. Buenos Aires.

VISSER, J.N.J. 1994. Sea-level changes in a back-arc-foreland transition: the Late Carboniferous-Permian Karoo Basin of South Africa. Sediment. Geol. 83, 115-131. VISSER, J.N.J. 1996. Controls on Early Permian shelf deglaciation in the Karroo Basin of South Africa. Palaeogeography, Palaeoclimatology, Palaeoecology, 125: 129139.

VISSER, J.N.J. 1997. Deglaciation sequences in the Permo-Carboniferous Karoo and Kalahari basins of southern Africa: a tool in the analysis of cyclic glaciomarine basin fills. Sedimentology 44, 507-521.

VISSER, J.N.J. y LOOCK, J.C. 1982. An Investigation of the Basal Dwyka Tillite in the southern part of the Karoo Basin, South Africa. Transactions Geological Society. South Africa, 85: 179-187.

VISSCHER, H, BRINKHUIS, H, DILCHER, D L, ELSIK, W C, ESHET, Y, LOOY, C, RAMPINO, M R. y TRAVERSE, A. 1996. The terminal Paleozoic fungal event: evidence of terrestial ecosystem destabilisation and collapse. Proceedings of the National Academy of Science USA, 93: 2155-2158.

VOLKHEIMER, W. y PAPÚ, O.H. 1993. Una microflora del Triásico Superior de la Cuenca de Malargüe, localidad Llantenes, provincia de Mendoza, Argentina. Ameghiniana, 30(1): 93-100.

VOLKHEIMER, W. y PRÁMPARO, M.B. 1984. Datos palinológicos del Cretácico en el borde austral de la Cuenca Neuquina, localidad Estancia Santa Elena, Argentina. Parte I: especies terrestres. Memorias III Congreso Latinoamericano de Paleontología (Méjico): 269-279.

VOLKHEIMER, W. y QUATTROCCHIO, M.E. 1981. Distribución estratigráfica de los palinomorfos jurásicos y cretácicos en la Faja Andina y áreas adyacentes de América del Sur Austral con especial consideración de la Cuenca Neuquina. Comité Sudamericano del Jurásico y Cretácico, Cuencas Sedimentarias del Jurásico y Cretácico de América del Sur, vol. 2: 407-444. Buenos Aires.

VOKHEIMER, W. y ZAVATTIERI, A.M. 1985. Una microflora triásica de la localidad de Divisadero Largo (Mendoza, Argentina). III Congreso Latinoamericano de 
Paleontología, México. Simposio sobre floras del Triásico Tardío, su fitogeografía y paleoecología. Memoria: 43-50.

VOLKHEIMER, W., FILICE M.A.C. y SEPÚLVEDA, E. 1977. Datos palinológicos de la Formación Ortiz (Grupo La Amarga), Cretácico Inferior de la Cuenca Neuquina (República Argentina). Ameghiniana, 14(1-4): 59-74.

WEISS, R.H. 2001. Middle to Late Permian microfloral assemblages from the Ruhuhu and Selous basins, Tanzania. Pp. 497-529; en R. H. Weiss (ed.), Contributions to Geology and Palaeontology of Gondwana -In Honour of Helmut Wopfner. Cologne. Geological Institute, University of Cologne.

WEISS, R.H. y WOPFNER, H. 1997. Palynology and palaeoecology of Late Palaeozoic glacigene Idusi Formation of southern Tanzania. Geologisches Institut, Universität Köln, Sondervero“ffentlichungen Nr. 114 (Festschrift E. Kempf), pp. 535-559.

WILSON, L.R. 1962. Permian plant microfossils from the Flowerpot Formation, Greer Country, Oklahoma. Oklahoma Geological Survey, Circular 49: 1-50.

WILSON, L.R. 1962b. A Permian fungus spore type from the Flowerpot Formation of Oklahoma. Oklahoma Geology Notes, 22: 91-96.

WILSON, L.R. y VENKATACHALA, B.S. 1963. A morphological study and emendation of Vesicaspora Schemel, 1951. Geological Survey Circular, Oklahoma, 49: 1-40.

WILSON, L.R. y VENKATACHALA, B.S. 1963. Thymospora, a new name for Verrucososporites . Oklahoma Geology Notes 23: 75 -79.

WILSON, L.R. y WEBSTER, R.M. 1946. Plant microfossils from a Fort Union coal of Montana. American Journal of Botany, 33: 271-278.

WINN, R.D. y STEINMETZ, J.C. 1998. Upper Paleozoic strata of the Chaco-Paraná Basin,

Argentina, and the great Gondwana glaciation. Journal of South American Earth

Sciences, 11: 153-168.

WNUK, C. 1996. The Development of Floristic Provinciality during the Middle and Late Paleozoic. Rev. Palaeobotany, Palynology, 90: 5-40.

WODEHOUSE, R.P. 1933. Tertiary pollen. 2. The oil shales of the Eocene Green River Formation. Bulletin of the Torrey Botany Club, 60: 479-524. Lancaster. 
WOPFNER, H. 1999. The Early Permian deglaciation event between East Africa and northwestern Australia. J. Afr. Earth Sci. 29: 77-90.

WOPFNER, H. 2002. Tectonic and climatic events controlling deposition in Tanzanian Karoo basins. J. Afr. Earth Sci. 34: 167-177.

WOPFNER, H. y DIEKMANN, B. 1996. The Late Palaeozoic Idusi Formation of southwestern Tanzania: a record of change from glacial to postglacial conditions. $J$. Afr. Earth Sci. 22: 575-595.

WOOD, G.D. y ELSIK, W.C. 1999. Paleoecologic and stratigraphic importance of the fungus Reduviasporonites stoschianus from the Early-Middle Pennsylvanian of the Copacabana Formation, Peru. Palynology, 23: 43-53.

WOOD, G.D., GABRIEL, A.M. y LAWSON, J.C. 1996. Palynological techniquesprocessing and microscopy. En: Palynology: principles and applications (J. Jansonius y D.C.McGregor, eds.), 1: 29-50. American Associations of Stratigraphic Palynologists Foundation, Dallas

YBERT, J.P. 1975. Etudé des miospores du bassin Houiller de Candiota-Hula Negra, Rio Grande do Sul Brasil. Pesquisas, 5: 181-227. Porto Alegre.

YBERT, J.P. y MARQUES-TOIGO, M. 1970. Polarisaccites nov. gen. Pollen et Spores, 12(3): 469-481.

YRIGOYEN, M.R. 1975. Geología del Subsuelo y Plataforma continental. $6^{\circ}$ Congreso Geológico Argentino, Relatorio, pp. 139-168.

YRIGOYEN, M.R. 2000. Los depósitos cretácicos y terciarios de las cuencas del Salado y del Colorado. En: Geología Argentina (Caminos, R., ed.). Instituto de Geología y Minería, Anales 29(22):651-682.

YRIGOYEN, M. y STOVER, L.E. 1970. La palinología como elemento de correlación del Triásico de la Cuenca Cuyana. $4^{\circ}$ Jornadas Geológicas Argentinas (Mendoza, 1969), Actas 2: 427-447.

ZAMBRANO, J.J. 1972. Cuenca del Colorado. En: LEANZA, A.F., ed., Geología Regional Argentina, Academia Nacional de Ciencias, pp. 419-437. Córdoba

ZAMBRANO, J.J. 1974. Cuencas sedimentarias en el subsuelo de la provincia de Buenos Aires y zonas adyacentes. Revista de la Asociación Geológica Argentina, 29(4):443-469. 
ZAMBRANO, J.J. 1980. Comarca de la cuenca cretácica de Colorado. En: $2^{\circ}$ Simposio Argentino de Geología Regional Argentina, Academia Nacional de Ciencias, 2: 10331070.

ZAMUNER, A.B., ZAVATTIERI, A.M., ARTABE, A.E. y MOREL. E.M. 2001. Capítulo 8. Paleobotánica. En: El Sistema Triásico en la Argentina (A.E. Artabe, E.M. Morel y A.B. Zamuner, eds.). Fundación Museo de La Plata "Francisco Pascasio Moreno", La Plata, pp. 143-184.

ZAVAlA, C.A., SANTIAGO, M.F. y AMAOLO, G.E. 1993. Depósitos fluviales en la Formación Tunas (Pérmico) cuenca paleozoica de Ventania, provincia de Buenos Aires. Revista de la Asociación geológica Argentina, 48(3-4): 307-316.

ZAVATTIERI, A.M. 1986. Estudio palinológico de la Formación Potrerillos (Triásico) en su localidad tipo, Cuenca Cuyana (provincia de Mendoza, Argentina). Parte 1. Esporas triletes y monoletes. Revista Española de Micropaleontología 18(3): 247294.

ZAVATTIERI, A.M. 1987. Estudio palinológico de la Formación Potrerillos (Triásico) en su localidad tipo, Cuenca Cuyana (provincia de Mendoza, Argentina). Parte II. Granos de polen. Aspectos estadísticos. Correlación palinoestratigráfica. Revista Española de Micropaleontología, 19(2): 173-213.

ZAVATTIERI, A.M. 1990. Stratigraphic and paleoecologic evaluation of the palynofloras of the Triassic Las Cabras Formation at the type locality Cerro Las Cabras, Mendoza, Argentina. Neues Jahrbuch fur Geologie und Paläontologie. Abhandlungen, 181(1-3): 117-142.

ZAVATTIERI, A.M. 1991a. Granos de polen de la Formación Las Cabras (Triásico), en su Localidad tipo, Provincia de Mendoza, Argentina. Parte I. Ameghiniana, 28(1-2): $3-29$.

ZAVATTIERI, A.M. 1991b. Granos de polen de la Formación Las Cabras (Triásico), en su localidad tipo, provincia de Mendoza, Argentina. Parte 2. Ameghiniana 28: 205-224.

ZAVATTIERI, A.M. 1992. Palinología de la Formación El Tranquilo (Triásico), provincia de Santa Cruz, Argentina. Ameghiniana, 29(4): 305-214.

ZAVATTIERI, A.M. 2002. Anexo 4: Microfloras. En: P.N. Stipanicic y C.A. Marsicano (eds.), Léxico Estratigráfico de la Argentina, Volumen 8: Triásico. 
Asociación Geológica Argentina, Serie "B" (Didáctica y Complementaria) 26: 318321.

ZAVATTIERI, A.M. y BATTEN, D.J. 1996. Chapter 20b. Mesozoic from Argentinian Triassic deposits and their potential for intercontinental correlation. En: Palynology: principles and applications (Jansonius, J. y McGregor, D.C., eds). American Association of Striatigraphic Palynologist Foundation, vol. 2: 767-778.

ZAVATTIERI, A.M. y MELCHOR, R.N., 1999. Estudio palinológico preliminar de la Fm. Ischichuca (Triásico), en su localidad tipo (Quebrada de Ischichuca Chica), provincia de La Rioja, Argentina. Publicación Especial $n^{\circ} 6$, Asociación Paleontológica Argentina: 33-38.

ZAVATTIERI, A.M. y PAPÚ, O.H. 1993. Microfloras mesozoicas. En: V. Ramos (ed.), Geología y Recursos Naturales de Mendoza. $12^{\circ}$ Congreso Geológico Argentino y $2^{\circ}$ Congreso de Exploración de Hidrocarburos (Mendoza), Relatorio Capítulo II-9: 309-316.

ZAVATTIERI, A.M. y ROJO, D. 2005. Estudio microflorístico de las formaciones Potrerillos y Cacheuta (Triásico) en el sur del cerro Cacheuta, Mendoza, Argentina. Parte 2. Ameghiniana, 42 (3): 513-534.

ZAVATTIERI, A.M. y VOLKHEIMER, W. 1992. Granos de polen sacados (Saccites) de la Formación Potrerillos (Triásico) en la Localidad de Divisadero Largo, provincia de Mendoza, Argentina. Ameghiniana, 29 (1): 27-44.

ZAVATTIERI, A.M. y VOLKHEIMER, W. 2003. Palynostratigraphy and paleoenvironments of Early Jurassic strata (Nestares Formation) in northern Patagonia, Argentina. Part 1. Terrestrial species. Ameghiniana, 40(4): 545-558.

ZAVATTIERI, A.M., GUTIÉRREZ, P.R., EZPELETA, M. y ASTINI, R.A. 2008. Palinología de la Formación La Veteada en su región tipo, Famatina Central (La Rioja): primera asociación palinológica del Pérmico Superior tardío de Argentina. $V$ Simposio Argentino del Paleozoico Superior, MACN 2008, Resúmenes: 42.

ZAVATTIERI, A.M., HERBST, R. y MUÑOZ BRAVO, J. 2003. Microflora de la Formación Panguipulli (Triásico Superior), en Licán Ray, Lago Calafquén, $10^{\circ}$ Región, Chile. Ameghiniana, 40(4): 585-600. 
ZAVATTIERI, A.M., VOLKHEIMER, W. y ROSENFELD, D. 1994. Palynology and facies of the Late Triassic of Comallo (Northern Patagonia, Argentina). Zentralblatt für Geologie und Paläontologie, Teil I: 133-154.

ZIEGLER, A.M., HULVER, M.L. y ROWLEY, D.B. 1997. Permian world topography and climate. En Late glacial and postglacial environmental changes: Quaternary, Carboniferous-Permian, Proterozoic (Martini, I.P., ed.),. Oxford University Press, Oxford, pp. 111-146. 


\section{ANEXOS}

1. Distribución estratigráfica de las especies identificadas en la perforación La Estrella $\mathrm{x}-1$ : esporas.

2. Distribución estratigráfica de las especies identificadas en la perforación La Estrella $\mathrm{x}-1$ : granos de polen monosacados.

3. Distribución estratigráfica de las especies identificadas en la perforación La Estrella $\mathrm{x}-1$ : granos de polen bisacados.

4. Distribución estratigráfica de las especies identificadas en la perforación La Estrella $\mathrm{x}-1$ : granos de polen estriados.

5. Distribución estratigráfica de las especies identificadas en la perforación La Estrella $\mathrm{x}-1$ : granos de polen plicados y monosulcados.

6. Distribución estratigráfica de las especies identificadas en la perforación La Estrella $\mathrm{x}-1$ : acritarcas-prasinophytas y algas.

7. Distribución estratigráfica de las especies identificadas en la perforación Cruz del Sur $\mathrm{x}-1$ : esporas.

8. Distribución estratigráfica de las especies identificadas en la perforación Cruz del Sur $\mathrm{x}-1$ : granos de polen monosacados.

9. Distribución estratigráfica de las especies identificadas en la perforación Cruz del Sur $\mathrm{x}-1$ : granos de polen bisacados.

10. Distribución estratigráfica de las especies identificadas en la perforación Cruz del Sur X-1: granos de polen estriados.

11. Distribución estratigráfica de las especies identificadas en la perforación Cruz del Sur $\mathrm{x}-1$ : granos de polen plicados y monosulcados..

12. Distribución estratigráfica de las especies identificadas en la perforación Cruz del Sur $\mathrm{x}-1$ : acritarcas-prasinophytas y algas. 


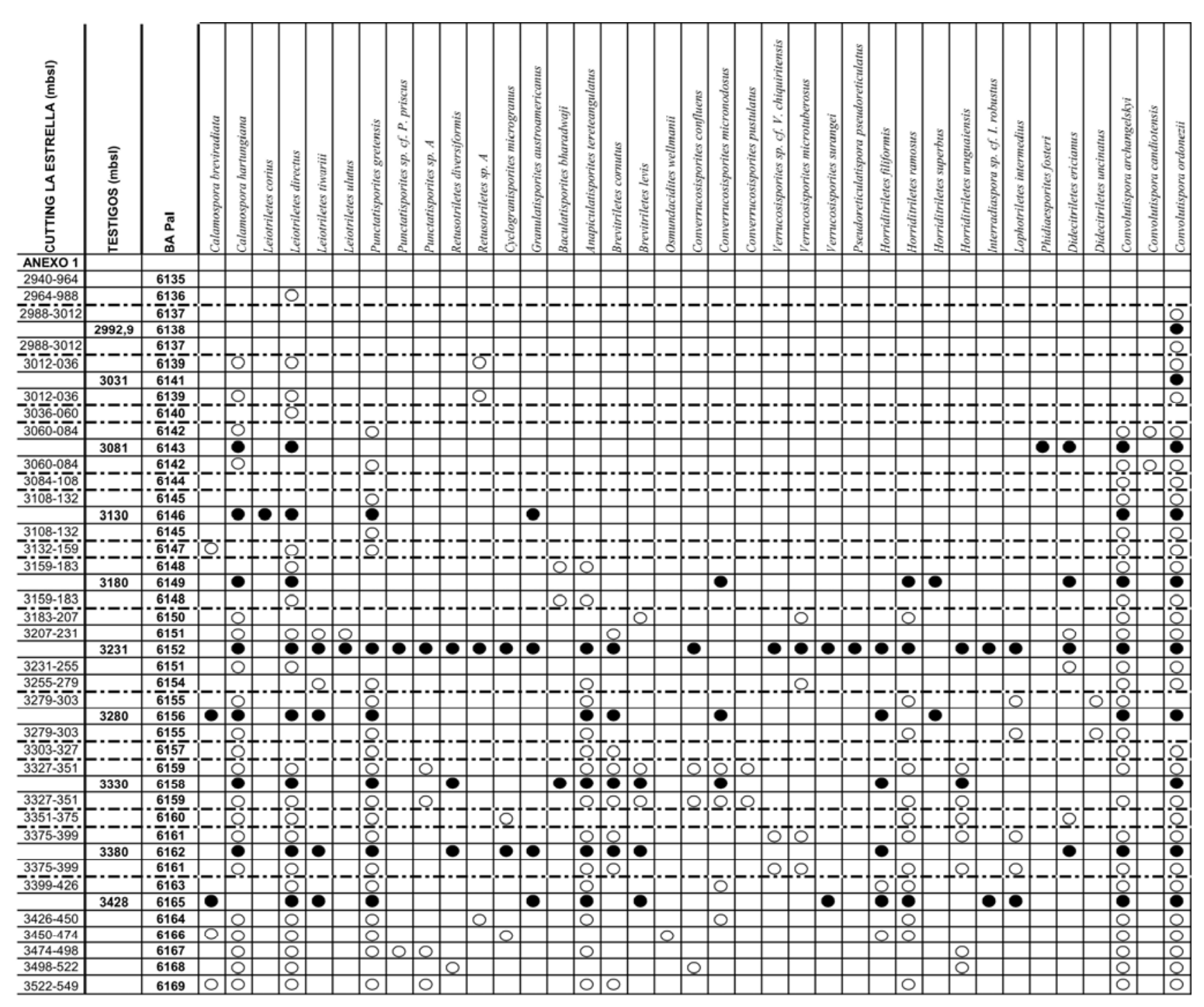




\begin{tabular}{|c|c|c|c|c|c|c|c|c|c|c|c|c|c|c|c|c|c|c|c|c|c|c|c|}
\hline 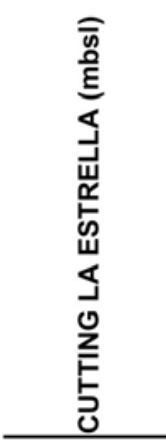 & 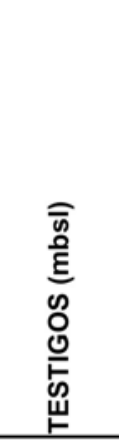 & 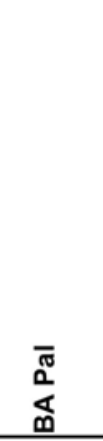 & 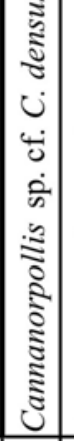 & $\begin{array}{c}\vdots \\
\vdots \\
\vdots \\
\vdots \\
\vdots \\
\vdots \\
\vdots \\
0 \\
\vdots \\
\vdots \\
\vdots \\
\vdots \\
0\end{array}$ & 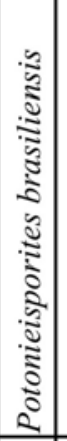 & 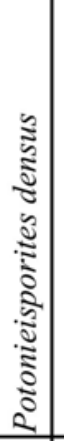 & 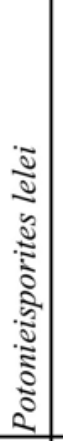 & $\begin{array}{l}0 \\
0 \\
0 \\
6 \\
0 \\
0 \\
0 \\
0 \\
0 \\
0 \\
0 \\
0 \\
0 \\
0 \\
0\end{array}$ & 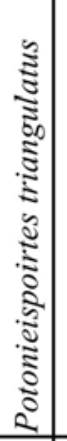 & 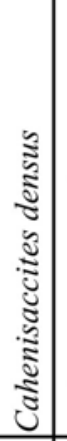 & 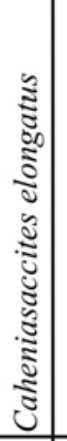 & 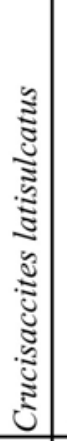 & 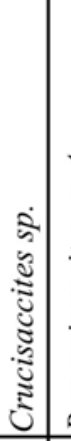 & $\begin{array}{c}\pi \\
0 \\
0 \\
0 \\
\vdots \\
0 \\
0 \\
\vdots \\
0 \\
0 \\
0 \\
0\end{array}$ & 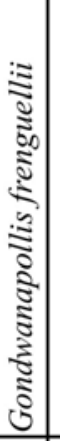 & 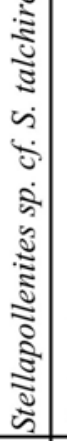 & 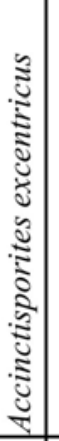 & 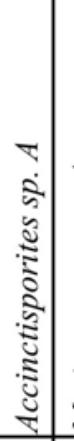 & 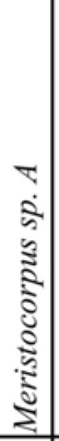 & 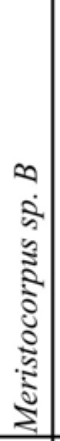 & 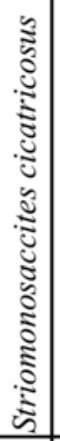 & 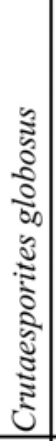 & 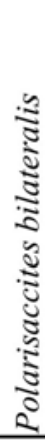 \\
\hline ANEXO 2 & & & & & & & & & & & & & & & & & & & & & & & \\
\hline $2940-964$ & & 6135 & & & & & & & & & & & & & & & & & & & & & \\
\hline 2964-988 & & 6136. & & & & & & & & & & & & & & & & & & & & & \\
\hline $2988-3012$ & & $6 \overline{137}$ & & - & - & & & & & - & -\{ & -- & & & & - & -1 & - & & & & & 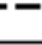 \\
\hline & 2992,9 & 6138 & & & & & & & & & & & & & & & 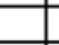 & 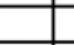 & & & & & \\
\hline $2988-3012$ & & 6137. & & & & & & & & & -7 & & & & & & - & - & & & & & \\
\hline $3012-036$ & & $61 \overline{39}$ & 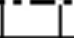 & - & - & & & & & 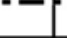 & 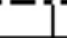 & - & & & 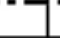 & 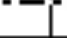 & - & - & & & & & \\
\hline & 3031 & 6141 & & & & & & & & & & & & & & & - & 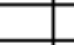 & & & & & \\
\hline 3012-036- & & 6139. & & & & & & & & & & & & & & & & & & & & & \\
\hline $36-060$ & & $6140^{\circ}$ & & & $=$ & & & & & & - & & & & & & -1 & $=$ & & & & & \\
\hline $3060-084$ & & 6142 & & & & & & & & & - & & & & & & & & & & & & \\
\hline & 3081 & 6143 & & 은 & 잉 & & 은 & & & & 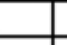 & - & & & & & 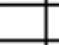 & - & & & & & \\
\hline $3060-084$ & & 6142. & & & & & & & & & & & & & & & & & & & & & \\
\hline$\frac{308-108}{3108-132}$ & & 6144. & & & & & & & & & - & & & & & & - & - & & & & & \\
\hline $3108-132$ & & 6145 & & 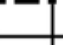 & & & & & & & 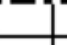 & & & & & & -1 & & & & & & \\
\hline & 3130 & 6146 & & - & & & & & & & - & 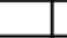 & & & & & 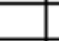 & 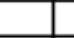 & & & & & \\
\hline $3108-132$ & & 6145 & & & & & & & & & & & & & & & & & & & & & \\
\hline$\frac{3132-159}{3159-183}-$ & & $\begin{array}{r}6147 \\
-6148\end{array}$ & & - & & & & & & 으 & - & & & & & & - & - & & & & & - \\
\hline & 3180 & 6149 & & & & & & & & & & & & & & & & 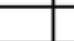 & & & & & \\
\hline - $3159-183$ & & 6148. & & & & & & & & & & & & & & & & & & & & O & \\
\hline $3183-207$ & & $6150^{\circ}$ & $5^{-\infty}$ & - & - & & & & & - & - & - & & & 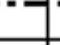 & 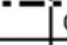 & $\overline{0}$ & - & & & & & \\
\hline $3207-231$ & & 6151 & & & & & & & & & & & & & & & & & & & & & \\
\hline & 3231 & 6152 & & - & & & & & & 0 & - & 0 & & 0 & 이 & 은 & 이 & 인 & - & - & 인 & & \\
\hline $3231-255$ & & 6151 & 0 & & & & & & & & & & & & & & & & & & & & \\
\hline $3255-279$ & & 6154. & & & & 으. & & & 으 & & & & & & & & & & & & & & \\
\hline $3 \overline{2} \overline{9}-\overline{3} 0 \overline{3}$ & & $61 \overline{5}$ & 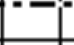 & - & - & & & of & 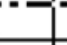 & - & - & - & & & - & & $\overline{0}$ & - & & & 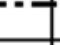 & 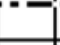 & - \\
\hline & 3280 & 6156 & & 이 & & & & & & & & 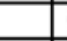 & 은 & & & & & 인 & & & & & \\
\hline $3279-303$ & & 6155 & & & & & & ㅇ. & 음 & & - & & & & & & 으. & & & & & & - \\
\hline & & 6157. & & & & & & & & & $=$ & & & & & & & - & & & & & \\
\hline $3327-351$ & & $6159^{\circ}$ & & 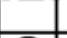 & & & & & & 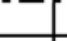 & 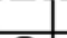 & & & & & & -1 & & & & & 0 & 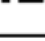 \\
\hline & 3330 & 6158 & & 0 & & & 0 & & & & 인 & & & & & & 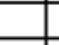 & 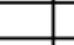 & & - & & 0 & \\
\hline $3327-351$ & & 6159. & & & & & & & & & - & & & & & & - & & & & & 이 & \\
\hline & & 6160. & & & & & & & & & - & & & & & & Z. & - & & & & & \\
\hline $3 \overline{3} 75-399$ & & $61 \overline{1}$ & & 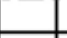 & & & & & & 이 & 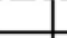 & & & & & & 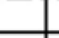 & & & & & & 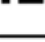 \\
\hline & 3380 & 6162 & & & & 0 & & & & & & 은 & & & & & 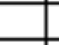 & & & & - & & \\
\hline $3375-399$ & & 6161 & & & & & & & & 으 & & & & & & & & & & & & & \\
\hline $3399-426$ & & 6163 & & - & & & & & & - & - & & & & & & - & - & & - & & 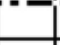 & \\
\hline & 3428 & 6165 & & & & & & & & 0 & & & & & & & & 0 & & & & & \\
\hline $3426-450$ & & 6164 & & & & & & & & & & & & & & & 0 & & & & & & \\
\hline $3450-474$ & & 6166 & & & & & & & & & & & & & & & & & & & & & 0 \\
\hline \begin{tabular}{|l|l|l}
$3474-49$ \\
\end{tabular} & & 6167 & & & & & & & & & & & & & & & & & & 0 & & 0 & \\
\hline $3498-522$ & & 6168 & & & & & & & & & & & & & & & & & & 0 & & & \\
\hline $3522-549$ & & 6169 & \begin{tabular}{l|l}
0 \\
\end{tabular} & & & & & & & & & & & & & & & & & & & & \\
\hline
\end{tabular}




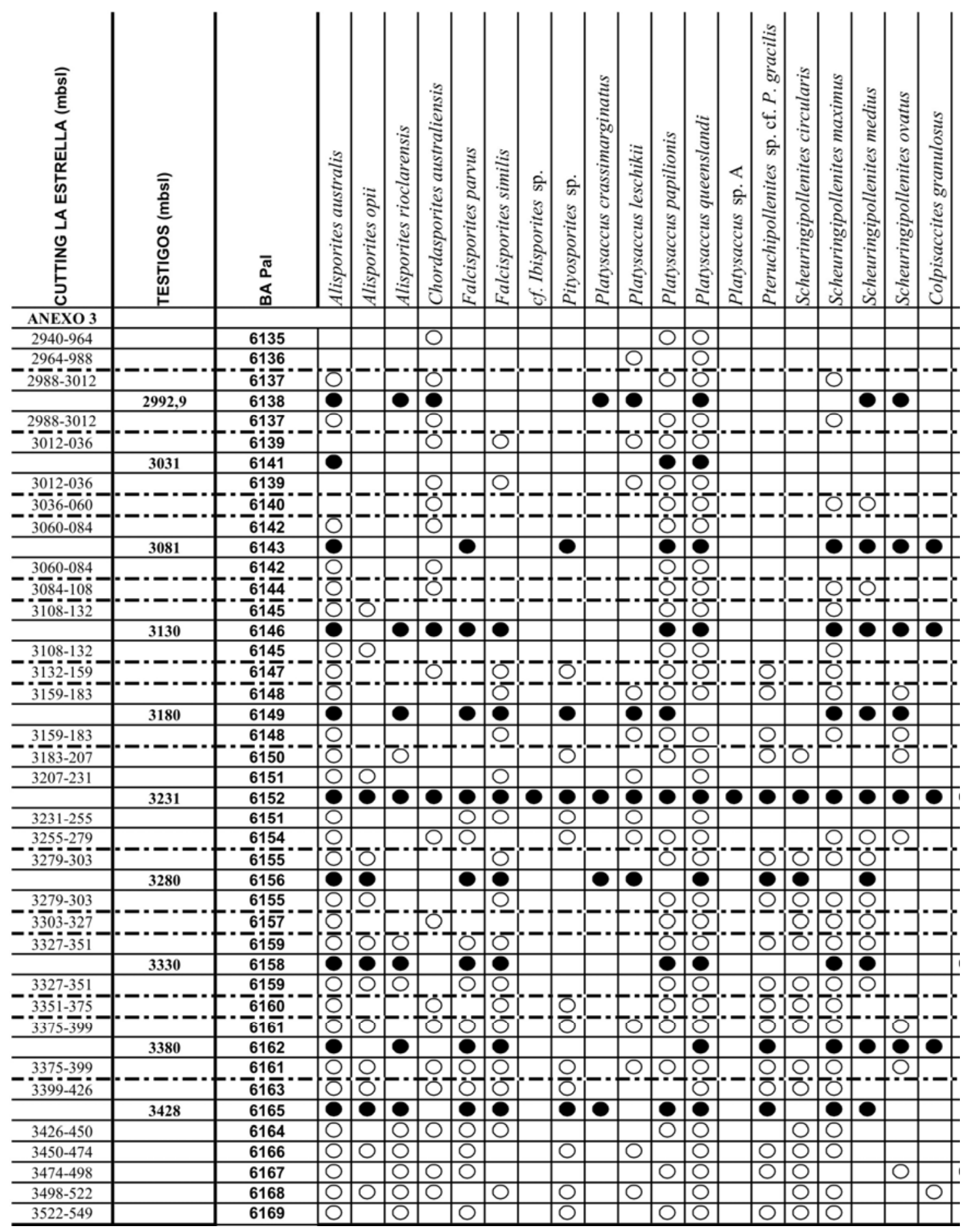




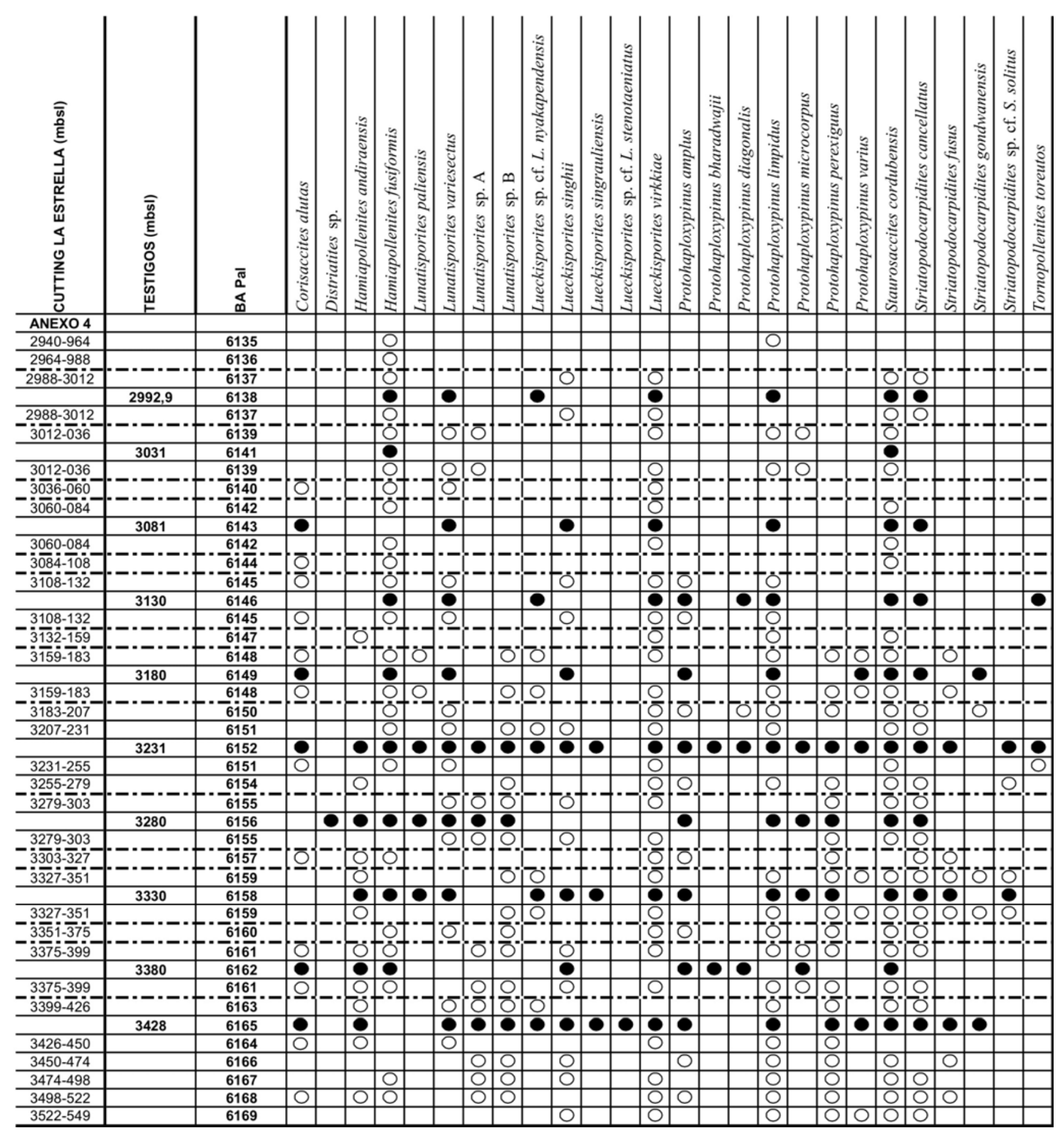




\begin{tabular}{|c|c|c|c|c|c|c|c|c|c|c|c|c|c|c|c|c|c|c|}
\hline ANEXO 5 & & & \multicolumn{11}{|c|}{ PLICADOS } & \multicolumn{5}{|c|}{ MONOSULCADOS } \\
\hline 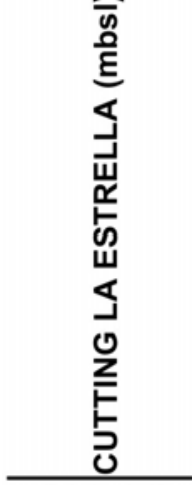 & 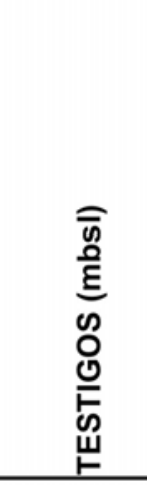 & 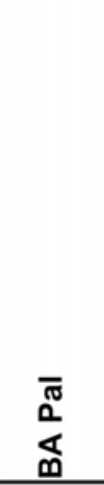 & 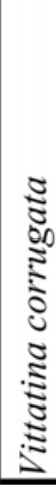 & 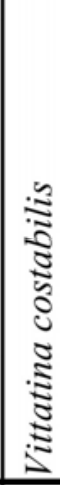 & 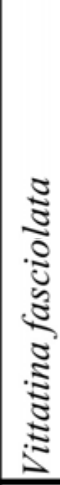 & 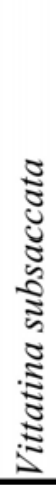 & 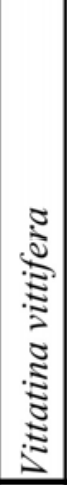 & 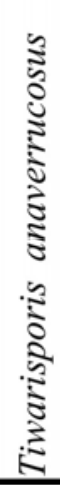 & 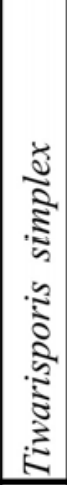 & 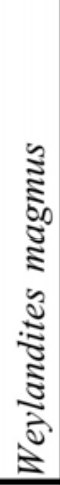 & 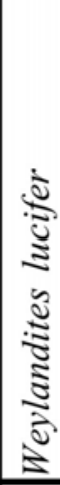 & 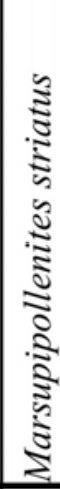 & 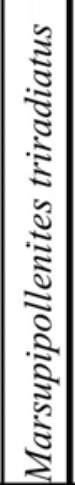 & 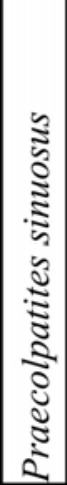 & 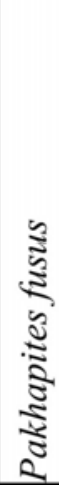 & 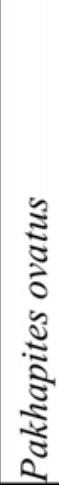 & 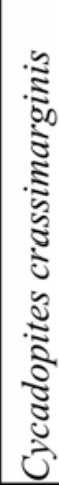 & 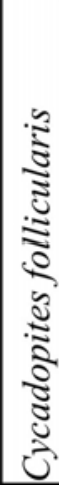 \\
\hline $2940-960$ & & 6135 & & 0 & 0 & & & & & 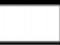 & & & & & 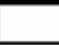 & & & \\
\hline $2964-988$ & & 6136 & & 0 & 0 & & & & & 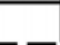 & & & & & & & L & 0 \\
\hline $2988-301 \overline{2}$ & & $6 \overline{137}$ & & $0^{\circ}$ & $\overline{0}$ & & & & - & - & & & - & - & $=$ & - & - & \\
\hline & 2992,9 & 6138 & & 0 & 0 & 0 & & & & & & & & & & & & \\
\hline 2988-3012 & & 6137. & & 0 & 으. & & & & & & & & & & & & & \\
\hline$\overline{3012}-036$ & & $\overline{6} \overline{139}$ & & $0^{\circ}$ & & - & & & - & - & & & - & & & - & - & \\
\hline & 3031 & 6141 & & 0 & & 0 & & & & & & & & & & & & \\
\hline $3012-036$ & & 6139 & & 0 & & & & & & & & & & & & & & \\
\hline$\frac{30}{30} \div-060$ & & 614 & & & & 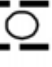 & & & & & & & & & & - & - & \\
\hline $3060-084$ & 3081 & $\begin{array}{l}6142 \\
6143\end{array}$ & & 0 & & 0 & & & & 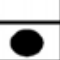 & & 0 & 0 & & & & & \begin{tabular}{|l} 
\\
\end{tabular} \\
\hline 3060-084 & & 6142 & & O & & & & & & & & & & & & & & \\
\hline 3084-108 & & $61 \overline{44}$. & & & & - & & & & - & & 으. & & & & - & - & \\
\hline $3108-132$ & & $\overline{61 \overline{45}}$ & & & & $\overline{0}$ & & & & - & & & - & & & - & - & \\
\hline & 3130 & 6146 & & 0 & 0 & 0 & & & & & 0 & & & & 0 & & 0 & \\
\hline 3108-132 & & 6145. & & & & 으 & & & & & & & & & & & & \\
\hline $3132-159$ & & 6147. & & & & & & & & -2 & & & & & & 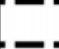 & E- & \\
\hline$\overline{3} 1 \overline{59}-\overline{183}$ & & $6 \overline{148}$ & & $\overline{0}$ & & 6 & & $\overline{0}$ & $\overline{0}$ & - & & $\overline{0}$ & $\overline{0}$ & & 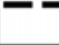 & - & - & \\
\hline & 3180 & 6149 & & 0 & & O & & & & & & 0 & 0 & & & & & \\
\hline $3159-183$ & & 6148 & & 0 & & 0 & & 0 & 0 & & & 0 & 0 & & & & & \\
\hline $3183-207$ & & $6 \overline{150}$ & & $0^{-}$ & $\overline{0}$ & 8 & & & $=-1$ & & & $\overline{0}$ & 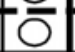 & & 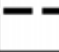 & - & - & \\
\hline $3207-231$ & & 6151 & & 0 & 0 & $\mathrm{O}$ & & 0 & 0 & & & 0 & 0 & & & & & \\
\hline & 3231 & 6152 & & 0 & 0 & 0 & 0 & 0 & & 0 & 0 & 0 & 0 & 0 & 0 & 0 & 0 & 0 \\
\hline $3231-255$ & & 6151 & & 0 & & 0 & & & & & & 0 & & & & & & \\
\hline $3255-279$ & & 6154 & & 0 & & 0 & & & & & & 0 & Oㅇ & & & & & \\
\hline$\overline{32} \overline{79}-\overline{30} \overline{3}$ & & $61 \overline{5}$ & & 0 & - & 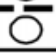 & & & - & 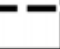 & & $\overline{0}$ & - & - & F & - & - & 0 \\
\hline & 3280 & 6156 & & 0 & & 0 & & & & & & 0 & 0 & 0 & & & & \\
\hline 3279-303 & & 6155. & & 0. & & 으 & & & & & & 으. & 으 & & & & & 0 \\
\hline $3303-327$ & & 6157. & & & & 으 & & & & & & & [o- & & & & - & \\
\hline $3327-35 \overline{1}$ & & $\overline{6} \overline{159}$ & 0 & $0^{\circ}$ & & 8 & & & & & & $\overline{0}$ & 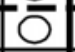 & & & - & - & \\
\hline & 3330 & 6158 & 0 & 0 & & 0 & & & & & & 0 & 0 & & & $\square$ & & 0 \\
\hline $3327-351$ & & 6159. & O & 음. & & 으 & & & & & & 음. & & & & & & \\
\hline $331-375$ & & 6160. & & - & 으. & 으 & & 으. & & & & 으. & [0ㅡ. & & 0 & & & \\
\hline $3375-399$ & & 6161 & 0 & 0 & $\overline{0}$ & 0 & & & + & 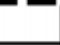 & & $\overline{0}$ & $\overline{0}$ & 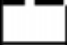 & 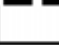 & - & - & 0 \\
\hline & 3380 & 6162 & 0 & 0 & 0 & O & 0 & 0 & & & 0 & 0 & 0 & 0 & & 0 & 0 & \\
\hline 3375-399 & & 6161. & 0 & 0 & 으. & ○ & & & & & & 0 & O & & & & 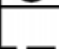 & 0 \\
\hline $3399-426$ & & 6163 & 0 & 0 & $\overline{0}$ & 0 & & 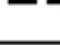 & - & & & $\overline{0}$ & $\overline{0}$ & -1 & 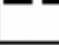 & $1-$ & - & \\
\hline & 3428 & 6165 & & 0 & 0 & 0 & & & & & & 0 & 0 & 0 & 0 & 0 & & 0 \\
\hline $3426-450$ & & 6164 & 0 & 0 & 0 & 0 & & & & & & 0 & 0 & & & & & \\
\hline $3450-474$ & & 6166 & & 0 & 0 & 0 & & 0 & & & 0 & 0 & 0 & & & & 0 & \\
\hline $3474-498$ & & 6167 & & & & $\mathrm{O}$ & & & & & & 0 & $\mathrm{O}$ & & & & & 0 \\
\hline $3498-522$ & & 6168 & & 0 & 0 & & & 0 & 0 & & & 0 & 0 & & & & & \\
\hline $3522-549$ & & 6169 & 5 & & & 0 & & & & & & O & 5 & & & & & \\
\hline
\end{tabular}




\begin{tabular}{|c|c|c|c|c|c|c|c|c|c|c|c|c|c|c|c|c|c|}
\hline ANEXO 6 & & & & & & ALC & JAS & & & & & & $\mathrm{CR}$ & TAR & $\mathrm{CAs}$ & & \\
\hline 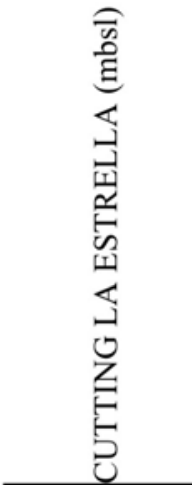 & 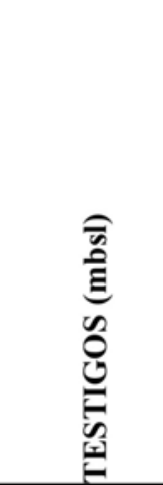 & $\begin{array}{l}\bar{\Xi} \\
\stackrel{\leftrightarrow}{\oplus}\end{array}$ & 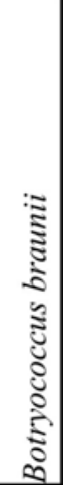 & 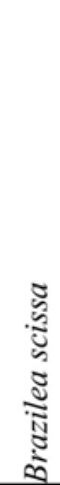 & 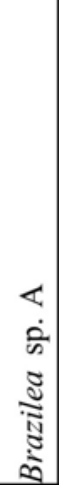 & 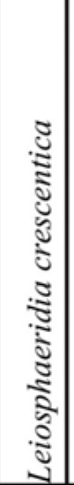 & 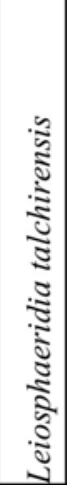 & 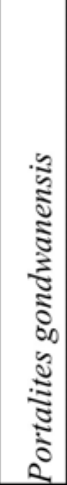 & 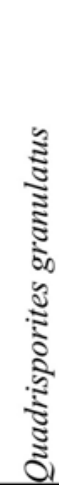 & 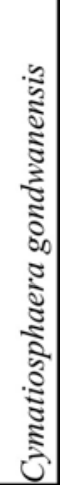 & 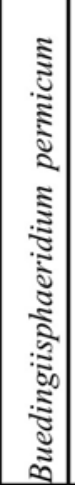 & $\begin{array}{c}0 \\
\vdots \\
0 \\
0 \\
0 \\
0 \\
0 \\
0 \\
0 \\
0 \\
0 \\
0 \\
0\end{array}$ & 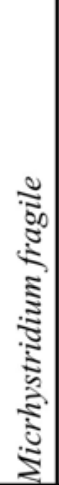 & 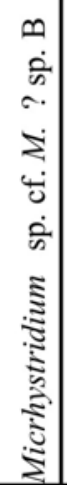 & 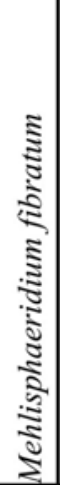 & 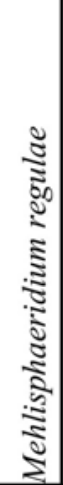 & 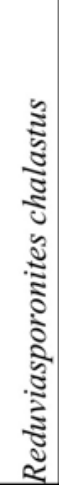 \\
\hline $2940-964$ & & 6135 & & & & & & & & & & & & & & & \\
\hline 2964-988 & & 6136 & & & & & & & & & & & & & & & \\
\hline $2988-3012$ & & 6137 & & & & & 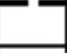 & & - & & & 87 & - & 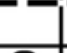 & & - & \\
\hline & 2992,9 & 6138 & & & & & & & & & & 0 & & 0 & & & \\
\hline 2988-3012 & & 6137 & & & & & & & & & & 으. & - & & & & \\
\hline $3012-036$ & & 6139 & & & & & & & & & & 0 & -1 & 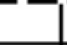 & & 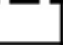 & 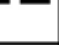 \\
\hline & 3031 & 6141 & & & & & & & & & & - & & & & & \\
\hline $3012-036$ & & 6139 & & & & & & & & & & 으. & & & & & \\
\hline $3036-060$ & & 61 & & & & & & & & & & 으. & & - & & - & - \\
\hline $3060-084$ & & $61 \overline{42}$ & & & & 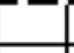 & 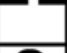 & & 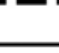 & & - & - & - & 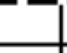 & & - & \\
\hline & 3081 & 6143 & 0 & & & & 0 & & & 0 & 0 & & & & 0 & & 0 \\
\hline $3060-084$ & & 6142 & & & & & & & & & & & & & & & \\
\hline$-3084-108$ & & 61 & & & & & - & & & & & - & & & & - & - \\
\hline $3108-132$ & & $61 \overline{45}$ & & & & 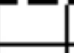 & 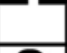 & & 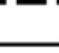 & & & & - & & & & 0 \\
\hline & 3130 & 6146 & & & & & 0 & & & 0 & & & & & & & \\
\hline $3108-132$ & & 6145 & & & & & & & & & & & & & & & 으 \\
\hline $3132-159$ & & 6147 & 8 & & & & - & & & & & & - & & & - & - \\
\hline $3159-183$ & & $61 \overline{48}$ & & & $\overline{0}$ & & 7 & 07 & 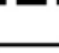 & & & & - & & & - & \\
\hline & 3180 & 6149 & 0 & & & & 0 & & & & 0 & & 0 & & & & \\
\hline $3159-183$ & & 6148 & & & 으. & & & 으 & & & & & & & & & - \\
\hline $3183-207$ & & 6150 & & & & & 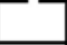 & & 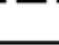 & & 0 & & -1 & - & & 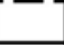 & - \\
\hline $3207-231$ & & 6151 & & & $\mathrm{O}$ & & & & & & & & & & & & \\
\hline & 3231 & 6152 & 0 & 0 & 0 & 0 & 0 & 0 & 0 & 0 & 0 & & 0 & & & & \\
\hline $3231-255$ & & 6151 & 0 & & & & & & & & & & & & & & \\
\hline $3255-279$ & & 6154 & & & & & & & & & & & & & & & 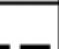 \\
\hline $3279-303$ & & $61 \overline{5}$ & 0 & & - & - & 7 & & - & 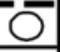 & & & -1 & 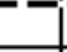 & & - & - \\
\hline & 3280 & 6156 & & & 0 & & 0 & & & & & & & & & & \\
\hline $3279-303$ & & 6155 & O & & & & & & & 으 & & & & & & & \\
\hline $3303-327$ & & 6157 & 0 & & 으. & & & & 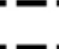 & & & & 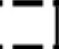 & & & 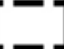 & - \\
\hline $3327-351$ & & $61 \overline{59}$ & & & $\overline{0}$ & - & 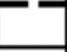 & & - & - & & & -1 & 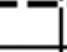 & & - & - \\
\hline & 3330 & 6158 & & & 0 & & & & & & 0 & & & & & & \\
\hline $3327-351$ & & 6159 & & & 으. & & & & & & & & & & & & \\
\hline $3351-375$ & & 6160 & & & & & & & -7 & & 8 & & - & & & $=$ & - \\
\hline $3375-399$ & & $61 \overline{161}$ & & & & & & & - & & 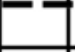 & & - & 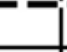 & & 一 & - \\
\hline & 3380 & 6162 & & O & 0 & & 0 & & & & & & 0 & & & & \\
\hline $3375-399$ & & 6161 & & & & & & & & & & & & & & & \\
\hline $3399-426$ & & $61 \overline{6}$ & & & & - & 0 & & $\overline{0}$ & & & & -1 & & & - & - \\
\hline & 3428 & 6165 & 0 & & 0 & & & & & & & & 0 & & & & \\
\hline $3426-450$ & & 6164 & & & & & & & & & & & & & & & \\
\hline $3450-474$ & & 6166 & & & & & 0 & & & & & & & & & & \\
\hline $3474-498$ & & 6167 & & & & & & & & & & & & & & & \\
\hline $3498-522$ & & 6168 & & & & & 0 & & & 0 & & & & & & & \\
\hline $3522-549$ & & 6169 & & & & & & & & & & & & & & & \\
\hline
\end{tabular}




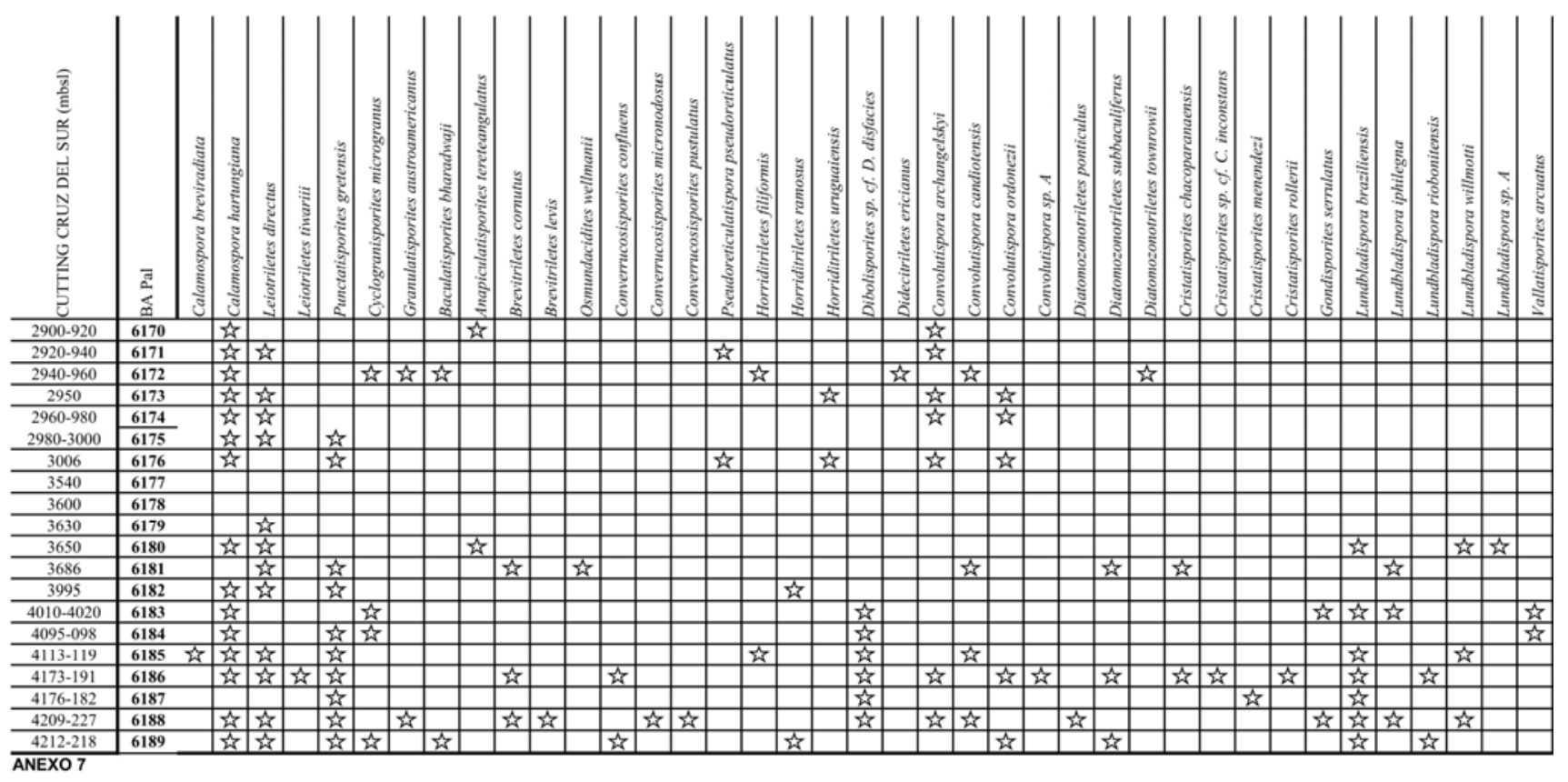




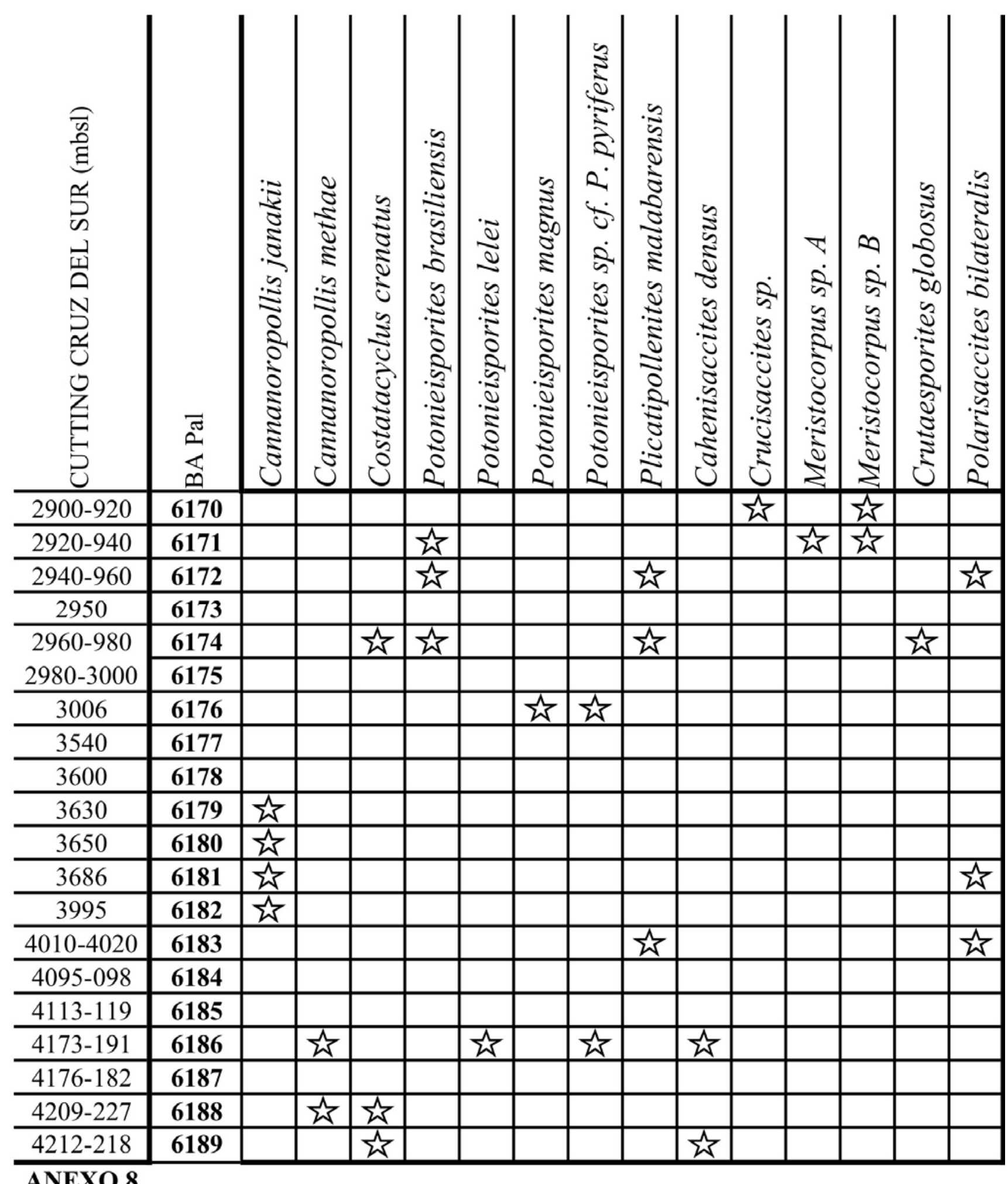




\begin{tabular}{|c|c|c|c|c|c|c|c|c|c|c|c|c|c|c|c|c|c|c|}
\hline 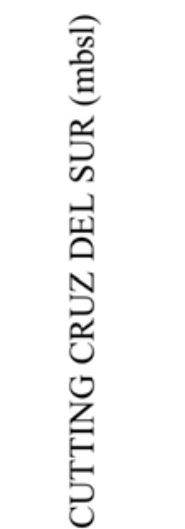 & $\begin{array}{l}\bar{\Xi} \\
\stackrel{\infty}{\infty}\end{array}$ & 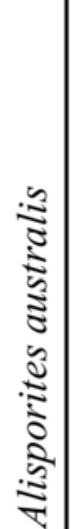 & 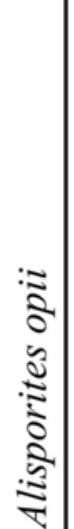 & 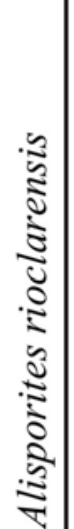 & 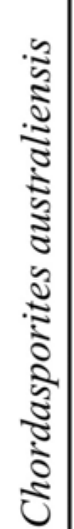 & $\begin{array}{c}0 \\
\vdots \\
0 \\
0 \\
0 \\
0 \\
0 \\
0 \\
0 \\
0 \\
0 \\
0 \\
0\end{array}$ & 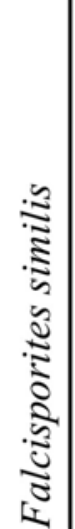 & 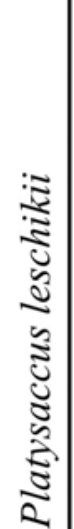 & 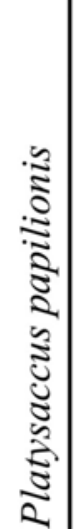 & 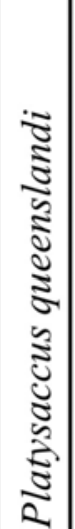 & 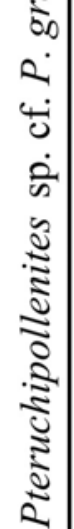 & 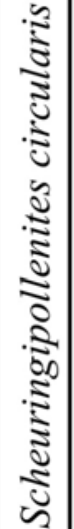 & 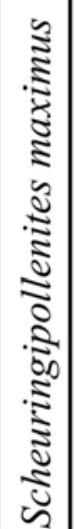 & 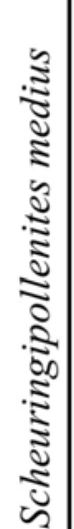 & 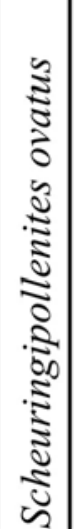 & 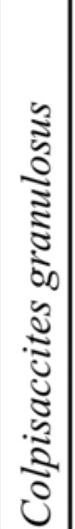 & 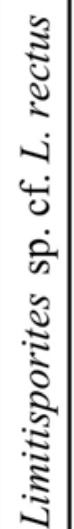 & 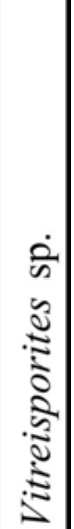 \\
\hline $2900-920$ & 6170 & & & & & & & & $\underline{2}$ & $\underline{2}$ & & & $\underline{2}$ & $\underline{2}$ & & & & \\
\hline $2920-940$ & 6171 & $\underline{\underline{4}}$ & & & & & & & $\frac{1}{2}$ & $\sqrt{2}$ & & & $\underline{2}$ & $\underline{2}$ & & & $\underline{2}$ & \\
\hline $2940-960$ & 6172 & 立 & & $\underline{\Delta}$ & & & & $\underline{2}$ & $\underline{2}$ & $\underline{2}$ & $\underline{2}$ & & $\underline{2}$ & & $\underline{2}$ & & & \\
\hline 2950 & 6173 & $\underline{\Delta}$ & & & & & & $\underline{2}$ & $\underline{2}$ & & $\underline{2}$ & $\underline{2}$ & & & & & & \\
\hline $2960-980$ & 6174 & $\underline{\underline{\alpha}}$ & & & & $\underline{\alpha}$ & & $\underline{2}$ & & $\underline{2}$ & & & $\underline{2}$ & & $\underline{2}$ & & 起 & \\
\hline $2980-3000$ & 6175 & & $\underline{\underline{4}}$ & & & $\underline{2}$ & & $\underline{2}$ & & $\underline{2}$ & $\underline{2}$ & $\underline{2}$ & & & $\sum$ & & & \\
\hline 3006 & 6176 & $\underline{n}$ & & & $\underline{2}$ & $\underline{a}$ & & $\underline{2}$ & $\underline{a}$ & $\underline{2}$ & 党 & & & & $\underline{2}$ & & & \\
\hline 3540 & 6177 & & & & & & & & & & & & & & & & & \\
\hline 3600 & 6178 & & & & & & & & & & & & $\sqrt{2}$ & $\sqrt{2}$ & & & & \\
\hline 3630 & 6179 & $\underline{4}$ & & & & & & $\underline{2}$ & & & & & $\underline{2}$ & $\underline{2}$ & & & & \\
\hline 3650 & 6180 & & & & & & & & & & & & $\underline{2}$ & & & & & \\
\hline 3686 & 6181 & $\underline{\underline{3}}$ & & $\underline{\underline{w}}$ & & & & & $\underline{2}$ & & $\underline{2}$ & & & & & & & \\
\hline 3995 & 6182 & $\underline{2}$ & & & & & & & $\underline{2}$ & $\underline{2}$ & 充 & & & & 点 & & & \\
\hline $4010-4020$ & 6183 & 充 & & & & & $\underline{x}$ & & & 光 & & & & & & & & \\
\hline $4095-098$ & 6184 & & & & & & & 光 & & & & & 光 & 光 & 光 & & & \\
\hline 4113-119 & 6185 & $\underline{\underline{4}}$ & & & $\underline{n}$ & & & $\underline{\mu}$ & $\underline{a}$ & & & & & & & & & $\underline{a}$ \\
\hline 4173-191 & 6186 & 点 & & & $\underline{2}$ & & $\underline{2}$ & & & $\underline{2}$ & & $\underline{a}$ & & & $\underline{1}$ & & & \\
\hline $4176-182$ & 6187 & & & & & & $\underline{2}$ & & & $\underline{2}$ & $\underline{2}$ & & & & $\underline{1}$ & & & $\underline{1}$ \\
\hline $4209-227$ & 6188 & $\underline{2}$ & & & & & $\underline{2}$ & & & $\underline{2}$ & & & 起 & & & $\underline{2}$ & & $\underline{2}$ \\
\hline $4212-218$ & 6189 & 充 & & & & & 党 & & 党 & 党 & 党 & 党 & & & 党 & & 党 & 党 \\
\hline
\end{tabular}




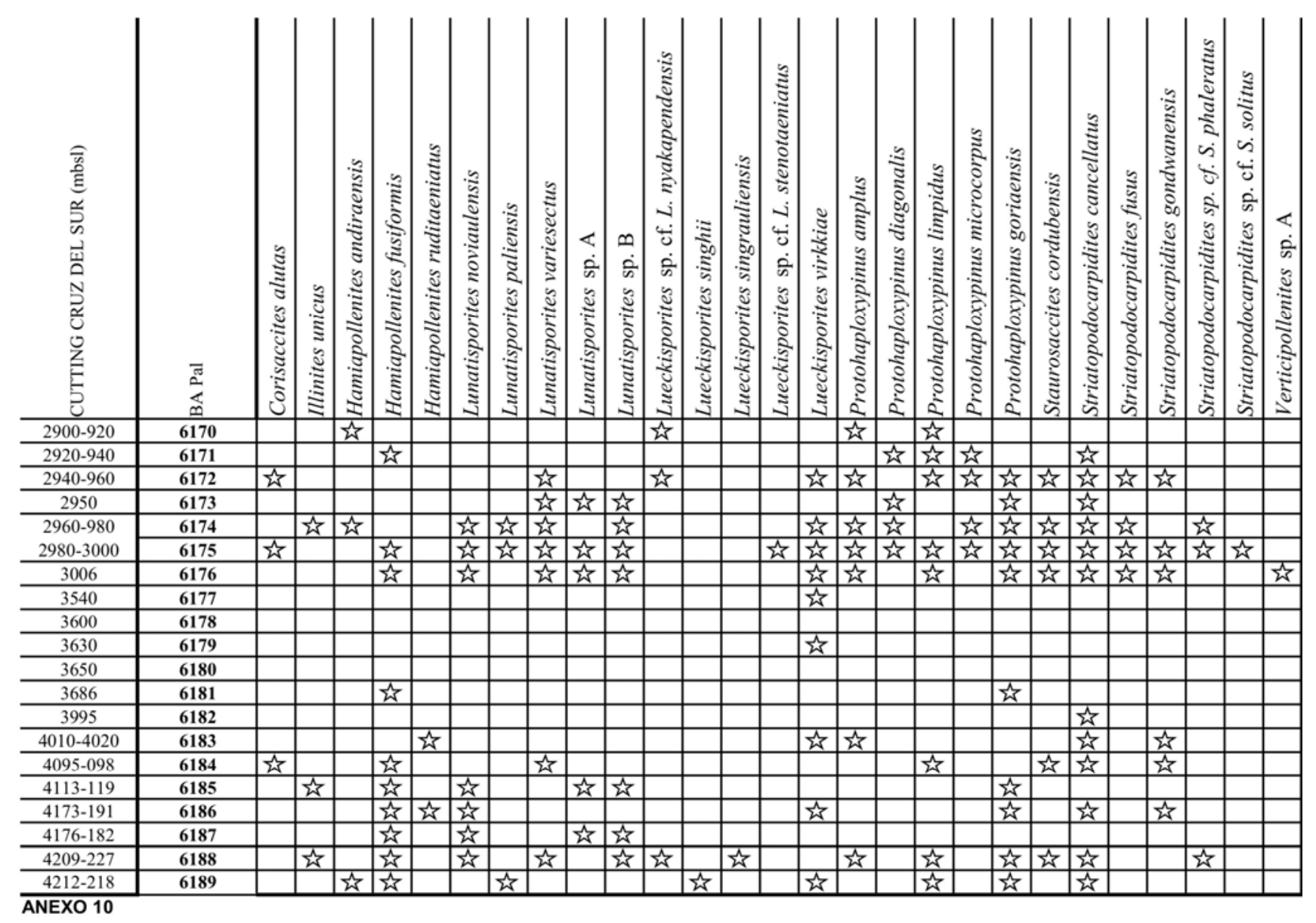


PLICADOS

MONOSULC

\begin{tabular}{|c|c|c|c|c|c|c|c|c|c|c|c|c|c|c|c|c|c|}
\hline & & \multicolumn{11}{|c|}{ PLICADOS } & \multicolumn{5}{|c|}{ MONOSULC } \\
\hline 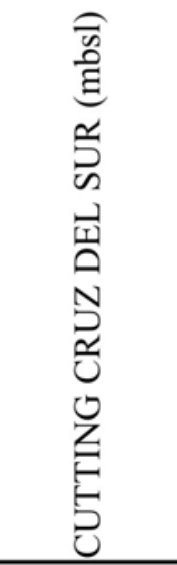 & 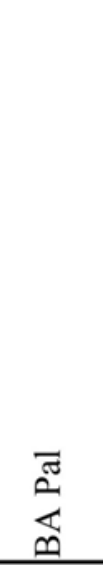 & 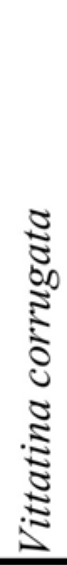 & 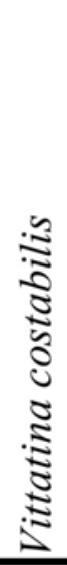 & 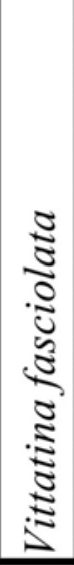 & 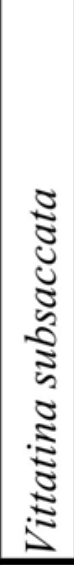 & 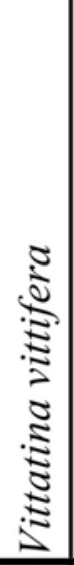 & 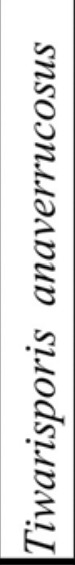 & 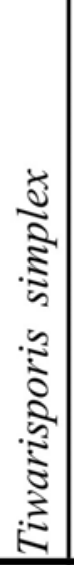 & 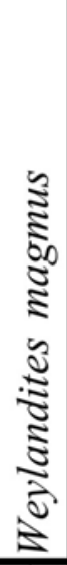 & 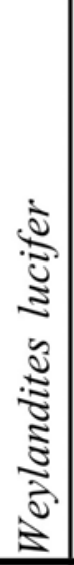 & 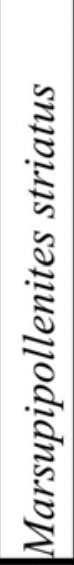 & 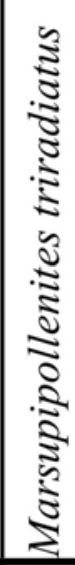 & 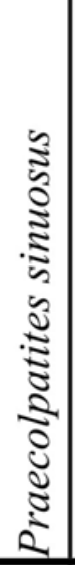 & 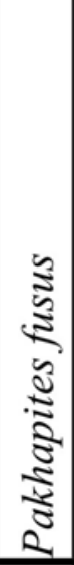 & 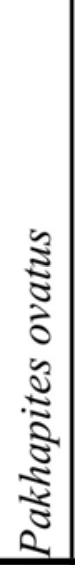 & 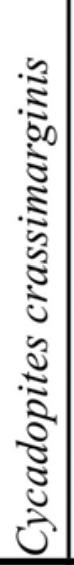 & 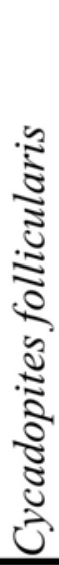 \\
\hline $2900-920$ & 6170 & & & & & & & & $\underline{n}$ & & $\underline{s}$ & 㺼 & & & 卖 & & \\
\hline $2920-940$ & 6171 & & $\underline{s}$ & & 点 & & & & & & & 光 & & $\underline{2}$ & & & \\
\hline $2940-960$ & 6172 & & & & $\underline{s}$ & & & & & & & $\frac{1}{2}$ & & & & & \\
\hline 2950 & 6173 & & & & $\underline{s}$ & & & & & & & 㺼 & & $\underline{s}$ & & & \\
\hline $2960-980$ & 6174 & & $\underline{s}$ & & $\underline{t}$ & & & & & & & 卖 & & & & & \\
\hline $2980-3000$ & 6175 & & $\underline{\underline{2}}$ & & 党 & & & & & & & 充 & & & & & \\
\hline 3006 & 6176 & & 近 & $\underline{\underline{s}}$ & & & $\underline{\underline{u}}$ & & & & & 놋 & & & & & \\
\hline 3540 & 6177 & & 运 & & & & & & & & 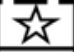 & $\sqrt{2}$ & & 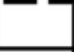 & & & \\
\hline 3600 & 6178 & & 点 & & & & & & & & & & & & & & \\
\hline 3630 & 6179 & & & $\underline{s}$ & $\underline{s}$ & & & & & & $\underline{\alpha}$ & 交 & & & & & \\
\hline 3650 & 6180 & & & & & & & & & & & & & $\underline{\alpha}$ & & & \\
\hline 3686 & 6181 & & $\underline{n}$ & & $\underline{t}$ & & 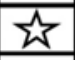 & & & & & & & $\underline{\alpha}$ & & & \\
\hline 3995 & 6182 & $\underline{\underline{4}}$ & $\underline{2}$ & & 占 & & & & & & & & & $\underline{\underline{4}}$ & & & \\
\hline $4010-4020$ & 6183 & & $\underline{s}$ & $\frac{1}{2}$ & & & & & & & & & & $\sqrt{2}$ & & & \\
\hline $4095-098$ & 6184 & & 尝 & & & $\underline{2}$ & & & & & & & & & & & \\
\hline 4113-119 & 6185 & & $\underline{n}$ & & & $\underline{2}$ & & & & & & & & & & & \\
\hline 4173-191 & 6186 & & & & 索 & 党 & $\underline{\omega}$ & $\underline{\underline{\alpha}}$ & & & $\underline{\omega}$ & & & $\underline{1}$ & 党 & & \\
\hline $4176-182$ & 6187 & & & $\frac{1}{2}$ & & & & & & & & 交 & & $\underline{\underline{r}}$ & & & \\
\hline $4209-227$ & 6188 & & $\underline{4}$ & $\underline{x}$ & $\underline{s}$ & & & & & & $\underline{\Delta}$ & & & $\underline{n}$ & & & \\
\hline $4212-218$ & 6189 & & 氛 & $\underline{s}$ & $\underline{s}$ & & & & & & & & & $\underline{c}$ & & & \\
\hline
\end{tabular}




\begin{tabular}{|c|c|c|c|c|c|c|c|c|c|c|c|c|c|c|}
\hline & & \multicolumn{7}{|c|}{ ALGAS } & \multicolumn{6}{|c|}{ ACRITARCAS } \\
\hline 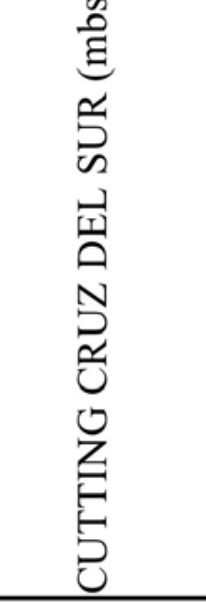 & 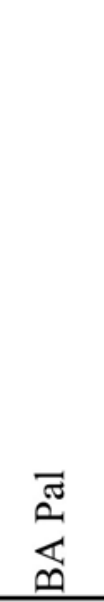 & 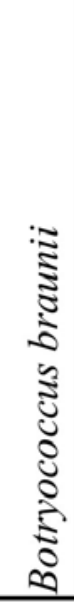 & 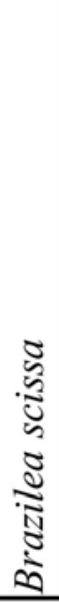 & 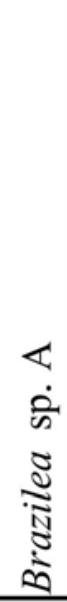 & 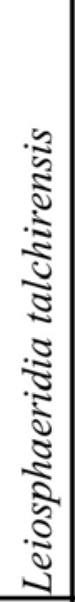 & 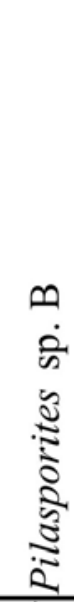 & 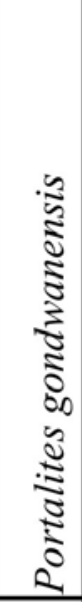 & 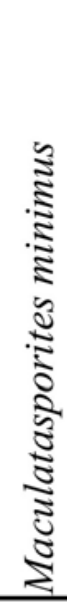 & 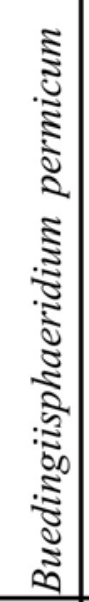 & 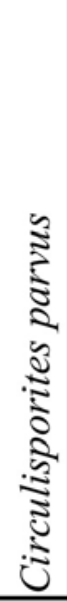 & 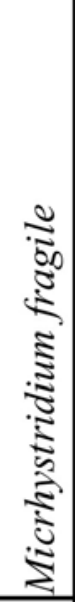 & 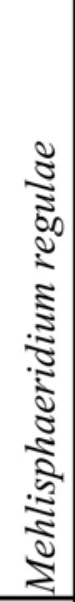 & 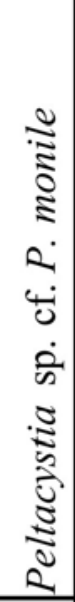 & 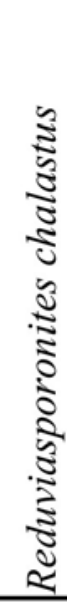 \\
\hline $2900-920$ & 6170 & & & & & 光 & & & & & & & & \\
\hline $2920-940$ & 6171 & & & & $\bar{c}$ & & & & & & & & & \\
\hline $2940-960$ & 6172 & 茨 & & 㺼 & & & & & & & & & & $\underline{\Delta}$ \\
\hline 2950 & 6173 & & & & 䋆 & & 管 & & 资 & & & & 幽 & \\
\hline $2960-980$ & 6174 & & & & & & & & & & & & & \\
\hline 2980-3000 & 6175 & 负 & & & & & & & & & & & & \\
\hline 3006 & 6176 & $\underline{2}$ & & & & & & & & & & & & \\
\hline 3540 & 6177 & & & & & & & & & $\underline{2}$ & & & & \\
\hline 3600 & 6178 & $\widehat{\mu}$ & & & & & & & & & & & & \\
\hline 3630 & 6179 & & & & & & $\underline{\mu}$ & & & & $\underline{n}$ & & & \\
\hline 3650 & 6180 & & & $\underline{\Delta}$ & & & $\underline{\mu}$ & & & & & & & \\
\hline 3686 & 6181 & & & & & & & & & & & & & \\
\hline 3995 & 6182 & & & & $\underline{4}$ & & & & & & & $\underline{2}$ & & \\
\hline $4010-4020$ & 6183 & $\underline{2}$ & & & & & & & & & & & & \\
\hline 4095-098 & 6184 & 崖 & & & & & $\underline{\mu}$ & & & & & & & \\
\hline 4113-119 & 6185 & 卖 & & & & 公 & 趈 & & & & & 幽 & & \\
\hline $4173-191$ & 6186 & $\underline{h}$ & & $\underline{1}$ & & & $\underline{\omega}$ & & & & & $\underline{\underline{h}}$ & & \\
\hline $4176-182$ & 6187 & $\sqrt{2}$ & & & & & & 茨 & & & & & & \\
\hline $4209-227$ & 6188 & & & 它 & & & $\underline{\lambda}$ & & & & & $\underline{n}$ & & \\
\hline $4212-218$ & 6189 & 承 & & & & & 象 & & & & & & & \\
\hline
\end{tabular}




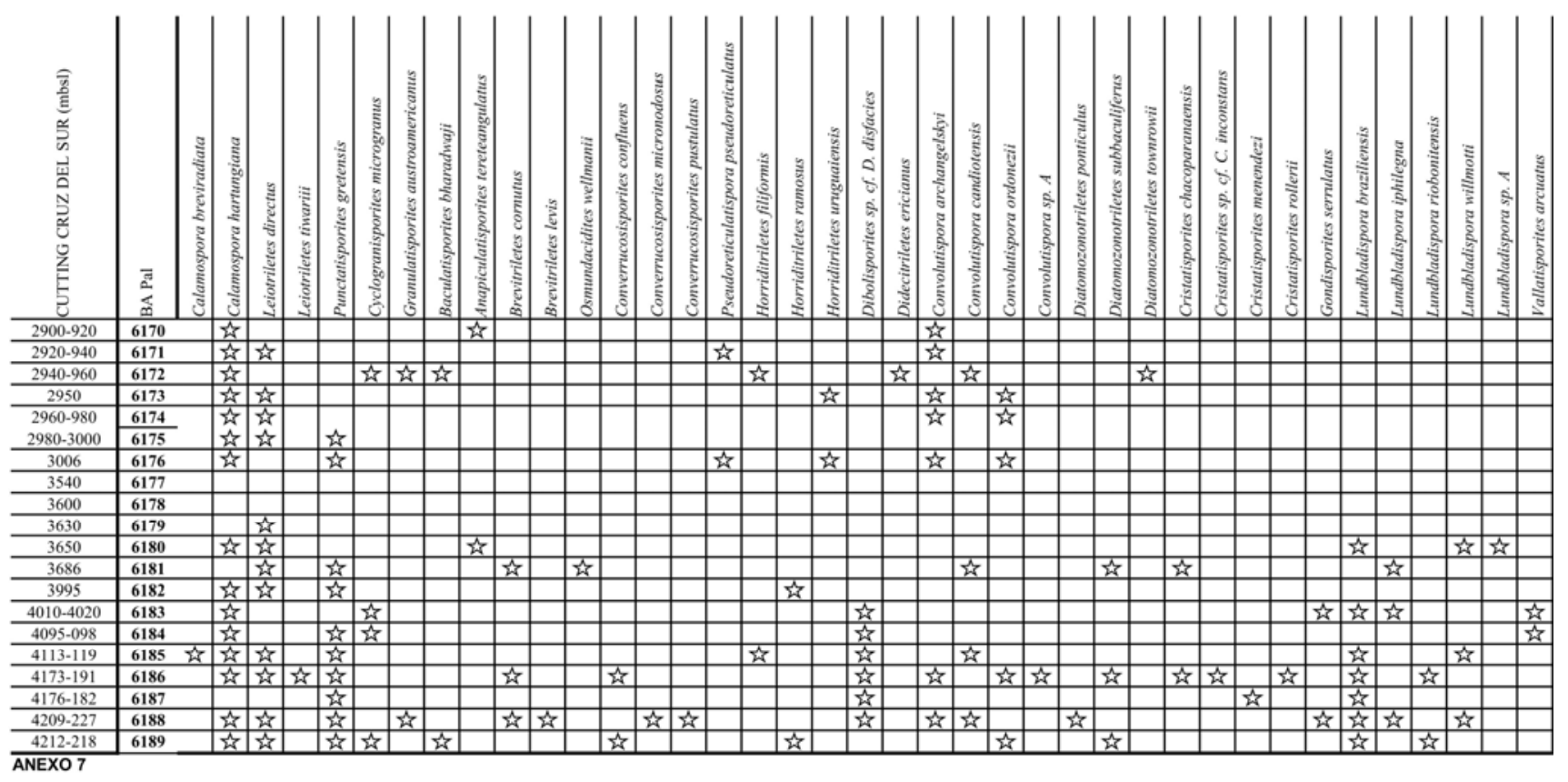




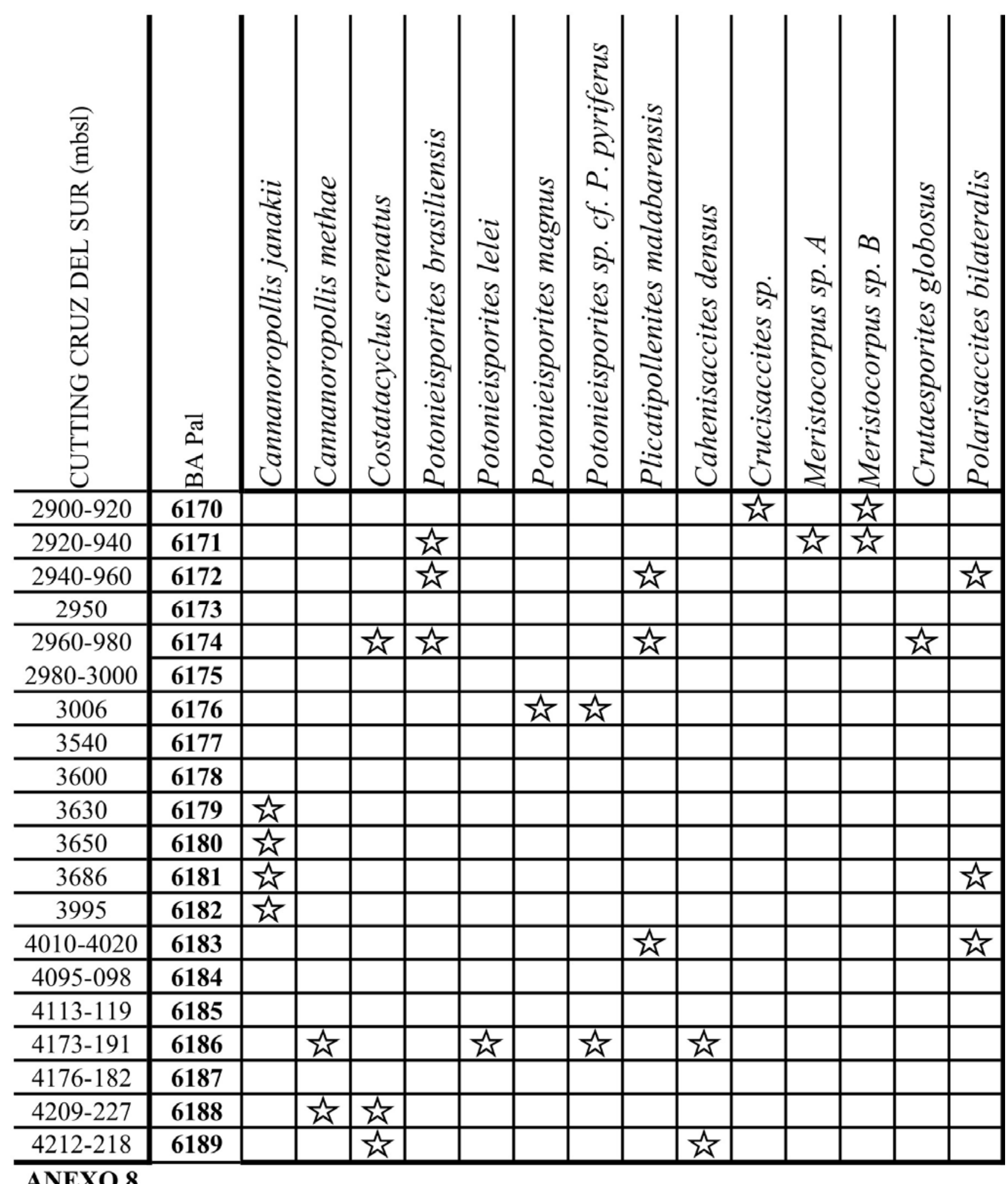




\begin{tabular}{|c|c|c|c|c|c|c|c|c|c|c|c|c|c|c|c|c|c|c|}
\hline 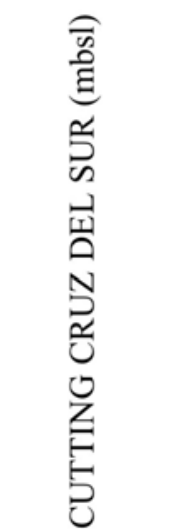 & $\begin{array}{l}\bar{\Xi} \\
\stackrel{\infty}{\infty}\end{array}$ & 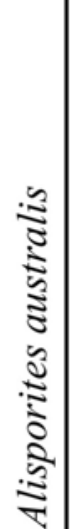 & 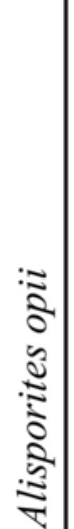 & 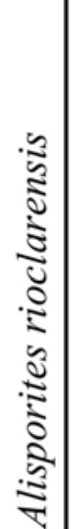 & 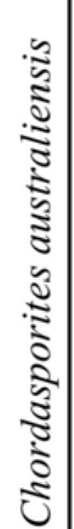 & $\begin{array}{c}0 \\
\vdots \\
0 \\
0 \\
0 \\
0 \\
0 \\
0 \\
0 \\
0 \\
0 \\
0 \\
0\end{array}$ & 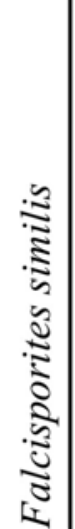 & 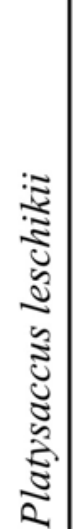 & 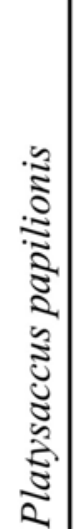 & 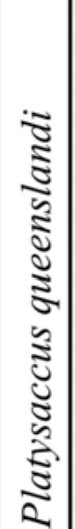 & 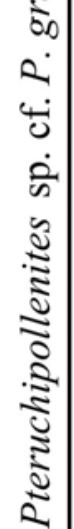 & 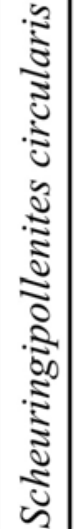 & 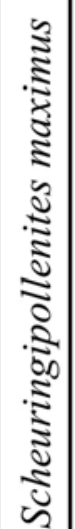 & 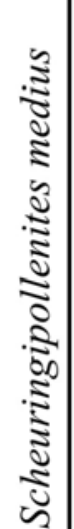 & 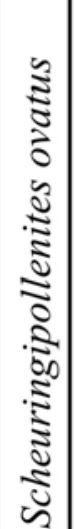 & 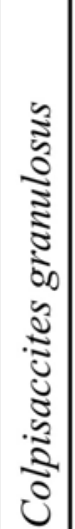 & 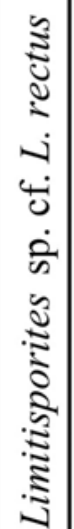 & 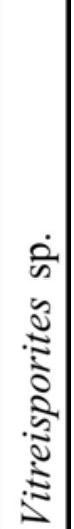 \\
\hline $2900-920$ & 6170 & & & & & & & & $\underline{2}$ & $\underline{2}$ & & & $\underline{2}$ & $\underline{2}$ & & & & \\
\hline $2920-940$ & 6171 & $\underline{\underline{4}}$ & & & & & & & $\frac{1}{2}$ & $\sqrt{2}$ & & & $\underline{2}$ & $\underline{2}$ & & & $\underline{2}$ & \\
\hline $2940-960$ & 6172 & 立 & & $\underline{\Delta}$ & & & & $\underline{2}$ & $\underline{2}$ & $\underline{2}$ & $\underline{2}$ & & $\underline{2}$ & & $\underline{2}$ & & & \\
\hline 2950 & 6173 & $\underline{\Delta}$ & & & & & & $\underline{2}$ & $\underline{2}$ & & $\underline{2}$ & $\underline{2}$ & & & & & & \\
\hline $2960-980$ & 6174 & $\underline{\underline{\alpha}}$ & & & & $\underline{\alpha}$ & & $\underline{2}$ & & $\underline{2}$ & & & $\underline{2}$ & & $\underline{2}$ & & 起 & \\
\hline $2980-3000$ & 6175 & & $\underline{\underline{4}}$ & & & $\underline{2}$ & & $\underline{2}$ & & $\underline{2}$ & $\underline{2}$ & $\underline{2}$ & & & $\sum$ & & & \\
\hline 3006 & 6176 & $\underline{n}$ & & & $\underline{2}$ & $\underline{a}$ & & $\underline{2}$ & $\underline{a}$ & $\underline{2}$ & 党 & & & & $\underline{2}$ & & & \\
\hline 3540 & 6177 & & & & & & & & & & & & & & & & & \\
\hline 3600 & 6178 & & & & & & & & & & & & $\sqrt{2}$ & $\sqrt{2}$ & & & & \\
\hline 3630 & 6179 & $\underline{4}$ & & & & & & $\underline{2}$ & & & & & $\underline{2}$ & $\underline{2}$ & & & & \\
\hline 3650 & 6180 & & & & & & & & & & & & $\underline{2}$ & & & & & \\
\hline 3686 & 6181 & $\underline{\underline{3}}$ & & $\underline{\underline{w}}$ & & & & & $\underline{2}$ & & $\underline{2}$ & & & & & & & \\
\hline 3995 & 6182 & $\underline{2}$ & & & & & & & $\underline{2}$ & $\underline{2}$ & 充 & & & & 点 & & & \\
\hline $4010-4020$ & 6183 & 充 & & & & & $\underline{x}$ & & & 光 & & & & & & & & \\
\hline $4095-098$ & 6184 & & & & & & & 光 & & & & & 光 & 光 & 光 & & & \\
\hline 4113-119 & 6185 & $\underline{\underline{4}}$ & & & $\underline{n}$ & & & $\underline{\mu}$ & $\underline{a}$ & & & & & & & & & $\underline{a}$ \\
\hline 4173-191 & 6186 & 点 & & & $\underline{2}$ & & $\underline{2}$ & & & $\underline{2}$ & & $\underline{a}$ & & & $\underline{1}$ & & & \\
\hline $4176-182$ & 6187 & & & & & & $\underline{2}$ & & & $\underline{2}$ & $\underline{2}$ & & & & $\underline{1}$ & & & $\underline{1}$ \\
\hline $4209-227$ & 6188 & $\underline{2}$ & & & & & $\underline{2}$ & & & $\underline{2}$ & & & 起 & & & $\underline{2}$ & & $\underline{2}$ \\
\hline $4212-218$ & 6189 & 充 & & & & & 党 & & 党 & 党 & 党 & 党 & & & 党 & & 党 & 党 \\
\hline
\end{tabular}




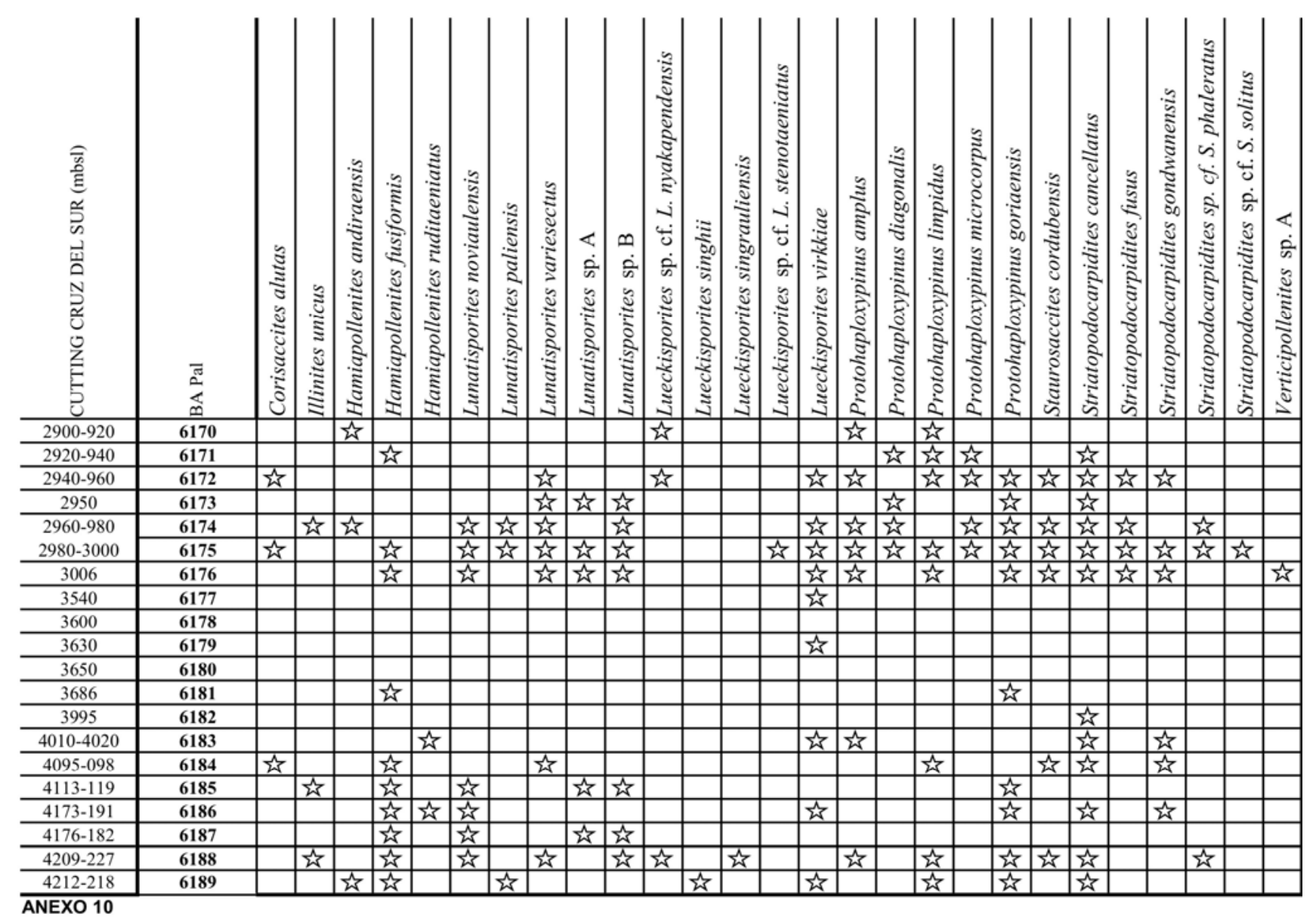


PLICADOS

MONOSULC

\begin{tabular}{|c|c|c|c|c|c|c|c|c|c|c|c|c|c|c|c|c|c|}
\hline & & \multicolumn{11}{|c|}{ PLICADOS } & \multicolumn{5}{|c|}{ MONOSULC } \\
\hline 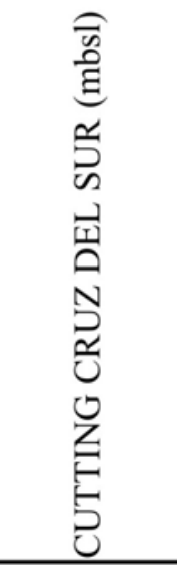 & 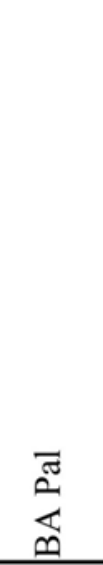 & 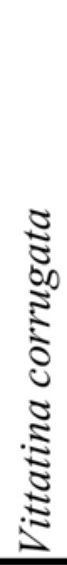 & 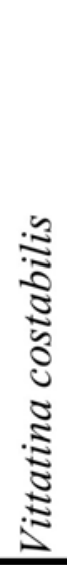 & 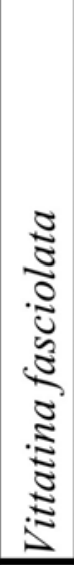 & 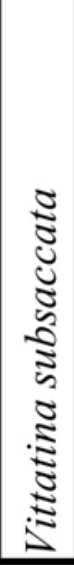 & 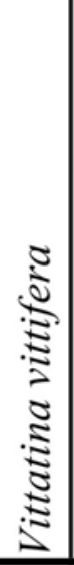 & 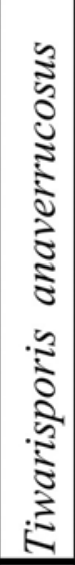 & 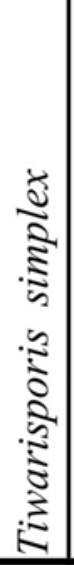 & 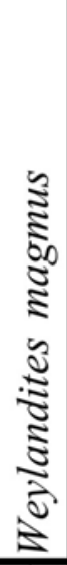 & 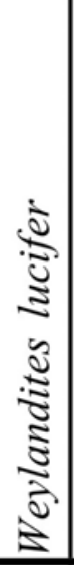 & 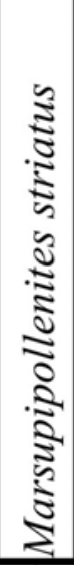 & 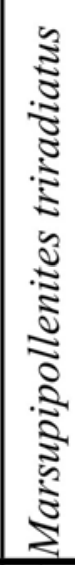 & 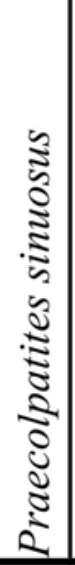 & 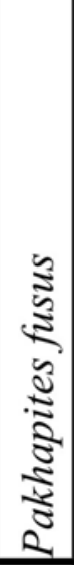 & 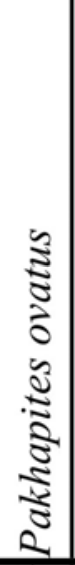 & 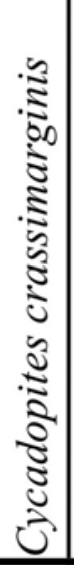 & 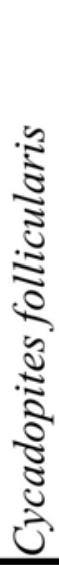 \\
\hline $2900-920$ & 6170 & & & & & & & & $\underline{n}$ & & $\underline{s}$ & 㺼 & & & 卖 & & \\
\hline $2920-940$ & 6171 & & $\underline{s}$ & & 点 & & & & & & & 光 & & $\underline{2}$ & & & \\
\hline $2940-960$ & 6172 & & & & $\underline{s}$ & & & & & & & $\frac{1}{2}$ & & & & & \\
\hline 2950 & 6173 & & & & $\underline{s}$ & & & & & & & 㺼 & & $\underline{s}$ & & & \\
\hline $2960-980$ & 6174 & & $\underline{s}$ & & $\underline{t}$ & & & & & & & 卖 & & & & & \\
\hline $2980-3000$ & 6175 & & $\underline{\underline{2}}$ & & 党 & & & & & & & 充 & & & & & \\
\hline 3006 & 6176 & & 近 & $\underline{\underline{s}}$ & & & $\underline{\underline{u}}$ & & & & & 놋 & & & & & \\
\hline 3540 & 6177 & & 运 & & & & & & & & 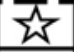 & $\sqrt{2}$ & & 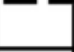 & & & \\
\hline 3600 & 6178 & & 点 & & & & & & & & & & & & & & \\
\hline 3630 & 6179 & & & $\underline{s}$ & $\underline{s}$ & & & & & & $\underline{\alpha}$ & 交 & & & & & \\
\hline 3650 & 6180 & & & & & & & & & & & & & $\underline{\alpha}$ & & & \\
\hline 3686 & 6181 & & $\underline{n}$ & & $\underline{t}$ & & 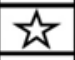 & & & & & & & $\underline{\alpha}$ & & & \\
\hline 3995 & 6182 & $\underline{\underline{4}}$ & $\underline{2}$ & & 占 & & & & & & & & & $\underline{\underline{4}}$ & & & \\
\hline $4010-4020$ & 6183 & & $\underline{s}$ & $\frac{1}{2}$ & & & & & & & & & & $\sqrt{2}$ & & & \\
\hline $4095-098$ & 6184 & & 尝 & & & $\underline{2}$ & & & & & & & & & & & \\
\hline 4113-119 & 6185 & & $\underline{n}$ & & & $\underline{2}$ & & & & & & & & & & & \\
\hline 4173-191 & 6186 & & & & 索 & 党 & $\underline{\omega}$ & $\underline{\underline{\alpha}}$ & & & $\underline{\omega}$ & & & $\underline{1}$ & 党 & & \\
\hline $4176-182$ & 6187 & & & $\frac{1}{2}$ & & & & & & & & 交 & & $\underline{\underline{r}}$ & & & \\
\hline $4209-227$ & 6188 & & $\underline{4}$ & $\underline{x}$ & $\underline{s}$ & & & & & & $\underline{\Delta}$ & & & $\underline{n}$ & & & \\
\hline $4212-218$ & 6189 & & 氛 & $\underline{s}$ & $\underline{s}$ & & & & & & & & & $\underline{c}$ & & & \\
\hline
\end{tabular}




\begin{tabular}{|c|c|c|c|c|c|c|c|c|c|c|c|c|c|c|}
\hline & & \multicolumn{7}{|c|}{ ALGAS } & \multicolumn{6}{|c|}{ ACRITARCAS } \\
\hline 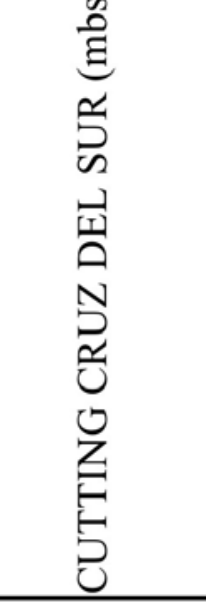 & 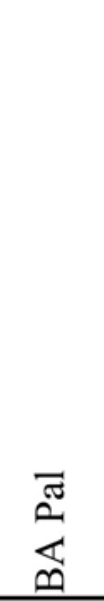 & 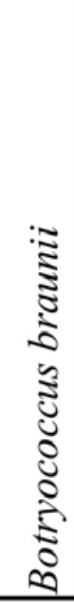 & 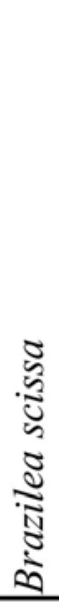 & 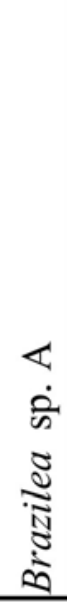 & 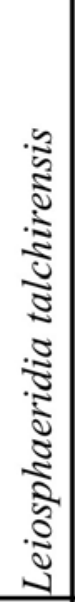 & 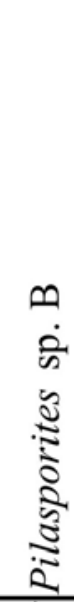 & 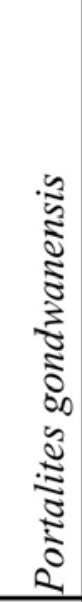 & 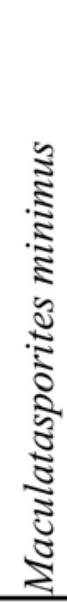 & 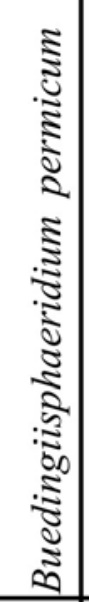 & 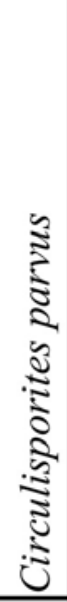 & 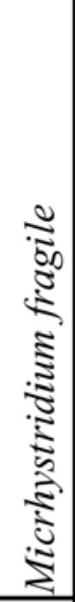 & 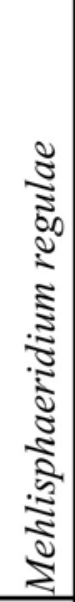 & 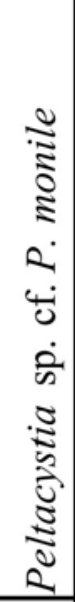 & 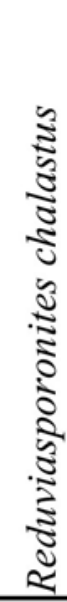 \\
\hline $2900-920$ & 6170 & & & & & 光 & & & & & & & & \\
\hline $2920-940$ & 6171 & & & & $\bar{c}$ & & & & & & & & & \\
\hline $2940-960$ & 6172 & 茨 & & 㺼 & & & & & & & & & & $\underline{\Delta}$ \\
\hline 2950 & 6173 & & & & 䋆 & & 管 & & 资 & & & & 幽 & \\
\hline $2960-980$ & 6174 & & & & & & & & & & & & & \\
\hline 2980-3000 & 6175 & 负 & & & & & & & & & & & & \\
\hline 3006 & 6176 & $\underline{2}$ & & & & & & & & & & & & \\
\hline 3540 & 6177 & & & & & & & & & $\underline{2}$ & & & & \\
\hline 3600 & 6178 & $\widehat{\mu}$ & & & & & & & & & & & & \\
\hline 3630 & 6179 & & & & & & $\underline{\mu}$ & & & & $\underline{n}$ & & & \\
\hline 3650 & 6180 & & & $\underline{\Delta}$ & & & $\underline{\mu}$ & & & & & & & \\
\hline 3686 & 6181 & & & & & & & & & & & & & \\
\hline 3995 & 6182 & & & & $\underline{4}$ & & & & & & & $\underline{2}$ & & \\
\hline $4010-4020$ & 6183 & $\underline{2}$ & & & & & & & & & & & & \\
\hline 4095-098 & 6184 & 崖 & & & & & $\underline{\mu}$ & & & & & & & \\
\hline 4113-119 & 6185 & 卖 & & & & 公 & 趈 & & & & & 幽 & & \\
\hline $4173-191$ & 6186 & $\underline{h}$ & & $\underline{1}$ & & & $\underline{\omega}$ & & & & & $\underline{\underline{h}}$ & & \\
\hline $4176-182$ & 6187 & $\sqrt{2}$ & & & & & & 茨 & & & & & & \\
\hline $4209-227$ & 6188 & & & 它 & & & $\underline{\lambda}$ & & & & & $\underline{n}$ & & \\
\hline $4212-218$ & 6189 & 承 & & & & & 象 & & & & & & & \\
\hline
\end{tabular}

